Federal Building and Fire Safety Investigation of the World Trade Center Disaster

\title{
Analysis of Aircraft Impacts into the World Trade Center Towers Chapters 1, 2, 3, 4, 5, 6, 7 \& 8
}

Steven W. Kirkpatrick

Robert T. Bocchieri

Fahim Sadek

Robert A. MacNeill

Samuel Holmes

Brian D. Peterson

Robert W. Cilke

Claudia Navarro 

NIST NCSTAR 1-2B

Federal Building and Fire Safety Investigation of the World Trade Center Disaster

\section{Analysis of Aircraft Impacts into the World Trade Center Towers}

Steven W. Kirkpatrick

Robert T. Bocchieri

Fahim Sadek

Robert A. MacNeill

Samuel Holmes

Brian D. Peterson

Robert W. Cilke

Claudia Navarro 

Federal Building and Fire Safety Investigation of the World Trade Center Disaster

\section{Analysis of Aircraft Impacts into the World Trade Center Towers}

Steven W. Kirkpatrick

Robert T. Bocchieri

Applied Research Associates

Fahim Sadek

Building and Fire Research Laboratory

National Institute of Standards and Technology

Robert A. MacNeill

Samuel Holmes

Brian D. Peterson

Robert W. Cilke

Claudia Navarro

Applied Research Associates

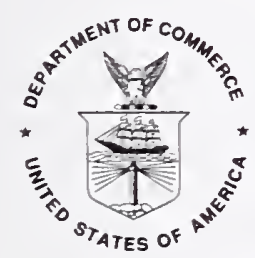

U.S. Department of Commerce

Carlos M. Gutierrez, Secretary

Technology Administration

Michelle O'Neill, Acting Under Secretary for Technology

National Institute of Standards and Technology

William Jeffrey, Director 


\title{
Disclaimer No. 1
}

Certain commercial entities, equipment, products, or materials are identified in this document in order to describe a procedure or concept adequately or to trace the history of the procedures and practices used. Such identification is not intended to imply recommendation, endorsement, or implication that the entities, products, materials, or equipment are necessarily the best available for the purpose. Nor does such identification imply a finding of fault or negligence by the National Institute of Standards and Technology.

\section{Disclaimer No. 2}

The policy of NIST is to use the International System of Units (metric units) in all publications. In this document, however, units are presented in metric units or the inch-pound system, whichever is prevalent in the discipline.

\section{Disclaimer No. 3}

Pursuant to section 7 of the National Construction Safety Team Act, the NIST Director has determined that certain evidence received by NIST in the course of this Investigation is "voluntarily provided safety-related information" that is "not directly related to the building failure being investigated" and that "disclosure of that information would inhibit the voluntary provision of that type of information" (15 USC 7306c).

In addition, a substantial portion of the evidence collected by NIST in the course of the Investigation has been provided to NIST under nondisclosure agreements.

\section{Disclaimer No. 4}

NIST takes no position as to whether the design or construction of a WTC building was compliant with any code since, due to the destruction of the WTC buildings, NIST could not verify the actual (or as-built) construction, the properties and condition of the materials used, or changes to the original construction made over the life of the buildings. In addition, NIST could not verify the interpretations of codes used by applicable authorities in determining compliance when implementing building codes. Where an Investigation report states whether a system was designed or installed as required by a code provision, NIST has documentary or anecdotal evidence indicating whether the requirement was met, or NIST has independently conducted tests or analyses indicating whether the requirement was met.

\section{Use in Legal Proceedings}

No part of any report resulting from a NIST investigation into a structural failure or from an investigation under the National Construction Safety Team Act may be used in any suit or action for damages arising out of any matter mentioned in such report (15 USC 281a; as amended by P.L. 107-231).

National Institute of Standards and Technology National Construction Safety Team Act Report 1-2B Natl. Inst. Stand. Technol. Natl. Constr. Sfty. Tm. Act Rpt. 1-2B, 496 pages (September 2005) CODEN: NSPUE2

\author{
U.S. GOVERNMENT PRINTING OFFICE \\ WASHINGTON: 2005
}

For sale by the Superintendent of Documents, U.S. Government Printing Office Internet: bookstore.gpo.gov — Phone: (202) 512-1800 - Fax: (202) 512-2250 Mail: Stop SSOP, Washington, DC 20402-0001 


\section{ABSTRACT}

The objective of this report was to analyze the aircraft impacts into each of the World Trade Center (WTC) towers to provide the following: (1) estimates of probable damage to structural systems due to aircraft impact, including exterior walls, floor systems, and interior core columns; (2) estimates of the aircraft fuel dispersal during the impact; (3) estimates of debris damage to the interior tower contents, including partitions and workstations. Thus, this analysis established the initial conditions for the fire dynamics modeling and the thermal-structural response and collapse initiation analysis.

The impact analyses were conducted at various levels of complexity including: (1) the component level, (2) the subassembly level, and (3) the global level to estimate the probable damage to the towers due to aircraft impact. Simplified analyses were also used to support the development of the global finite element models. Analysis of uncertainties using the component and subassembly analyscs were conducted to assess the effects of variability associated with various input parameters and identify the most influential parameters that affect the damage estimates using orthogonal factorial design. Based on the results of the sensitivity analyses, the most influential parameters identified were varied in the global models to provide a range of damage estimates for WTC 1 and WTC 2.

As part of the tower and aircraft models, constitutive relationships describing the actual behavior of the structures under the dynamic impact conditions of the aircraft were developed based on test results of the tower steels and from the open literature for other materials. Various grades of steels used in the exterior walls and core columns of the towers, weldment metal, bolts, reinforced concrete, aircraft materials, and nonstructural contents were considered. The constitutive relationships included high strain-rate effects and failure criteria for the various materials.

The tower models used in the global impact analyses were developed based on the original WTC drawings and the structural databases of the towers developed within the framework of the baseline structural performance analysis. The tower models included the primary structural components of the towers in the impact zone, including exterior walls, floor systems, core columns, and connections. A refined finite element mesh was used for the areas in the path of the aircraft and a coarser mesh was used elsewhere. The models also included the nonstructural building contents, such as partitions and workstations, in the path of the aircraft debris.

The Boeing 767 aircraft model was developed based on information gathered from documentary aircraft structural information, and data from measurements on a Boeing 767 aircraft. The model included the aircraft engines, wings, fuselage, empennage, and landing gear, as well as nonstructural components of the aircraft. A detailed analysis was carried out to estimate the fuel distribution in the aircraft wings at the time of impact.

The WTC towers and Boeing 767 aircraft are complex structural systems. In the global model development process, the objective was to include all of the primary structural components and details of both the aircraft and towers. This approach, however, results in very large models. The component and subassembly analyses were used to determine model simplifications to reduce the overall model size while maintaining fidelity in the analysis. Therefore, a series of component impact and subassembly 
analyses were performed. The primary objectives of the component and subassembly modeling were to (1) develop an understanding of the interactive failure phenomenon of the aircraft and tower components and (2) develop the simulation techniques required for the global analysis of the aircraft impacts into the WTC towers, including variations in mesh density and numerical tools for modeling fluid-structure interaction for fuel impact and dispersion. The approach taken for component modeling was to start with finely meshed models of key components of the tower and aircraft structures and progress to relatively coarsely meshed beam and shell element representations that were used for the global models. An example of component level analysis is the analysis of exterior wall panels impacted by a segment of an aircraft wing with and without fuel. An example of the subassembly analysis is an aircraft engine impacting a strip from the exterior wall to the core of the tower.

The initial conditions of the impact of the aircraft into the WTC towers were estimated. This task utilized the two videos that captured the approach and impact of the American Airlines flight 11, which impacted WTC 1, and the several videos that captured United Airlines flight 175, that impacted WTC 2. In addition, a large body of photographic evidence was used to determine the impact location and orientation relative to the towers. These videos and photographs were analyzed to estimate, with the best accuracy possible, the speed, horizontal and vertical angles of incidence, and roll angle of each aircraft. Uncertainties in each of these parameters were also quantified.

The analysis of aircraft impact into the WTC towers is subject to large uncertainties in the input parameters such as the initial conditions of the impact, material properties, mass properties of aircraft and building contents, connection behavior, modeling uncertainties, etc. Sensitivity analyses were performed at the component and subassembly levels. The objectives of these analyses were to assess the effect of uncertainties on the level of damage to the towers after impact and to determine the most influential parameters that affect the damage estimates.

The primary objective of this analysis was to determine the condition of the WTC towers immediately following the aircraft impacts using the global tower and aircraft models. This assessment included the estimation of the structural damage that degraded their strength and the condition and position of nonstructural contents such as partitions, workstations, aircraft fuel, and other debris that influenced the behavior of the subsequent fires in the towers. The global impact analyses were the primary method by which the damage to the towers was estimated. The global analyses included, for each tower, a "base case" based on a best estimate of all input parameters. They also provided more and less severe damage estimates based on variations of the most influential parameters. These more and less severe damage scenarios provided a range of damage estimates of the towers due to aircraft impact. Comparisons between the simulation results and observables obtained from video and photographic evidence as well as eyewitness interviews were also conducted. Not all of these observables were perfectly matched by the simulations due to the uncertainties in exact impact conditions, the imperfect knowledge of the interior tower contents, the chaotic behavior of the aircraft break up and subsequent debris motion, and the limitations of the models. In general, however, the results of the simulations matched these observables reasonably well. A comparison with prior estimates of the damage obtained from other studies was also provided. 
Approximate impact analyses were carried out to provide guidance to the global finite element impact analyses. These included: (1) the analysis of the overall aircraft impact forces and assessment of the relative importance of the airframe strength and weight distribution, (2) the evaluation of the potential effects of the energy in the rotating engine components on the calculated engine impact response, (3) the influence of the static preloads in the towers on the calculated impact damage and residual strength predictions, and (4) the analysis of the load characteristics required to damage core columns compared to the potential loading from impact of aircraft components.

Keywords: Aircraft impact, aircraft model, dynamic analysis, failure, finite element analysis, fuel dispersion, structural dynamics, World Trade Center. 
This page intentionally left blank. 


\section{TABLE OF CONTENTS}

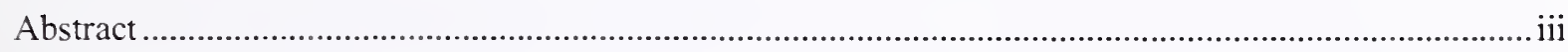

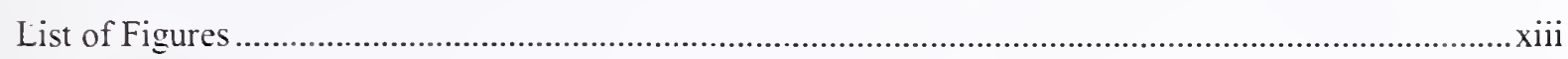

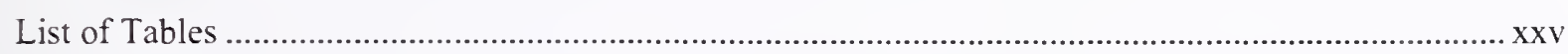

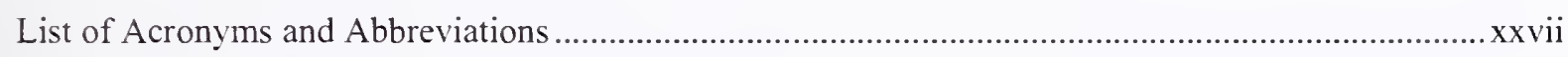

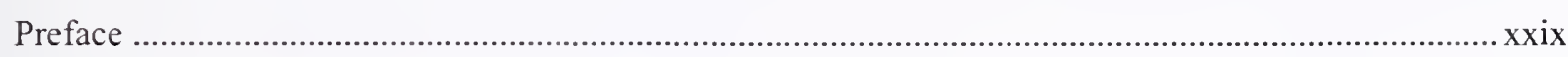

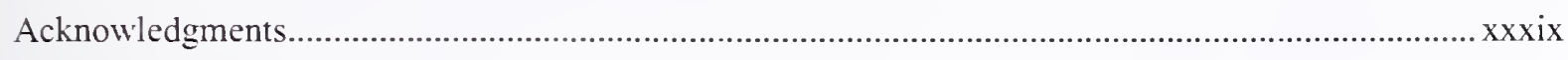

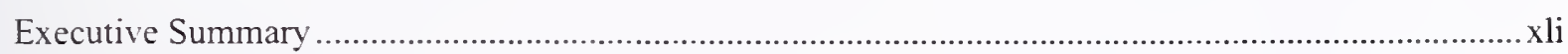

Chapter 1

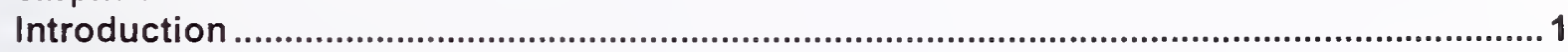

Chapter 2

Material Constitutive Modeling...................................................................................

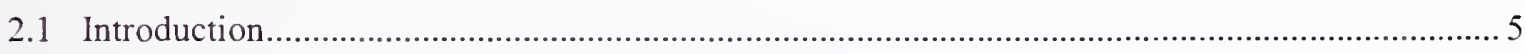

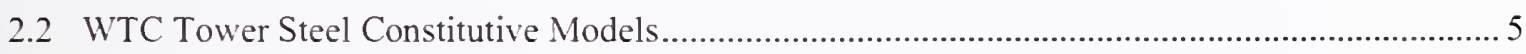

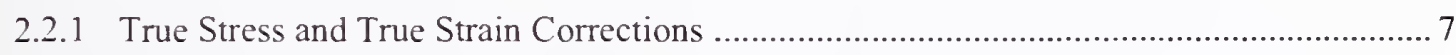

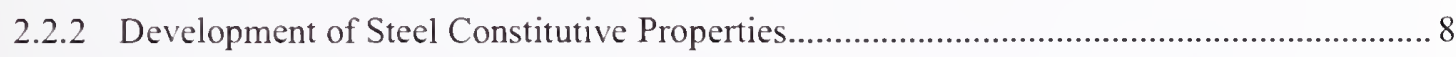

2.2.3 Summary of Steel Constitutive Properties ..................................................................... 11

2.2.4 Strain Rate Effects in Steel Constitutive Models ................................................. 14

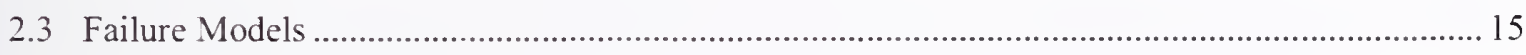

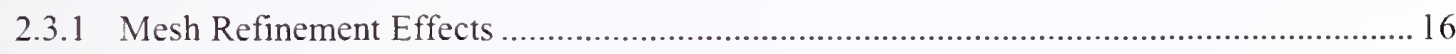

2.3.2 Weld Zone Constitutive Modeling ........................................................................... 19

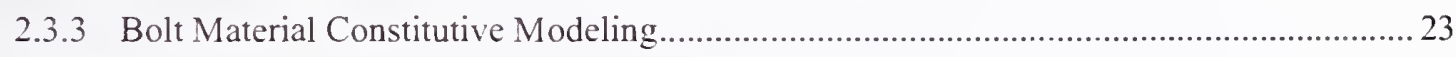

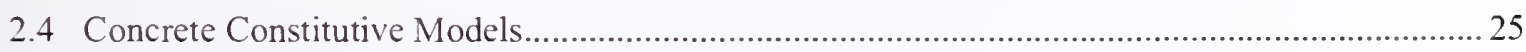

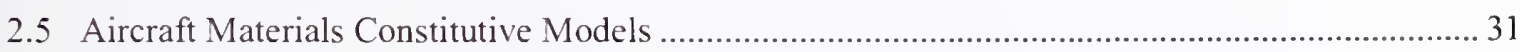

2.6 Nonstructural Materials Constitutive Models ..................................................................... 34

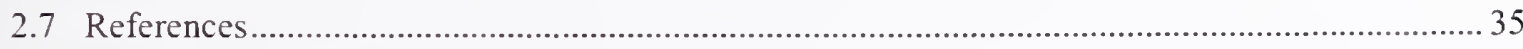

\section{Chapter 3}

Tower Model Development .................................................................................. 37

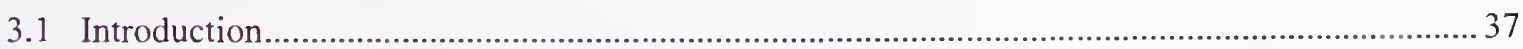

3.2 methodology for Tower Model Development ….................................................................. 37

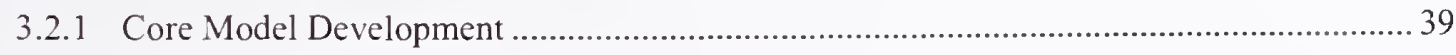

3.2.2 Exterior Wall Model Development .......................................................................... 44

NIST NCSTAR 1-2B, WTC Investigation vii 


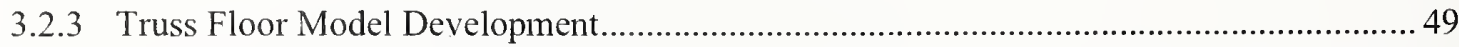

3.2.4 Interior Contents Model Development .................................................................... 52

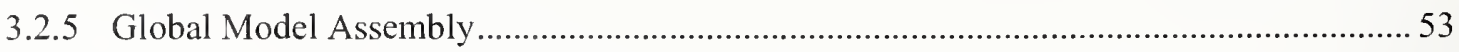

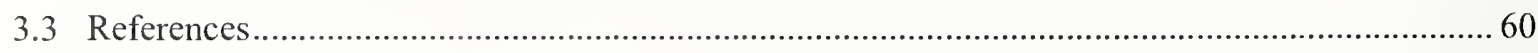

\section{Chapter 4}

Aircraft Model Development ...........................................................................................61

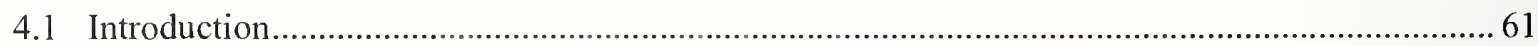

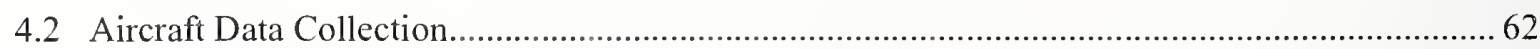

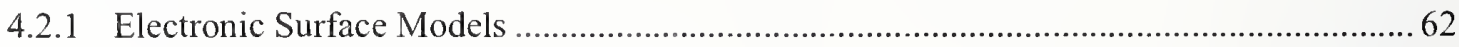

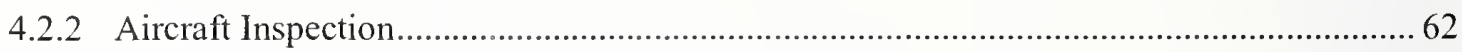

4.2.3 Pratt \& Whitney PW4000 Engine Reference Manuals ................................................... 66

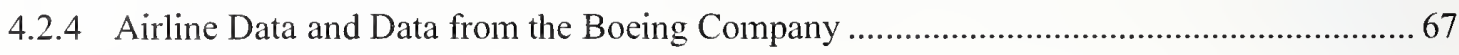

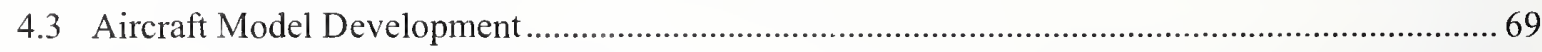

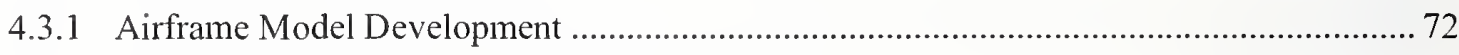

4.3.2 Wing Section Component Model Development........................................................... 76

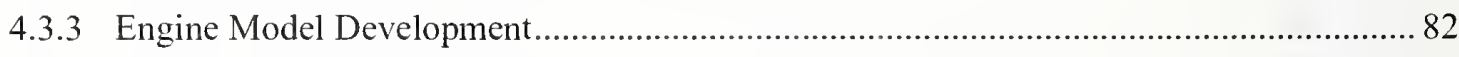

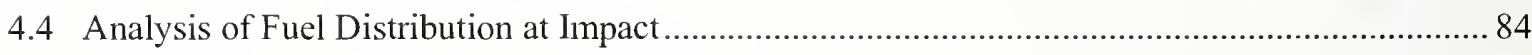

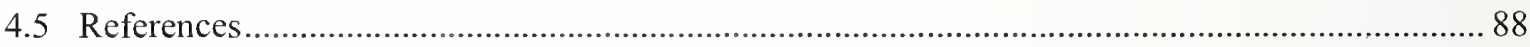

\section{Chapter 5}

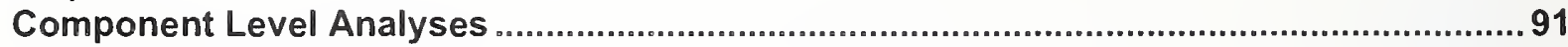

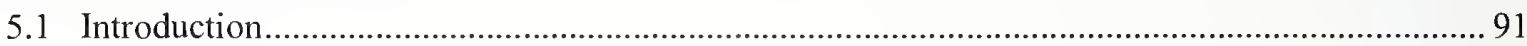

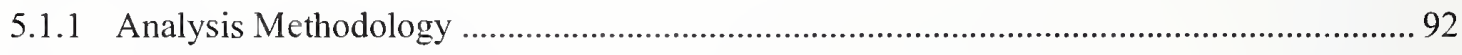

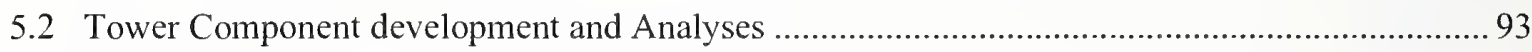

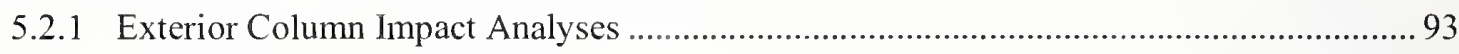

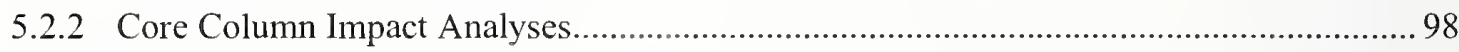

5.2.3 Bolted Connection Modeling ................................................................................... 101

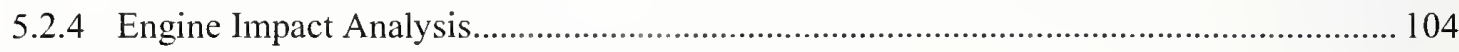

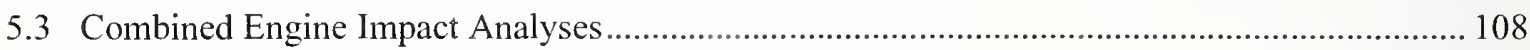

5.4 Floor Assembly Component Analyses.................................................................................. 110

5.5 Aircraft Wing Section Component Analyses.................................................................. 116

5.5.1 Empty Wing Section Component Model Development and Analysis ............................ 116

5.5.2 Modeling of Aircraft Wing Section Impact with Fuel .................................................. 124

5.5.3 Impact Analysis of a Wing Section with Fuel ......................................................... 126

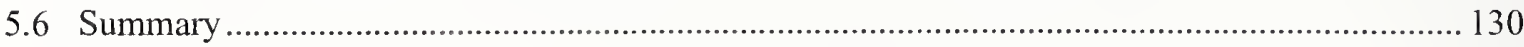




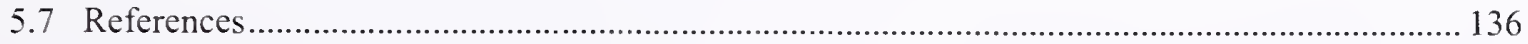

\section{Chapter 6}

Subassembly Impact Analyses .......................................................................... 137

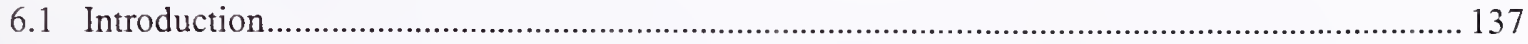

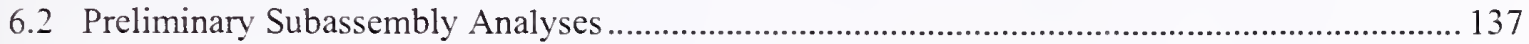

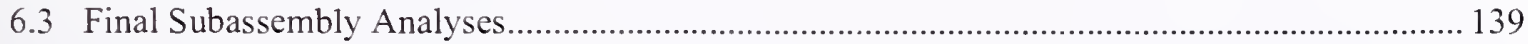

6.3.1 Engine Impact Subassembly Analyses ..................................................................... 142

6.3.2 Wing Section Impact Subassembly Analyses .............................................................. 150

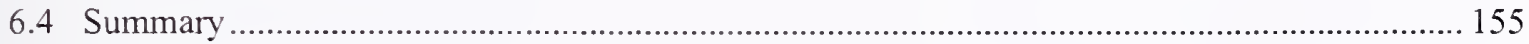

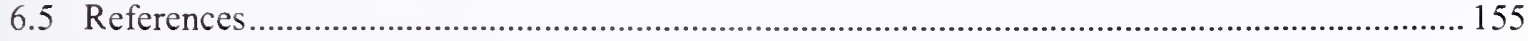

\section{Chapter 7}

Analyses of Aircraft Impact Conditions .................................................................... 157

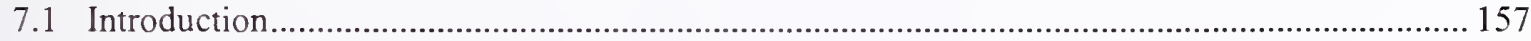

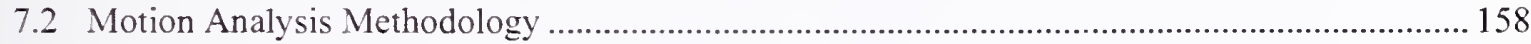

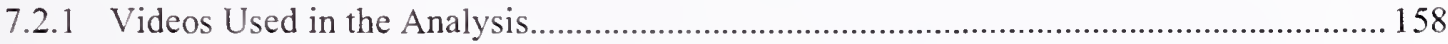

7.2.2 Complex Motion Analysis Procedures .......................................................................... 159

7.2.3 Simplified Motion Analysis Procedures........................................................................ 163

7.3 Refinement of Aircraft Impact Conditions .......................................................................... 166

7.4 Comparison with Alternate Aircraft Impact conditions .......................................................... 172

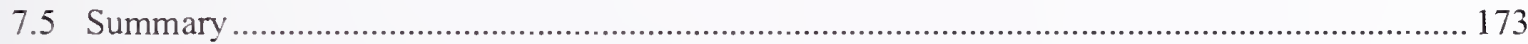

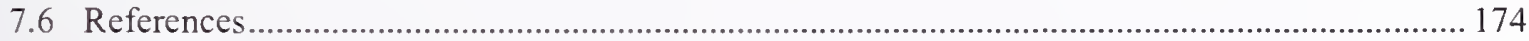

Chapter 8

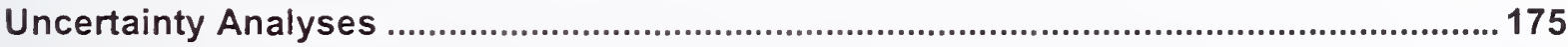

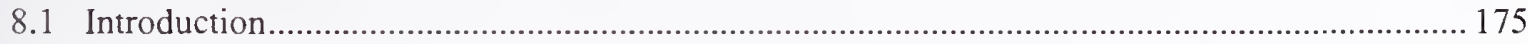

8.2 Component and Subassembly Level Uncertainty Analyses.................................................... 176

8.2.1 Engine - Core Column Component Uncertainty Analyses.............................................. 176

8.2.2 Empty Wing Segment - Exterior Panel Uncertainty Analysis ........................................ 182

8.2.3 Engine-Subassembly Uncertainty Analysis................................................................. 186

8.3 Global Impact Analyses parameter selection....................................................................... 191

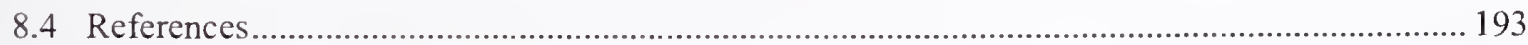

Chapter 9

Global Impact Analyses .................................................................................. 195

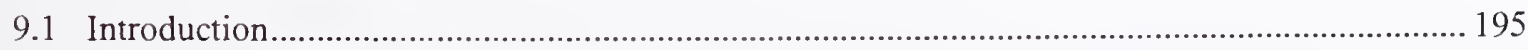


9.2 Assumptions and Limitations 195

9.3 Models for the base case Impact Analyses ...................................................................... 197

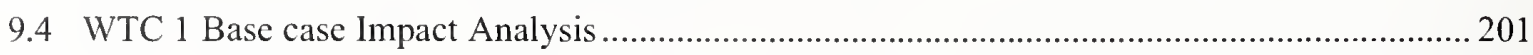

9.4.1 WTC 1 Base Case Impact Analysis - Structural Damage ............................................... 208

9.4.2 WTC 1 Base Case Impact Analysis - Fuel and Debris Distributions ............................. 218

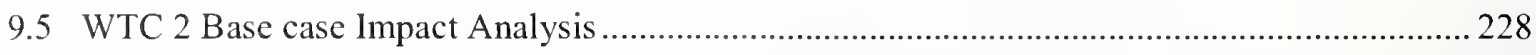

9.5.1 WTC 2 Base Case Impact Analysis - Structural Damage .............................................235

9.5.2 WTC 2 Base Case Impact Analysis - Fuel and Debris Distributions ............................. 246

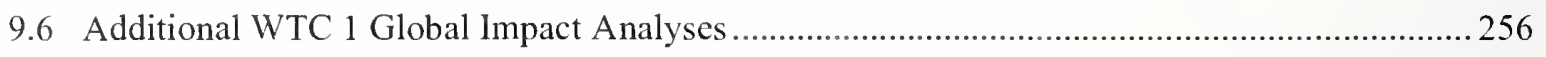

9.6.1 More Severe WTC 1 Global Impact Analysis ........................................................ 257

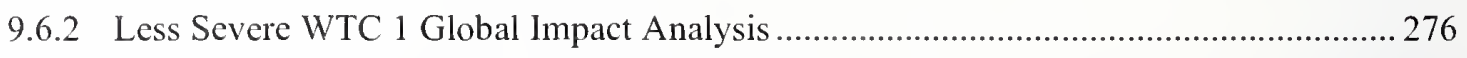

9.7 Additional WTC 2 Global Impact Analyses ..................................................................... 290

9.7.1 More Severe WTC 2 Global Impact Analyses .............................................................. 292

9.7.2 Less Severe WTC 2 Global Impact Analyses ............................................................ 312

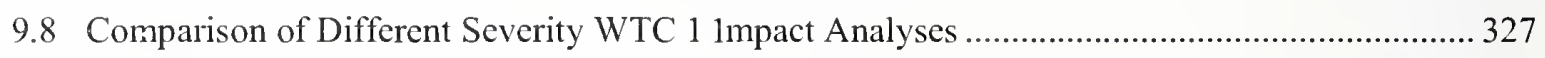

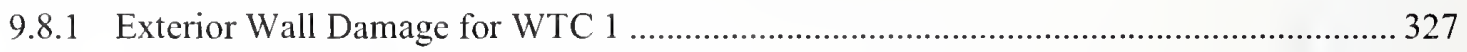

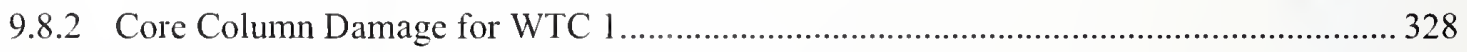

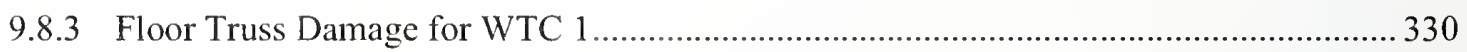

9.9 Comparison of Different Severity WTC 2 Impact Analyses ............................................... 331

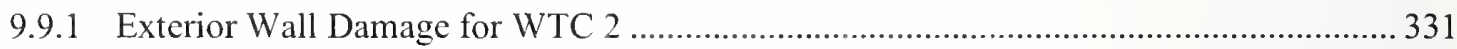

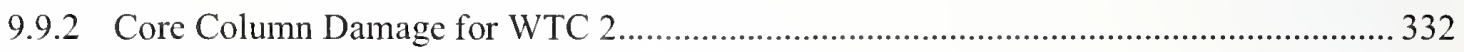

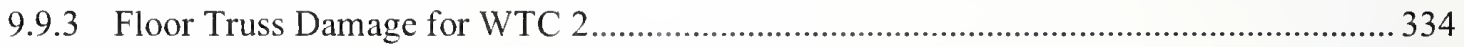

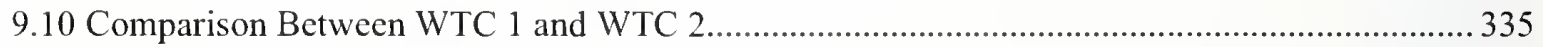

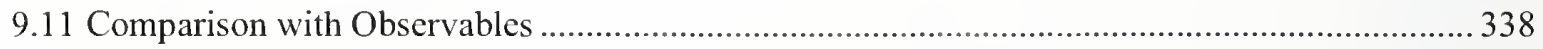

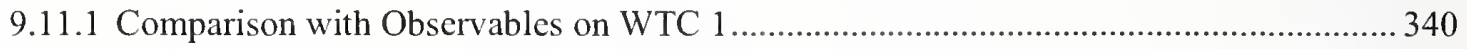

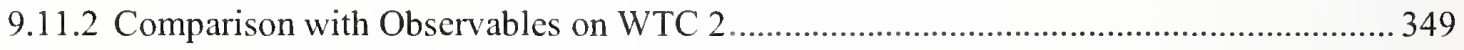

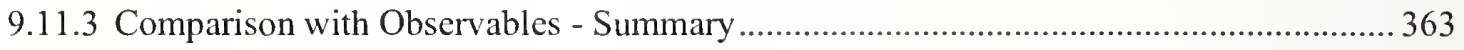

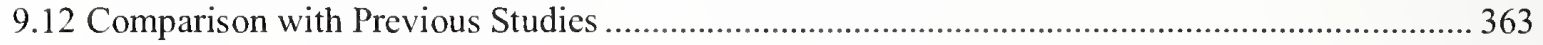

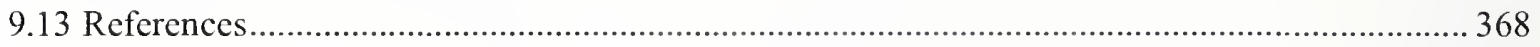

\section{Chapter 10}

Supporting Simplified Analyses ....................................................................... 369

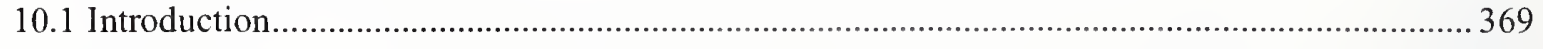

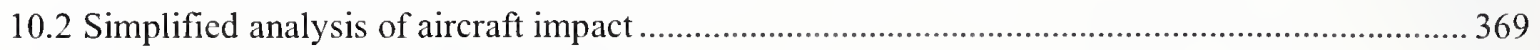

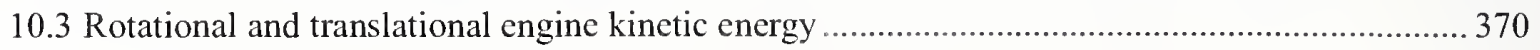




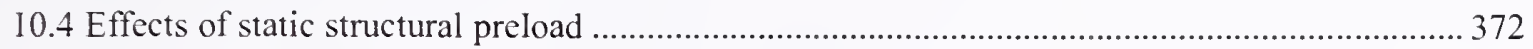

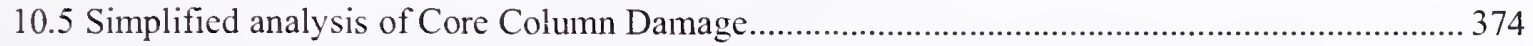

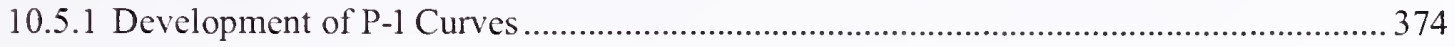

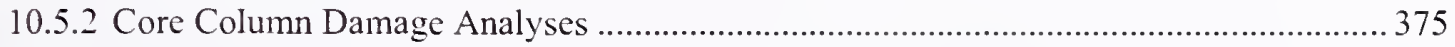

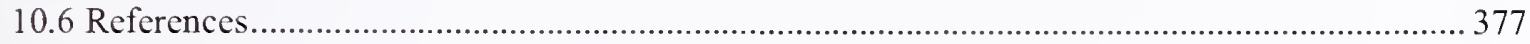

\section{Chapter 11}

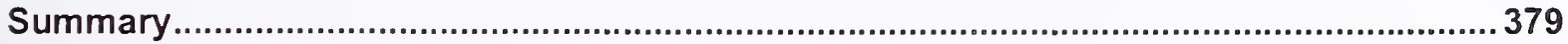

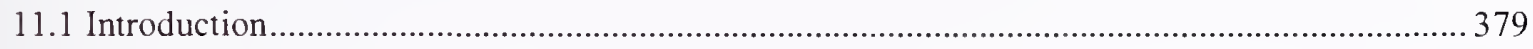

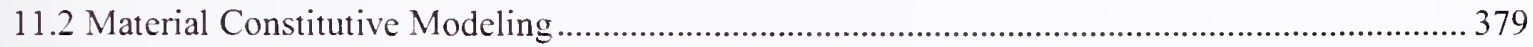

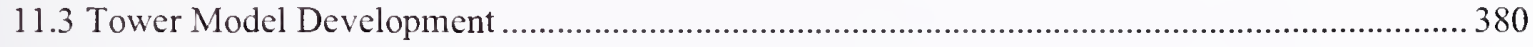

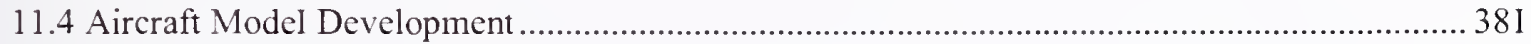

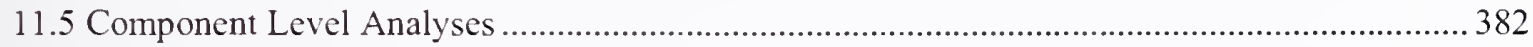

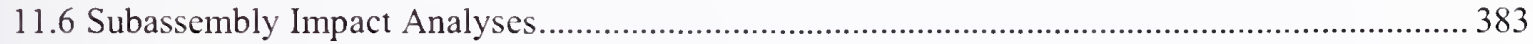

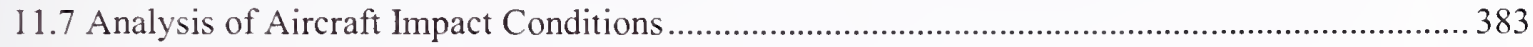

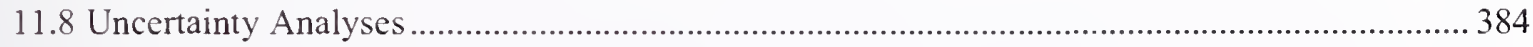

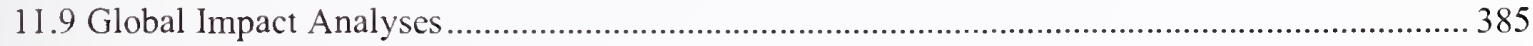

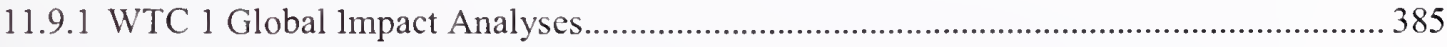

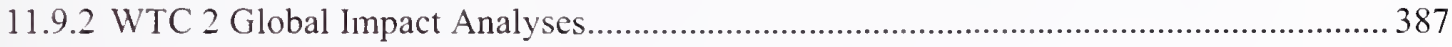

11.9.3 Different Severity Global Impact Analyses ............................................................. 388

11.9.4 Comparison with Observables...................................................................................... 390

11.9.5 Comparison with Previous Studies .......................................................................... 390

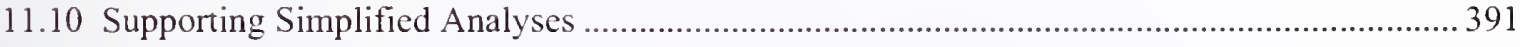

\section{Appendix A}

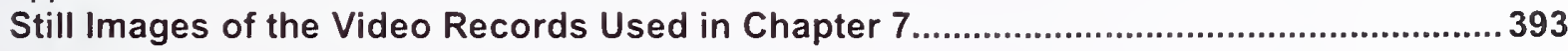


This page intentionally left blank. 


\section{LIST OF FIGURES}

Figure $\mathrm{P}-1$. The eight projects in the federal building and fire safety investigation of the WTC disaster. xxxi

Figure 2-1. Example finite element models of the ASTM 370 rectangular tensile specimen. 6

Figure 2-2. Example finite element models of the ASTM 370 round bar tensile specimen. 7

Figure 2-3. Test data and true stress-strain conversion for the $75 \mathrm{ksi}$ steel...................................... 9

Figure 2-4. Tabular true stress-strain constitutive model curve for the $75 \mathrm{ksi}$ steel............................ 9

Figure 2-5. Calculated tensile test response with necking for the $75 \mathrm{ksi}$ steel. ................................. 10

Figure 2-6. Comparison of measured and calculated engineering stress-strain curves for the $75 \mathrm{ksi}$ steel. 10

Figure 2-7. Comparison of the constitutive model and synthetic steel behaviors for the $75 \mathrm{ksi}$ steel.

Figure 2-8. Tabular true stress-strain constitutive model curves. 12

Figure 2-9. Comparison of the constitutive model and synthetic steel behaviors for the higher strength perimeter steels..

Figure 2-10. Comparison of the constitutive model and synthetic steel behaviors for the lower strength perimeter steels.

Figure 2-11. Comparison of the constitutive model and synthetic steel behaviors for the core steels.

Figure 2-12. Comparison of rate effects model and test data. 15

Figure 2-13. Calculated necking response in the $75 \mathrm{ksi}$ tensile specimen. .17

Figure 2-14. Coarse shell element mesh for the $75 \mathrm{ksi}$ tensile specimen. 18

Figure 2-15. Mesh refinement effects in the calculated $75 \mathrm{ksi}$ tensile test. 18

Figure 2-16. Photograph of an exterior column with weld zone fractures. 19

Figure 2-17. Micrograph of an exterior column weld geometry. 20

Figure 2-18. Microhardness characterization of the weld and HAZ materials. 20

Figure 2-19. Drop test model for column weld fracture analysis. 21

Figure 2-20. Models developed for column weld fracture analysis..... .22

Figure 2-21. Calculated energy balance for the 2-D weldment models. .22

Figure 2-22. Calculated drop test fracture behavior. .23

Figure 2-23. Measured bolt load-displacement behavior. 24

Figure 2-24. Comparison of the measured and calculated bolt behavior. 24

Figure 2-25. Intact and completely damaged concrete strength as a function of pressure. 26 
Figure 2-26. Finite element analysis of the unconfined compression test. 27

Figure 2-27. Comparison of the calculated unconfined compression behavior with concrete compression test data.

Figure 2-28. Comparison of the calculated unconfined compression behavior with lightweight concrete behavior.

Figure 2-29. Comparison of the calculated unconfined compression behavior of $3 \mathrm{ksi}$ and $4 \mathrm{ksi}$ concrete. 29

Figure 2-30. Strain rate effects on concrete compressive strength 30

Figure 2-31. Strain rate effects on concrete compressive strength. 30

Figure 2-32. Tabular concrete strain rate effects curve. 31

Figure 2-33. Digitized engineering stress-strain curves for various 2024 aluminum alloys. 32

Figure 2-34. Digitized engineering stress-strain curves for various 7075 aluminum alloys. 32

Figure 2-35. True stress-strain curves developed for various aircraft aluminum alloys. 33

Figure 2-36. True stress-strain curves developed for various aircraft aluminum alloys. 33

Figure 3-1. Model user interface for the core column generator. 38

Figure 3-2. User interface for exterior panel generator. 39

Figure 3-3. Model of the WTC 1 95th-97th core columns and connections. 40

Figure 3-4. Detail of wide flange core columns splices. 41

Figure 3-5. Detail of box columns-to-wide flange core columns splice. .42

Figure 3-6. Model of the WTC 196 th floor core columns and beams (with and without floor slab). .43

Figure 3-7. Model detail of core column and beam connections..................................................... 44

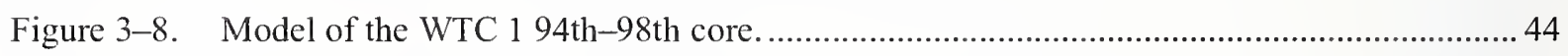

Figure 3-9. Example models for exterior wall panel types............................................................ 45

Figure 3-10. Impact face of the WTC 1 model - floors 91-101 ......................................................46

Figure 3-11. Impact face of the WTC 2 model - floors 75-86 .......................................................... 47

Figure 3-12. Model of spandrel splice plate connection.................................................................... 48

Figure 3-13. Placement of spandrel splice plates in the exterior wall model. ........................................ 48

Figure 3-14. Model of a truss floor segment. ................................................................................... 49

Figure 3-15. Truss floor connection detail at exterior wall. ............................................................ 50

Figure 3-16. Truss floor connection detail at core perimeter.............................................................50

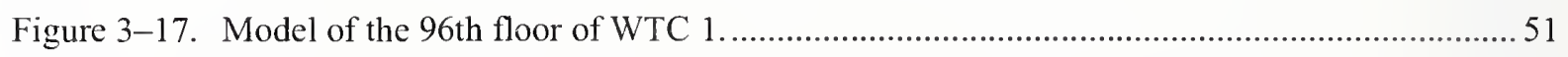

Figure 3-18. Model plan view and framing plan drawing of the 96 th floor of WTC 1....................... 51

Figure 3-19. Model of the 96th floor of WTC 1, including interior contents.....................................5 52

Figure 3-20. Coordinate system used for the WTC 1 model. .......................................................... 54 


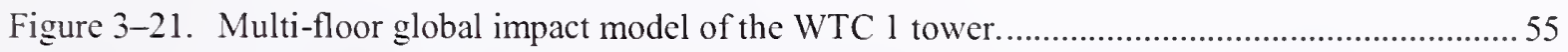

Figure 3-22. Interior structures and contents of the WTC 1 global impact model. ............................... 56

Figure 3-23. Building contents in the WTC 1 global impact model ...................................................... 57

Figure 3-24. Truss floor components in the WTC 1 global impact model. …...................................... 57

Figure 3-25. Far field truss floor model in the WTC towers. ........................................................... 58

Figure 3-26. Multi-floor global impact model of the WTC 2 tower..................................................... 59

Figure 3-27. Interior structures and contents of the WTC 2 global impact model...............................59

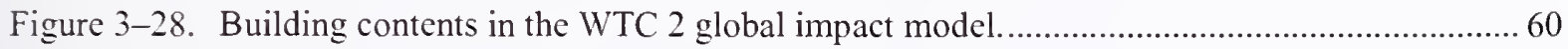

Figure 4-1. Surface models superimposed on Boeing CAD drawings of a 767-200ER....................... 62

Figure 4-2. Superimposed CAD drawings of the 767-200ER and 767-300ER .................................63

Figure 4-3. Photographic documentation of Boeing 767-300ER. …................................................. 64

Figure 4-4. Ultrasonic thickness measurement of landing gear components. .................................... 65

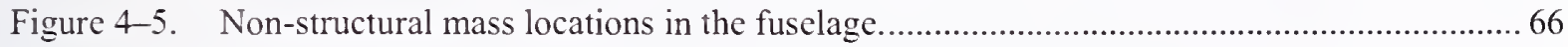

Figure 4-6. Cutaway of a Pratt and Whitney PW4000 turbofan from the Engine Reference Manual.

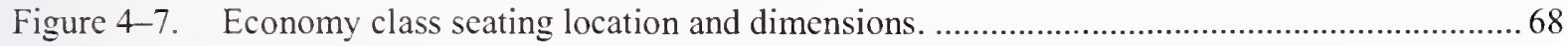

Figure 4-8. Location and characteristics of the unit load devices......................................................69

Figure 4-9. Finite element model of the Boeing 767-200ER ........................................................ 70

Figure 4-10. Boeing 767-200ER with fuel load at time of impact. .................................................... 71

Figure 4-11. Boeing 767-200ER model wing deflections. ........................................................... 72

Figure 4-12. Empennage model for the 767-200ER aircraft model. ................................................ 73

Figure 4-13. Retracted landing gear components for the 767-200ER aircraft model........................... 73

Figure 4-14. Underside of the 767 airframe model (skin removed) showing retracted landing gear...... 74

Figure 4-15. Complete wing structures for the Boeing 767 aircraft model........................................ 74

Figure 4-16. Wing structural diagram of a Boeing 767-200 ......................................................... 75

Figure 4-17. Model of fuselage interior frame and stringer construction......................................... 75

Figure 4-18. Integration of the fuselage and wing structures........................................................ 76

Figure 4-19. Wing section model for component level and subassembly analyses............................... 77

Figure 4-20. Simplified wing section model and impact analysis used for the effective skin model

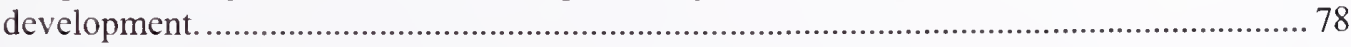

Figure 4-21. Riveted joint configuration and failure data under mixed-mode loading. ........................ 79

Figure 4-22. Comparison of wing section damage with the different modeling options........................ 80

Figure 4-23. Kinetic energy of the wing model............................................................................ 80

Figure 4-24. Internal energy of the exterior column......................................................................... 81 
Figure 4-25. Damage to an exterior column from a wing section with each skin type 81

Figure 4-26. Pratt \& Whitney PW4000 turbofan engine. 82

Figure 4-27. PW4000 engine cross-sectional geometry and simplification. 82

Figure 4-28. PW4000 engine cross-sectional geometry digitization. 83

Figure 4-29. Pratt \& Whitney PW4000 turbofan engine model. 83

Figure 4-30. Flammable material locations in a Boeing 767. 85

Figure 4-31. Layout of fuel tanks in the Boeing 767 wing 85

Figure 4-32. Approximate fuel tank dimensions. 86

Figurc 4-33. Wing cross-sections at various rib locations. 87

Figure 4-34. Fuel tank capacity. 87

Figure 4-35. Approximate fuel locations for smooth and level flight. 88

Figure 5-1. Preliminary model of a wing section with fuel impacting an exterior column. 94

Figure 5-2. Calculated wing with fuel impact response on the exterior column. 95

Figure 5-3. Observed impact damage in the recovered WTC exterior columns. 96

Figure 5-4. Exterior column response comparison, showing contours of the displacement magnitude.

Figure 5-5. Exterior column response comparison, showing contours of the displacement magnitude.

Figure 5-6. Wide flange core column response comparison, showing contours of the displacement magnitude.

Figure 5-7. Displacement and kinetic energy comparison for wide flange core column wing impact analysis.

Figure 5-8. Box core column response comparison, showing contours of the displacement magnitude.

Figure 5-9. Displacement and kinetic energy comparison for box core column wing impact analysis.

Figure 5-10. Failure behavior observed in the external column bolted joints. .................................. 101

Figure 5-11. Typical bolt bearing shear failures of spandrel connections......................................... 102

Figure 5-12. Exterior column end connection treatments........................................................ 103

Figure 5-13. Failure comparison of exterior column end connection treatments................................ 103

Figure 5-14. Bolted spandrel connection treatments. ....................................................................... 104

Figure 5-15. Example engine impact analysis with exterior columns............................................ 105

Figure 5-16. Engine velocity history for the exterior wall impact.................................................. 106

Figure 5-17. Example engine impact analysis with different impact locations.................................. 107

Figure 5-18. Example engine impact analysis with different spandrel connection treatments............. 107 
Figure 5-19. Engine velocity history for the exterior wall impact............................................... 108

Figure 5-20. Example engine impact analysis with interior and exterior columns............................... 109

Figure 5-21. Example engine impact analysis with exterior and interior columns............................. 110

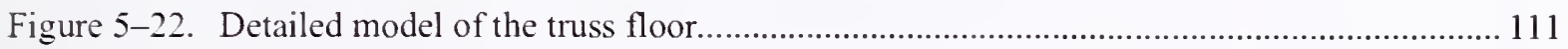

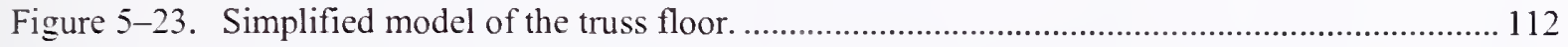

Figure 5-24. Constitutive behavior for the combined concrete and metal decking. .......................... 113

Figure 5-25. Floor assembly impact analysis with brick element concrete slab.................................. 114

Figure 5-26. Floor assembly impact analysis with shell element concrete slab. ............................. 115

Figure 5-27. Comparison of brick and shell element floor assembly impact analyses......................... 116

Figure 5-28. Empty wing section impact model with two exterior panels. ......................................... 117

Figure 5-29. Wing segment showing the initial impact conditions on the exterior panels.................... 118

Figure 5-30. Coarse and fine mesh used in the small wing component model................................... 118

Figure 5-31. Calculated impact of a fine-mesh empty wing section with two exterior panels at $442 \mathrm{mph}$.

Figure 5-32. Fine-mesh empty wing section impact damage to the exterior panel............................ 120

Figure 5-33. Failure modeling approaches for the coarse wing section model. .................................. 121

Figure 5-34. Wing section response for two material failure criteria................................................. 122

Figure 5-35. Fine and coarse mesh fragmentation........................................................................ 123

Figure 5-36. Aluminum model for coarse-mesh aircraft components............................................. 124

Figure 5-37. Calculated impact of a coarse-mesh empty wing section with two exterior panels at $442 \mathrm{mph}$.

Figure 5-38. Impact damage to the exterior panel from a coarse-mesh empty wing section at 442 mph contours of effective plastic strain are shown.................................................... 126

Figure 5-39. SPH and ALE fuel in the small wing segment................................................... 127

Figure 5-40. Wing segment, fuel, and exterior panel configuration............................................... 128

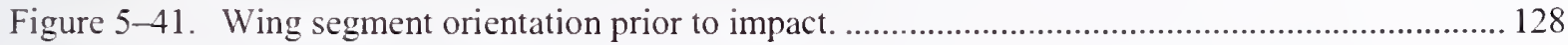

Figure 5-42. Calculated impact of a coarse mesh wing section laden with fuel modeled using ALE elements.

Figure 5-43. Calculated impact of a coarse mesh wing section laden with fuel modeled using SPH particles.

Figure 5-44. Exterior panels after impact with a wing segment with fuel......................................... 133

Figure 5-45. SPH analysis of structural damage and fuel dispersion at 0.04 s (top view).................... 133

Figure 5-46. ALE analysis of structural damage and fuel dispersion at 0.04 s (top view).................... 134

Figure 5-47. SPH analysis of structural damage and fuel dispersion (side view).............................. 134

Figure 5-48. ALE analysis of structural damage and fuel dispersion (side view).............................. 135 


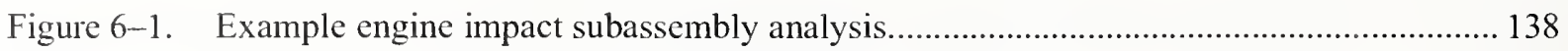

Figure 6-2. Oblique view of the subassembly engine impact damage. ........................................... 139

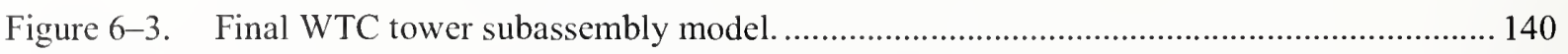

Figure 6-4. Details of the final WTC tower subassembly model. ................................................ 141

Figure 6-5. Final subassembly model for engine impact analysis................................................. 143

Figure 6-6. Calculated response for the baseline engine impact analysis....................................... 143

Figure 6-7. Baseline engine impact and break up behavior (side view) .......................................... 144

Figure 6-8. Speed history for the baseline engine subassembly impact analysis. .............................. 145

Figure 6-9. Effect of the building content strength on engine impact behavior. ............................... 146

Figure 6-10. Engine impact for concrete strength evaluation (side view) ....................................... 147

Figure 6-11. Effect of the concrete strength on engine impact behavior.......................................... 148

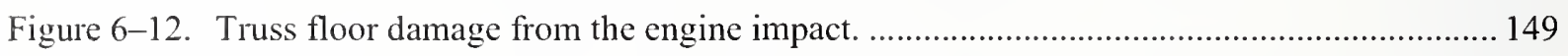

Figure 6-13. Final subassembly model for wing section impact analysis. .......................................... 150

Figure 6-14. Baseline wing section impact and break up behavior (side view). ................................. 151

Figure 6-15. Impactor momentum histories for the engine and wing section analyses........................ 152

Figure 6-16. Exterior wall damage for the wing section impact analyses......................................... 153

Figure $6-17$. Effect of the weld strength on wing section impact response. ....................................... 154

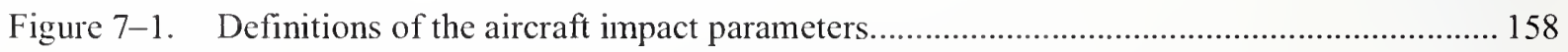

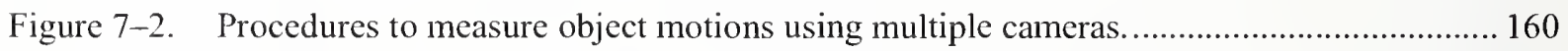

Figure 7-3. Reference locations on the WTC towers for video footage motion analysis................... 161

Figure 7-4. Plan view of the reference locations on the WTC towers........................................... 162

Figure 7-5. Simplified motion analysis procedure to determine aircraft speed.................................. 163

Figure 7-6. Dimensions of the Boeing 767-200 aircraft and fuselage.............................................. 164

Figure 7-7. Estimated impact locations of aircraft components superimposed on the damaged

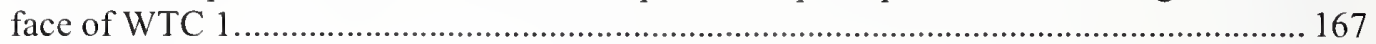

Figure 7-8. An orientation and trajectory of AA 11 that matches the impact pattern (vertical approach angle $=10.6^{\circ}$, lateral approach angle $=0^{\circ}$ ).

Figure 7-9. Estimated impact locations of aircraft components superimposed on the damaged

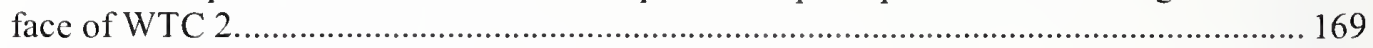

Figure 7-10. Baseline orientation and trajectory of UAL 175 from video analysis............................ 169

Figure 7-11. An orientation and trajectory of UAL 175 that matches the impact pattern (vertical approach angle $=6^{\circ}$, lateral approach angle $=13^{\circ}$ ).

Figure 7-12. An orientation and trajectory of UAL 175 that matches the impact pattern (vertical approach angle $=6^{\circ}$, lateral approach angle $=17^{\circ}$ ) 
Figure 7-13. Projected trajectory of the starboard engine of UAL 175 with an initial lateral approach angle of $13^{\circ}$.

Figure 8-1. Example engine impact into an assembly of core columns. 177

Figure 8-2. Measures of cross-section damage to a core column. 180

Figure 8-3. Main effects plot for the engine - core column impact analyses. 181

Figure 8-4. Impact configuration for the wing-panel analyses. 182

Figure 8-5. Wing segment showing the variation in impact conditions on the exterior panels. 184

Figure 8-6. Main effects plot for the wing-panel impact analyses. 185

Figure 8-7. Impact configuration for the engine-subassembly impact analyses. 187

Figure 8-8. Variation in vertical impact location for the engine-subassembly impact analyses. 188

Figure 8-9. Main effects plot for the engine subassembly impact analyses. 189

Figure 8-10. Engine impact response and trajectory for run 1. 190

Figure 9-1. WTC 1 global impact model. 199

Figure 9-2. WTC 2 global impact model. 200

Figure 9-3. WTC 1 base case global impact model. 201

Figure 9-4. WTC 1 base case global impact analysis (side view). 202

Figure 9-5. WTC 1 base case global impact analysis (plan view). 204

Figure 9-6. Normalized aircraft momentum for the WTC 1 base case impact..................................206

Figure 9-7. Aircraft breakup and debris in the base case WTC 1 impact........................................ 207

Figure 9-8. Base case impact damage to the WTC 1 exterior wall....................................................209

Figure 9-9. Base case impact damage to the WTC 1 core frame structures. .......................................210

Figure 9-10. Base case impact damage to the WTC 1 core columns. ............................................... 212

Figure 9-11. Summary of core column damage for the base case WTC 1 impact. ............................213

Figure 9-12. Classification of damage levels in core columns.......................................................214

Figure 9-13. Base case impact damage to the WTC 1 core floor framing (plan view), ........................215

Figure 9-14. Base case impact damage to the WTC 1 floor trusses (front view).................................216

Figure 9-15. Base case impact damage to the WTC 1 floor trusses (plan view)................................ 217

Figure 9-16. Base case impact damage to the WTC 1 floor slab (plan view). ....................................218

Figure 9-17. Calculated fuel distribution in the base case WTC 1 analysis (plan view).....................220

Figure 9-18. Calculated fuel distribution in the base case WTC 1 analysis (side view). ..................... 221

Figure 9-19. Calculated WTC 1 building contents, fuel, and aircraft debris distribution. ....................222

Figure 9-20. Calculated floor 94 contents, fuel, and aircraft debris distribution...................................2223

Figure 9-21. Calculated floor 95 contents, fuel, and aircraft debris distribution..................................224 
Figure 9-22. Calculated floor 96 contents, fuel, and aircraft debris distribution. 225

Figure 9-23. Calculated floor 97 contents, fuel, and aircraft debris distribution. 226

Figure 9-24. Calculated floor 98 contents, fuel, and aircraft debris distribution. 227

Figure 9-25. WTC 2 base case global impact model. 229

Figure 9-26. WTC 2 base case global impact analysis (side view). 230

Figure 9-27. WTC 2 base case global impact analysis (plan view) 232

Figure 9-28. Normalized aircraft momentum for the WTC 2 base case impact. 235

Figure 9-29. Aircraft breakup and debris in the base case WTC 2 impact. 236

Figure 9-30. Base case impact damage to the WTC 2 exterior wall. 238

Figure 9-31. Base case impact damage to the WTC 2 core. 239

Figure 9-32. Base case impact damage to the WTC 2 core columns. 240

Figure 9-33. Summary of core column damage for the base case WTC 2 impact. 241

Figure 9-34. Base case impact damage to the WTC 2 core floor framing (plan view). 242

Figure 9-35. Base case impact damage to the WTC 2 floor truss (front view). 243

Figure 9-36. Base case impact damage to the WTC 2 floor trusses (plan view). 244

Figure 9-37. Base case impact damage to the WTC 2 floor slab (plan view). 245

Figure 9-38. Calculated fuel distribution in the base case WTC 2 analysis (plan view) 247

Figure 9-39. Calculated fuel distribution in the base case WTC 2 analysis (side view). 248

Figure 9-40. Calculated WTC 2 building contents, fuel, and aircraft debris distribution. 249

Figure 9-41. Calculated floor 78 contents, fuel, and aircraft debris distribution. 250

Figure 9-42. Calculated floor 79 contents, fuel, and aircraft debris distribution. 251

Figure 9-43. Calculated floor 80 contents, fuel, and aircraft debris distribution.. 252

Figure 9-44. Calculated floor 81 contents, fuel, and aircraft debris distribution. 253

Figure 9-45. Calculated floor 82 contents, fuel, and aircraft debris distribution.. 254

Figure 9-46. Calculated floor 83 contents, fuel, and aircraft debris distribution. 255

Figure 9-47. More severe WTC 1 global impact analysis (side view). 259

Figure 9-48. More severe WTC 1 global impact analysis (plan view) 261

Figure 9-49. More severe impact damage to the WTC 1 exterior wall. 263

Figure 9-50. More severe impact response of the WTC 1 core. 264

Figure 9-51. More severe impact response of the WTC 1 core columns. 265

Figure 9-52. More severe impact damage to the WTC 1 core floor framing (plan view). 266

Figure 9-53. Summary of core column damage for the more severe WTC 1 impact. 268

Figure 9-54. More severe impact damage to the WTC 1 floor truss (front view). 269

Figure 9-55. More severe impact damage to the WTC 1 floor truss (plan view). 270

Figure 9-56. More severe impact damage to the WTC 1 floor slabs (plan view). 271 
Figure 9-57. Calculated more severe WTC 1 impact response of floor 94 contents............................ 272

Figure 9-58. Calculated more severe WTC 1 impact response of floor 95 contents............................2 273

Figure 9-59. Calculated more severe WTC 1 impact response of floor 96 contents...........................274

Figure 9-60. Calculated more severe WTC 1 impact response of floor 97 contents............................275

Figure 9-61. Calculated more severe WTC 1 impact response of floor 98 contents............................2 276

Figure 9-62. Less severe impact damage to the WTC 1 exterior wall................................................277

Figure 9-63. Less severe impact response of the WTC 1 core. ........................................................2 279

Figure 9-64. Less severe impact response of the WTC 1 core columns............................................228

Figure 9-65. Less severe impact damage to the WTC 1 core floor framing (plan view). .....................281

Figure 9-66. Summary of core column damage for the less severe WTC 1 impact.............................282

Figure 9-67. Less severe impact damage to the WTC 1 floor truss (front view)...................................283

Figure 9-68. Less severe impact damage to the WTC 1 floor truss (plan view)..................................284

Figure 9-69. Less severe impact damage to the WTC 1 floor slab (plan view).................................... 285

Figure 9-70. Calculated less severe WTC 1 impact response of floor 94 contents. .............................286

Figure 9-71. Calculated less severe WTC 1 impact response of floor 95 contents............................2287

Figure 9-72. Calculated less severe WTC 1 impact response of floor 96 contents.............................228

Figure 9-73. Calculated less severe WTC 1 impact response of floor 97 contents. ............................289

Figure 9-74. Calculated less severe WTC 1 impact response of floor 98 contents. ............................. 290

Figure 9-75. More severe WTC 2 global impact analysis (side view). ............................................ 293

Figure 9-76. More severe WTC 2 global impact analysis (plan view) ............................................2295

Figure 9-77. More severe impact damage to the WTC 2 cxterior wall. .............................................297

Figure 9-78. More severe impact response of the WTC 2 core...................................................... 298

Figure 9-79. More severe impact response of the WTC 2 core columns. ...........................................2 299

Figure 9-80. More severe impact damage to the WTC 2 core floor framing (plan view).................... 300

Figure 9-81. Summary of core column damage for the more severc WTC 2 impact...........................302

Figure 9-82. Representative exterior wall strain rates for the more severe WTC 2 impact (vicw

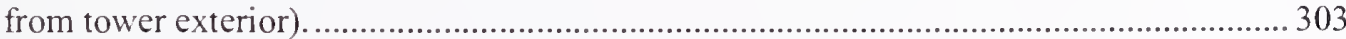

Figure 9-83. Representative core frame strain rates for the more severe WTC 2 impact (impact

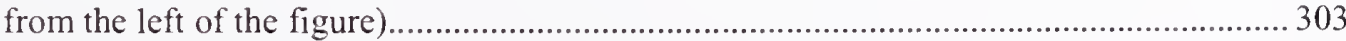

Figure 9-84. More severe impact damage to the WTC 2 floor truss (front view)..............................304

Figure 9-85. More severe impact damage to the WTC 2 floor truss (plan view)................................ 305

Figure 9-86. More severe impact damage to the WTC 2 floor slab (plan view)................................ 306

Figure 9-87. Calculated more severe WTC 2 impact response of floor 78 contents........................... 307

Figure 9-88. Calculated more severe WTC 2 impact response of floor 79 contents......................... 308

Figure 9-89. Calculated more severe WTC 2 impact response of floor 80 contents............................309 
Figure 9-90. Calculated more severe WTC 2 impact response of floor 81 contents. ........................... 310

Figure 9-91. Calculated more severe WTC 2 impact response of floor 82 contents. .......................... 311

Figure 9-92. Calculated more severe WTC 2 impact response of floor 83 contents.......................... 312

Figure 9-93. Less severe impact damage to the WTC 2 exterior wall............................................... 313

Figure 9-94. Less severe impact response of the WTC 2 core ........................................................ 315

Figure 9-95. Less severe impact response of the WTC 2 core columns............................................ 316

Figure 9-96. Less severe impact damage to the WTC 2 core floor framing (plan view)..................... 317

Figure 9-97. Summary of core column damage for the less severe WTC 2 impact. ............................ 318

Figure 9-98. Less severe impact damage to the WTC 2 floor truss (front view)................................... 319

Figure 9-99. Less severe impact damage to the WTC 2 floor truss (plan view). ................................ 320

Figure 9-100. Less severe impact damage to the WTC 2 floor slab (plan view).................................. 321

Figure 9-101. Calculated less severe WTC 2 impact response of floor 78 contents. ............................. 322

Figure 9-102. Calculated less severe WTC 2 impact response of floor 79 contents. ............................ 323

Figure 9-103. Calculated less severe WTC 2 impact response of floor 80 contents. ............................. 324

Figure 9-104. Calculated less severe WTC 2 impact response of floor 81 contents. ............................ 325

Figure 9-105. Calculated less severe WTC 2 impact response of floor 82 contents. ........................... 326

Figure 9-106. Calculated less severe WTC 2 impact response of floor 83 contents. ........................... 327

Figure 9-107. Impact damage to the north exterior wall of WTC 1 ............................................... 328

Figure 9-108. Comparison of core column damage for the WTC 1 impact analyses.............................. 329

Figure 9-109. Comparison of floor truss damage for the WTC 1 impact analyses. ............................. 331

Figure 9-1 10. Impact damage to the south exterior wall of WTC 2 ............................................... 332

Figure 9-111. Comparison of core column damage for the WTC 2 impact analyses............................ 333

Figure 9-112. Comparison of floor truss damage for the WTC 2 impact analyses. .............................. 334

Figure 9-113. Comparison of base case impact damage to the exterior wall. ........................................ 336

Figure 9-1 14. Comparison of base case impact damage to the core columns. ....................................... 337

Figure 9-115. Comparison of base case impact damage to floor truss (front view).............................. 338

Figure 9-116. Impact damage to the exterior walls of the WTC towers..............................................339

Figure 9-117. Representative floor plan (based on floors 94 to 95 of WTC 1).................................... 340

Figure 9-1 18. Base case aircraft debris distribution in WTC 1...................................................... 341

Figure 9-1 19. More severe damage aircraft debris distribution in WTC 1....................................... 342

Figure 9-120. Less severe damage aircraft debris distribution in WTC 1 ....................................... 343

Figure 9-121. Damage to the south face of WTC 1 from the more severe damage global analysis......... 344

Figure 9-122. Landing gear found at the corner of West and Rector streets. ...................................... 345

Figure 9-123. Landing gear found embedded in exterior panel knocked free from WTC 1.................. 346

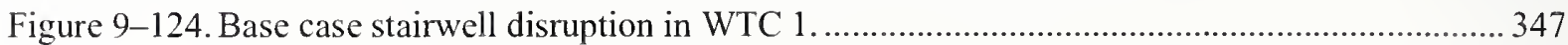


Figure 9-125. Calculated and observed WTC 1 damage (front view)................................................. 348

Figure 9-126. Impact Damage to the Northeast Corner of the Exterior Wall of WTC 2 ...................... 349

Figure 9-127. Documented damage to the 81 st floor of the northeast corner of WTC 2......................350

Figure 9-128. Base case analysis on the 81st floor of the northeast corner of WTC 2 .......................... 351

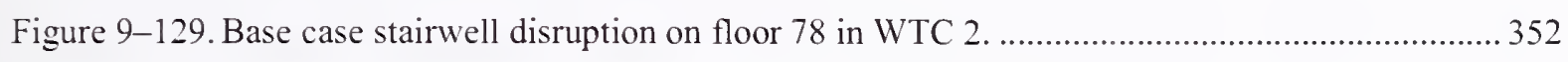

Figure 9-130. Base case damage aircraft debris distribution in WTC 2 ............................................ 354

Figure 9-131. Aircraft debris distribution in the more severe WTC 2 impact......................................355

Figure 9-132. Aircraft debris distribution in the less severe WTC 2 impact.........................................356

Figure 9-133. Starboard engine fragment trajectory in the base case global analysis of WTC 2........... 357

Figure 9-134. Speed of the aft portion of the starboard engine. ........................................................ 358

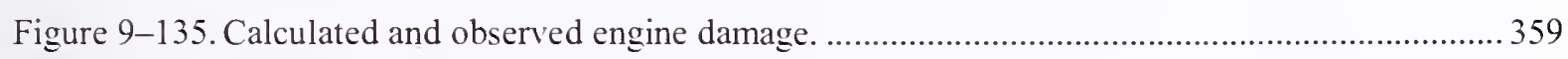

Figure 9-136. Starboard engine impact with the south face of WTC 2 in the base case global

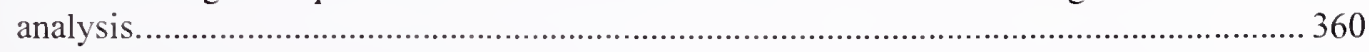

Figure 9-137. Projected debris path for the WTC 2 north face cold spot............................................. 362

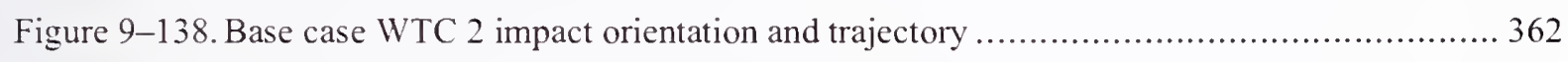

Figure 9-139. Comparison of impact damage to the WTC 1 exterior wall. ............................................ 365

Figure 9-140. Comparison of impact damage to the WTC 2 exterior wall. ......................................... 366

Figure 10-1. Internal components of the aircraft engine model.................................................. 371

Figure 10-2. Problem geometry for analysis of axial preload effects............................................... 372

Figure 10-3. Dynamic column response with and without axial preload. …..................................... 373

Figure 10-4. Development of damage and failure P-1 curves for a structure..................................... 375

Figure 10-5. Core column P-I failure curves and concentrated fuel impact loading........................... 376

Figure 10-6. P-I curves and expanded fuel cloud impact loading. ................................................. 377 
This page intentionally left blank. 


\section{LIST OF TABLES}

Table P-1. Federal building and fire safety investigation of the WTC disaster...............................xxx

Table P-2. Public meetings and briefings of the WTC Investigation. xxxiii

Table 2-1. Material constitutive parameter table - WTC tower steels........................................... 15

Table 2-2. Strength parameters for the concrete material model. .....................................................26

Table 3-1. Summary of superimposed dead loads and live loads (per floor).................................... 53

Table 3-2. Summary of the global impact models for the WTC towers........................................... 60

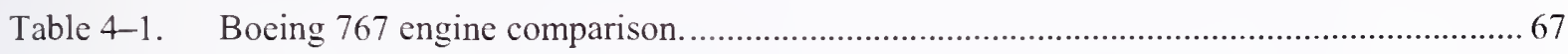

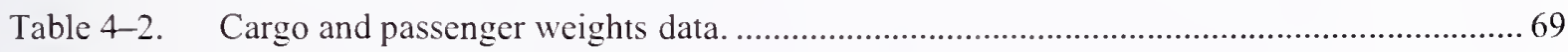

Table 4-3. Boeing 767-200ER aircraft model parameters.......................................................... 71

Table 4-4. Density scale factors and weights for aircraft components............................................ 77

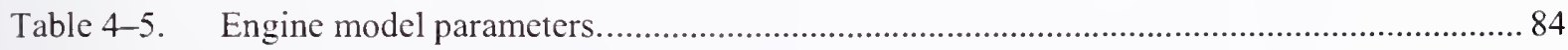

Table 5-1. Exterior column component analyses comparison...................................................... 97

Table 5-2. Truss floor assembly component analyses comparison. .................................................. 111

Table 5-3. Wing with fuel component modeling parameters. ......................................................... 127

Table 5-4. Fuel and air model parameters................................................................................... 129

Table 7-1. Videos used for the analysis of aircraft impact conditions. .......................................... 159

Table 7-2. Measured UAL 175 impact speed using the simplified analysis technique..................... 165

Table 7-3. Summary of measured aircraft impact conditions from video analysis.......................... 166

Table 7-4. Summary of refined aircraft impact conditions. ................................................... 170

Table 7-5. Aircraft impact locations on the WTC towers. ....................................................... 170

Table 7-6. AA 11 (WTC 1) aircraft impact analysis comparison. ................................................ 173

Table 7-7. UAL 175 (WTC 2) aircraft impact analysis comparison............................................ 173

Table 8-1. Engine-core column impact uncertainty parameters.................................................. 178

Table 8-2. Fractional factorial $2^{13-9}$ experimental design (with centerpoint) for the engine- core column impact analyses. .................................................................................. 179

Table 8-3. Wing-panel impact uncertainty parameters. ........................................................... 183

NIST NCSTAR 1-2B, WTC Investigation XXV 
Table 8-4. Fractional factorial $2^{13-9}$ experimental design (with centerpoint) for the wing-panel

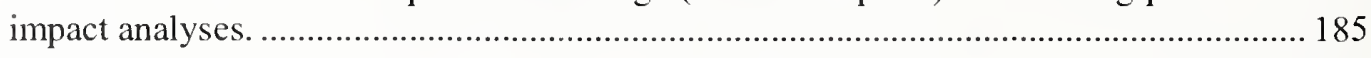

Table 8-5. Engine-subassembly impact uncertainty parameters. ............................................. 187

Table 8-6. Placket-Burman experimental design of 11 factors for the engine-subassembly

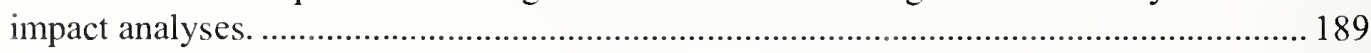

Table 8-7. Summary of significant modeling parameters. ........................................................... 192

Table 9-1. Summary of the WTC global impact models................................................................. 198

Table 9-2. Summary of base case impact conditions. .................................................................. 198

Table 9-3. Summary of core column damage for the base case WTC 1 impact. ............................213

Table 9-4. Fuel and aircraft debris distribution for the base case WTC 1 impact............................228

Table 9-5. Summary of core column damage for the base case WTC 2 impact. ........................... 241

Table 9-6. Fuel and aircraft debris distribution for the base case WTC 2 impact............................ 256

Table 9-7. Input parameters for additional WTC 1 global impact analyses..................................... 257

Table 9-8. Core column response for the more severe WTC 1 impact. ..........................................267

Table 9-9. Core column response for the less severe WTC 1 impact. ...........................................2 278

Table 9-10. Input parameters for additional WTC 2 global impact analyses....................................291

Table 9-11. Core column response for the more severe WTC 2 impact. .......................................... 301

Table 9-12. Core column response for the less severe WTC 2 impact. ............................................ 318

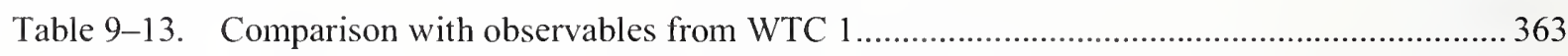

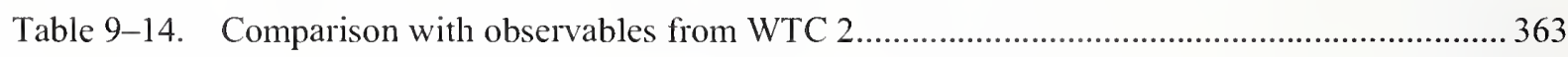

Table 9-15. Comparison of damage to core columns from various studies. ...................................... 367

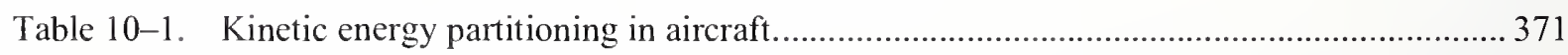




\section{LIST OF ACRONYMS AND ABBREVIATIONS}

\section{Acronyms}

$\begin{array}{ll}\text { AA } & \text { American Airlines } \\ \text { ALE } & \text { Arbitrary-Lagrangian-Eulerian } \\ \text { ARA } & \text { Applied Research Associates, Incorporated } \\ \text { ASTM } & \text { American Society for Testing and Materials } \\ \text { CPU } & \text { central processing unit } \\ \text { FEMA } & \text { Federal Emergency Management Agency } \\ \text { HAZ } & \text { heat affected zone } \\ \text { LERA } & \text { Leslie E. Robertson Associates } \\ \text { LSTC } & \text { Livermore Software Technology Corporation } \\ \text { MIT } & \text { Massachusetts Institute of Technology } \\ \text { MDF } & \text { medium density fiberboard } \\ \text { NIST } & \text { National Institute of Standards and Technology } \\ \text { SPH } & \text { Smoothed Particle Hydrodynamics } \\ \text { UAL } & \text { United Airlines } \\ \text { ULD } & \text { unit load device } \\ \text { WTC } & \text { World Trade Center } \\ \text { WTC 1 } & \text { World Trade Center 1 (North Tower) } \\ \text { WTC 2 } & \text { World Trade Center 2 (South Tower) } \\ \text { WTC 7 } & \text { World Trade Center 7 }\end{array}$

\section{Abbreviations}

$\pm \quad$ plus or minus

ft foot

$\mathrm{ft}^{2} \quad$ square foot

$\mathrm{ft}^{3} \quad$ cubic foot

gal gallon

$\mathrm{GHz} \quad$ gigahertz

in. inch 


$\begin{array}{ll}\text { kip } & \text { a force equal to } 1,000 \text { pounds } \\ \text { ksi } & 1,000 \text { pounds per square inch } \\ \mathrm{lb} & \text { pound } \\ \mathrm{min} & \text { minute } \\ \mathrm{mph} & \text { miles per hour } \\ \mathrm{ms} & \text { millisecond } \\ \mathrm{psf} & \text { pounds per square foot } \\ \text { psi } & \text { pounds per square inch } \\ \mathrm{s} & \text { second }\end{array}$




\section{PREFACE}

\section{Genesis of This Investigation}

Immediately following the terrorist attack on the World Trade Center (WTC) on September 11, 2001, the Federal Emergency Management Agency (FEMA) and the American Society of Civil Engineers began planning a building performance study of the disaster. The week of October 7, as soon as the rescue and search efforts ceased, the Building Performance Study Team went to the site and began its assessment. This was to be a brief effort, as the study team consisted of experts who largely volunteered their time away from their other professional commitments. The Building Performance Study Team issued its report in May 2002, fulfilling its goal "to determine probable failure mechanisms and to identify areas of future investigation that could lead to practical measures for improving the damage resistance of buildings against such unforeseen events."

On August 21, 2002, with funding from the U.S. Congress through FEMA, the National Institute of Standards and Technology (NIST) announced its building and fire safety investigation of the WTC disaster. On October 1, 2002, the National Construction Safety Team Act (Public Law 107-231), was signed into law. The NIST WTC Investigation was conducted under the authority of the National Construction Safety Team Act.

The goals of the investigation of the WTC disaster were:

- To investigate the building construction, the materials used, and the technical conditions that contributed to the outcome of the WTC disaster.

- To serve as the basis for:

- Improvements in the way buildings are designed, constructed, maintained, and used;

- Improved tools and guidance for industry and safety officials;

- Recommended revisions to current codes, standards, and practices; and

- Improved public safety.

The specific objectives were:

1. Determine why and how WTC 1 and WTC 2 collapsed following the initial impacts of the aircraft and why and how WTC 7 collapsed;

2. Determine why the injuries and fatalities were so high or low depending on location, including all technical aspects of fire protection, occupant behavior, evacuation, and emergency response;

3. Determine what procedures and practices were used in the design, construction, operation, and maintenance of WTC 1, 2, and 7; and

4. Identify, as specifically as possible, areas in current building and fire codes, standards, and practices that warrant revision. 
NIST is a nonregulatory agency of the U.S. Department of Commerce's Technology Administration. The purpose of NIST investigations is to improve the safety and structural integrity of buildings in the United States, and the focus is on fact finding. NIST investigative teams are authorized to assess building performance and emergency response and evacuation procedures in the wake of any building failure that has resulted in substantial loss of life or that posed significant potential of substantial loss of life. NIST does not have the statutory authority to make findings of fault nor negligence by individuals or organizations. Further, no part of any report resulting from a NIST investigation into a building failure or from an investigation under the National Construction Safety Team Act may be used in any suit or action for damages arising out of any matter mentioned in such report (15 USC 281a, as amended by Public Law 107-231).

\section{Organization of the Investigation}

The National Construction Safety Team for this Investigation, appointed by the then NIST Director, Dr. Arden L. Bement, Jr., was led by Dr. S. Shyam Sunder. Dr. William L. Grosshandler served as Associate Lead Investigator, Mr. Stephen A. Cauffman served as Program Manager for Administration, and Mr. Harold E. Nelson served on the team as a private sector expert. The Investigation included eight interdependent projects whose leaders comprised the remainder of the team. A detailed description of each of these eight projects is available at http://wtc.nist.gov. The purpose of each project is summarized in Table $\mathrm{P}-1$, and the key interdependencies among the projects are illustrated in Fig. P-1.

Table P-1. Federal building and fire safety investigation of the WTC disaster.

Technical Area and Project Leader

Analysis of Building and Fire Codes and Practices; Project Leaders: Dr. H. S. Lew and Mr. Richard W. Bukowski

Baseline Structural Performance and Aircraft Impact Damage Analysis; Project Leader: Dr. Fahim H. Sadek

Mechanical and Metallurgical Analysis of Structural Steel; Project Leader: Dr. Frank W. Gayle Investigation of Active Fire Protection Systems; Project Leader: Dr. David D. Evans; Dr. William Grosshandler Reconstruction of Thermal and Tenability Environment; Project Leader: Dr. Richard G. Gann

Structural Fire Response and Collapse Analysis; Project Leaders: Dr. John L. Gross and Dr. Therese P. McAllister

Occupant Behavior, Egress, and Emergency Communications; Project Leader: Mr. Jason D. Averill

Emergency Response Technologies and Guidelines; Project Leader: Mr. J. Randall Lawson

Project Purpose

Document and analyze the code provisions, procedures, and practices used in the design, construction, operation, and maintenance of the structural, passive fire protection, and emergency access and evacuation systems of WTC 1,2, and 7. Analyze the baseline performance of WTC 1 and WTC 2 under design, service, and abnormal loads, and aircraft impact damage on the structural, fire protection, and egress systems.

Determine and analyze the mechanical and metallurgical properties and quality of steel, weldments, and connections from steel recovered from WTC 1,2 , and 7 .

Investigate the performance of the active fire protection systems in WTC 1,2 , and 7 and their role in fire control, emergency response, and fate of occupants and responders.

Reconstruct the time-evolving temperature, thermal environment, and smoke movement in WTC 1, 2, and 7 for use in evaluating the structural performance of the buildings and behavior and fate of occupants and responders.

Analyze the response of the WTC towers to fires with and without aircraft damage, the response of WTC 7 in fires, the performance of composite steel-trussed floor systems, and determine the most probable structural collapse sequence for WTC 1, 2, and 7.

Analyze the behavior and fate of occupants and responders, both those who survived and those who did not, and the performance of the evacuation system.

Document the activities of the emergency responders from the time of the terrorist attacks on WTC 1 and WTC 2 until the collapse of WTC 7 , including practices followed and technologies used. 


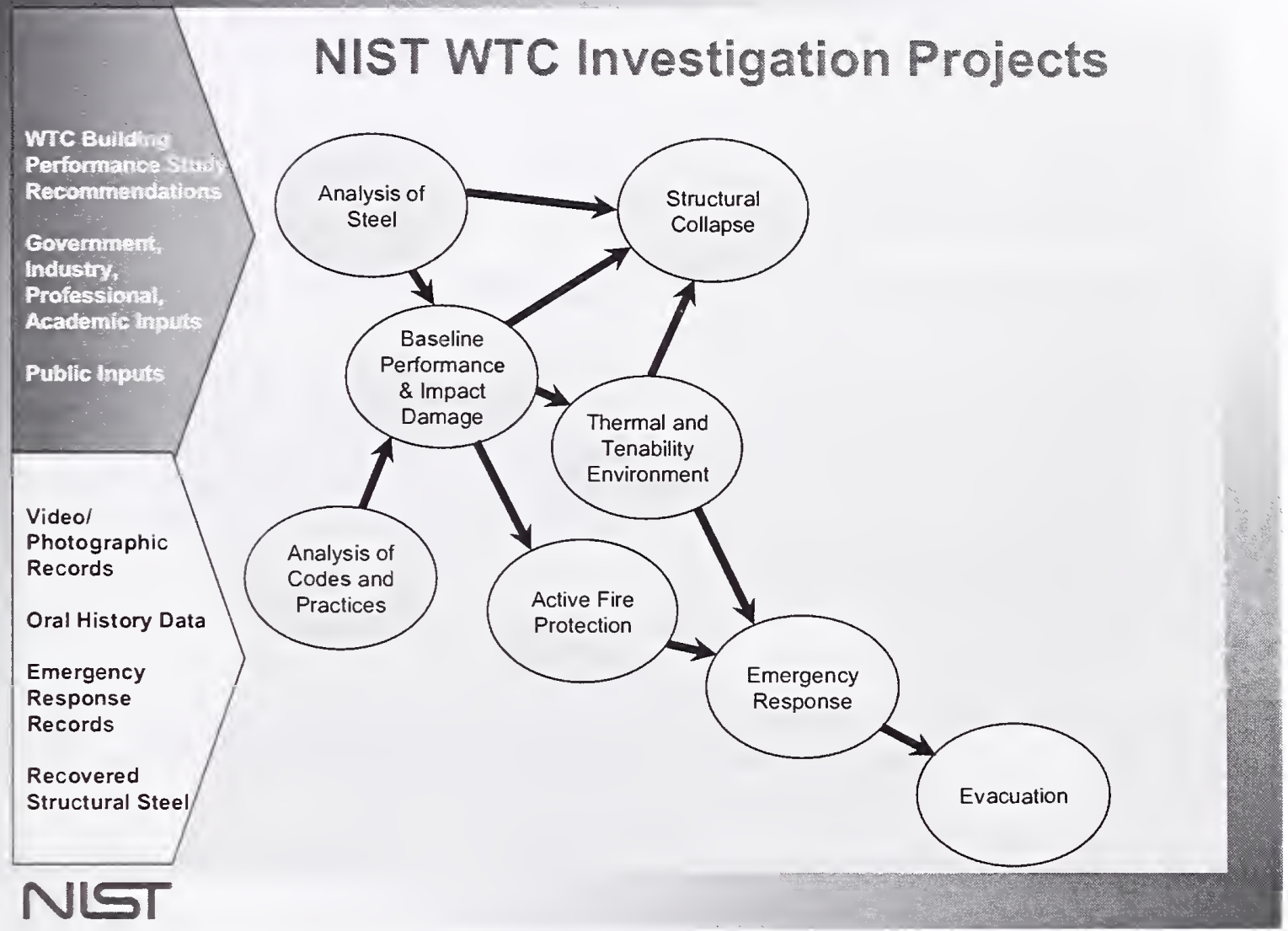

Figure P-1. The eight projects in the federal building and fire safety investigation of the WTC disaster.

\section{National Construction Safety Team Advisory Committee}

The NIST Director also established an advisory committee as mandated under the National Construction Safety Team Act. The initial members of the committee were appointed following a public solicitation. These were:

- Paul Fitzgerald, Executive Vice President (retired) FM Global, National Construction Safety Team Advisory Committee Chair

- John Barsom, President, Barsom Consulting, Ltd.

- John Bryan, Professor Emeritus, University of Maryland

- David Collins, President, The Preview Group, Inc.

- Glenn Corbett, Professor, John Jay College of Criminal Justice

- Philip DiNenno. President, Hughes Associates, Inc. 
- Robert Hanson, Professor Emeritus, University of Michigan

- Charles Thornton, Co-Chairman and Managing Principal, The Thornton-Tomasetti Group, Inc.

- Kathleen Tierney, Director, Natural Hazards Research and Applications Information Center, University of Colorado at Boulder

- Forman Williams, Director, Center for Energy Research, University of California at San Diego

This National Construction Safety Team Advisory Committee provided technical advice during the Investigation and commentary on drafts of the Investigation reports prior to their public release. NIST has benefited from the work of many people in the preparation of these reports, including the National Construction Safety Team Advisory Committee. The content of the reports and recommendations, however, are solely the responsibility of NIST.

\section{Public Outreach}

During the course of this Investigation, NIST held public briefings and meetings (listed in Table P-2) to solicit input from the public, present preliminary findings, and obtain comments on the direction and progress of the Investigation from the public and the Advisory Committee.

NIST maintained a publicly accessible Web site during this Investigation at http://wtc.nist.gov. The site contained extensive information on the background and progress of the Investigation.

\section{NIST's WTC Public-Private Response Plan}

The collapse of the WTC buildings has led to broad reexamination of how tall buildings are designed, constructed, maintained, and used, especially with regard to major events such as fires, natural disasters, and terrorist attacks. Reflecting the enhanced interest in effecting necessary change, NIST, with support from Congress and the Administration, has put in place a program, the goal of which is to develop and implement the standards, technology, and practices needed for cost-effective improvements to the safety and security of buildings and building occupants, including evacuation, emergency response procedures, and threat mitigation.

The strategy to meet this goal is a three-part NIST-led public-private response program that includes:

- A federal building and fire safety investigation to study the most probable factors that contributed to post-aircraft impact collapse of the WTC towers and the 47-story WTC 7 building, and the associated evacuation and emergency response experience.

- A research and development (R\&D) program to (a) facilitate the implementation of recommendations resulting from the WTC Investigation, and (b) provide the technical basis for cost-effective improvements to national building and fire codes, standards, and practices that enhance the safety of buildings, their occupants, and emergency responders. 
Table P-2. Public meetings and briefings of the WTC Investigation.

\begin{tabular}{|c|c|c|}
\hline Date & Location & Principal Agenda \\
\hline June 24,2002 & New York City, NY & $\begin{array}{l}\text { Public meeting: Public comments on the Draft Plan for the } \\
\text { pending WTC Investigation. }\end{array}$ \\
\hline August 21,2002 & Gaithersburg, MD & Media briefing announcing the formal start of the Investigation. \\
\hline December 9, 2002 & Washington, DC & $\begin{array}{l}\text { Media briefing on release of the Public Update and NIST request } \\
\text { for photographs and videos. }\end{array}$ \\
\hline April 8, 2003 & New York City, NY & $\begin{array}{l}\text { Joint public forum with Columbia University on first-person } \\
\text { interviews. }\end{array}$ \\
\hline April 29-30, 2003 & Gaithersburg, MD & $\begin{array}{l}\text { NCST Advisory Committee meeting on plan for and progress on } \\
\text { WTC Investigation with a public comment session. }\end{array}$ \\
\hline May 7,2003 & New York City, NY & Media briefing on release of May 2003 Progress Report. \\
\hline August $26-27,2003$ & Gaithersburg, MD & $\begin{array}{l}\text { NCST Advisory Committee meeting on status of the WTC } \\
\text { investigation with a public comment session. }\end{array}$ \\
\hline September 17,2003 & New York City, NY & $\begin{array}{l}\text { Media and public briefing on initiation of first-person data } \\
\text { collection projects. }\end{array}$ \\
\hline December 2-3, 2003 & Gaithersburg, MD & $\begin{array}{l}\text { NCST Advisory Committee meeting on status and initial results } \\
\text { and release of the Public Update with a public comment session. }\end{array}$ \\
\hline February 12,2004 & New York City. NY & $\begin{array}{l}\text { Public meeting on progress and preliminary findings with public } \\
\text { comments on issues to be considered in formulating final } \\
\text { recommendations. }\end{array}$ \\
\hline June 18.2004 & New York City. NY & Media/public briefing on release of June 2004 Progress Report. \\
\hline June $22-23,2004$ & Gaithersburg, MD & $\begin{array}{l}\text { NCST Advisory Committee meeting on the status of and } \\
\text { preliminary findings from the WTC Investigation with a public } \\
\text { comment session. }\end{array}$ \\
\hline August 24,2004 & Northbrook, IL & $\begin{array}{l}\text { Public viewing of standard fire resistance test of WTC floor } \\
\text { system at Underwriters Laboratories, Inc. }\end{array}$ \\
\hline October 19-20, 2004 & Gaithersburg, MD & $\begin{array}{l}\text { NCST Advisory Committee meeting on status and near complete } \\
\text { set of preliminary findings with a public comment session. }\end{array}$ \\
\hline November 22,2004 & Gaithersburg, MD & $\begin{array}{l}\text { NCST Advisory Committee discussion on draft annual report to } \\
\text { Congress, a public comment session, and a closed session to } \\
\text { discuss pre-draft recommendations for WTC Investigation. }\end{array}$ \\
\hline April 5, 2005 & New York City. NY & $\begin{array}{l}\text { Media and public briefing on release of the probable collapse } \\
\text { sequence for the WTC towers and draft reports for the projects on } \\
\text { codes and practices, evacuation, and energency response. }\end{array}$ \\
\hline June 23,2005 & New York City, NY & $\begin{array}{l}\text { Media and public briefing on release of all draft reports for the } \\
\text { WTC towers and draft recommendations for public comment. }\end{array}$ \\
\hline $\begin{array}{l}\text { September 12-13, } \\
2005\end{array}$ & Gaithersburg, MD & $\begin{array}{l}\text { NCST Advisory Committee meeting on disposition of public } \\
\text { comments and update to draft reports for the WTC towers. }\end{array}$ \\
\hline $\begin{array}{l}\text { September 13-15, } \\
2005\end{array}$ & Gaithersburg, MD & $\begin{array}{l}\text { WTC Technical Conference for stakeholders and technical } \\
\text { community for dissemination of findings and recommendations } \\
\text { and opportunity for public to make technical comments. }\end{array}$ \\
\hline
\end{tabular}

- A dissemination and technical assistance program (DTAP) to (a) engage leaders of the construction and building community in ensuring timely adoption and widespread use of proposed changes to practices, standards, and codes resulting from the WTC Investigation and the R\&D program, and (b) provide practical guidance and tools to better prepare facility owners, contractors, architects, engineers, emergency responders, and regulatory authorities to respond to future disasters.

The desired outcomes are to make buildings, occupants, and first responders safer in future disaster events. 


\section{National Construction Safety Team Reports on the WTC Investigation}

A final report on the collapse of the WTC towers is being issued as NIST NCSTAR 1. A companion report on the collapse of WTC 7 is being issued as NIST NCSTAR 1A. The present report is one of a set that provides more detailed documentation of the Investigation findings and the means by which these technical results were achieved. As such, it is part of the archival record of this Investigation. The titles of the full set of Investigation publications are:

NIST (National Institute of Standards and Technology). 2005. Federal Building and Fire Safety Investigation of the World Trade Center Disaster: Final Report on the Collapse of the World Trade Center Towers. NIST NCSTAR 1. Gaithersburg, MD, September.

NIST (National Institute of Standards and Technology). 2006. Federal Building and Fire Safety Investigation of the World Trade Center Disaster: Final Report on the Collapse of World Trade Center 7. NIST NCSTAR 1A. Gaithersburg, MD.

Lew, H. S., R. W. Bukowski, and N. J. Carino. 2005. Federal Building and Fire Safety Investigation of the World Trade Center Disaster: Design, Construction, and Maintenance of Structural and Life Safety Systems. NIST NCSTAR 1-1. National Institute of Standards and Technology. Gaithersburg, MD, September.

Fanella, D. A., A. T. Derecho, and S. K. Ghosh. 2005. Federal Building and Fire Safety Investigation of the World Trade Center Disaster: Design and Construction of Structural Systems. NIST NCSTAR 1-1A. National Institute of Standards and Technology. Gaithersburg, MD, September.

Ghosh, S. K., and X. Liang. 2005. Federal Building and Fire Safety Investigation of the World Trade Center Disaster: Comparison of Building Code Structural Requirements. NIST

NCSTAR 1-1B. National Institute of Standards and Technology. Gaithersburg, MD, September.

Fanella, D. A.. A. T. Derecho, and S. K. Ghosh. 2005. Federal Building and Fire Safety Investigation of the World Trade Center Disaster: Maintenance and Modifications to Structural Systems. NIST NCSTAR 1-1C. National Institute of Standards and Technology. Gaithersburg, MD, September.

Grill, R. A., and D. A. Johnson. 2005. Federal Building and Fire Safety Investigation of the World Trade Center Disaster: Fire Protection and Life Safety Provisions Applied to the Design and Construction of World Trade Center 1, 2, and 7 and Post-Construction Provisions Applied after Occupancy. NIST NCSTAR 1-1D. National Institute of Standards and Technology. Gaithersburg, $\mathrm{MD}$, September.

Razza, J. C., and R. A. Grill. 2005. Federal Building and Fire Safety Investigation of the World Trade Center Disaster: Comparison of Codes, Standards, and Practices in Use at the Time of the Design and Construction of World Trade Center 1, 2, and 7. NIST NCSTAR 1-1E. National Institute of Standards and Technology. Gaithersburg, MD, September.

Grill, R. A., D. A. Johnson, and D. A. Fanella. 2005. Federal Building and Fire Safety Investigation of the World Trade Center Disaster: Comparison of the 1968 and Current (2003) New 
York City Building Code Provisions. NIST NCSTAR 1-1F. National Institute of Standards and Technology. Gaithersburg, MD, September.

Grill, R. A., and D. A. Johnson. 2005. Federal Building and Fire Safety Investigation of the World Trade Center Disaster: Amendments to the Fire Protection and Life Safety Provisions of the New York City Building Code by Local Laws Adopted While World Trade Center 1, 2, and 7 Were in Use. NIST NCSTAR 1-1G. National Institute of Standards and Technology. Gaithersburg, MD, September.

Grill, R. A., and D. A. Johnson. 2005. Federal Building and Fire Safety Investigation of the World Trade Center Disaster: Post-Construction Modifications to Fire Protection and Life Safety Systems of World Trade Center 1 and 2. NIST NCSTAR 1-1H. National 1nstitute of Standards and Technology. Gaithersburg, MD, September.

Grill, R. A., D. A. Johnson, and D. A. Fanella. 2005. Federal Building and Fire Safety Investigation of the World Trade Center Disaster: Post-Construction Modifications to Fire Protection, Life Safety, and Structural Systems of World Trade Center 7. NIST NCSTAR 1-11. National Institute of Standards and Technology. Gaithersburg, MD, September.

Grill, R. A.. and D. A. Johnson. 2005. Federal Building and Fire Safety Investigation of the World Trade Center Disaster: Design, Installation, and Operation of Fuel System for Emergency Power in World Trade Center 7. NIST NCSTAR 1-1J. National 1nstitute of Standards and Technology. Gaithersburg, MD, September.

Sadek, F. 2005. Federal Building and Fire Safety Investigation of the World Trade Center Disaster: Baseline Structural Performance and Aircraft Impact Damage Analysis of the World Trade Center Tower's. NIST NCSTAR 1-2. National Institute of Standards and Technology. Gaithersburg, MD, September.

Faschan, W. J., and R. B. Garlock. 2005. Federal Building and Fire Safety Investigation of the World Trade Center Disaster: Reference Structural Models and Baseline Performance Analysis of the World Trade Center Towers. N1ST NCSTAR 1-2A. National 1nstitute of Standards and Technology. Gaithersburg, MD, September.

Kirkpatrick, S. W., R. T. Bocchieri, F. Sadek, R. A. MacNeill, S. Holmes, B. D. Peterson, R. W. Cilke, C. Navarro. 2005. Federal Building and Fire Safety Investigation of the World Trade Center Disaster: Analysis of Aircraft Impacts into the World Trade Center Towers, NIST NCSTAR 1-2B. National Institute of Standards and Technology. Gaithersburg, MD, September.

Gayle, F. W., R. J. Fields, W. E. Luecke, S. W. Banovic, T. Foecke, C. N. McCowan, T. A. Siewert, and J. D. McColskey. 2005. Federal Building and Fire Safety Investigation of the World Trade Center Disaster: Mechanical and Metallurgical Analysis of Structural Steel. NIST NCSTAR 1-3. National Institute of Standards and Technology. Gaithersburg, MD, September.

Luecke, W. E., T. A. Siewert, and F. W. Gayle. 2005. Federal Building and Fire Safety Investigation of the World Trade Center Disaster: Contemporaneous Structural Steel Specifications. N1ST Special Publication 1-3A. National Institute of Standards and Technology. Gaithersburg, MD, September. 
Banovic, S. W. 2005. Federal Building and Fire Safety Investigation of the World Trade Center Disaster: Steel Inventory and Identification. NIST NCSTAR 1-3B. National Institute of Standards and Technology. Gaithersburg, MD, September.

Banovic, S. W., and T. Foecke. 2005. Federal Building and Fire Safety Investigation of the World Trade Center Disaster: Damage and Failure Modes of Structural Steel Components. NIST NCSTAR 1-3C. National Institute of Standards and Technology. Gaithersburg, MD, September.

Luecke, W. E., J. D. McColskey, C. N. McCowan, S. W. Banovic, R. J. Fields, T. Foecke, T. A. Siewert, and F. W. Gayle. 2005. Federal Building and Fire Safety Investigation of the World Trade Center Disaster: Mechanical Properties of Structural Steels. NIST NCSTAR 1-3D. National Institute of Standards and Technology. Gaithersburg, MD, September.

Banovic, S. W., C. N. McCowan, and W. E. Luecke. 2005. Federal Building and Fire Safety Investigation of the World Trade Center Disaster: Physical Properties of Structural Steels. NIST NCSTAR 1-3E. National Institute of Standards and Technology. Gaithersburg, MD, September.

Evans, D. D., R. D. Peacock, E. D. Kuligowski, W. S. Dols, and W. L. Grosshandler. 2005. Federal Building and Fire Safety Investigation of the World Trade Center Disaster: Active Fire Protection Systemn. NIST NCSTAR 1-4. National Institute of Standards and Technology. Gaithersburg, MD, September.

Kuligowski, E. D., D. D. Evans, and R. D. Peacock. 2005. Federal Building and Fire Safety Investigation of the World Trade Center Disaster: Post-Construction Fires Prior to September I1, 2001. NIST NCSTAR 1-4A. National Institute of Standards and Technology. Gaithersburg, MD, September.

Hopkins, M., J. Schoenrock, and E. Budnick. 2005. Federal Building and Fire Safety Investigation of the World Trade Center Disaster: Fire Suppression Systents. NIST NCSTAR 1-4B. National Institute of Standards and Technology. Gaithersburg, MD, September.

Keough, R. J., and R. A. Grill. 2005. Federal Building and Fire Safety Investigation of the World Trade Center Disaster: Fire Alarm Systenis. NIST NCSTAR 1-4C. National Institute of Standards and Technology. Gaithersburg, MD, September.

Ferreira, M. J., and S. M. Strege. 2005. Federal Building and Fire Safety Investigation of the World Trade Center Disaster: Snoke Management Systems. NIST NCSTAR 1-4D. National Institute of Standards and Technology. Gaithersburg, MD, September.

Gann, R. G., A. Hamins, K. B. McGrattan, G. W. Mulholland, H. E. Nelson, T. J. Ohlemiller, W. M. Pitts, and K. R. Prasad. 2005. Federal Building and Fire Safety Investigation of the World Trade Center Disaster: Reconstruction of the Fires in the World Trade Center Towers. NIST NCSTAR 1-5. National Institute of Standards and Technology. Gaithersburg, MD, September.

Pitts, W. M., K. M. Butler, and V. Junker. 2005. Federal Building and Fire Safety Investigation of the World Trade Center Disaster: Visual Evidence, Damage Estimates, and Timeline Analysis. NIST NCSTAR 1-5A. National Institute of Standards and Technology. Gaithersburg, MD, September. 
Hamins, A., A. Maranghides, K. B. McGrattan, E. Johnsson, T. J. Ohlemiller, M. Donnelly, J. Yang, G. Mulholland, K. R. Prasad, S. Kukuck, R. Anleitner and T. McAllister. 2005. Federal Building and Fire Safety Investigation of the World Trade Center Disaster: Experiments and Modeling of Structural Steel Elements Exposed to Fire. NIST NCSTAR 1-5B. National Institute of Standards and Technology. Gaithersburg, MD, September.

Ohlemiller, T. J., G. W. Mulholland, A. Maranghides, J. J. Filliben, and R. G. Gann. 2005. Federal Building and Fire Safety Investigation of the World Trade Center Disaster: Fire Tests of Single Office Workstations. NIST NCSTAR 1-5C. National Institute of Standards and Technology. Gaithersburg, MD, September.

Gann, R. G.. M. A. Riley, J. M. Repp, A. S. Whittaker, A. M. Reinhorn, and P. A. Hough. 2005. Federal Building and Fire Safety Investigation of the World Trade Center Disaster: Reaction of Ceiling Tile Systems to Shocks. NIST NCSTAR 1-5D. National Institute of Standards and Technology. Gaithersburg, MD, September.

Hamins, A., A. Maranghides, K. B. McGrattan, T. J. Ohlemiller, and R. Anleitner. 2005. Federal Building and Fire Safety Investigation of the World Trade Center Disaster: Experiments and Modeling of Multiple Workstations Burning in a Conpartment. NIST NCSTAR 1-5E. National Institute of Standards and Technology. Gaithersburg, MD, September.

McGrattan, K. B., C. Bouldin, and G. Forney. 2005. Federal Building and Fire Safety Investigation of the World Trade Center Disaster: Computer Simulation of the Fires in the World Trade Center Towers. NIST NCSTAR 1-5F. National Institute of Standards and Technology. Gaithersburg, MD, September.

Prasad, K. R., and H. R. Baum. 2005. Federal Building and Fire Safety Investigation of the World Trade Center Disaster: Fire Structure Interface and Thermial Response of the World Trade Center Towers. NIST NCSTAR 1-5G. National Institute of Standards and Technology. Gaithersburg, MD, September.

Gross, J. L., and T. McAllister. 2005. Federal Building and Fire Safety Investigation of the World Trade Center Disaster: Stmictural Fire Response and Probable Collapse Sequence of the World Trade Center Towers. NIST NCSTAR 1-6. National Institute of Standards and Technology. Gaithersburg, MD, September.

Carino, N. J., M. A. Starnes, J. L. Gross, J. C. Yang, S. Kukuck, K. R. Prasad, and R. W. Bukowski. 2005. Federal Building and Fire Safety Investigation of the World Trade Center Disaster: Passive Fire Protection. NIST NCSTAR 1-6A. National Institute of Standards and Technology. Gaithersburg, MD, September.

Gross, J., F. Hervey, M. Izydorek, J. Mammoser, and J. Treadway. 2005. Federal Building and Fire Safety Investigation of the World Trade Center Disaster: Fire Resistance Tests of Floor Truss Systems. NIST NCSTAR 1-6B. National Institute of Standards and Technology. Gaithersburg, $\mathrm{MD}$, September.

Zarghamee, M. S., S. Bolourchi, D. W. Eggers, Ö. O. Erbay, F. W. Kan, Y. Kitane, A. A. Liepins, M. Mudlock, W. I. Naguib, R. P. Ojdrovic, A. T. Sarawit, P. R Barrett, J. L. Gross, and 
T. P. McAllister. 2005. Federal Building and Fire Safety Investigation of the World Trade Center Disaster: Component, Connection, and Subsystem Structural Analysis. NIST NCSTAR 1-6C. National Institute of Standards and Technology. Gaithersburg, MD, September.

Zarghamee, M. S., Y. Kitane, Ö. O. Erbay, T. P. McAllister, and J. L. Gross. 2005. Federal Building and Fire Safety Investigation of the World Trade Center Disaster: Global Structural Allalysis of the Response of the World Trade Center Towers to Inpact Damage and Fire. NIST NCSTAR 1-6D. National Institute of Standards and Technology. Gaithersburg, MD, September.

McAllister, T., R. W. Bukowski, R. G. Gann, J. L. Gross, K. B. McGrattan, H. E. Nelson, L. Phan, W. M. Pitts, K. R. Prasad, F. Sadek. 2006. Federal Building and Fire Safety Investigation of the World Trade Center Disaster: Structural Fire Response and Probable Collapse Sequence of World Trade Center 7. (Provisional). NIST NCSTAR 1-6E. National Institute of Standards and Technology. Gaithersburg, MD.

Gilsanz, R., V. Arbitrio, C. Anders, D. Chlebus, K. Ezzeldin, W. Guo, P. Moloney, A. Montalva, J. Oh, K. Rubenacker. 2006. Federal Building and Fire Safety Investigation of the World Trade Center Disaster: Structural Analysis of the Response of World Trade Center 7 to Debris Damage and Fire. (Provisional). NIST NCSTAR 1-6F. National Institute of Standards and Technology. Gaithersburg, MD.

Kim, W. 2006. Federal Building and Fire Safety Investigation of the World Trade Center Disaster: Analysis of September 11, 2001, Seismogram Data. (Provisional). NIST NCSTAR 1-6G. National Institute of Standards and Technology. Gaithersburg, MD.

Nelson, K. 2006. Federal Building and Fire Safety Investigation of the World Trade Center Disaster: The Con Ed Substation in World Trade Center 7. (Provisional). NIST NCSTAR 1-6H. National Institute of Standards and Technology. Gaithersburg, MD.

Averill, J. D., D. S. Mileti, R. D. Peacock, E. D. Kuligowski, N. Groner, G. Proulx, P. A. Reneke, and H. E. Nelson. 2005. Federal Building and Fire Safety Investigation of the World Trade Center Disaster: Occupant Behavior, Egress, and Emergency Colnmunication. NIST NCSTAR 1-7. National Institute of Standards and Technology. Gaithersburg, MD, September.

Fahy, R., and G. Proulx. 2005. Federal Building and Fire Safety Investigation of the World Trade Center Disaster: Analysis of Published Accounts of the World Trade Center Evacuation. NIST NCSTAR 1-7A. National Institute of Standards and Technology. Gaithersburg, MD, September.

Zmud, J. 2005. Federal Building and Fire Safety Investigation of the World Trade Center Disaster: Technical Documentation for Survey Administration. NIST NCSTAR 1-7B. National Institute of Standards and Technology. Gaithersburg, MD, September.

Lawson, J. R., and R. L. Vettori. 2005. Federal Building and Fire Safety Investigation of the World Trade Center Disaster: The Emergency Response Operations. NIST NCSTAR 1-8. National Institute of Standards and Technology. Gaithersburg, MD, September. 


\section{ACKNOWLEDGMENTS}

Applied Research Associates, Inc. (ARA) supported the National Institute of Standards and Technology (NIST) World Trade Center (WTC) Investigation by performing analyses of aircraft impacts into the WTC towers. A collaborative relationship was developed among the NIST Investigation Team that greatly contributed to the success of this effort. The high level of commitment and cooperation of all the Investigation participants both at NIST and their various contractors was greatly appreciated by ARA.

The results presented in this report are from the analysis efforts at ARA in collaboration with Dr. Fahim Sadek of NIST. Leader of Project 2 of the NIST Investigation. The authors would like to acknowledge several investigation team members that participated directly to the success of this project. Leslie E. Robertson Associates (LERA) developed the structural databases in an electronic format that were crucial in the development of the WTC tower models for the impact analyses. Several NIST investigators, including Dr. William Luecke, Dr. Richard Fields, Dr. Frank Gayle, Dr. Tim Foecke, and Dr. Stephen Banovic contributed to the development of the WTC tower material models by providing invaluable materials test data.

The development of the aircraft model could not have been completed without the support of Dr. Peter Dunn (ARA) who contributed to the data collection effort on the Boeing 767 structure. Similarly, Dr. Matthew Koebbe of GADAB engineering provided significant support in the development of the finite element mesh for the Boeing 767 model.

The methodologies used in the uncertainty analyses were developed by Dr. Justin Wu, Marsh Hardy, and Dr. Youngwon Shin of ARA. The authors also want to thank Dr. James Filliben of NIST for his guidance in the performance of the uncertainty analyses. Dr. Filliben contributed significantly to the methodologies that allowed a large reduction in the total number of analyses required and to the presentation of the probabilistic analyses.

Several other NIST investigators made important contributions to this effort. In particular, Dr. Therese McAllister provided guidance throughout the Investigation and contributed to the characterization and presentation of the WTC tower damage states in the impact analyses. In addition, Dr. William Pitts provided considerable assistance in the interprctation of the video and photographic data collected by NIST. This visual data was used as the basis of both the analysis of the aircraft impact conditions and the comparison of calculated impact response to observables. 
This page intentionally left blank. 


\section{EXECUTIVE SUMMARY}

\section{E.1 INTRODUCTION}

As part of the National Institute of Standards and Technology (NIST) Investigation into the collapse of the World Trade Center (WTC) towers, under contract from NIST, Applied Research Associates. Inc. (ARA) conducted the analysis of the aircraft impacts into the WTC towers. The objective of this effort was to analyze the aircraft impacts to determine the following: (1) estimates of probable damage to structural systems, including the exterior walls, floor systems, and interior core columns; (2) estimates of the aircraft fuel dispersal during the impact; and (3) estimates of debris damage to the interior tower contents, including partitions and workstations to be used for estimating damage to fire proofing and to the mechanical and architectural systems inside the towers. Thus, this analysis established the initial conditions for the fire dynamics modeling and the thermal-structural response and collapse initiation analysis of the NIST Investigation.

The WTC aircraft impact analysis is very complex. with large scale fracture and fragmentation of both tower and aircraft structures, nonlinear rate-dependent material behaviors, and the fluid-structure interaction of the aircraft fuel. The analyses of the aircraft impacts performed for this investigation are believed to be the highest-fidelity simulations ever performed for this impact behavior using state-of-the art analysis methodologies. Wherever possible, the models were validated against observables or supporting test data developed by the WTC Investigation.

The impact analyses were conducted at various levels of complexity including: (1) the component level, (2) the subassembly level, and (3) the global level to estimate the probable damage to the towers due to aircraft impact. Analysis of uncertainties using the component, subassembly, and global analyses were also conducted to assess the effect of uncertainties associated with various parameters on the damage estimates and to identify the most influential parameters that affect the impact response.

\section{E.2 MATERIAL CONSTITUTIVE MODELING}

An important requirement for high fidelity simulation of the aircraft impact damage was the development of constitutive models that represent the actual behavior of the WTC towers and aircraft under the dynamic impact conditions. The materials that were considered included: (1) the several grades of steel used in the columns, spandrels, and floor trusses and beams of the WTC towers, (2) the concrete floor slabs, (3) the various aluminum and titanium alloys used in the aircraft, and (4) the nonstructural contents of the towers. These materials exhibit significant nonlinear rate-dependent deformation and failure behavior that need to be represented in the constitutive relationship. The following is a brief summary of the constitutive models used for these materials.

\section{WTC Tower Steel Constitutive Models}

The primary constitutive model that was used for the tower steels was the Piecewise Linear Plasticity model in LS-DYNA. This model is sufficient to model the nonlinear rate-dependent deformation and failure of the steel structures. A tabular effective stress versus effective strain curve was used in this 
model with various definitions of strain rate dependency. The constitutive model parameters for each grade of steel were based on engineering stress-strain data obtained from the mechanical and metallurgical analysis of the NIST Investigation. Finite element analyses of the test specimens were conducted with a fine and a medium mesh (similar to that used in the component level analysis) to capture the nonlinear material behavior up to failure (Figure E-1). The finite element analysis provided a validation that the constitutive model parameters were defined accurately and that the model could reproduce the measured response for the test conditions.

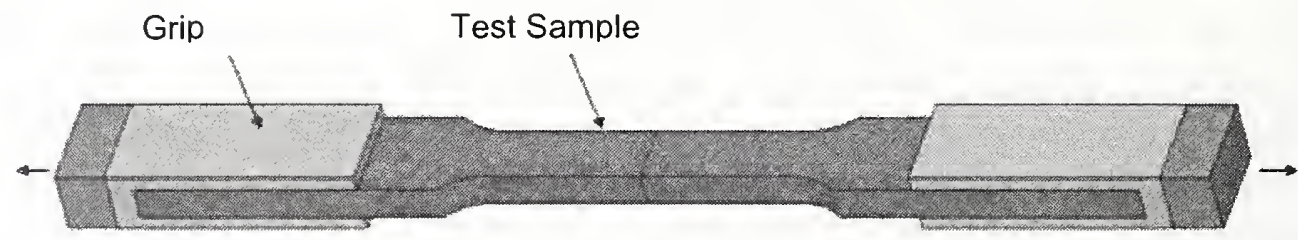

Fine Mesh
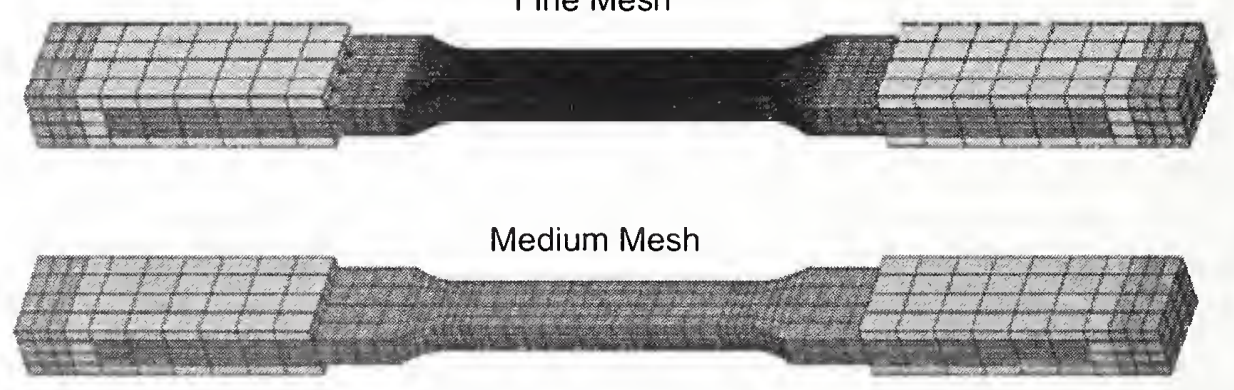

Figure E-1. Finite element models of the ASTM 370 rectangular tensile specimen.

The first step in the constitutive model development process was to obtain a true stress-true strain curve. The typical approach was to select a representative test for each grade of steel and convert the engineering stress-strain curve to true stress-strain. The true stress-strain curve was extrapolated beyond the point of necking onset. This curve was the input used to specify the mechanical behavior in the simulation of the tensile test (Figure E-1). If necessary, the extrapolation of the true stress-strain behavior was adjusted until the simulation matched the measured engineering stress-strain response, including necking and failure. A summary of the true stress-strain curves used in the constitutive models for the various WTC tower steels are summarized in Figure E-2.

Strain-rate effects on the steel yield strength were included in the constitutive model for tower steels with the Cowper and Symonds rate effect model. The resulting rate effects used in the constitutive modeling of tower steels based on this model are compared to the measured high rate test data for the $50 \mathrm{ksi}, 75 \mathrm{ksi}$, and $100 \mathrm{ksi}$ tower steels in Figure E-3. In the figure, the dashed lines with open symbols are the fits using the Cowper and Symonds model, while the corresponding solid symbols are the experimental data. The comparison showed that the Cowper and Symonds model was capable of reproducing the rate effects for the range of data available. 


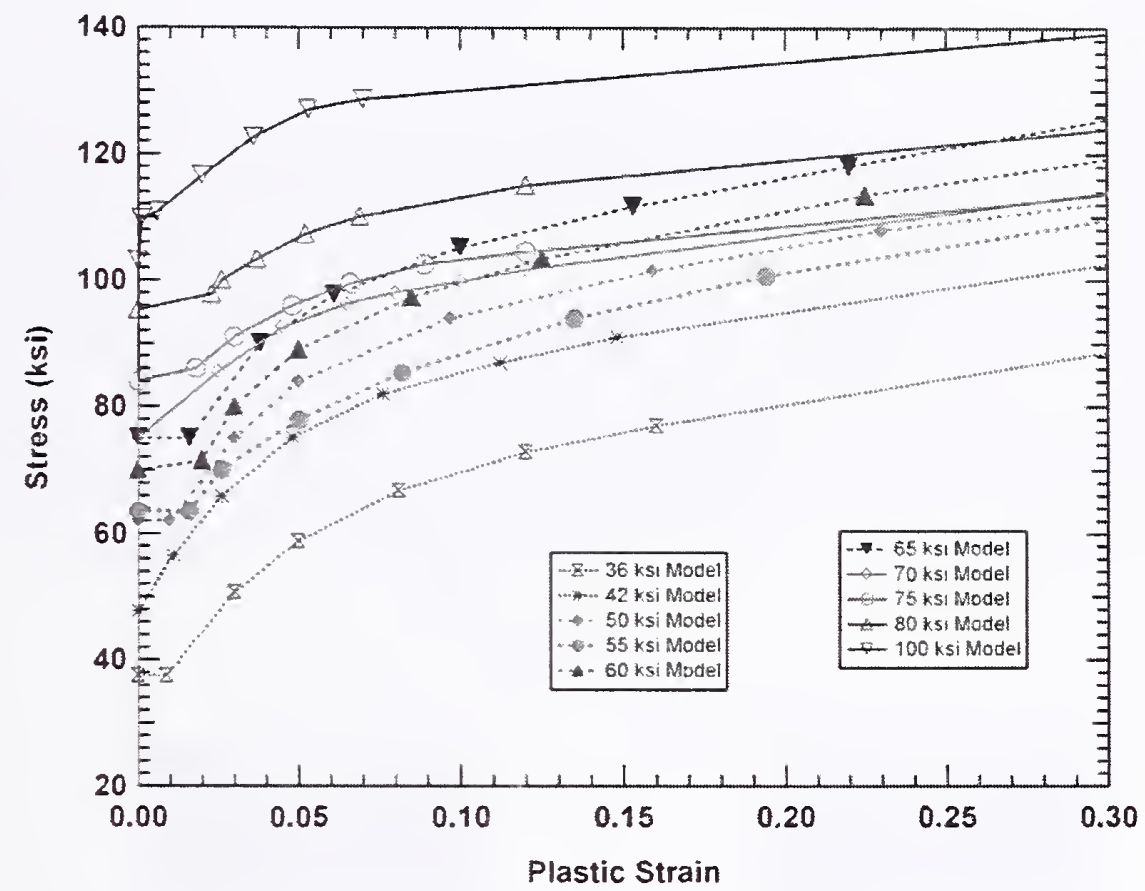

Figure E-2. Tabular true stress-strain constitutive model curves for the tower steels.

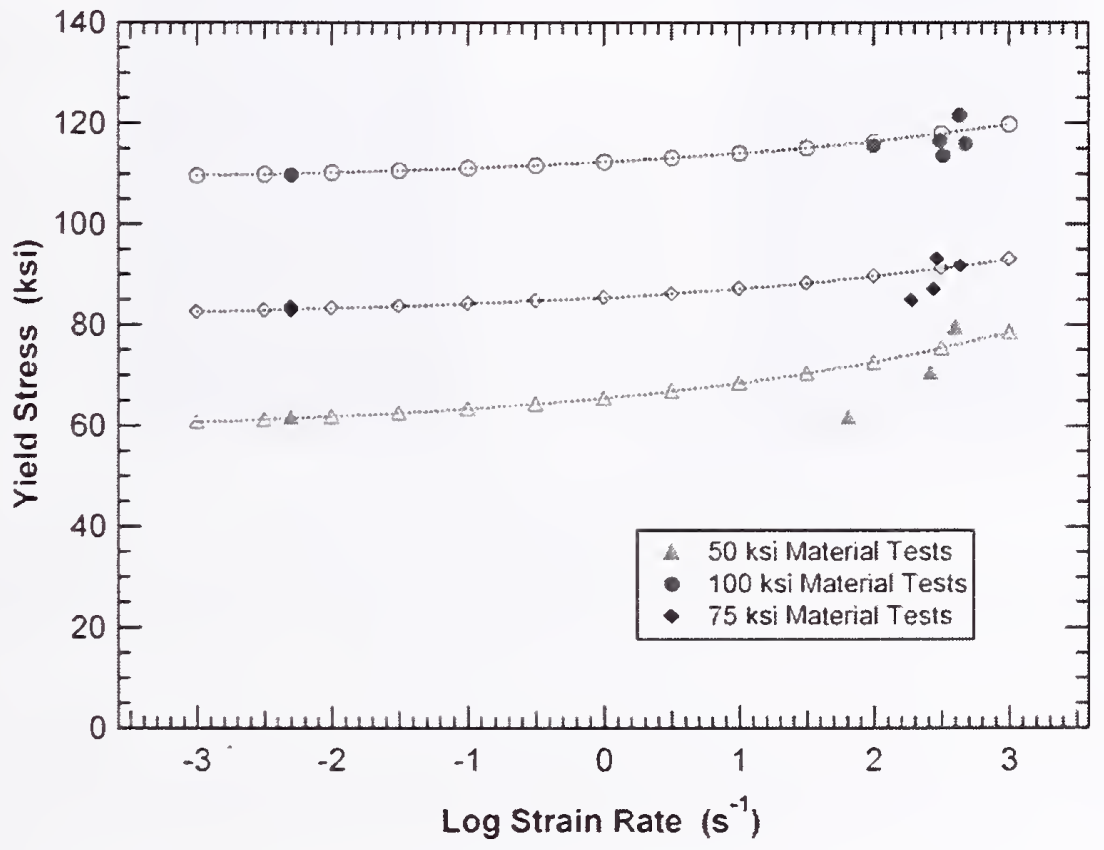

Figure E-3. Comparison of rate effects model and test data. 


\section{Concrete Constitutive Models}

The LS-DYNA material Type 16 (pseudo-tensor concrete model) was selected for modeling the concrete floor slabs due to its ability to accurately model the damage and softening behavior of concrete associated with low confinement conditions. The model uses two pressure-dependent yield functions and a damagedependent function to migrate between curves. This allows for implementation of tensile failure and damage scaling, which are more dominant material behaviors at low confinement. The pseudo-tensor model also accounts for the sensitivity of concrete to high strain-rates. Material constitutive parameters for the pseudo-tensor model were developed. A simulation was performed of a standard unconfined concrete compression test to check the constitutive model behavior. The simulated behavior of the concrete specimen is shown in Figure $\mathrm{E}-4$. The calculated compressive stress-strain response for the $3 \mathrm{ksi}$ concrete was compared to measured compression data for $2.3 \mathrm{ksi}$ and $3.8 \mathrm{ksi}$ strength concretes in Figure E-5.
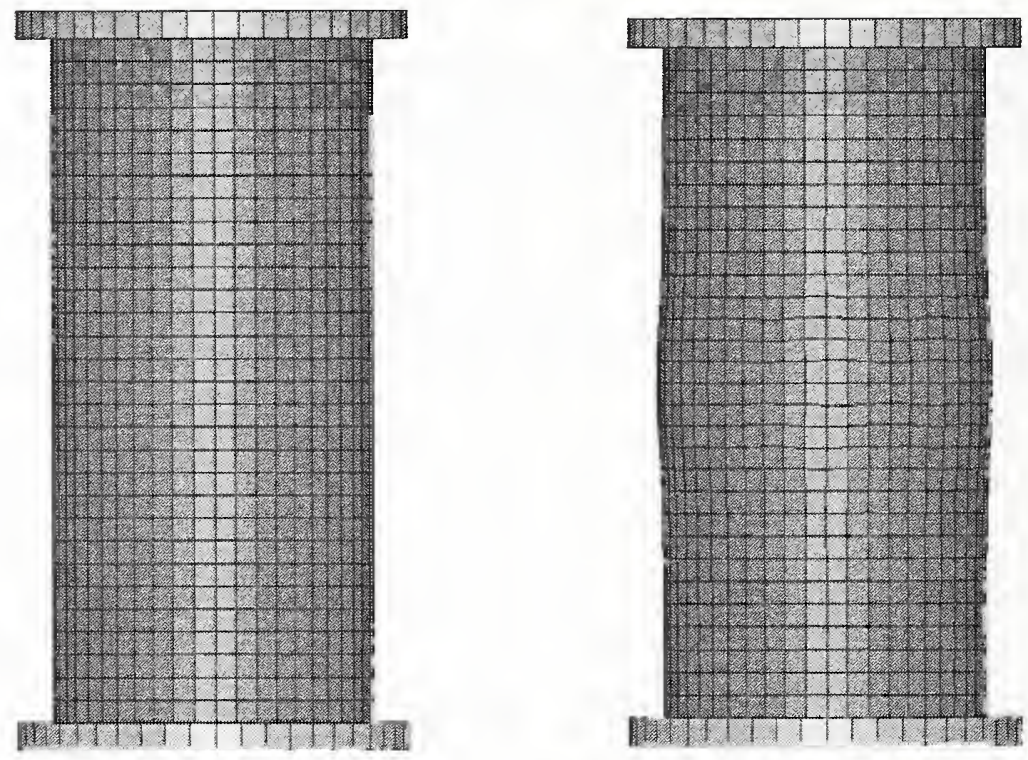

Initial configuration $2 \%$ compression

Figure E-4. Finite element analysis of the unconfined compression test. 


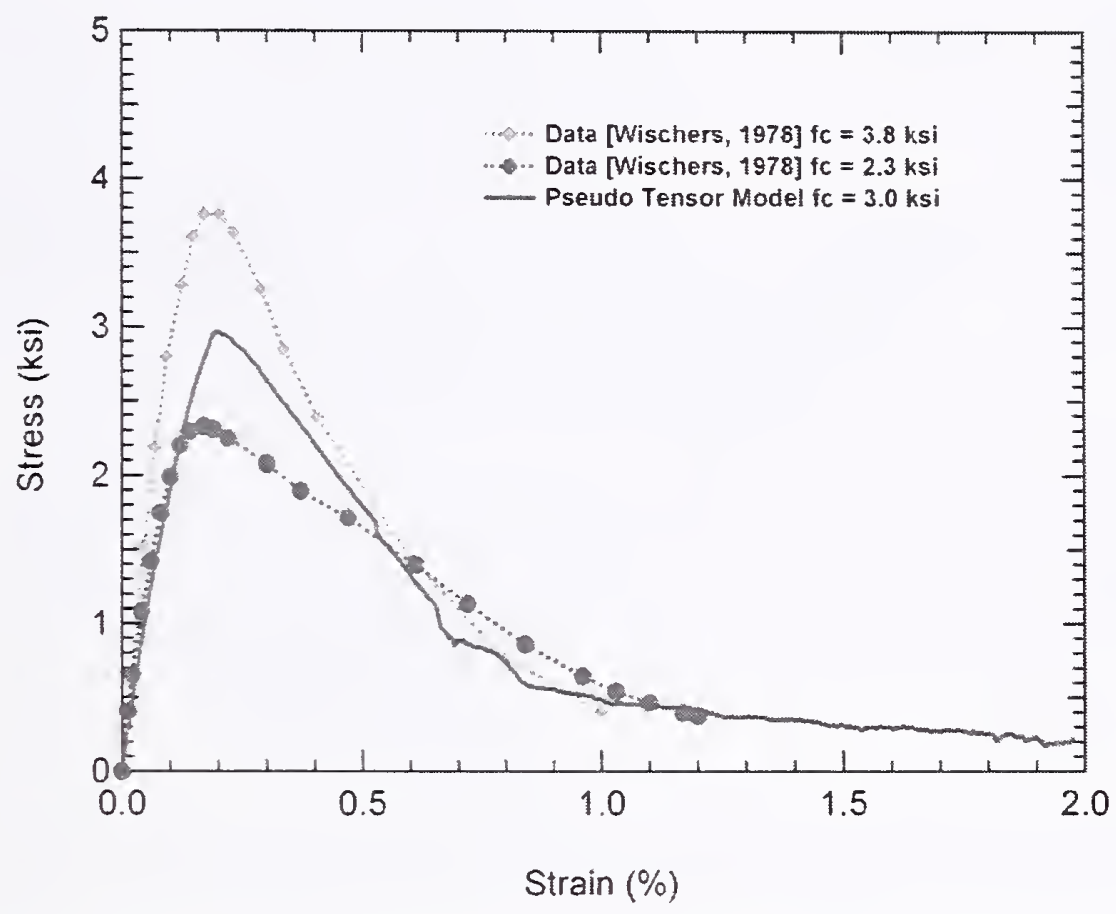

Figure E-5. Comparison of the calculated unconfined compression behavior with concrete compression test data.

\section{Aircraft Materials Constitutive Models}

The constitutive and failure properties for the aircraft materials were developed from data available in the open literature. Complete engineering stress-strain curves were obtained for various 2024 and 7075 aluminum alloys that are commonly used in the construction of the Boeing 767 airframe structures. These curves were digitized for the various aluminum alloys. Representative stress-strain curves were then converted into true stress and true strain and used to develop tabular curves for constitutive models. The tabular constitutive model fits are shown in Figure E-6. No rate sensitivity of the aircraft materials was considered.

\section{Nonstructural Materials Constitutive Models}

The primary influence of the nonstructural components on the impact behavior is their inertial contribution. The effects of their strength are small. As a result, relatively simple approximations of their constitutive behavior were used. Typically, a bilinear elastic-plastic constitutive model was applied for these materials to allow for efficient modeling of deformation and subsequent erosion from the calculations as their distortions become large. The ability to include material failure and erosion of these soft materials was important for the stability of the impact analyses. 


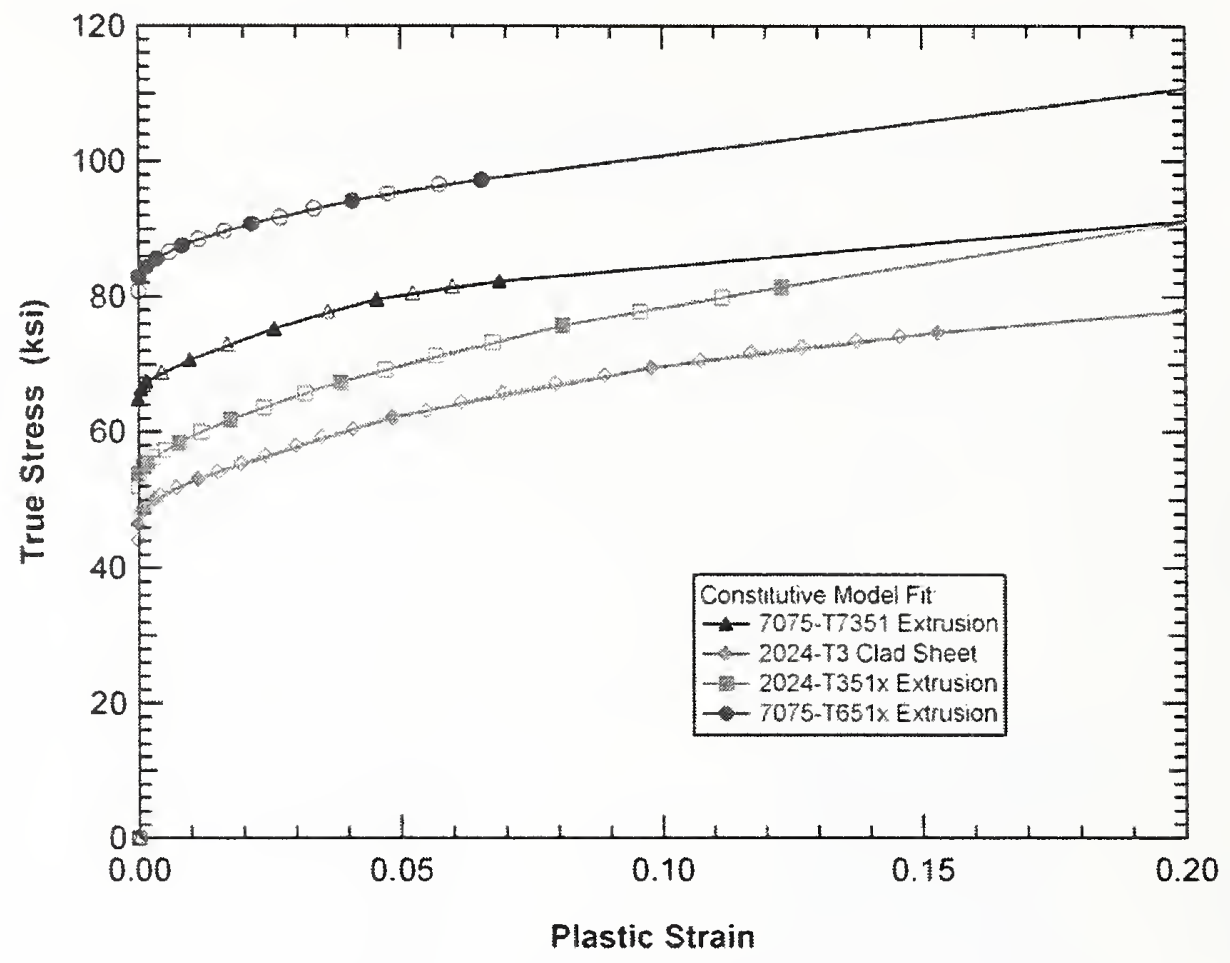

Figure E-6. True stress-strain curves developed for various aircraft aluminum alloys.

\section{E.3 TOWER MODEL DEVELOPMENT}

One of the significant challenges in developing the tower and aircraft models for the global impact analyses was to minimize the model size while keeping sufficient fidelity in the impact zone to capture the deformations and damage distributions. The limitation was that the combined aircraft and tower models should not exceed approximately 2.3 million nodes. These were distributed between the global WTC tower model and the aircraft so that the tower model would be about 1.5 million nodes and the aircraft about 0.8 million nodes. The approach used to meet this objective was to develop models for the various tower components at different levels of refinement. Components in the path of the impact and debris field were meshed with a higher resolution to capture the local impact damage and failure, while components outside the impact zone were meshed more coarsely to primarily capture their structural stiffness and inertial properties.

A summary of the size of the global impact models of both towers is presented in Table E-1. As the table indicates, the towers were modeled primarily with shell elements with the exception of the exterior wall bolted connections (beam and brick elements) and the floor truss diagonals (beam elements). The WTC 1 model extended between floors 92 and 100, while the WTC 2 model extended between floors 85 and 77 . 
Table E-1. Summary of the global impact models for the WTC towers.

\begin{tabular}{|l|c|c|}
\hline & WTC 1 Tower Model & WTC 2 Tower Model \\
\hline Number of Nodes & $1,300,537$ & $1,312,092$ \\
\hline Hughes-Liu Beam Elements & 47.952 & 53,488 \\
\hline Belytschko-Tsay Shell Elements & $1,156,947$ & $1,155,815$ \\
\hline Constant Stress Solid Elements & 2,805 & 2,498 \\
\hline
\end{tabular}

The global impact models of the WTC towers included the following components:

- Core columns and floors: Core columns were modeled using shell elements with two mesh densities, a refined density in the direct impact area and a coarser far field density elsewhere. The spliced column connections were included in the model with proper failure criteria. The floors within the core were modeled using shell elements representing the floor slabs and beams. A generated model for the core of WTC 1 between floors 94 and 98 is shown in Figure E-7.

- Exterior walls: The exterior columns and spandrels were modeled using shell elements with two mesh densities. a refined density in the immediate impact zone and a coarser far field density elsewhere. For the bolted connections between exterior panels in the refined mesh areas, brick elements were used to model the butt plates and beam elements were used for the bolts. The model of the impact face of WTC 1 is shown in Figure E-8.

- Truss floor: In the direct impact area, the floor model included shell elements for the combined floor slab and metal decking, and for the upper and lower chords of both the primary and bridging trusses. Beam elements were used for the truss diagonals. In the far field floor segments, simplified shell element representations were used for the floor slab and trusses. A model assembled for the entire 96th floor of WTC 1 is shown in Figure E-9.

- Interior building contents: The interior nonstructural contents of the towers were modeled explicitly. These included the partitions and workstations, which were modeled with shell elements in the path of the aircraft debris. The live load mass was distributed between the partitions and cubicle workstations. The resulting model of a floor with interior contents is shown in Figure E-10.

Figure E-11 shows the assembled global impact model of WTC 1. 


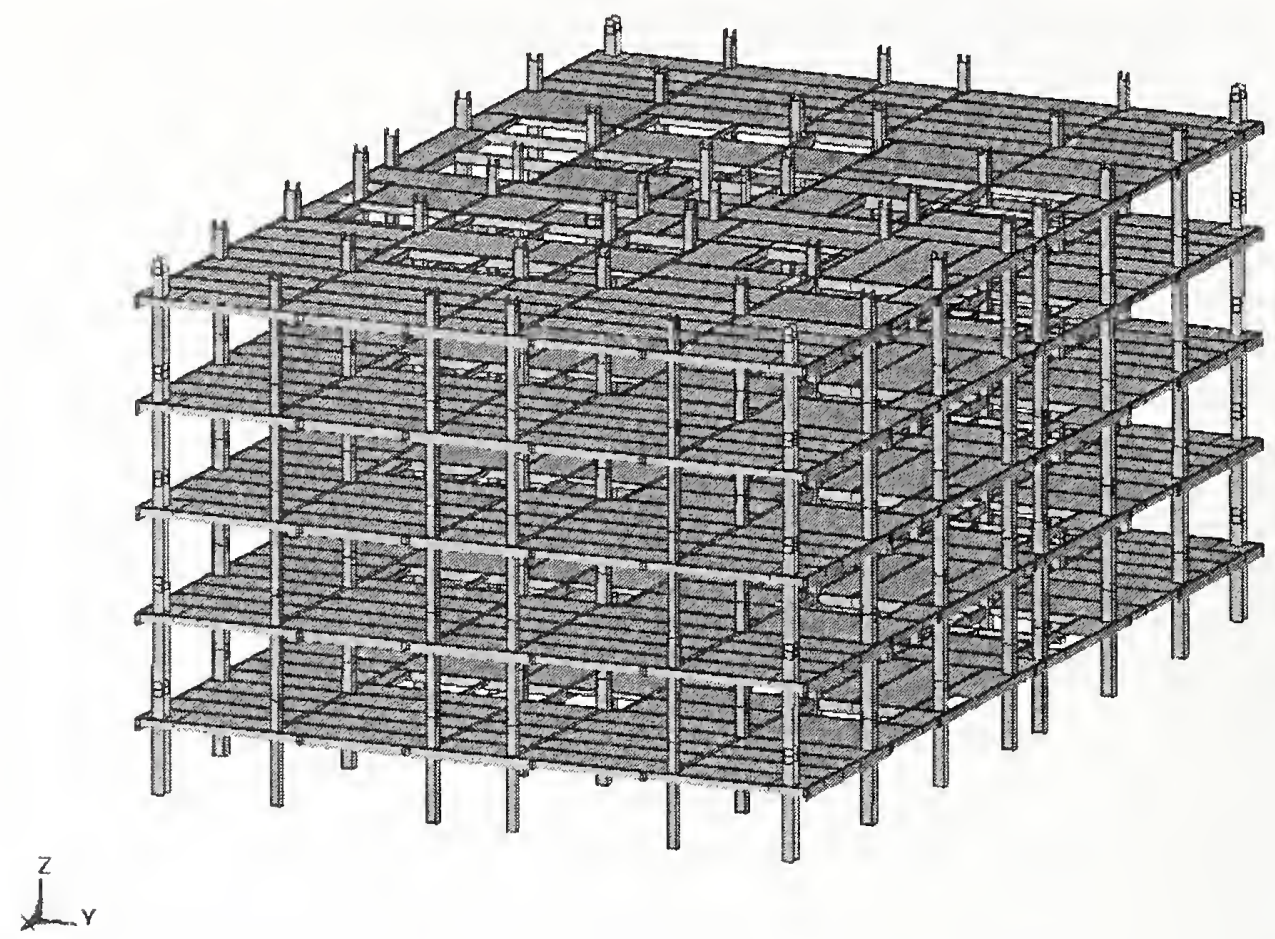

Figure E-7. Model of the WTC 1 core, floors 94-98.

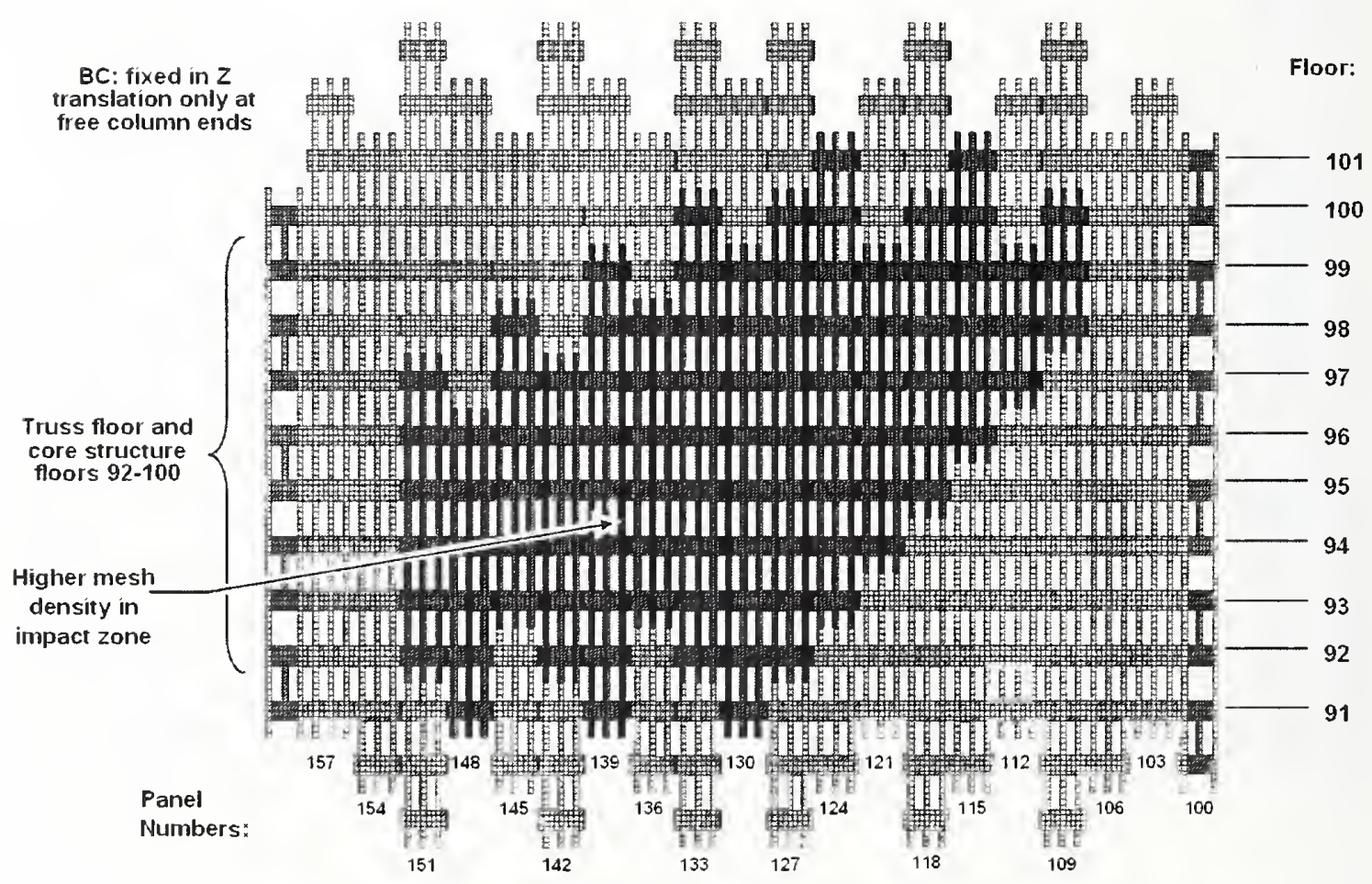

Figure E-8. Impact face of the WTC 1 model, floors 91-101. 


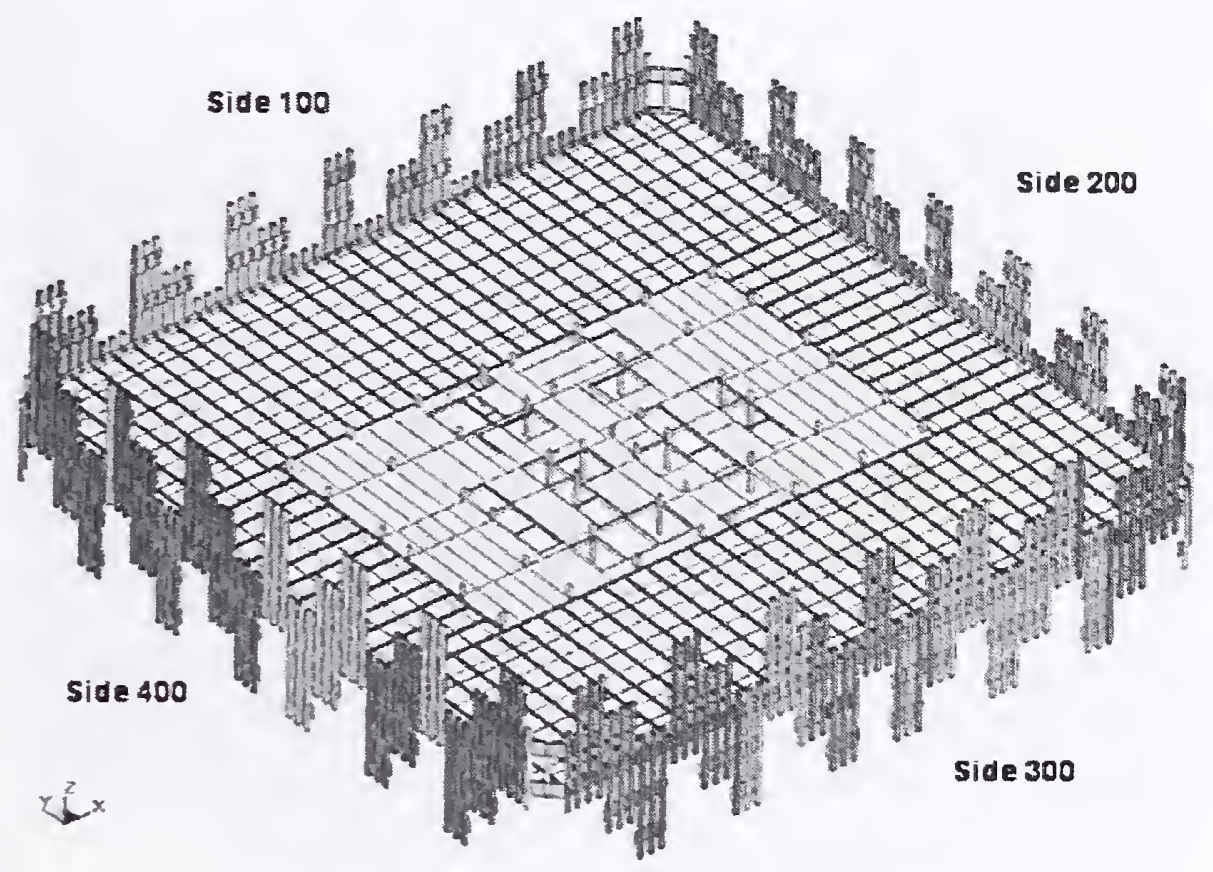

Figure E-9. Model of the 96th floor of WTC 1.

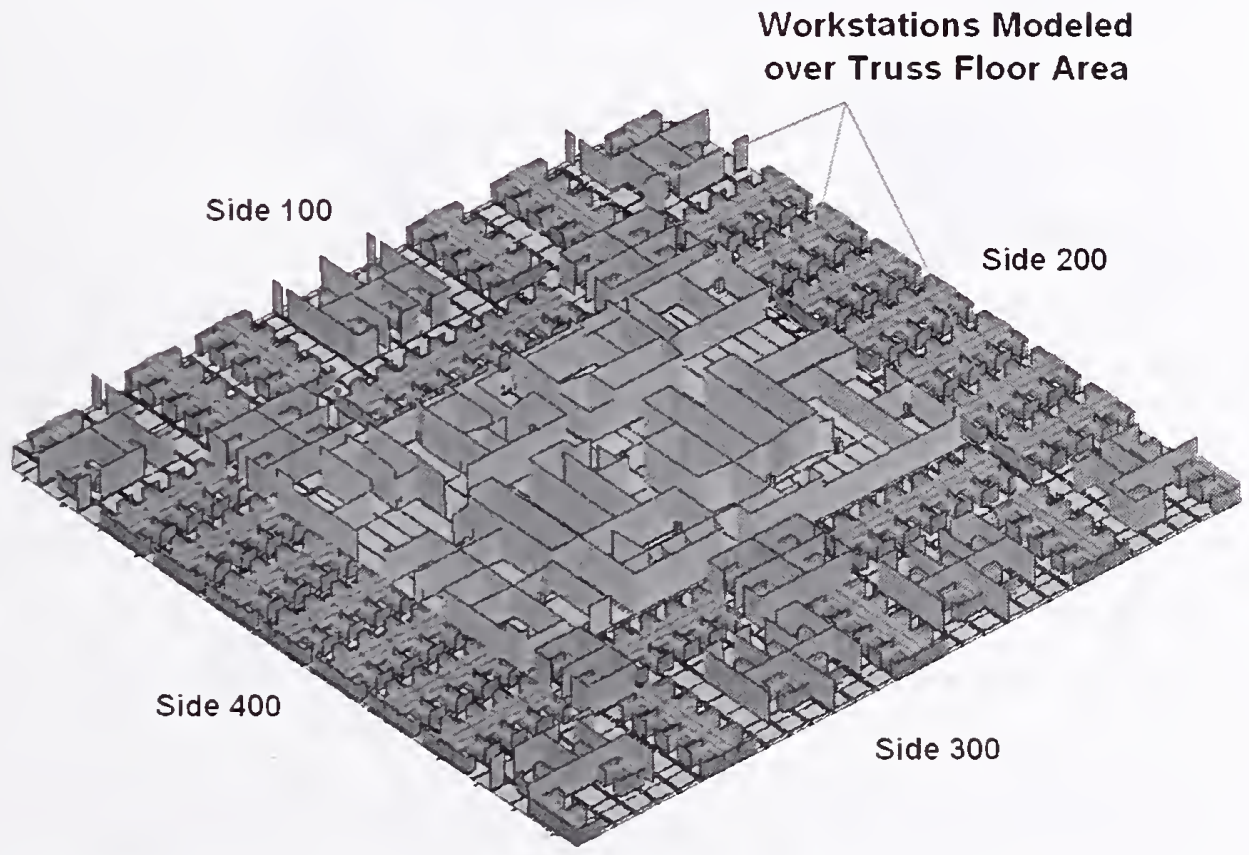

Figure E-10. Model of the 96th floor of WTC 1, including interior contents. 


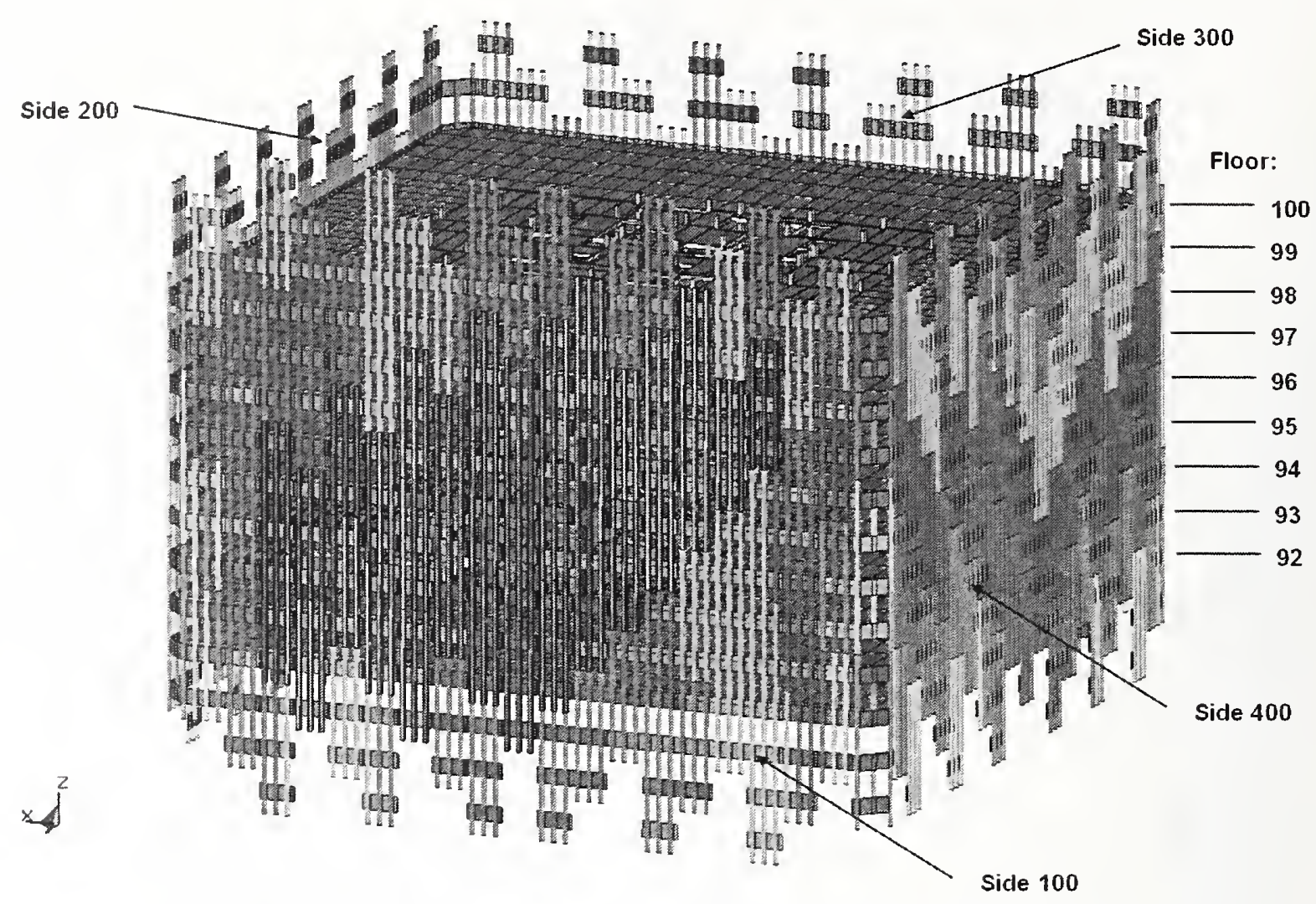

Figure E-11. Multi-floor global impact model of the WTC 1 tower.

\section{E.4 AIRCRAFT MODEL DEVELOPMENT}

The finite element model for the Boeing 767-200ER aircraft was constructed through a three-step process: (1) data collection, (2) data interpretation and engineering analysis, and (3) meshing of the structure. The focus of this effort was on gathering sufficient structural data and including adequate detail in the aircraft model so that the mass and strength distribution of the aircraft and contents were properly captured for implementation in the impact analyses. Structural data were collected for the Boeing 767-200ER aircraft from (1) documentary aircraft structural information and (2) data from measurements on Boeing 767 aircraft.

The complete model of the Boeing 767-200ER is shown in Figure E-12. A summary of the aircraft model size and parameters is presented in Table E-2 for American Airlines 11 (AA 11) and United Airlines 175 (UAL 175) that impacted WTC 1 and WTC 2, respectively. The airframe model contained most of the significant structural components in the aircraft. The models of the fuselage, empennage, and wing structures were developed completely using shell elements. Models for the landing gear and engines were developed primarily using shell elements, but contained some brick elements as well. The typical element dimensions were between $1 \mathrm{in}$. and $2 \mathrm{in}$. for small components, such as spar or rib flanges, and 3 in. to 4 in. for large parts such as the wing or fuselage skin. 


$$
\frac{1 x}{x}
$$


Table E-2. Boeing 767-200ER aircraft model parameters.

\begin{tabular}{|l|c|c|}
\hline & AA 11 & UAL 175 \\
\hline No. Brick Elements & 70,000 & 70,000 \\
\hline No. Shell Elements & 562,000 & 562,000 \\
\hline No. SPH Fuel Particles & 60,672 & 60,672 \\
\hline Total Nodes & 740,000 & 740,000 \\
\hline \hline Total Weight (Empty) & $183,500 \mathrm{lb}$ & $183,500 \mathrm{lb}$ \\
\hline ULD/Cargo Weight & $12,420 \mathrm{lb}$ & $21,660 \mathrm{lb}$ \\
\hline Cabin Contents Weight & $21,580 \mathrm{lb}$ & $10,420 \mathrm{lb}$ \\
\hline Fuel Weight & $66,100 \mathrm{lb}$ & $62,000 \mathrm{lb}$ \\
\hline Total Weight (Loaded) & $283,600 \mathrm{lb}$ & $277,580 \mathrm{lb}$ \\
\hline
\end{tabular}

Special emphasis was placed on modeling the aircraft engines due to their potential to produce significant damage to the tower components. The engine model was developed primarily with shell elements. The objective was to develop a mesh with typical element dimensions between 1 in. and 2 in. However, smaller element dimensions were required at many locations to capture details of the engine geometry. Brick elements were used for some of the thicker hubs and the roots of the compressor blades. The various components of the resulting engine model are shown in Figure E-13. Fuel was distributed in the wing as shown in Figure E-14 based on a detailed analysis of the fuel distribution at the time of impact.
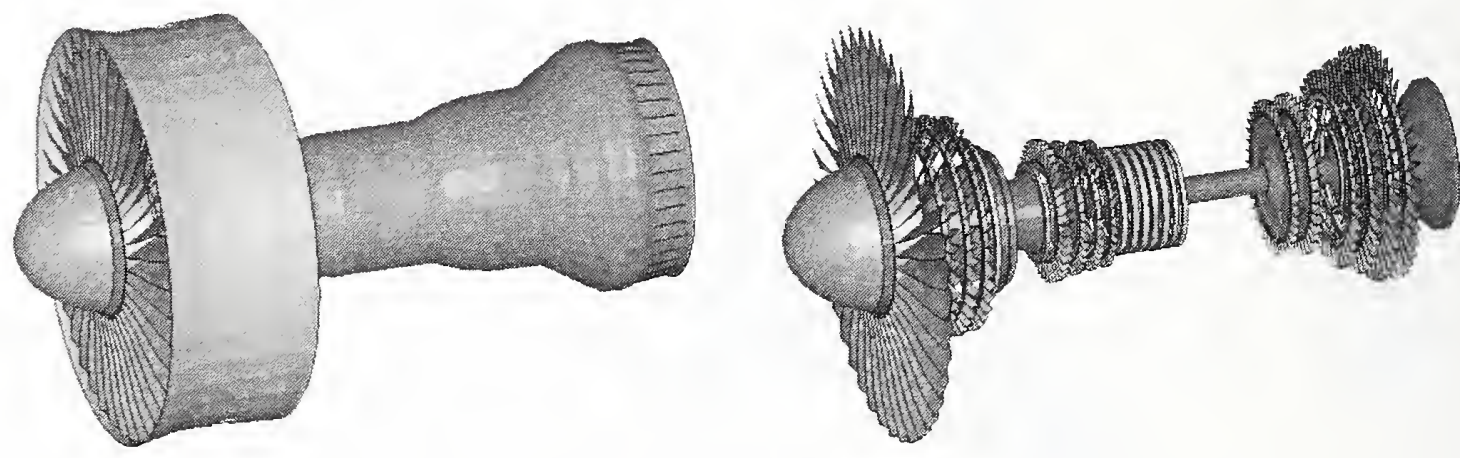

Figure E-13. Pratt \& Whitney PW4000 turbofan engine model. 


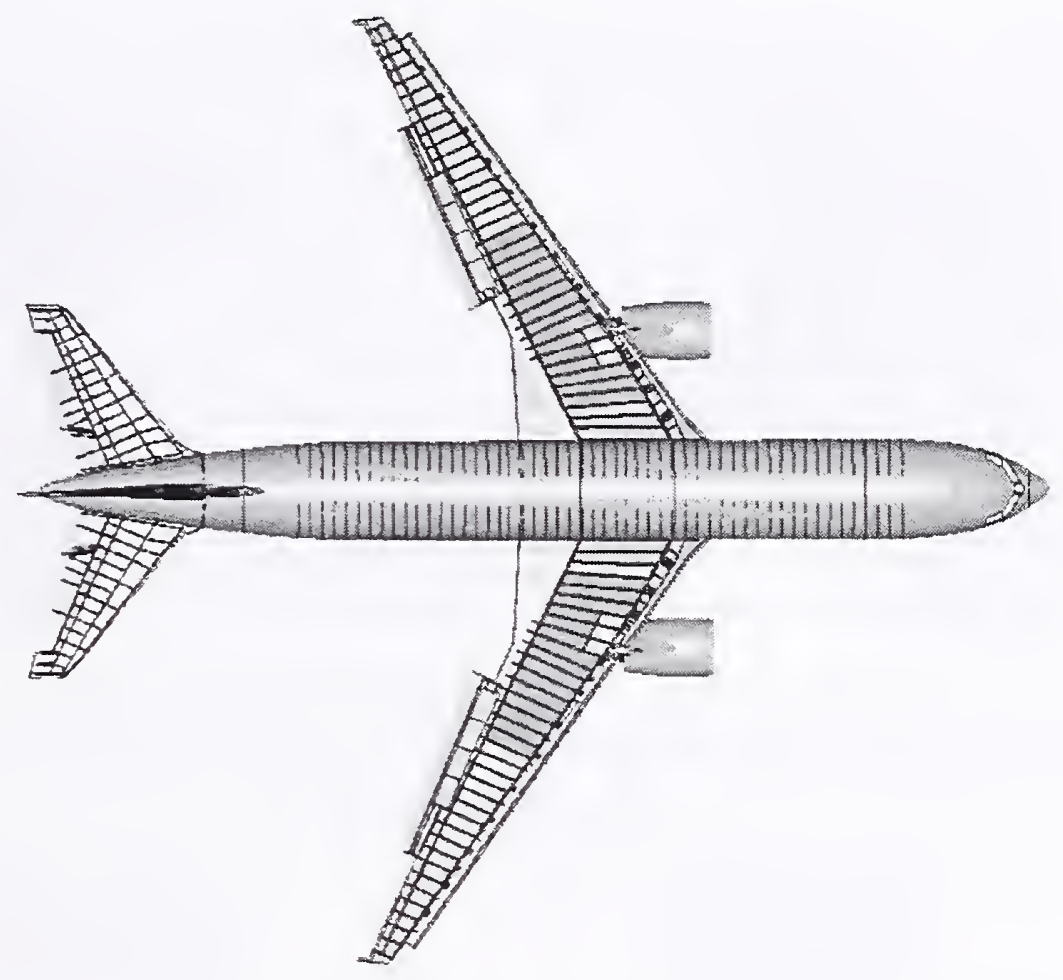

Figure E-14. Boeing 767-200ER with fuel load at time of impact.

\section{E.5 COMPONENT LEVEL ANALYSES}

A series of component impact analyses were performed using models of tower core and exterior columns impacted by models for a wing section and an engine. The primary objectives of the component modeling were to (1) develop understanding of the interactive failure phenomenon of the aircraft and tower components and (2) develop the simulation techniques required for the global analysis of the aircraft impacts into the WTC towers. The approach taken for component modeling was to start with finely meshed, brick and shell element models of key components of the tower and aircraft structures and progress to relatively coarsely meshed beam and shell element representations used in the global models. In addition to determining the optimal element size and type for global modeling, other key technical areas were addressed in the component modeling, including material constitutive modeling, treatment of connections, and modeling of aircraft fuel. Examples of the component impact analyses included:

- Impact of a segment of an aircraft wing with an exterior column.

- Impact of a segment of an aircraft wing with a core column.

- Detailed and simplified modeling of exterior panel bolted connection under impact loading and modeling of the bolted spandrel connection.

- Impact of an aircraft engine with exterior wall panels (Figure E-15).

- Impact of a simplified plow type impactor with truss floor assembly. 
- Impact of an empty wing segment with exterior wall panels (Figure E-16).

- Impact of fuel-filled wing segment with exterior wall panels (Figure E-17).

The following results were obtained from the component impact analyses:

- A $500 \mathrm{mph}$ engine impact against an exterior wall panel resulted in a penetration of the exterior wall and failure of impacted exterior columns. If the engine did not impact a floor slab, the majority of the engine core would remain intact through the exterior wall penetration with a reduction in speed between 10 percent and 20 percent. The residual velocity and mass of the engine after penetration of the exterior wall was sufficient to fail a core column in a direct impact condition. Interaction with additional interior building contents prior to impact or a misaligned impact against the core column could change this result.

- A normal impact of the exterior wall by an empty wing segment from approximately midspan of the wing produced significant damage to the exterior columns but not complete failure. Impact of the same wing section, but filled with fuel, resulted in extensive damage to the external panels of the tower, including complete failure of the exterior columns. The resulting debris propagating into the building maintained the majority of its initial momentum prior to impact.

- Three different numerical techniques were investigated for modeling impact effects and dispersion of fuel: (1) standard Lagrangian finite element analysis with erosion, (2) Smoothed Particle Hydrodynamics (SPH) analysis, and (3) Arbitrary-Lagrangian-Eulerian (ALE) analysis. Of these approaches, use of the SPH offered the best viable option due to its computational efficiency.

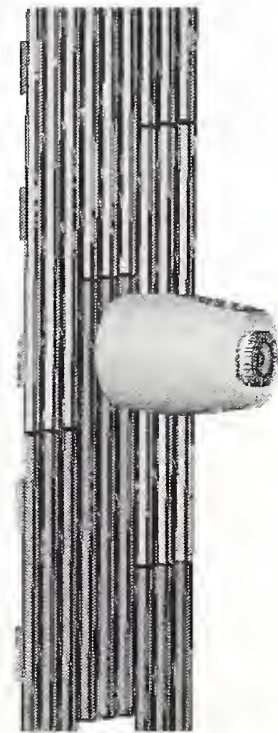

(a) Initial configuration

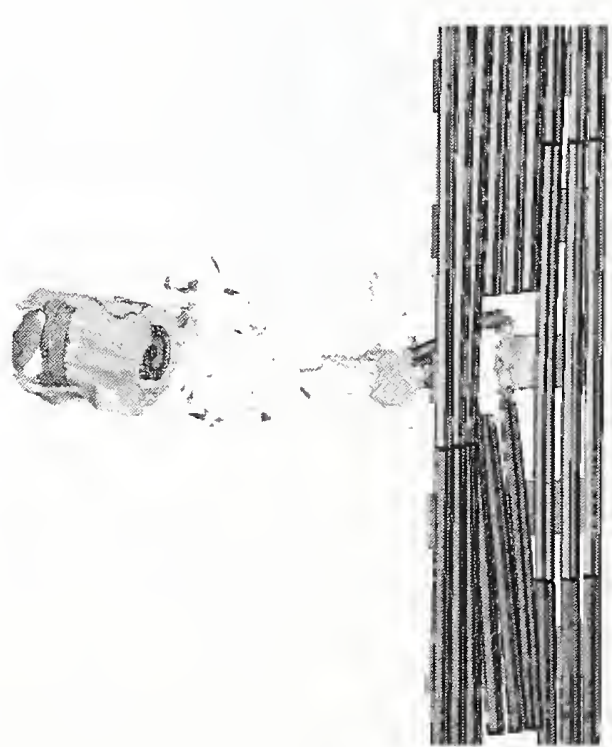

(b) Impact response at $80 \mathrm{~ms}$

Figure E-15. Example engine impact analysis with exterior columns. 

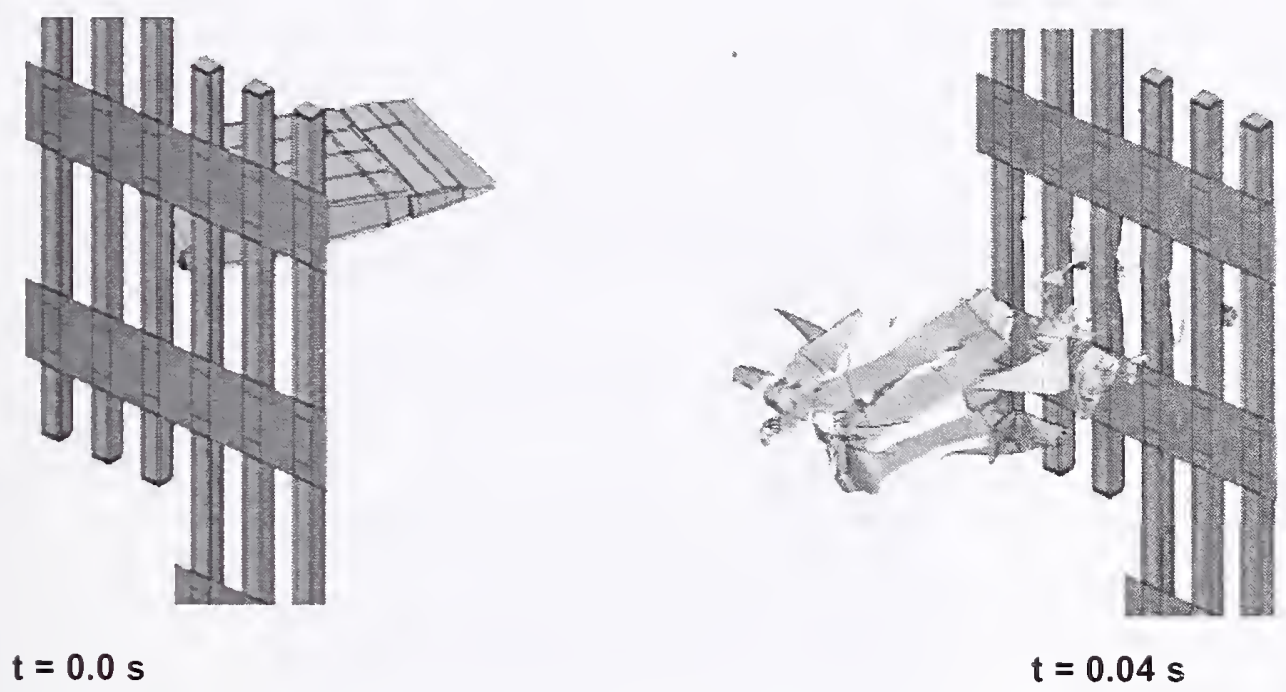

$\mathrm{t}=0.0 \mathrm{~s}$

$\mathrm{t}=0.04 \mathrm{~s}$

Figure E-16. Calculated impact of a fine-mesh empty wing section with two exterior panels at $442 \mathrm{mph}$.

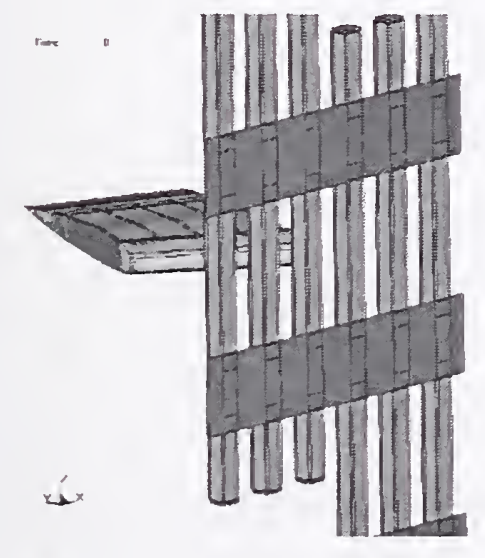

$t=0.0 s$
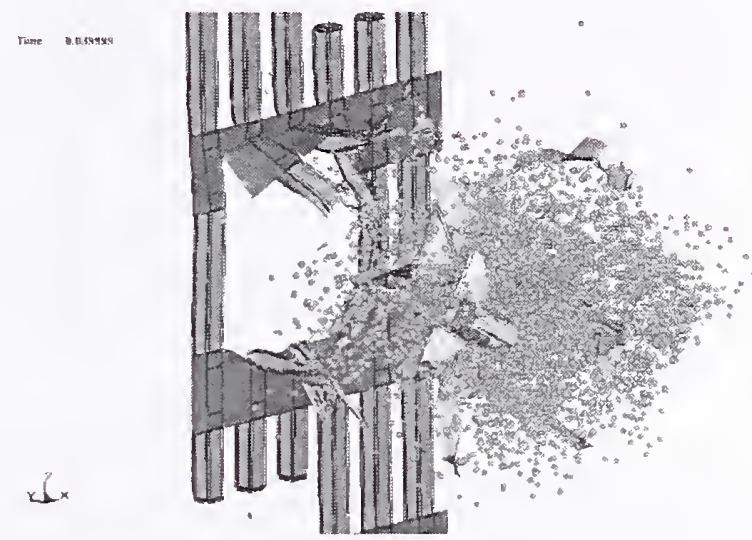

$\mathrm{t}=0.04 \mathrm{~s}$

Figure E-17. Calculated impact of a coarse mesh wing section laden with fuel modeled using SPH particles.

\section{E.6 SUBASSEMBLY IMPACT ANALYSES}

The subassembly analyses were used as a transition between the component level analyses and the global impact analyses. With the subassembly analyses, more complex structural behavior not captured in the component analyses could be investigated with significantly shorter run times than required for the global analyses. The subassembly analyses were primarily used to investigate different modeling techniques and associated model size, run times, numerical stability, and impact response. The final subassembly model used structural components from the impact zone on the north face of WTC 1. The structural components in the final subassembly model included the exterior panels, core framing, truss floor structures, and interior contents (workstations), Figure E-18. 


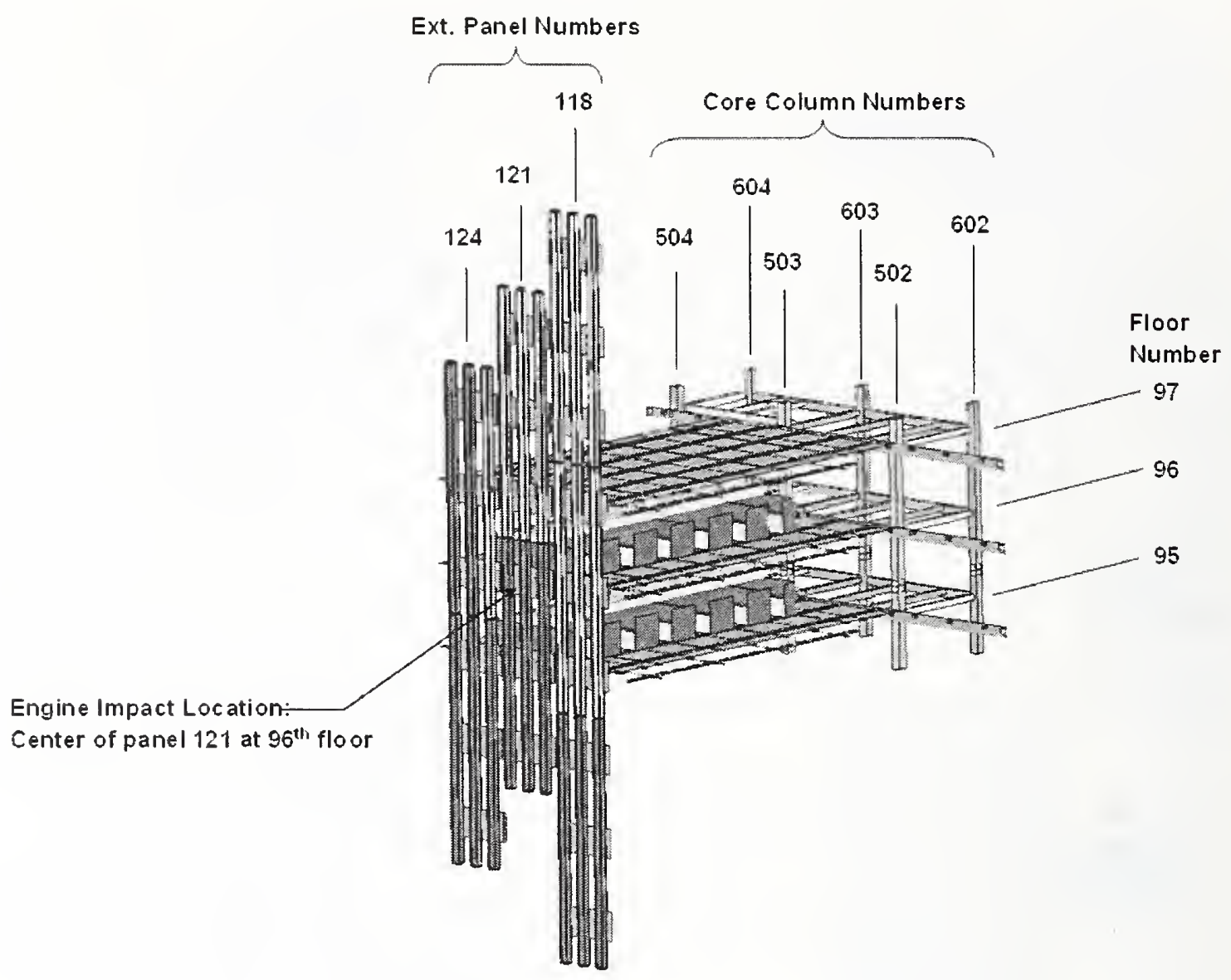

Figure E-18. Final WTC tower subassembly model.

The subassembly model was impacted by an aircraft engine and by a segment of a fuel-filled wing. The response of the structure to the engine impact is shown in Figure E-19 and to the wing impact in Figure E-20. The subassembly model was used to investigate the effect of a number of modeling parameters on the response and damage estimates. For the engine impact simulations, these parameters included the strength of the building nonstructural contents and the concrete slab strength. For the wing impact simulations, the effect of the ductility of the exterior column weldment on the impact response was investigated. The results of these parametric studies indicated the following:

The deceleration profile of the impacting engine indicated that the response of the nonstructural building contents was dominated by the mass of the workstations, rather than by their strength.

Varying the strength of the floor concrete slab from $4 \mathrm{ksi}$ to $3 \mathrm{ksi}$ did not result in significant change in the impact response. It appears that the mass of the concrete slab had a greater effect on the engine deceleration and damage to the floor than did the concrete strength.

Varying the ductility of the weld zone in the exterior columns from 8 percent to 1 percent did not result in any noticeable difference in the damage pattern (Figure E-21) or the energy absorbed by the exterior panels, indicating that the weld ductility had a negligible effect on the impact response. 


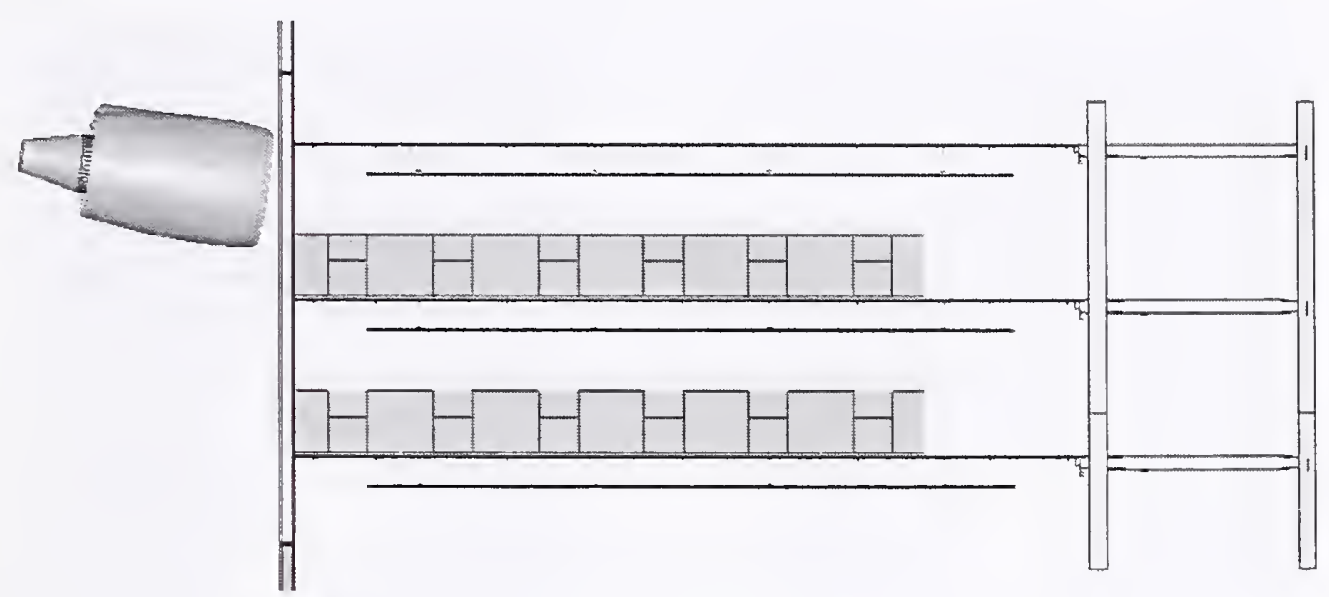

(a) Time $=0.00 \mathrm{~s}$

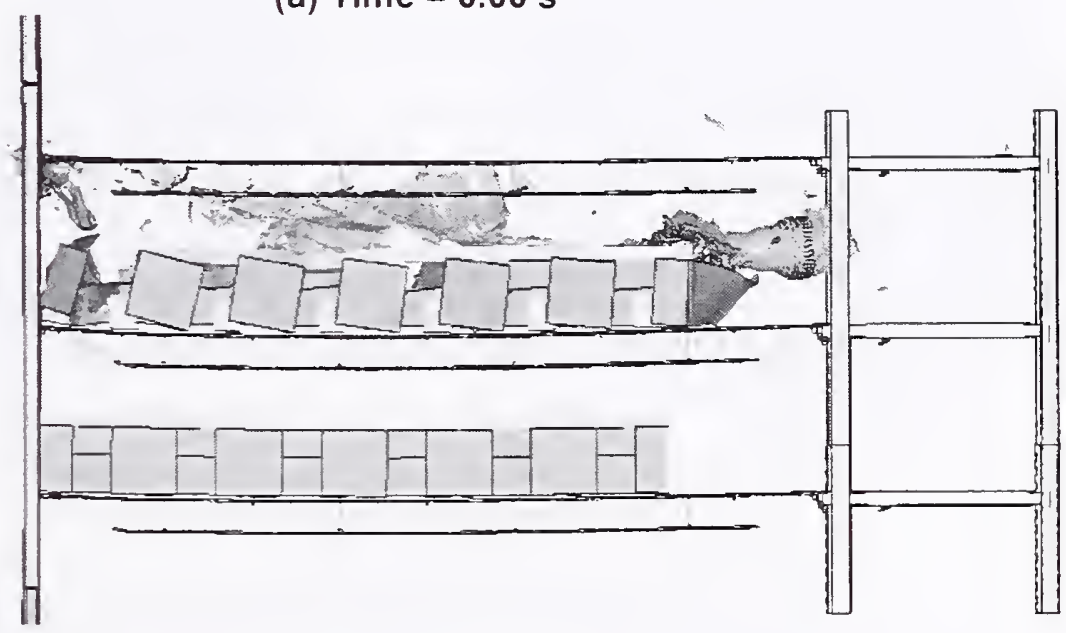

(b) Time $=0.25 \mathrm{~s}$

Figure E-19. Engine impact and break up behavior (side view). 


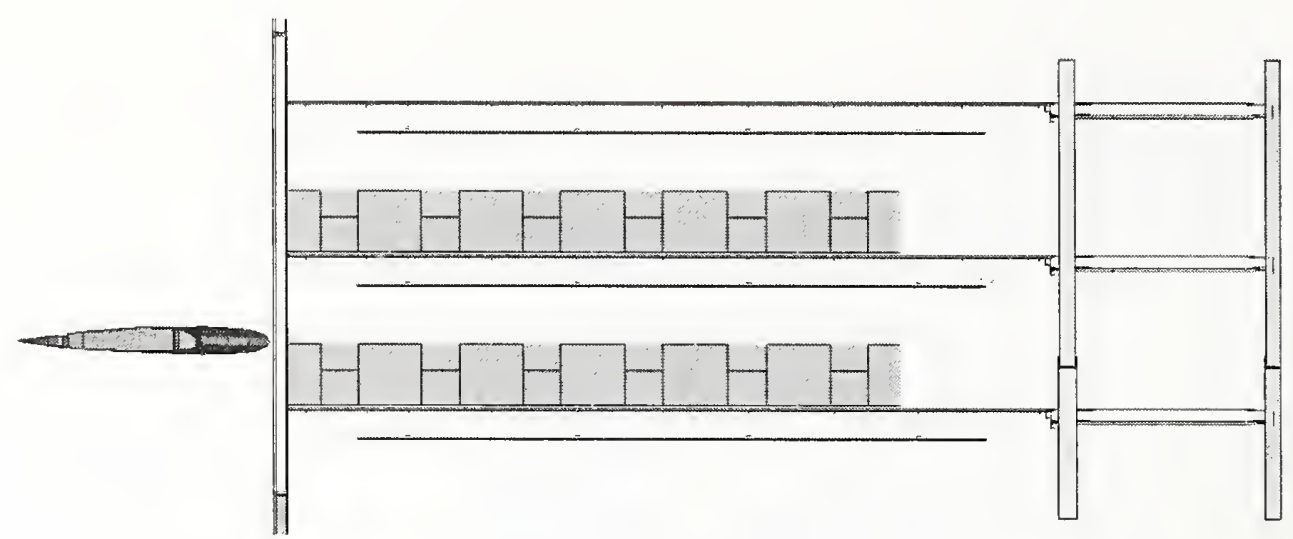

(a) Time $=0.00 \mathrm{~s}$

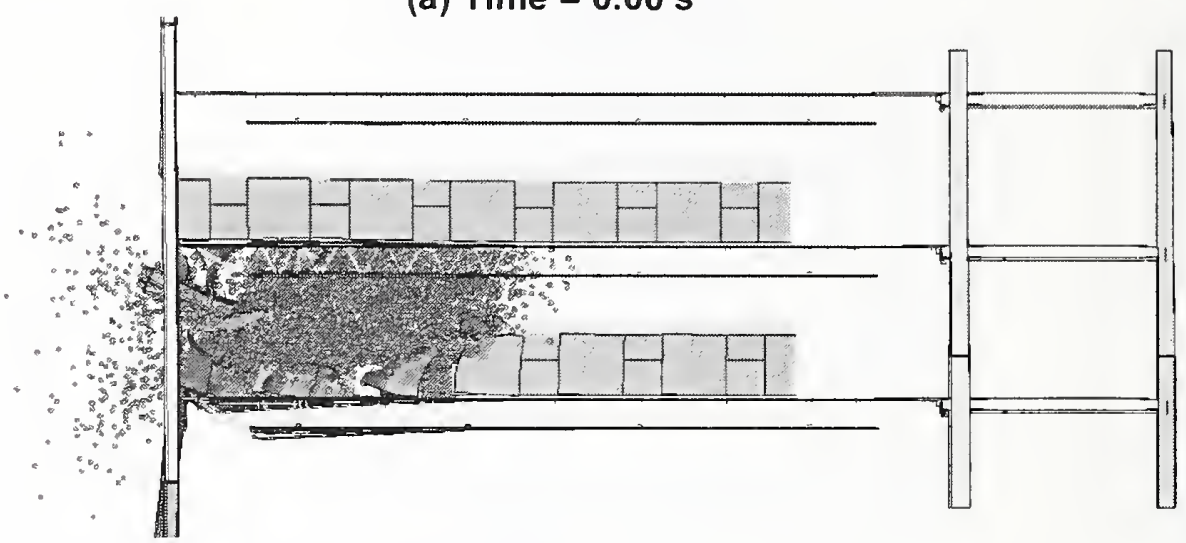

(b) Time $=0.05 \mathrm{~s}$

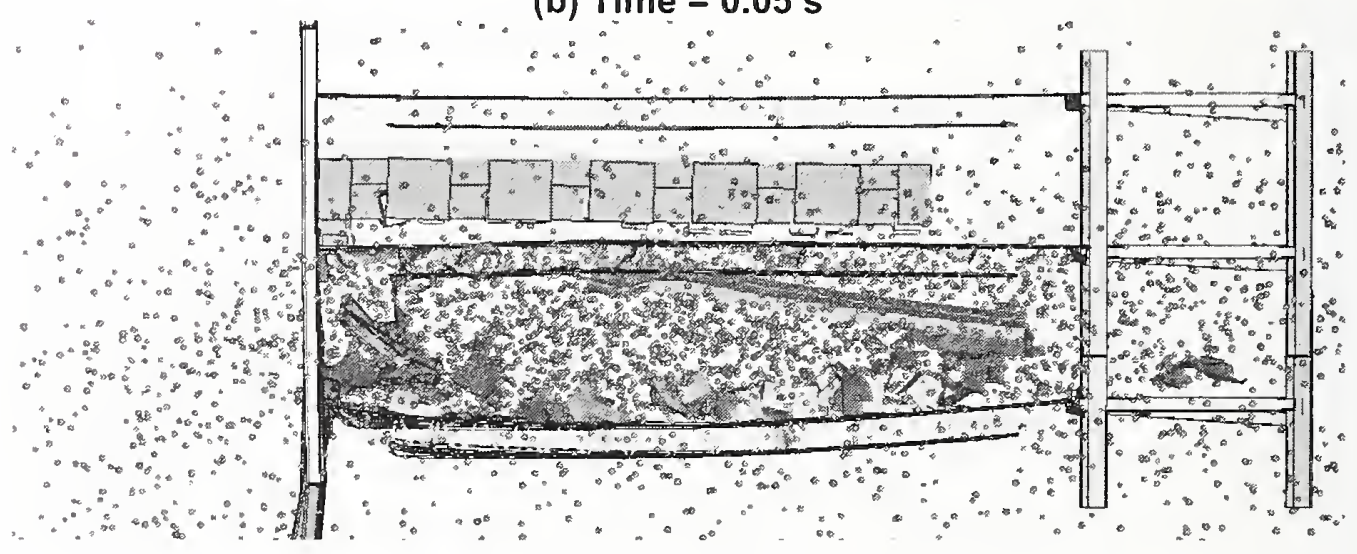

(c) Time $=0.25 \mathrm{~s}$

Figure E-20. Wing section impact and break up behavior (side view). 


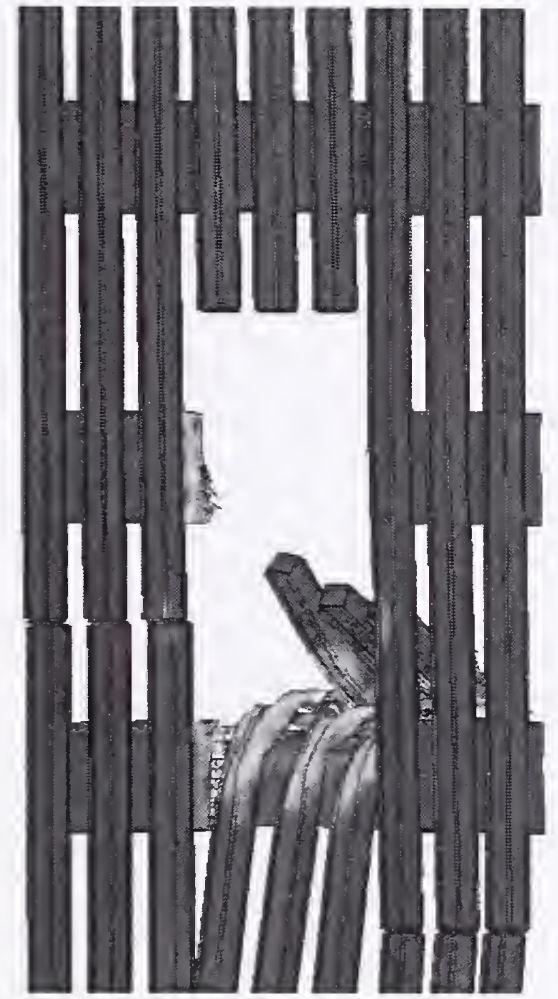

(a) 8 percent weld ductility

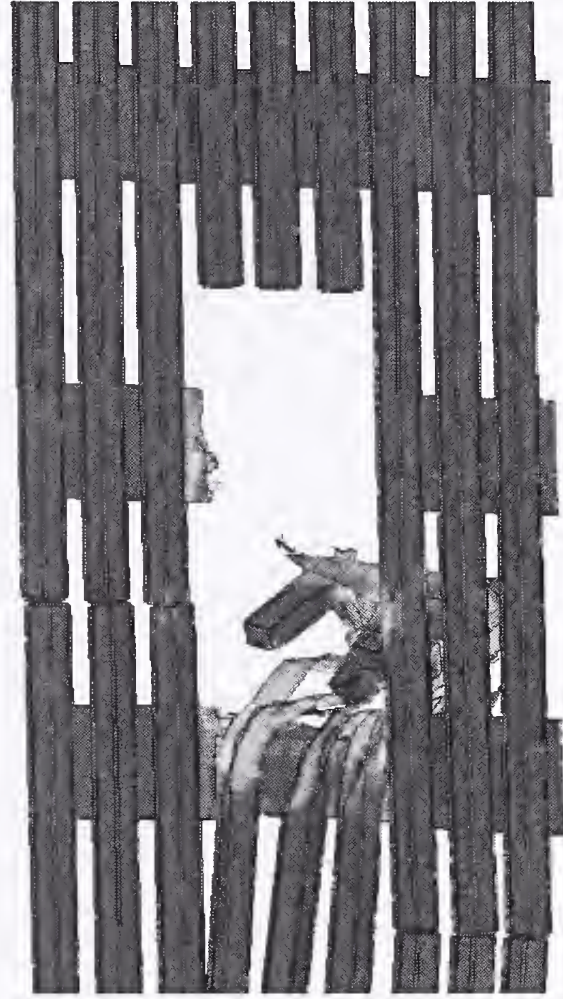

(b) 1 percent weld ductility

Figure E-21. Exterior wall damage for the wing section impact analyses.

\section{E.7 ANALYSIS OF AIRCRAFT IMPACT CONDITIONS}

Three different methods were applied to determine the impact conditions for the two aircraft that impacted the towers. The first method used a comparison of videos from different positions to calculatc the three-dimensional trajectory of the aircraft. The second method used the relative frame-by-frame motion in a single video scaled to the length of the aircraft in the video to calculate the impact speed. Finally, analysis of the impact damage on the face of each tower was used to refine the relative impact orientation and trajectory.

The aircraft impact conditions matching the observed exterior wall damage are shown in Figure E-22 and Figure E-23 for WTC 1 and WTC 2, respectively. The aircraft and exterior wall models were used to visualize the impact scenario in the figures, and the view shown was aligned with the aircraft trajectory. Matching the projected impact points of the wings, fuselage, engines, and vertical stabilizer onto the exterior wall of each tower to the observed damage pattern was an important constraint in the determination of impact conditions. The final set of impact conditions from the analyses are summarized in Table E-3. 


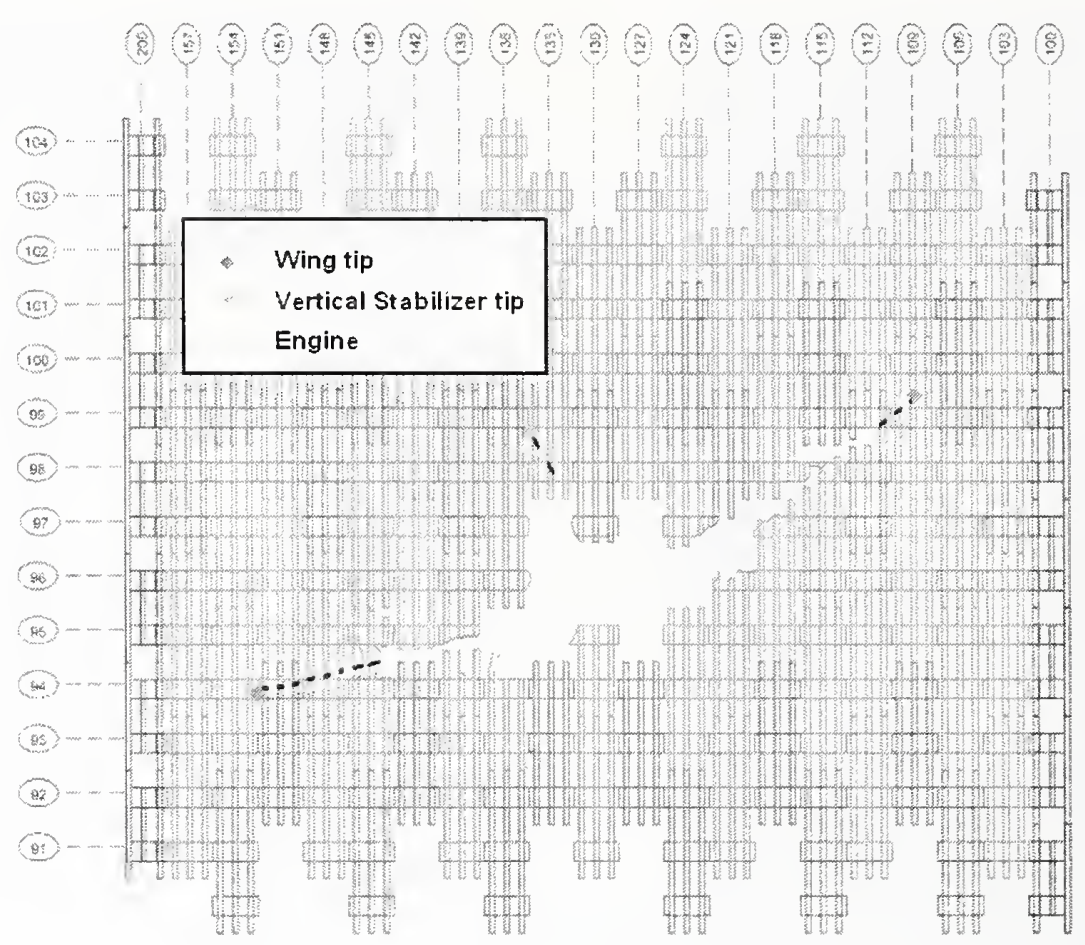

(a) Impact damage

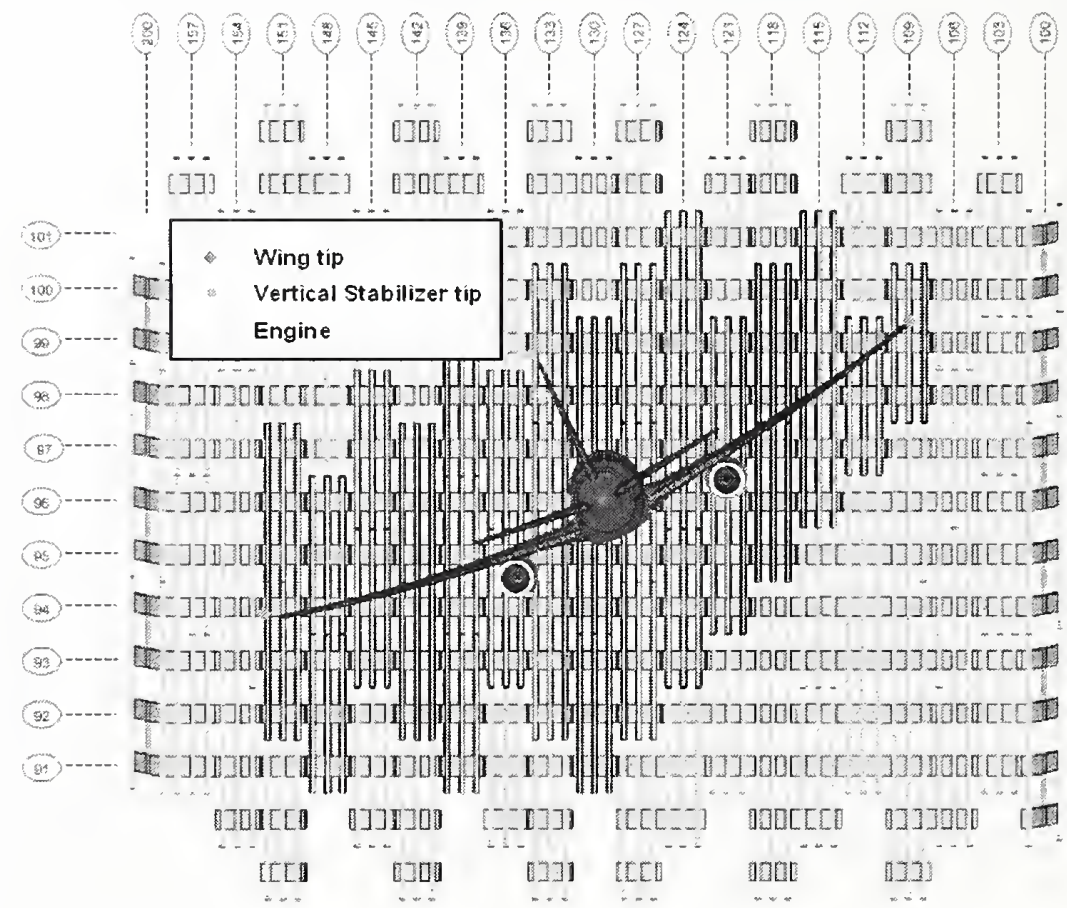

(b) Impact conditions (vertical angle $=10.6^{\circ}$, lateral angle $=0^{\circ}$ )

Figure E-22. WTC 1 impact damage and impact conditions. 


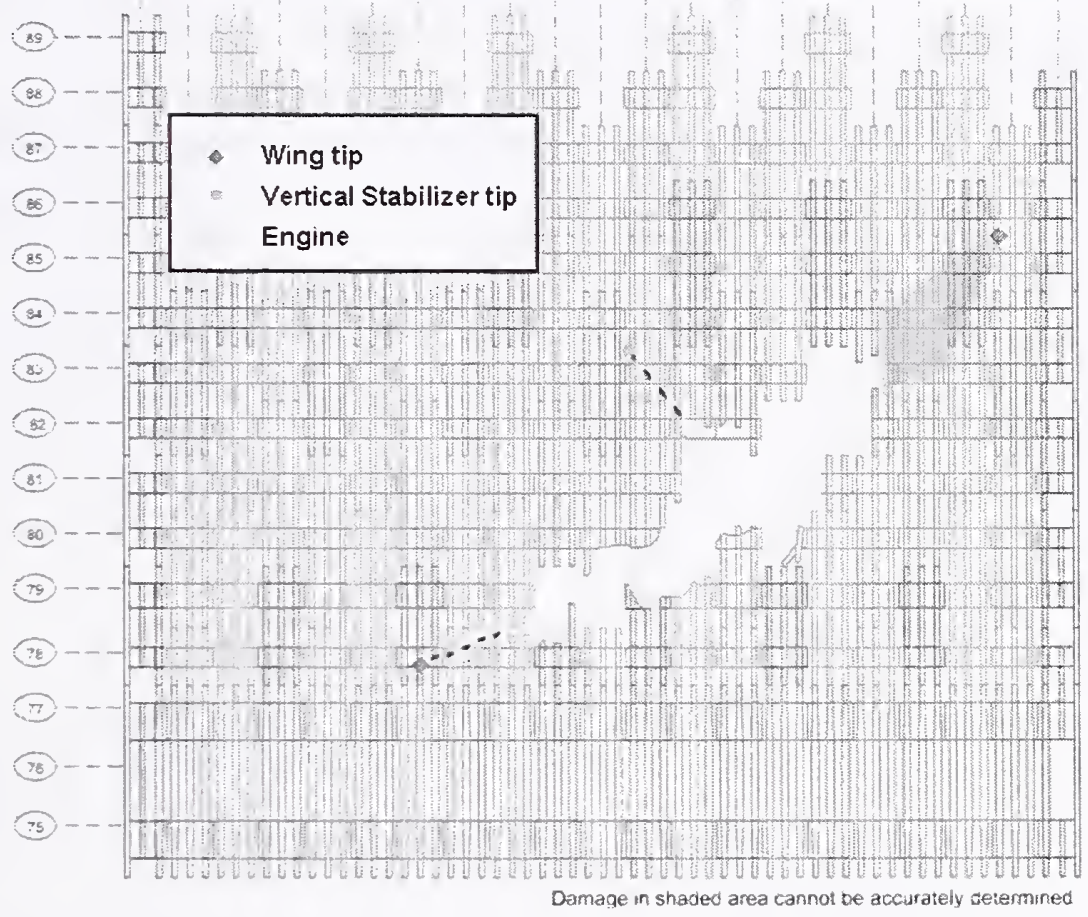

(a) Impact damage

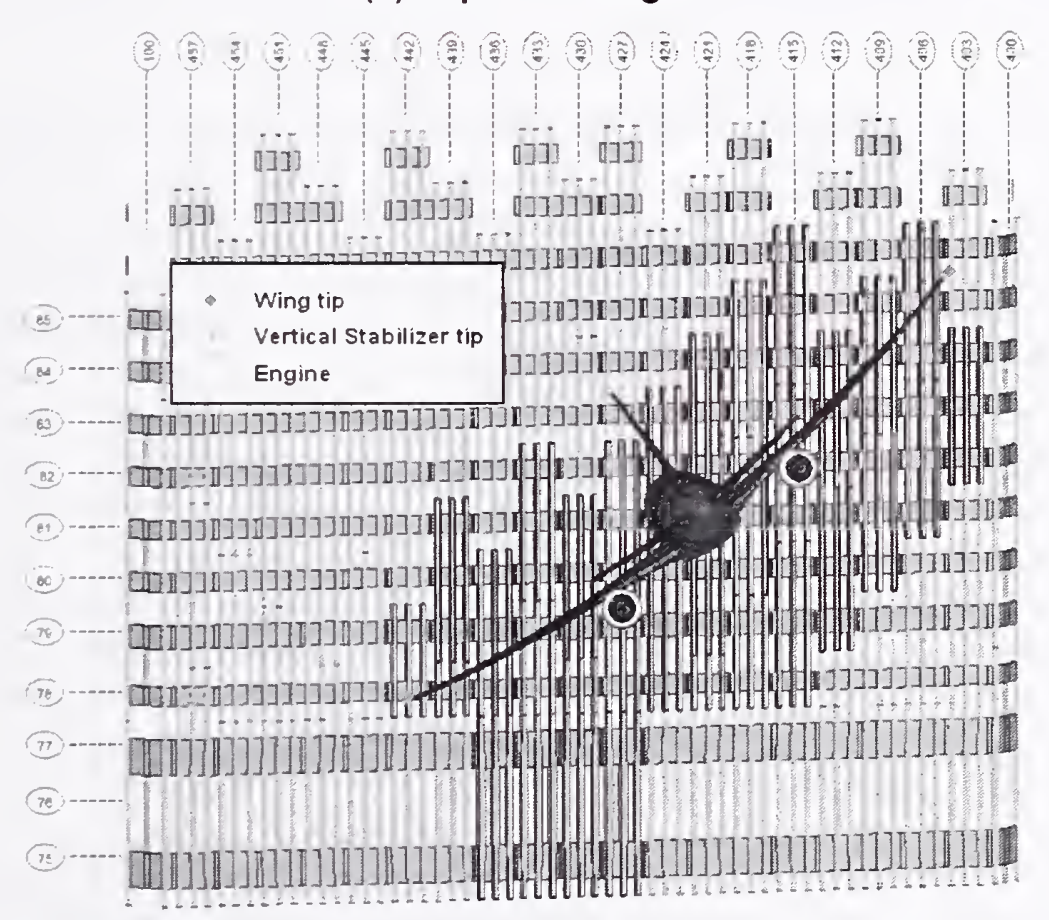

(b) Impact conditions (vertical angle $=6^{\circ}$, lateral angle $=13^{\circ}$ )

Figure E-23. WTC 2 impact damage and impact conditions. 
Table E-3. Summary of refined aircraft impact conditions.

\begin{tabular}{|l|c|c|}
\hline & AA 11 (WTC 1) & UAL 175 (WTC 2) \\
\hline Impact Speed (mph) & $443 \pm 30$ & $542 \pm 24$ \\
\hline $\begin{array}{l}\text { Vertical Approach Angle } \\
\text { (Velocity vector) }\end{array}$ & $\begin{array}{c}10.6^{\circ} \pm 3^{\circ} \text { below horizontal } \\
\text { (heading downward) }\end{array}$ & $\begin{array}{c}6^{\circ} \pm 2^{\circ} \text { below horizontal } \\
\text { (heading downward) }\end{array}$ \\
\hline $\begin{array}{l}\text { Lateral Approach Angle } \\
\text { (Velocity vector) }\end{array}$ & $\begin{array}{c}180.3^{\circ} \pm 4^{\circ} \text { clockwise from } \\
\text { Structure North }\end{array}$ & $\begin{array}{c}15^{\circ} \pm 2^{\circ} \text { clockwise from } \\
\text { Structure North }\end{array}$ \\
\hline $\begin{array}{l}\text { Vertical Fuselage Orientation } \\
\text { Relative to Trajectory }\end{array}$ & $\begin{array}{c}2^{\circ} \text { nose-up from the vertical } \\
\text { approach angle }\end{array}$ & $\begin{array}{c}1^{\circ} \text { nose-up from the vertical } \\
\text { approach angle }\end{array}$ \\
\hline $\begin{array}{l}\text { Lateral Fuselage Orientation } \\
\text { Relative to Trajectory }\end{array}$ & $\begin{array}{c}0^{\circ} \text { clockwise from lateral } \\
\text { approach angle }\end{array}$ & $\begin{array}{c}-3^{\circ} \text { clockwise from lateral } \\
\text { approach angle }\end{array}$ \\
\hline Roll Angle (left wing downward) & \multicolumn{2}{|c|}{$25^{\circ} \pm 2^{\circ}$} \\
\hline
\end{tabular}

a. Structure North is approximately 29 degrees clockwise from True North.

\section{E.8 UNCERTAINTY ANALYSES}

The objectives of the uncertainty analyses were to assess the effect of uncertainties associated with the aircraft and WTC towers parameters on the level of damage to the towers after impact and to determine the most influential modeling parameters that affect the damage estimates. Uncertainty arises in these analyses from the following key parameters:

- Aircraft impact parameters: aircraft speed, horizontal and vertical angles of incidence, orientation, and location of impact.

- Material properties: high strain rate material constitutive behavior and failure criteria for the towers and the aircraft.

- Aircraft mass and stiffness properties, and the jet fuel distribution in the aircraft.

- Tower parameters: structural strength and mass distribution, connection and joint positions relative to impact and joint failure behavior.

- Nonstructural building contents that may share in absorbing energy imparted by the aircraft impact.

An important source of uncertainty that is not listed in these key parameters is the inaccuracy associated with mathematical or numerical models. The inaccuracies of models, also known as modeling errors, are deterministic in nature, but are often treated as random variables to characterize the effects of the analysis methodologies on the calculated response. All of these variables did not necessarily have a significant effect on the estimated impact damage to the WTC towers.

Because of the complexity of the problem and the limited number of parameters that could be varied in the global analyses, it was necessary to down-select a refined list of uncertainty parameters from all of the possible parameters. Therefore, variable screening was conducted using design of experiments methodology. Screening was first conducted at component and subassembly levels using orthogonal factorial design techniques in order to identify the most influential parameters and reduce the number of 
parameters to a more manageable number for the global impact analyses. The sensitivity analyses included engine impacts against core columns, wing section impacts against exterior panels, and engineimpact subassembly analyses.

Based on the three sensitivity analyses, the set of influential modeling parameters was reduced. The following parameters were selected for variation in the global impact analyses:

- Impact speed.

- Vertical approach angle of the aircraft.

- Lateral approach angle of the aircraft.

- Total aircraft weight.

- Aircraft materials failure strain.

- Tower materials failure strain.

- Building contents weight.

The impact speed and vertical approach angle were selected as significant parameters in the global analyses due to their importance in the component and subassembly impact response. The vertical approach angle played a primary role in the magnitude of the vertical impact loads on the truss floor structures. Lateral approach angle was also selected as this parameter dictated to a large extent where aircraft debris traveled and what part of the core was affected by this debris.

Variations in the strength and ductility (failure strain) of materials had a similar effect on the amount of absorbed energy. An increase in yield strength or an increase in failure strain resulted in an increase in the energy absorbing capacity of the structure. The yield strength of materials was typically known more accurately than the failure strains. This was particularly true within the finite element analyses where the value of the failure strain needed to be assigned based on the model resolution and failure criteria used. As a result, only the uncertainties in the material failure strain were used as a material uncertainty parameter for both the aircraft and the towers in the subsequent global impact analyses.

The uncertainty in the weights associated with building contents (corresponding to service live loads) was found to be of secondary importance in the engine-subassembly impact analysis. In the global impact analyses, the live load contents were expected to play a more significant role in confining the fuel and debris dispersion. In addition, the partition walls were significant for controlling the subsequent spread of fire through the towers. As a result, the uncertainty in building contents weight was included as an uncertainty parameter in the global analyses.

\section{E.9 GLOBAL IMPACT ANALYSES}

The primary objective of this analysis was to determine the condition of the two WTC towers immediately following the aircraft impacts. This assessment included the estimation of the structural damage that degraded their strength and the condition and position of nonstructural contents such as 
partitions, workstations, aircraft fuel, and other debris that influenced the behavior of the subsequent fires in the towers. The global impact analyses were the primary method by which the damage to the towers was estimated.

\section{E.9.1 WTC 1 Base Case Global Impact Analysis}

The combined aircraft and tower model for the base case WTC 1 global impact analysis is shown in Figure E-24. The base case impact analysis was performed for a 0.715 second duration following initial impact of the aircraft nose with the north exterior wall. The analysis was performed on a computer cluster using twelve $2.8 \mathrm{GHz}$ Intel Xeon processors, each on a separate node of the cluster. The run time for this analysis was approximately two weeks. The progress of the global impact simulations was monitored on average every two days. The calculations were terminated when the damage to the towers reached a steady state and the motion of the debris was reduced to a level that was not expected to produce any significant increase in the impact damage. The residual kinetic energy of the airframe components at the termination of a global impact simulation was typically less than 1 percent of the initial kinetic energy at impact.

A side view of the base case WTC 1 global impact response is shown in Figure E-25. In the figure, the tower interior contents were removed, and the tower structures were shown as transparent so that the impact response in the tower interior could be seen. A corresponding top view of the impact response is shown in Figure E-26. The aircraft impact response was dominated by the impact, penetration, and fragmentation of the airframe structures. The entire aircraft fully penetrated the tower at approximately $0.25 \mathrm{~s}$. The fuselage structures were severely damaged both from the penetration through the exterior columns and the penetration of the 96 th floor slab that sliced the fuselage structures in half. The downward trajectory of the aircraft structures caused the airframe to collapse against the floor, and the subsequent debris motion was redirected inward along a more horizontal trajectory parallel to the floor. The downward trajectory of the aircraft structures transferred sufficient vertical load such that the truss floor structures on the 95th and 96th floors collapsed in the impact zone. 

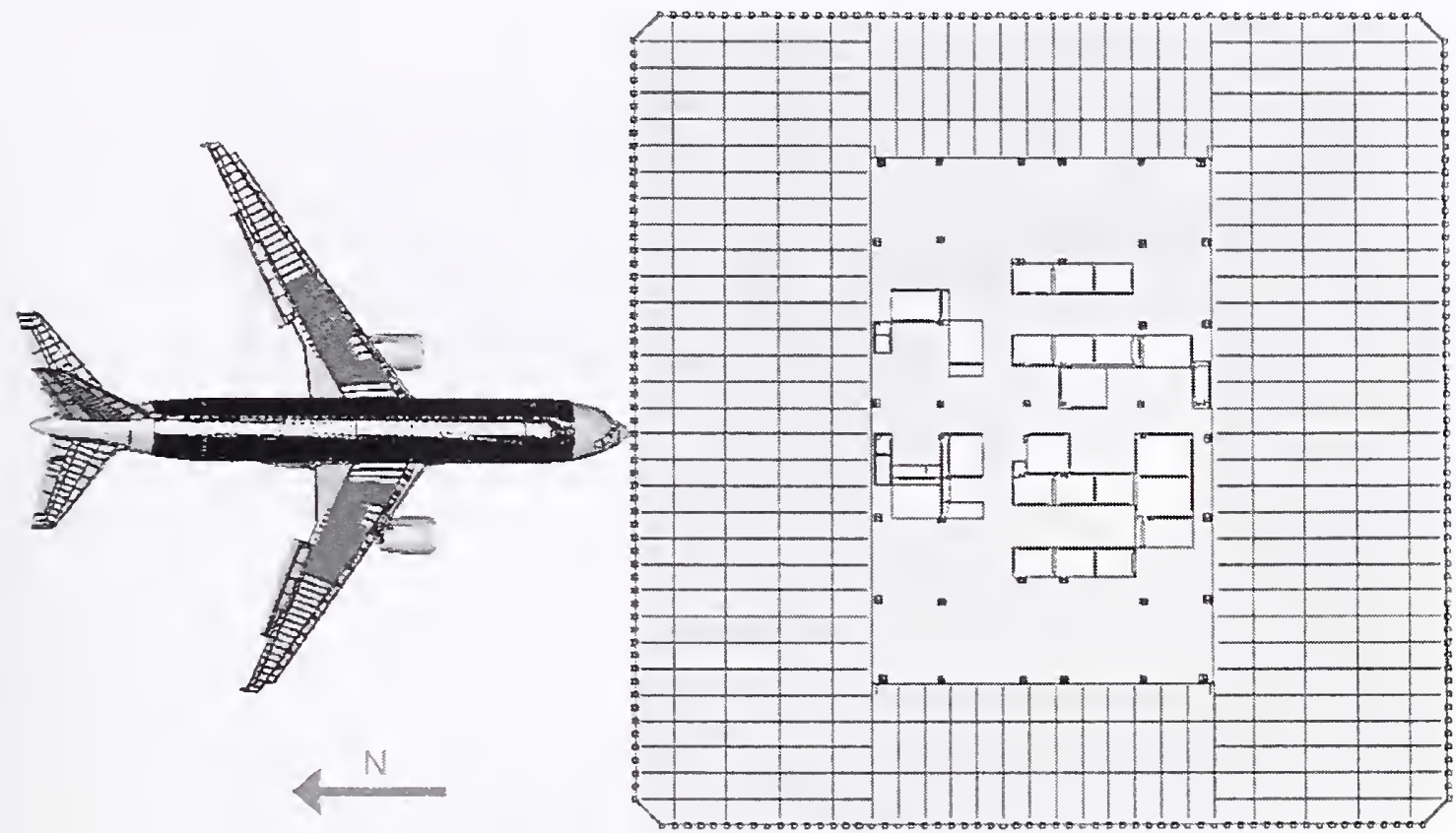

(a) Top view

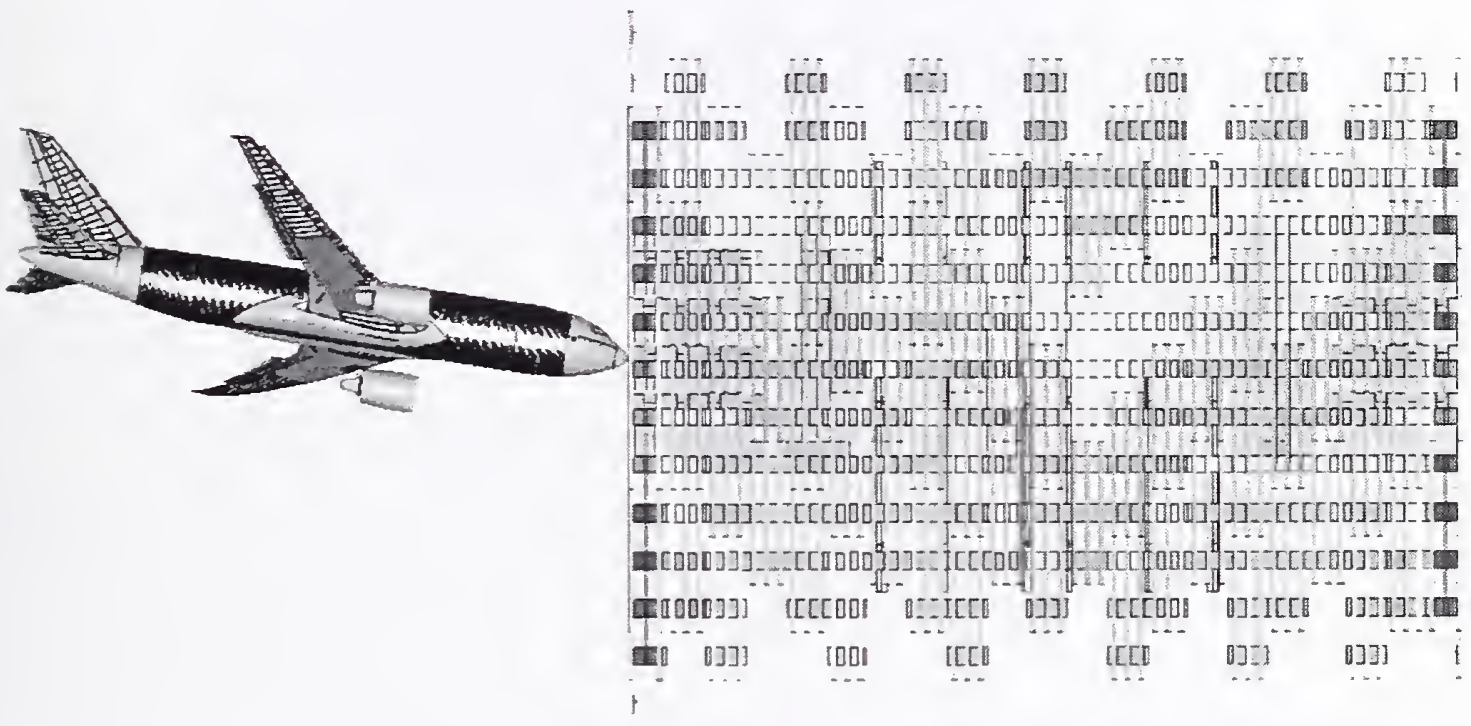

(b) Side view

Figure E-24. WTC 1 global impact model. 


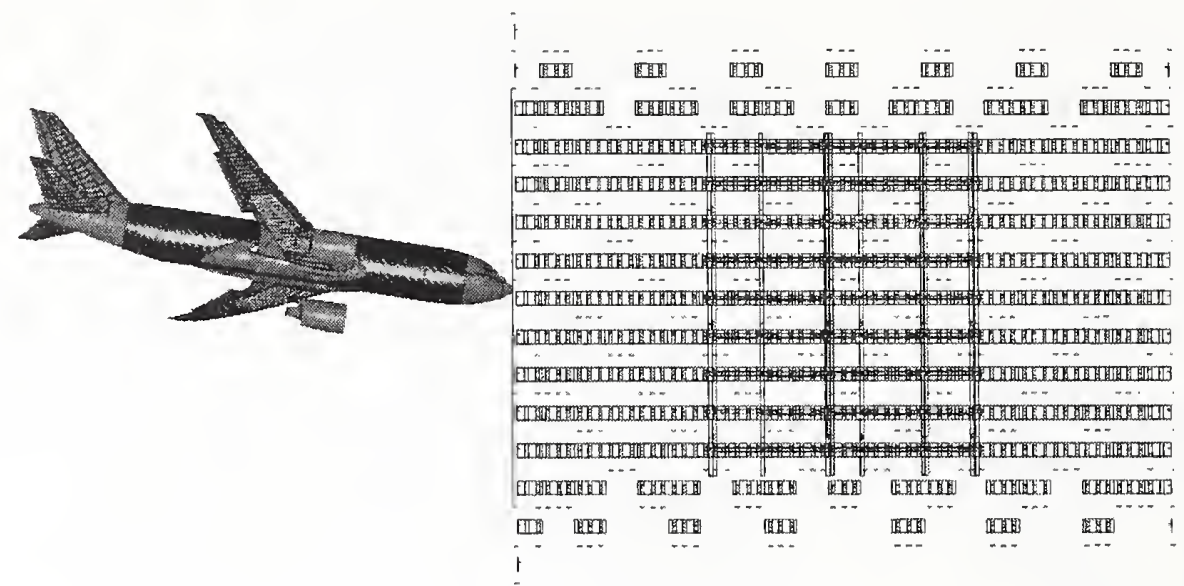

(a) Time $=0.00 \mathrm{~s}$

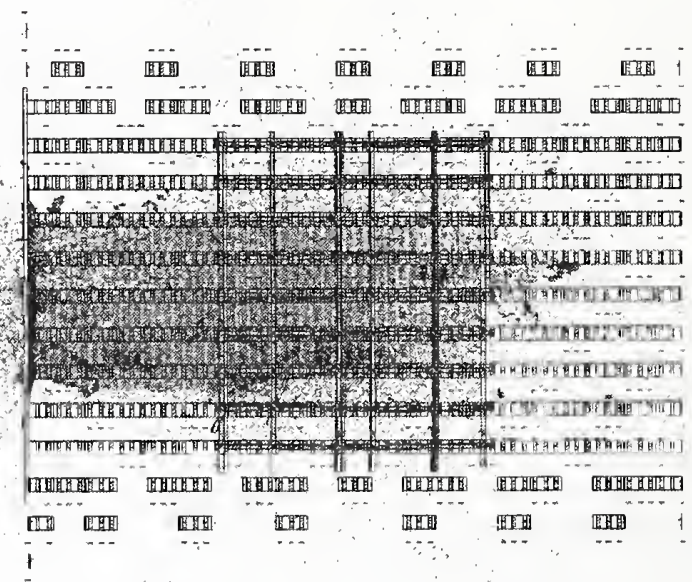

(b) Time $=0.50 \mathrm{~s}$

Figure E-25. WTC 1 base case global impact analysis - side view. 


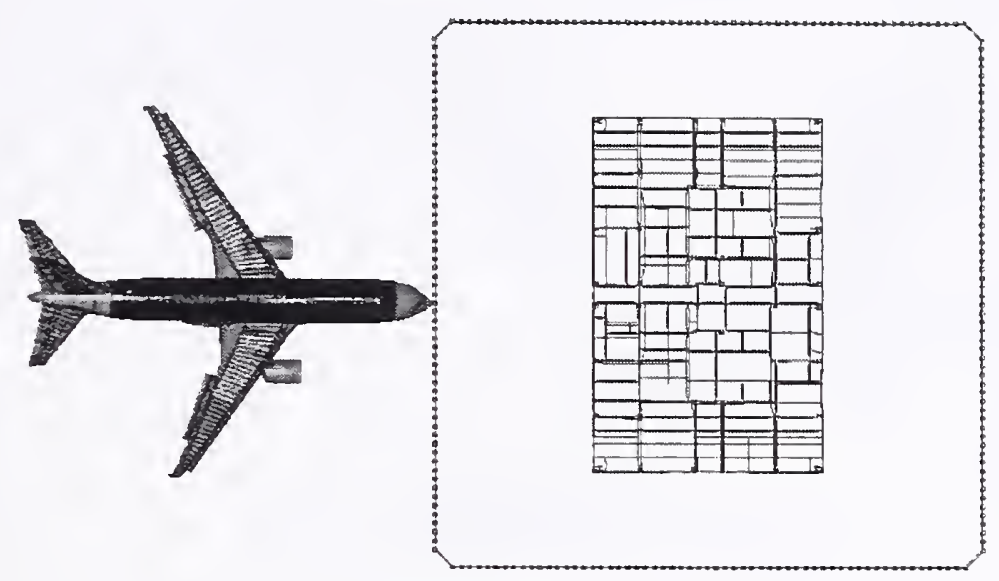

(a) Time $=0.00 \mathrm{~s}$

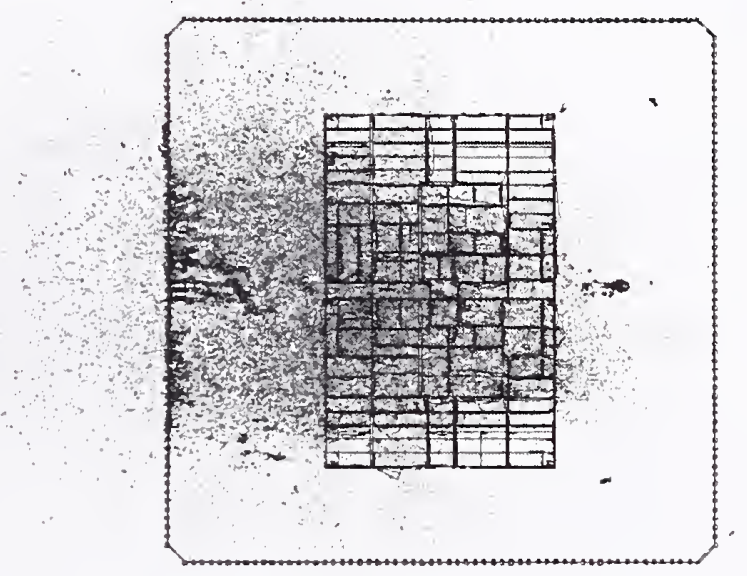

(b) Time $=0.50 \mathrm{~s}$

Figure E-26. WTC 1 base case global impact analysis - top view.

The wing structures were completely fragmented by the exterior wall. The aircraft fuel cloud began to spread out after impact but remained relatively dense until the leading edge of the fuel reached the tower core. The aircraft fuel and debris cloud eventually penetrated most of the distance through the core before their motion was halted.

Load transfer of the aircraft momentum into the tower structure is shown in Figure E-27. The momentum plotted was for all of the aircraft structures and contents (including fuel) and was normalized by the initial momentum magnitude. During the first $0.1 \mathrm{~s}$ of impact, the forward fuselage penetrated the exterior wall and impacted the interior structures. Between $0.1 \mathrm{~s}$ and $0.25 \mathrm{~s}$ a more rapid load transfer rate was observed as the area of the impact was larger (extending outward in the wing impact regions) and a higher percentage of the aircraft mass was impacting the interior structures. At $0.25 \mathrm{~s}$, as indicated in Figure E-27, the aircraft completely penetrated the building and retained approximately 30 percent of its initial momentum. Beyond this time, the rate of load transfer steadily decreased with very little load transfer after approximately $0.5 \mathrm{~s}$. 


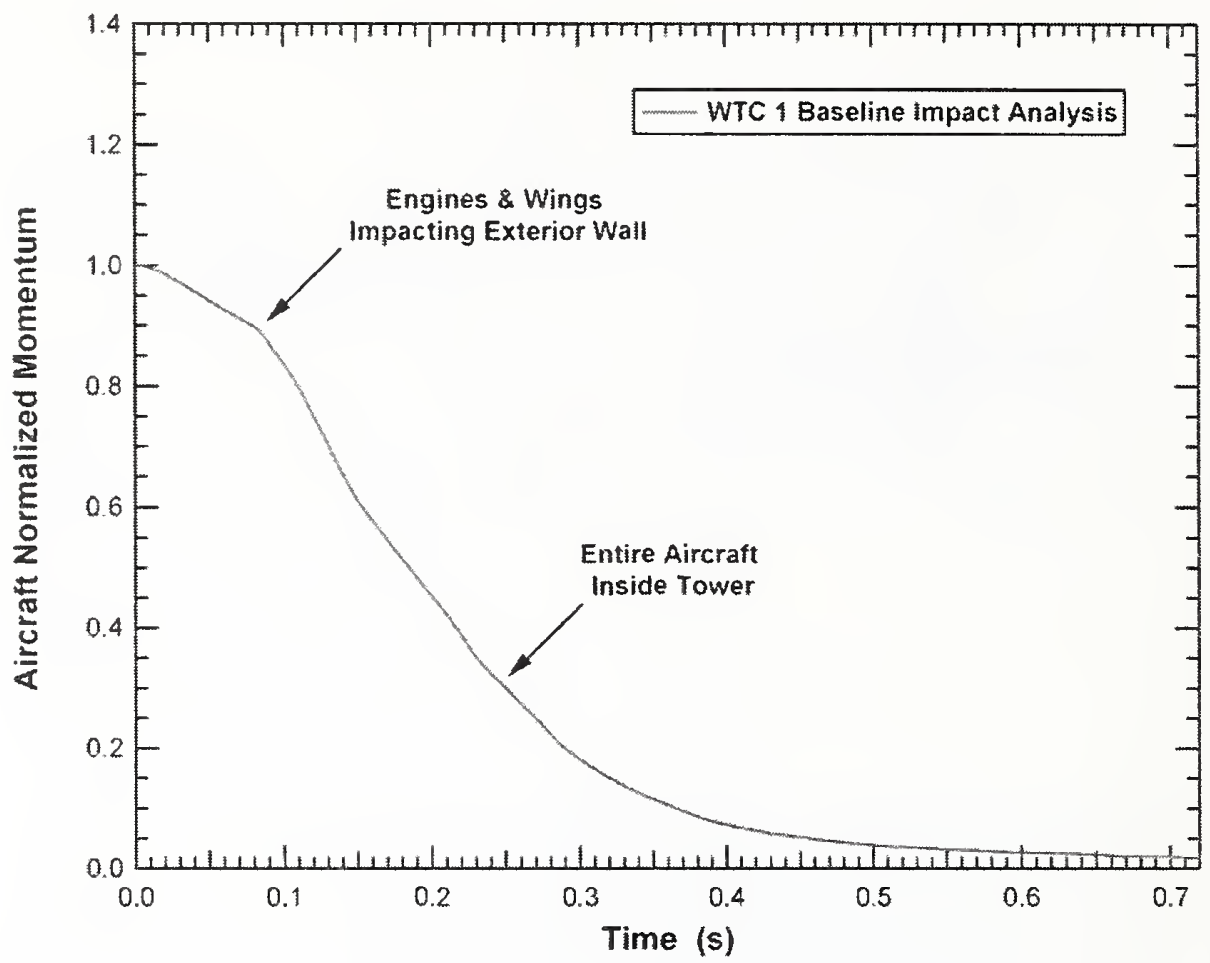

Figure E-27. Normalized aircraft momentum for the WTC 1 base case impact.

The aircraft was severely broken into debris as a result of the impact with the tower as shown in Figure E-28. At the end of the impact analysis, the aircraft was broken into thousands of debris fragments of various size and mass, as shown in Figure E-28(b). A closer inspection of the debris field shows that larger fragments still existed for specific components such as the engines, shown in Figure E-28(c). Both engines had significant impact damage with one of the engines broken into two large pieces. At the end of the simulation, the port engine was still inside the core, and the starboard engine was roughly one-third of the distance from the core to the south exterior wall. Each had a speed of less than $50 \mathrm{mph}$. 


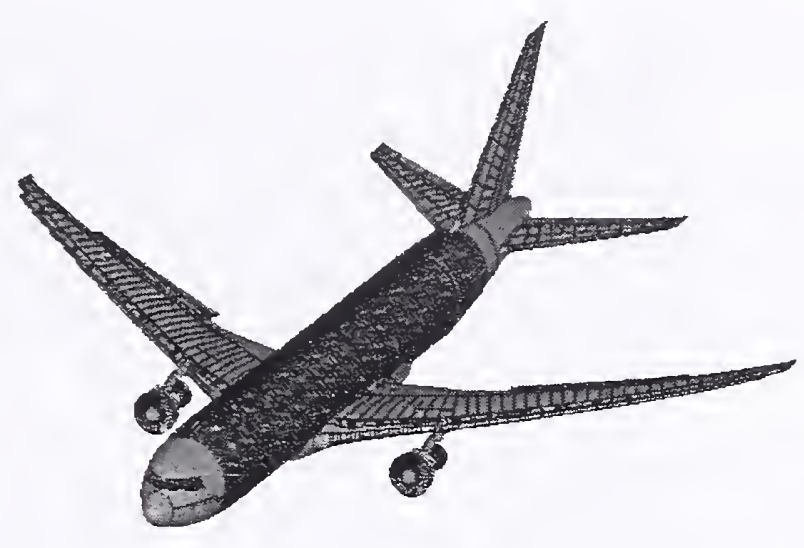

(a) Aircraft structure (time $=0.00 \mathrm{~s}$ )

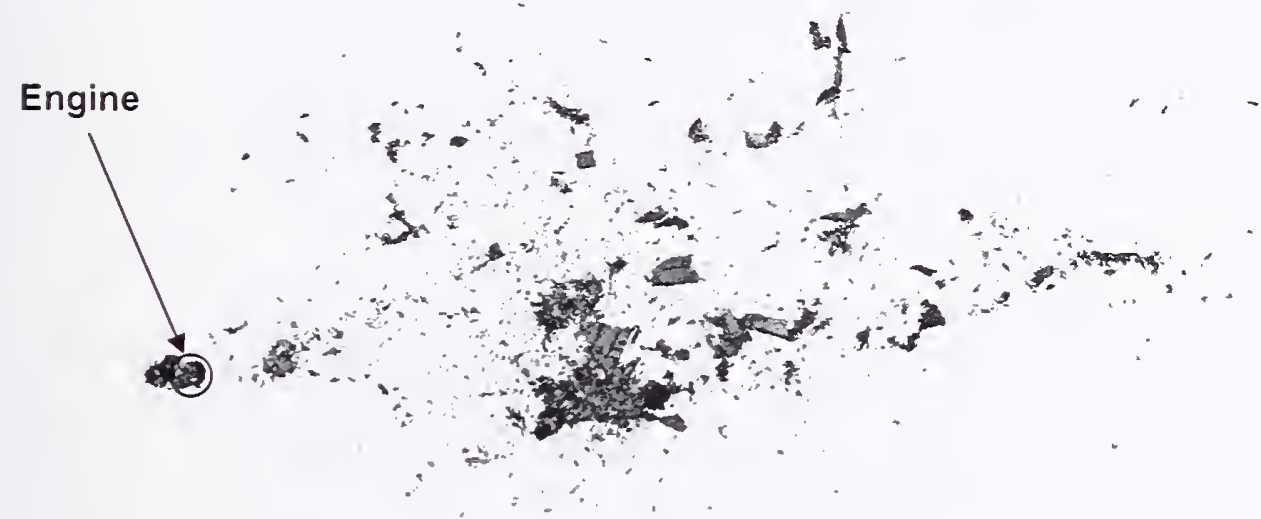

(b) Aircraft debris field (time $=0.715 \mathrm{~s}$ )
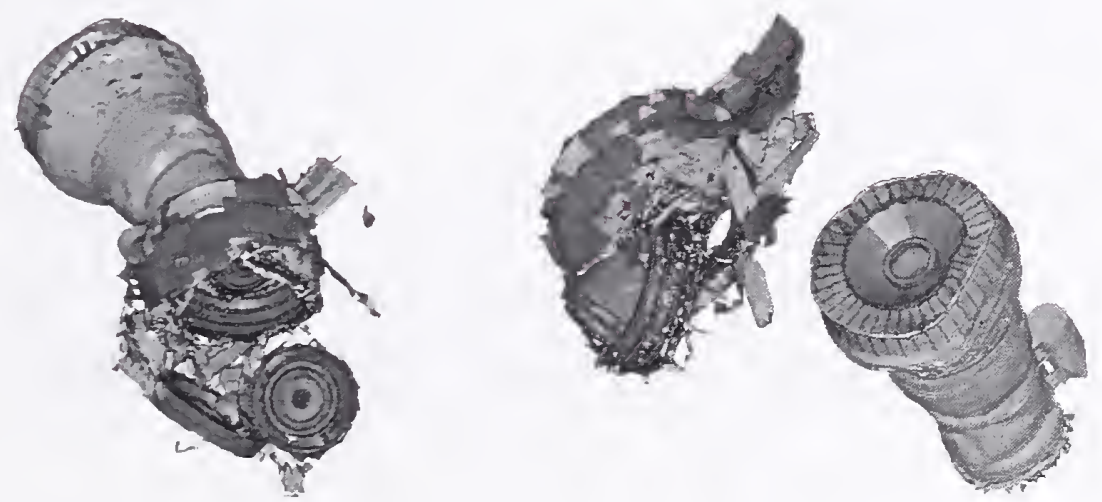

(c) Major engine debris (time=0.715 s)

Figure E-28. Aircraft break up and debris in the base case WTC 1 impact. 


\section{Exterior Wall Damage}

The calculated damage to the exterior wall was significant for two reasons: (1) the exterior wall carried a significant portion of the load in the tower, and the degradation in exterior wall strength was important for the collapse analyses, and (2) the exterior wall was the one structural system for which direct visual evidence of the impact damage was available. Therefore, the comparison of the calculated and observed exterior wall damage could provide a partial validation of the analysis methodologies used in the global impact analyses.

Damage to the north exterior wall calculated in the base case WTC 1 global impact analysis is shown in Figure E-29. This damage was compared with a schematic of observed damage developed from inspections of the video and photographic data collected on the tower after impact. The calculated and observed damage in the impact damage zone were in good agreement. That both the position and shape of the impact damage agreed provided partial validation of the modeled geometry of the aircraft, including the aircraft orientation, trajectory, and flight distortions of the wings.

The calculated magnitude and mode of impact damage on the exterior wall also agreed well with the observed damage. The exterior wall completely failed in the regions of the fuselage, engine, and fuelfilled wing section impacts. Damage to the exterior wall was observed out to the wing tips, but the exterior columns were not completely failed in the outer wing and vertical stabilizer impact regions. Failure of the exterior columns occurred both at the bolted connections between column ends and at various locations in the column, depending on the local severity of the impact load and the proximity of the bolted connection to the impact. The agreement of both the mode and magnitude of the impact damage served to partially validate the constitutive and damage modeling of the aircraft and exterior wall of the tower.

\section{Core Damage}

The magnitude of damage to the core columns and core beams was important because this damage affected the residual strength of the tower. This strength was a critical input to subsequent structural stability and collapse analyses. The overall model for the core structure and calculated impact damage to the core is shown in Figure E-30. The figure shows that the core had significant damage in the region close to the impact point. The columns in line with the aircraft fuselage failed on the impact side, and several of the core beams were also severely damaged or failed in the impact zone.

A summary of the column damage is shown graphically in Figure E-31. The damage classification levels shown in the figure are light damage, moderate damage, heavy damage, and failed (severed). The light damage level was defined as showing evidence of impact (low level plastic strains), but without significant structural deformations. The moderate damage level had visible local distortions of the column cross section (e.g., bending in a flange), but no lateral displacements of the column centerline. The heavy damage classification was for impacts that produced global deformation of the column, resulting in a permanent deflection of the column centerline. The severed columns were completely failed and could carry no residual load. The calculated damage to the core of WTC 1 consisted of three severed columns and four heavily damaged columns. 


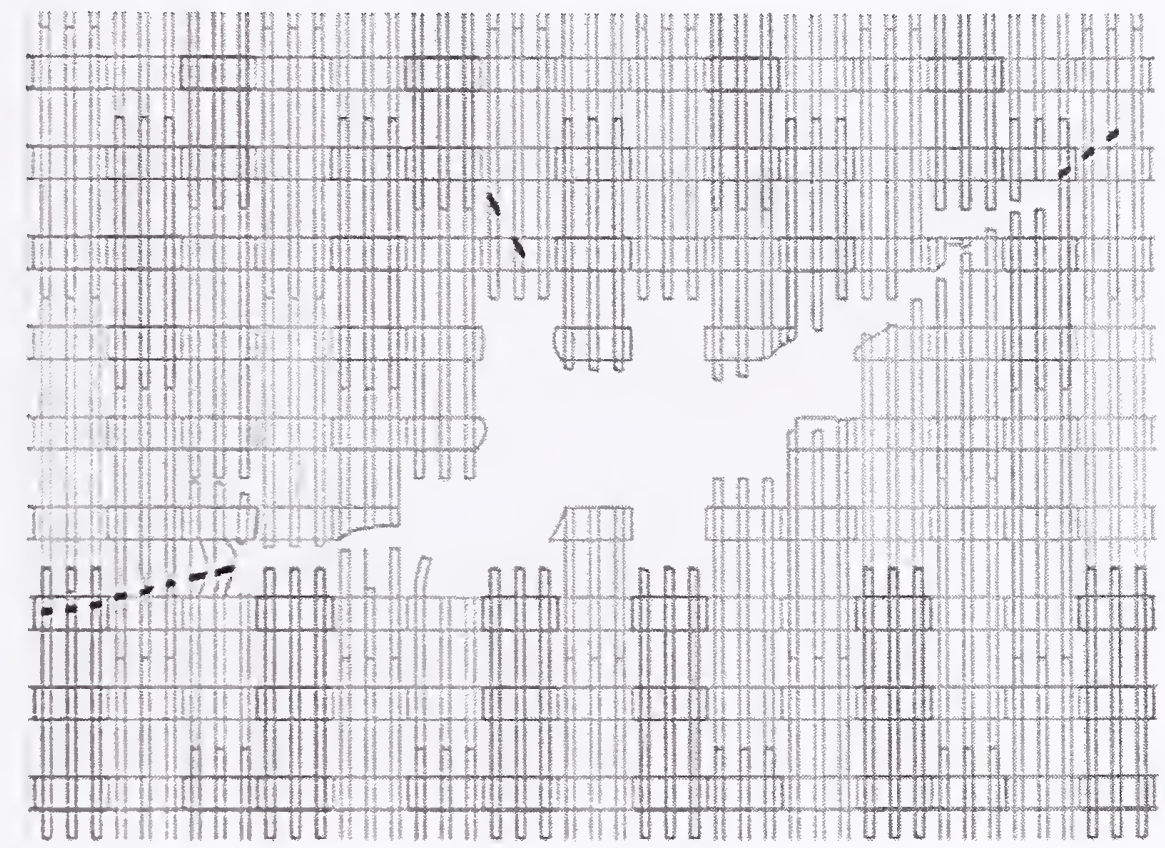

(a) Schematic of observed damage

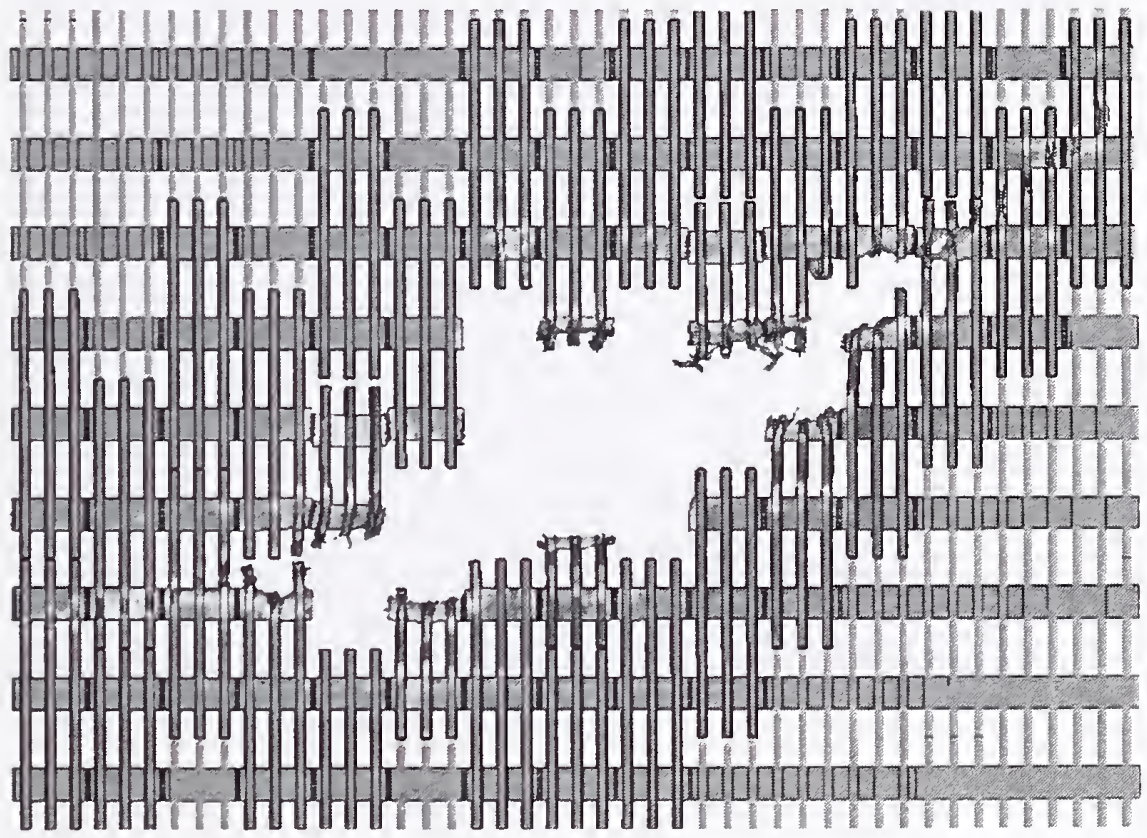

(b) Calculated damage ( $\mathrm{t}=0.715 \mathrm{~s})$

Figure E-29. Base case impact damage to the WTC 1 exterior wall. 


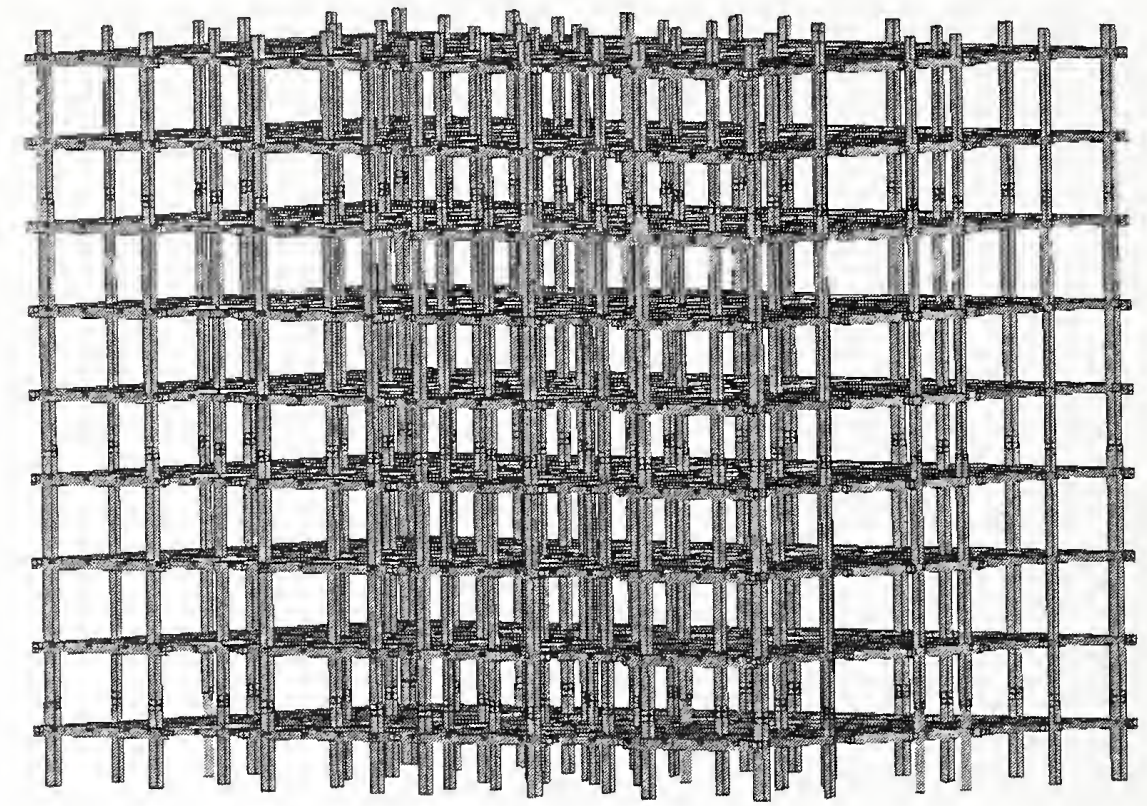

(a) Initial geometry

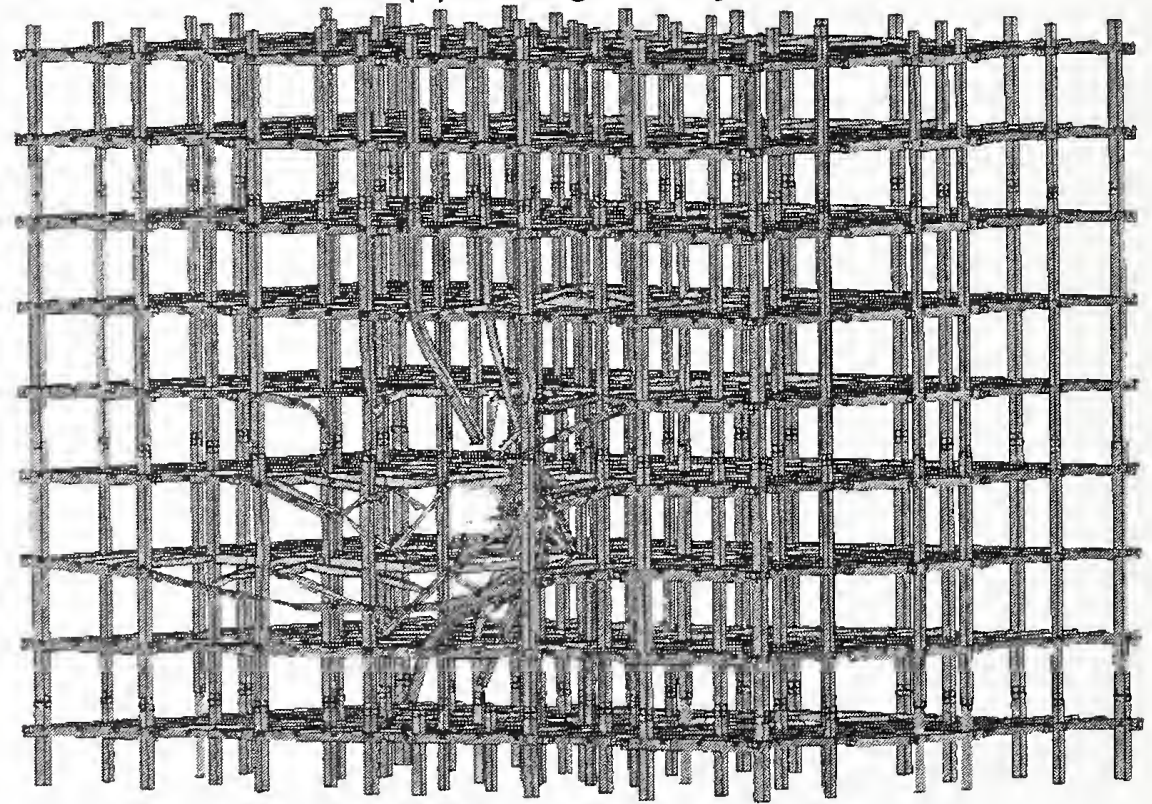

(a) Calculated impact damage

Figure E-30. Core column damage for the base case WTC 1 impact. 


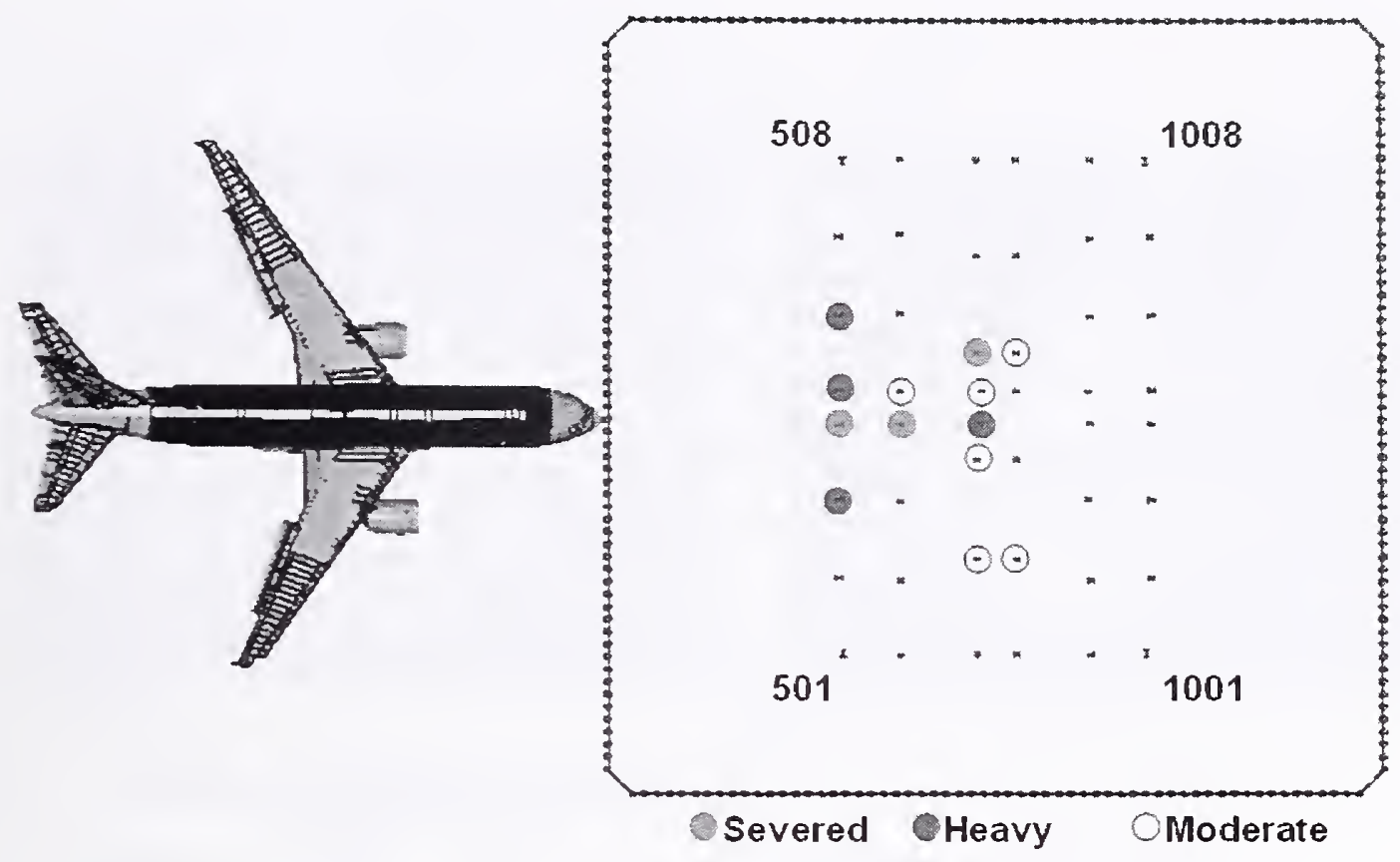

Figure E-31. Core column damage for the base case WTC 1 impact.

\section{Truss Floor Damage}

Impact damage to the floor trusses and floor slabs could have significantly contributed to the loss of structural strength and subsequent collapse. The truss floor sections provided lateral support to the exterior wall at each floor level. Any damage or holes in the concrete floor slab could provide a path for the fires to spread from floor-to-floor. Therefore, the calculation of the floor system damage was an important component of the global impact analyses.

An overall view of the floor truss structure in the impact zone, along with the calculated impact damage to the floor trusses, is shown in Figure E-32. The figure shows that the trusses experienced significant damage in the impact zone. The calculated impact response produced severe damage to the truss structures in the primary impact path of the fuselage. The truss structures were severely damaged from the exterior wall to the core. The truss floor system on floors 94 through 96 were damaged and sagging downward as a result of the impact loading. 


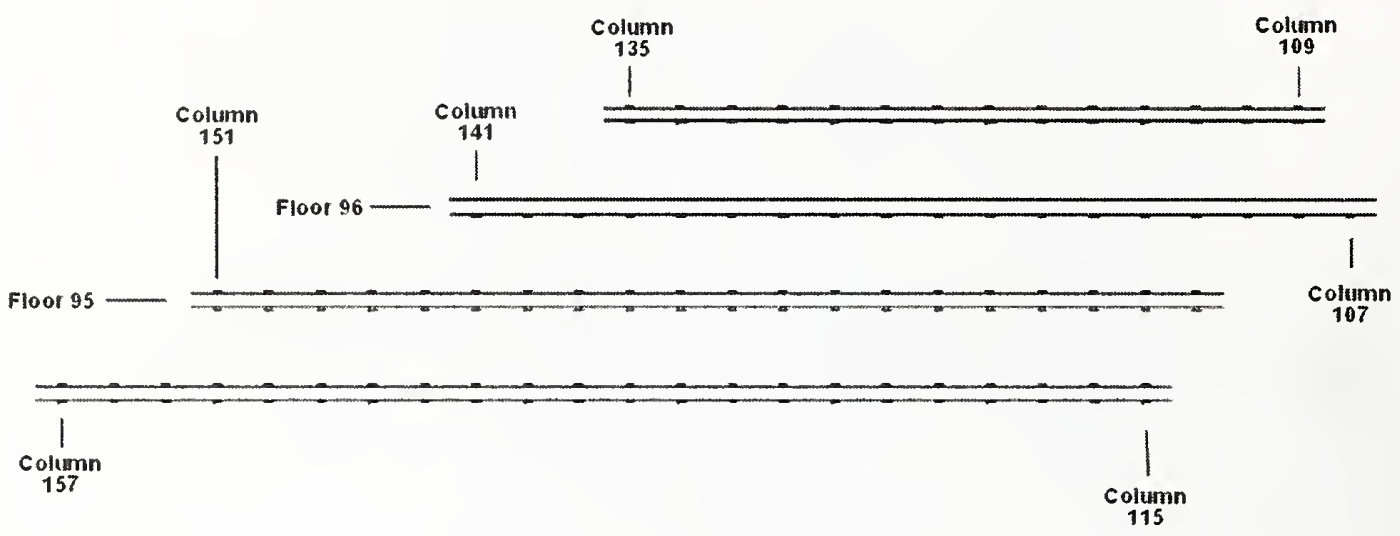

(a) Initial detailed truss structures

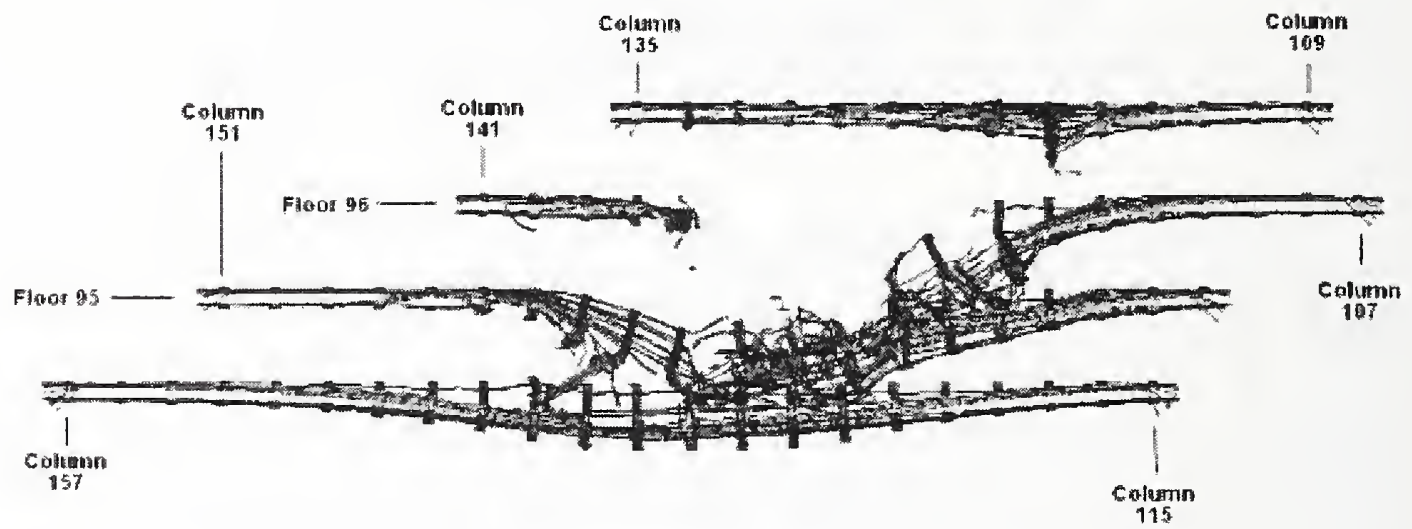

(b) Calculated damage $(t=0.715 \mathrm{~s})$

Figure E-32. Base case impact damage to the WTC 1 floor truss (front view).

The calculated damage to the floor slabs on floors 94 through 97 of WTC 1 is shown in Figure E-33. Fringes of damage were set such that the concrete slab failed in the regions colored red ( 2 percent plastic strain was used corresponding to the zero strength strain limit for the concrete in unconfined compression). At these strain levels the concrete was severely damaged, indicating that it was probably removed, exposing the supporting metal decking.

After concrete failure, break up, and removal, the strength of the floor slab was severely reduced in the analyses to model the residual strength of the metal deck. At a plastic strain of 30 percent, corresponding to failure levels for the metal decking material, the elements were eroded (seen as holes ruptured in the floor slabs shown). Figure E-33 shows that the truss floor and associated slab were heavily damaged or completely destroyed in the impact zone. The zone of heavy damage to the floor slab extended beyond the truss floor and was approximately one-third of the distance through the core on floors 94 through 96. 


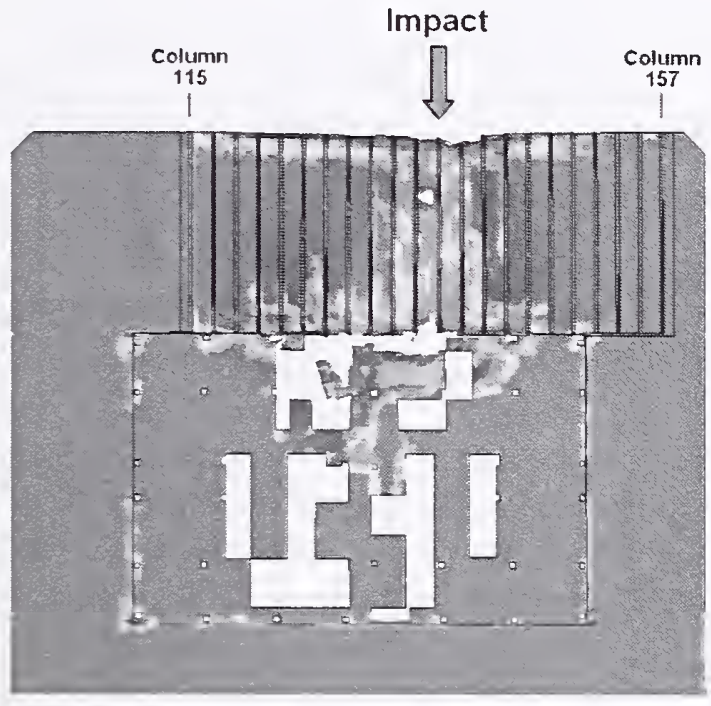

(a) Floor 94 slab damage

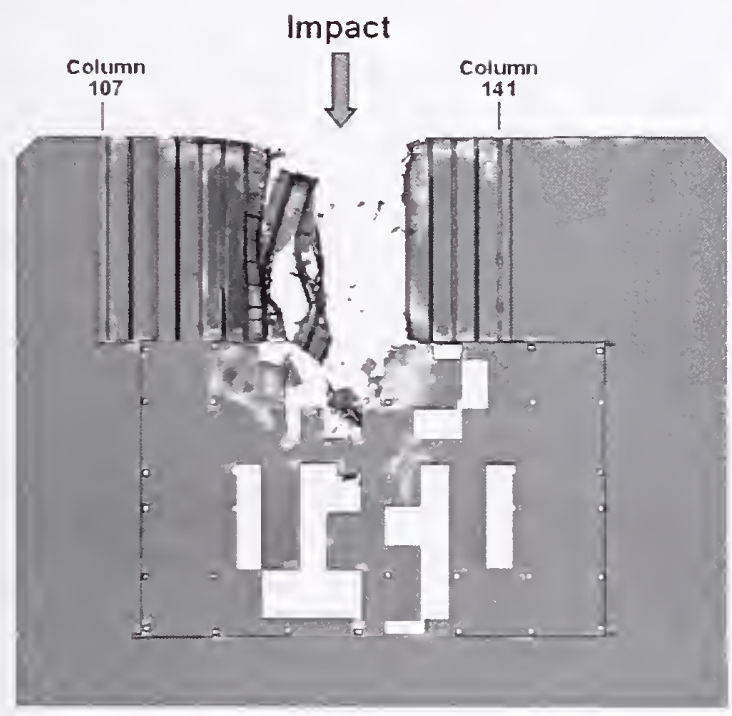

(c) Floor 96 slab damage

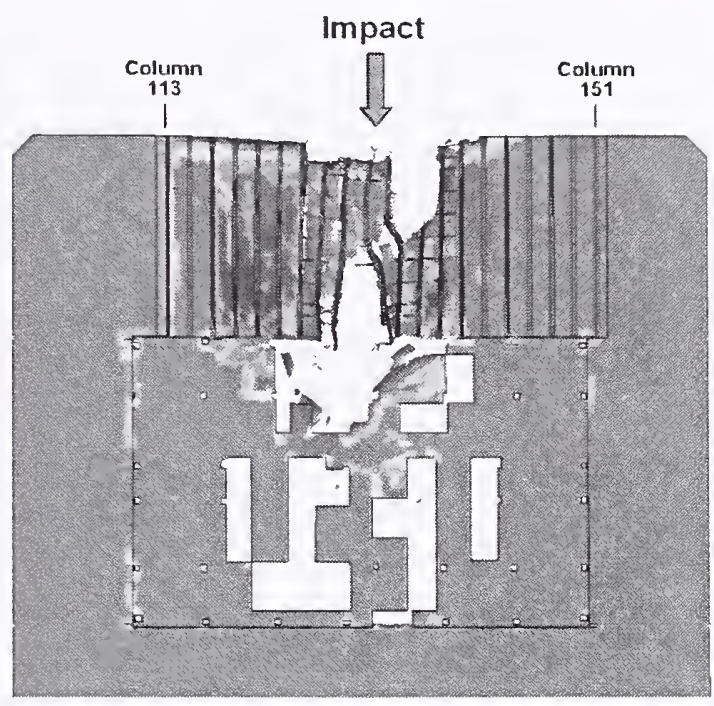

(b) Floor 95 slab damage

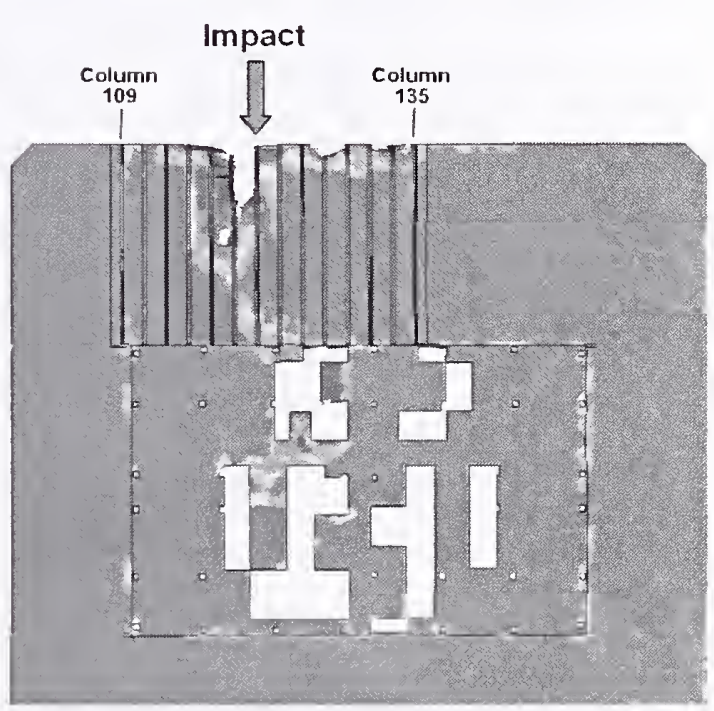

(d) Floor 97 slab damage

Figure E-33. Base case impact damage to the WTC 1 floor slab (plan view).

\section{Fuel and Debris Distribution}

Another primary objective of the global impact analyses was to determine the initial conditions that influenced the initiation and propagation of the fires in the towers. These initial conditions included the distribution of the jet fuel in the towers, the distribution of tower contents and aircraft debris that provided flammable materials for the fires, and the condition of the partitions and walls that provided barriers to air flow and spreading of the fires. The jet fuel was modeled using the smoothed particle hydrodynamics (SPH) algorithm in LS-DYNA. For the base case WTC 1 global impact analysis, the calculated distribution of the fuel in the tower and shape of the fuel cloud in a plan view and side view were shown 
previously in Figure E-25 and Figure E-26, respectively. At the termination of the global impact analysis $(0.715 \mathrm{~s})$, the residual momentum of the jet fuel in the impact direction was less than 1 percent of the initial momentum, indicating that the fuel cloud was nearly at rest. The bulk of the aircraft debris and fuel was arrested prior to exiting the far side of the tower core. A small amount of aircraft debris was calculated to exit the far side of the tower (south wall of WTC 1).

A quantitative characterization of the fuel and aircraft debris distribution is given in Table E-4. The bulk of the fuel and aircraft debris was deposited on floors 93 through 97, with the greatest concentration on floor 94 . The calculated debris cloud included $17,400 \mathrm{lb}$ of debris and $6,700 \mathrm{lb}$ of aircraft fuel outside of the tower at the end of the impact analysis, either rebounding from the impact face (north wall) or passing through the tower (south wall). This amount might have been larger in the calculation since the exterior walls were not modeled with windows that would contain the fuel cloud and other small debris inside the towers. In addition, the impact behavior of the aircraft fuel cloud did not include the ability to stick to, or wet, interior components. Rather, the aircraft fuel SPH particles tended to bounce off of internal structures.

Table E-4. Fuel and aircraft debris distribution for the base case WTC 1 impact.

\begin{tabular}{|l|c|c|}
\hline \multicolumn{1}{|c|}{ Tower Location } & Aircraft Fuel & Aircraft Debris \\
\hline Total Outside Tower & $6,700 \mathrm{lb}$ & $17,400 \mathrm{lb}$ \\
\hline WTC 1 Floor 92 & $810 \mathrm{lb}$ & $260 \mathrm{lb}$ \\
\hline WTC 1 Floor 93 & $6,100 \mathrm{lb}$ & $22,600 \mathrm{lb}$ \\
\hline WTC 1 Floor 94 & $16,100 \mathrm{lb}$ & $96,000 \mathrm{lb}$ \\
\hline WTC 1 Floor 95 & $12,200 \mathrm{lb}$ & $28,000 \mathrm{lb}$ \\
\hline WTC 1 Floor 96 & $11,700 \mathrm{lb}$ & $19,400 \mathrm{lb}$ \\
\hline WTC 1 Floor 97 & $9,500 \mathrm{lb}$ & $6,000 \mathrm{lb}$ \\
\hline WTC 1 Floor 98 & $2,200 \mathrm{lb}$ & $6,000 \mathrm{lb}$ \\
\hline WTC 1 Floor 99 & $770 \mathrm{lb}$ & $90 \mathrm{lb}$ \\
\hline Total Weight & $66,100 \mathrm{lb}$ & $196,000 \mathrm{lb}$ \\
\hline
\end{tabular}

\section{E.9.2 WTC 2 Base Case Global Impact Analysis}

The WTC 2 base case impact analysis was performed for a $0.62 \mathrm{~s}$ duration following initial impact of the aircraft nose with the south exterior wall. The side view and top view of the base case WTC 2 global impact response is shown in Figure E-34 and Figure E-35, respectively. Full penetration of the aircraft into the tower was completed at $0.2 \mathrm{~s}$ after impact. The aircraft impact response was very similar to that of the WTC 1 impact and was dominated by the penetration and fragmentation of the airframe structures. The fuselage structures were severely damaged both from the penetration through the exterior columns and the penetration of the 81 st floor slab that sliced the fuselage structures in half. The downward trajectory of the aircraft structures caused the airframe to collapse against the floor, and the subsequent debris motion was redirected inward along a more horizontal trajectory parallel to the floor. The downward trajectory of the aircraft structures had transferred sufficient vertical load that the truss floor structures on the 80 th and 81 st floors began to collapse in the impact zone by the end of the simulation. 


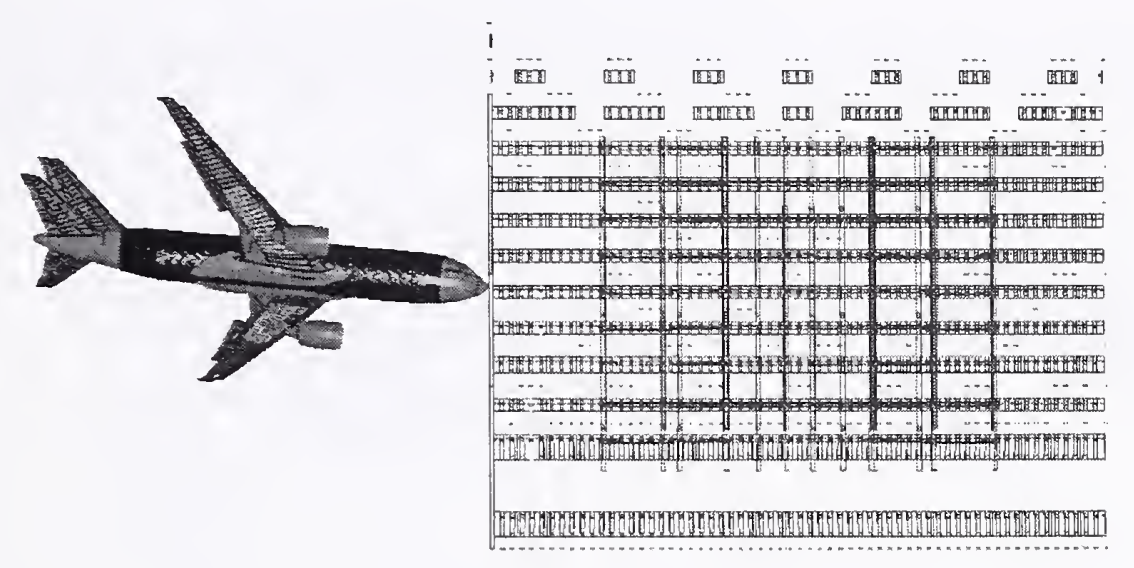

(a) Time $=0.00 \mathrm{~s}$

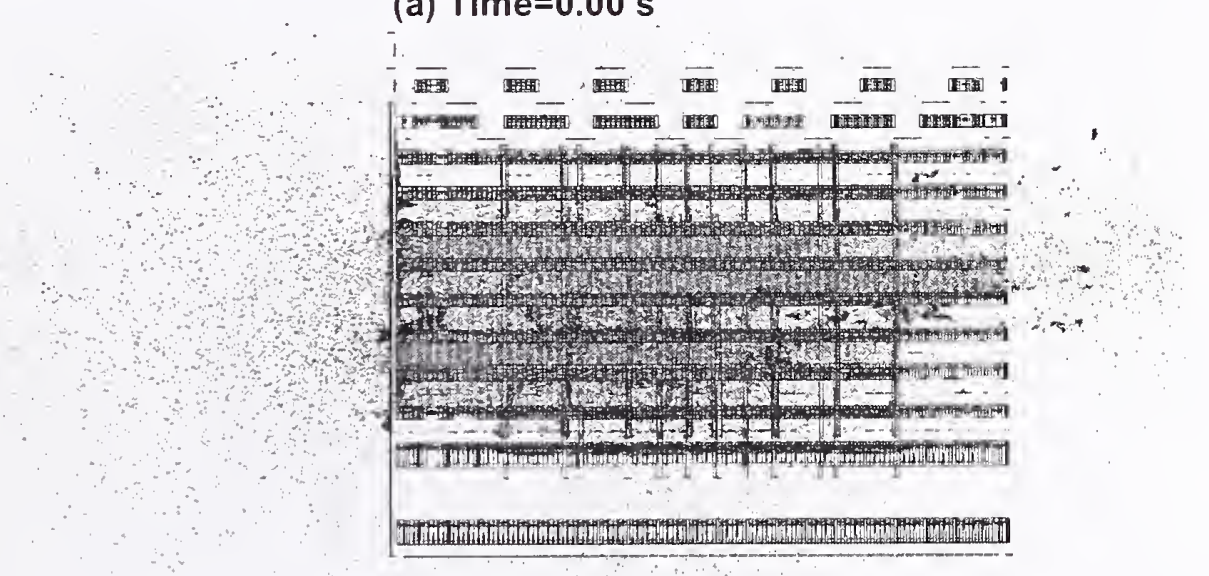

(b) Time $=0.50 \mathrm{~s}$

Figure E-34. WTC 2 base case global impact analysis - side view. 


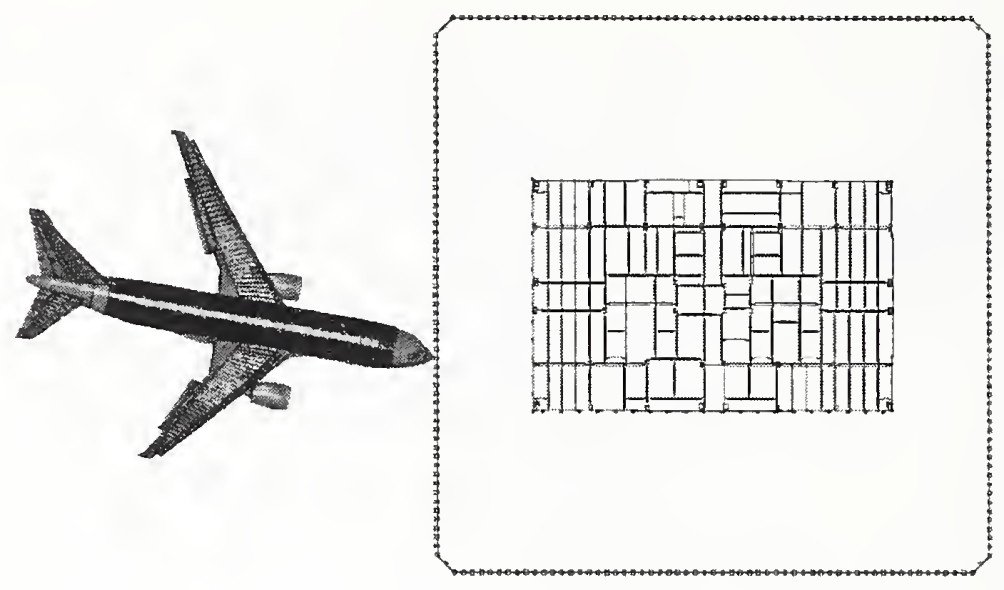

(a) Time $=0.00 \mathrm{~s}$

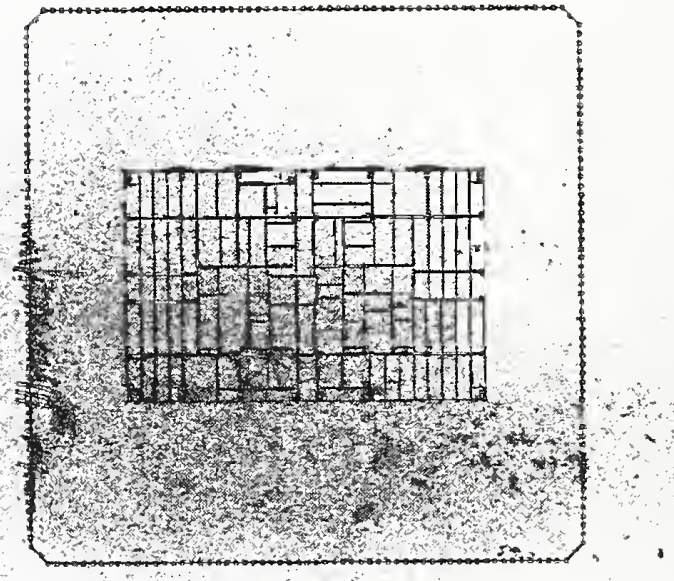

(b) Time $=0.50 \mathrm{~s}$

Figure E-35. WTC 2 base case global impact analysis - plan view.

The aircraft wing structures and fuel tank were fragmented by the impact with the tower exterior. The aircraft fuel cloud started to spread out immediately after impact, but the leading edge of the fuel remained relatively dense until passing approximately one-third of the lateral distance through the tower core (approximately $0.2 \mathrm{~s}$ after impact). At $0.3 \mathrm{~s}$ after impact, the aircraft fuel cloud had penetrated approximately two-thirds the distance through the core and was spreading out. Beyond this time, the subsequent motion of the aircraft fragments and fuel debris cloud was noticeably slowed. The spread of the fuel and debris cloud was more rapid and extensive in the open truss floor regions than through the core as a result of the open volume above the workstations in the truss floor zone.

Load transfer of the aircraft momentum into the tower structure is shown in Figure E-36. During the first $0.1 \mathrm{~s}$ of impact, the forward fuselage penetrated the exterior wall and impacted the interior structures. Between $0.1 \mathrm{~s}$ and $0.2 \mathrm{~s}$ a more rapid load transfer rate was obscrved as the area of the impact increased (extending outward in the wing impact regions) and a higher percentage of the aircraft mass impacted the interior structures. At $0.2 \mathrm{~s}$, the aircraft completely penetrated the building and retained approximately 30 percent of its initial momentum. Beyond this time, the rate of load transfer steadily decreased with 
very little load transfer after approximately $0.4 \mathrm{~s}$. The behavior was very similar to that of the base case WTC 1 impact, shown in Figure E-27, but with a slightly compressed time scale due to the higher impact speed on WTC 2.

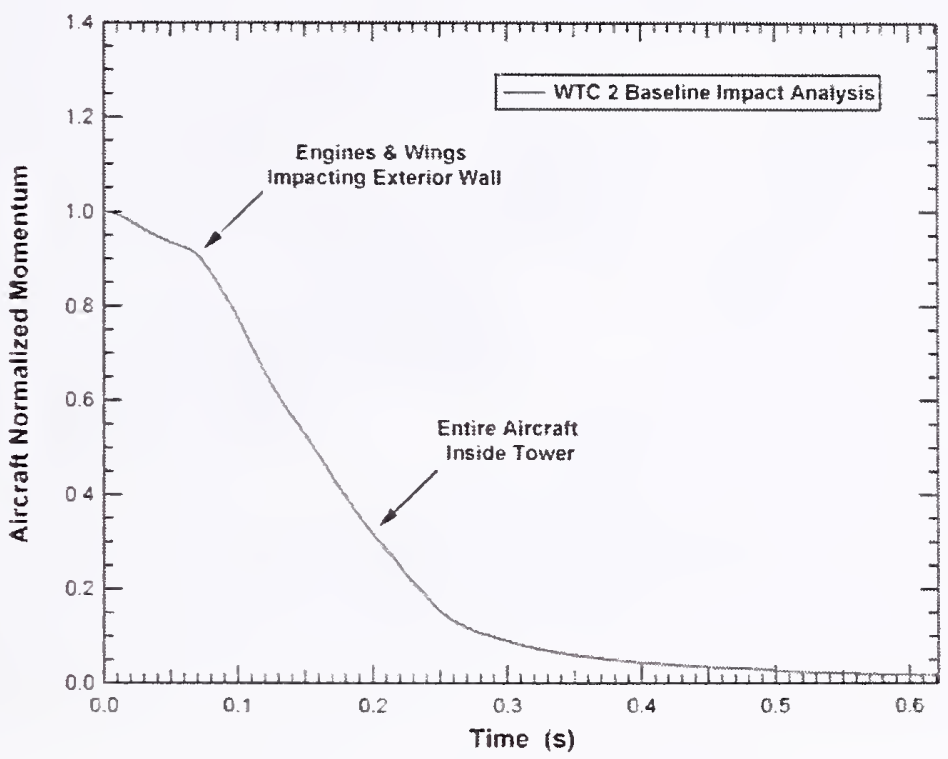

Figure E-36. Normalized aircraft momentum for the WTC 2 base case impact.

The aircraft was severely broken into debris as a result of the impact with WTC 2 as shown in Figure E-37. At the end of the impact analysis, the aircraft was broken into thousands of debris fragments of various size and mass, as shown in Figure E-37(b). A closer inspection of the debris field showed that larger fragments still occurred for specific components such as the engines and landing gear components. This behavior was very similar to the WTC 1 aircraft break up shown in Figure E-28.

\section{Exterior Wall Damage}

Damage to the north exterior wall calculated in the base case WTC 2 global impact analysis is shown in Figure E-38. The exterior wall completely failed in the regions where the fuselage, engine, and fuelfilled wing section impacted the structure. Damage to the exterior wall extended to the wing tips, but the exterior columns were not completely failed in the outer wing and vertical stabilizer impact regions. Failure of the exterior columns occurred both at the bolted connections between column ends and at various locations in the column, depending on the local severity of the impact load and the proximity of the bolted connection to the impact.

The calculated and observed geometry and magnitude of impact damage were in good agreement. That the position and shape of the impact damage agreed served to partially validate the geometry of the aircraft model, including the aircraft orientation, trajectory, and flight distortions of the wings.

Agreement of both the mode and magnitude of the impact damage partially validated the constitutive and damage modeling of the aircraft and exterior wall of the tower. 


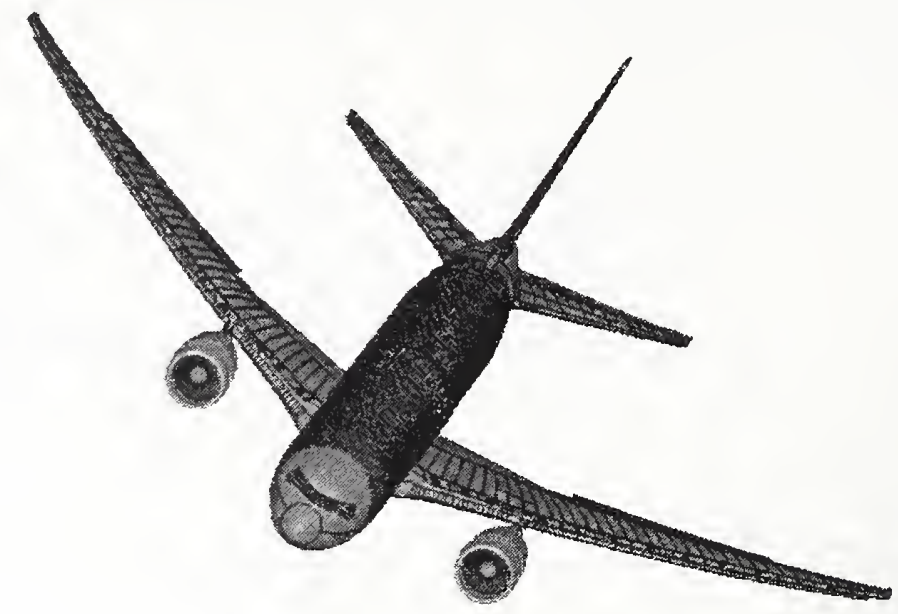

(a) Aircraft structure (time $=0.00 \mathrm{~s})$

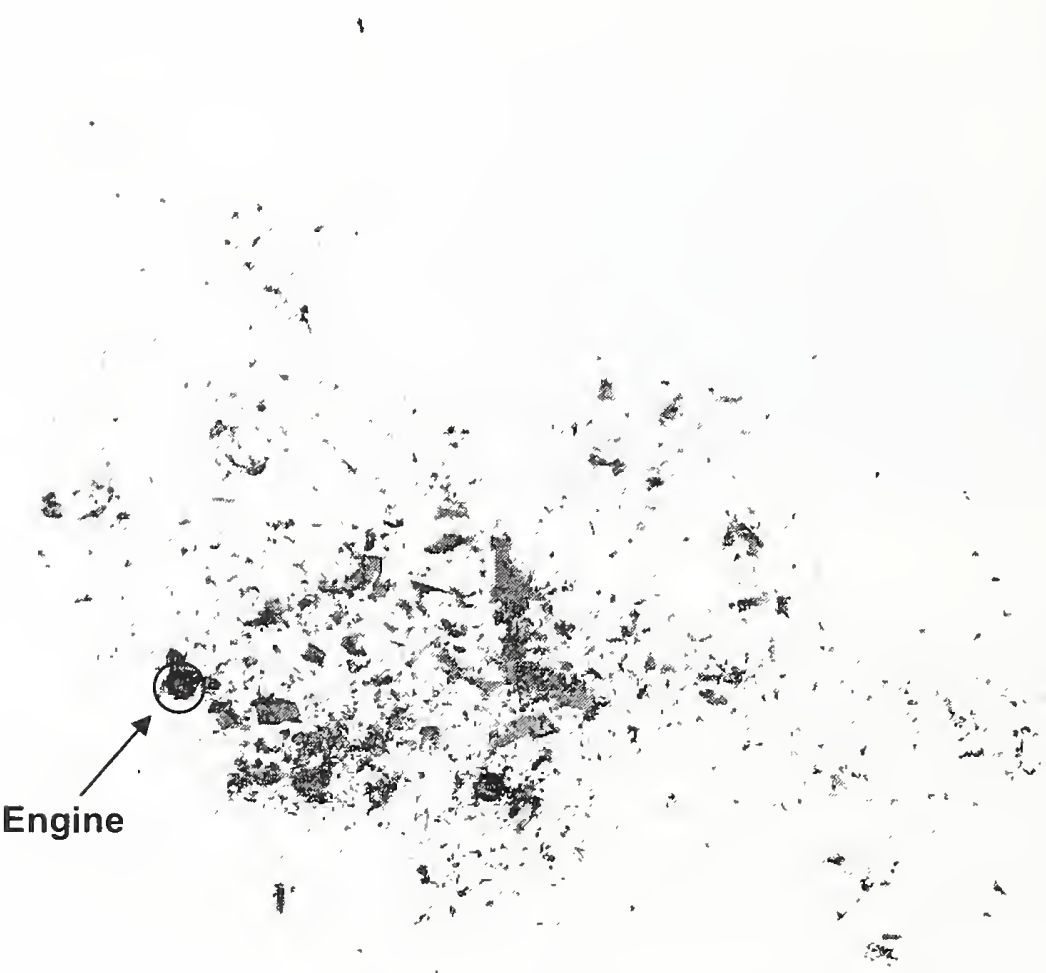

(b) Aircraft debris field (time $=0.62 \mathrm{~s}$ )

Figure E-37. Aircraft break up and debris in the base case WTC 2 impact. 


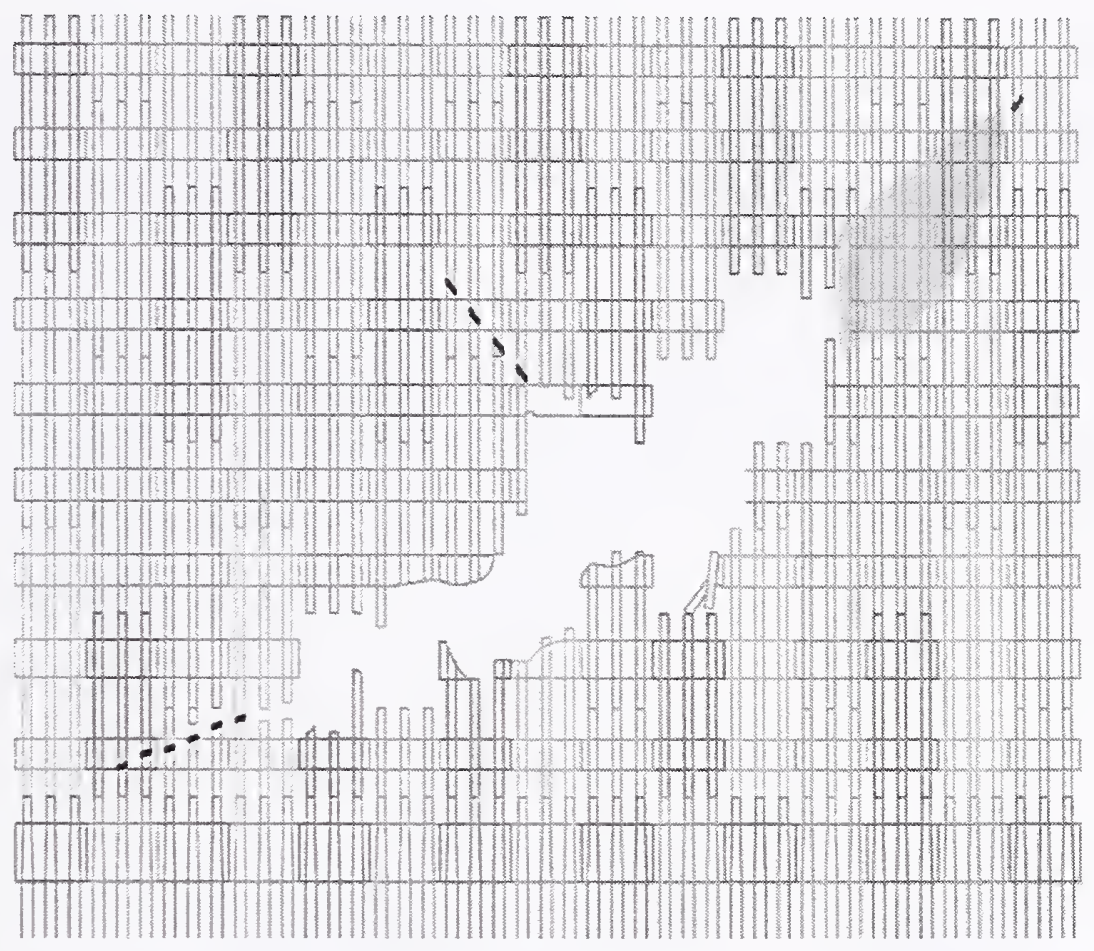

(a) Schematic of observed damage

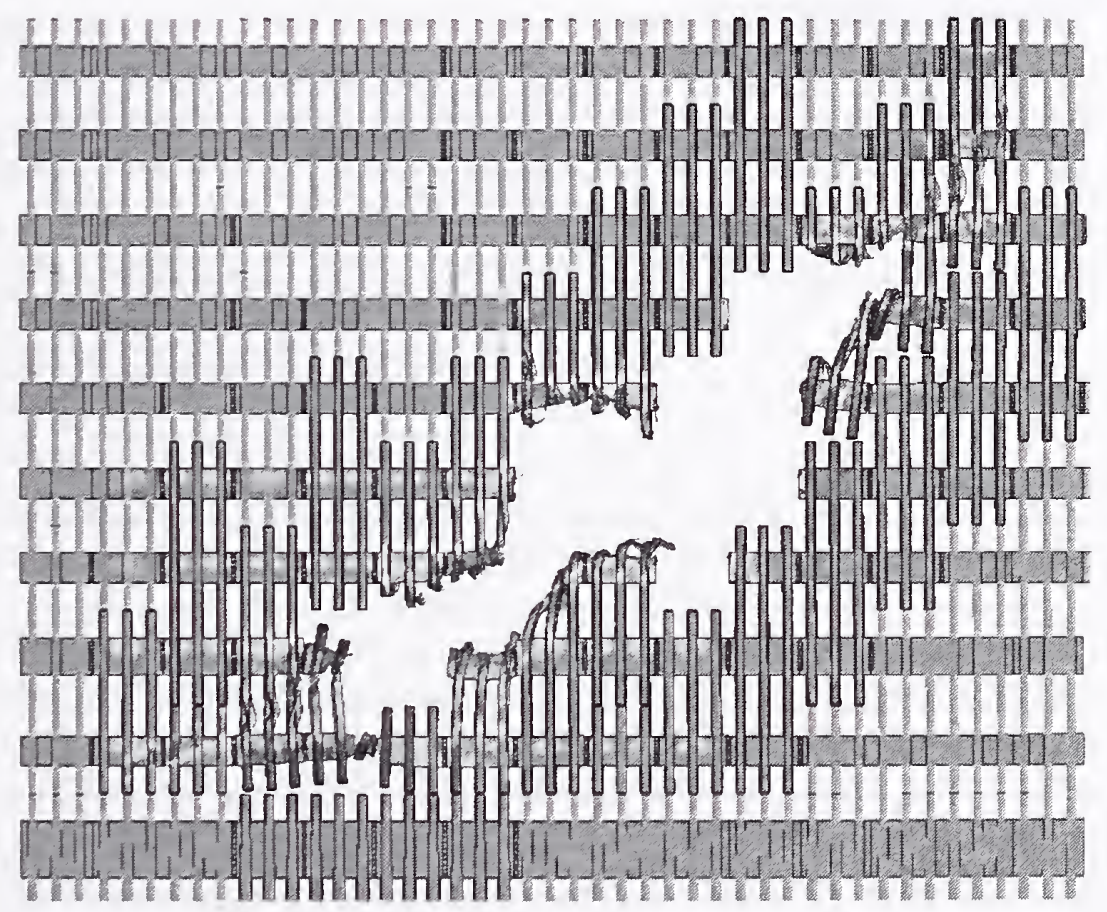

(b) Calculated damage ( $\mathrm{t}=0.62 \mathrm{~s}$ )

Figure E-38. Base case impact damage to the WTC 2 exterior wall. 


\section{Core Damage}

In the base case WTC 2 impact damage analysis, significant damage to the core was calculated in the region close to the impact point (the south east corner of the core). The columns in line with the aircraft fuselage failed on the impact side of the tower and several of the core beams were also severely damaged or failed in the impact zone. In some cases, failure of the column splices located on floors 77,80 , and 83 contributed significantly to the failure of the core columns. This was particularly true for the heavy column number 1001 at the southeast corner of the core that failed at three splice locations. A summary of the column damage is shown graphically in Figure E-39. A total of five columns were severed and four columns were heavily damaged.

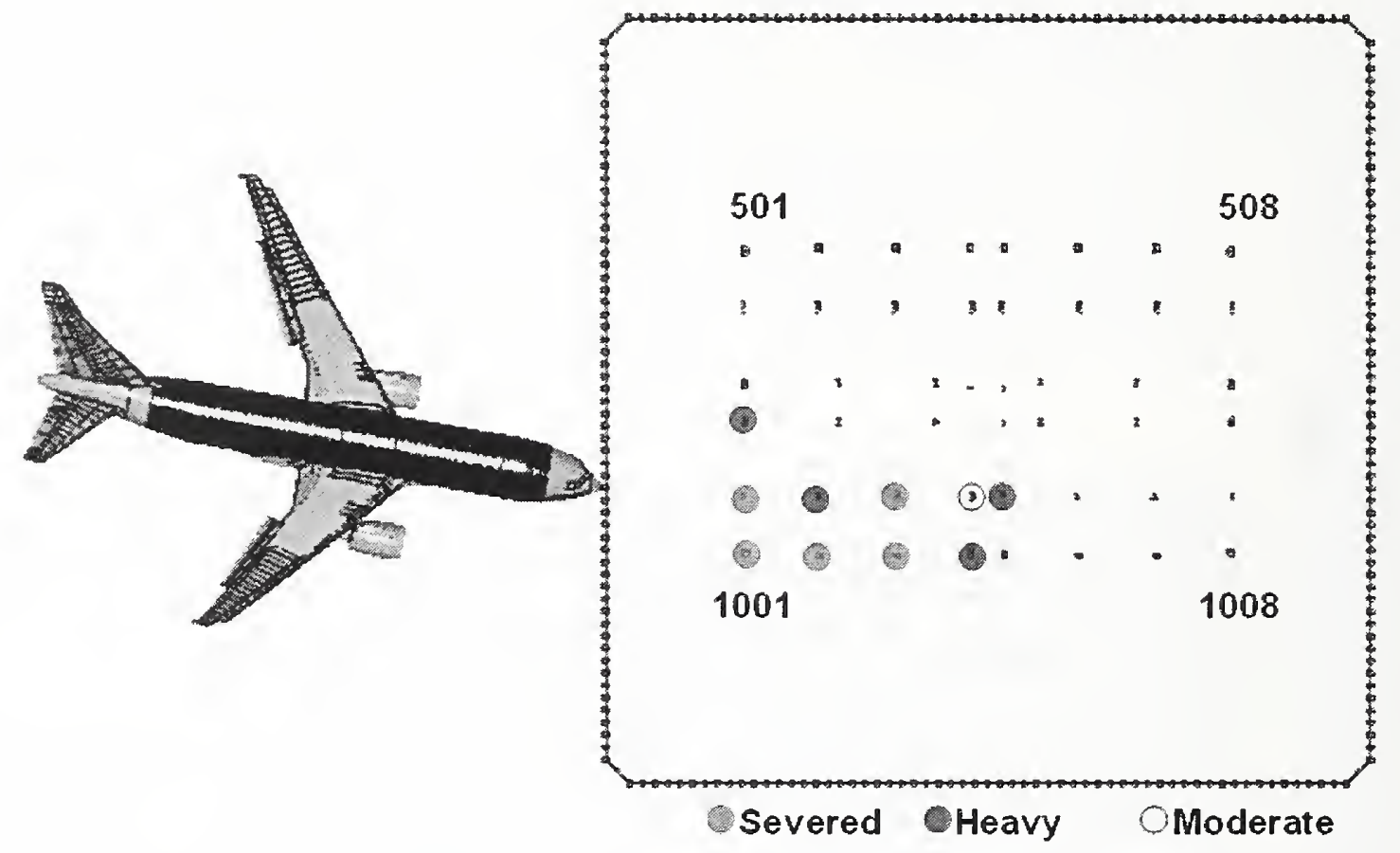

Figure E-39. Summary of core column damage for the base case WTC 2 impact.

\section{Truss Floor Damage}

An overall view for the floor truss structure in the WTC 2 impact zone, along with the calculated base case impact damage to the trusses, is shown in Figure E-40. The figure shows that the trusses experienced significant damage in the impact zone, with the greatest damage on floor 81 . This severe damage to the floor 81 truss structure and floor slab was in the primary impact path of the fuselage and extended from the exterior wall to the core. The truss floor system on floors 79 and 81 had sufficient damage from the impact that truss floor sections were sagging downward as a result of the impact.

The calculated truss floor damage to WTC 2 was less than that of WTC 1, shown previously in Figure E-32, despite the higher aircraft impact energy for WTC 2. The higher truss floor damage and deflection in WTC 1 can be explained by two factors. The primary factor was that the WTC 1 downward impact trajectory was nearly twice as steep as that of the WTC 2 impact. As a result, the steeper impact 
angle directed more impact energy normal to the floor slab. The vertical component of the impact load in WTC 1 was approximately 40 percent higher than in WTC 2 . The secondary factor was that the damage to the long span truss floor in the WTC 1 impact zone produced larger displacements than the corresponding damage to the short span truss region in WTC 2.

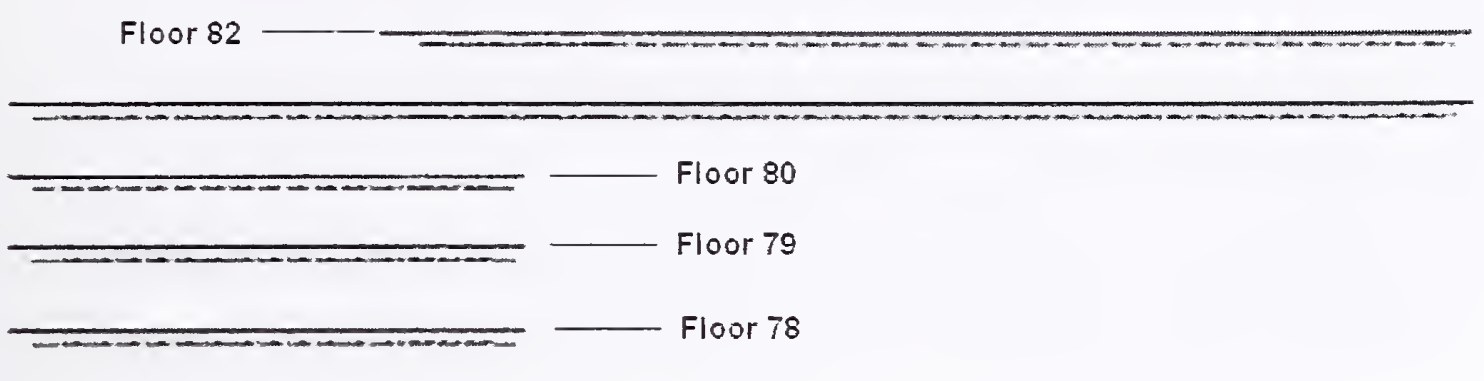

(a) Initial detailed truss structures

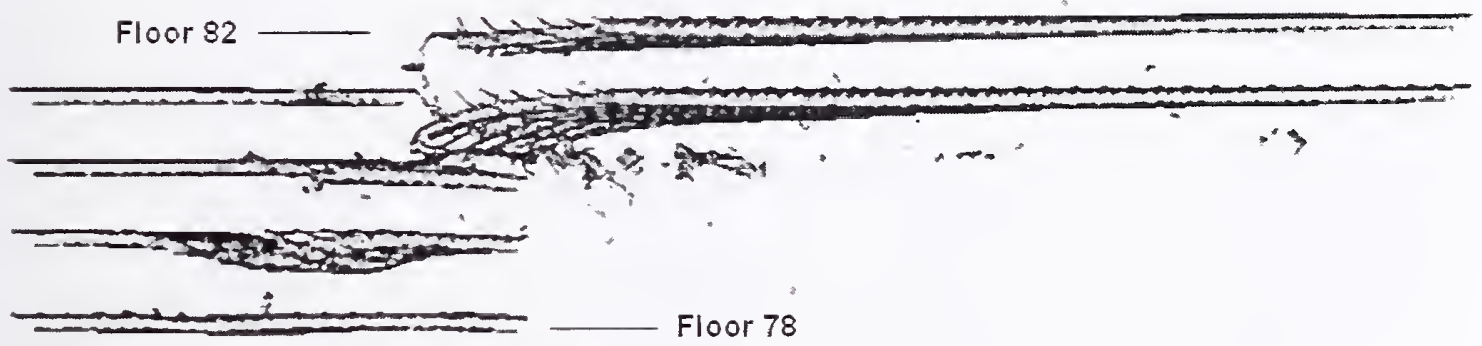

(b) Calculated damage

Figure E-40. Base case impact damage to the WTC 2 floor truss (front view).

\section{Fuel and Debris Distribution}

The calculated distribution of the aircraft debris and fuel cloud from the base case WTC 2 global impact analysis is shown in Figure E-34 and Figure E-35. At the end of the analysis, the residual momentum of the jet fuel in the impact direction was less than 1 percent of the initial momentum, indicating that the fuel cloud was nearly at rest at about $0.62 \mathrm{~s}$. The bulk of the aircraft debris and fuel was arrested prior to exiting the tower structures. However, a significant amount of aircraft debris was calculated to exit the north and east sides of the tower (sides 300 and 200 of WTC 2). A portion of an engine exited the tower at the northeast corner of the building from the northeast corner of WTC 2. Based on the engine trajectory, it was estimated that the engine exited the building at approximately $120 \mathrm{mph}$. In the simulation, neither engine was calculated to exit WTC 2. At the end of the simulation, the speed of the aft portion of the starboard engine was below $80 \mathrm{mph}$ and it was more than $60 \mathrm{ft}$ away from the northeast corner of the building. For these calculations, it was estimated that the building contents would likely stop the engine fragment prior to impacting the northeast corner of the exterior wall. If the starboard engine impact location was lowered in the analysis by 1 to $2 \mathrm{ft}$, which is within the aircraft impact geometry uncertainty range, the engine would likely have not interacted with floor 82 , and that would result in a larger residual speed inside the tower of over $100 \mathrm{mph}$. Also, if any portion of the east side of 
WTC 2 was relatively free of office materials the enginc fragment would have been free to move relatively unrestricted and would experience little loss of speed. As a result, in either case, the engine would likely have exited the tower in the simulation.

A quantitative characterization of the fuel and aircraft debris distribution is given in Table E-5. The bulk of the fuel and aircraft debris was deposited in floors 78 through 80 , with the greatest concentration of aircraft debris on floor 80, and the largest concentration of aircraft fuel on floors 79,81 , and 82 . The calculated debris distribution included $55,800 \mathrm{lb}$ of debris and 10,600 lb of aircraft fuel outside of the tower at the end of the impact analysis, either rebounding from the impact face or passing through the tower. The calculated mass outside the tower is believed to be larger than is realistic since the exterior walls were not modeled with windows that could contain the fuel cloud and small debris inside the tower. In addition, trcatment of the aircraft fuel cloud did not include the ability to stick to, or wet, interior components. Rather the aircraft fuel SPH particles would tend to bounce off of internal structures.

Table E-5. Fuel and aircraft debris distribution for the base case WTC 2 impact.

\begin{tabular}{|l|c|c|}
\hline \multicolumn{1}{|c|}{ Tower Location } & Aircraft Fuel & Aircraft Debris \\
\hline Total Outside Tower & $10,600 \mathrm{lb}$ & $55,800 \mathrm{lb}$ \\
\hline WTC 2 Floor 77 & $1,300 \mathrm{lb}$ & $400 \mathrm{lb}$ \\
\hline WTC 2 Floor 78 & $6,200 \mathrm{lb}$ & $4,800 \mathrm{lb}$ \\
\hline WTC 2 Floor 79 & $11,400 \mathrm{lb}$ & $16,200 \mathrm{lb}$ \\
\hline WTC 2 Floor 80 & $6,000 \mathrm{lb}$ & $83,800 \mathrm{lb}$ \\
\hline WTC 2 Floor 81 & $14,400 \mathrm{lb}$ & $27,300 \mathrm{lb}$ \\
\hline WTC 2 Floor 82 & $10,600 \mathrm{lb}$ & $3,600 \mathrm{lb}$ \\
\hline WTC 2 Floor 83 & $1,500 \mathrm{lb}$ & $4,300 \mathrm{lb}$ \\
\hline WTC 2 Floor 84 & $200 \mathrm{lb}$ & $500 \mathrm{lb}$ \\
\hline Total Weight & $62,000 \mathrm{lb}$ & $197,600 \mathrm{lb}$ \\
\hline
\end{tabular}

\section{E.9.3 Different Severity Global Impact Analyses}

Additional impact analyses were performed for each tower to provide a range of damage estimates due to the uncertainties in the calculated impact response. Two additional global impact analyses were performed for each tower in order to evaluate the impact response for a more severe and less severe impact scenario. The variations in impact conditions for the different severity global impact analyses were primarily obtained from the uncertainty analyses.

\section{WTC 1 Global Impact Analyses}

Impact conditions for the more and less severe WTC 1 impact scenarios are compared to the corresponding parameters in the base case analysis in Table E-6. The impact speeds were $414 \mathrm{mph}$ and $472 \mathrm{mph}$ in the less severe and more severe impact scenarios, respectively. These were the upper and lower bounds obtained from the analysis of aircraft impact conditions. The vertical trajectory of the aircraft was also varied from 13.6 degrees in the less severe case to 7.6 degrees for the more severe impact scenario. The reduced vertical trajectory angle resulted in a greater impact energy directed inward toward the core. The lateral trajectory was not varied since the impact was close to centered on the tower 
and normal to the north face of WTC 1. A small variation in the lateral approach angle would have little effect on the energy of the aircraft debris entering the tower and core.

Table E-6. Input parameters for additional WTC 1 global impact analyses.

\begin{tabular}{|c|c|c|c|c|}
\hline \multicolumn{2}{|c|}{ Analysis Parameters } & Base case & More Severe & Less Severe \\
\hline \multirow{5}{*}{$\begin{array}{c}\text { Flight } \\
\text { Parameters }\end{array}$} & Impact Velocity & $443 \mathrm{mph}$ & $472 \mathrm{mph}$ & $414 \mathrm{mph}$ \\
\hline & Trajectory - pitch & $10.6^{\circ}$ & $7.6^{\circ}$ & $13.6^{\circ}$ \\
\hline & Trajectory - yaw & $0.0^{\circ}$ & $0.0^{\circ}$ & $0.0^{\circ}$ \\
\hline & Orientation - pitch & $8.6^{\circ}$ & $5.6^{\circ}$ & $11.6^{\circ}$ \\
\hline & Orientation - yaw & $0.0^{\circ}$ & $0.0^{\circ}$ & $0.0^{\circ}$ \\
\hline \multirow{2}{*}{$\begin{array}{c}\text { Aircraft } \\
\text { Parameters }\end{array}$} & Weight & 100 percent & 105 percent & 95 percent \\
\hline & Failure Strain & 100 percent & 125 percent & 75 percent \\
\hline \multirow{2}{*}{$\begin{array}{c}\text { Tower } \\
\text { Parameters }\end{array}$} & Failure Strain & 100 percent & 80 percent & 120 percent \\
\hline & Live Load Weight ${ }^{2}$ & 25 percent & 20 percent & 25 percent \\
\hline
\end{tabular}

a. Live load weight expressed as a percentage if the design live load.

The calculated damage to the north exterior wall of WTC 1 from the three different severity impact analyses is shown in Figure E-41, along with a schematic of the observed damage. The overall agreement with the observed damage was good for all three analyses, with the base case global impact analysis providing the best match to the observed damage. The calculated damage magnitude was similar in each of the global analyses. The small differences in apparent damage were largely due to panels that may have severed columns in one case and were removed at the connections in another. In general, the trend was for a larger opening produced by the less severe impact and a smaller opening in the more severe impact. The increase in the opening with reduced severity impacts can be explained by the increased tower panel material toughness, resulting in a transition from severing of columns to the failure of connection bolts and panel removal.

Toward the wing tips, where the columns and spandrels were not completely severed, the more severe impact damage analysis calculated higher damage to the exterior wall panels. These columns had the largest amount of material with plastic strains above 5 percent (shown in red in the figure). As would be expected, the less severe impact damage analysis calculated lower damage to the exterior wall, and the base case analysis calculated an intermediate level of damage near the wing tips.

The calculated damage to the WTC 1 core columns for the three different severity impacts is shown in Figure E-42. The figure shows that the core damage was concentrated in the region of the core closest to the fuselage impact point, and there was a clear correlation in damage magnitude with the impact severity. A total of one column severed and two columns were heavily damaged in the less severe impact, compared to three columns severed and four columns heavily damaged in the base case impact analysis and six columns severed and three columns heavily damaged in the more severe WTC 1 impact analysis.

A strong correlation in core damage with impact severity was expected. All of the parameter variations in the three increasing severity analyses were selected to produce an increase in core damage. A higher impact speed and a shallower impact angle were selected to direct more energy toward the core. The aircraft mass was increased and given a higher material toughness. The mass of the tower contents was 
reduced, and the tower materials were given a lower toughness. All of these variations contributed toward the increased core damage with impact severity.

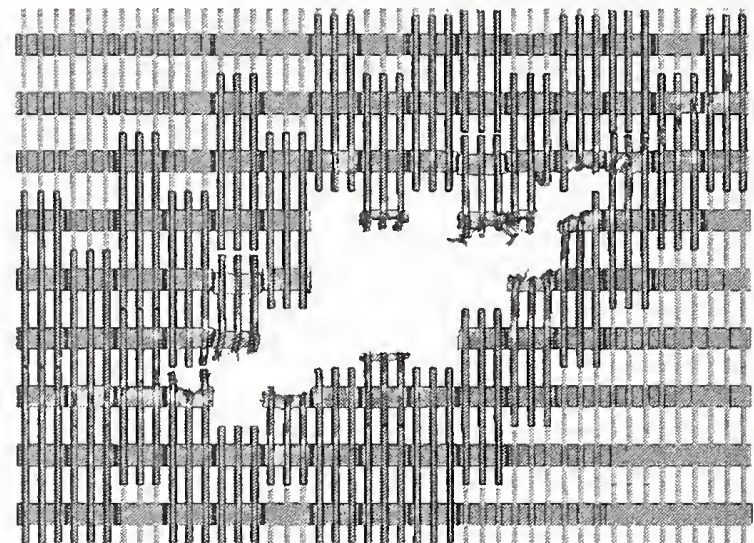

(a) Base case impact damage

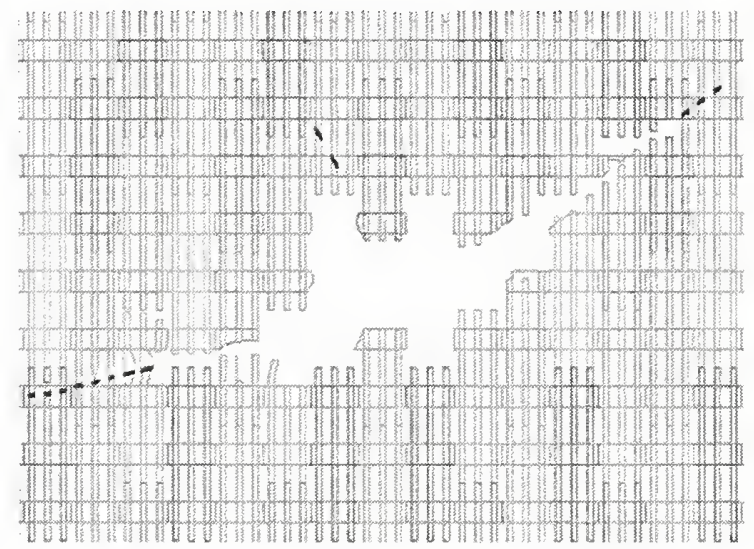

(c) Schematic of observed damage

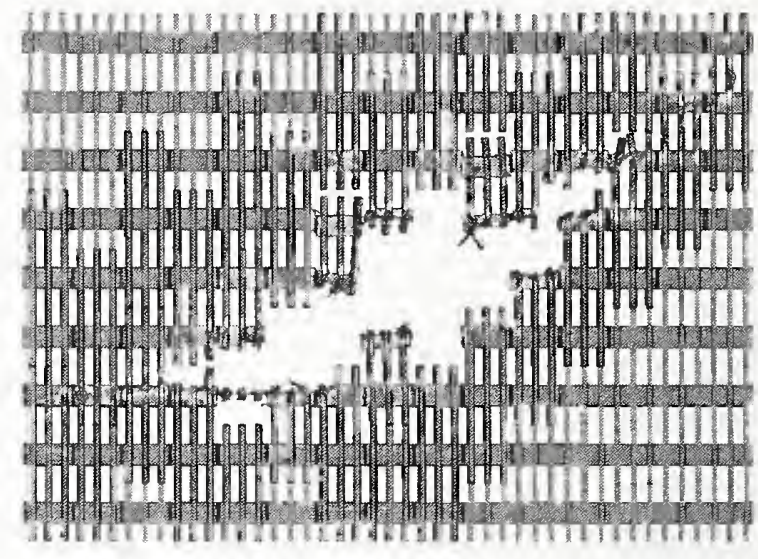

(b) More severe impact damage

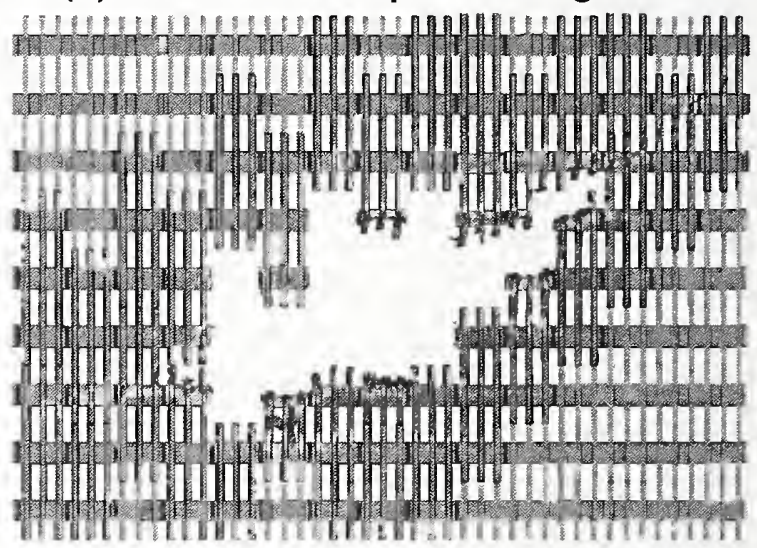

(d) Less severe impact damage

Figure E-41. Comparison of exterior wall damage for the WTC 1 impact analyses.

All of the WTC 1 global impact analyses resulted in a similar amount of damage to the truss floor and floor slab. Competing parameters cancel their respective effects on the floor damage. Variations in many of the parameters should cause greater damage to the floor system in the more severe impact analysis. However, the downward impact trajectory angle was also reduced to direct more energy into the core. Therefore, less of the impact energy was oriented into the floor system. The combined effects of varying these parameters led to very similar damage to the floor system in all of the analyses. 


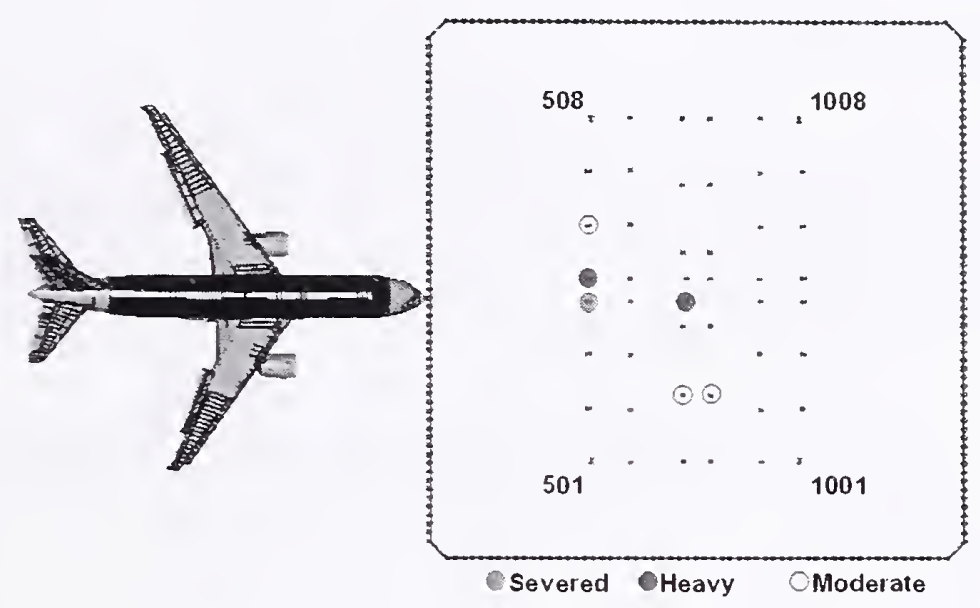

(a) Calculated less severe impact analysis

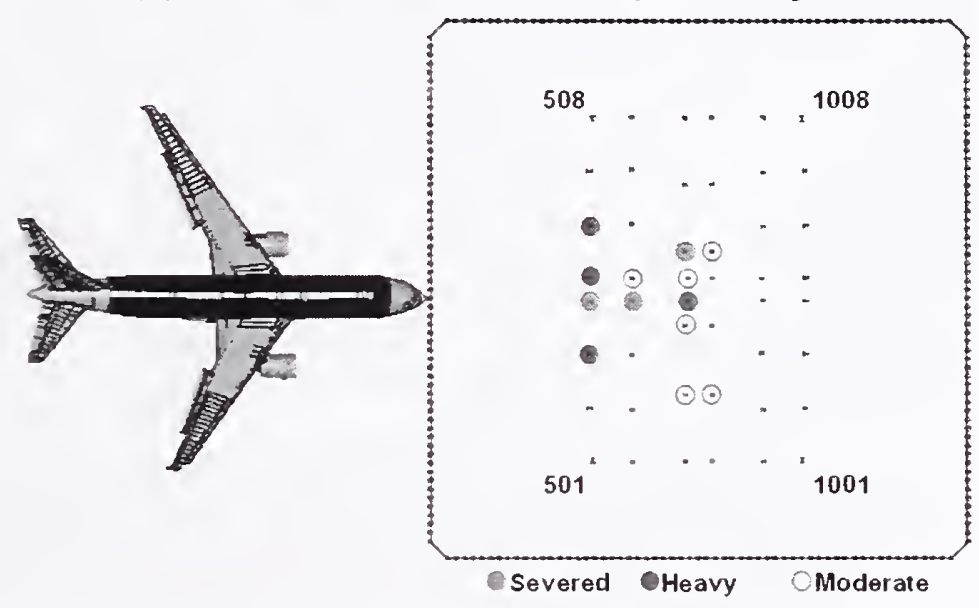

(b) Calculated base case impact damage

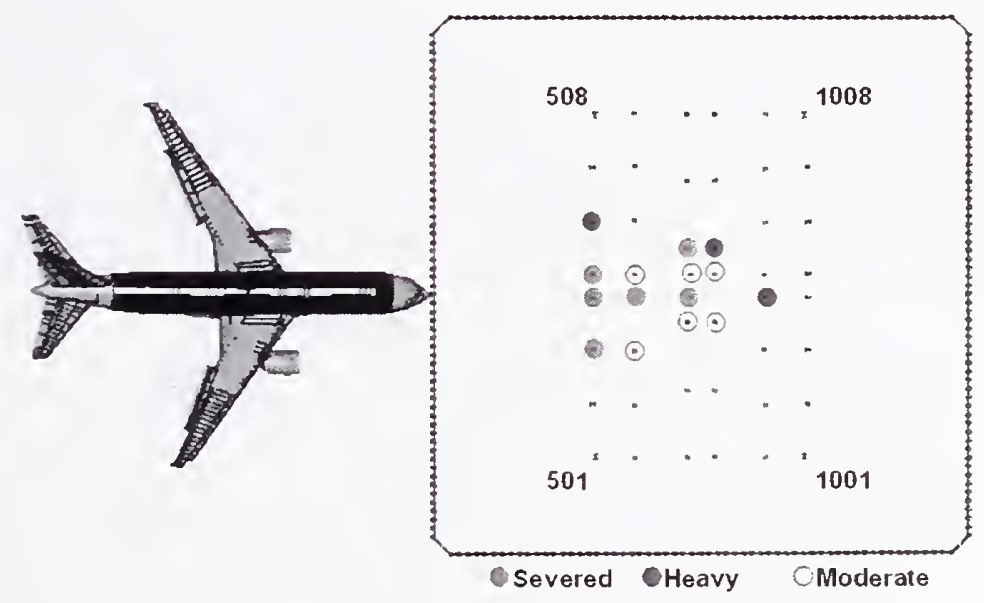

(c) Calculated more severe impact analysis

Figure E-42. Comparison of core column damage for the WTC 1 impact analyses. 


\section{WTC 2 Global Impact Analyses}

Impact conditions for the more and less severe WTC 2 impact scenarios are compared to the corresponding parameters in the base case analysis in Table E-7. The impact speeds were $521 \mathrm{mph}$ and $570 \mathrm{mph}$ in the less severe and more severe impact scenarios, respectively. These speeds were the upper and lower bounds obtained from the analysis of aircraft impact conditions. The vertical trajectory of the aircraft was also varied from 5 (more severe case) to 8 degrees (less severe case) in order to direct less energy into the core for the less severe case.

Table E-7. Input parameters for additional WTC 2 global impact analyses.

\begin{tabular}{|c|c|c|c|c|}
\hline \multicolumn{2}{|c|}{ Analysis Parameters } & Base case & More Severe & Less Severe \\
\hline \multirow{5}{*}{$\begin{array}{c}\text { Flight } \\
\text { Parameters }\end{array}$} & Impact Velocity & $546 \mathrm{mph}$ & $570 \mathrm{mph}$ & $521 \mathrm{mph}$ \\
\hline & Trajectory - pitch & $6.0^{\circ}$ & $5.0^{\circ}$ & $8.0^{\circ}$ \\
\hline & Trajectory - yaw & $13.0^{\circ}$ & $13.0^{\circ}$ & $13.0^{\circ}$ \\
\hline & Orientation - pitch & $5.0^{\circ}$ & $4.0^{\circ}$ & $7.0^{\circ}$ \\
\hline & Orientation - yaw & $10.0^{\circ}$ & $10.0^{\circ}$ & $10.0^{\circ}$ \\
\hline \multirow{2}{*}{$\begin{array}{c}\text { Aircraft } \\
\text { Parameters }\end{array}$} & Weight & 100 percent & 105 percent & 95 percent \\
\hline & Failure Strain & 100 percent & 115 percent & 75 percent \\
\hline \multirow{3}{*}{$\begin{array}{c}\text { Tower } \\
\text { Parameters }\end{array}$} & Contents Strength & 100 percent & 80 percent & 100 percent \\
\hline & Failure Strain & 100 percent & 90 percent & 120 percent \\
\hline & Live Load Weight ${ }^{a}$ & 25 percent & 20 percent & 25 percent \\
\hline
\end{tabular}

a. Live load weight expressed as a percentage if the design live load.

Calculated damage to the exterior wall and truss floor of WTC 2 showed similar trends to those seen in the WTC 1 analyses. Only slight changes in damage to these structures were calculated from the different severity impacts. Damage to the exterior was relatively insensitive to the parameter variations. Truss floor damage did not vary significantly due to the competing effect of the parameters varied.

Damage calculated for the WTC 2 core columns is shown in Figure E-43 for the three analyses performed. The figure shows that core damage was concentrated in the core region closest to the impact point. There is also a clear correlation in damage magnitude with the impact severity. A total of three columns were severed and two columns were heavily damaged in the less severe impact, compared to five columns severed and four columns heavily damaged in the base case analysis and ten columns severed and one columns heavily damaged in the more severe WTC 2 impact analysis. 


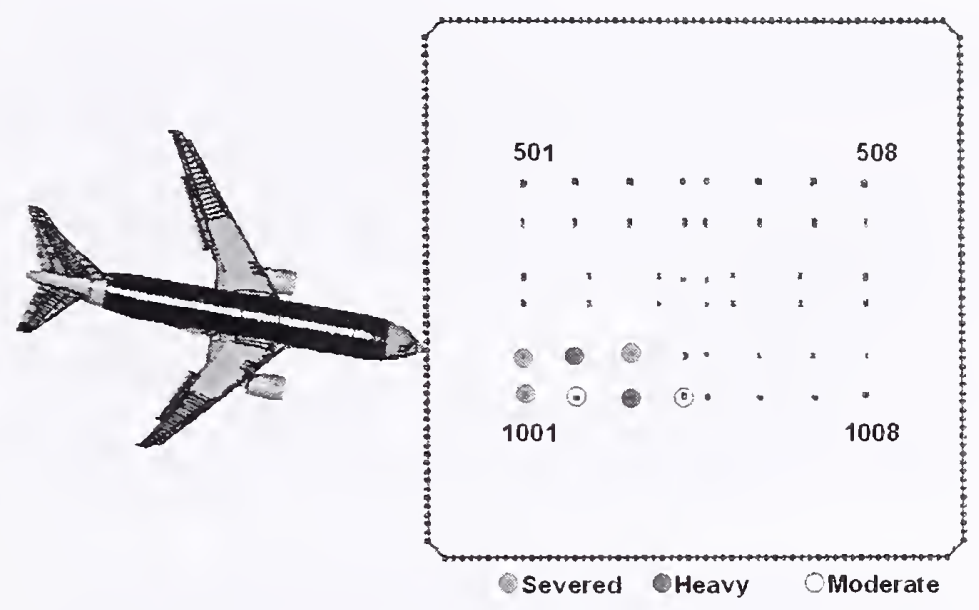

(a) Calculated less severe impact analysis

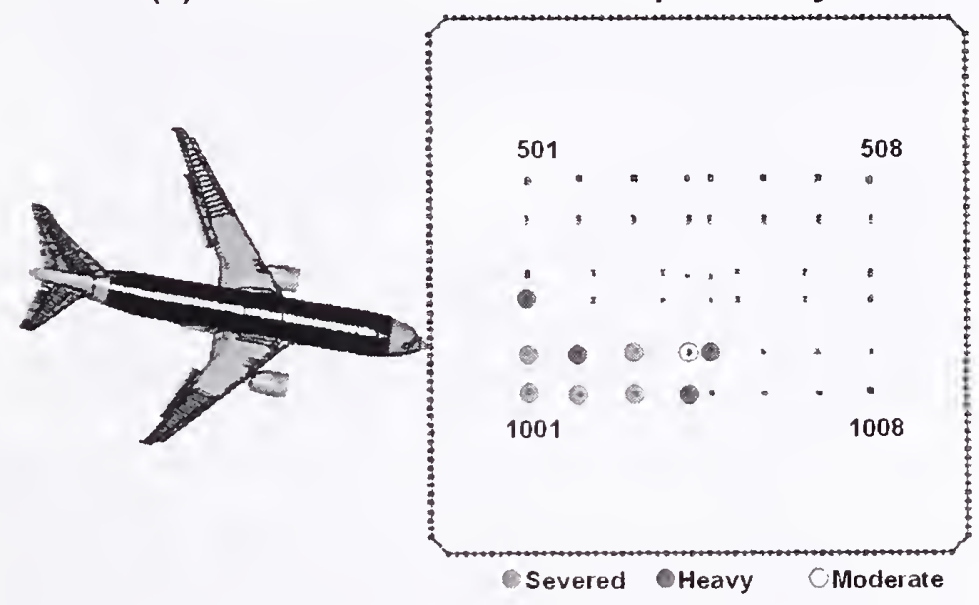

(b) Calculated base case impact damage

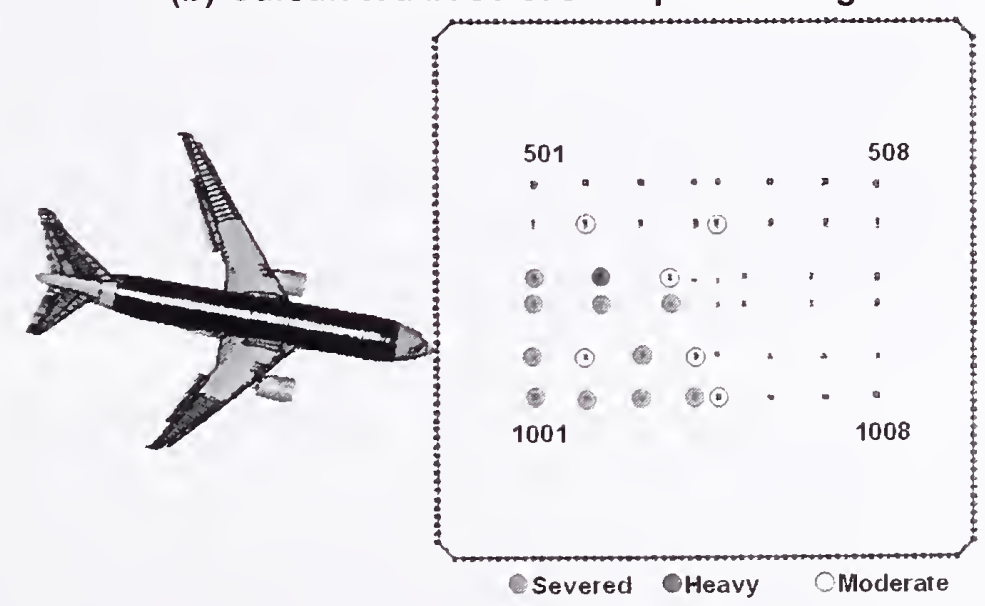

(c) Calculated more severe impact analysis

Figure E-43. Comparison of core column damage for the WTC 2 impact analyses. 


\section{E.9.4 Comparison with Observables}

The observables available to help validate the global impact analyses included the following:

- Damage to the building exterior (exterior walls and floors in the immediate vicinity of the impact) documented by photographic evidence.

- Aircraft debris external to the towers (landing gear for WTC 1 and landing gear and engine for WTC 2) as documented by photographic evidence.

- Eyewitness accounts from survivors who were inside the towers (blocked or passable stairwells).

Not all of these observables were perfectly matched by the simulations due to the uncertainties in exact impact conditions, the imperfect knowledge of the interior tower contents, the chaotic behavior of the aircraft break up and subsequent debris motion, and the limitations of the models. In general, however, the results of the simulations matched the observables reasonably well.

\section{E.9.5 Comparison with Previous Studies}

Two studies to estimate the impact damage to the WTC towers were previously conducted. These studies were performed by staff at Massachusetts Institute of Technology (MIT) and Weidlinger Associates, Inc. (WAI). The MIT study used an energy balance approach to estimate damage to the core columns. The WAI study used the FLEX finite element code to calculate the aircraft impact damage to both towers. FLEX is an explicit, nonlinear, large deformation transient analysis finite element code with an overall code architecture similar to that of LS-DYNA. In the WAI calculations, the aircraft and WTC towers models were composed of beam and shell elements with 27,000 shell elements and 23,000 beam elements in the aircraft model. The aircraft fuel was included in the model by increasing the mass of the structures in the wing box.

Impact damage to the exterior north wall of WTC 1 calculated in this study is compared to the impact damage calculated by WAI in Figure E-44. The figure also shows a schematic of the damage observed in photographic evidence. The impact damage estimated in this study closely matched the observed damage for both towers. The damage profiles in the WAI impact simulations had some noticeable differences. Damage predictions from WAI included complete failure of the exterior columns over the entire length of the wings and top of the vertical stabilizer, and displayed local rupture of the columns adjacent to the impact point with less influence of the bolted connections on panel failure.

The differences in the damage profiles in the two calculations most likely resulted from a variety of differences in the models. One major difference between the two studies was in the fidelity of the aircraft models. The WAI aircraft model was based on their model of a Lockheed C-141B military transport rather than the Boeing 767. The NIST aircraft model contained an order of magnitude more elements and modeled the fuel explicitly. Secondary differences between the WAI and NIST impact analyses included, but were not limited to, variations in impact conditions (impact velocity, angle, location, etc.), aircraft model differences (airframe geometry, component thicknesses, mass distribution, material properties, etc.) and tower model differences (material properties, geometry, joint modeling, number of elements, etc.). 


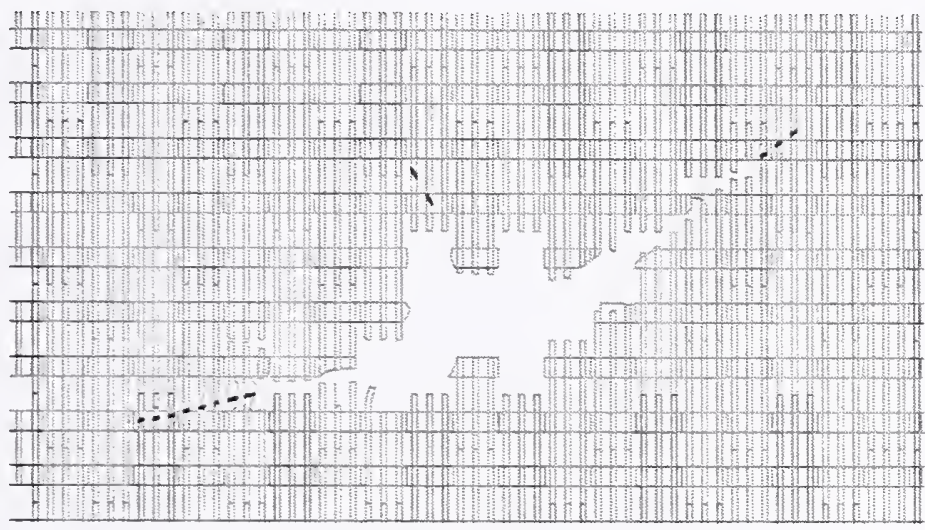

(a) Schematic of observed damage

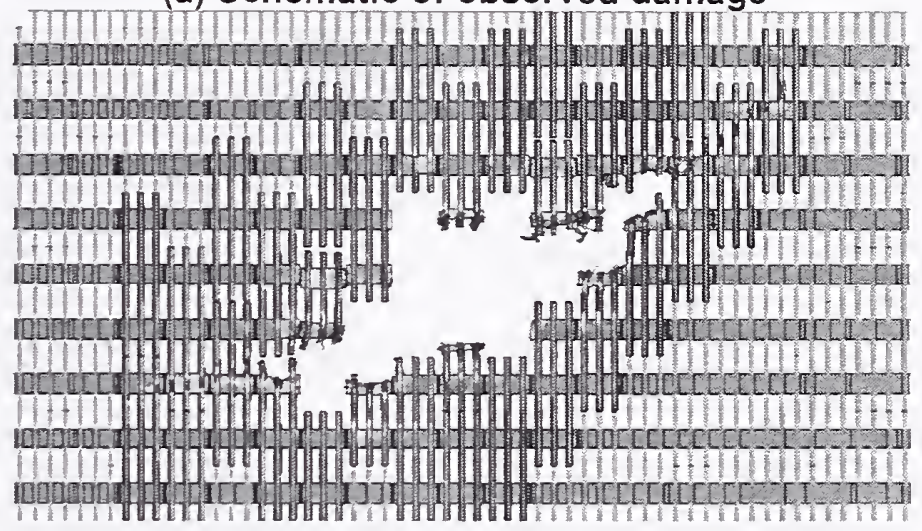

(b) NIST base case impact damage

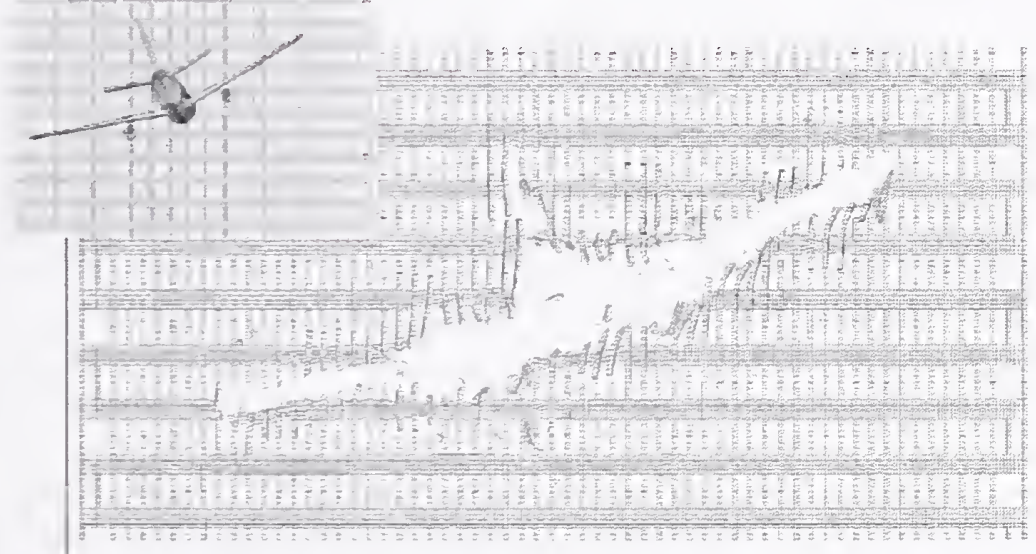

(c) WAl calculated damage

Figure E-44. Comparison of impact damage to the WTC 1 exterior wall.

Table E-8 compares the estimated core column damage from the various studies. For WTC 1, MIT estimated 4-12 core columns were failed ( 4 columns failed over a three-story length or 12 columns failed over a single floor length). The expected distribution of damage would fall between these bounds with some columns damaged on a single floor and others with damage distributed on multiple floors. WAI gave two estimates for core column failure. The first estimate of 23 core columns failed and 5 damaged was obtained from the FLEX impact analysis. The second estimate of 20 failed columns was the number 
used in their collapse analysis. The NIST base case impact damage of 3 severed and 4 heavily damaged and less severe estimate of 1 severed and 2 heavily damaged falls below both the MIT and WAI estimates. The more severe estimate of 6 severed and 3 heavily damaged falls in the middle of the MIT range, but still well below the WAI estimates.

Table E-8. Comparison of damage to core columns from various studies.

\begin{tabular}{|l|c|c|}
\hline \multicolumn{1}{|c|}{$\begin{array}{l}\text { WTC Impact } \\
\text { Investigation }\end{array}$} & WTC 1 Core Column Damage & WTC 2 Core Column Damage \\
\hline $\begin{array}{l}\text { MIT } \\
\text { lmpact Analysis }\end{array}$ & $4-12$ Failed & $7-20$ Failed \\
\hline $\begin{array}{l}\text { WA1 } \\
\text { lmpact Analysis }\end{array}$ & $\begin{array}{c}\text { 23 failed \& significantly damaged } \\
\text { Plus 5 Damaged }\end{array}$ & $\begin{array}{c}\text { 14 failed and significantly damaged } \\
\text { Plus 10 damaged }\end{array}$ \\
\hline $\begin{array}{l}\text { WA1 } \\
\text { Collapse Analysis }\end{array}$ & 20 Failed & 5 Failed \\
\hline $\begin{array}{l}\text { NIST Base Case } \\
\text { lmpact Analysis }\end{array}$ & 3 Severed & $\begin{array}{c}\text { 5 Severed } \\
\text { Plus 4 Heavily Damaged }\end{array}$ \\
\hline $\begin{array}{l}\text { N1ST More Severe } \\
\text { lmpact Analysis }\end{array}$ & $\begin{array}{c}\text { 6 Severed } \\
\text { 10 Severed }\end{array}$ \\
\hline $\begin{array}{l}\text { N1ST Less Severe } \\
\text { Impact Analysis }\end{array}$ & Plus 3 Heavily Damaged & Plus 1 Heavily Damaged \\
\hline
\end{tabular}

A similar trend in the predicted damage to the core columns was found in the WTC 2 analysis. MIT estimated 7-20 columns failed (from 7 columns failed over a three-story length to 20 columns failed over a single floor length). WAI calculated 14 core columns failed and another 10 damaged in their FLEX analysis, but reduced the number of failed columns to 5 for their collapse analysis. The NIST base case impact damage of 5 severed and 4 heavily damaged, as well as the more severe estimate of 10 severed and 1 heavily damaged fell in the middle of the range predicted by MIT. The less severe impact scenario predicted fewer columns severed and heavily damaged than the MIT and WAI studies.

The MIT prediction for the number of failed core columns agrees remarkably well with the NIST estimates using their simplified analysis. The WAI impact analysis predicted higher core column failure and damage than the NIST estimates. One reason for the higher damage prediction may be attributed to the lack of internal tower contents in the WAI model, such as workstations and other building contents. Another reason for the higher damage prediction in the WAI study could result from the aircraft model.

In conducting a collapse analysis, WAI used engineering estimates to reduce the number of failed columns from that predicted by their FLEX model to stabilize the tower immediately after impact. For WTC 2 their adjusted estimate fell in line with the MIT and NIST studies.

\section{E.10 SUPPORTING SIMPLIFIED ANALYSES}

Approximate impact analyses were carried out to provide guidance to the global finite element impact analyses. The specific analyses included:

- The analysis of the overall aircraft impact forces: This analysis indicated that the momentum transfer was more important than the strength of the impacting aircraft in determining the overall impact loads on the building. 
- The effects of the energy in the rotating engine components: This analysis indicated that the potential for the rotational kinetic energy of the engine to significantly change the magnitude of the tower impact damage is small.

- The influence of the static preloads on the calculated impact damage: This analysis showed that the initialization of a static preload in the columns of the towers would not have a significant effect on the tower impact response, damage, or residual strength.

- The analysis of the load characteristics required to damage core columns: This analysis determined the characteristics of a debris cloud (i.e., density and speed) necessary to fail a core column. Application of this analysis indicated that the dispersed fuel cloud alone would not be sufficient to fail core columns. 
This page intentionally left blank. 


\section{Chapter 1 \\ INTRODUCTION}

The objective of this effort was to analyze the aircraft impacts into each of the World Trade Center (WTC) towers to provide the following: (1) estimates of probable damage to structural systems due to aircraft impact, including exterior walls, floor systems, and interior core columns; (2) estimates of the aircraft fuel dispersal during the impact; and (3) estimates of debris damage to the interior tower contents, including partitions and workstations. Thus, this analysis established the initial conditions for the fire dynamics modeling and for the thermal-structural response and collapse initiation analysis.

The WTC aircraft impact analysis is very complex, with large scale fracture and fragmentation of both tower and aircraft structures, nonlinear rate-dependent material behaviors, and the fluid-structure interaction of the aircraft fuel. The analyses of the aircraft impacts performed for this investigation are believed to be the highest-fidelity simulations ever performed for this type of impact behavior using stateof-the art analysis methodologies. Wherever possible, the models were validated against observables or supporting test data developed by the WTC Investigation.

The impact analyses were conducted at various levels of complexity including: (1) the component level, (2) the subassembly level, and (3) the global level to estimate the probable damage to the towers due to aircraft impact. Analyses of uncertainties using the component, subassembly, global, and simplified analyses were conducted to assess the effects of variability associated with various input parameters and identify the most influential parameters that affect the damage estimates using orthogonal factorial design. Based on the results of the sensitivity analyses, the most influential parameters that were identified were varied in the global models to provide a range of damage estimates for WTC 1 and WTC 2.

As part of the tower and aircraft models, constitutive relationships describing the actual behavior of the structures under the dynamic impact conditions of the aircraft were developed based on test results of the tower steels and from the open literature for other materials. Various grades of steels used in the exterior walls and core columns of the towers, weldment metal, bolts, reinforced concrete, and aircraft materials were considered. The constitutive relationships included high strain-rate effects and failure criteria for the various materials. Details on the development of the materials constitutive models are provided in Chapter 2.

The development of the tower and aircraft global models are explained in Chapters 3 and 4, respectively. The tower models were developed based on the original WTC drawings and the structural databases of the towers developed within the framework of the baseline structural performance. The tower models included the primary structural components of the towers in the impact zone, including exterior walls, floor systems, core columns, and connections. A refined finite element mesh was used for the areas in the path of the aircraft, and a coarser mesh was used elsewhere. The Boeing 767 aircraft model was developed based on information gathered from documentary aircraft structural information and data from measurements on a Boeing 767 aircraft. The model included the aircraft engines, wings, fuselage, empennage, and landing gear, as well as nonstructural components of the aircraft. 
The WTC towers and Boeing 767 aircraft are complex structural systems. In the global model development process, the objective was to include all of the primary structural components and details of both the aircraft and towers. This approach, however, results in very large models. The component and subassembly analyses were used to determine model simplifications to reduce the overall model size while maintaining fidelity in the analysis. Therefore, a series of component impact and subassembly analyses were performed. The primary objectives of the component and subassembly modeling were to (1) develop an understanding of the interactive failure phenomenon of the aircraft and tower components and (2) develop the simulation techniques required for the global analysis of the aircraft impacts into the WTC towers, including variations in mesh density and numerical tools for modeling fluid-structure interaction for fuel impact and dispersion. The approach taken for component modeling was to start with finely meshed models of key components of the tower and aircraft structures and progress to relatively coarsely meshed beam and shell element representations that were used for the global models. An example of component level analysis is the analysis of exterior wall panels impacted by a segment of an aircraft wing with and without fuel. An example of the subassembly analysis is an aircraft engine impacting a strip from the exterior wall to the core of the tower. Component and subassembly analyses are described in Chapters 5 and 6, respectively.

Chapter 7 provides the initial conditions of the impact of the aircraft into the WTC towers. These include impact speed, aircraft orientation and trajectory, and impact location of the aircraft nose. This task utilized the two videos that captured the approach and impact of the American Airlines flight 11, which impacted WTC 1, and the several videos that captured United Airlines flight 175, that impacted WTC 2. In addition, a large body of photographic evidence was used to determine the impact location and orientation relative to the towers. These videos and photographs were analyzed to estimate, with the best accuracy possible, the speed, horizontal and vertical angles of incidence, and roll angle of each aircraft. Uncertainties in each of these parameters were also quantified.

The analysis of aircraft impact into the WTC towers is subject to large uncertainties in the input parameters, such as the initial conditions of the impact, material properties, mass properties of aircraft and building contents, connection behavior, modeling uncertainties, etc. Uncertainty analyses were performed at the component and subassembly levels, as reported in Chapter 8 . The objectives of these analyses were to assess the effect of uncertainties on the level of damage to the towers after impact and to determine the most influential parametcrs that affect the damage estimates.

Chapter 9 presents the results of the global analyses of aircraft impact into WTC 1 and WTC 2 using the global tower and aircraft models. The analysis results included the estimation of the structural damage that degraded their strength and the condition and position of nonstructural contents such as partitions, workstations, aircraft fuel, and other debris that influenced the behavior of the subsequent fires in the towers. The global analyses included, for each tower, a "base case" based on a best estimate of all input parameters. They also provided more and less severe damage estimates based on variations of the most influential parameters. These more and less severe damage scenarios provided a range of damage estimates of the towers due to aircraft impact. Comparisons between the simulation results and observables obtained from video and photographic evidence, as well as eyewitness interviews, were also conducted. The chapter also provides a comparison with prior estimates of the damage obtained from other studies. 
Approximate analyses were carried out to provide guidance to the global finite element impact analyses. As reported in Chapter 10, these analyses included: (1) the analysis of the overall aircraft impact forces and assessment of the relative importance of the airframe strength and weight distribution, (2) the evaluation of the potential effects of the energy in the rotating engine components on the calculated engine impact response, (3) the influence of the static preloads in the towers on the calculated impact damage and residual strength predictions, and (4) the analysis of the load characteristics required to damage core columns compared to the potential loading from impact of aircraft components. 
This page intentionally left blank. 


\section{Chapter 2 \\ MATERIAL CONSTITUTIVE MOdELING}

\subsection{INTRODUCTION}

An important requirement for high fidelity simulation of the aircraft impact damage is the development of constitutive models that represent the actual behavior of the World Trade Center (WTC) towers and aircraft structure under the dynamic impact conditions of the aircraft. The primary materials considered for the impact analyses included the several grades of steel used in the columns, spandrels, and floor trusses and beams of the WTC towers, the concrete floor slabs, and the aluminum airframe structure of the Boeing 767 aircraft. All of these materials played a significant role in the aircraft impact damage analyses. These materials exhibit significant nonlinear rate-dependent deformation and failure behavior over the range of strain rates expected in the impact scenario.

Secondary materials of interest included the nonstructural aircraft components and masses such as fuel, seats, interior trim, cargo, and luggage. Furthermore, a significant part of the mass of the WTC towers was material not included in the primary structural steel frame, such as nonstructural walls, partitions, furniture and other building contents, flooring, mechanical equipment, and insulation. The strength of these materials is relatively small compared to the structural materials, and a simple description of their constitutive behavior is adequate.

The analysis of the aircraft impact damage was performed with the LS-DYNA finite element code (LS-DYNA Version 971). LS-DYNA has an extensive library of more than 130 different constitutive models and was capable of accurately reproducing the important material behaviors required in this analysis. Material models currently available in LS-DYNA have been utilized for the analyses using material data from tests conducted by the National Institute of Standards and Technology (NIST) or available in the public domain.

\subsection{WTC TOWER STEEL CONSTITUTIVE MODELS}

Various constitutive models are available in LS-DYNA that can capture the nonlinear behavior of the steel under impact conditions, including strain rates effects and failure. The primary constitutive model applied was the Piecewise Linear Plasticity model. This model was sufficient to model the nonlinear dynamic deformation and failure of the steel structures. A tabular effective stress versus effective strain curve can be used in this model with various definitions of strain rate dependency.

The constitutive model parameters were developed for each grade of steel used in the construction of the WTC towers based on engineering stress-strain data provided by the NIST mechanical and metallurgical analysis of structural steel (see NIST NCSTAR 1-3). ' The approach to developing the constitutive parameters for each grade of steel was:

1 This reference is to one of the companion documents from this Investigation. A list of these documents appears in the Preface to this report. 
- Convert the engineering stress-strain curve to a true stress versus true strain curve. The conversion process is described below and is valid up to the onset of necking in the specimen.

- Extrapolate the true stress-strain curve beyond the point of necking onset.

- Perform iterative finite element analyses of the tensile test and adjust the true stress-strain curve extrapolation and failure strain until the necking behavior and failure point were accurately captured. The primary criterion was the quantitative agreement of the measured and calculated engineering stress-strain behavior in the softening region beyond maximum stress. These analyses required a fine mesh resolution in the specimen to accurately model the large strain deformation response during necking.

- Perform a final finite element analysis of the material test using a coarser mesh resolution (medium mesh corresponding to the mesh resolution applied in the component analyses). Adjust the failure criteria (strain at failure) to obtain failure at the same engineering strain level.

The advantage of this approach was that the measured nonlinear material behavior up to failure was accurately captured in the constitutive model. In addition, the simulation of the material testing provided a validation that the constitutive model parameters were defined accurately and that the model could reproduce the measured response for the test conditions.

The tensile tests performed by NIST applied the ASTM 370 test standard (ASTM Designation A 370-03a 2003). Example finite element models of a rectangular test specimen with the fine and medium mesh resolutions are shown in Figure 2-1. This specimen type was used for all of the tests on WTC exterior column materials. A similar figure of the round bar specimen models used for testing of the WTC core column steels is shown in Figure 2-2. The typical element length used in the gage section for the fine meshes was approximately $0.015 \mathrm{in}$. and for the medium meshes was approximately $0.10 \mathrm{in}$. The use of the specimen models to develop the constitutive model parameters is described in the following sections.

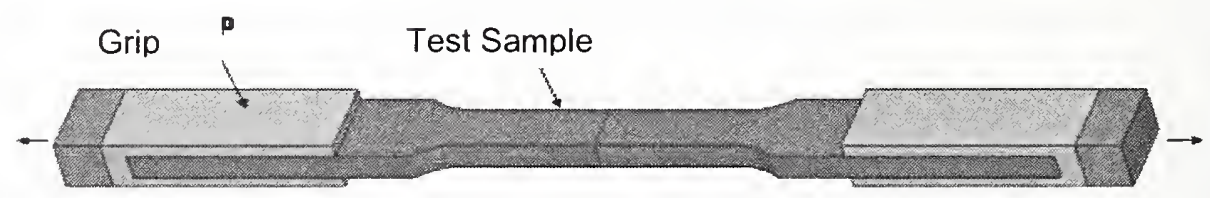

Fine Mesh

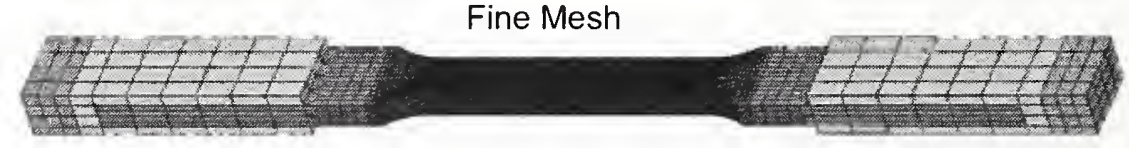

Medium Mesh

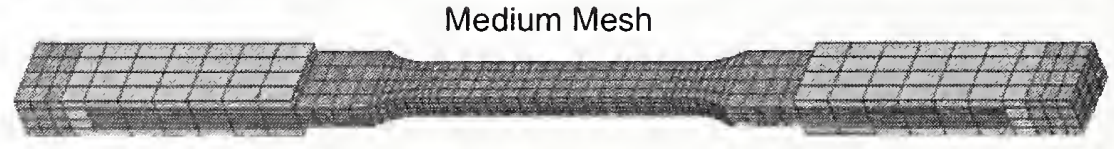

Figure 2-1. Example finite element models of the ASTM 370 rectangular tensile specimen. 

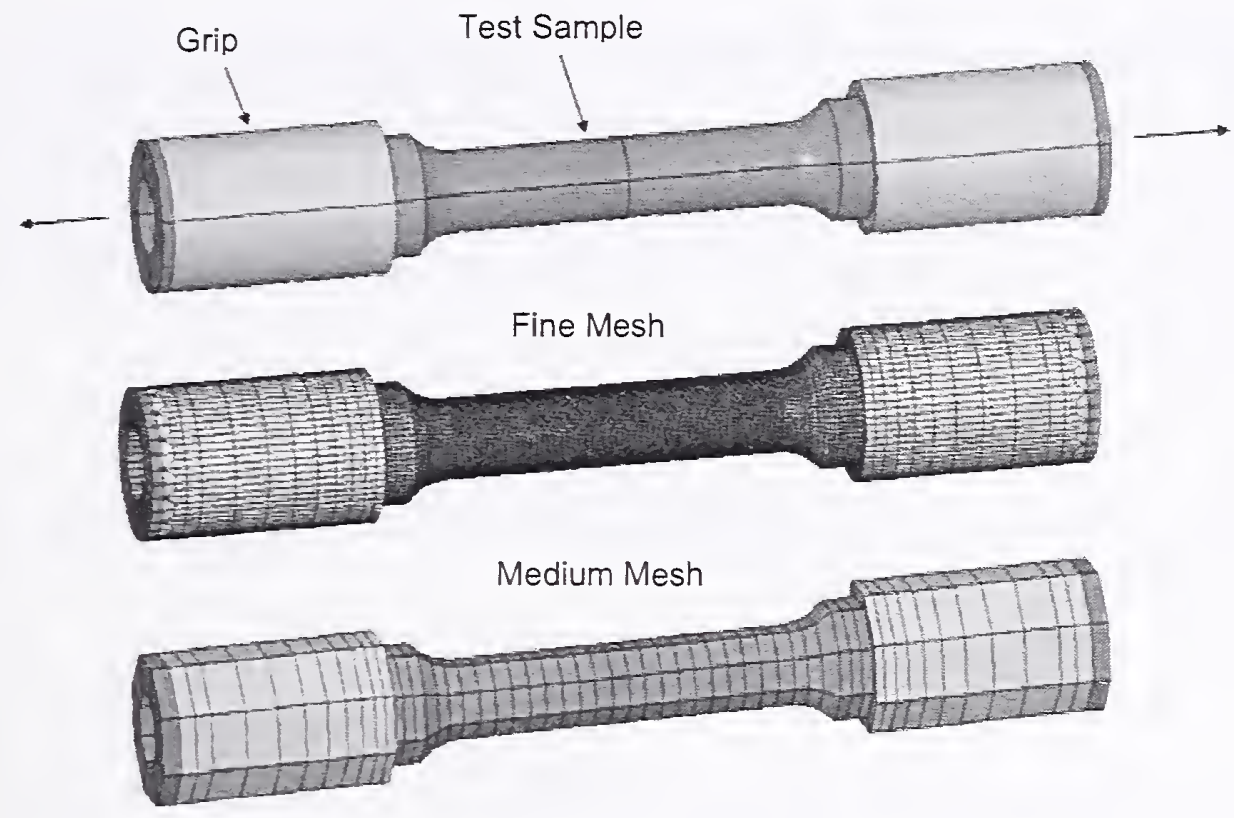

Figure 2-2. Example finite element models of the ASTM 370 round bar tensile specimen.

\subsubsection{True Stress and True Strain Corrections}

In most tensile tests, a plot is generated of the load measured at the cross head of the testing machine against the displacement of the specimen. A plot of engineering stress versus strain can be generated from this plot by dividing the load by the original cross sectional area of the specimen and the displacement by the original length of the specimen. If the changes in area and length are small during the test, these measures give a good indication of material behavior. However, in reality, the cross section changes (shrinks) significantly during the test, and the engineering stress does not yield the "true" stress in the cross section. Similarly, the engineering strain is not representative of the material behavior, especially when a general three-dimensional state of strain exists. As a result, the engineering stress decreases as some materials approach failure, implying a weakening of the material. In reality, the stress in the cross section is increasing due to the reduction in the cross sectional area (i.e., necking).

There are several different ways to measure stress and strain based on the coordinate system used. Some are based on material (Lagrangian) coordinates and some on spatial (Eulerian) coordinates. These give rise to terms such as "Green" and "Almansi" strain tensors. These are important in writing a computer code to solve large strain problems. An alternate approach is to define a "true" or "natural" stress and strain. The true stress is based on the load divided by the actual cross sectional area of the specimen and is equal to the engineering stress multiplied by a term to correct for the change in cross section.

$$
\sigma_{T}=\sigma_{\text {eng }}(1+e)
$$

where $\sigma_{T}$ and $\sigma_{\text {eng }}$ are the true and engineering stresses, respectively, and $e$ is the engineering strain. 
Prior to the onset of localization (necking), the natural or true strain, $\varepsilon_{T}$, is defined as

$$
\varepsilon_{T}=\ln \left(\frac{l}{l_{o}}\right)=\ln (1+e)
$$

This definition comes about from defining the incremental true or "natural" strain as the current "change in length" divided by the current length, or

$$
d \varepsilon_{T}=\frac{d l}{l}
$$

This is in contrast with the definition of engineering strain that references the change in length, $\Delta l$, divided by the original length, $l_{0}$, or

$$
e=\frac{\Delta l}{l_{0}}
$$

After the onset of localization, the determination of the true strain in the necked region becomes more complex and requires measurement of the local neck geometry.

\subsubsection{Development of Steel Constitutive Properties}

In this section, examples are provided to illustrate the methodology for constitutive model development of the WTC tower steels, as well as typical results. Figure 2-3 shows an example of the measured engineering stress-strain behavior for the $75 \mathrm{ksi}$ perimeter column steel. Four tests were performed by the NIST Investigation (NIST NCSTAR 1-3) on each grade of steel, and the data clearly indicated anisotropy in the behavior introduced by the roll forming process (longitudinal tests L1 and L2 versus transverse tests T1 and T2 in the figure). This particular grade of steel had a larger anisotropy than seen in most of the other steel grades. Whenever anisotropy was observed, the material had greater ductility for specimens aligned with the rolling direction. The largest effects of the anisotropy were observed in the behavior after the onset of necking.

The first step in the constitutive model development process was to obtain a true stress-true strain curve. The typical approach was to select a representative test and perform the data conversion process described in Section 2.2.1. In this example, the data from test Ll was used to create the true stress-strain curve shown in Figure 2-3. This true stress-strain curve was then approximated by a piecewise linear curve in tabular form as shown in Figure 2-4. This tabular curve was the input used to specify the mechanical behavior in the constitutive model.

The final step was to apply the tabular true stress-strain behavior in the constitutive model to simulate the tensile test as shown in Figure 2-5. If necessary, the extrapolation of the true stress-strain behavior was adjusted until the simulation matched the measured engineering stress-strain response, including necking and failure (the portion of the stress-strain curve beyond the maximum engineering stress). A comparison of the calculated and measured tensile behavior for the $75 \mathrm{ksi}$ perimeter steel is shown in Figure 2-6. In this example, the constitutive model was developed as an average between the longitudinal and transverse properties. Results of tests conducted by the NIST Investigation on the tower steels indicated that the stress-strain behavior was very similar in the longitudinal and transverse directions up to the onset of 
necking. The difference between the longitudinal and transverse properties was in the ductility, where the average ratio of the longitudinal to transverse strain to failure in the exterior column steels is about 1.22:1. The approach used in the constitutive modeling was to use an average of the longitudinal and transverse properties and ignore the orthotropic characteristics of the material in the impact analyses. The effects produced by the variation of ductility between the longitudinal and transverse directions were assessed as part of the uncertainty analyses.

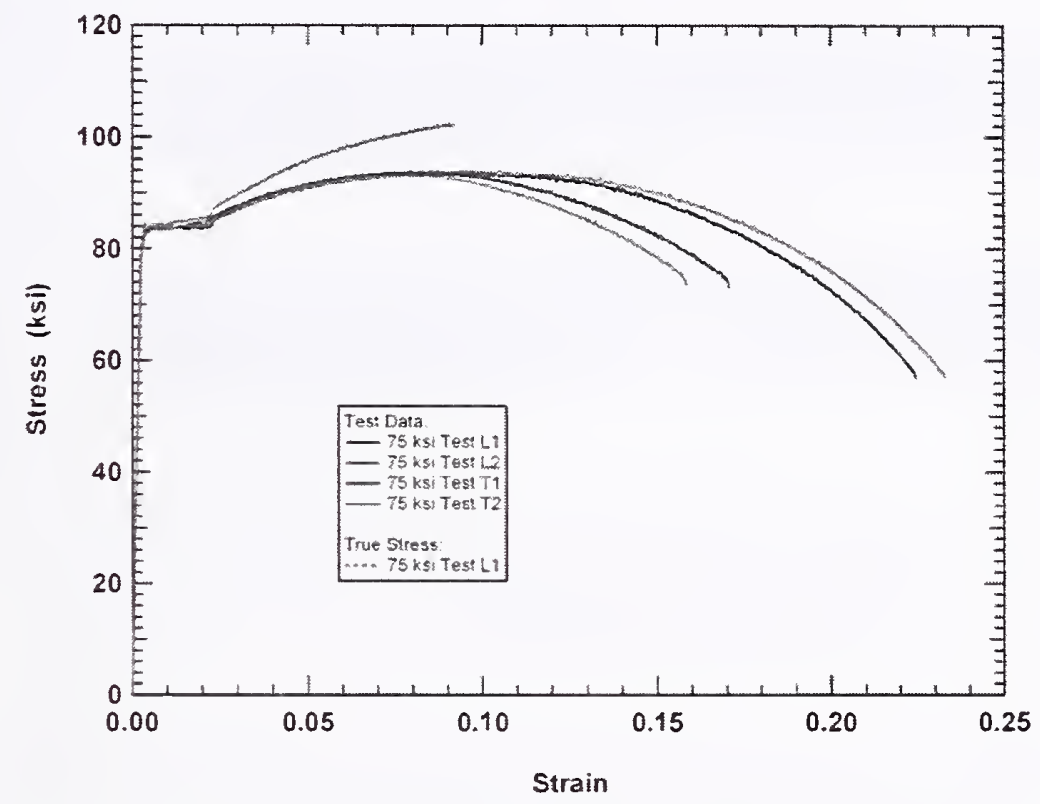

Figure 2-3. Test data and true stress-strain conversion for the $75 \mathrm{ksi}$ steel.

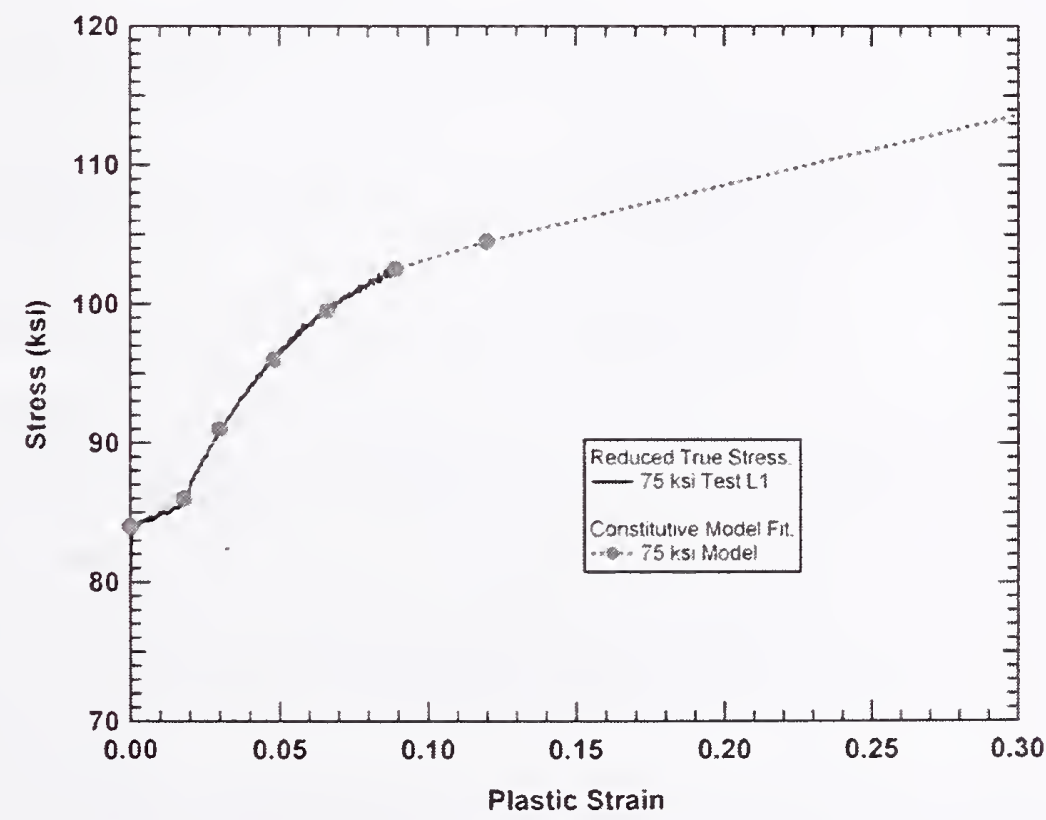

Figure 2-4. Tabular true stress-strain constitutive model curve for the 75 ksi steel. 


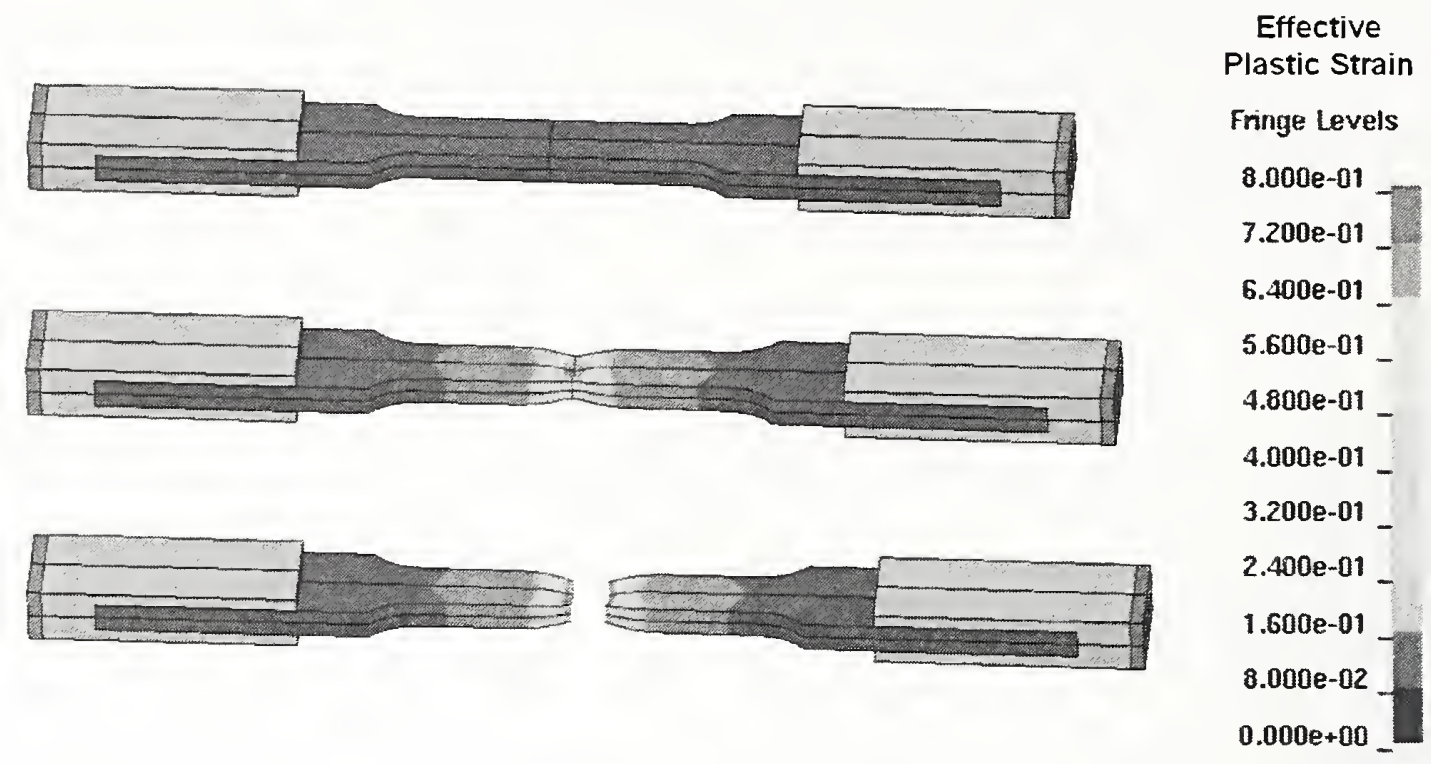

Figure 2-5. Calculated tensile test response with necking for the $75 \mathrm{ksi}$ steel.

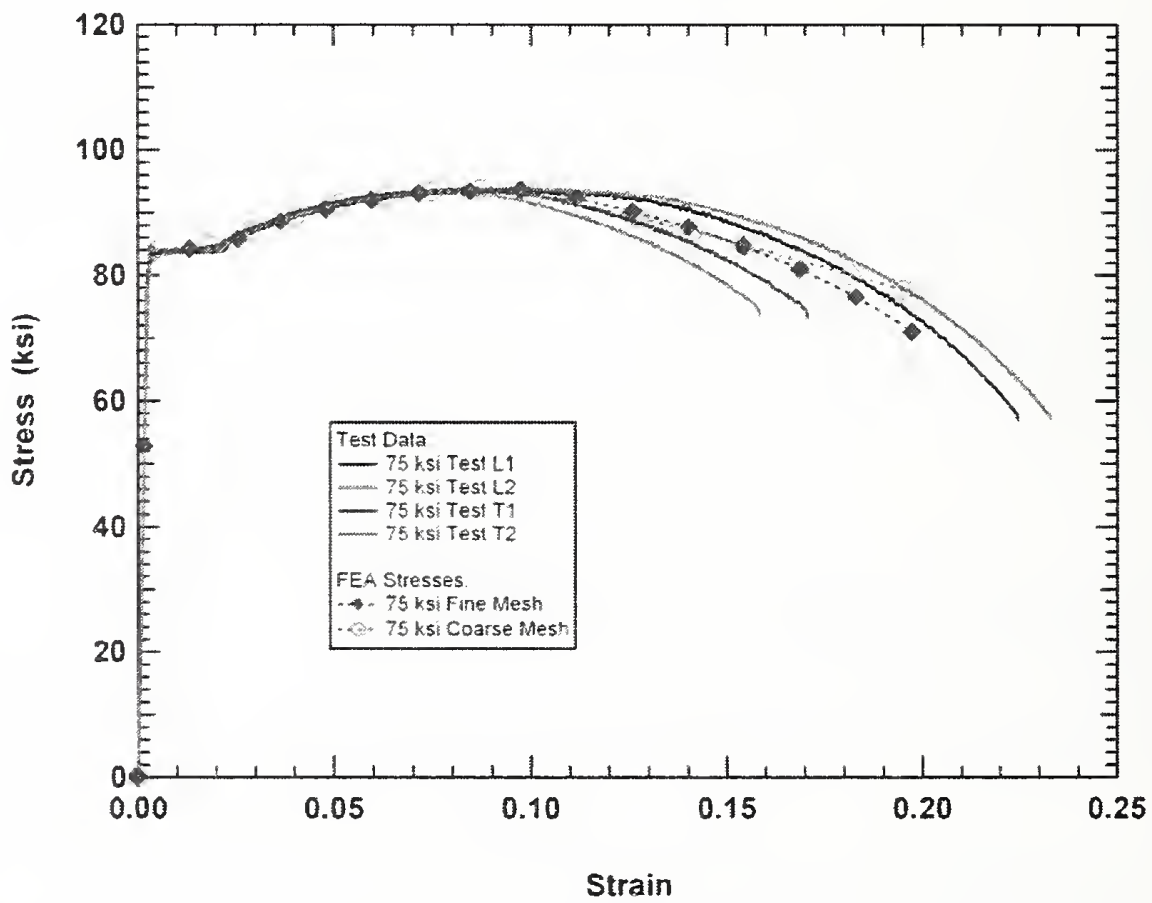

Figure 2-6. Comparison of measured and calculated engineering stress-strain curves for the $75 \mathrm{ksi}$ steel.

The resulting true stress-true strain behavior incorporated into the constitutive model was representative of the steels tested in this Investigation. However, there were multiple sources (suppliers) of steel used in the construction of the WTC towers. The NIST Investigation (NIST NCSTAR 1-3) developed synthetic stress-strain curves for each grade of steel based on several data sources. As indicated in Section 2.2, the 
test data were used as the input for the material modeling to provide validated stress-strain properties up to failure. A comparison of this synthetic curve with the constitutive model behavior for the $75 \mathrm{ksi}$ steel is shown in Figure 2-7. There were observable differences in the curves, such as the representation of a yield point behavior in the constitutive model. However, the differences were not sufficiently large to produce a large variation in the calculated structural impact behavior. In addition, the effect of material strength variation on impact damage was assessed in the uncertainty analyses.

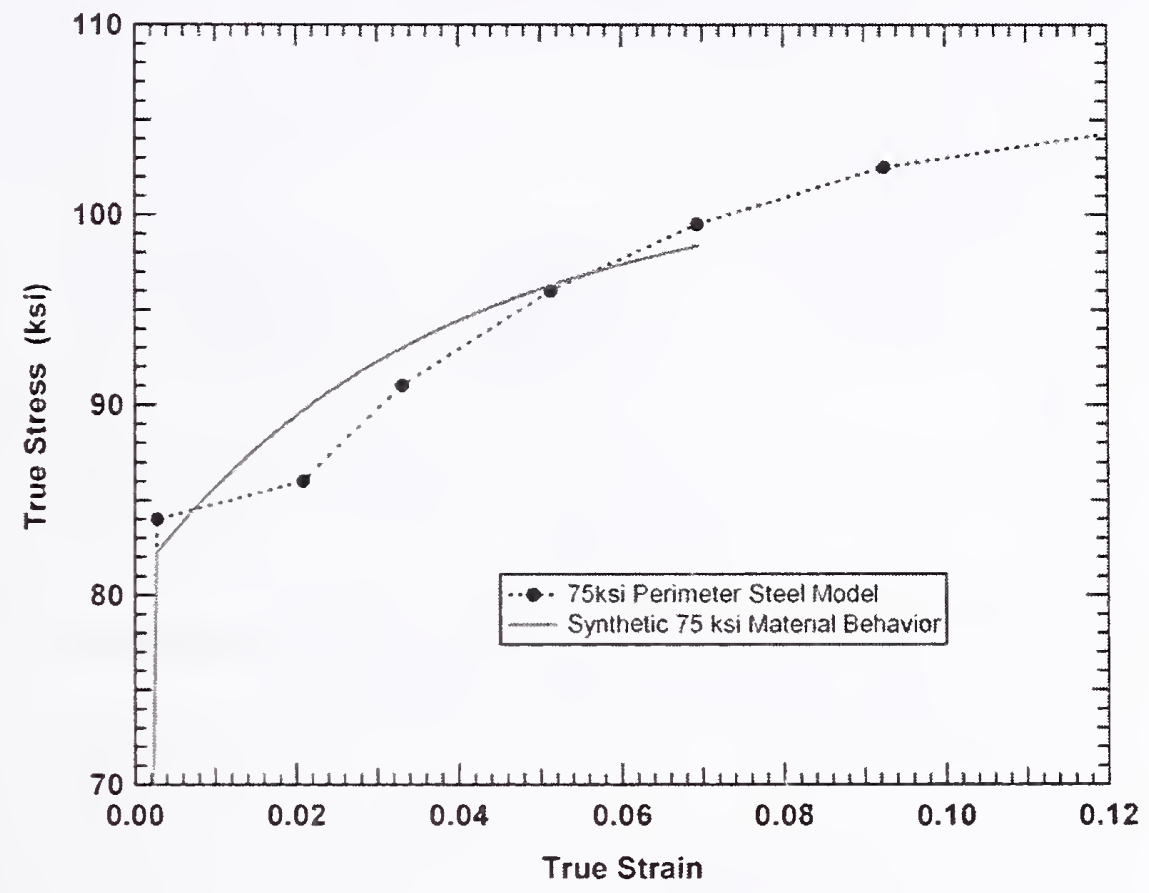

Figure 2-7. Comparison of the constitutive model and synthetic steel behaviors for the $75 \mathrm{ksi}$ steel.

The procedure described above was applied to develop constitutive models for all of the WTC tower steels for which test data were provided by the NIST mechanical and metallurgical analysis.

\subsubsection{Summary of Steel Constitutive Properties}

A summary of the true stress-strain curves used in the constitutive models for the various WTC tower steels are summarized in Figure 2-8. Similarly, a comparison of the true stress-strain constitutive curves with the synthetic stress-strain curves, developed during the mechanical and metallurgical analysis of structural steel, for the various exterior column steels is shown in Figure 2-9 and Figure 2-10, and for core column steels in Figure 2-11. In general, the true stress-strain curves developed from the test data and the synthetic curves developed from multiple sources agreed to within approximately 10 percent. This variation in measured and expected material strengths was considered in the uncertainty analyses described in Chapter 8. 


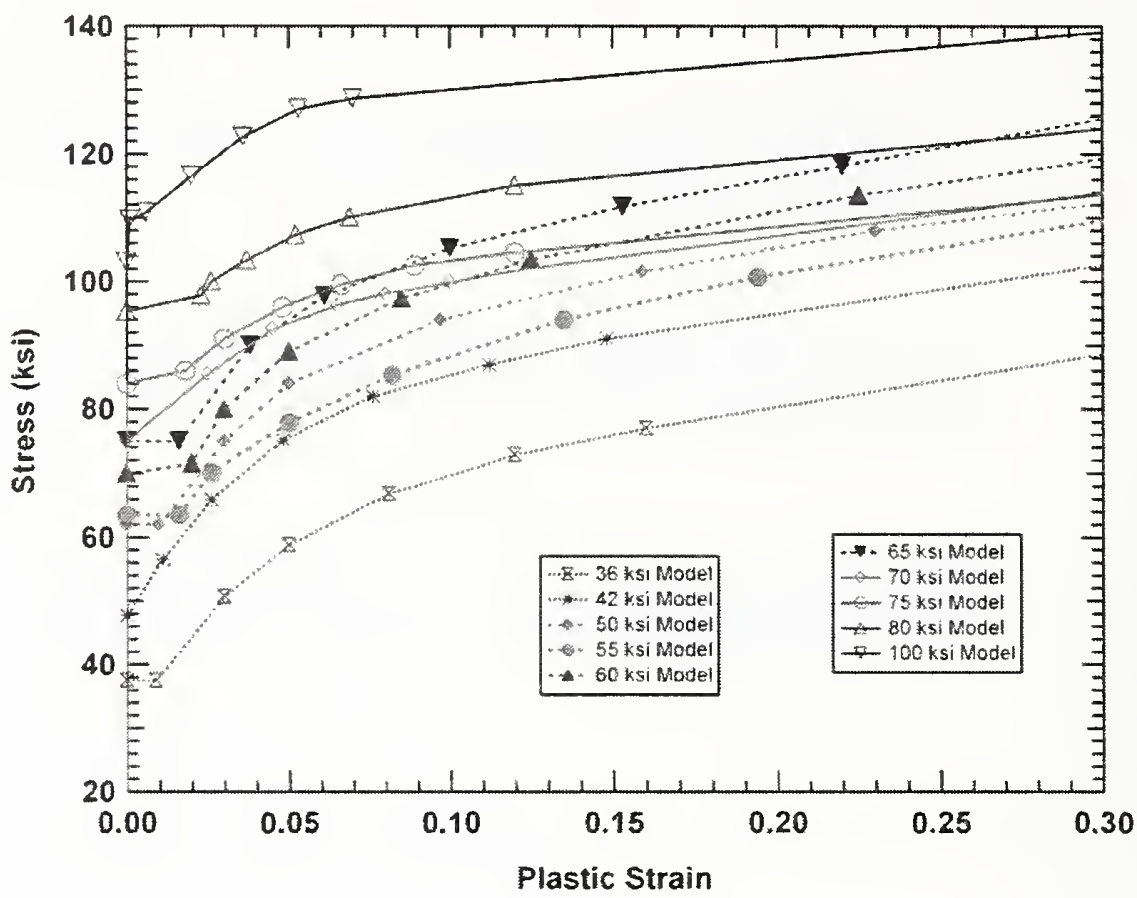

Figure 2-8. Tabular true stress-strain constitutive model curves.

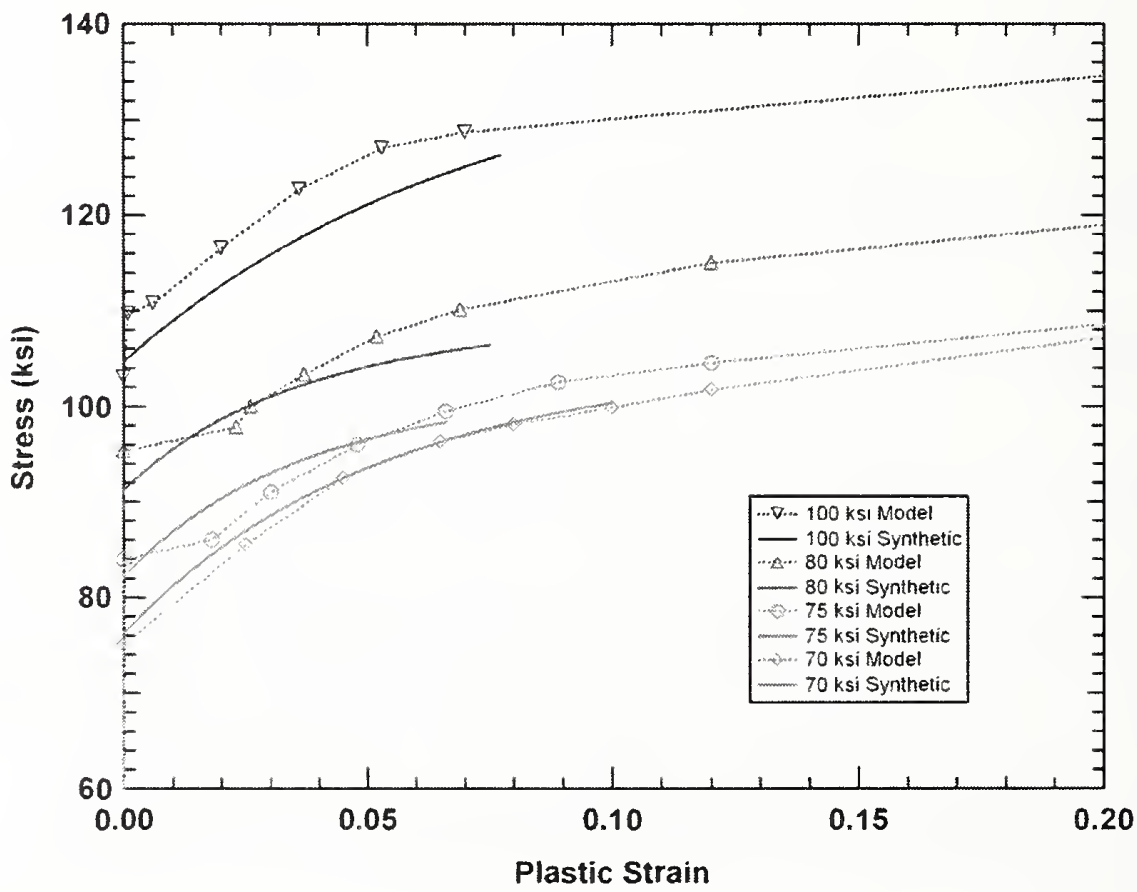

Figure 2-9. Comparison of the constitutive model and synthetic steel behaviors for the higher strength perimeter steels. 


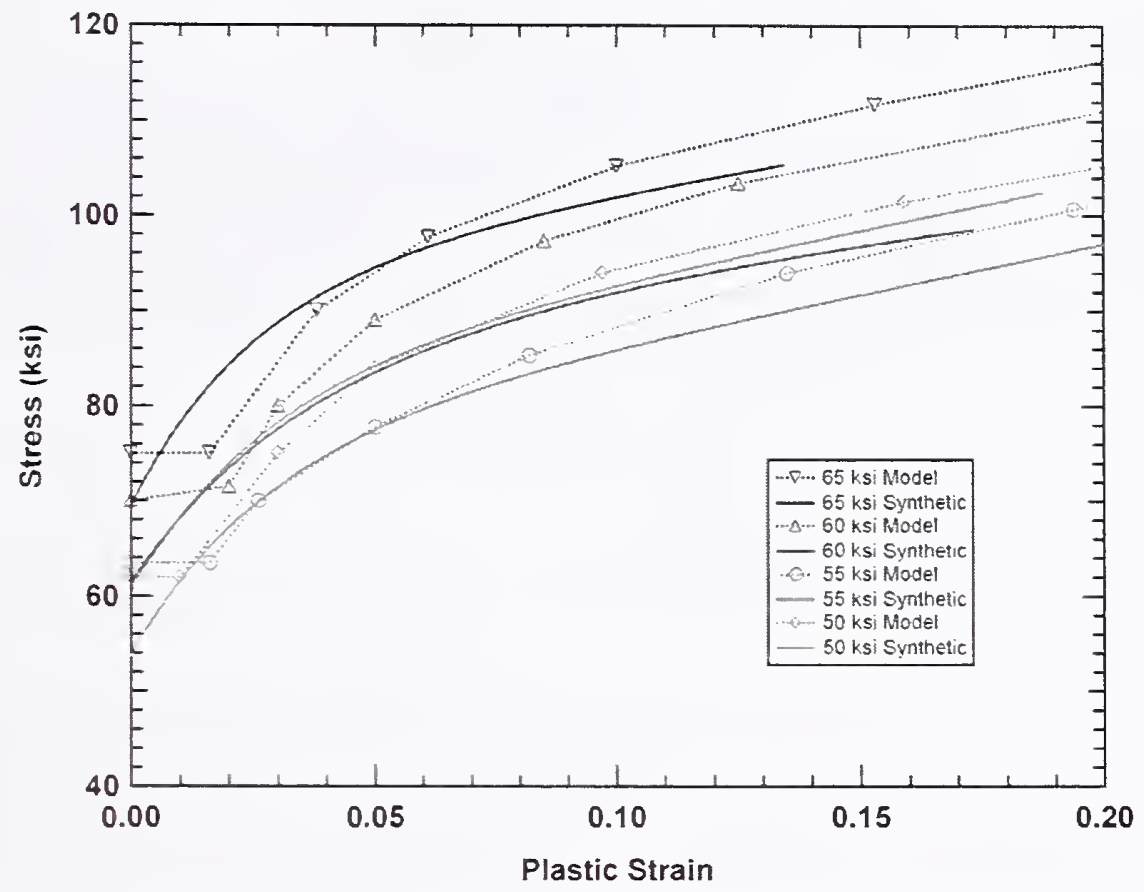

Figure 2-10. Comparison of the constitutive model and synthetic steel behaviors for the lower strength perimeter steels.

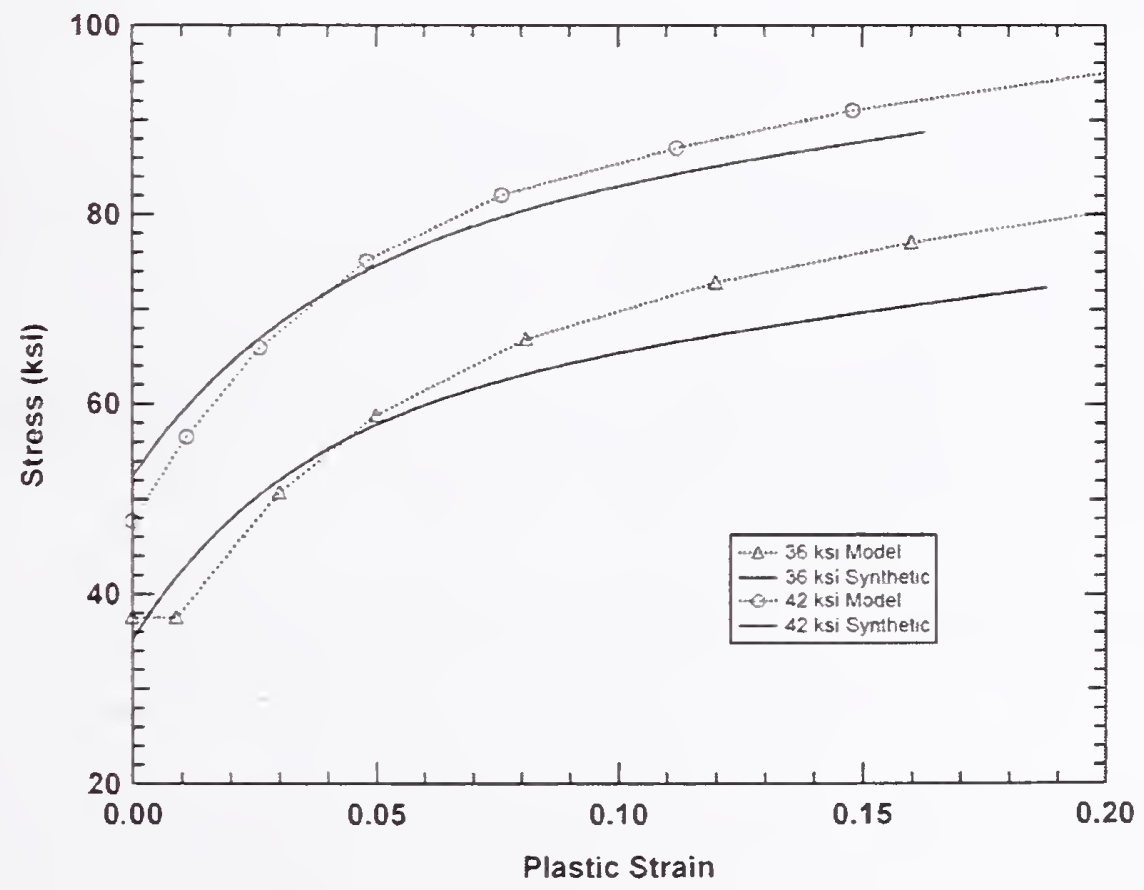

Figure 2-11. Comparison of the constitutive model and synthetic steel behaviors for the core steels. 


\subsubsection{Strain Rate Effects in Steel Constitutive Models}

Elevated strain rates can influence the strength and ductility of structural materials. For the materials and strain rates of the WTC tower impact analyses, these strain rate effects are expected to be somewhat small compared to the effects of the baseline (static) strength and failure modeling. The strain-rate effects on the yield strength were included in the constitutive model for the tower steels with the Cowper and Symonds rate effect model. The functional form for the rate effects on strength is governed by the equation:

$$
\sigma_{y}=\sigma_{y_{0}}\left[1+\left(\frac{\dot{\varepsilon}}{C}\right)^{1 / p}\right]
$$

where $\sigma_{y}$ and $\sigma_{y_{0}}$ are the yield strengths at strain rates of $\dot{\varepsilon}$ and zero, respectively. $C$ and $p$ are the Cowper and Symonds parameters.

A series of high-rate characterization tests was performed on tower steels as part of the NIST mechanical and metallurgical analysis of structural steel. In addition to quasi-static tests (performed at a rate below $0.001 \mathrm{~s}^{-1}$ ), a series of high rate tests were performed, primarily at strain rates between 100 and $1000 \mathrm{~s}^{-1}$. The Cowper and Symonds model parameters, $\mathrm{C}$ and $\mathrm{p}$, were then fit to the test data and are provided in the following functional form for a strain rate in $\mathrm{s}^{-1}$ and a yield strength in ksi:

- $\log (\mathrm{C})=-7.55+0.324 \sigma_{\mathrm{y} 0}-0.00153\left(\sigma_{\mathrm{y0}}\right)^{2}$

- $p=6.7824$

The specific values used for each of the different tower steels are summarized in Table 2-1. The $36 \mathrm{ksi}$ and $42 \mathrm{ksi}$ steels were materials used in the core columns, and the remaining steels were used in the exterior columns. The brick element failure strains in Table 2-1 are presented for the medium mesh resolution corresponding to the mesh density used in the component analyses. The resulting rate effects used in the constitutive modeling of tower steels, based on Equation (5), are compared to the measured high rate tcst data for the $50 \mathrm{ksi}, 75 \mathrm{ksi}$, and $100 \mathrm{ksi}$ tower steels in Figure 2-12. In the figure, the dashed lines with open symbols are the fits using the Cowper and Symonds model, while the corresponding solid symbols are the experimental data. The comparison shows that the Cowper and Symonds model is capable of reproducing the rate effects for the range of data available.

Test results indicated that the influence of strain rate on the ductility of the tower steels did not follow a consistent trend. Several grades of steel had an increased ductility at high rates (more common for low strength steels), some had a reduced ductility at high rates (more common for high strength steels), and some showed no significant effect of strain rate on ductility. The approach used in the constitutive modeling is to ignore the changes in ductility produced by elevated strain rates. The effects of the variation of ductility over the expected range of strain rates were assessed as part of the uncertainty analyses. 


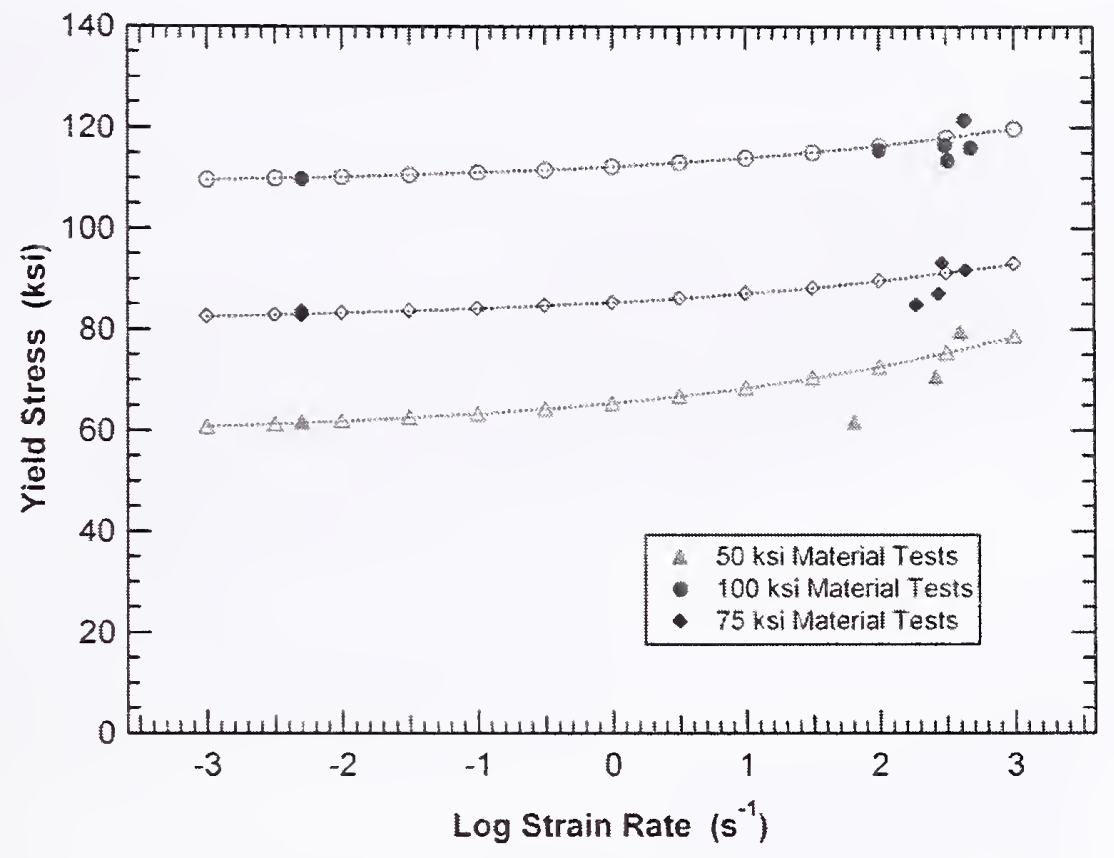

Figure 2-12. Comparison of rate effects model and test data.

Table 2-1. Material constitutive parameter table - WTC tower steels.

\begin{tabular}{|c|c|c|c|c|c|}
\hline $\begin{array}{c}\text { Material Yield } \\
\text { Specification }\end{array}$ & $\begin{array}{c}\text { Young's } \\
\text { Modulus }\end{array}$ & Poisson's Ratio & $\begin{array}{c}\text { Strain-Rate } \\
\text { Coefficient (C) }\end{array}$ & $\begin{array}{c}\text { Strain-Rate } \\
\text { Exponent (p) }\end{array}$ & $\begin{array}{c}\text { Brick Element } \\
\text { Failure Strain }\end{array}$ \\
\hline $36 \mathrm{ksi}$ & $29.7 \mathrm{Msi}$ & 0.288 & $7.900 \mathrm{e}+01$ & $6.782 \mathrm{e}+00$ & 0.32 \\
\hline $42 \mathrm{ksi}$ & $29.7 \mathrm{Msi}$ & 0.288 & $1.360 \mathrm{e}+05$ & $6.782 \mathrm{e}+00$ & 0.32 \\
\hline $50 \mathrm{ksi}$ & $29.7 \mathrm{Msi}$ & 0.288 & $4.220 \mathrm{e}+06$ & $6.782 \mathrm{e}+00$ & 0.50 \\
\hline $55 \mathrm{ksi}$ & $29.7 \mathrm{Msi}$ & 0.288 & $6.700 \mathrm{e}+06$ & $6.782 \mathrm{e}+00$ & 0.64 \\
\hline $60 \mathrm{ksi}$ & $29.7 \mathrm{Msi}$ & 0.288 & $3.950 \mathrm{e}+07$ & $6.782 \mathrm{e}+00$ & 0.56 \\
\hline $65 \mathrm{ksi}$ & $29.7 \mathrm{Msi}$ & 0.288 & $1.270 \mathrm{e}+08$ & $6.782 \mathrm{e}+00$ & 0.51 \\
\hline $70 \mathrm{ksi}$ & $29.7 \mathrm{Msi}$ & 0.288 & $1.270 \mathrm{e}+08$ & $6.782 \mathrm{e}+00$ & 0.62 \\
\hline $75 \mathrm{ksi}$ & $29.7 \mathrm{Msi}$ & 0.288 & $6.710 \mathrm{e}+08$ & $6.782 \mathrm{e}+00$ & 0.56 \\
\hline $80 \mathrm{ksi}$ & $29.7 \mathrm{Msi}$ & 0.288 & $2.440 \mathrm{e}+09$ & $6.782 \mathrm{e}+00$ & 0.49 \\
\hline $100 \mathrm{ksi}$ & $29.7 \mathrm{Msi}$ & 0.288 & $3.430 \mathrm{e}+09$ & $6.782 \mathrm{e}+00$ & 0.53 \\
\hline
\end{tabular}

\subsection{FAILURE MODELS}

A challenge for calculating the aircraft impact response and damage to the WTC towers was the wide range of failure mechanisms that occurred in both the aircraft and tower structures. These failures resulted from severe loads and large scale deformations of the materials, as well as from exceeding the strength of bolted, welded, and riveted connections. At the connection locations, complex behaviors were influenced by variations in material cross sectional geometry and material properties that produced stress and strain concentrations. 
The approach used to model the impact damage and failure of the structurcs was to apply engineering failure models within the framework of the LS-DYNA finite element analyses. Detailed fracture mechanics analysis of all of the failures that occurred was beyond the scope of this effort. Material failure in the impact analyses was calculated at the element where damage development was based on local (element) quantities including plastic strain and stress state. When the specified failure criterion in an element was exceeded, the element was eroded (deleted) from the calculation. The erosion of elements allowed for the propagation of failure through a structure.

Calculation of the failure of structural components was further complicated by the scale of the global impact analyses. Damage modeling is often applied to the analysis of smaller components and failure initiation. In these applications, a relatively fine mesh can be applied, and damage regions around a local fracture can be resolved on a fine scale. For the global impact of an aircraft into the WTC towers, element sizes had to be on average a few inches to maintain a model size at approximately 2 million elements. At this resolution, the gradients around a fracture cannot be accurately resolved, and the damage criteria required adjustment to obtain the appropriate strength and ductility of the structures. In the following sections, various failure modeling techniques applied to the aircraft and tower structures are described.

\subsubsection{Mesh Refinement Effects}

One of the significant modeling issues for the analysis of aircraft impact damage and failure is the effect of mesh refinement. The global impact analyses of the aircraft impacts into the WTC towers were very large analyses of complex structures and required the refinement of the model to be reduced significantly from the detailed component analyses. As the mesh refinement was reduced, it was important to ensure that the damage mechanisms and extent of impact damage were properly captured.

A preliminary example of the effects of mesh refinement on the response was introduced earlier in the analysis of the material tests on the WTC tower steels. Figure 2-1 showed both fine mesh and a coarser mesh (referred to as medium mesh) versions of the ASTM 370 rectangular tensile specimen for plate material. A comparison of the calculated necking behavior for the two $75 \mathrm{ksi}$ specimen meshes immediately preceding failure is shown in Figure 2-13. The fine mesh was able to better resolve the strain gradients in the necking region and as a result had higher peak strain values at the same level of specimen displacement. 


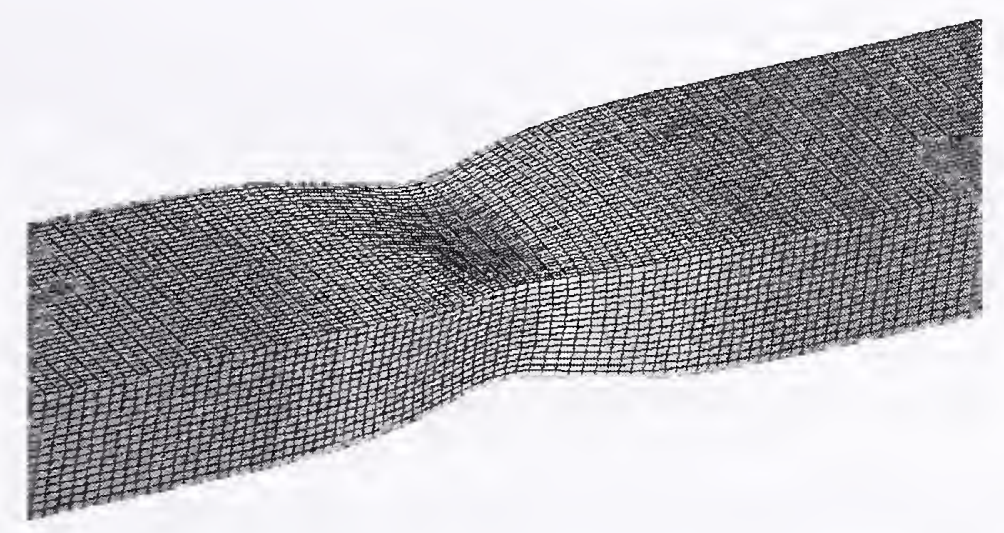

(a) Fine mesh necking behavior (red $=75$ percent plastic strain)

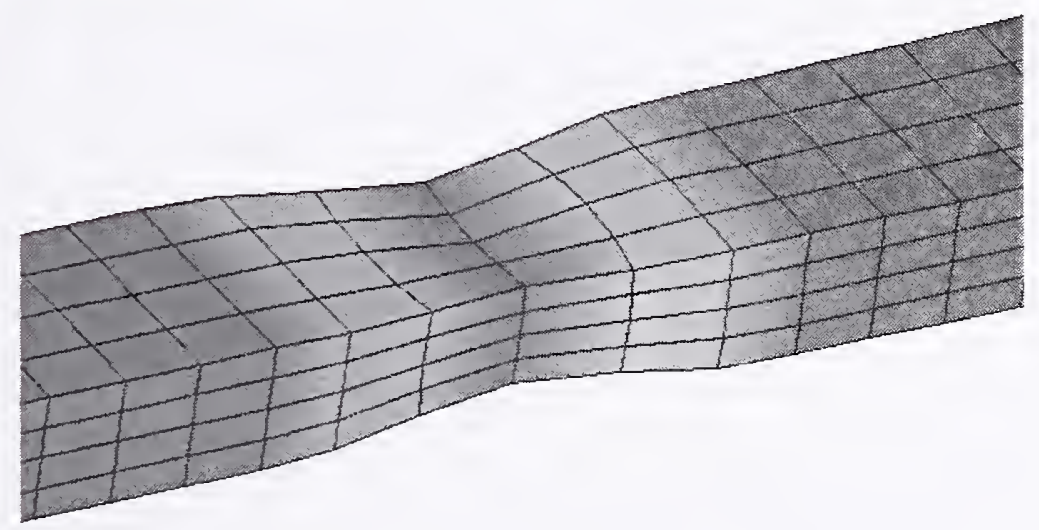

(b) Medium mesh necking behavior (red $=50$ percent plastic strain)

Figure 2-13. Calculated necking response in the $75 \mathrm{ksi}$ tensile specimen.

The effects of further reductions in mesh refinement required for global impact analyses can be demonstrated with the ASTM 370 tensile test example used in this section. To most closely resemble the mesh and element type used in the global analyses, three full width shell elements were used to model the entire specimen gage section, as shown in Figure 2-14. This coarse tensile specimen model had a single stress and a single strain value across the specimen gage section and did not have sufficient independent degrees of freedom to capture the localization that occurred during necking. To most closely match the behavior of the fine-mesh model, a failure strain of 0.18 was needed to model failure for this single shell element. Note that this closely matches the engineering failure strain of 0.20 for this material (see Figure 2-6).

The calculated engineering stress-strain behavior obtained with the three different mesh resolutions (fine, medium, and coarse) is shown in Figure 2-15. In these calculations, a maximum plastic strain criterion was used, and the critical failure strain was shifted until each calculation failed at a value matching the average measured engineering failure strain. The corresponding critical plastic strains were 1.00 for the fine mesh resolution, 0.56 for the medium mesh resolution, and 0.18 for the coarse mesh resolution (shell element model). 


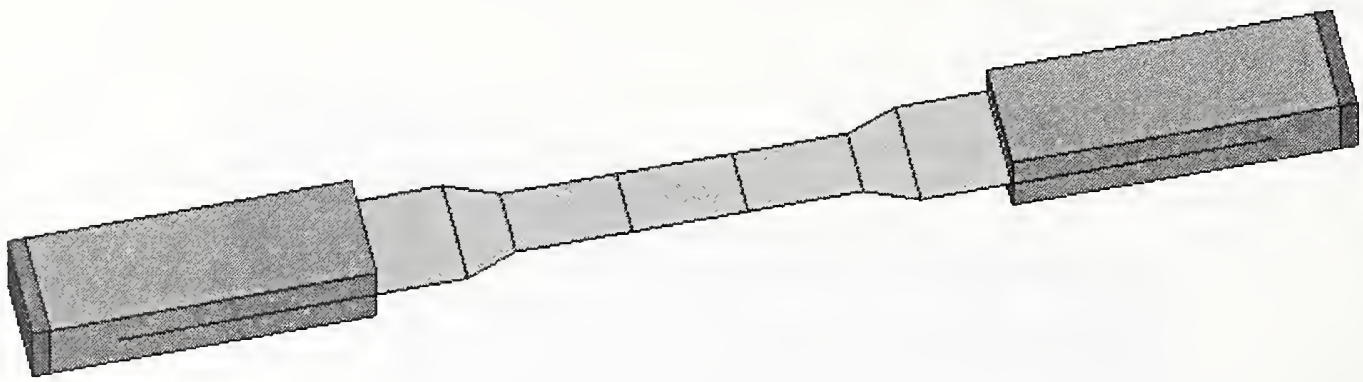

Figure 2-14. Coarse shell element mesh for the $75 \mathrm{ksi}$ tensile specimen.

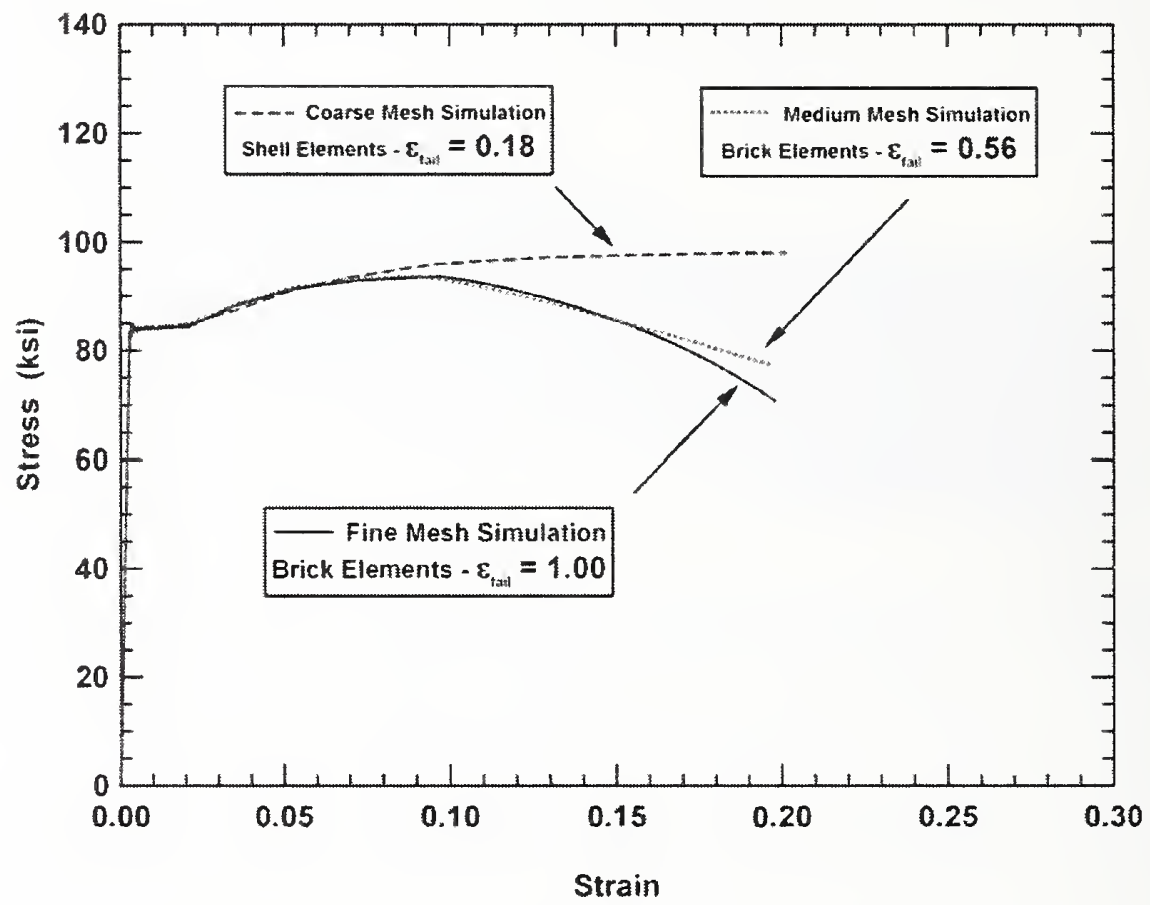

Figure 2-15. Mesh refinement effects in the calculated 75 ksi tensile test.

The medium mesh resolution used in the analysis of the tensile test described above corresponded to the mesh resolution applied in the exterior column component impact analyses described in Section 5.2.1. Therefore, the critical failure strain of 0.56 was carried forward to the detailed component analyses. The coarser shell element subassembly and global impact models were typically developed with shell elements and a resolution corresponding to the coarse model shown in Figure 2-14. Therefore, the measured engineering elongation of the specimens was used for the critical strain. Additional modification for the weld regions, with significant stress concentrations, is described below in Section 2.3.2. 


\subsubsection{Weld Zone Constitutive Modeling}

Photographs of the WTC towers immediately after impact, and inspection of the recovered exterior wall panels in the impact zone, have shown that failure along the weld heat affected zone (HAZ) was a characteristic feature of the impact damage. An example exterior column from the impact zone that had significant fractures along the weld zone for the outer web is shown in Figure 2-16. Inspections of the weld zone failures indicated that these fractures were either brittle or very low energy ductile fractures (small plastic strains in the fracture zone). As a result, the amount of energy dissipated by these HAZ fractures was very small compared to the overall impact energy. The failure of the welds had little effect on the subsequent damage to the interior structures and contents of the towers. However, to capture the damage mechanisms of the impacted exterior columns and to develop models and failure criteria for the global impact analysis, a failure model for the weld zone was required.

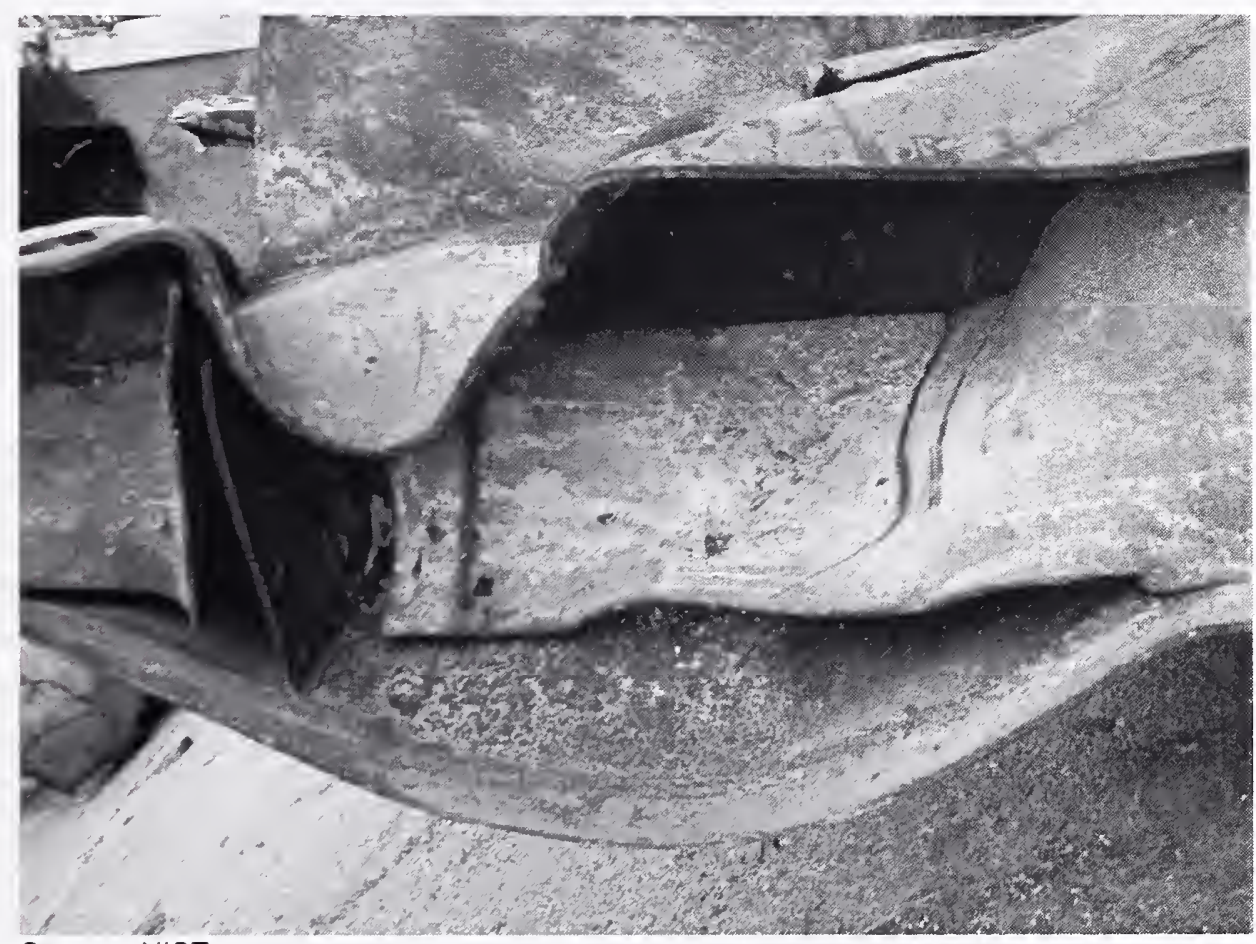

Source: NIST

Figure 2-16. Photograph of an exterior column with weld zone fractures.

Modeling of the constitutive behavior for the weld and HAZ material is a challenging task due to the lack of significant material testing in these regions. The data obtained on the weld and HAZ properties consisted of a micrographic characterization of an exterior column weld with microhardness indentation tests performed at various locations across the weld geometry. The specific weld geometry and microhardness characterization locations are shown in Figure 2-17. The corresponding hardness measurements across the base, HAZ, and weld materials are shown in Figure 2-18. 


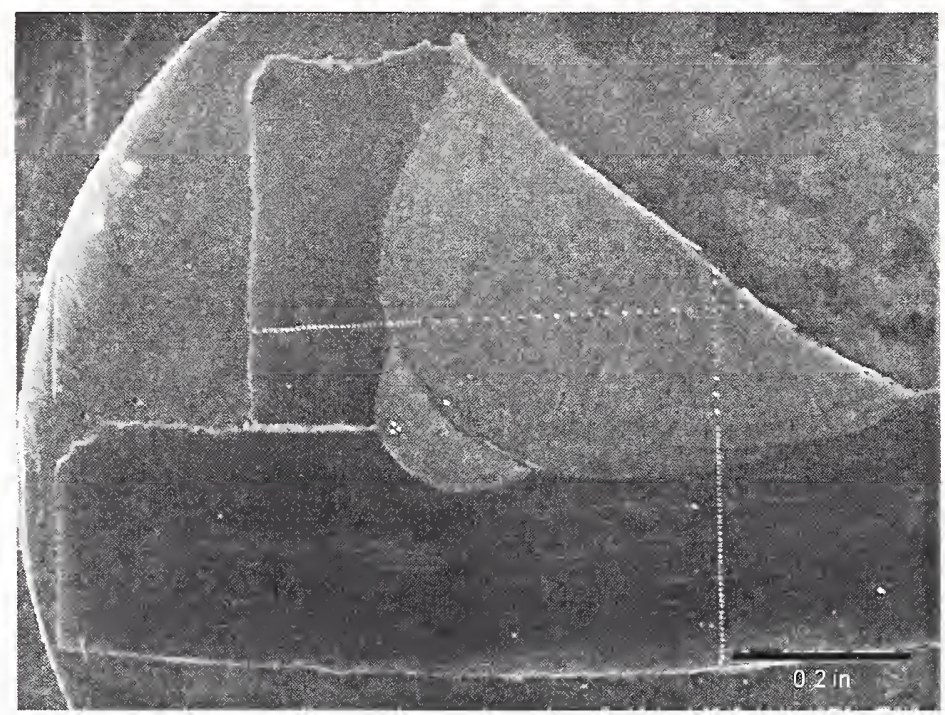

Source: NIST.

Figure 2-17. Micrograph of an exterior column weld geometry.

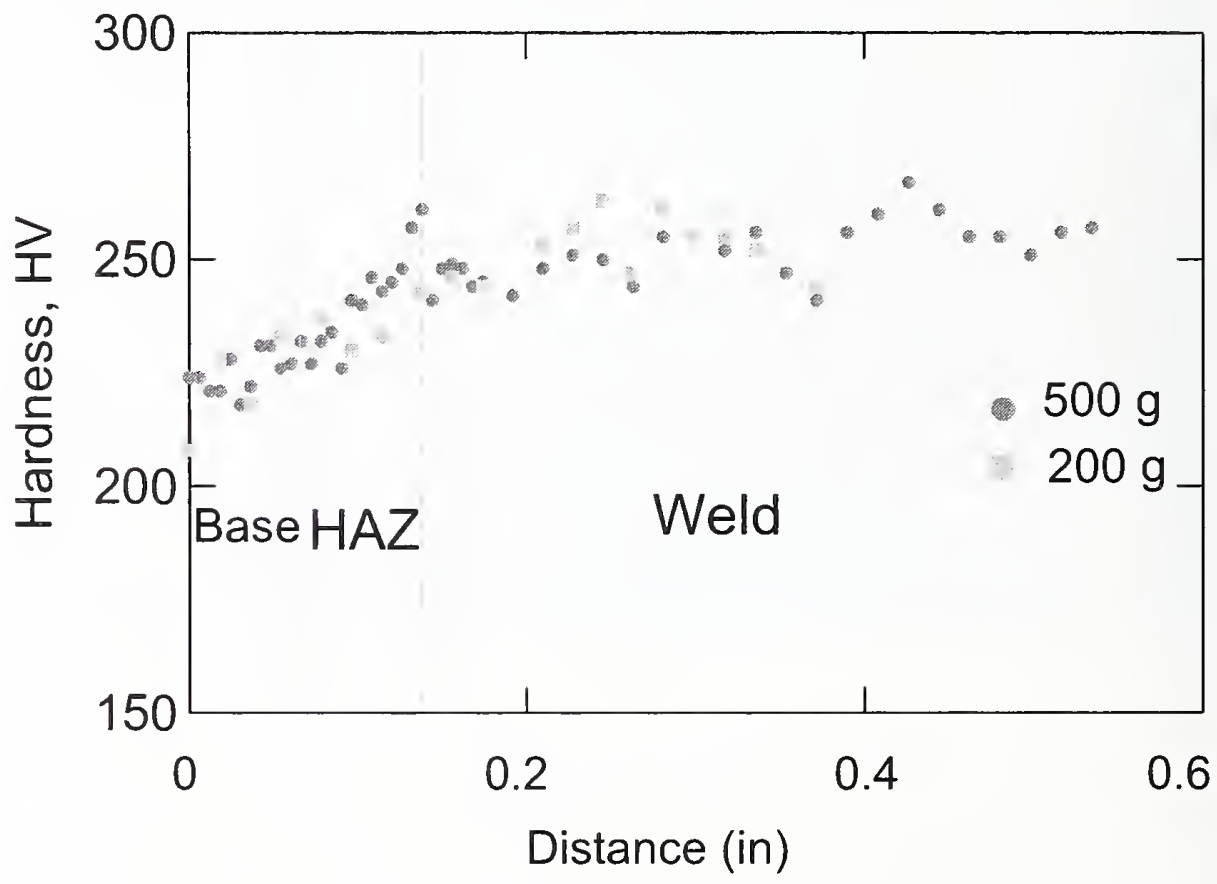

Figure 2-18. Microhardness characterization of the weld and HAZ materials.

Microhardness measurements shown in Figure 2-18 were used to develop approximate plasticity behaviors for the weld and HAZ material regions. The flow stresses of the HAZ and weld materials were increased from that of the base material by 12 percent and 18 percent, respectively. These shifts correspond to the relative magnitude of the average measured hardness in each material region. 
The remaining stage in developing the weldment failure model was to perform three-dimensional component impact analyses of the external column and develop a coarser shell element description of the weld region that could be applied in the global aircraft impact analyses. The problem analyzed was the drop test configuration shown in Figure 2-19. The drop test configuration had a $550 \mathrm{lb}$ steel impactor with an impact speed of $37.4 \mathrm{mph}$. The impactor was $12 \mathrm{in}$. wide and $5 \mathrm{in}$. across. The nose of the impactor had a reduced area, that is $12 \mathrm{in}$. wide and $2 \mathrm{in}$. across, with a $1 / 2 \mathrm{in}$. radius rounded edge around the impact face. The length of the column section represented a portion of an exterior column between spandrels.

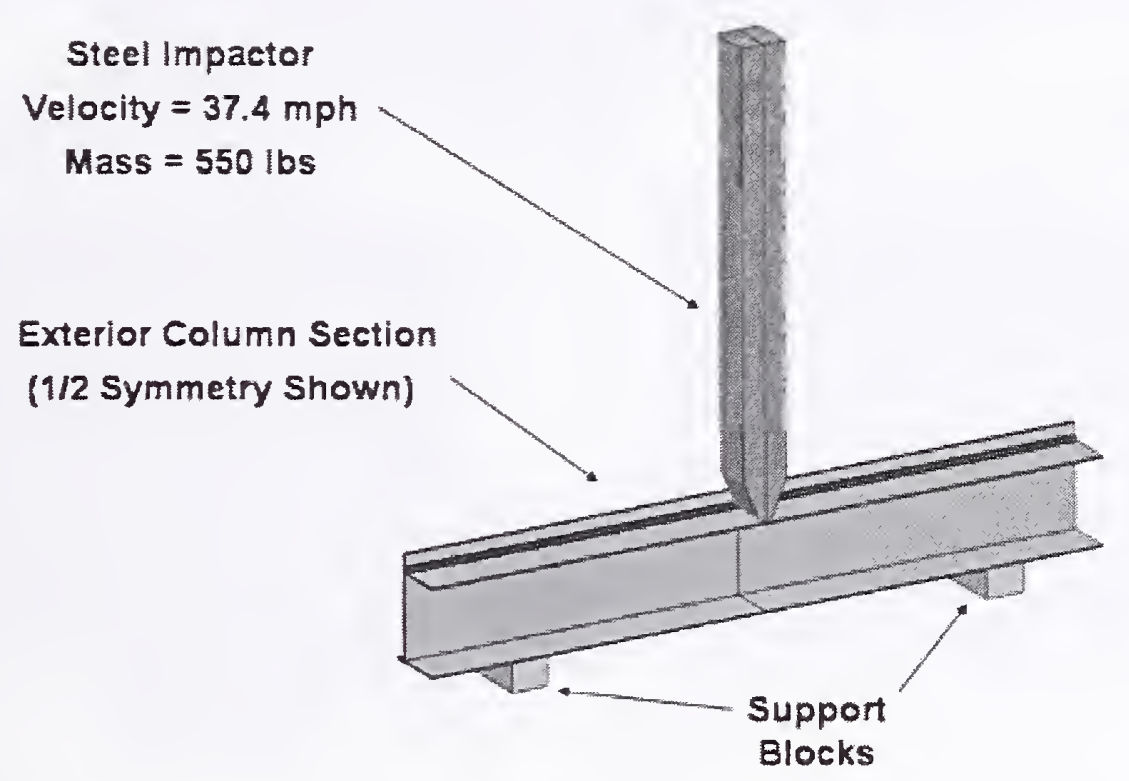

Figure 2-19. Drop test model for column weld fracture analysis.

The two different column models used for the weld zone failure analysis are shown in Figure 2-20. The brick element model had a mesh similar to the medium resolution tensile specimen model shown in Figure 2-13(b). This quarter-symmetry brick element column model contained 63,680 linear solid elements. The coarse shell element model had approximately 4 in. elements to define the column and 1 in. wide elements in the weld zone. The quarter-symmetry coarse shell element column model contained 144 linear shell elements. Obviously, the coarse shell-element model was not able to capture the stress and strain gradients in the weld zone to the same extent as the brick element model.

The drop test was simulated first using both the brick and shell element models. The results of the calculated impact response and failure were used to determine an upper bound for the failure strain of the weld zone. The strain profiles calculated in elements across the web in the weld region are plotted in Figure 2-21 (each black dot in the figure corresponds to a specific element plastic strain magnitude). The figure shows that the brick element model calculated a strong gradient in strain, with the peak strains near the toe of the weld, that were several times larger than the average strain in that region. The corresponding shell element model could calculate only a single strain value for the $1 \mathrm{in}$. wide weld zone as shown by the red line in Figure 2-21. 
An average critical strain of approximately one-quarter of that in the corresponding base metal was selected for the $1 \mathrm{in}$. wide single shell element weld zone. This weld zone failure strain was 8 percent in the current example ( $55 \mathrm{ksi}$ steel). The comparison of the resulting impact behavior for the brick and shell element models is shown in Figure 2-22. Both models had similar impact deformations, and the length of the weld failures were in good agreement. These analyses provided an upper bound value for the engineering fracture criteria in the weld region. Additional investigation of the weld failure and the effects of a more brittle fracture response were investigated in the subassembly analyses (Section 6.3.2). These subassembly impact analyses demonstrated that the weld zone fracture criterion had a negligible effect on the impact energy absorption and little significance on the impact damage.

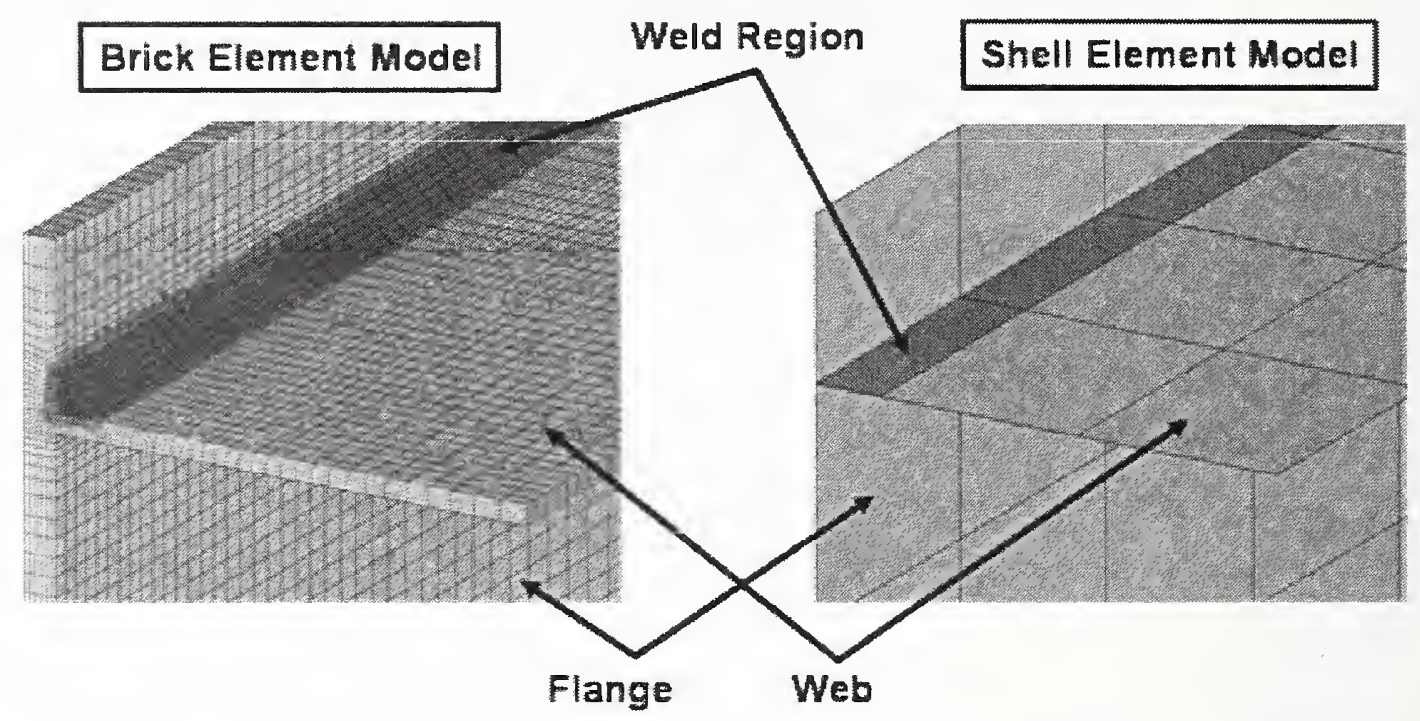

(a) Medium mesh resolution

(b) Coarse mesh resolution

Figure 2-20. Models developed for column weld fracture analysis.

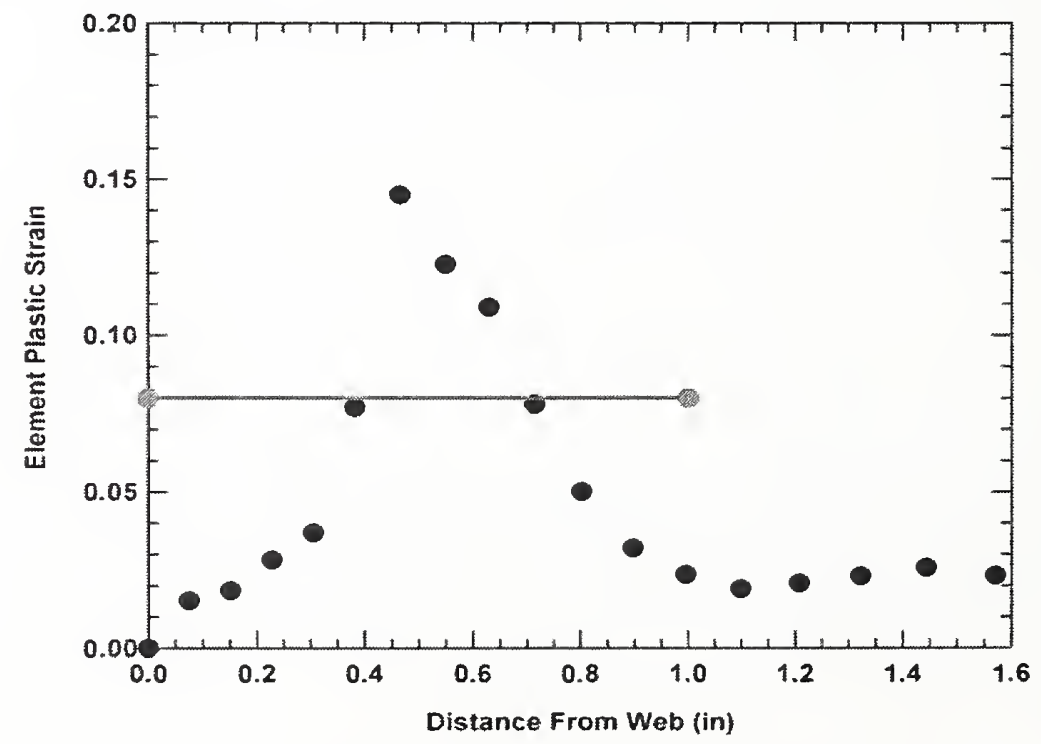

Figure 2-21. Calculated energy balance for the 2-D weldment models. 


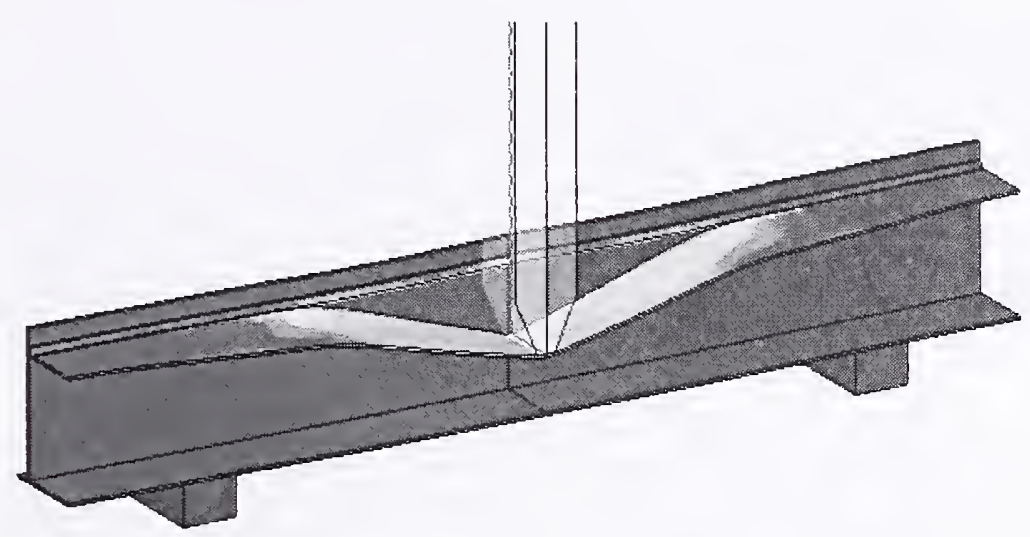

(a) Medium resolution brick element model

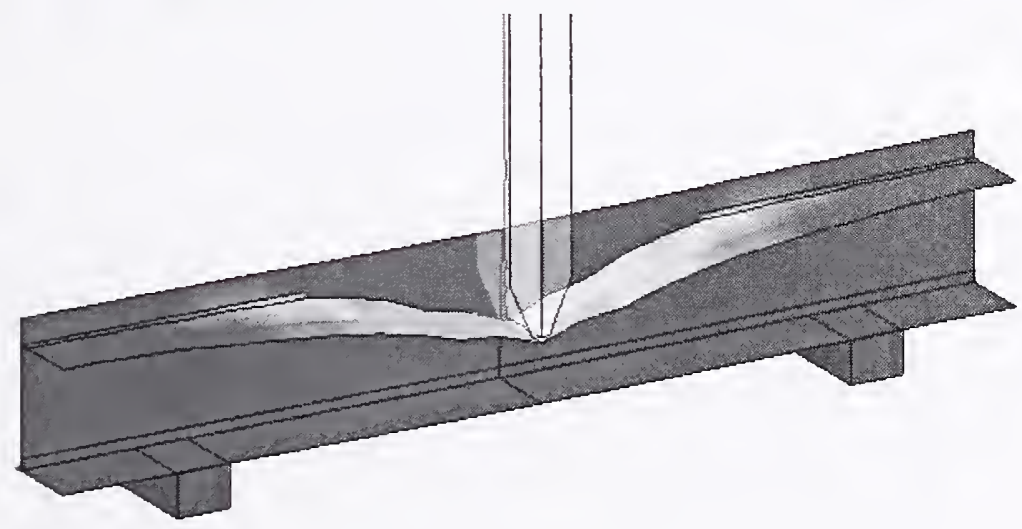

(b) Coarse resolution shell element model

Figure 2-22. Calculated drop test fracture behavior.

\subsubsection{Bolt Material Constitutive Modeling}

The primary bolts of interest for the impact analysis were those used at the connections between the exterior columns of the WTC towers. Within the impact zone, the connections were typically made using 0.875 in. diameter grade A325 steel bolts. Initially, there were no test data available that could be applied to develop a bolt model. The modeling approach was to develop a brick element model of the bolt and use it to develop a corresponding beam element bolt model for the majority of the impact analyses. A description of these bolt analyses are given in Section 5.2.3, along with the component analyses.

Subsequently, a series of tests was performed as part of the NIST mechanical and metallurgical analysis on bolts recovered from the WTC towers (NIST NCSTAR 1-3). A summary of the bolt testing is given in Figure 2-23. The bolts were found to yield at a load of approximately $50 \mathrm{kip}$ and to have an ultimate failure load of approximately $68 \mathrm{kip}$. The measured elongation at failure was approximately $0.18 \mathrm{in}$. The bolts did not exhibit any significant strain rate dependency. 


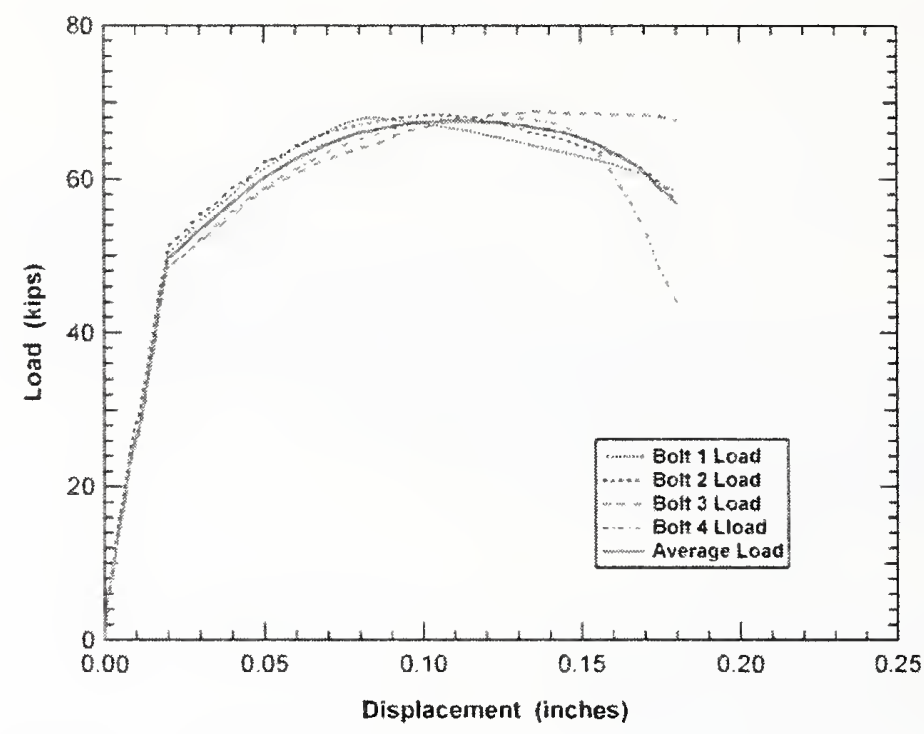

Figure 2-23. Measured bolt load-displacement behavior.

The beam element model for the bolt, described in Section 5.2.3, was compared to the bolt test data. The comparison showed good agreement in the strength of the bolt, but it also indicated that the beam model overestimated the ductility. This may be a result of not capturing the details of the stress concentrations in the region of the threaded connection and nut. The bolt test data were used to correct the ductility of the beam element bolt model, and the resulting comparison of the model and test data is shown in Figure 2-24. The bolt model shows a bilinear elastic-plastic behavior that is stiffer in the elastic region and yields at a higher stress level than the data. The inability of the simplified model to capture stress gradients in the regions of the bolt head, threads, and nut may cause this type of response. However, the overall strength and ductility of the model and data, as well as the strain energy capacity, agreed reasonably well so that further model development was not required.

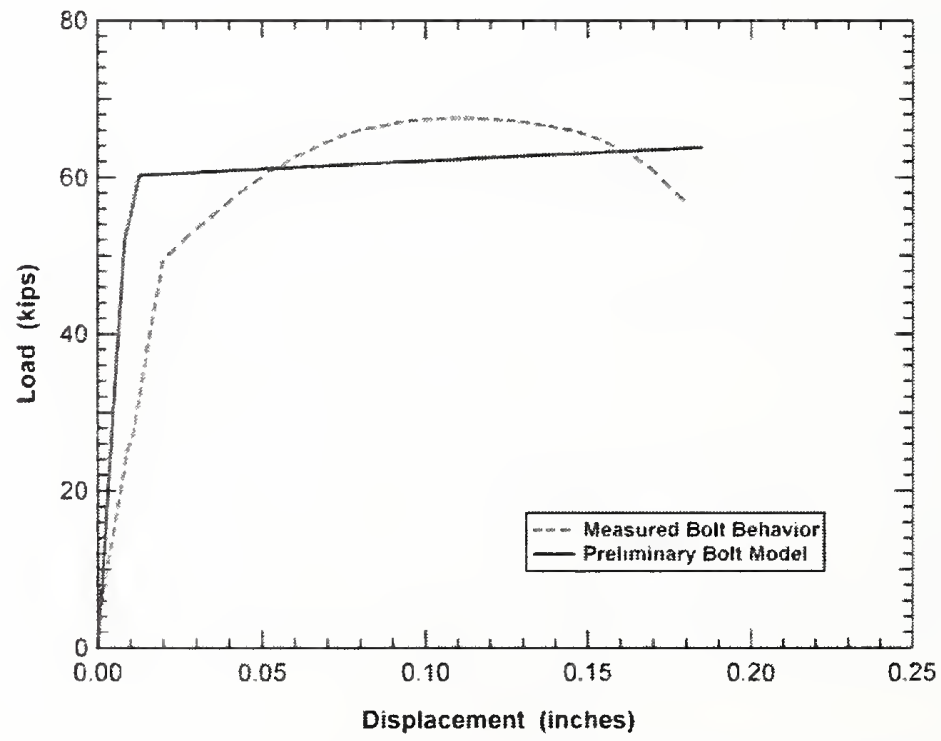

Figure 2-24. Comparison of the measured and calculated bolt behavior. 


\section{$2.4 \quad$ CONCRETE CONSTITUTIVE MODELS}

There are several concrete models in LS-DYNA. Each has different capabilities for modeling rate effects and nonlinearity associated with damage and failure behavior. Potential concrete models in LS-DYNA include Types 5 (soil and crushable/non-crushable foam model), 16 (pseudo-tensor concrete model), 25 (kinematic hardening cap model), 78 (soil and concrete model), 84 (Winfrith concrete model) and 111 (Holmquist-Johnson-Cook concrete model). An important factor in determining the behavior of a concrete structure in compression or bending is its lateral confinement. The concrete floor slabs in the WTC towers were not highly confined, therefore, a material model suitable for this loading condition was needed.

In this study, the ability to accurately model the damage and softening behavior of concrete associated with low confinement conditions is important. Damage caused by cracking in the concrete degrades the strength in the low confinement regime. Inclusion of this damage growth provides a more accurate representation of the stress-strain response. Based on this capability, the LS-DYNA material Type 16 (pseudo-tensor concrete model) was selected for modeling the concrete floor slabs. This model also accounts for the sensitivity of concrete to high strain rates.

As implemented in LS-DYNA, the pseudo-tensor model can be operated in two major modes: (1) a simple tabular pressure-dependent yield surface, and (2) a complex model with two pressure-dependent yield functions and a damage-dependent function to migrate between curves. The first option is well suited for modeling standard geologic material behaviors such as a Mohr-Coulomb yield surface with a Tresca limit and has been used successfully for the analysis of ground shock and soil-structure interactions under high confinement. The second option, applied in this study, allows for implementation of tensile failure and damage scaling, which are more dominant material behaviors at low confinement.

The pseudo-tensor model, as applied to the analysis of the lightweight concrete in the WTC towers, has two pressure dependent yield functions in the form:

$$
\sigma_{y}(p)=a_{0}+\frac{p}{a_{1}+a_{2} p}
$$

These yield functions are shown graphically in Figure 2-25, where the upper curve describes the maximum yield strength and the lower curve is the failed material curve. By defining suitable yield functions for the undamaged and fully damaged concrete and an appropriate tabular interpolation between the curves, the damage behavior under low confinement can be captured. For a detailed description of the model, the reader is referred to the LS-DYNA user's manual (2003). 


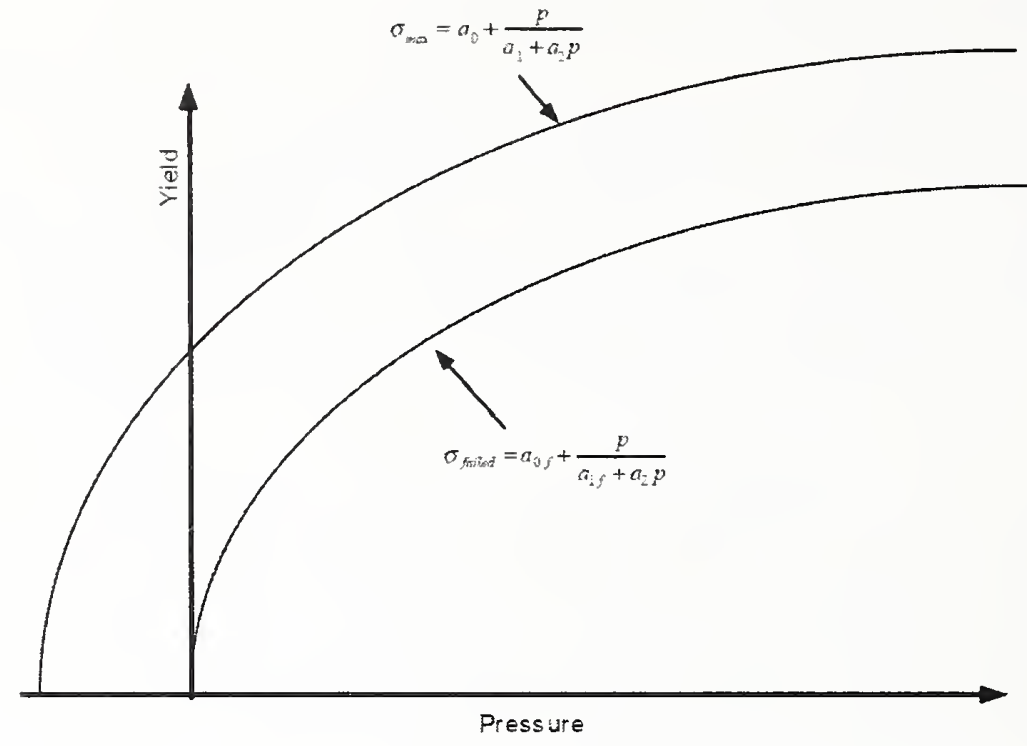

Source: Reprinted from "LS-DYNA User's Manual," Livermore Software Technology Corporation, Version 970, April 2003, Figure 20.6, page 20.70, with permission from Livermore Software Technology Corporation.

Figure 2-25. Intact and completely damaged concrete strength as a function of pressure.

Material constitutive parameters for the pseudo-tensor model, Equation (6) and Figure 2-25, were developed for both $3 \mathrm{ksi}$ and $4 \mathrm{ksi}$ compressive strength lightweight concrete, as shown in Table 2-2. A tensile cutoff with a 500 psi tensile strength was used for this model. In the absence of experimental data on the concrete, a simulation was performed of a standard unconfined concrete compression test to check the constitutive model behavior. The simulated behavior of the concrete specimen is shown in Figure 2-26. The calculated compressive stress-strain response for the $3 \mathrm{ksi}$ concrete is compared to measured compression data for $2.3 \mathrm{ksi}$ and $3.8 \mathrm{ksi}$ strength concretes in Figure 2-27 (Wischers 1978). The same material parameters were used for the concrete in both the core (normal weight concrete) and truss floor (lightweight concrete) areas.

Table 2-2. Strength parameters for the concrete material model.

\begin{tabular}{|lc|c|c|}
\hline \multicolumn{2}{c|}{ Strength Parameter } & $\boldsymbol{f}_{\boldsymbol{c}}{ }^{\prime}=\mathbf{3 ~ \mathbf { ~ k s }}$ & $\boldsymbol{f}_{\mathbf{c}}=\mathbf{4} \mathbf{~ k s i}$ \\
\hline $\mathrm{a}_{0}$ & $(\mathrm{psi})$ & 750 & 1000 \\
$\mathrm{a}_{1}$ & & 0.333 & 0.333 \\
$\mathrm{a}_{2}$ & $(\mathrm{psi})^{-1}$ & $1.11 \mathrm{E}-04$ & $8.33 \mathrm{E}-05$ \\
$\mathrm{a}_{0 \mathrm{f}}$ & $(\mathrm{psi})$ & 0.0 & 0.0 \\
$\mathrm{a}_{1 \mathrm{f}}$ & & 0.385 & 0.385 \\
\hline
\end{tabular}




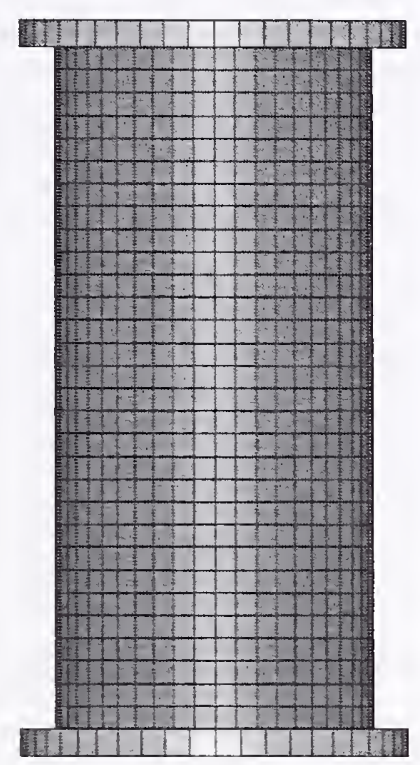

Initial configuration

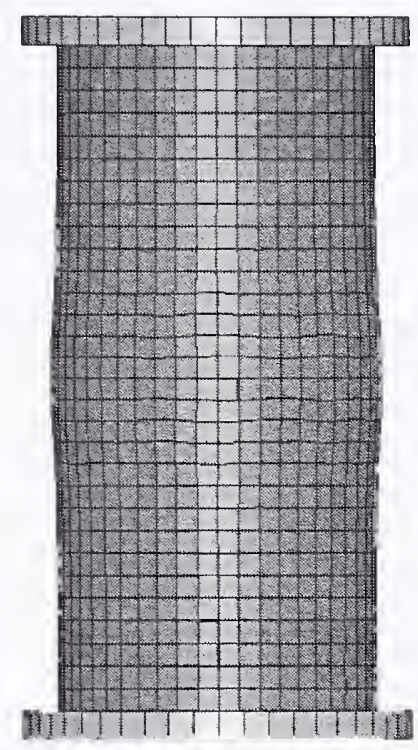

2 percent compression

Figure 2-26. Finite element analysis of the unconfined compression test.

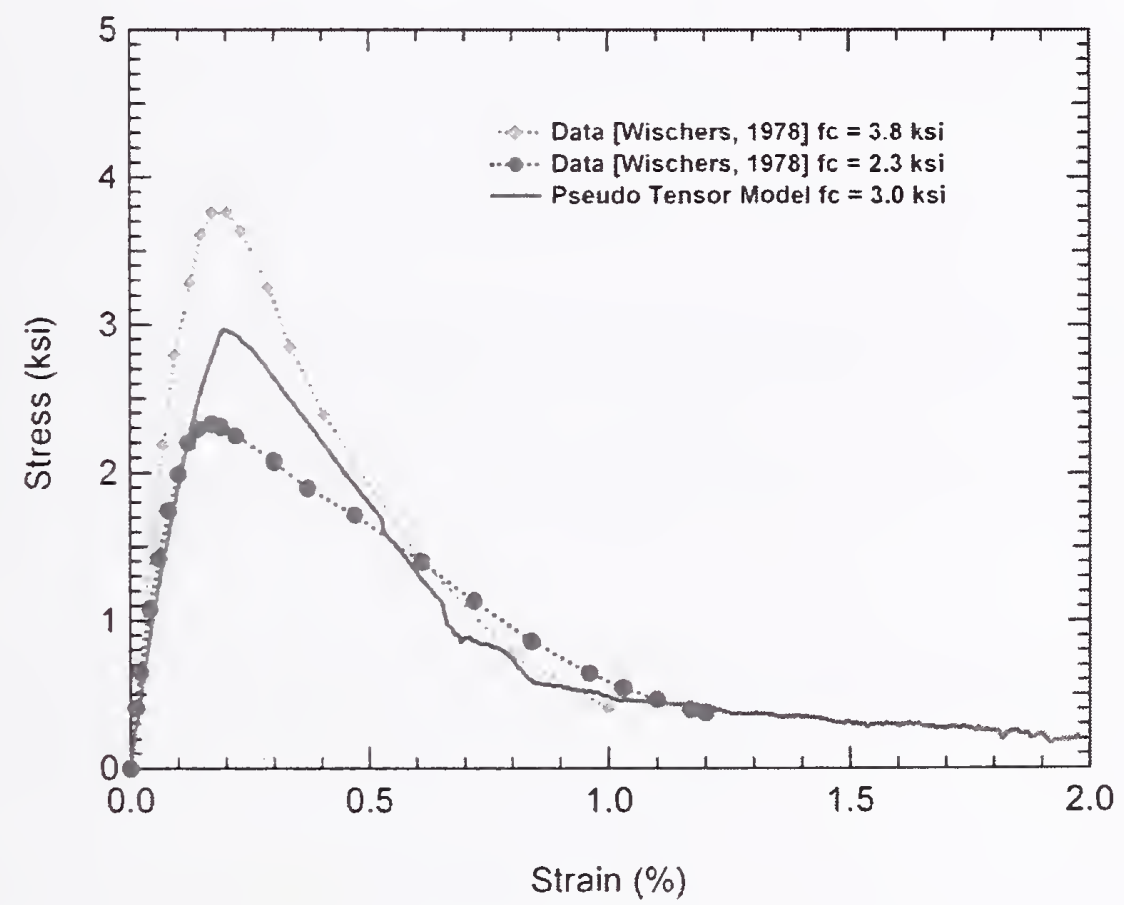

Figure 2-27. Comparison of the calculated unconfined compression behavior with concrete compression test data.

An additional comparison of the calculated compressive behavior to the stress-strain curve for the lightweight concrete response (Phan 1996) is shown in Figure 2-28. The agreement is good up to the 
peak load point. The softening behavior was not specified beyond the requirement for the zero stress point corresponding to 2 percent strain. The calculated nonlinear softening behavior is typical of concrete materials. For subsequent global analyses, a $4 \mathrm{ksi}$ concrete was used, instead of the $3 \mathrm{ksi}$ concrete strength specified in the original design (NIST NCSTAR 1-6), to account for factors such as aging and difference between specified nominal and actual concrete strength. The pseudo-tensor model was then modified to have an unconfined compression strength of $4 \mathrm{ksi}$, as shown in Figure 2-29.

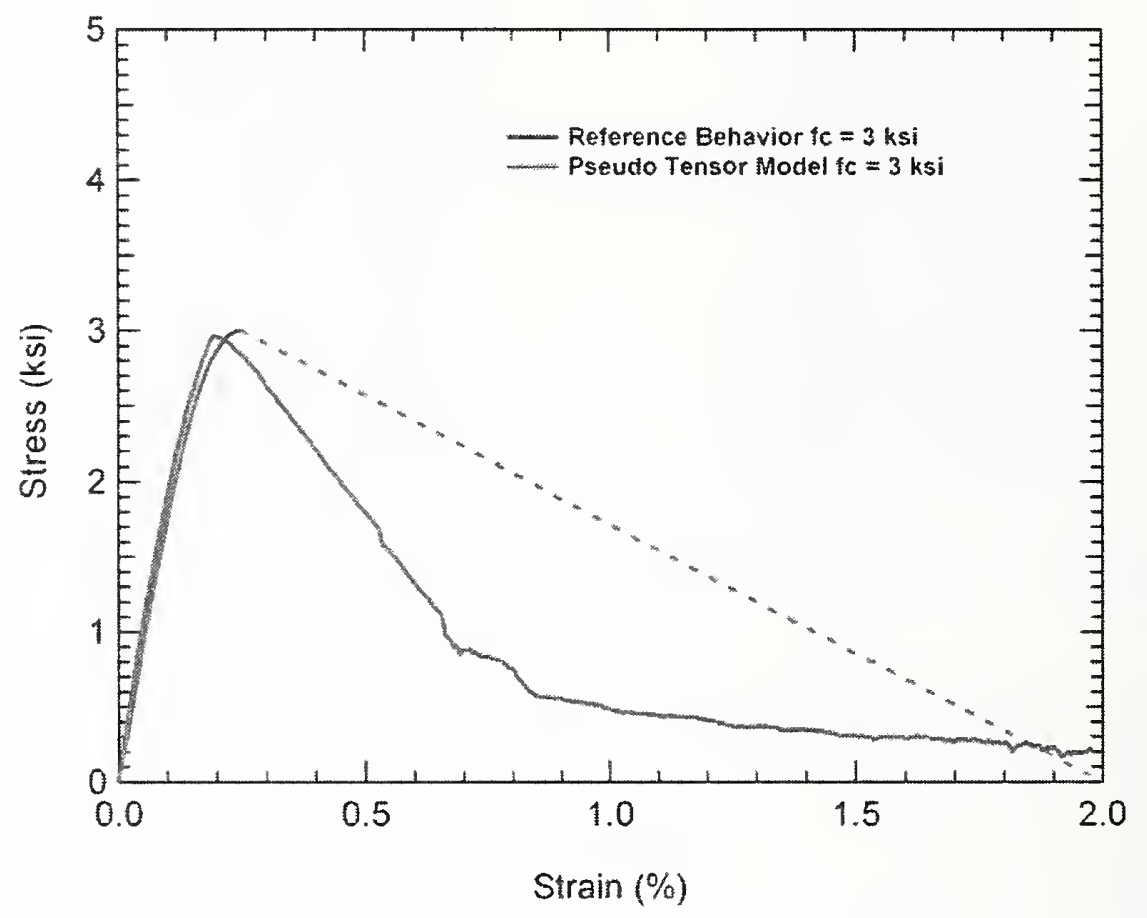

Source: Phan 1996.

Figure 2-28. Comparison of the calculated unconfined compression behavior with lightweight concrete behavior. 


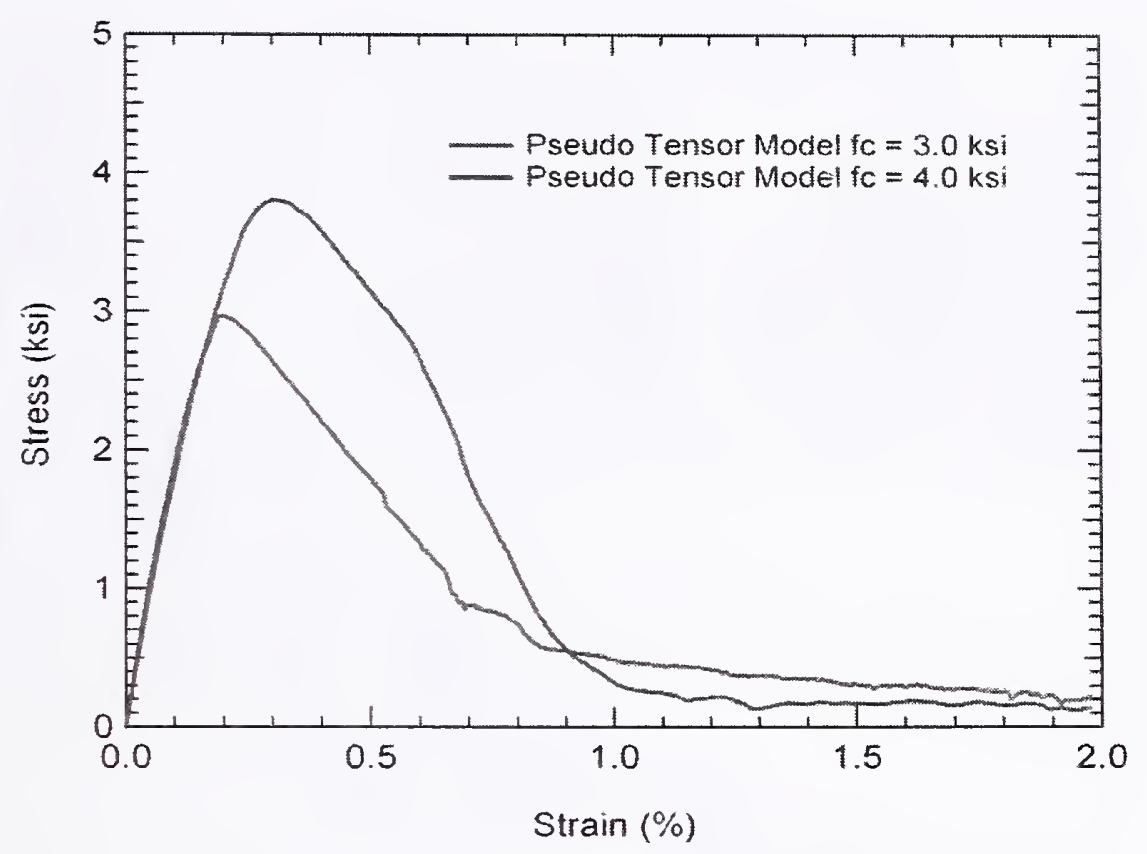

Figure 2-29. Comparison of the calculated unconfined compression behavior of $3 \mathrm{ksi}$ and $4 \mathrm{ksi}$ concrete.

Experimental characterization of the strain rate effects on concrete behavior is difficult, and there is a wide scatter in data that is influenced by concrete type, strength, and the testing methods applied. In general, elevated strain rate loading has a greater influence on the tensile strength than on the compressive strength. However, in the aircraft impact response of the WTC towers, the majority of the high-rate damage occurs with impact and penetration of the floor slab by hard components such as the engine. As a result, the strain rate effects for compressive loading were used for the constitutive model.

A collection of compressive strength data for elevated rates is shown in Figure 2-30 (Bischoff and Perry, 1991) and Figure 2-31 (see Ross et al., 1992). There is still a large scatter in the measured rate effects under compressive loading. In general, the effects of strain rate increase gradually up to a rate of approximately $30 \mathrm{~s}^{-1}$. Beyond a rate of $30 \mathrm{~s}^{-1}$, the compressive strength is more sensitive to strain rate. The majority of the aircraft impact damage to the concrete is expected to occur at loading rates below $30 \mathrm{~s}^{-1}$.

The strain rate effects were added to the model in tabular form. The rate effects curve used in the model is shown in Figure 2-32. The curve was selected to provide a relatively smooth fit to the available compressive rate effects data on compressive strength. 


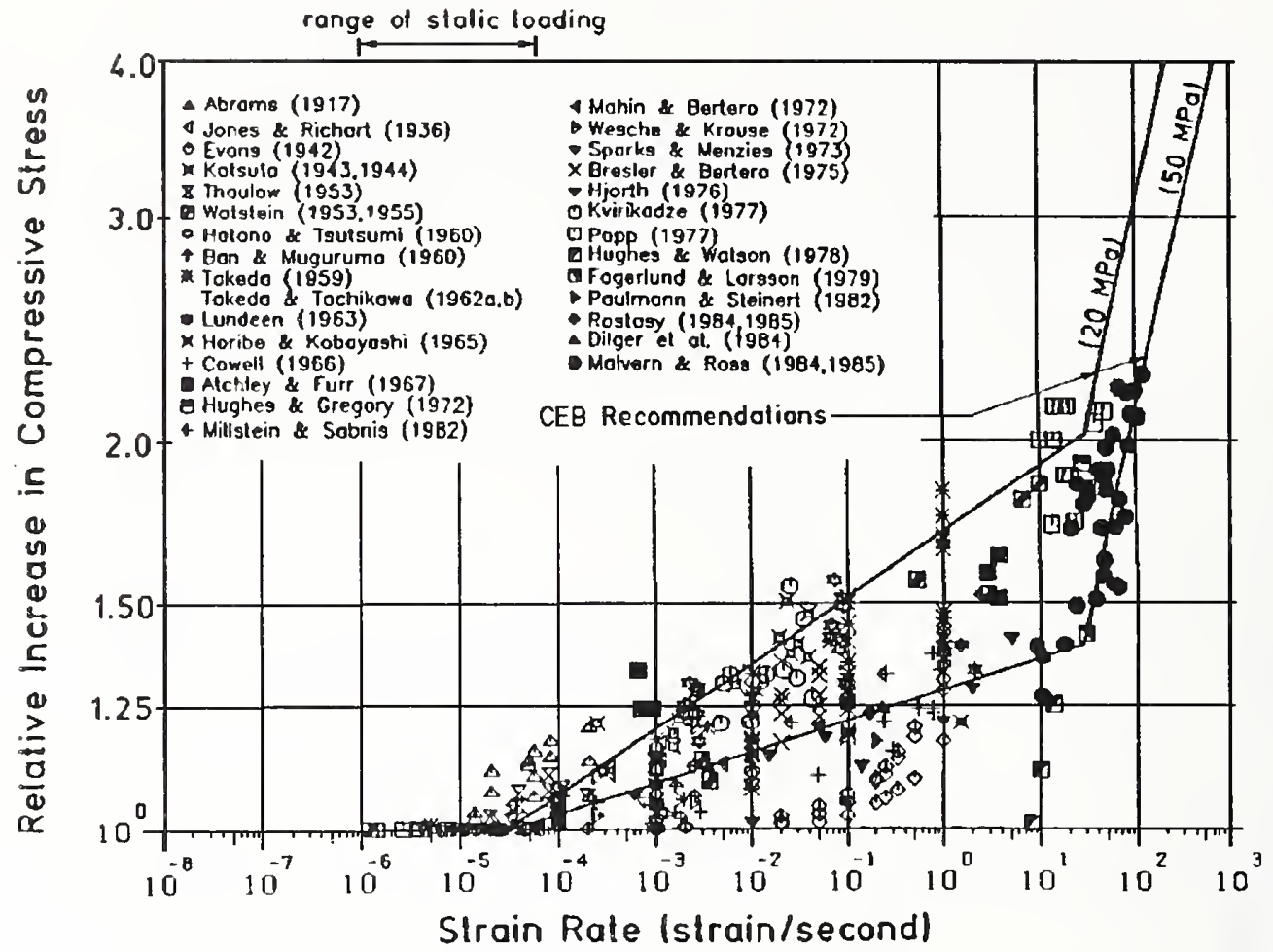

Source: From "Compressive behavior of concrete at high strain rates," published in Mater. Struct. 24 (1991) Courtesy RILEM.

Figure 2-30. Strain rate effects on concrete compressive strength.

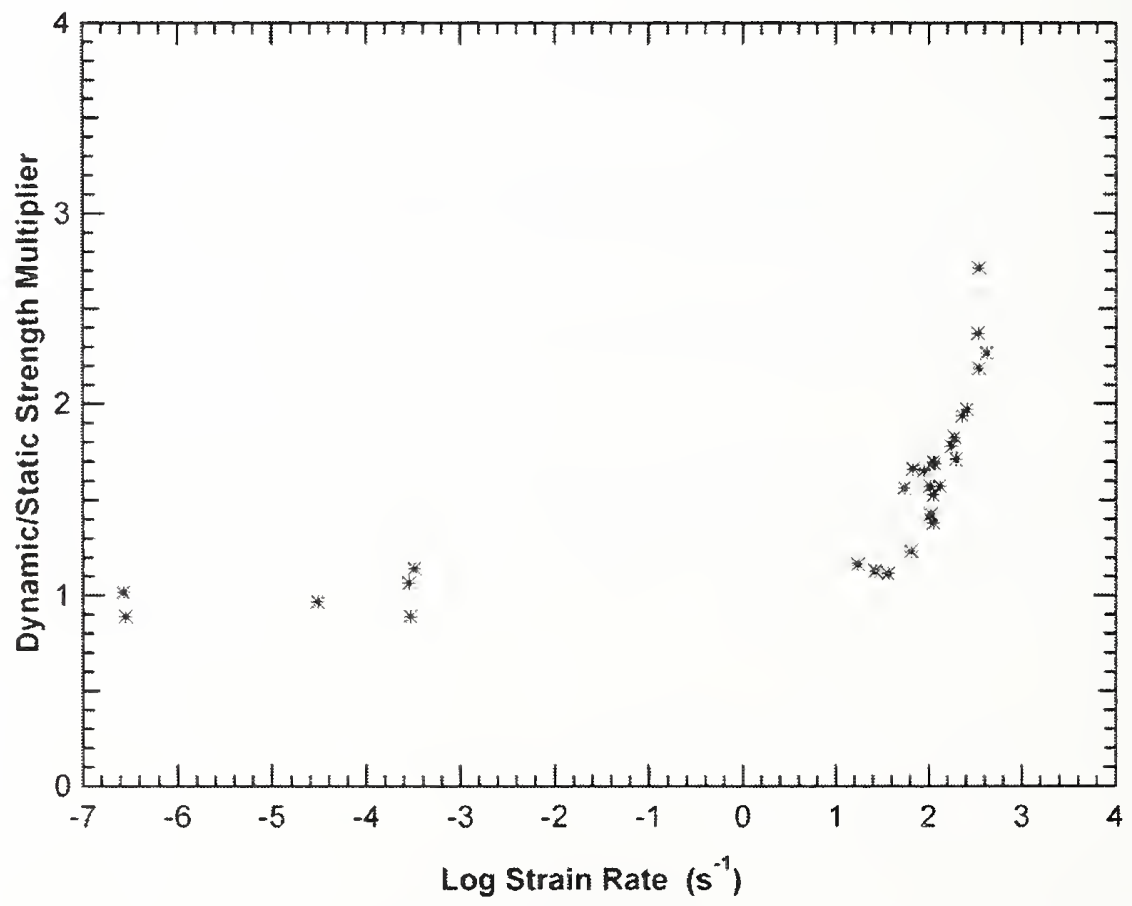

Figure 2-31. Strain rate effects on concrete compressive strength. 


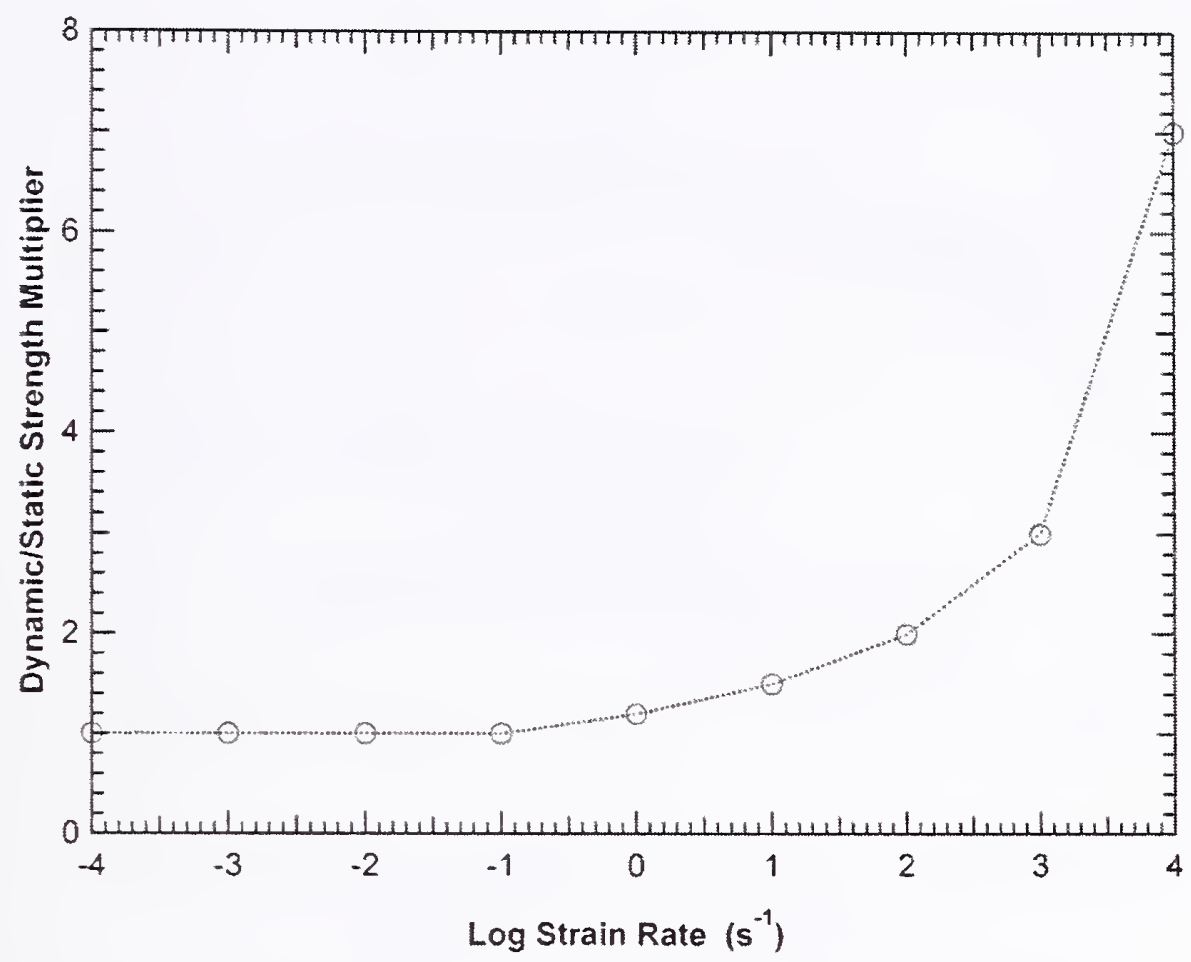

Figure 2-32. Tabular concrete strain rate effects curve.

\subsection{AIRCRAFT MATERIALS CONSTITUTIVE MODELS}

No material testing was performed to characterize the structural materials in the aircraft or develop the constitutive model parameters for these materials. Therefore, the constitutive and failure properties for the aircraft materials were developed from data available in the open literature. The principal sources of data for the airframe materials are the Military Handbook (MIL-HDBK-5F, 1987), and the Aerospace Structural Metals Handbook (Brown et al. 1991). Additional sources of data were used to verify and supplement the information obtained from these primary data sources.

Complete engineering stress-strain curves were provided in the MIL-HDBK-5F for various 2024 and 7075 aluminum alloys that are commonly used in the construction of the Boeing 767 airframe structures. These curves were digitized for the various 2024 and 7075 alloys as shown in Figure 2-33 and Figure 2-34, respectively. Representative stress-strain curves were then converted into true stress and true strain, as described in Section 2.2.1, and used to develop tabular curves for constitutive models. The calculated true stress-strain curves and tabular constitutive model fits are shown in Figure 2-35 and Figure 2-36, respectively. Appropriate failure criteria for the aircraft materials were developed using the fine and coarse wing component models discussed in Section 5.5.1.

Insufficient data were available on the effects of strain rates on the behavior of aircraft materials to determine appropriate values for the parameters for the Cowper and Symonds model. As a result, no rate sensitivity of the aircraft materials was explicitly included in the aircraft constitutive models.

Alternatively, a larger variation in the strength and ductility of the aircraft materials was included in the uncertainty analyses in Chapter 8 to account for the potential effects of elevated strain rates. 


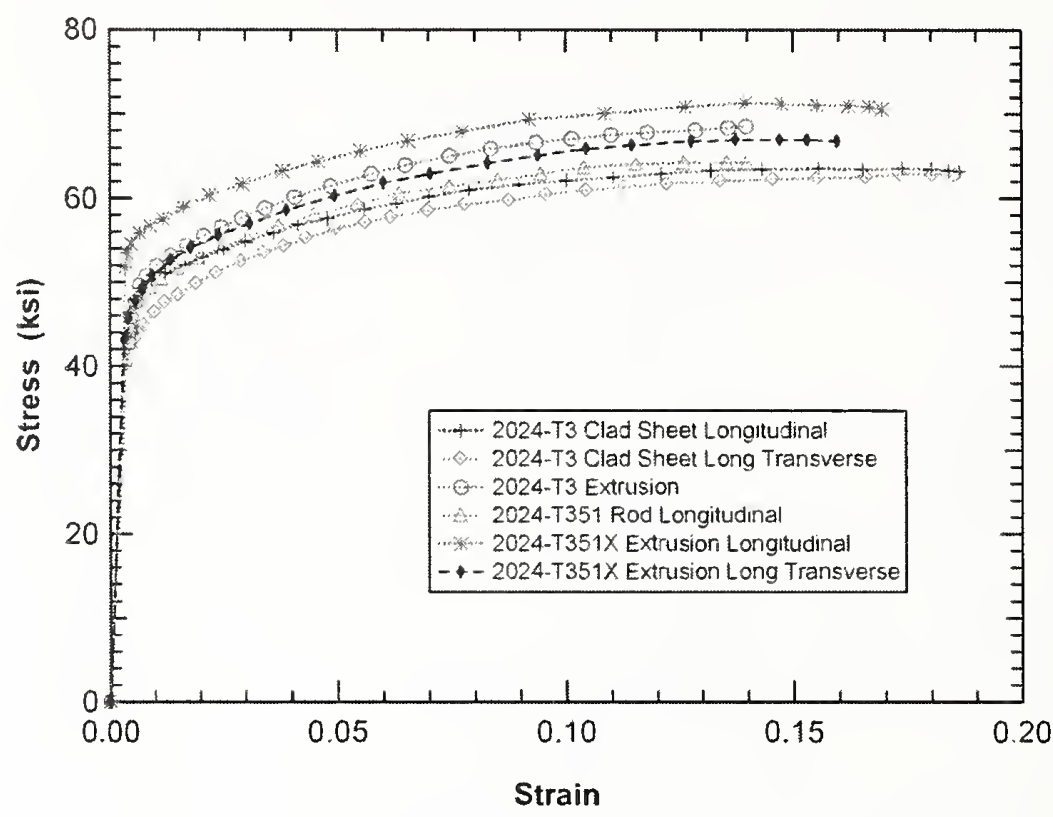

Figure 2-33. Digitized engineering stress-strain curves for various 2024 aluminum alloys.

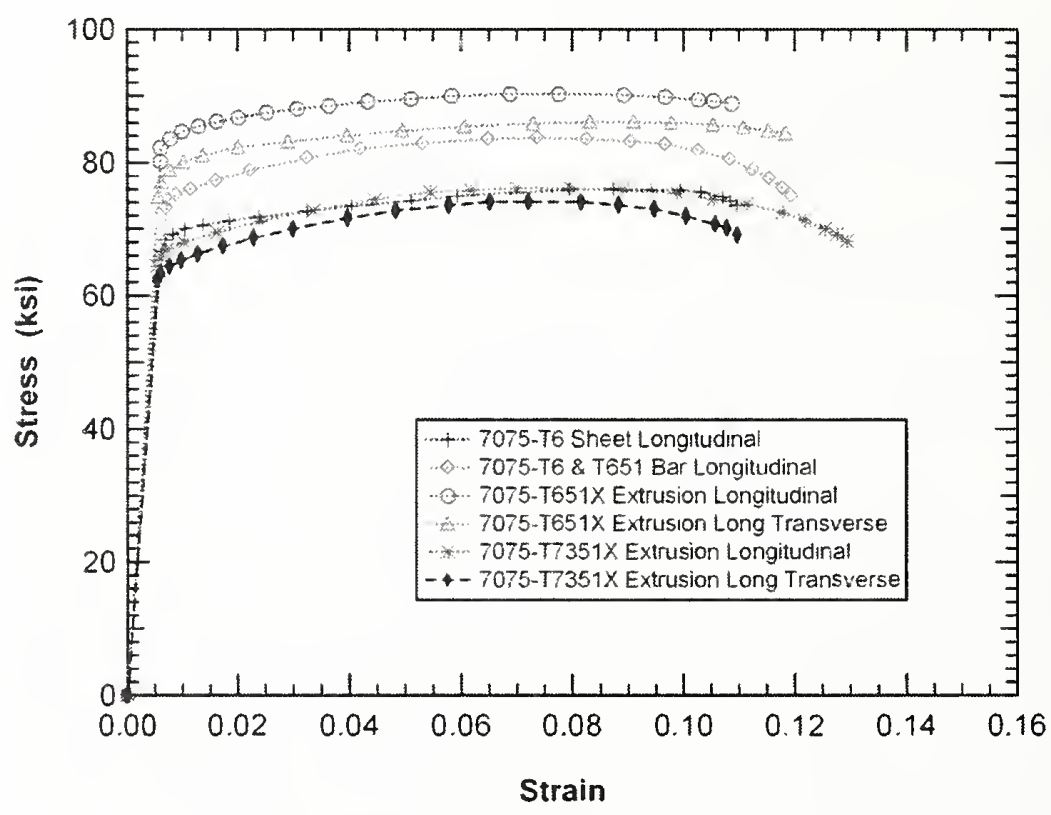

Figure 2-34. Digitized engineering stress-strain curves for various 7075 aluminum alloys. 


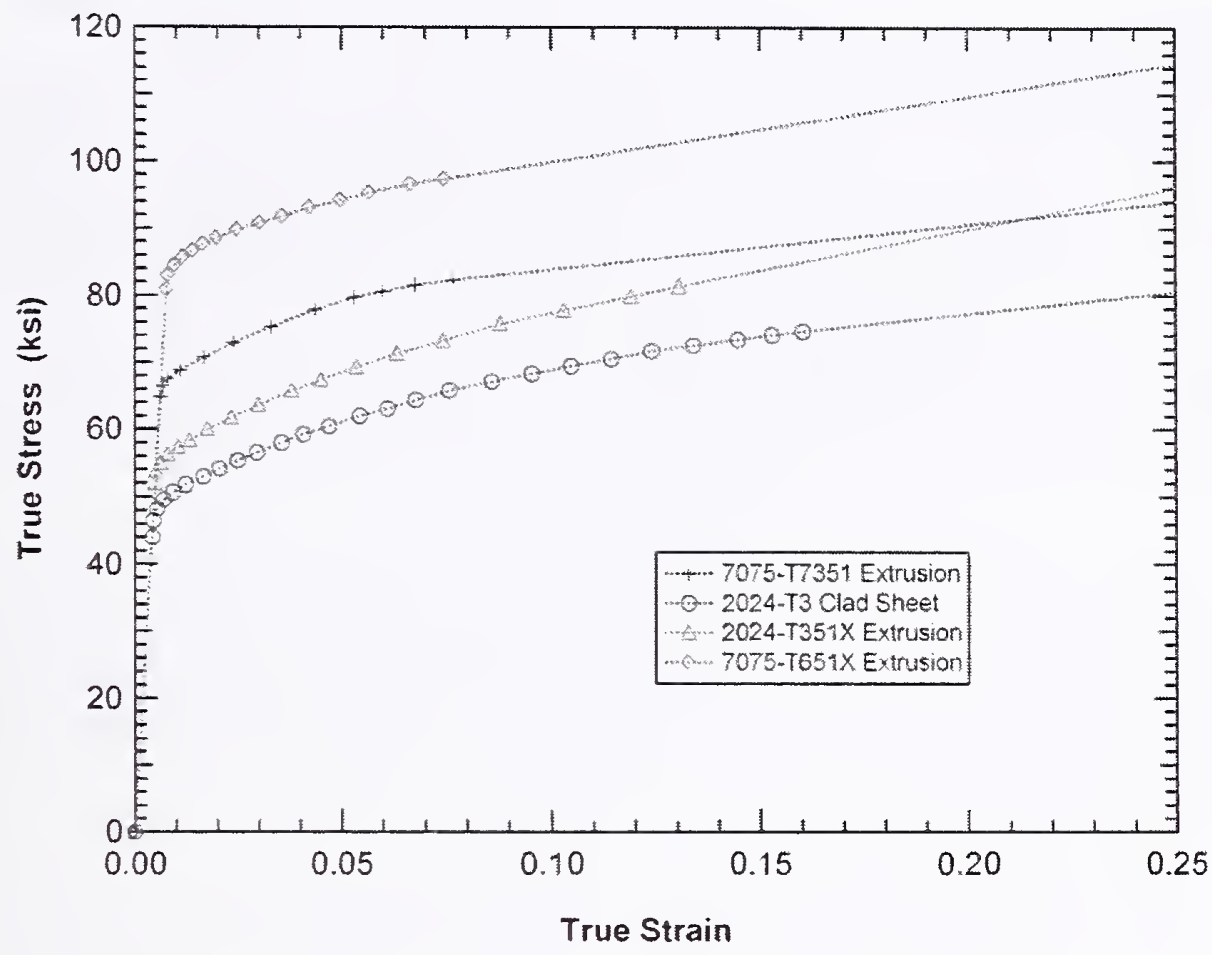

Figure 2-35. True stress-strain curves developed for various aircraft aluminum alloys.

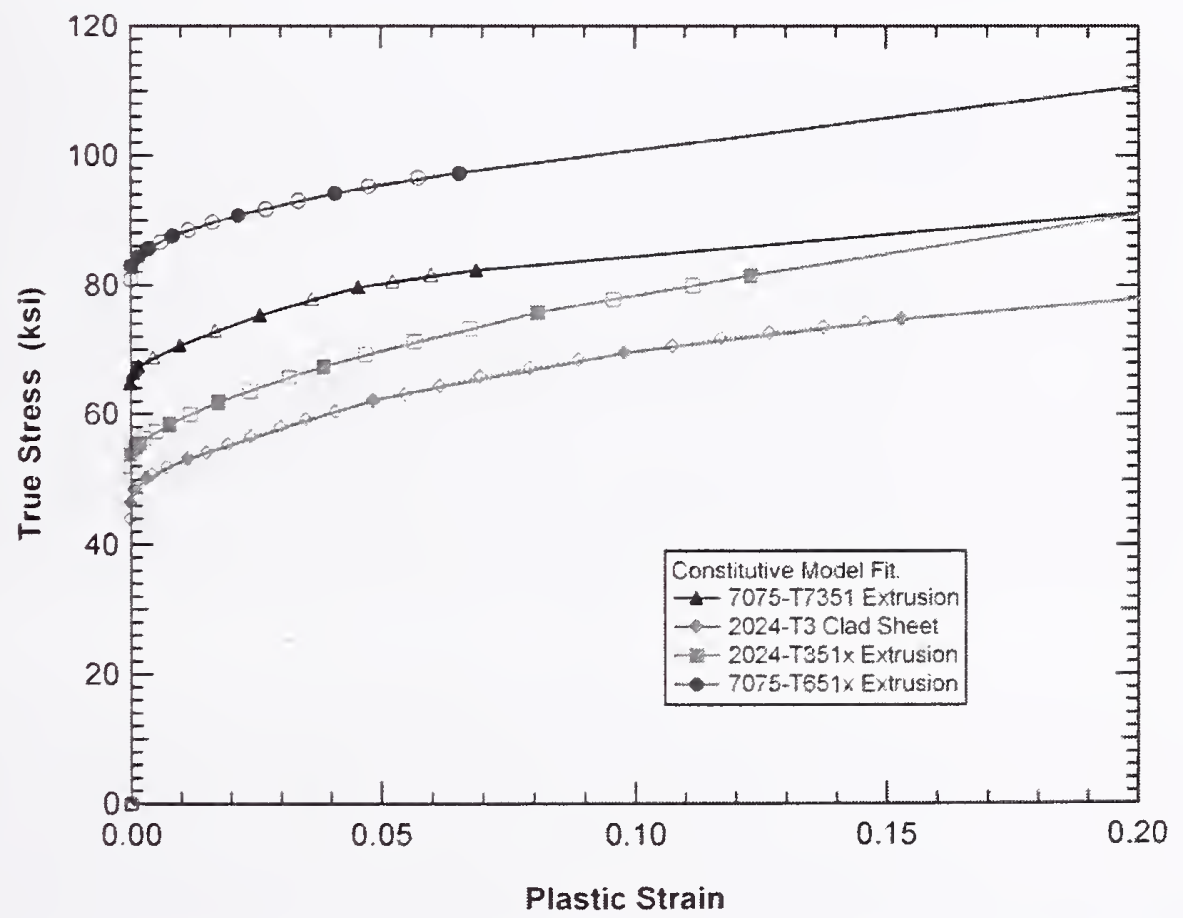

Figure 2-36. True stress-strain curves developed for various aircraft aluminum alloys. 


\subsection{NONSTRUCTURAL MATERIALS CONSTITUTIVE MODELS}

No material testing was performed to characterize the nonstructural materials in the aircraft or tower. These include various components on the aircraft such as the landing gear tires and interior furnishings and the tower contents and nonstructural walls. In general, the primary influence of the nonstructural components on the impact behavior is their inertial contribution (mass). The effects of their strength are small. As a result, relatively simple approximations of their constitutive behavior can be used. Typically, a simple elastic-plastic model was applied for these materials to allow for efficient modeling of deformation and subsequent erosion from the calculations as their distortions become large. The ability to include material failure and erosion of these soft materials is important for the stability of the impact analyses.

The majority of the nonstructural components in the aircraft were not modeled explicitly but were included by distributing their mass into the airframe structures. These aircraft components included the interior wall paneling and fixtures, insulation, wiring, carpeting, etc. Similarly the luggage and cargo mass was distributed into the models for the Unit Load Devices (ULDs or cargo containers). The mass of the seats and passenger compartment cargo were lumped together in a simplified seat model. A bilinear elastic-plastic constitutive behavior was assumed for the effective seats with a yield strength of $1.45 \mathrm{ksi}$ and a failure strain of 40 percent. The relatively large ductility was used to allow for the seats and cargo to be maintained in the simulation sufficiently long to transfer their inertial loading to the impacted tower components. Another nonstructural aircraft component modeled independently was the tires on the landing gear. Again, a bilinear elastic-plastic constitutive behavior was assumed for the tire material with a yield strength of $5.2 \mathrm{ksi}$ and a failure strain of 50 percent.

The primary nonstructural components of the WTC towers included in the impact analyses were the tower contents. Models were developed for the workstations (cubicle partitions, desks, and cabinets) and for the nonstructural walls (partitions) made primarily of gypsum. A search of material properties of the nonstructural building materials (gypsum, wood, engineered materials, etc.) resulted in a wide range of specified properties. Wood strength properties vary greatly with the wood species, grain direction, and loading applied (tension, shear, or compression). For example, maximum shear strengths of various U.S. commercial wood species vary from approximately $800 \mathrm{psi}$ to $2,500 \mathrm{psi}$ (www.woodbin.com). The compression strengths, both parallel and perpendicular to the wood grain, have a significantly larger variation on reported values. Gypsum board properties also vary with thickness and direction with reported Modulus of Rupture values from $220 \mathrm{psi}$ to $970 \mathrm{psi}$ and compressive strength of approximately 400 psi. Engineered materials, such as medium density fiberboard (MDF), used in desk and cabinet construction has a reported Modulus of Rupture on the order of 5,000 psi. Workstation partitions are generally made of a very low density engineered materials and would be expected to have a significantly lower strength.

The constitutive model used for the building contents attempted to obtain an approximate strength for all of the various materials inside the towers. This is complicated by the details of connections in the assembly of workstations, etc. that were not included in the model. A bilinear elastic-plastic constitutive model was used with a yield strength of $500 \mathrm{psi}$ and a failure strain of 60 percent. Again, the large failure strain for these materials was used to prevent large scale erosion of the contents before the momentum transfer from the aircraft debris had occurred. 


\section{$2.7 \quad$ REFERENCES}

ASTM Designation A 370 - 03a, "Standard Test Methods and Definitions for Mechanical Testing of Steel Products," Approved June 10, 2003.

Bischoff, P.H., Perry, S.H.. "Compressive Behavior of Concrete at High Strain Rates," Materials and Structures. vol. 24, 1991, pp. 425-450.

Brown, W. F. Jr., Mindlin, H., and Ho, C.Y., (Eds.). 1991. Aerospace Structural Metals Handbook, CINDAS/Purdue University Publishers, Volumes $3 \& 4$.

FEMA 304, May 2002. World Trade Center Building Performance Study: Data Collection, Preliminary Observations, and Recommendations, Federal Emergency Management Agency.

Kirkpatrick, S.W., Giovanola, J.H., and Simons, J.W., "DYNA3D Analysis of Dynamic Fracture of Weldments," IA'96, Proceedings of International Seminar on Quasi-Impulsive Analysis, Nov. 20-22, 1996, Osaka, Japan, pp. A6.1-15, K. Wakiyama, E. Tachibana, K. Imai and T. Kitano Eds.

"LS-DYNA Keyword User"s Manual.” 2003. Livermore Software Technology Corporation, Version 970, April.

Military Handbook. 1987, Metallic Materials and Elements for Aerospace Vehicle Structures, U.S. Dept. of Defense, MIL-HDBK-5F.

Phan, L.T. 1996. "Fire Performance of High-Strength Concrete: A Report of the State-of-the Art," NISTIR 5934, Gaithersburg, MD, December.

Ross, C.A., Kuennen, S.T., Tedesco, J.W. 1992. "Effects of Strain Rate on Concrete Strength," Session on Concrete Research in the Federal Government, ACI Spring Convention, Washington, D.C., March.

“TrueGrid Manual. 2001. Version 2.1.0,” XYZ Scientific Applications, Inc., September.

"Welds and Heat Affected Zones (preliminary NIST results)."

Wischers, G. 1978. "Application of Effects of Compressive Loads on Concrete," Betontech, Berlin, Nos. 2 and 3. 
This page intentionally left blank. 


\section{Chapter 3 \\ TOWER MODEL DEVELOPMENT}

\section{$3.1 \quad$ INTRODUCTION}

This chapter describes the methodology used in the development of the structural models of the two World Trade Center (WTC) towers for the global impact analyses. The initial efforts focused on the development of models for individual structural components used in the component and subassembly impact analyses (Chapters 5 and 6, respectively). These were developed in a parameterized form so that they could be used to generate the range of structural component models found throughout the towers. Additional information on the models used for the component impact analyses are provided in Chapter 5 . The subsequent efforts were to use the parameterized part models to assemble the large models of complete sections of the towers for the global impact analyses (Chapter 9). All models were developed for the LS-DYNA finite element code (LS-DYNA Version 971) using the TrueGrid model generation program (TrueGrid Manual 2001). The input data for TrueGrid included a set of commands that define the geometries, materials, boundary conditions, and mesh properties. The output from TrueGrid is a complete LS-DYNA input file for the desired analysis.

One of the significant requirements in developing the tower models for the global impact analysis was to minimize the model size as much as possible while keeping sufficient fidelity in the impact zone to capture the deformations and damage distributions. The limitation was a model size that could be executed on a 32-bit computer. Based on this limitation, it was found that the combined aircraft and tower models should not exceed approximately 2.3 million nodes. Decomposition of a model with a larger number of nodes would require additional memory beyond the memory that can be addressed by a 32-bit system. The target for the global WTC tower model, thus, was a maximum of about 1.5 million nodes. The typical approach used to meet this objective was to develop models for the various tower components at different levels of refinement. Structures and components in the path of the impact and debris field were meshed with a higher resolution to capture the local impact damage and failure, while structures and components outside the impact zone were meshed more coarsely to primarily capture their structural stiffness and inertial properties.

\subsection{METHODOLOGY FOR TOWER MODEL DEVELOPMENT}

The global models for the WTC 1 and WTC 2 towers were assembled in subsections based on components developed in the component modeling phase (see Chapter 5). Given the complexity of the towers' structure, a key aspect of developing the global models was automating the mesh generation process. The component model generation files were all developed in a parameterized format to support automated mesh generation. For that purpose, the electronic structural databases developed by the firm of Leslie E. Robertson Associates, R.L.L.P. (LERA), under a contract to the National Institute of Standards and Technology (NIST) within the framework of Project 2 of the NIST Investigation; and reviewed and approved by NIST, were used (see NIST NCSTAR 1-2 and NIST NCSTAR 1-2A). Visual Basic (VB) programs were developed to interface with the structural databases and to automatically write master level TrueGrid input files for mesh generation. 
A total of three VB programs were used for the tower mesh generation. Each program accessed different parts of the electronic structural database. The first program performed automatic core column generation, including column splice models connecting various sections of the columns. The user interface for this core column generation program is shown in Figure 3-1. The input to the column generation program included the tower being modeled (WTC 1 or WTC 2) and the upper and lower floor numbers for the desired model height. The program then read the appropriate databases and extracted the column details such as column type (box or wide-flange) and location, plate thicknesses, and material nominal yield strength. These column parameters were used to create a master TrueGrid input file that generated the desired core column models. The master TrueGrid input file contained a series of "include" statements for pre-existing parameterized generic column generation files. The core column models developed for the subassembly and global impact analyses consisted entirely of shell elements. Different mesh densities (e.g., inside and outside the impact zone in the global impact tower models) were generated by including different generic part generation files with various element size specifications.

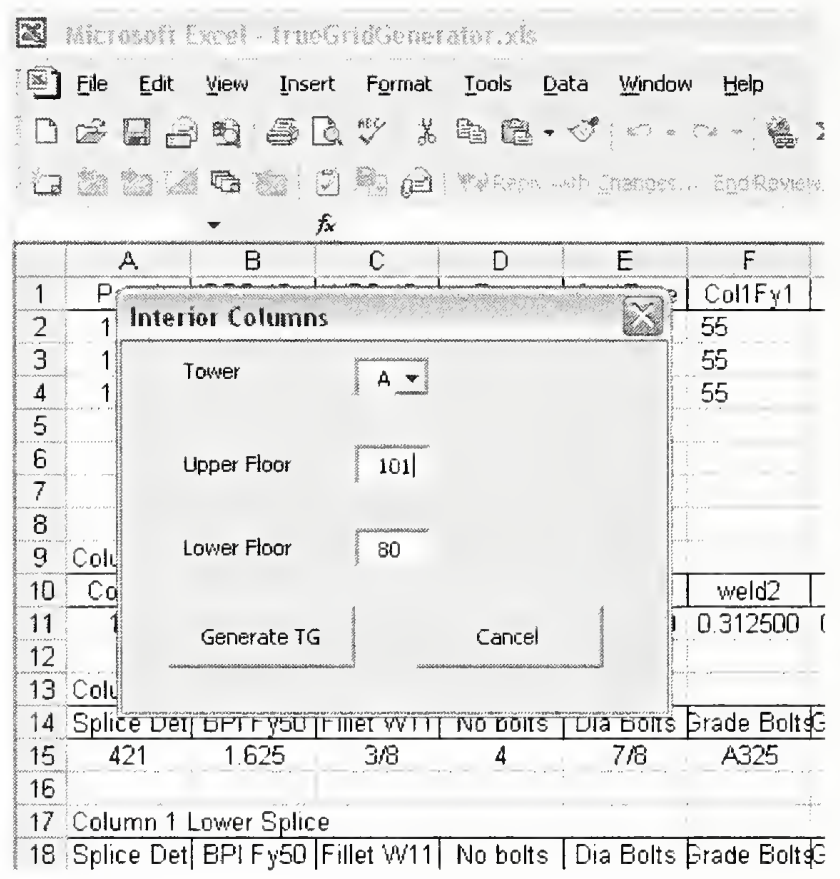

Figure 3-1. Model user interface for the core column generator.

The second program used the same input and a similar methodology as the first to generate a TrueGrid file for overall core assembly. The file included subassembly calls for core columns and core beam framing details. It also controlled mesh density and boundary condition assignment on a floor-by-floor basis. The user interfaces for programs 1 and 2 were very similar.

Figure 3-2 shows the user interface for the third program that generated a series of exterior wall panels. This program was the most complex of the three and required the user to identify the tower, upper and lower floor boundaries, and left and right (as viewed from outside the building) panel numbers. Additionally, the user could specify a fine mesh region, typically in the area of the aircraft impact. Similar to the other programs, this program extracted information from the database and generated a master TrueGrid file. Information not available in the database but included in the drawing books, such 
as the weld specifications, were included in the VB program. The automatically generated TrueGrid files included the geometry and material specification for the columns, butt plates, spandrels, welds, bolts, and spandrel splice plates. Node tolerance specifications (nodal merging commands) were also automatically generated to define the connectivity of adjacent parts in the model. For example, the boundary nodes in the exterior spandrels and columns away from the impact zone were merged to create a perfect connection between adjacent panels. However, in the impact zone, the bolted connections were included in the model, and commands were generated to make sure that nodes in adjacent panels in the impact zone were not merged.

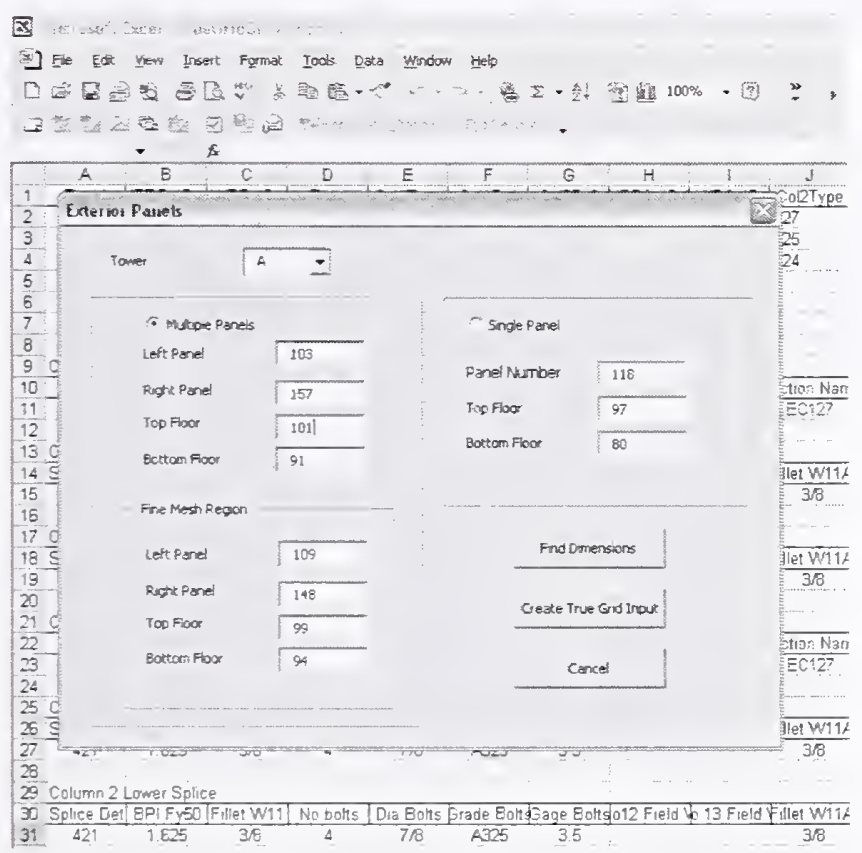

Figure 3-2. User interface for exterior panel generator.

Additional details of the model generation for various tower components are given in the following sections.

\subsubsection{Core Model Development}

Core column models were generated as a group in single floor sections. Dimensions and material specifications were assigned automatically, as specified in the WTC structural databases. The boundary conditions at the top and bottom of the core model and the column splices were automatically generated. An example model of the WTC 1 core columns for floors 95 to 97 is shown in Figure 3-3. Different colors correspond to different material assignments for the various column sections.

Both wide flange and box core columns were modeled with Belytschko-Tsay shell elements (LS-DYNA shell element type 2). These shell elements are four noded elements with single point integration, and are a computationally efficient alternative to the Hughes-Liu element in LS-DYNA. The Belytschko-Tsay shell elements are widely used for crash, impact, and metal forming applications. Results obtained with these elements typically agree with those obtained with the Hughes-Liu element. The reader is referred to the LS-DYNA Theoretical Manual for a complete discussion on this element type. Two mesh densities 
were used in the global impact analysis, a refined density in the area of impact and a coarse far field density elsewhere (typical element dimensions of 2 in. in the impact zone and 8 in. in the far field, respectively). In the impact zone, the mesh topology and density for both column types were identical to those used in the component analysis. A single wide flange column in the impact zone had 552 shell elements and 600 nodes per floor. A box column in the impact zone had 864 shell elements and 900 nodes per floor.

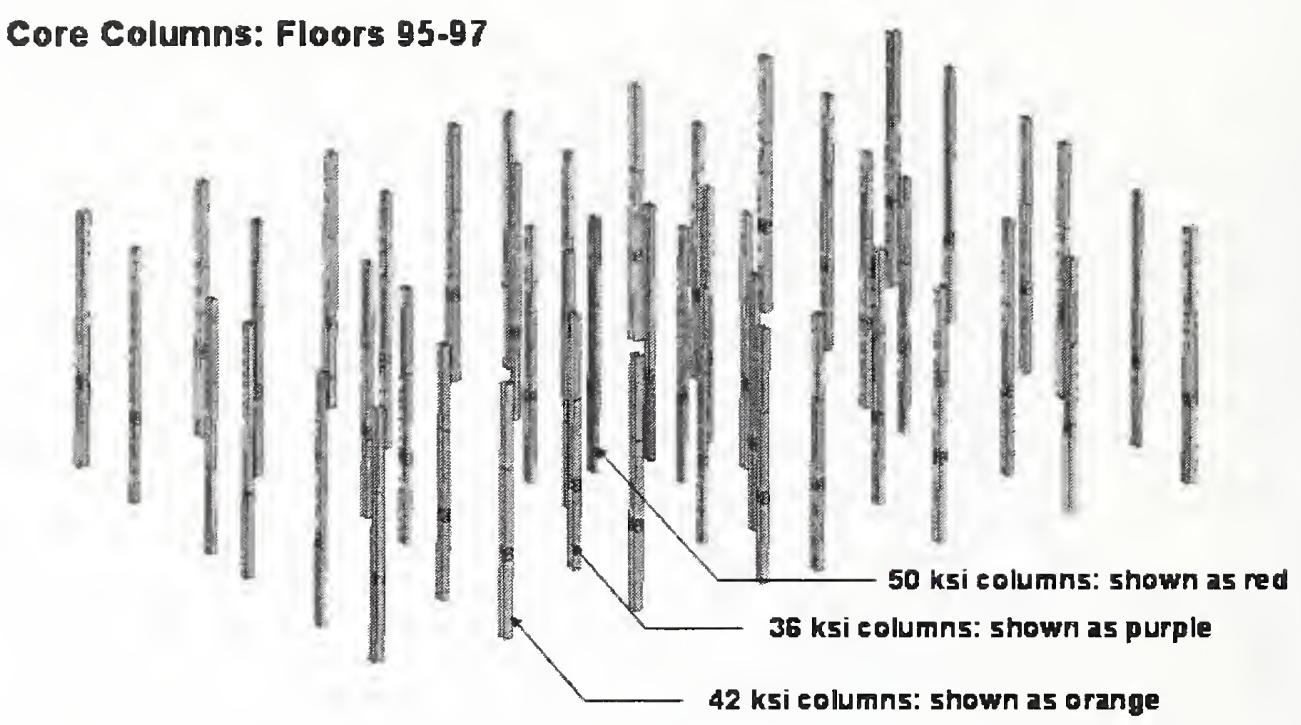

Figure 3-3. Model of the WTC 195 th-97th core columns and connections.

Details of column splices at floor 95 are shown in Figure 3-4 and Figure 3-5. The wide flange-to-wide flange core column connections were modeled by splice plates placed on the outside of each flange, as shown in Figure 3-4. The connection between the splice plate and column flange was modeled with a surface to surface tied interface without failure (LS-DYNA contact type 2 ). This effectively resuits in a perfect bond between the nodes of the splice plate and the flange of the adjacent column. If the columns are pulled apart, the elements at the splice plate spanning the gap between column ends would be stretched. Failure of the splice plate in the model resulted from ductile failure of the splice plate in the elements spanning the connection. A shear failure of the bolts or bolt bearing failure of the splice plates could not be reproduced by this model. 


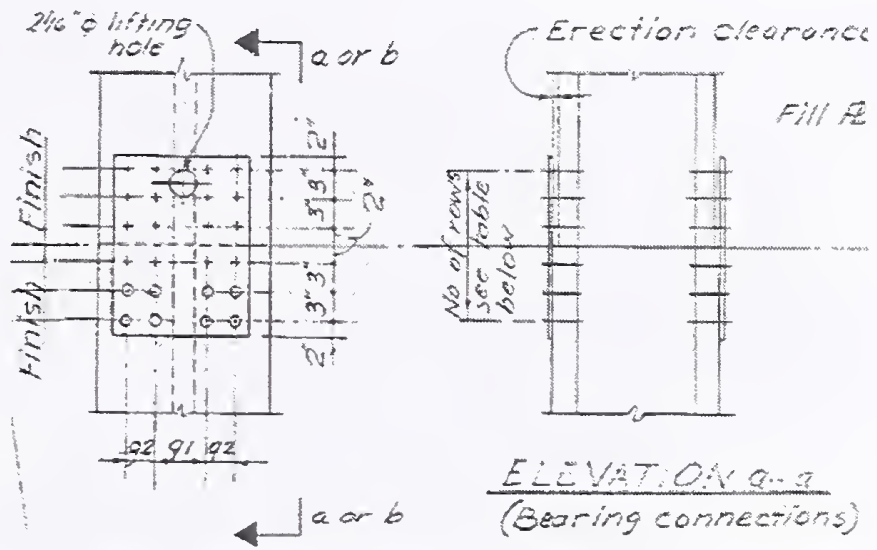

Source: Drawing reproduced with permission of The Port Authority of New York and New Jersey.

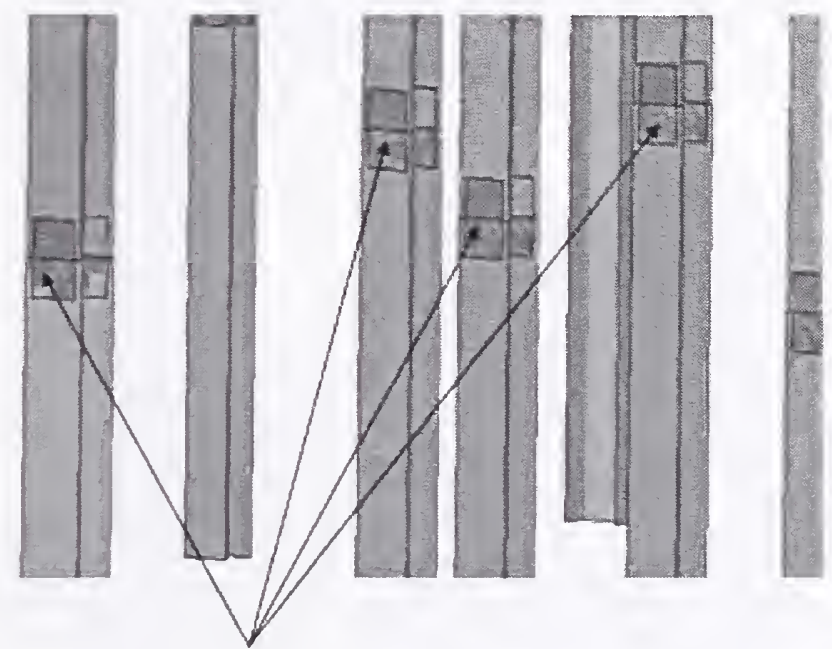

\section{Splice Plates}

Figure 3-4. Detail of wide flange core columns splices.

A typical box column-to-wide flange column connection is shown in Figure 3-5. The thick box column cap was modeled with shell elements and was perfectly merged into the lower box column. The connection between the wide flange column and the box column cap was an edge-to-surface tied interface without failure (LS-DYNA contact type 7). This tied connection results in the nodes of the wide flange column being perfectly bonded to the element segments of the box column cap plate. Failure of this connection would occur only when deformations and strains of this connection are sufficiently high to fail the elements in the columns adjacent to the joint. 


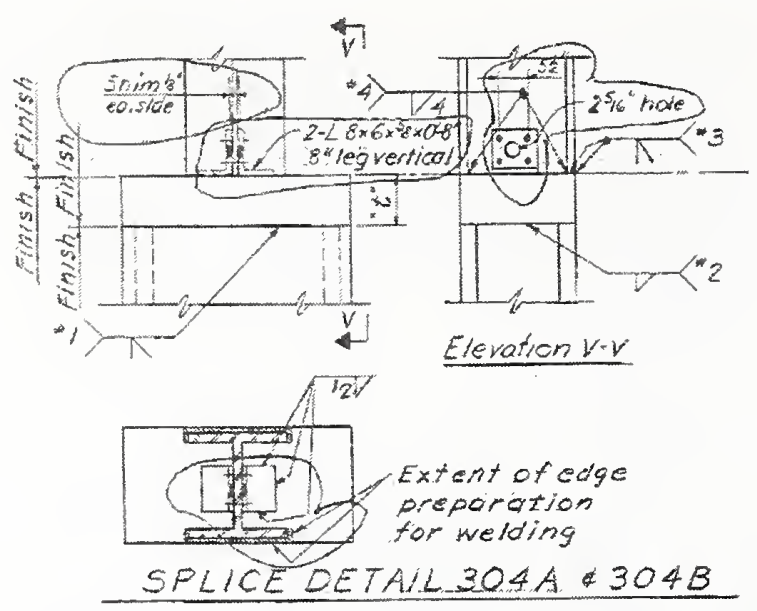

Source: Drawing reproduced with permission of The Port Authority of New York and New Jersey.

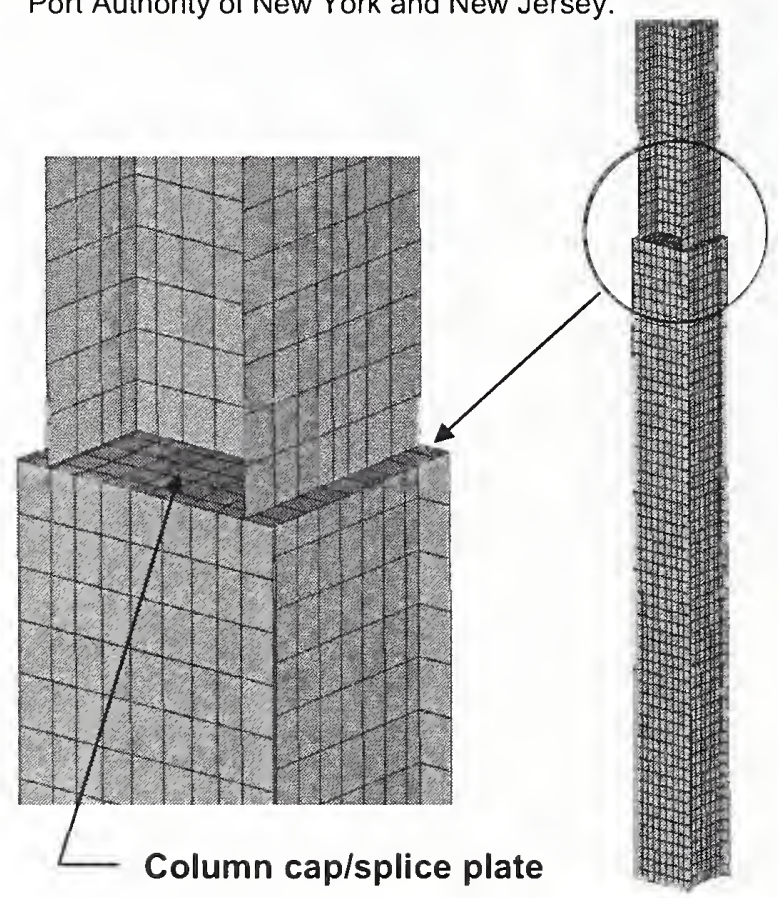

Figure 3-5. Detail of box columns-to-wide flange core columns splice.

The approach for assembling the core floors in the global model was to generate models of typical floors in the impact zone and repeat them in the surrounding floors. For WTC 1, a model of the 96th floor inside the core was developed and was used for modeling floors 92 through 100 . This approach was also used for floors 77 through 85 as the impact zone in WTC 2. Special details for mechanical, lower and upper elevator, and sky lobby floors were sufficiently far away from the impact to warrant this simplification. Figure 3-6 shows the WTC 1 core prototype of the 96th floor with and without the concrete floor slab. The entire model was developed with Belytschko-Tsay shell elements. Mesh density can be set independently from floor to floor to obtain higher accuracy in the impact zone and computational economy in the surrounding floors. A typical core floor with the higher impact zone mesh 
density (floor 96 of WTC 1 in this case) had approximately 66,000 shell elements and 76,000 nodes. This included core floor slab, floor beams, connections, and core columns over a height of one floor.
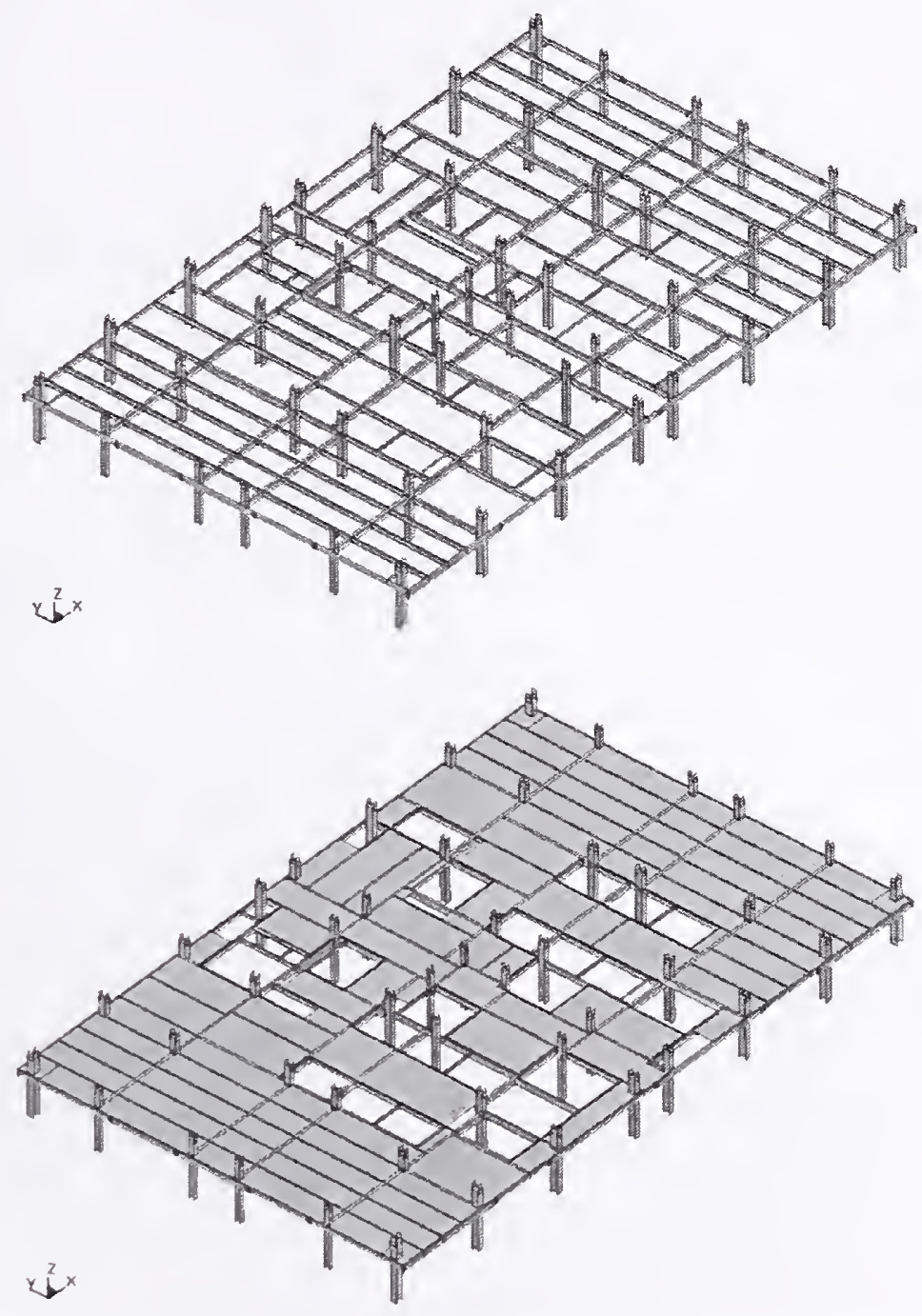

Figure 3-6. Model of the WTC 196 th floor core columns and beams (with and without floor slab).

The various connection details between core beams are illustrated in Figure 3-7. Core perimeter beams were joined with splice plates in the same manner as wide flange column end connections described above. Interior beams were connected with node-to-surface tied connections (contact type 7). The nodeto-surface contact algorithm constrains the nodes to move with the same relative motions as the adjacent surface elements and is appropriate for modeling a strong welded connection. An automatically generated model for the assembly of WTC 1 core floors 94 through 98 is shown in Figure 3-8. Floor beam and slab details in this model were replicates of the 96th floor prototype. 


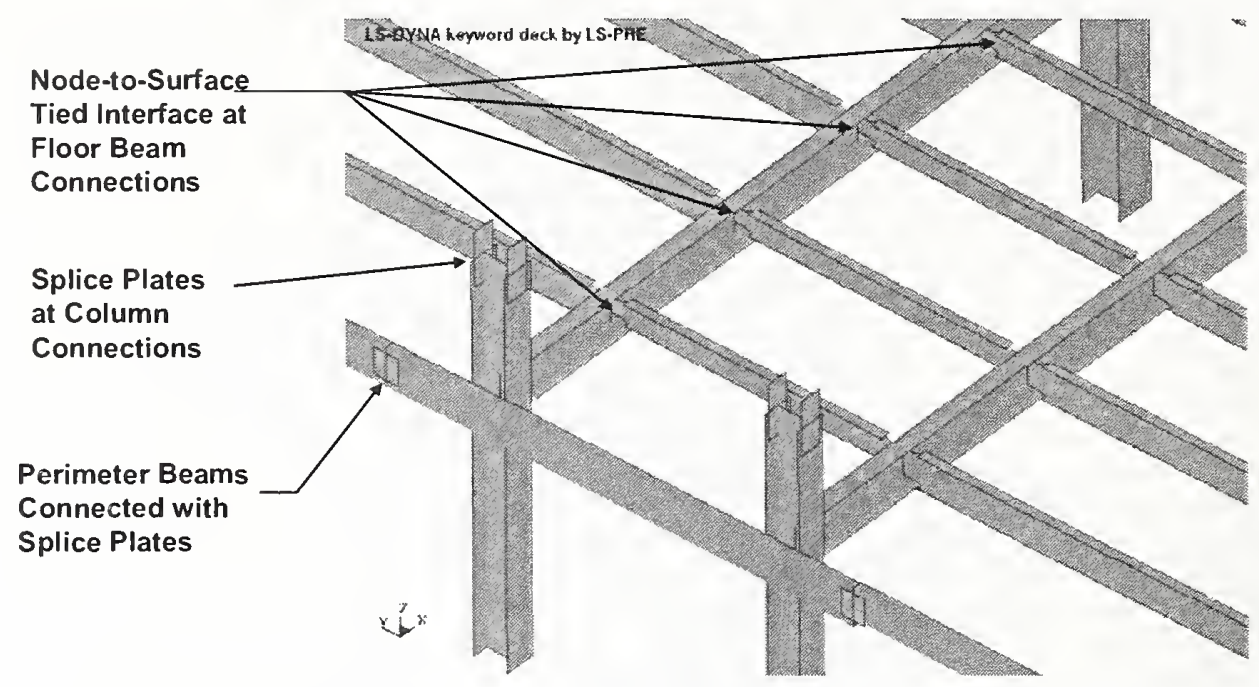

Figure 3-7. Model detail of core column and beam connections.

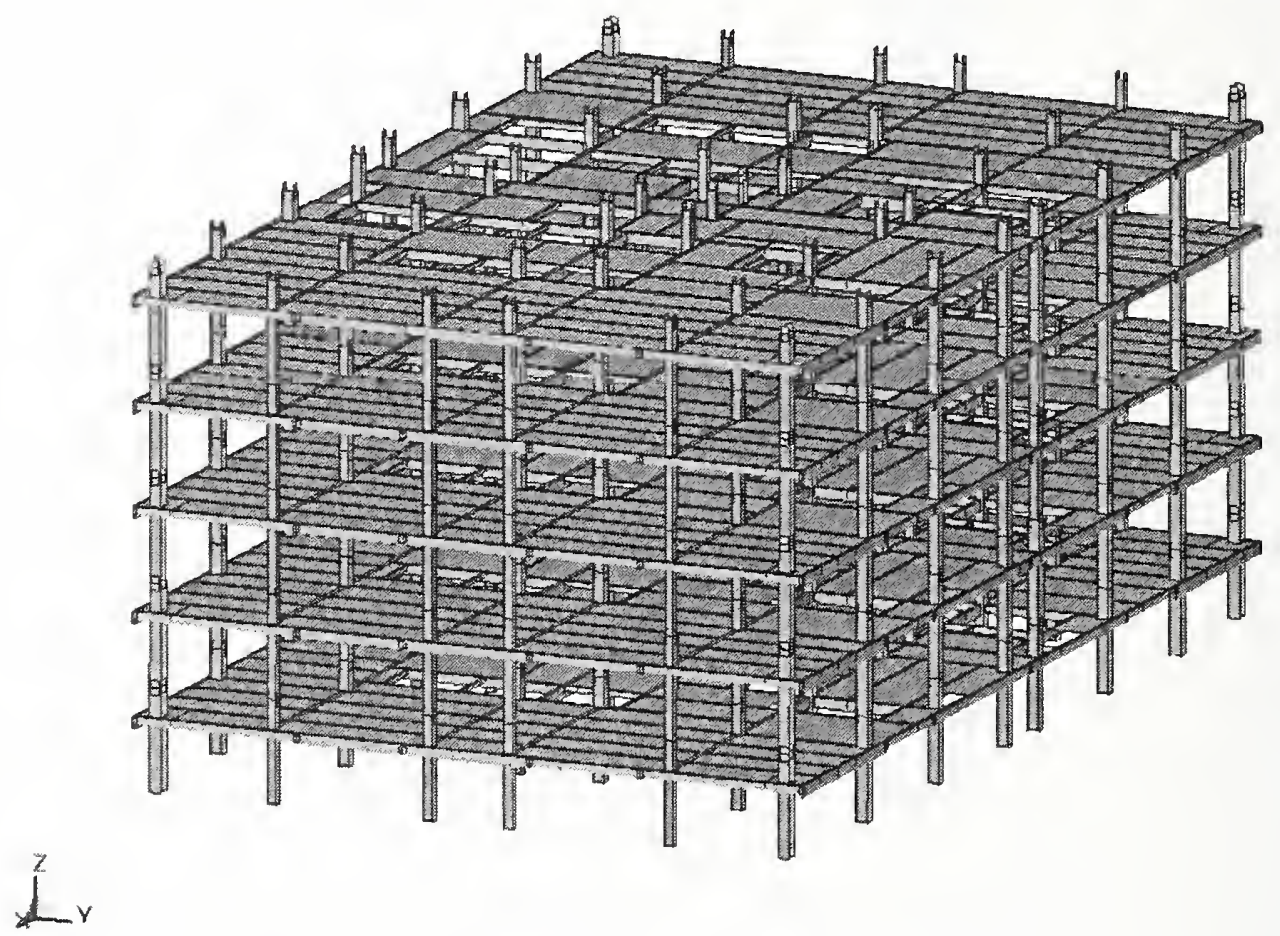

Figure 3-8. Model of the WTC 194 th-98th core.

\subsubsection{Exterior Wall Model Development}

The exterior walls were constructed as an assembly of panels. The most common panel types on the exterior of the towers consisted of three columns and spans over three floors. The columns in each panel were attached together by spandrel plates, typically at each floor level. The construction of the exterior wall model required the generation of a parameterized model for each panel type that was located in the tower regions near the impact zones. The extcrior wall in the WTC 1 impact zone was made up of panel 
type 300 on the sides and panel type 210 in the corners. Examples of the models for these panel types are shown in Figure 3-9. The exterior wall in the WTC 2 impact zone included a mixture of 100, 200, 300, and 400 series panels due to the proximity of the mechanical floors.
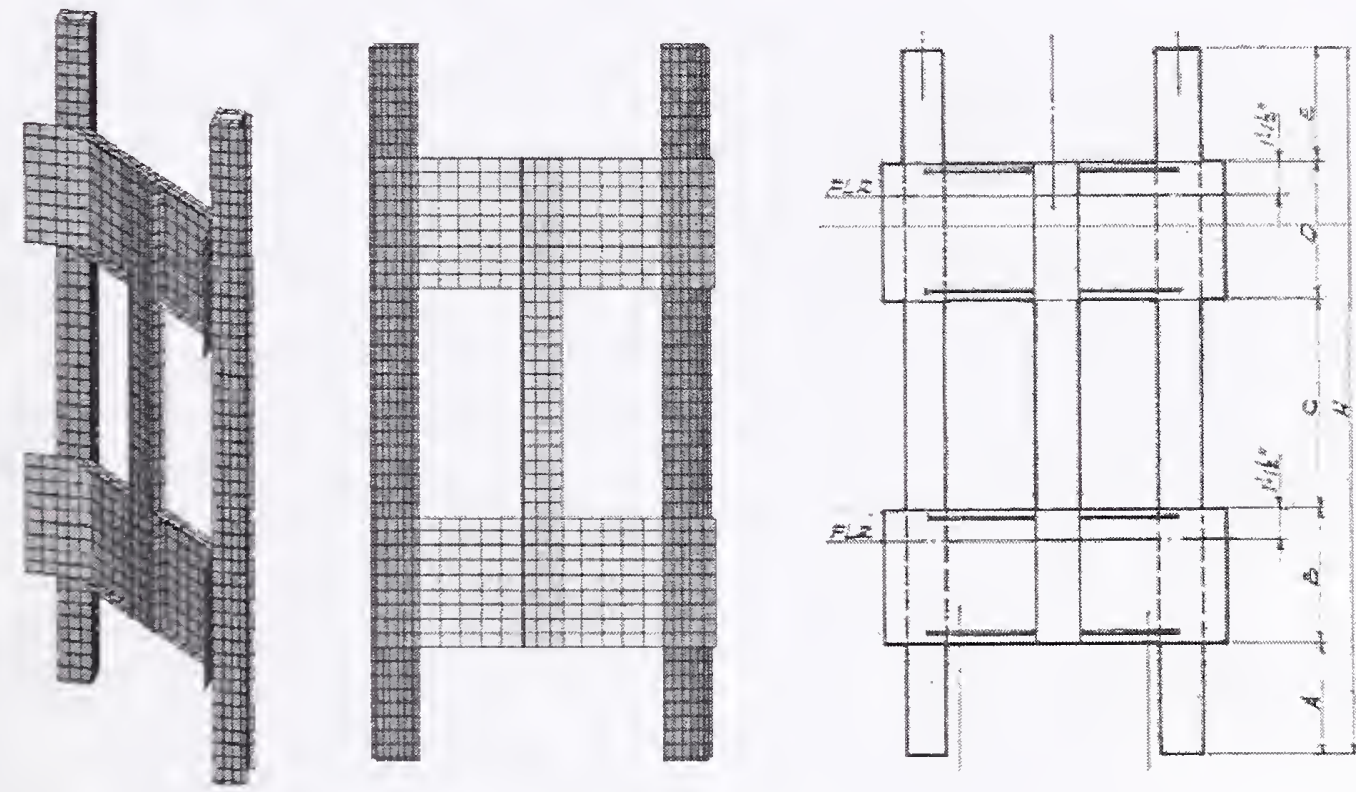

(a) Type 210 panel
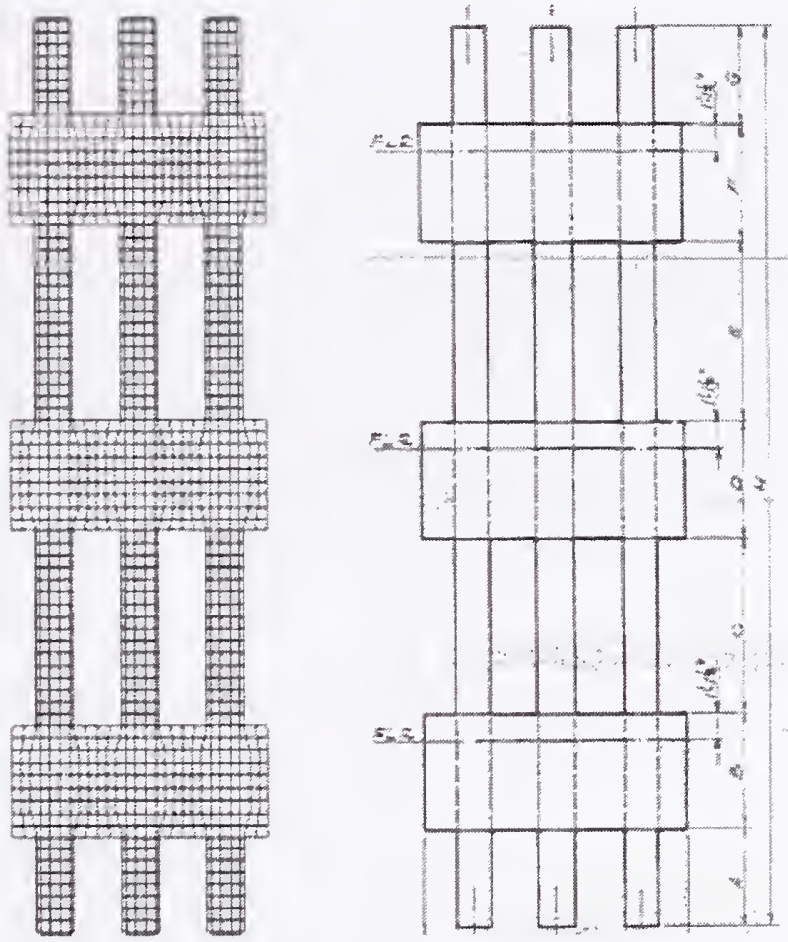

(b) Type 300 panel

Figure 3-9. Example models for exterior wall panel types. 
The complete exterior wall model in the impact zone for each tower was generated by placing the various panels in the actual locations with their dimensions and material specifications. These material and geometric parameters were extracted automatically from the tower database using the third VB program to automatically generate the exterior wall models (see Section 3.2). The impact face for the global WTC 1 (north wall) and WTC 2 tower (south face) models are shown in Figure 3-10 and Figure 3-11, respectively. The figures show a mixture of coarse and fine meshed panels. A refined mesh was used in the immediate impact zone for improved accuracy of the impact response, and a coarse mesh was used outside the impact zone for improved computational efficiency. All panels were primarily constructed from Belytschko-Tsay shell elements. Constant stress brick elements (LS-DYNA solid element type 1) were used to model the butt plates in the refined panels. Hughes-Liu beam elements (LS-DYNA beam element type 1) were used to model bolts connecting the butt plates in the refined impact zone as described in Section 2.3.3. As an example, each type 300 panel in the impact zone contained 5,304 nodes, 5,202 shell elements, 78 brick elements, and 12 beam elements. The corresponding element sizes in the impact zone were a 1 in. element for the weld zone and 4 in. elements for the exterior column. A typical element dimension for the far field exterior panels was $14 \mathrm{in}$.

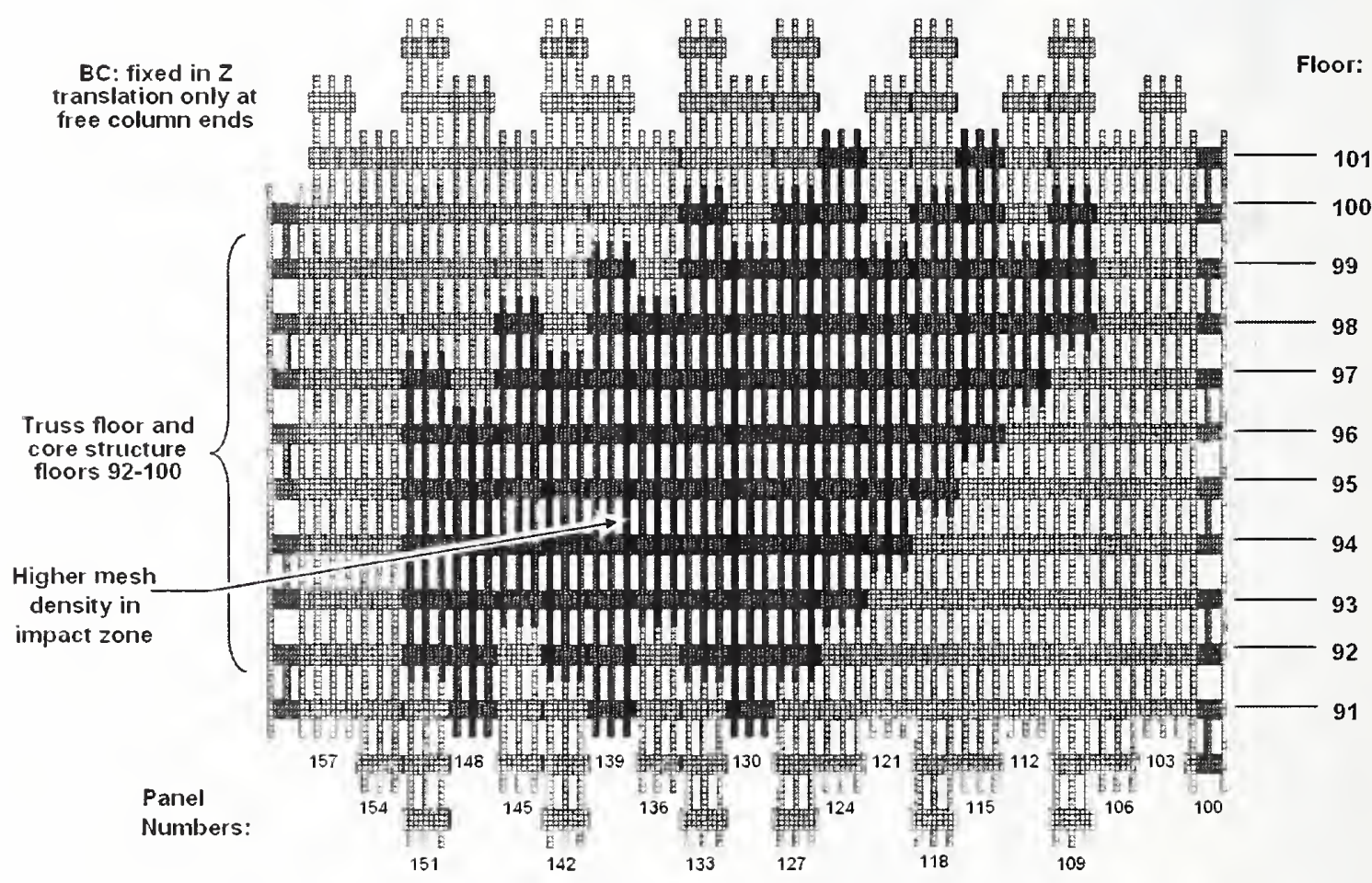

Figure 3-10. Impact face of the WTC 1 model - floors 91-101. 


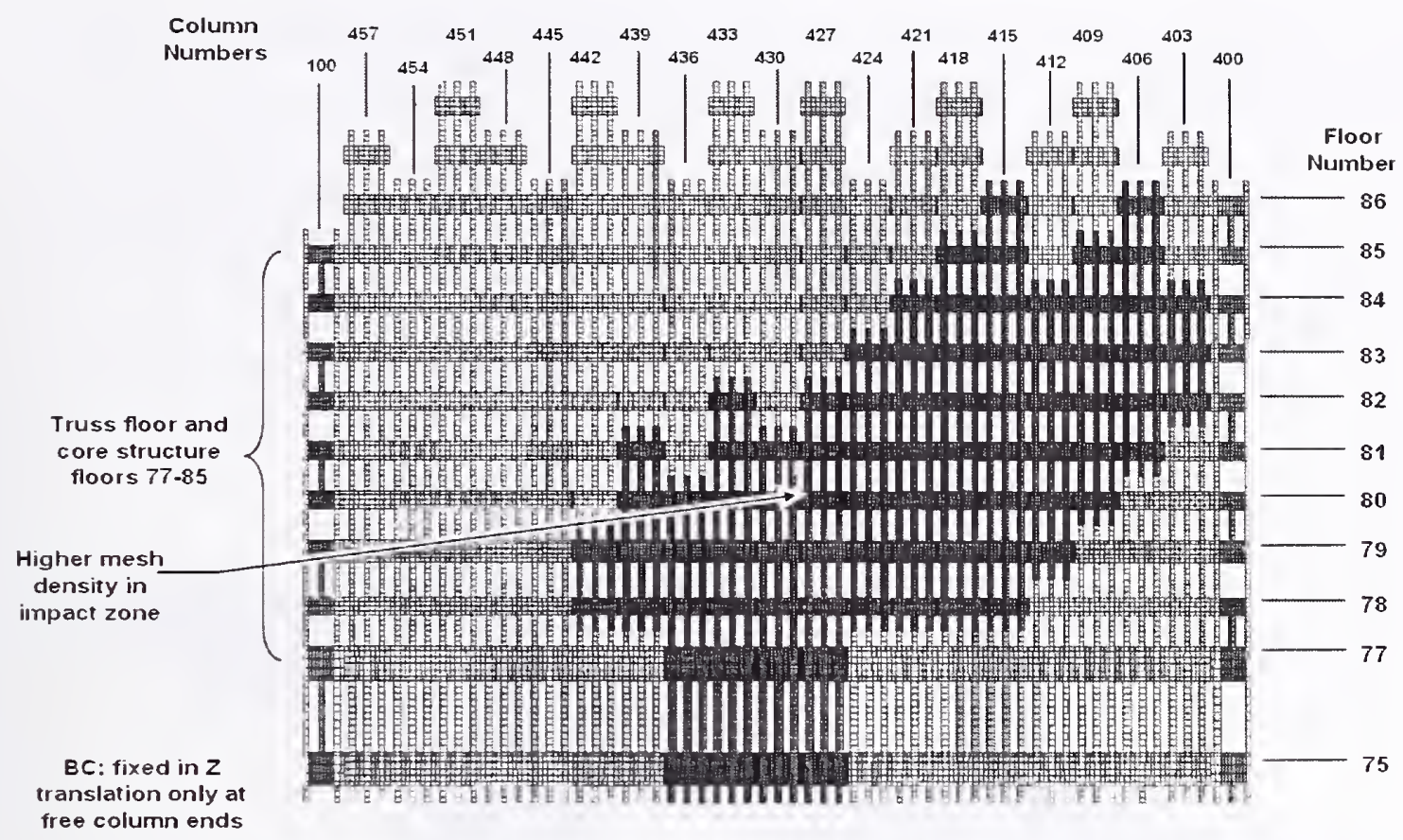

Figure 3-11. Impact face of the WTC 2 model - floors 75-86.

In addition to the generation of the exterior panels model, the VB program was also used to automatically specify the boundary conditions and various connection details between the panels. The boundary conditions at the top and bottom of the exterior wall were constrained vertical displacements. The lateral degrees of freedom and rotation about the vertical axis were not constrained. The free lateral displacements at the model boundary allowed for the tower model to have a rigid body velocity following the impact. Since the natural period of the tower was approximately 10 to $11 \mathrm{~s}$, the tower would provide little structural resistance to the translation at the model boundary during the less than $1 \mathrm{~s}$ impact event. The connections between panels included the bolted connections across the column end butt plates and the bolted splice plate connections between spandrels of adjacent panels.

The bolted connection between exterior column ends was modcled using beam elements to represent the individual bolts. The behavior of these beam element bolts was compared to the measured tensile data for the bolts in Chapter 5. This representation of the bolted column butt plate connections was only provided in the higher mesh density impact zone panels. The column ends for the coarse far field exterior wall panels were merged together to create a perfect bond between column ends.

The model for the spandrel splice plate connection is shown in Figure 3-12. Twelve nodes on the splice plate were attached to the spandrels using the spot weld tied node algorithm (LS-DYNA Type 7 ticd interface). The spot welds approximate the connection of the individual bolts connecting the spandrel splice plates. Failure of these connections occurred through deformation of the splice plates and/or spandrel and ductile failure of the materials.

The placement of the spandrel splice plates was again limited to the higher resolution impact zone for the exterior wall. The far-field coarse panel models were merged together as shown in Figure 3-13. The 
influence of the spandrel splice connection on the impact response and exterior wall damage was investigated using engine component impact analyses as described in Chapter 5.

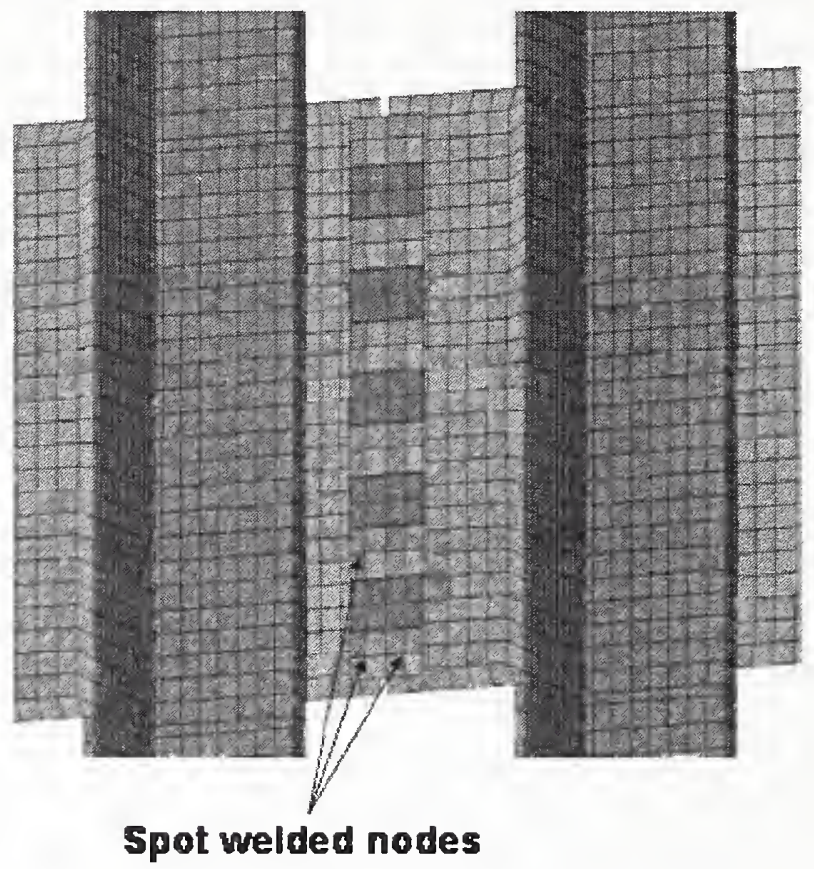

Figure 3-12. Model of spandrel splice plate connection.

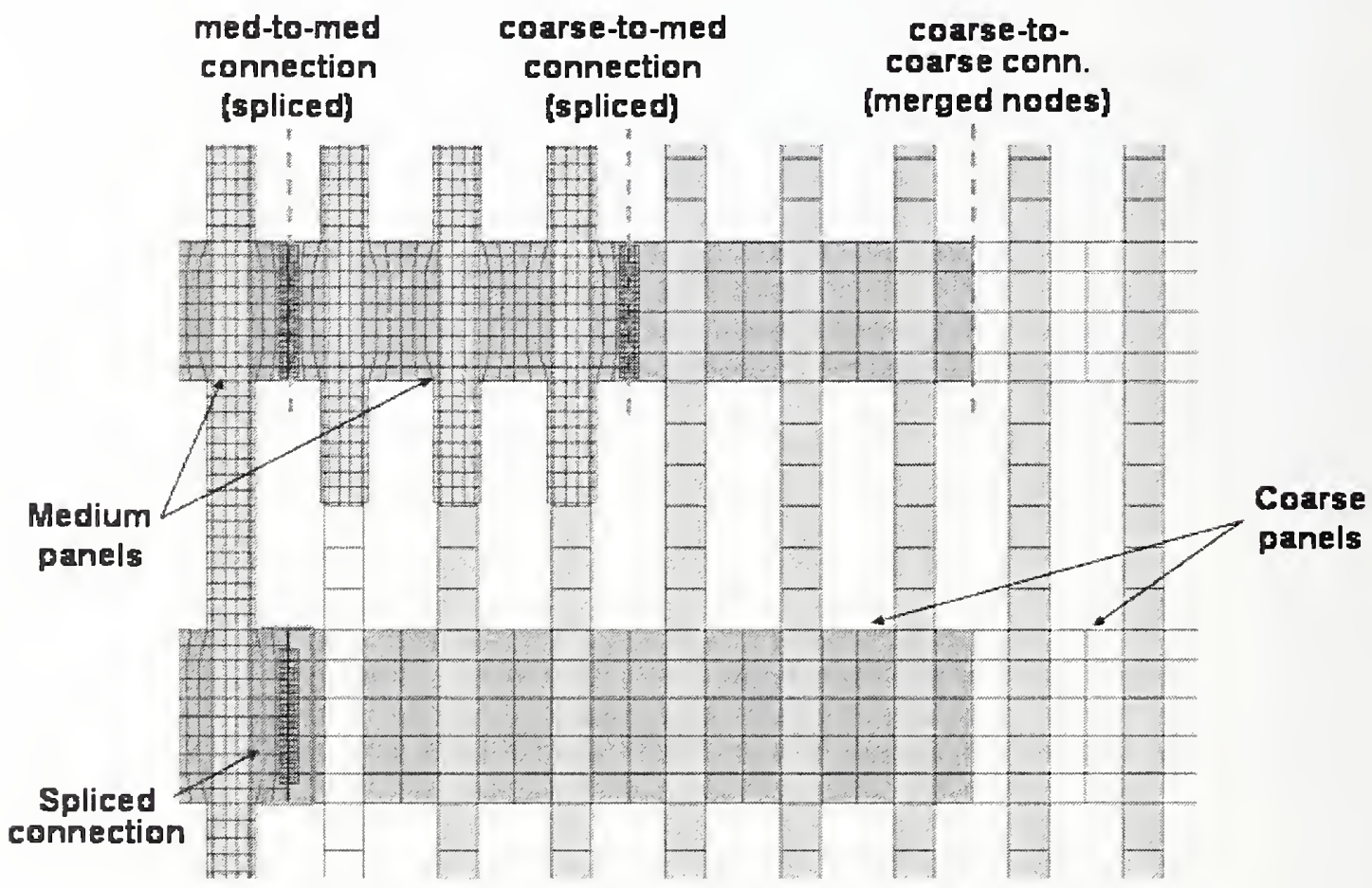

Figure 3-13. Placement of spandrel splice plates in the exterior wall model. 


\subsubsection{Truss Floor Model Development}

The approach to the development of the truss floor model was very similar to other portions of the tower structure. Initially, parameterized component models were developed for segments of long-span trusses, short-span trusses, and corner two-way trusses. These parameterized models were then called repeatedly for generation and placement of the floor truss segments within the complete tower models. The individual truss floor segments spanned the distance from the exterior wall to the core. An example of a truss floor segment used in the global model is shown in Figure 3-14. In the double truss sections, the two trusses were modeled explicitly with the proper dimensions. The model of the floor trusses accounted for the potential for buckling of the bottom chord under impact loading.

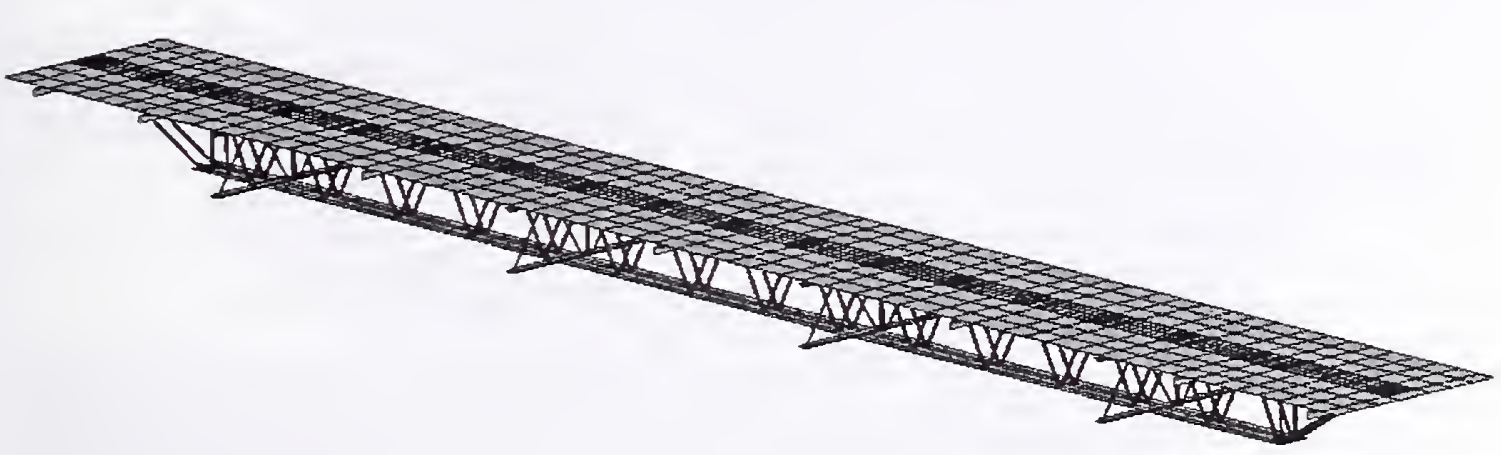

Figure 3-14. Model of a truss floor segment.

The model was developed using a uniform layer of Belytschko-Tsay shell elements for the combined floor slab and metal decking. Construction methodology was the same for both primary and bridging (secondary) trusses, using Belytschko-Tsay shell elements for the truss upper and lower chord components, Belytschko-Tsay shell elements for the cross supports, and Hughes-Liu beam elements for the round bar truss diagonals. The upper chords were attached to the floor slab using an offset tied interface for both the primary and bridging trusses. This approach, using shell elements as opposed to solid brick elements for the floor slab, was adapted to reduce the model size requirements. Development of a model with matching mesh density in the slab and truss structures (nodal alignment for a merged connection) resulted in a much larger model size.

The mesh refinement used in this model for the truss floor would result in a very large global tower model size if used throughout the structure. The model for the long-span truss floor segment, shown in Figure 3-14, contained 2,737 nodes, 362 beam elements, and 1,878 shell elements. Constructing a global impact tower model with these detailed floor segments was not practical due to model size limitations. A complete floor would result in approximately 200,000 nodes for a single truss floor structure. As a result, detailed floor segments were included only in the impact zone, and a simplified floor truss model was used elsewhere. Further discussion on the simplified model is included in Section 3.2.5.

Figure 3-15 and Figure 3-16 show truss floor connection details at the exterior wall and core, respectively. The models for the truss seat connections were developed using shell elements and attached using the tied interface algorithm. The failure of the seats only occurs as a result of exceeding the ductility of the seat or truss structures. 


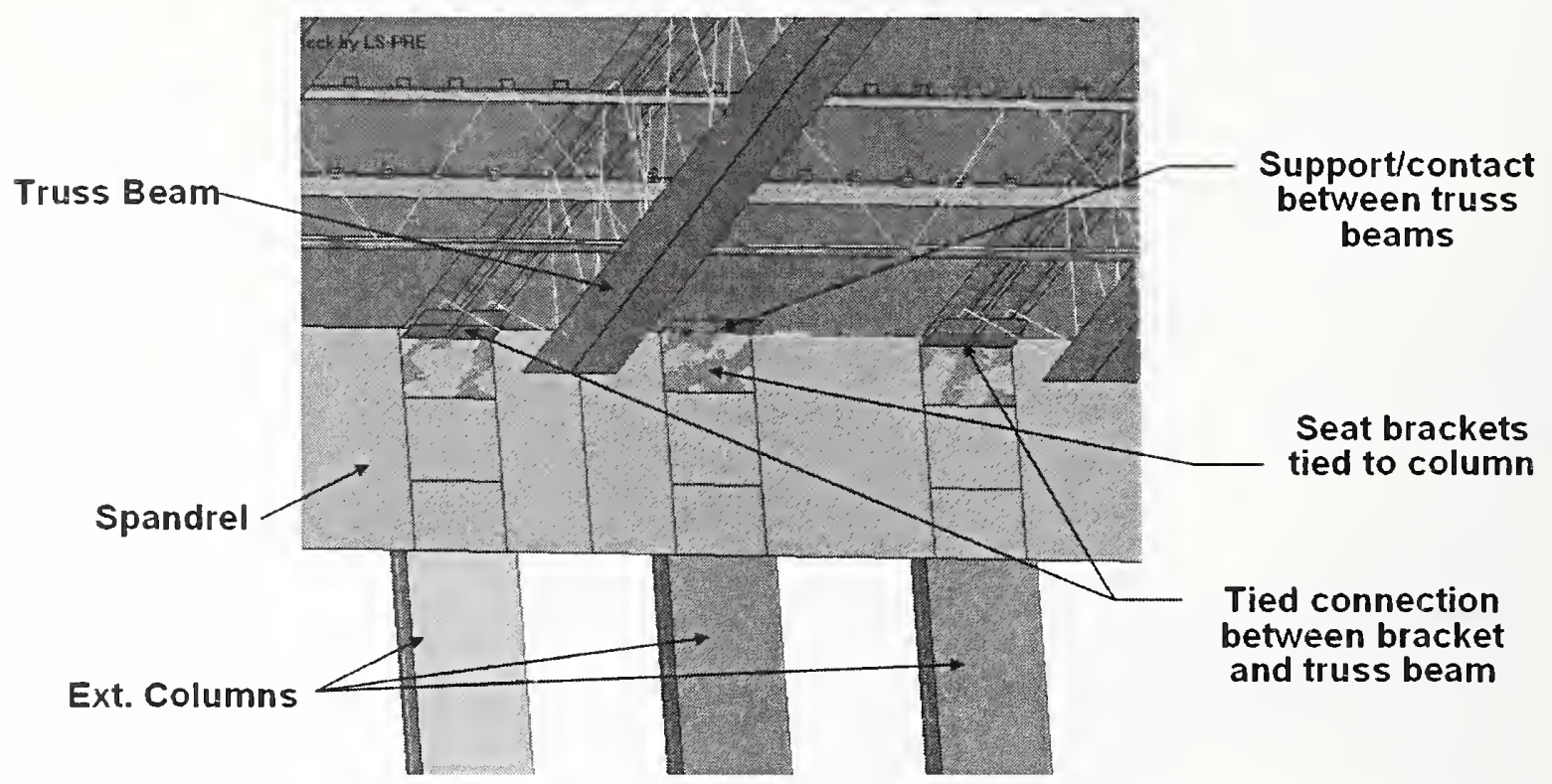

Figure 3-15. Truss floor connection detail at exterior wall.

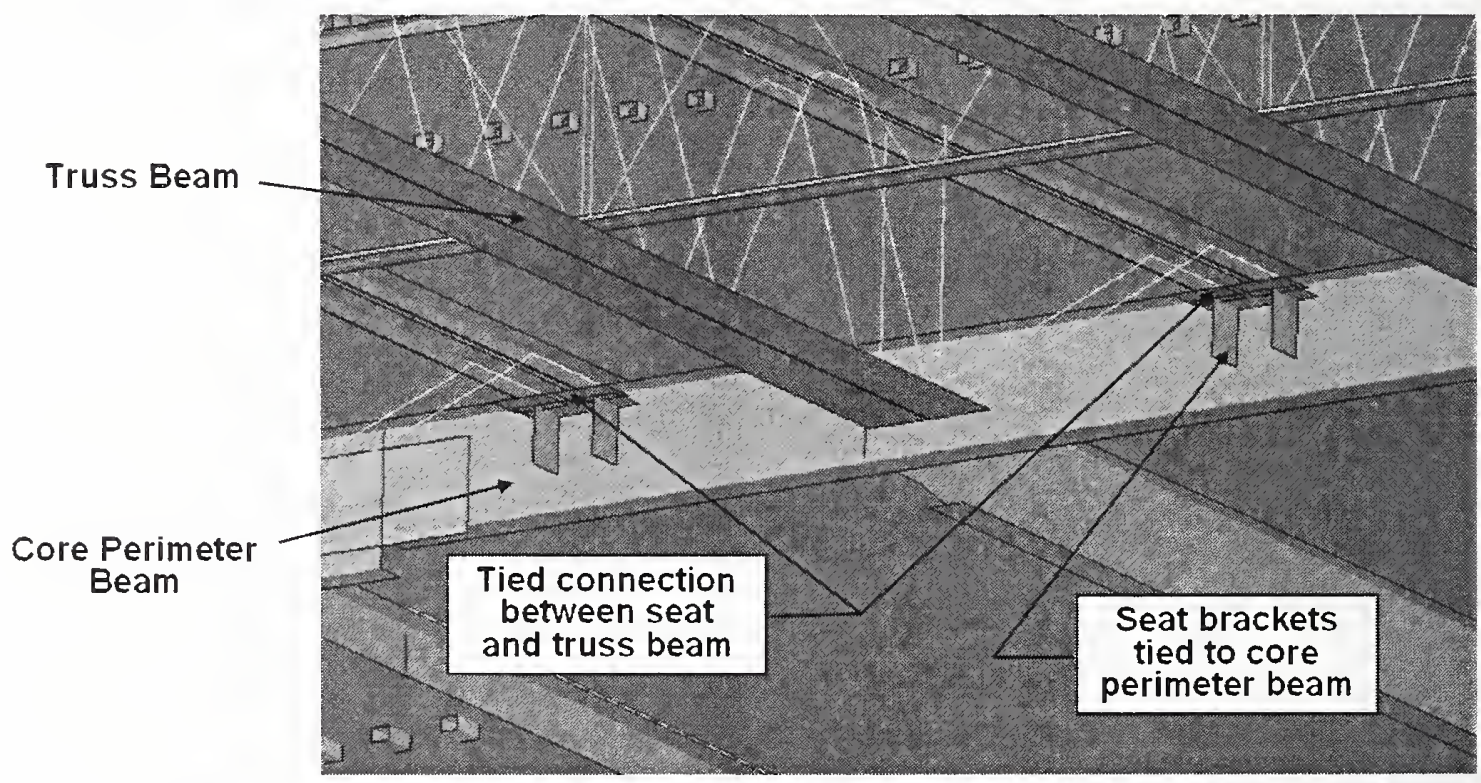

Figure 3-16. Truss floor connection detail at core perimeter.

A series of dampers were installed in the WTC towers between the floor truss lower chord and the spandrel on the exterior wall. The primary function of these dampers was to reduce the vibration of the building under wind loading. These dampers, however, were of low mass and the arrangement of the damper and saddle (member attaching the damper to the bottom chord of the truss), along with their connections, had virtually no strength in the transverse direction. Under impact conditions, the aircraft applied transverse forces to the damper assembly due to the downward motion of the aircraft (see Chapter 7). Also, due to the short duration of the impact event (less than $1 \mathrm{~s}$ ), damping was not included 
in the analyses. As a result, the dampers were considered to have sufficiently low mass and strength and were therefore not included in the impact analyses.

A model assembled for an entire floor (floor 96 of WTC 1), including the core and exterior wall structures, is shown in Figure 3-17. A comparison of the plan view and the associated framing plan drawing for this floor is shown in Figure 3-18.

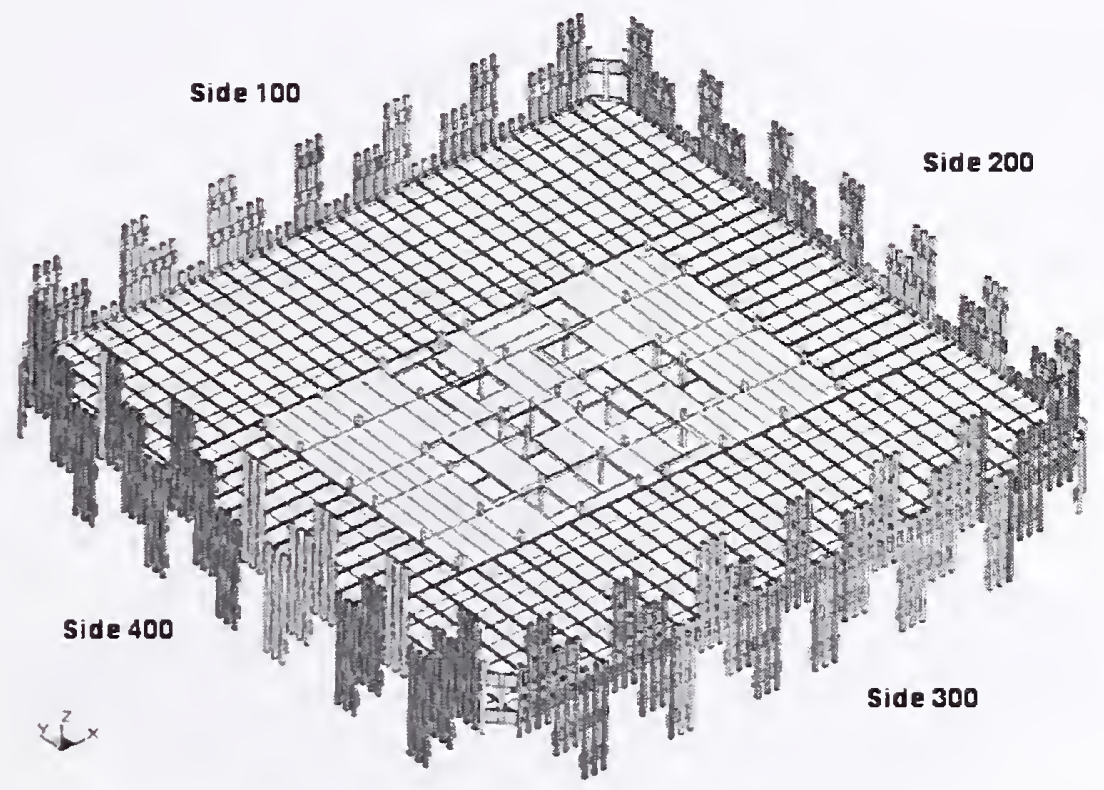

Figure 3-17. Model of the 96th floor of WTC 1.

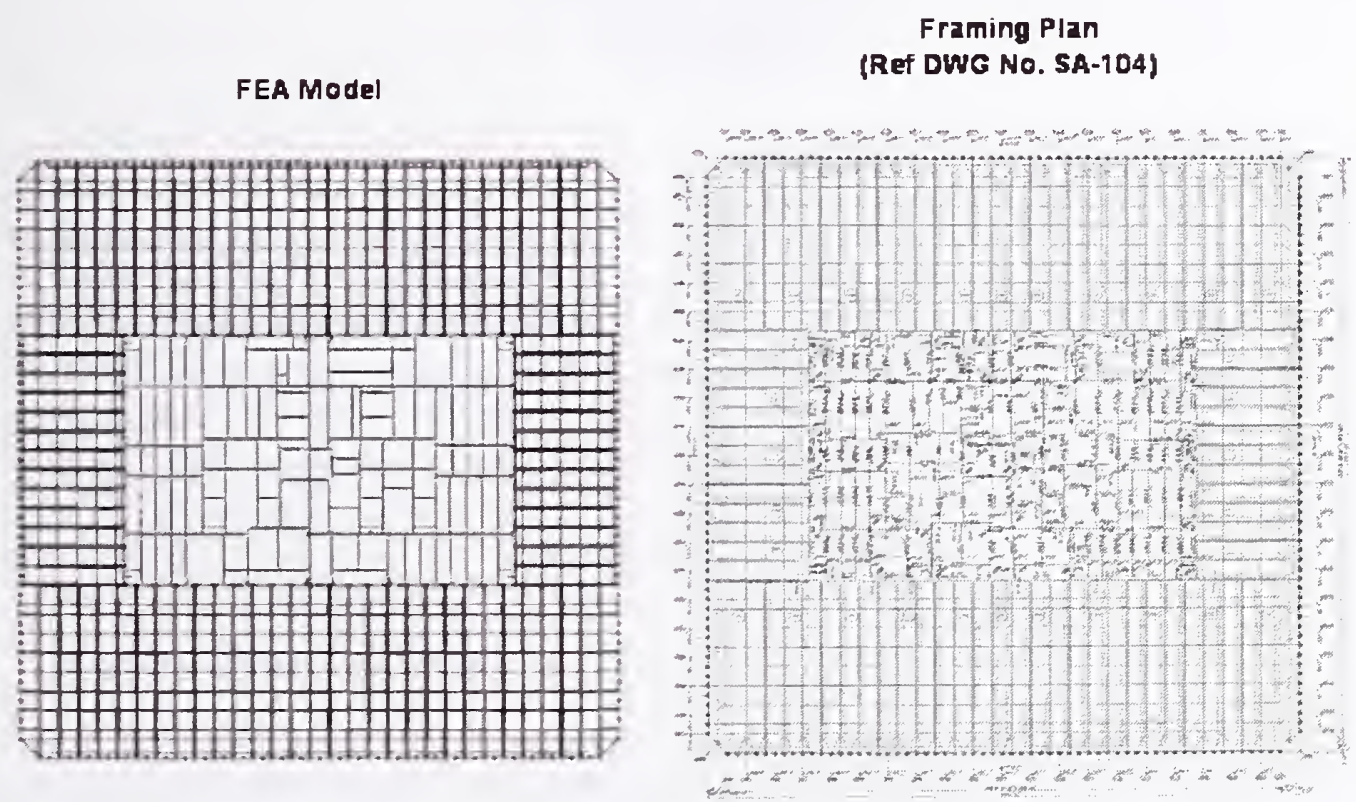

Source: Drawing reproduced with permission of The Port Authority of New York and New Jersey.

Figure 3-18. Model plan view and framing plan drawing of the 96th floor of WTC 1. 


\subsubsection{Interior Contents Model Development}

The interior nonstructural contents of the towers were modeled explicitly in the tower models used for the global impact analyses. The live load mass was distributed between gypsum walls and cubicle workstations that covered the truss floor area. The distribution of the gypsum walls was obtained from architectural drawings and other information gathered as part of the NIST reconstruction of the thermal environment. Similarly, data gathered by NIST for the floor layout plans in the impact zone were used to develop the approximate placement of workstations over the truss floor area. The resulting model of a floor with interior contents is shown in Figure 3-19. Heavy elevator components such as elevator cars and counterweights inside the core's elevator shafts were not included in the models since there was no way of determining their locations at the time of impact.

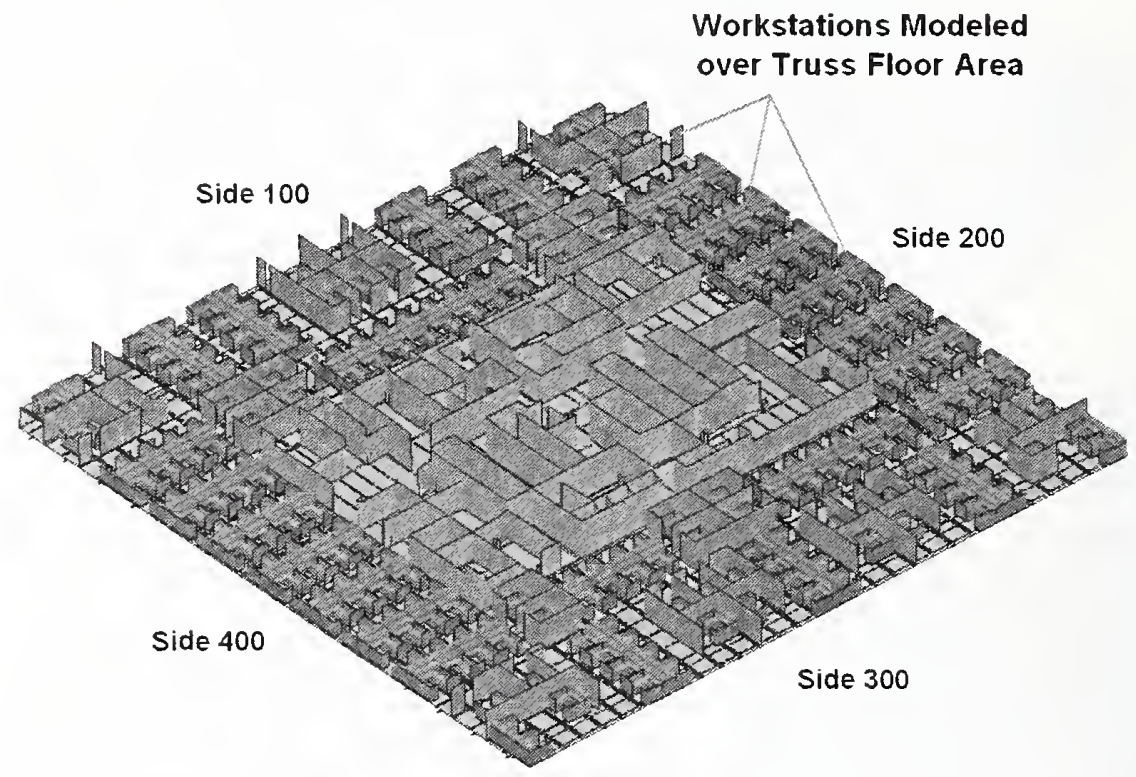

Figure 3-19. Model of the 96th floor of WTC 1, including interior contents.

The densities of specific materials were scaled to obtain the desired magnitudes for the live loads and superimposed dead loads. The densities of the tower contents (workstations and gypsum walls) were scaled by the appropriate ratios to get the desired distribution of live loads in the core and truss floor areas. The densities of all the remaining tower structural components were scaled proportionately to obtain the desired superimposed dead loads. These additional loads were important for obtaining an accurate mass distribution in the towers and inertial effects in the impact response. The live load used was based on a percentage of the design live load on the floors inside and outside the core. Using 25 percent of the design live loads resulted in $19.7 \mathrm{psf}$ uniformly distributed over the core and $16.2 \mathrm{psf}$ uniformly distributed over the outer truss floor area. Using the approximate floor areas of $8,700 \mathrm{ft}^{2}$ in the core and $31,250 \mathrm{ft}^{2}$ outside the core produced 170,000 lb and 500,000 lb of live load for the core and outer floor areas, respectively.

The superimposed dead loads added to the model were $36.2 \mathrm{psf}$ for the core area and $11.5 \mathrm{psf}$ outside the core producing 315,000 lb and 359,000 lb of superimposed dead load for the core and outer floor areas, respectively. These superimposed dead loads were included in the model by scaling the density of the structural components (slab, columns, beams, etc.) both inside the core and outside the core by uniform 
scale factors to obtain the appropriate dead loads. Superimposed dead loads were applied to the columns to account for nonstructural components such as insulation, cladding, and windows.

A summary of the live loads and superimposed dead load magnitudes and density scale factors are provided in Table 3-1. The total amount of added weight from the superimposed dead load and live load for a single floor was 1.35 million $\mathrm{lb}$ resulting in a total weight for the floor of 4.41 million $\mathrm{lb}$ (after the addition of the self weight of the floor).

Table 3-1. Summary of superimposed dead loads and live loads (per floor).

\begin{tabular}{|l|c|c|c|c|}
\hline & $\begin{array}{c}\text { Area } \\
\left(\mathrm{ft}^{2}\right)\end{array}$ & $\begin{array}{c}\text { Weighting } \\
(\mathbf{p s f})\end{array}$ & $\begin{array}{c}\text { Added Weight } \\
(\mathbf{I b})\end{array}$ & $\begin{array}{c}\text { Density } \\
\text { Multiplier }\end{array}$ \\
\hline Core Dead Load & 8,694 & 36.2 & $3.15 \mathrm{E} 5$ & 1.628 \\
\hline Outer Dead Load & 31.257 & 11.5 & $3.59 \mathrm{E} 5$ & 1.218 \\
\hline Core Live Load & 8,694 & 19.7 & $1.71 \mathrm{E} 5$ & 0.852 \\
\hline Outer Live Load & 31,257 & 16.2 & $5.06 \mathrm{E} 5$ & $0.447 / 0.757^{\mathrm{a}}$ \\
\hline Total & 39,951 & N/A & $1.35 \mathrm{E} 6$ & N/A \\
\hline
\end{tabular}

a. Value of multiplier dependent on model of workstation used.

The partitions and workstations were modeled using shell elements. The model of the building contents (partitions and workstations) over a single floor, as shown in Figure 3-19, had 101,733 nodes and 97,284 shell elements. To include the complete distribution of the building contents over five floors in the global impact model would require approximately 500,000 nodes. As a result, the global models included the partitions and workstations only in the region of each floor directly in the path of the aircraft impact and debris. Using this approach significantly reduced the computational requirements needed to include the building contents inertial contributions. For example, the WTC 1 global impact model included only 160,410 nodes and 148,858 shell elements for the partitions and workstations in the impact path over five floors (savings of about 300,000 elements). WTC 2 model simplification saved a similar amount of nodes and elements. These building content distributions for the two tower models are discussed in the following section.

All of the contents in the truss floor regions rested on the floor with a contact algorithm used to prevent penetration. Gravitational acceleration and friction included in the contact analyses resisted sliding motions of these contents. The bottoms of the gypsum walls in the core were rigidly connected to the floor slab using merged nodes. The core walls in the model did not extend the full height of the floor to avoid interference with the core beams of the floor above. As a result of this clearance, the tops of the core walls were not constrained. This approximation did not have a significant impact on the response in the core. An impact by a fragment with significant momentum resulted in a failure of the wall. The majority of the core wall damage in the simulations was failure and erosion rather than displacement or knocking over of the walls.

\subsubsection{Global Model Assembly}

The global model was assembled in the same coordinate system as defined in the structural databases. An assembly of exterior and core structure illustrating the global coordinate system is shown in Figure 3-20. The vertical $(Z)$ coordinate was shifted to be centered on the floor closest to the impact point (e.g., $Z=0$ at floor 96 of the WTC 1 model). This reference was selected to eliminate numerical precision problems 
associated with contact or small interference dimensions of components relative to large vertical coordinate values within the model.

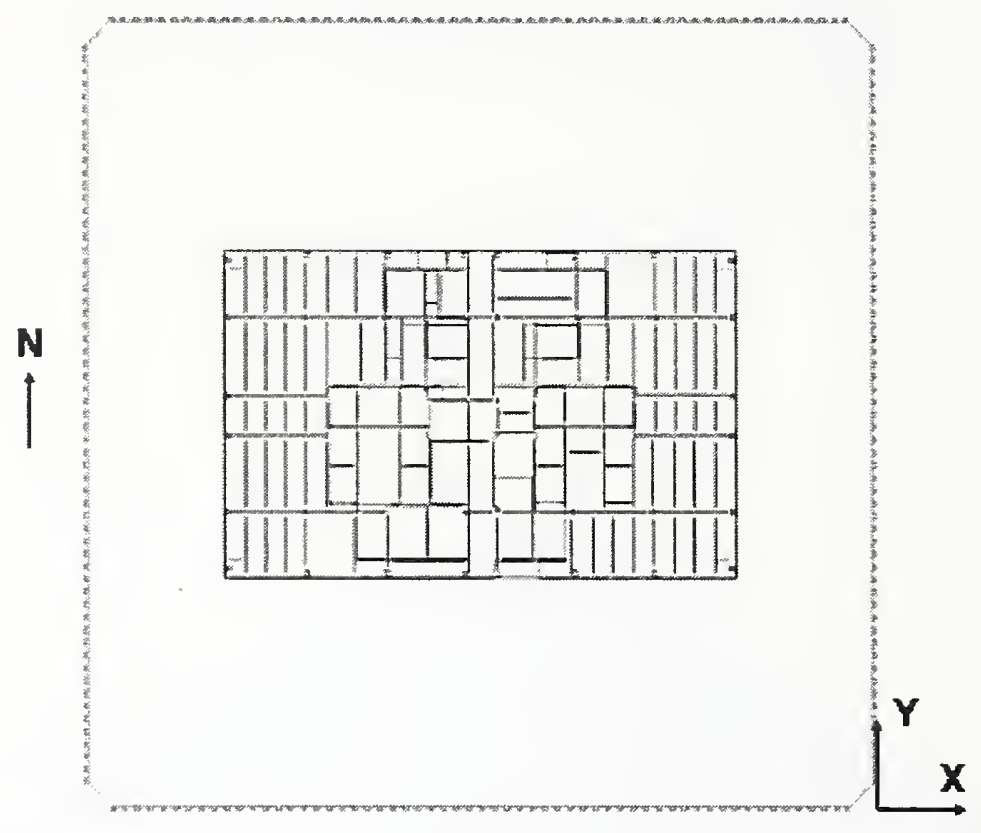

Figure 3-20. Coordinate system used for the WTC 1 model.

The multiple floor global model of the impact zone in WTC 1 is shown in Figure 3-21. The model included the complete floor inside and outside the core, the exterior walls, and core structures for floors 92 through 100. The boundary conditions for the ends of the exterior and core columns at the top and bottom of the model constrained vertical displacement. This allowed for free translations of the tower structure in the longitudinal and lateral directions and rotation about the vertical axis. The influence of these boundary conditions on the impact response was investigated separately, as described in Section 10.4, and found to have little influence on the impact damage. The higher resolution exterior wall panels in the impact zone, shown previously in Figure 3-10, can be seen on the impact face of the tower model (Side 100).

The WTC 1 global impact model with the exterior wall removed is shown in Figure 3-22. The figure shows how the model was optimized to reduce mesh size and eliminate computational requirements outside of the immediate impact and damage zone. The nonstructural building contents (partitions and workstations) were not modeled over the entire floors in the impact zone, but rather only in the path of the aircraft impact and debris cloud. These components are shown separately in Figure 3-23. As a result, the total live load mass modeled over the multiple floors within the impact zone was significantly less. The distribution and density of the building contents (partitions and workstations) in the path of the aircraft debris, however, were included in the model. The building contents outside this region were not expected to have a significant effect on the impact behavior since these components do not contribute significantly to the structural strength and they are not strongly coupled to the surrounding tower structures. The tower contents outside the impact zone were not sufficiently stiff or rigidly attached to the tower to have a 
strong influence on the dynamic stress waves propagating through the structure as a result of the aircraft impact.

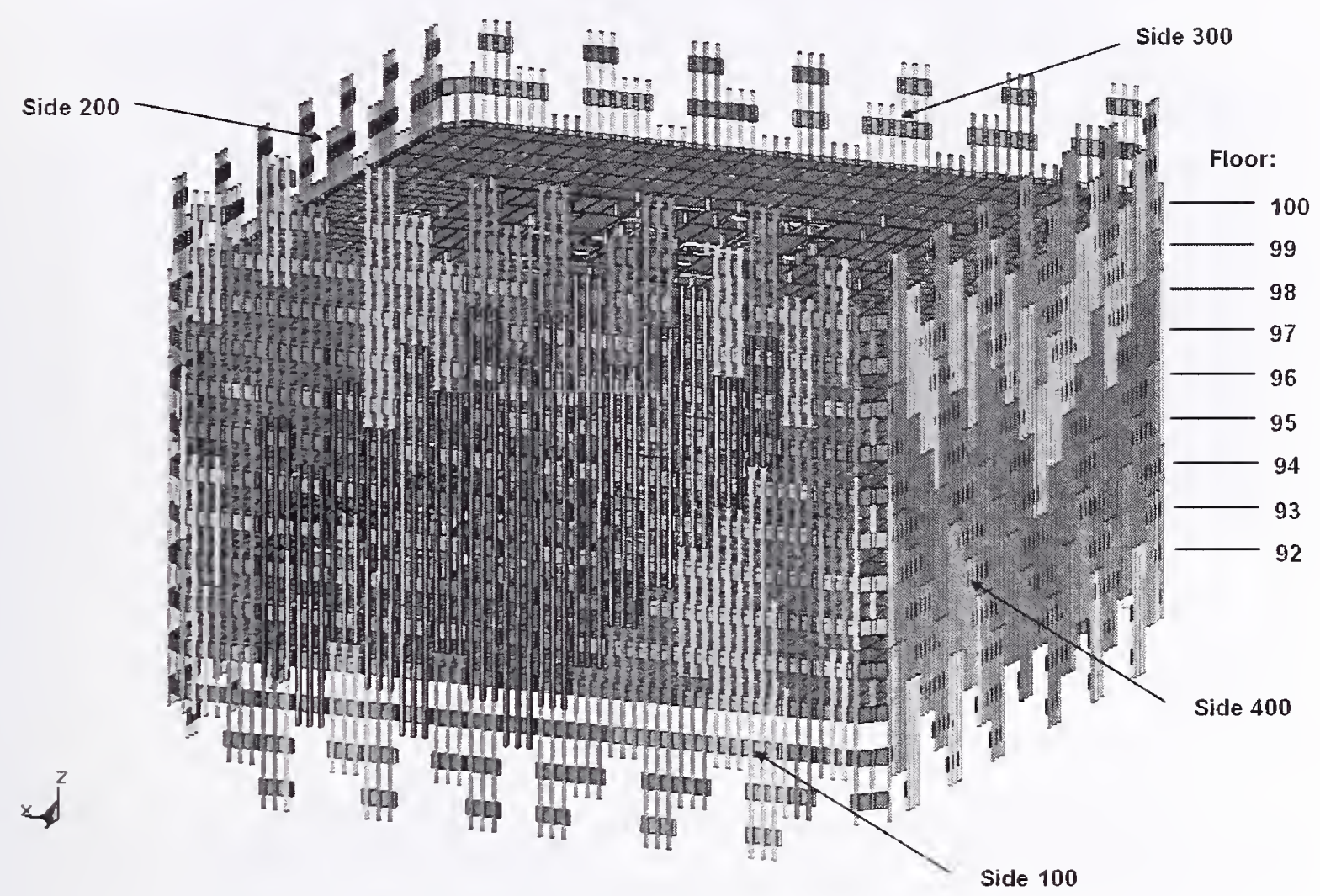

Figure 3-21. Multi-floor global impact model of the WTC 1 tower.

The truss floor structures near the impact zone were modeled in greater detail as secn in Figure 3-22(a). A separate view of the truss floor structures adjacent to Side 100 for floors 94 through 97 is shown in Figure 3-24. The sections of the truss floor in the path of the aircraft impact were modeled with the detailed truss floor model described in Section 3.2.3. The surrounding truss floor structures were modeled using a far-field truss model with a significantly reduced mesh resolution as shown in Figure 3-25. This far-field truss floor model was designed to have the appropriate inertial properties and structural stiffness. The truss was modeled with an effective shell element in place of the vertical truss structure and a beam element along the lower cord. These element dimensions were on the order of $30 \mathrm{in}$. and would not be able to accurately model a local collapse behavior of the truss. The floor slab was modeled with an identical approach as the floor slab in the impact zone, but with a typical element dimension of $30 \mathrm{in}$. compared to an element dimension of approximately $10 \mathrm{in}$. in the impact zone.

The side view of the internal structures, shown in Figure 3-22(b) looking from the west, illustrates that the core columns for floors 93 through 98 of WTC 1 were modeled with higher resolution than that in the floors above and below the direct impact zone. This higher mesh resolution was needed to capture the local damage that occurred from direct impact of aircraft structures and debris. 


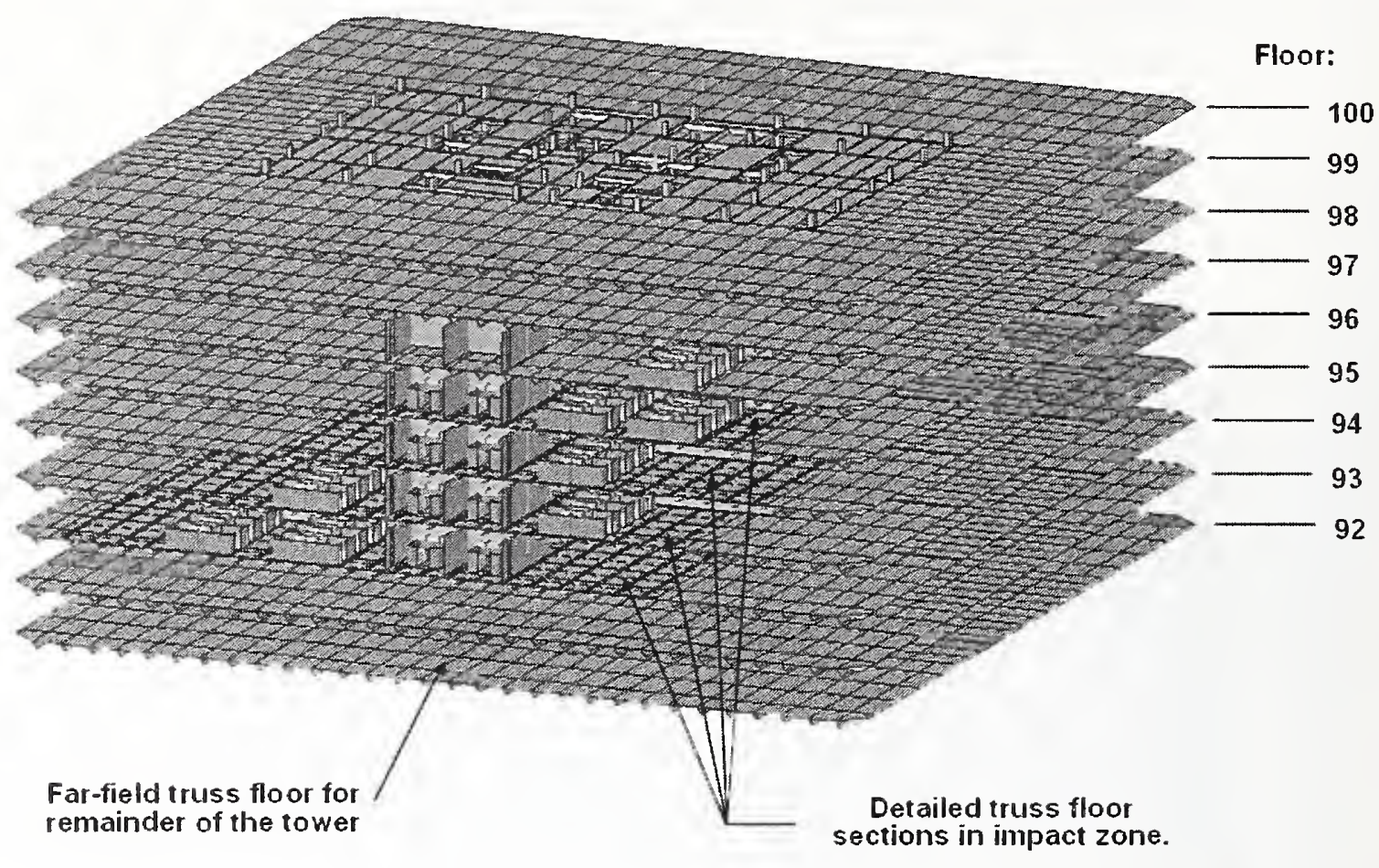

(a) Oblique view

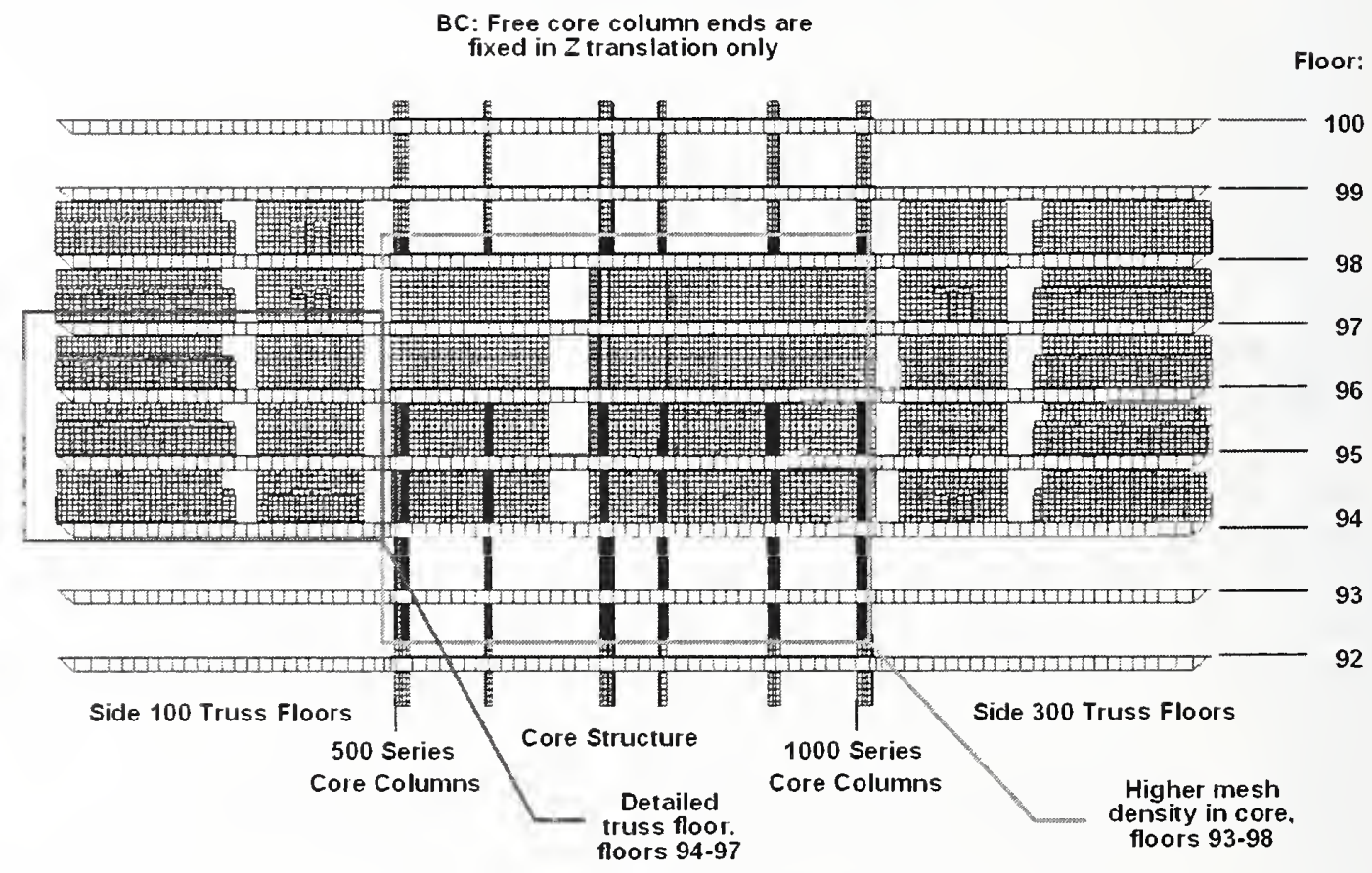

(b) West side view

Figure 3-22. Interior structures and contents of the WTC 1 global impact model. 


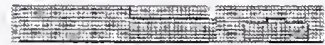

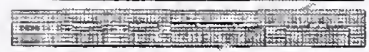

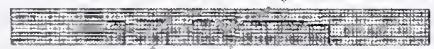 变 Hed}

View looking in impact direction

Workstations and

walls distributed in

impact path only

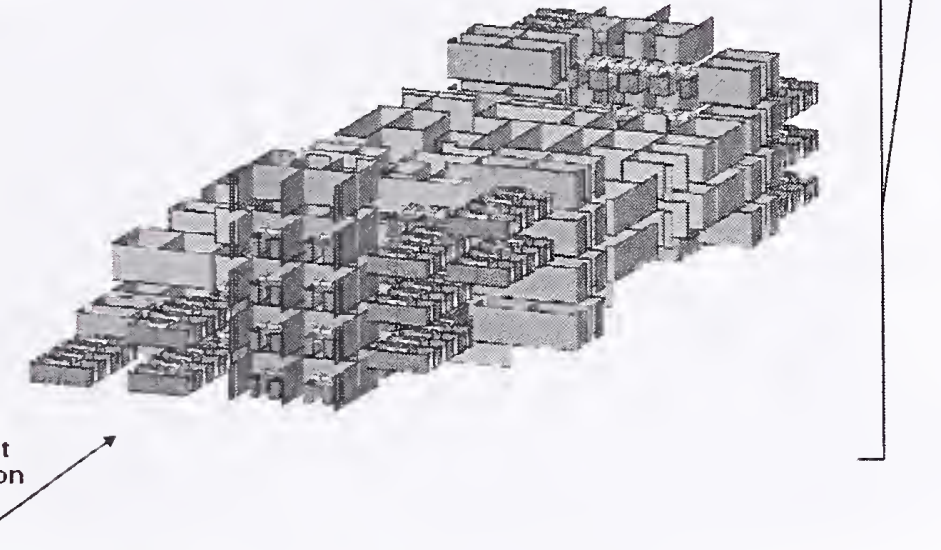

Figure 3-23. Building contents in the WTC 1 global impact model.

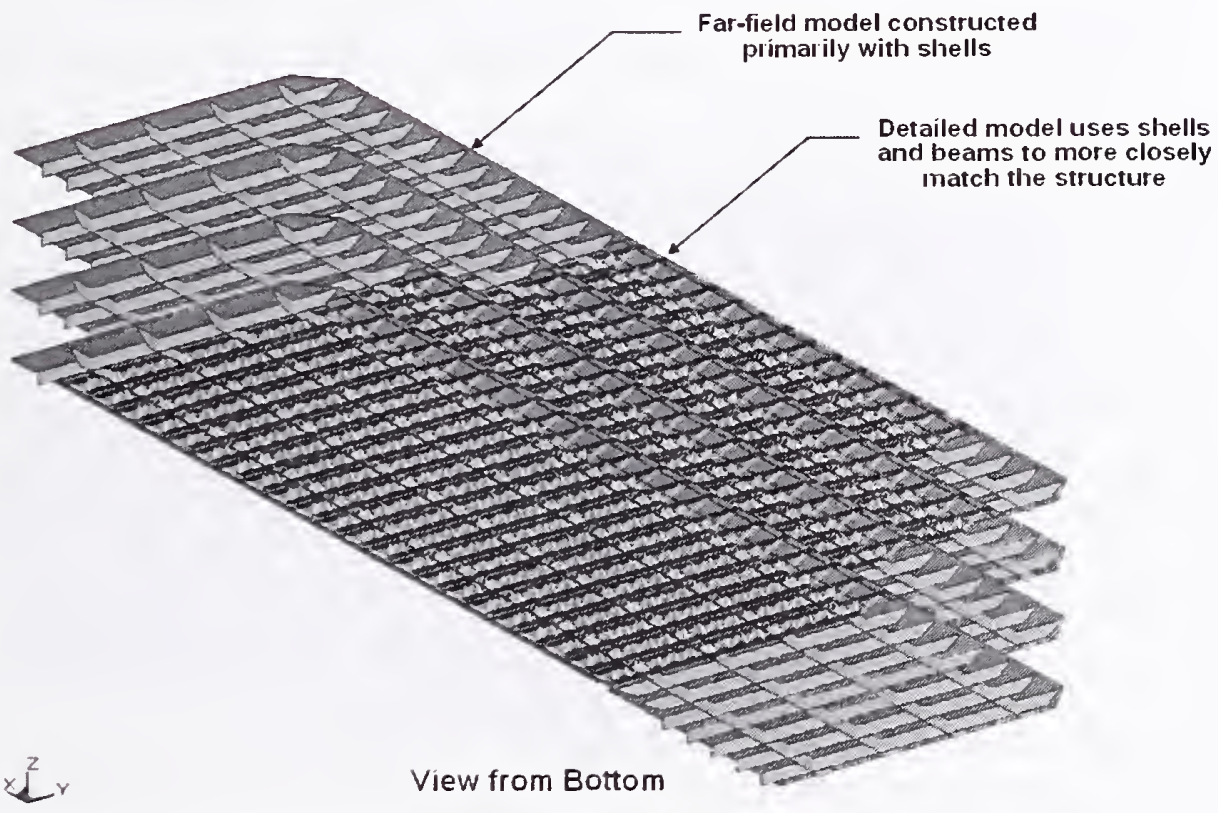

Figure 3-24. Truss floor components in the WTC 1 global impact model. 


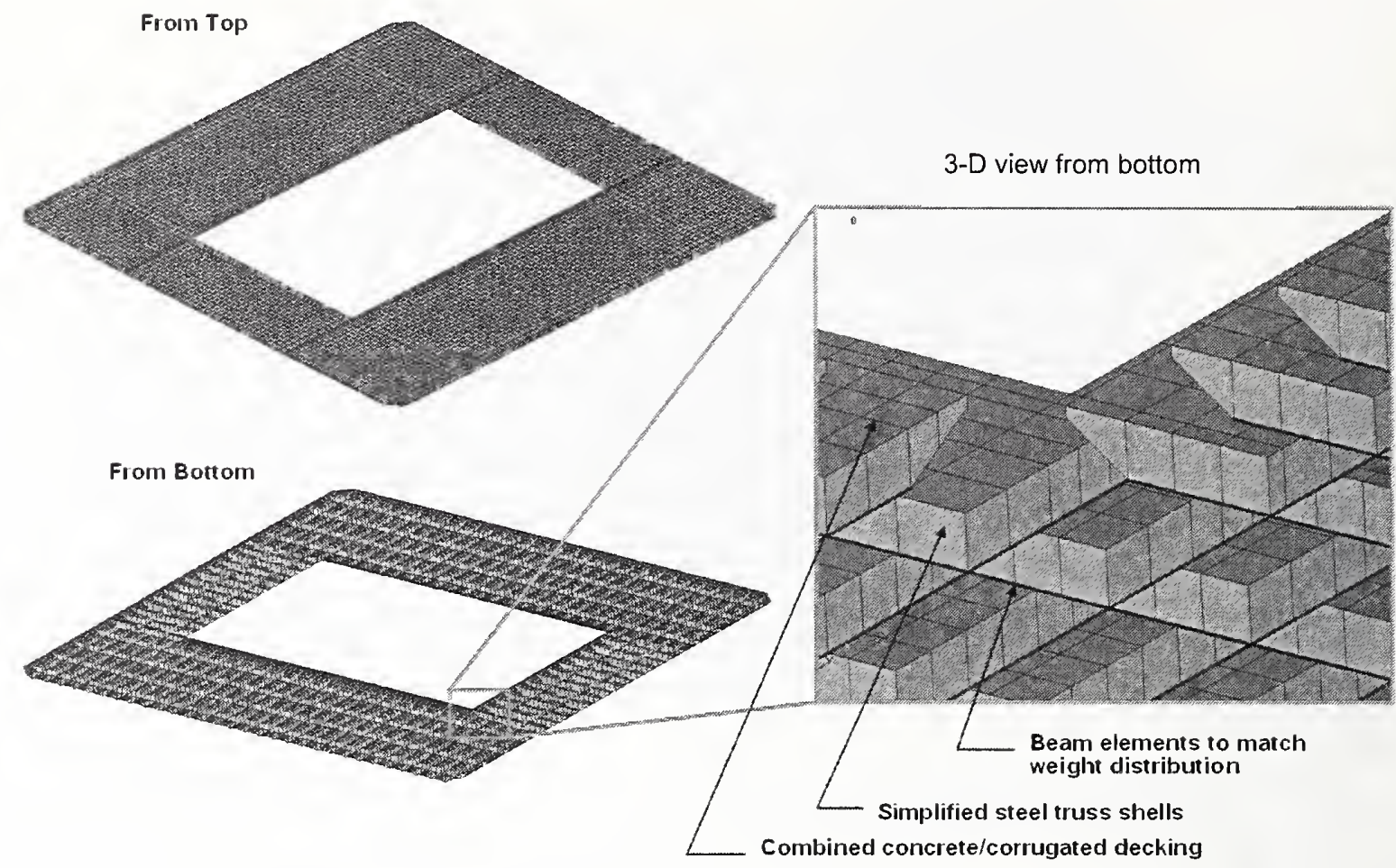

Figure 3-25. Far field truss floor model in the WTC towers.

The multiple floor global model for the impact zone of WTC 2 is shown in Figure 3-26. The model included the complete floor inside and outside the core for floors 77 through 85 . The exterior wall panels at the bottom end of the model extended downward below floor 75. The boundary conditions for the ends of the exterior and core columns at the top and bottom of the model were the same as those for the WTC 1 model. The higher resolution exterior wall panels in the impact zone, shown previously in Figure 3-11, can be seen on the impact face of the WTC 2 tower model (Side 400).

The WTC 2 global impact model with the exterior wall removed is shown in Figure 3-27. This figure shows how the WTC 2 model was optimized to reduce the mesh size and eliminate computational requirements outside of the immediate impact and damage zone. The nonstructural building contents were again modeled only in the path of the aircraft impact and debris cloud. These components are shown separately in Figure 3-28. Similarly, the truss floor structures near the impact zone were modeled in greater detail as seen in Figure 3-27. These detailed sections of the truss floor were positioned adjacent to Side 400 (south face) for floors 78 through 81 and Side 300 (east face) for floors 81 and 82 . The surrounding truss floor structures were again modeled with the far-field truss model shown previously in Figure 3-25.

To summarize, the approach adapted for the development of the global impact models for towers WTC 1 and WTC 2 was similar. The structures were modeled primarily with shell elements with some beam elements in the detailed truss floor sections and bolted connections between the column ends in the impact zone of the exterior wall. Some brick elements were used at the exterior column butt plates in the detailed impact zone. A summary of the model size and element types for the global tower models is presented in Table 3-2. 


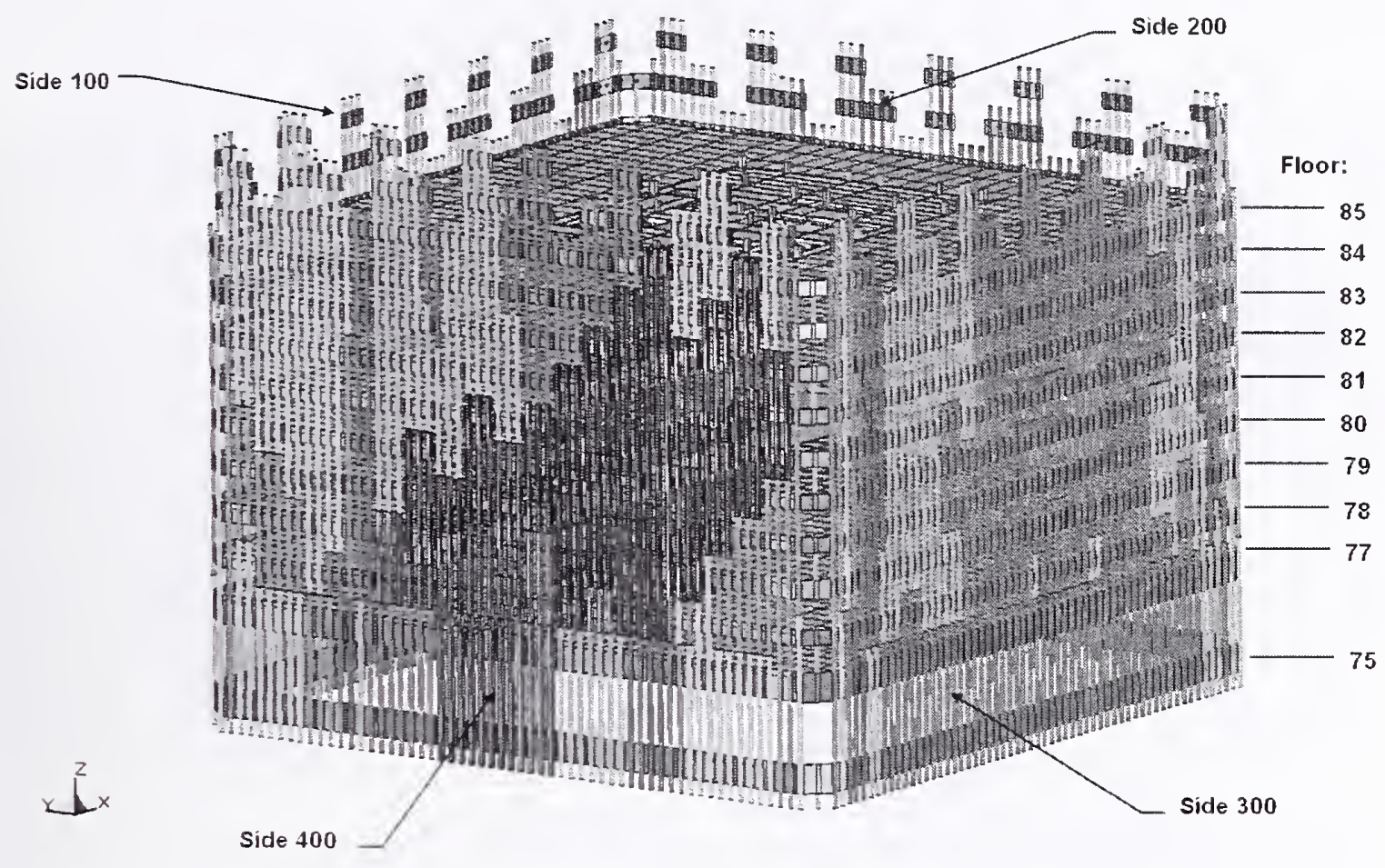

Figure 3-26. Multi-floor global impact model of the WTC 2 tower.

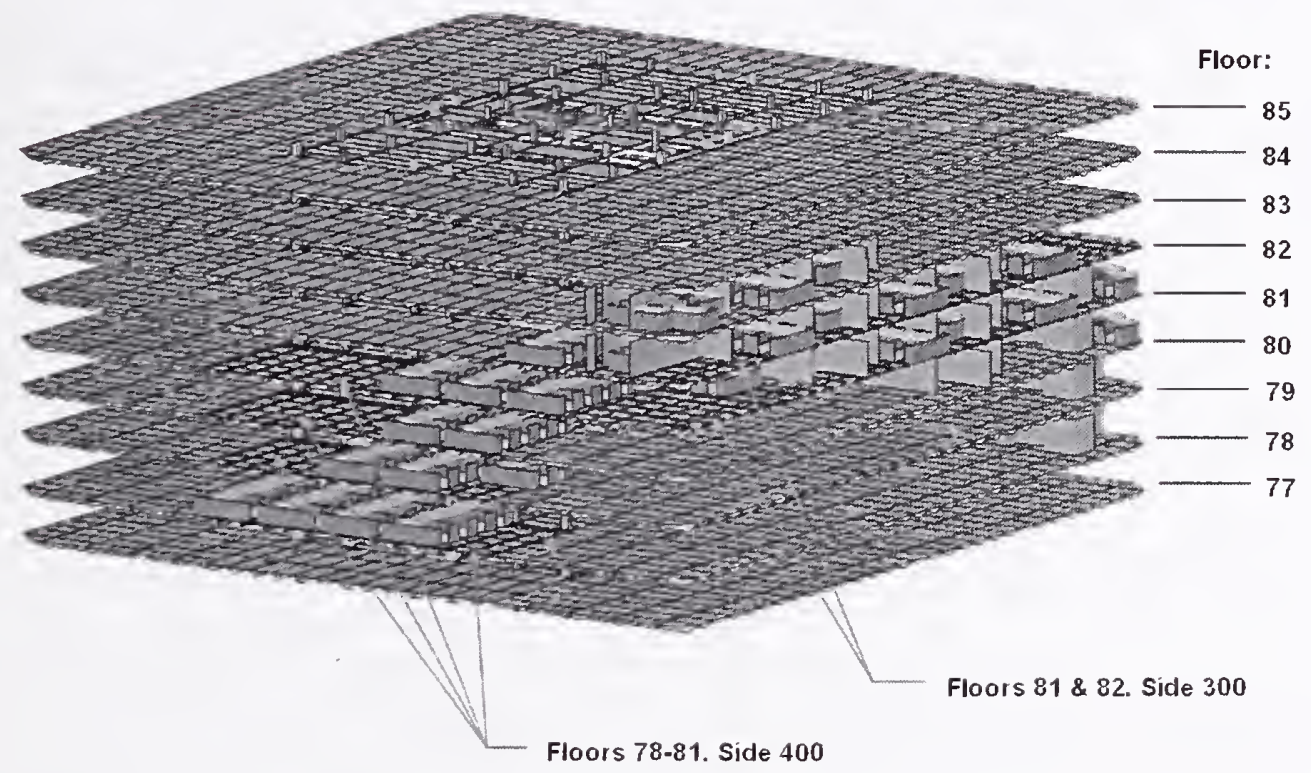

Figure 3-27. Interior structures and contents of the WTC 2 global impact model. 


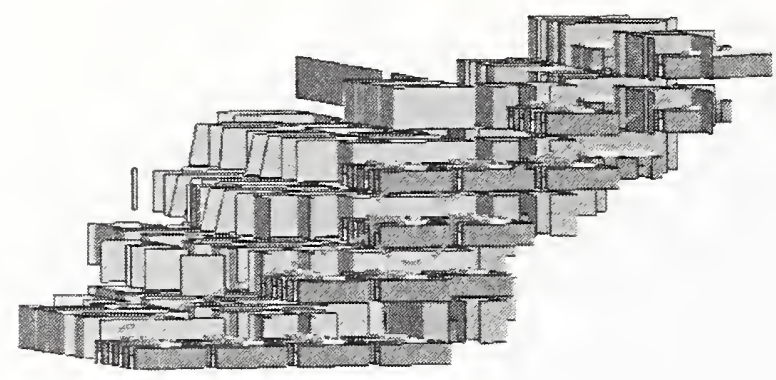

Workstations and

walls distributed in

View looking in approximate

impact direction

impact path only

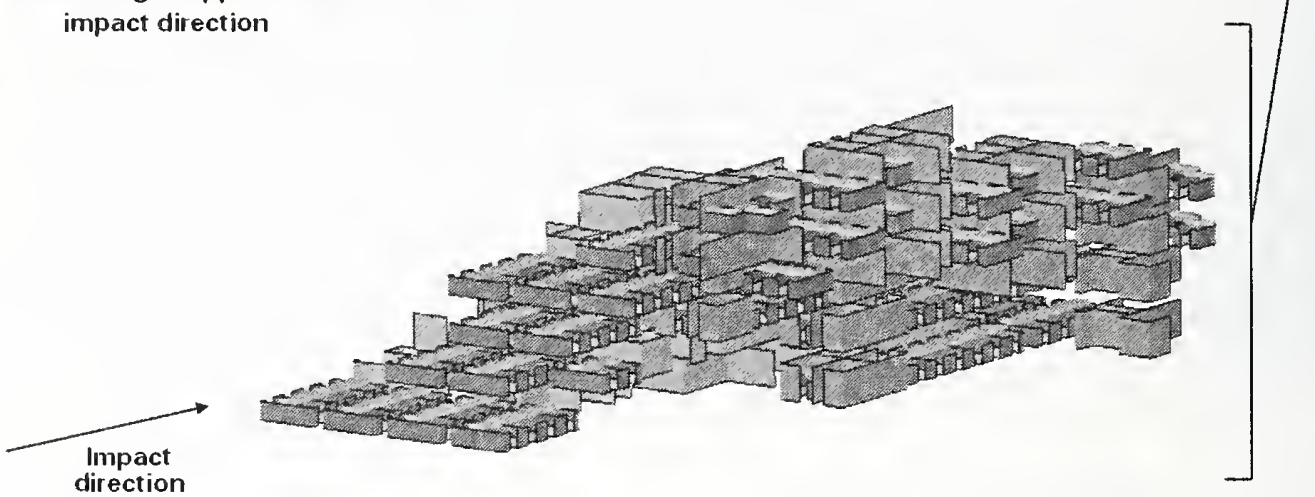

Figure 3-28. Building contents in the WTC 2 global impact model.

Table 3-2. Summary of the global impact models for the WTC towers.

\begin{tabular}{|l|c|c|}
\hline & WTC 1 Tower Model & WTC 2 Tower Model \\
\hline Number of Nodes & $1,300,537$ & $1,312,092$ \\
\hline Hughes-Liu Beam Elements & 47,952 & 53,488 \\
\hline Belytschko-Tsay Shell Elements & $1,156,947$ & $1,155,815$ \\
\hline Constant Stress Solid Elements & 2,805 & 2,498 \\
\hline
\end{tabular}

\subsection{REFERENCES}

"LS-DYNA Keyword User's Manual," Livermore Software Technology Corporation, Version 970, April 2003.

"TrueGrid Manual, Version 2.1.0," XYZ Scientific Applications, Inc., September 2001.

"World Trade Center Building Performance Study: Data Collection, Preliminary Observations, and Recommendations," Federal Emergency Management Agency, FEMA 403, May 2002. 


\section{Chapter 4 \\ AIRCRAFT MODEL DEVELOPMENT}

\section{$4.1 \quad$ INTRODUCTION}

The finite element model for the Boeing 767-200ER aircraft was constructed through a three-step process: (1) data collection, (2) data interpretation and engineering analysis, and (3) meshing of the structure. The focus of this effort was on gathering sufficient structural data and including adequate detail in the aircraft model so that the mass and strength distribution of the aircraft and contents were properly captured for implementation in the impact analyses.

A fundamental limitation in the simulations described herein was the maximum finite element model size that could be executed on the available 32-bit computer clusters. Since LS-DYNA uses addressable memory for domain decomposition, the combined aircraft and tower model could not exceed approximately 2.3 million nodes. Due to this model size limitation, the Boeing 767-200ER model could not exceed 750,000 nodes.

The objective of the aircraft model development was to properly simulate the impact damage and aircraft break up and their effects on the World Trade Center (WTC) towers. Key requirements were to simulate the mass distribution, dynamic impact response, fragmentation, and progress of the aircraft components and debris into and through the towers. The modeling approach was to model the airframe completely using shell elements as opposed to a shell element skin and beam elements for the airframe. Shell elements in the airframe provided higher fidelity simulation of the impact response and fragmentation behavior. As a result of the model size constraints, some of the details and smaller structural elements were not modeled explicitly. Where modeling simplifications were required, component analyses were applied to ensure that the impact strength and break up behavior were maintained.

An example of this approach was the development of the wing model. A section of the aircraft wing structure was first modeled with a very fine mesh of the detailed wing structure to establish a baseline behavior for aircraft structural failure and fragmentation upon impacting the exterior wall of the WTC towers. A coarser and simplified version of the same wing section was subsequently developed and the failure criteria were modified to obtain similar impact and fragmentation behavior to the fine, detailed version. Section 4.3.2 describes how this model was constructed and the methodology used for developing the coarsely meshed wing section. A similar mesh resolution and failure criteria were used throughout the rest of the aircraft.

The following sections outline the overall aircraft model developed for the impact analysis. Details in modeling each major component including the wings, engines, fuselage, empennage, and landing gear are provided. The final section provides an analysis of the fuel distribution in the aircraft at the time of impact. 


\subsection{AIRCRAFT DATA COLLECTION}

Structural data were collected for the Boeing 767-200ER aircraft from the open literature, electronic surface models and CAD drawings, an inspection of a 767-300ER, an Aircraft Structural Manual, Pratt and Whitney PW4000 Engine Reference Manuals, American and United Airlines, and the Boeing Company website. The following is a description of how these various sources were used for model development.

\subsubsection{Electronic Surface Models}

Two electronic surface models of a Boeing 767-200ER were obtained from Digimation. These surface models were part of a large database of models developed by several sources. As a result, Digimation was not able to provide reference information about the data used in the surface model development.

To evaluate the digital surface models, the model geometry was compared to electronic two-dimensional CAD descriptions obtained from the Boeing Company web site, as shown in Figure 4-1. The first model, VP3311 shown in Figure 4-1(a), did not match the CAD descriptions well. However, the second model, VP15710 shown in Figure 4-1(b), matched the CAD descriptions, showing only minor discrepancies in the position of the horizontal stabilizers. The VP15710 surface model geometry was subsequently modified to match the CAD description from Boeing and was used in the aircraft model generation to define the exterior surface geometry.

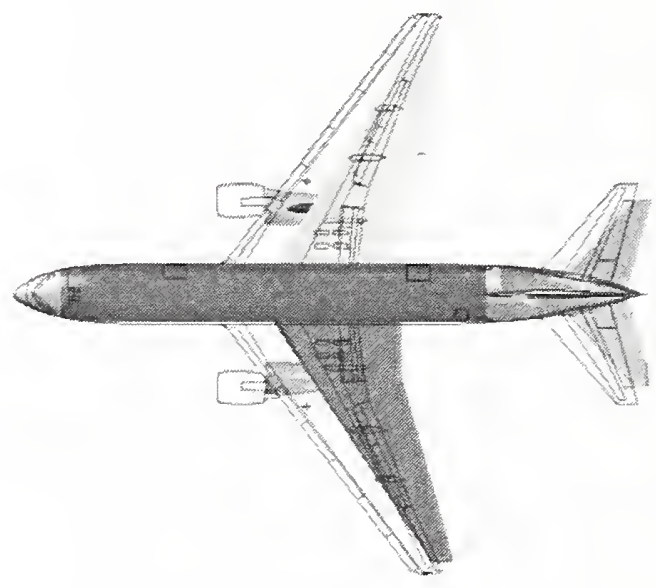

(a) Model VP3311

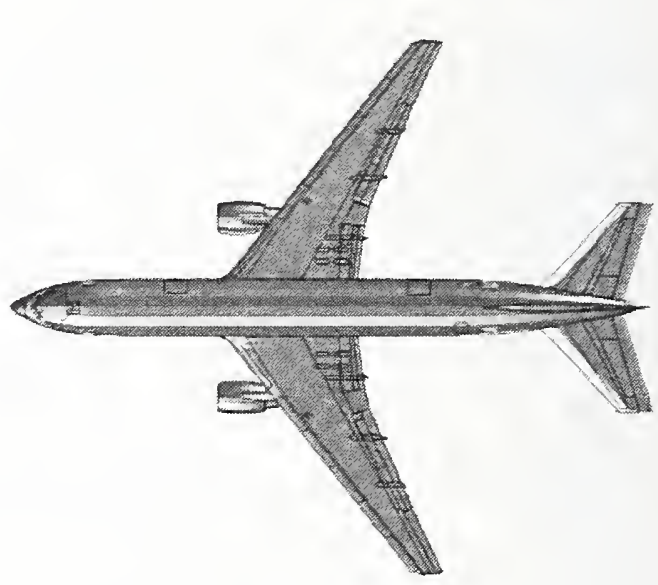

(b) Model VP15710

Figure 4-1. Surface models superimposed on Boeing CAD drawings of a 767-200ER.

\subsubsection{Aircraft Inspection}

No Boeing 767-200 aircraft was available for inspection. In order to obtain detailed structural information on the 767 aircraft, arrangements were made with an aviation company to inspect a 767-300ER. A comparison between the Boeing 767-200ER and the 767-300ER aircraft is shown in Figure 4-2. On the 767-300ER, the fuselage is extended, the horizontal stabilizers have a larger sweep angle, and parts of the structure are reinforced. Aside from these differences, the two aircraft are nearly identical. 


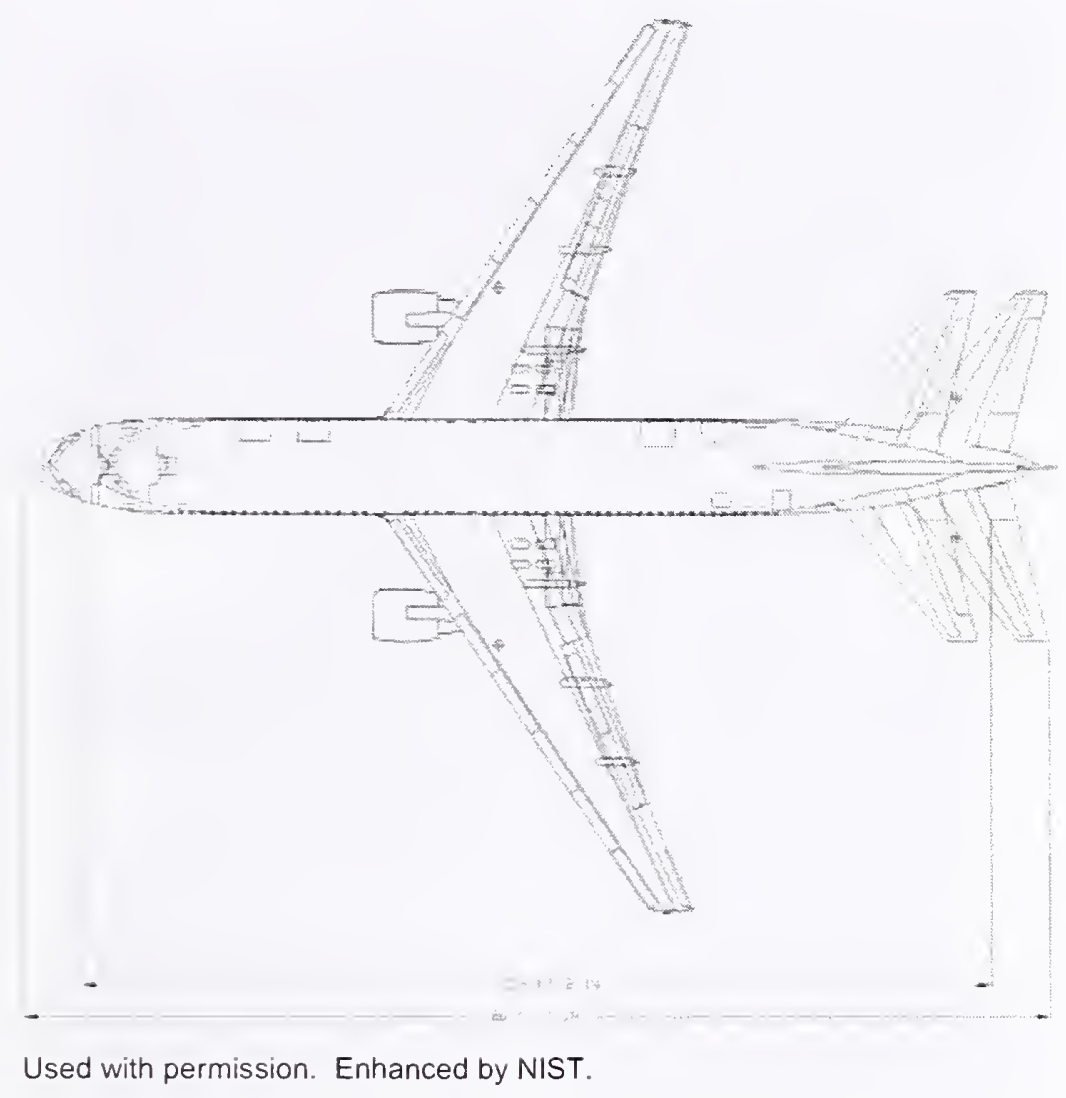

Figure 4-2. Superimposed CAD drawings of the 767-200ER and 767-300ER.

Three ARA personnel visited the aircraft storage location where they were allowed access to the 767-300ER to take photographic and dimensional data of the aircraft. Photographic documentation of various aircraft components are shown in Figure 4-3. Photographs similar to these were critical in developing the model of the aircraft.

For the landing gear, global dimensions were taken along with ultrasonic thickness measurements of the major structural components, as shown in Figure 4-4. Ultrasonic measurement locations are marked in the photograph by the blue tape positions in Figure 4-4. Locations, dimensions, and approximate masses of various non-structural components such as the overhead luggage containers, overhead electronics, and under floor electronics were also documented, as shown in Figure 4-5. 

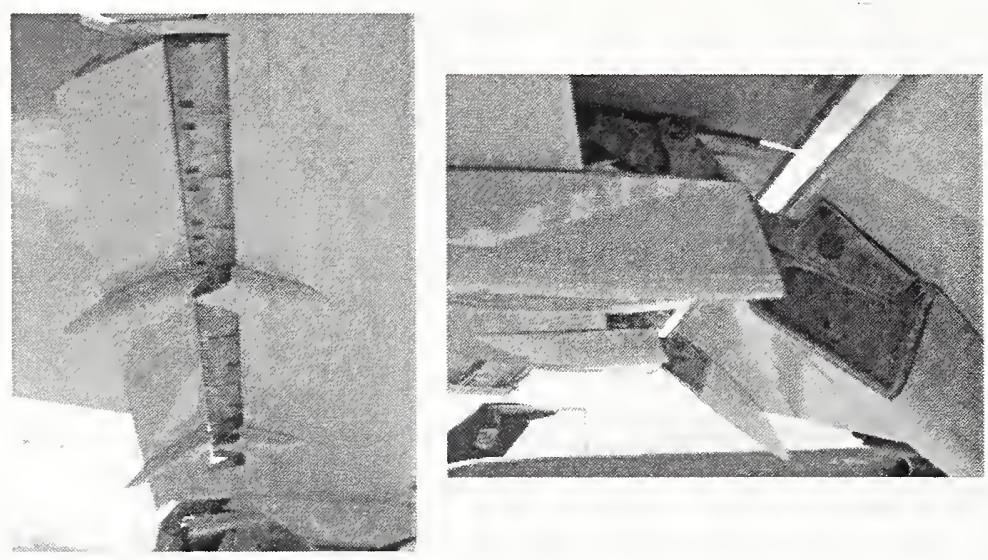

(a) Control surfaces and linkage
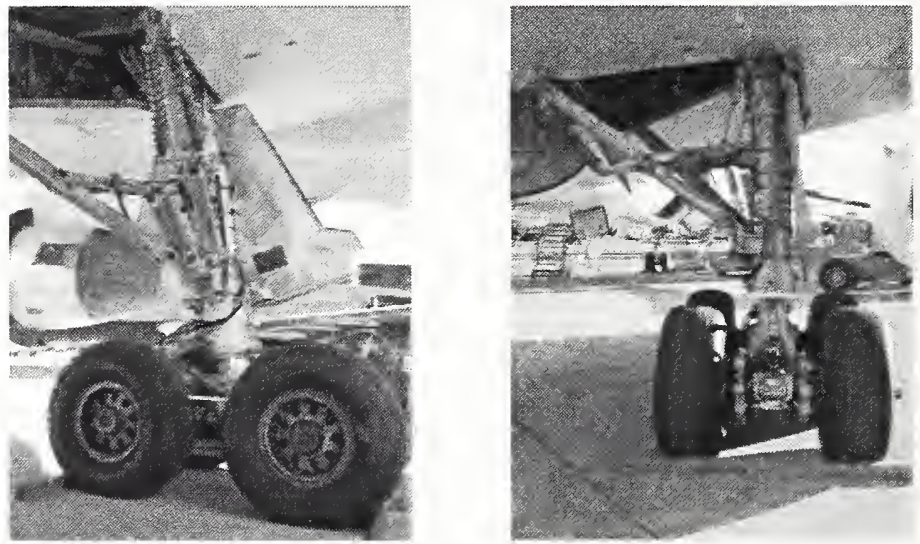

(b) Main landing gear
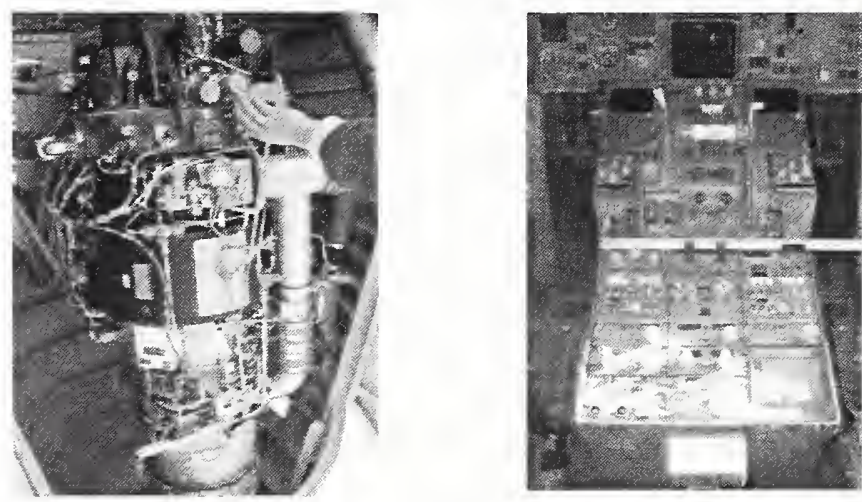

(c) Non-structural contents

Source: NIST.

Figure 4-3. Photographic documentation of Boeing 767-300ER. 


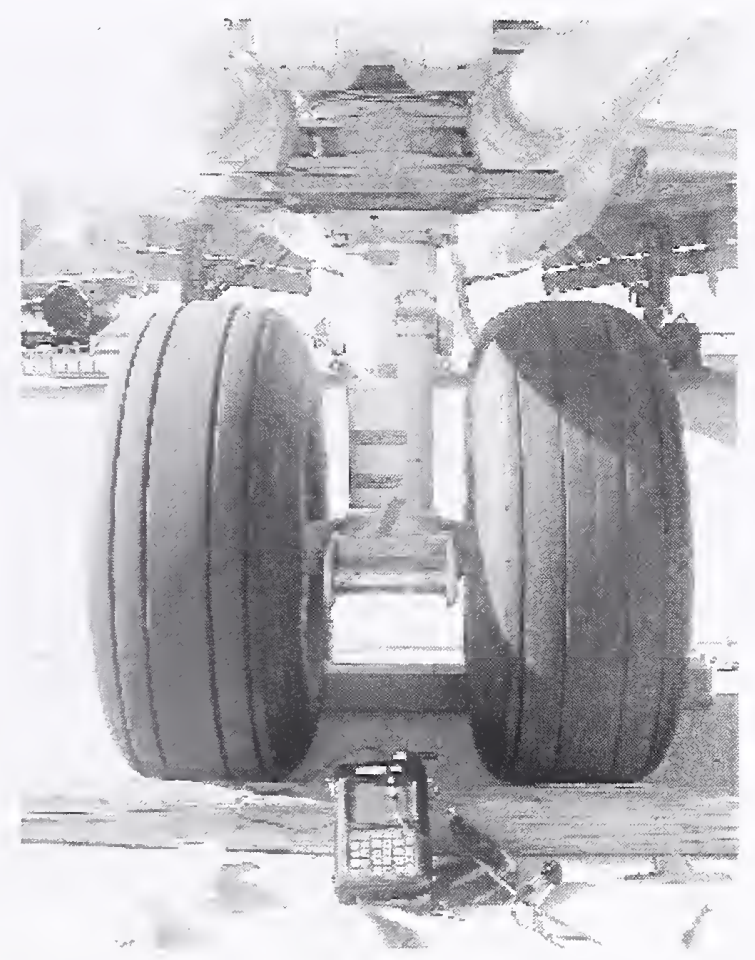

(a) Nose gear

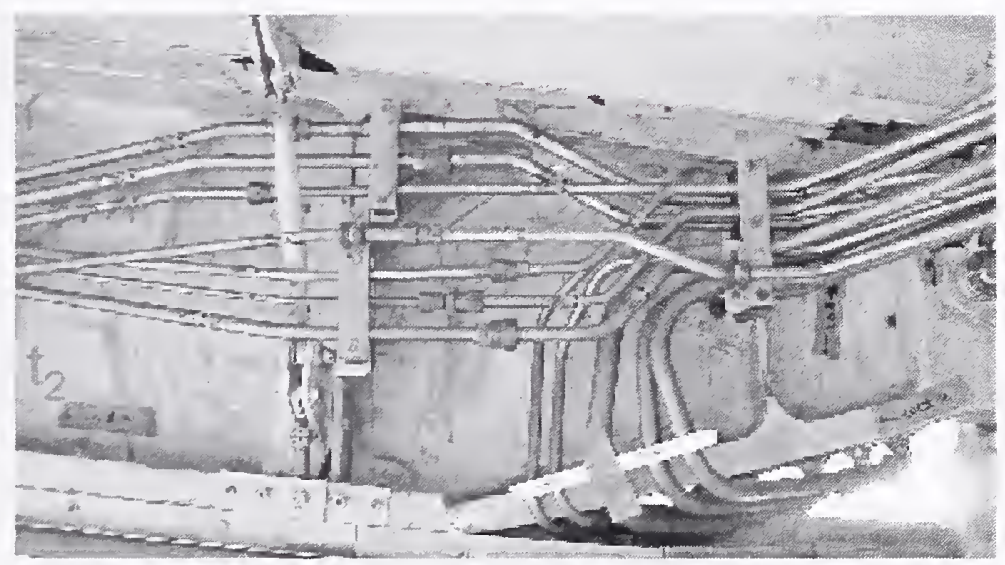

(b) Ultrasonic measurement locations

Source: NIST.

Figure 4-4. Ultrasonic thickness measurement of landing gear components. 


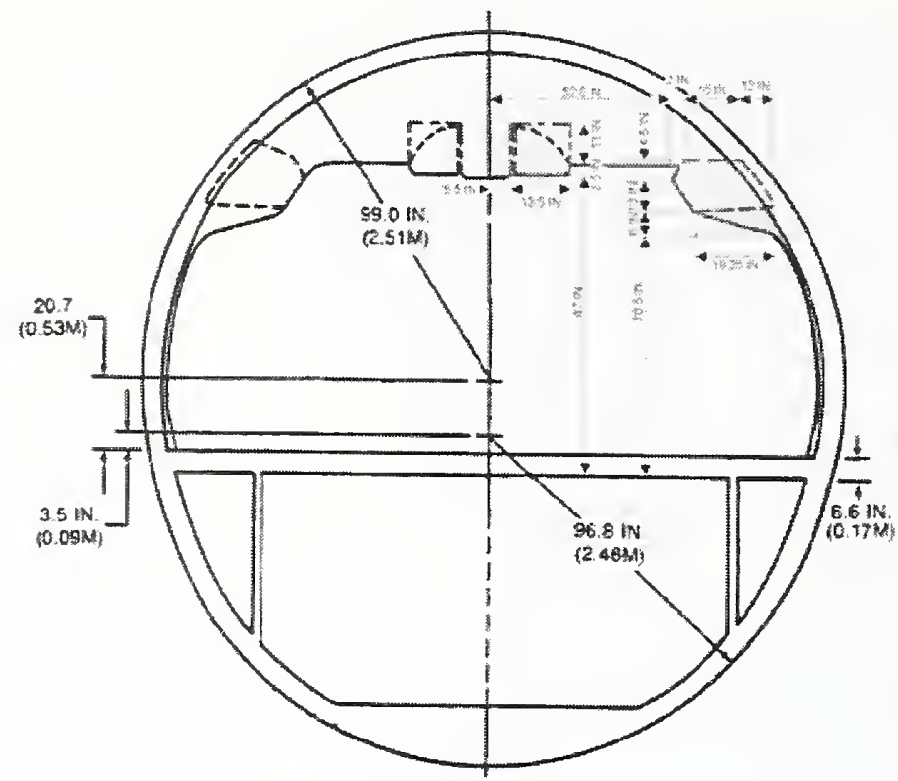

- Fore-Aft Length

- Section 53-00-00 pages

$2 \& 3$ indicate rough locations of doors and galleys

- Stowage bins extend from $275.5^{\prime \prime}$ to 737.5 " and from 862.5" to $1346.5^{\prime \prime}$

Shell (ras is $12^{\prime \prime}$ fiberglass honeycomb

Luggage |greger | and electronics (siduch fill remainder of space

- Listed load limit is $87 \mathrm{lb}$ per $8^{99}$ long bin $\approx 5.916 / \mathrm{ft}^{3}$

(a) Overhead luggage containers and contents
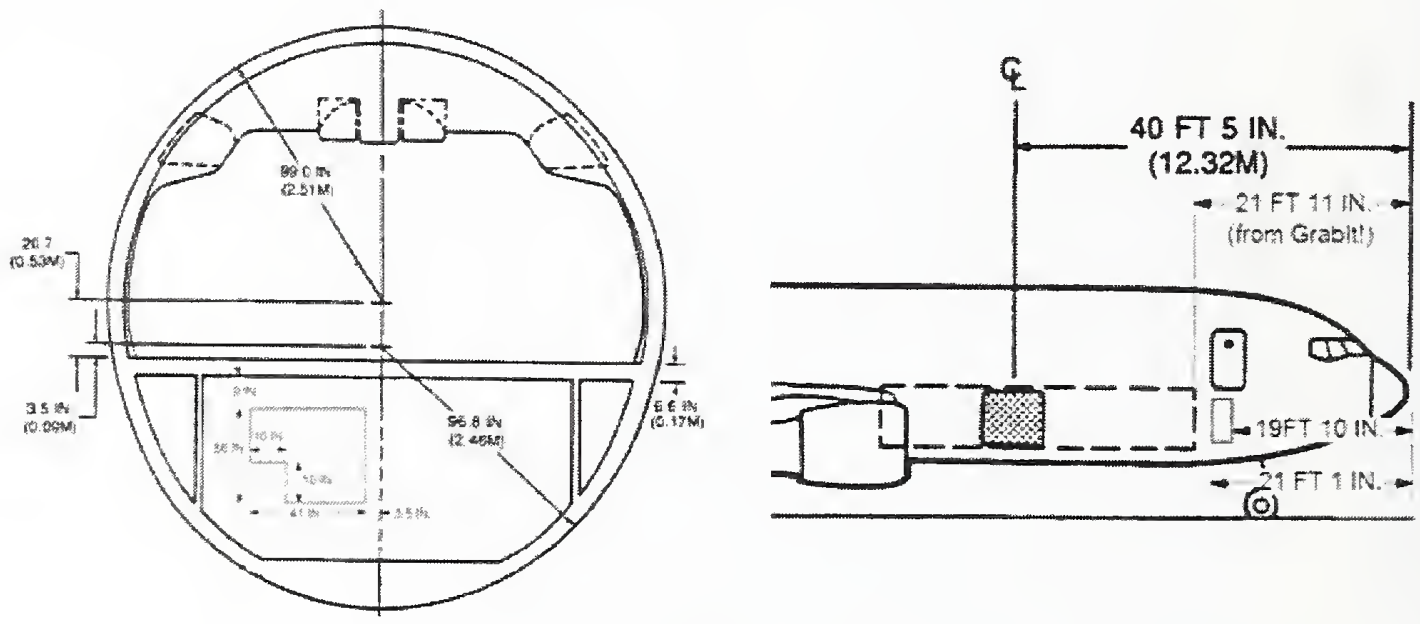

(b) Under floor electronics

Used with permission. Enhanced by NIST

Figure 4-5. Non-structural mass locations in the fuselage.

\subsubsection{Pratt \& Whitney PW4000 Engine Reference Manuals}

Initial sources indicated that the Pratt \& Whitney PW4000 engine and the General Electric CF6-80 engine were on the aircraft that impacted the WTC towers (FEMA 2002). For this reason, the Engine Reference Manuals were obtained from Pratt \& Whitney for the PW4000 turbofan engine. These manuals contained detailed information on the engine geometry and materials, as shown in Figure 4-6. A detailed finite element model of the PW4000 engine was developed from these manuals. 


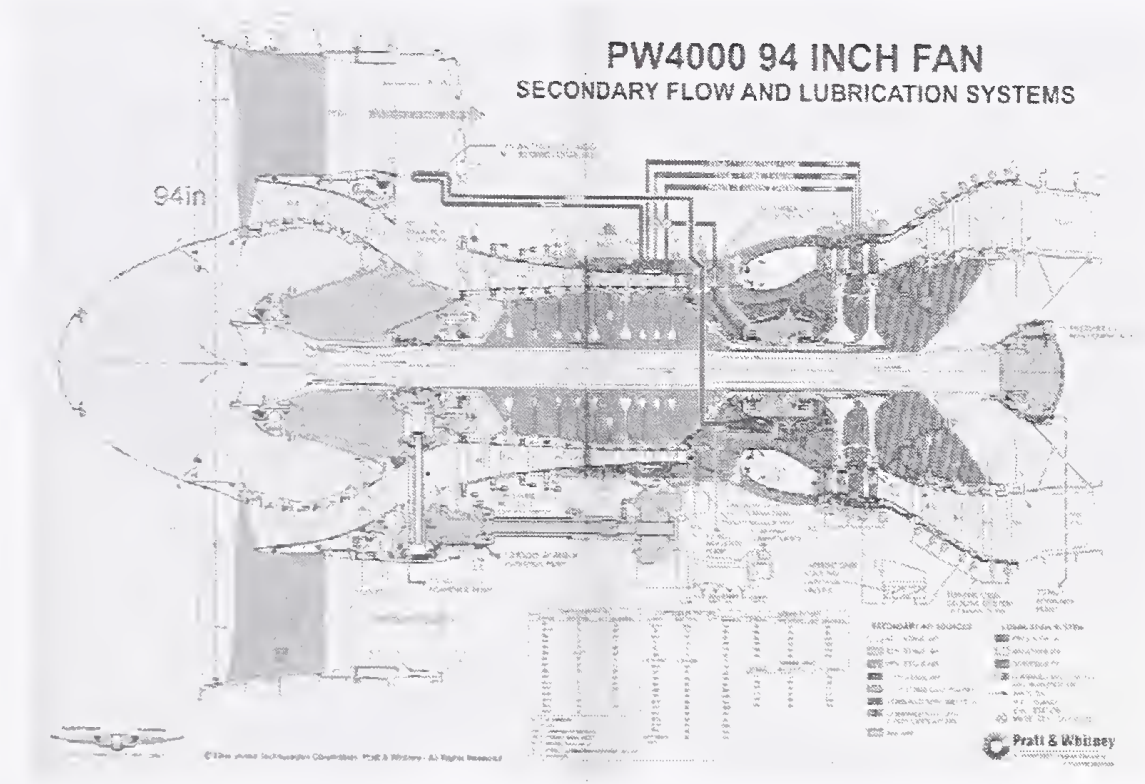

Used with permission.

\section{Figure 4-6. Cutaway of a Pratt and Whitney PW4000 turbofan from the Engine Reference Manual.}

After the engine model was developed, the engine types on each aircraft were clarified by the Aviation Safety Network (http://aviation-safety.net/). American Airlines flight 11 that impacted WTC I was powered by two General Electric CF6-80A2 engines. United Airlines flight 175 that impacted WTC 2 was powered by two Pratt \& Whitney JT9D-7R4D engines. However, careful review of these engines indicated that the PW4000 turbofan engine is very similar to the General Electric CF6-80A2 and the PW JT9D-7R4D engines. Comparisons of specific physical characteristics of the engines are given in Table 4-1. In fact, the JT9D-7R4 and PW4000-94 are almost identical as they are in the same family of Pratt \& Whitney aircraft engines. The PW4000 was labeled the "new technology JT9D" when it began replacing the latter engine on $767 \mathrm{~s}$ built after 1987 where the PW4000-94 is 5.8 percent heavier than the JT9D-7R4 but produces up to 10 percent more thrust. Aside from an additional set of long stator blades and elongated exit nozzle, the CF6-80C2 is also of similar weight and dimensions to the PW4000. Due to these similarities, the PW4000 engine model was used for all impact simulations. Differences in the weights of aircraft components were included in the uncertainty analyses.

Table 4-1. Boeing 767 engine comparison.

\begin{tabular}{|l|c|c|c|}
\hline \multicolumn{1}{|c|}{ Engine } & $\begin{array}{c}\text { Pratt \& Whitney } \\
\text { PW4000-94 }\end{array}$ & $\begin{array}{c}\text { Pratt \& Whitney } \\
\text { JT9D-7R4 }\end{array}$ & $\begin{array}{c}\text { General Electric } \\
\text { CF6-80C2 }^{\text {c,d }}\end{array}$ \\
\hline Fan Blade Diameter & 94 (in.) & 94 (in.) & 93 (in.) $)^{\mathrm{e}}$ \\
\hline Length & 153 (in.) & 153 (in.) & $161-168$ (in.) \\
\hline Dry Weight & 9,400 (lb) & 8,885 (lb) & $9,135-9,860(1 \mathrm{~b})$ \\
\hline
\end{tabular}

a. The JT9D-7R4 and PW4000-94 are almost identical: (1) They are in the same family of Pratt \& Whitney aircraft engines, and (2) the PW4000 was labeled the "new technology JT9D" when it began replacing the latter engine on 767s built after 1987.

b. The PW4000-94 is 5.8 percent heavier than the JT9D-7R4 but produces up to 10 percent more thrust.

c. The CF6-80C2 has an additional set of long stator blades for the excess fan air that is not present in the PW 4000 .

d. The second stage compressor blades in the CF6-80C2 are closer to the central shaft than the PW4000 and do not appear to have counter weights.

e. Reference value of 106 in. also found - may include cowling.

f. The "tail" of the CF6-80C2 is much longer than the PW4000. This potentially accounts for the additional 15 in. in length. 


\subsubsection{Airline Data and Data from the Boeing Company}

The Boeing Company provides some general information on the layout of their aircraft at their website (www.Boeing.com). Useful data on the seating layout and dimensions and the Unit Load Devices (ULDs or cargo containers) were available, as shown in Figure 4-7 and Figure 4-8. The cargo, fuel, and passenger and crew masses were also provided by the airlines for American Airlines flight 11 (AA11) (Condon \& Forsyth LLP, 2003) and United Airlines flight 175 (UAL175) [Midgett, 2003]. These data are outlined in Table 4-2. It was assumed in the global analyses that all 22 ULDs were onboard both flights for a total empty weight of 3,300 lb. Economy class seating was estimated at $25 \mathrm{lb}$ per seat for a total of $6,625 \mathrm{lb}$ when empty.
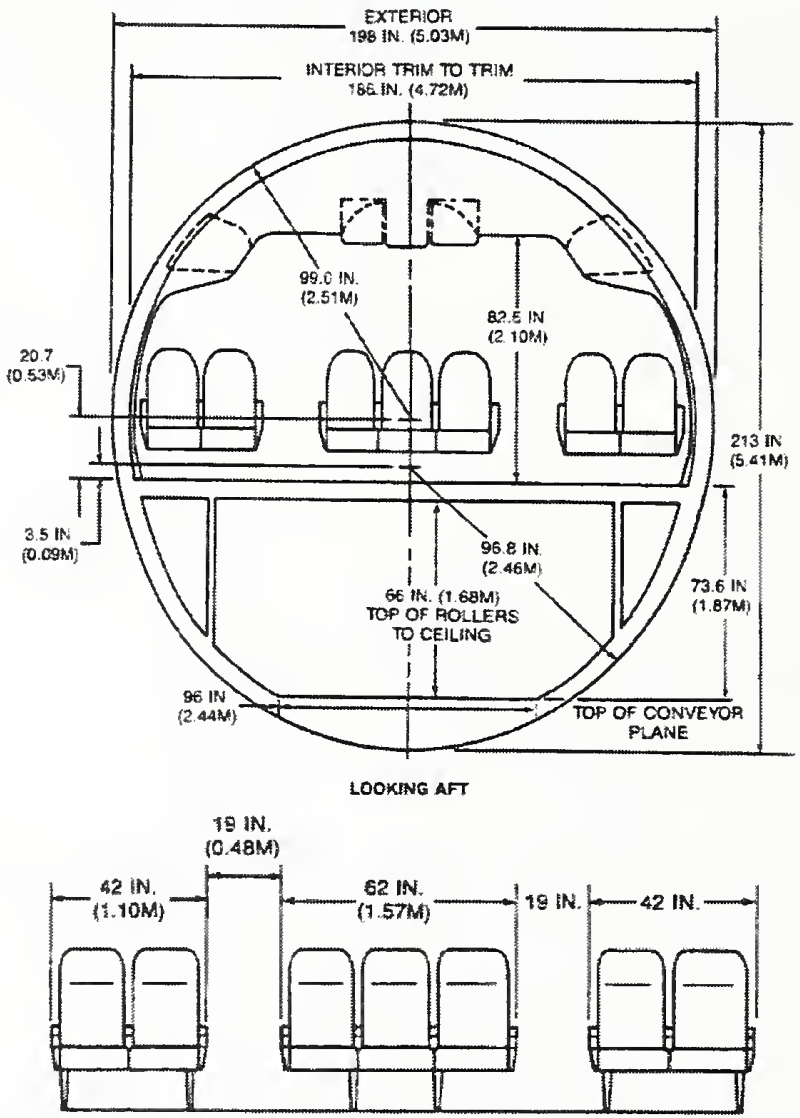

ECONOMY CLASS SEATNG

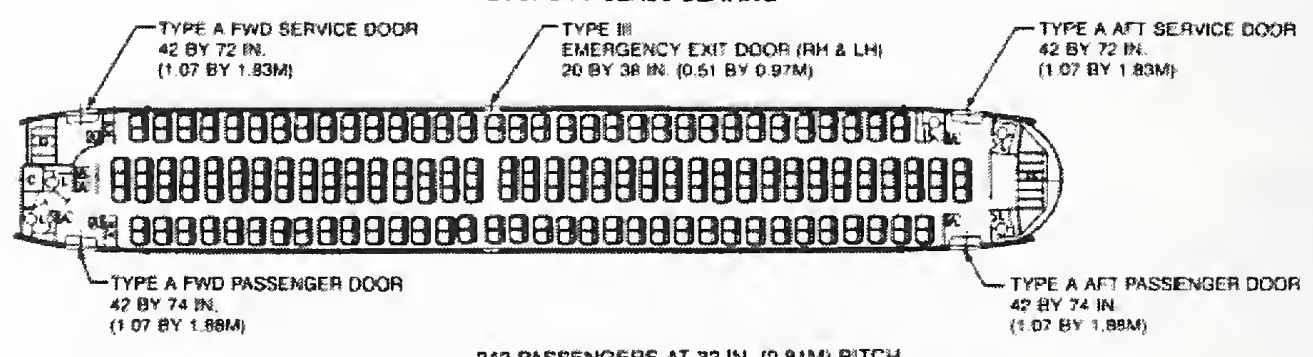

242 PASSENGEAS AT 32-1W (O A IM) PITCH

Used with permission.

Figure 4-7. Economy class seating location and dimensions (www.boeing.com). 

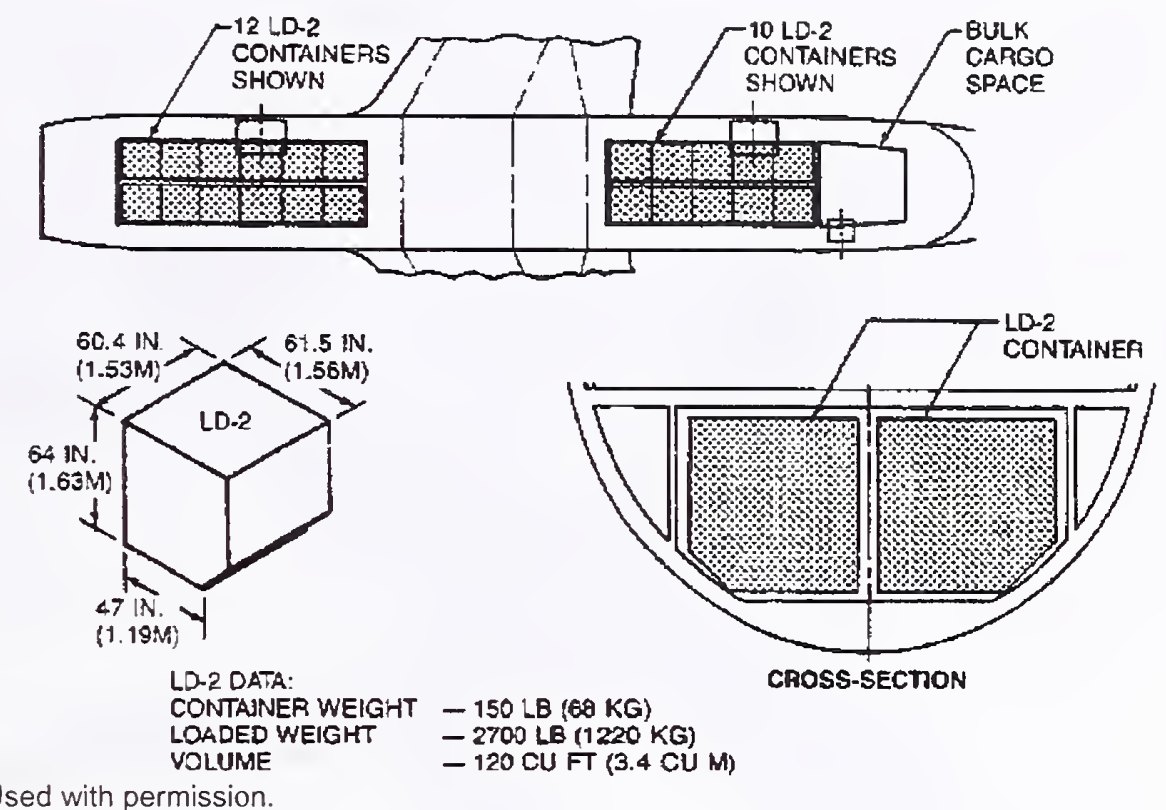

Used with permission.

Figure 4-8. Location and characteristics of the unit load devices (www.boeing.com).

Table 4-2. Cargo and passenger weights data.

\begin{tabular}{|l|c|c|}
\hline & AA 11 & UAL 175 \\
\hline Passengers and Crew & $14,720 \mathrm{lb}$ & $9.410 \mathrm{lb}$ \\
\hline Freight & $7,972 \mathrm{lb}$ & $16,970 \mathrm{lb}$ \\
\hline Luggage: Cargo hold & $1,150 \mathrm{lb}$ & $1,390 \mathrm{lb}$ \\
\hline Luggage: Carry on & $1,620 \mathrm{lb}$ & $1,010 \mathrm{lb}$ \\
\hline Catering & $5,234 \mathrm{lb}$ & - \\
\hline Total & $30,696 \mathrm{lb}$ & $28,780 \mathrm{lb}$ \\
\hline
\end{tabular}

\subsection{AIRCRAFT MODEL DEVELOPMENT}

Similar to the global towers structural model, the LS-DYNA model of the aircraft was generated and meshed using the TrueGrid software (TrueGrid Manual 2001). The complete model for the Boeing $767-$ 200ER is shown in Figure 4-9. A summary of the model parameters is presented in Table 4-3. The total empty mass represents an average cited by Jane's All the Worlds Aircraft (185,700 lb) (Jane's All the Worlds Aircraft 2001) and The Boeing Company (181,130 to 181,610 lb) (Boeing Company 1989) for an estimated empty weight of $183,500 \mathrm{lb}$. Notice that the weight cited for the ULD and seats includes the empty weights plus the passenger or cargo weight cited in Table 4-2. Carryon luggage and catering weight was distributed to the seats, and freight and cargo luggage weight was distributed to the ULDs.

Fuel was distributed in the wings as shown in Figure 4-10. Analysis of the fuel distribution is discussed later in Section 4.4. The wings of the aircraft were also deflected from the surface model geometry to represent their in-flight condition, as shown in Figure 4-11. A cubic function of the wing span was used with a tip deflection of approximately $52 \mathrm{in.} \mathrm{Tip} \mathrm{deflection} \mathrm{was} \mathrm{estimated} \mathrm{from} \mathrm{the} \mathrm{impact} \mathrm{pattern} \mathrm{seen} \mathrm{in}$ photographs of the WTC towers and from the damage documented on the exterior panels by NIST. 


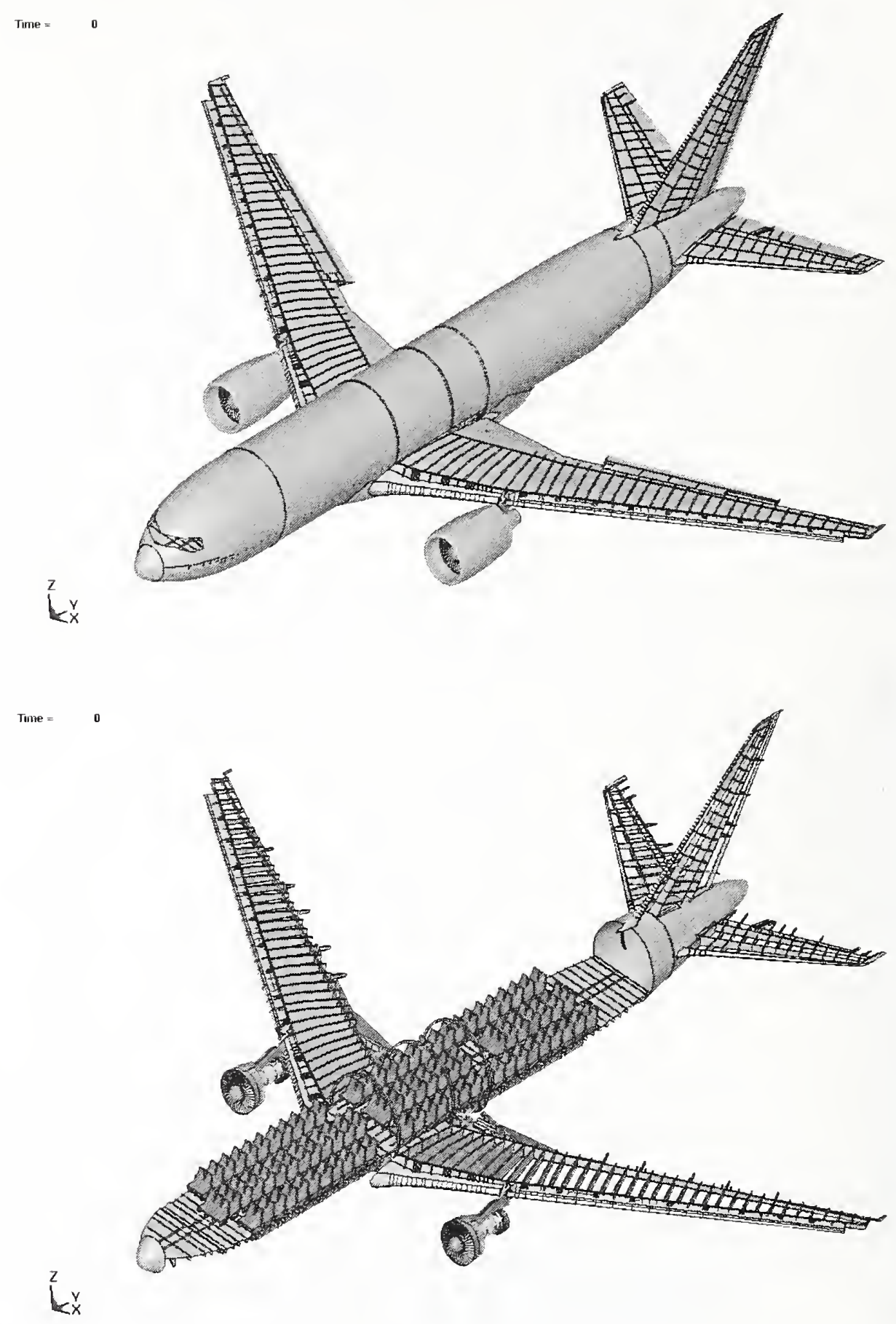

Figure 4-9. Finite element model of the Boeing 767-200ER. 
Table 4-3. Boeing 767-200ER aircraft model parameters.

\begin{tabular}{|l|c|c|}
\hline & AA 11 & UAL 175 \\
\hline No. Brick Elements & 70,000 & 70,000 \\
\hline No. Shell Elements & 562.000 & 562.000 \\
\hline No. SPH Fuel Particles & 60,672 & 60,672 \\
\hline Total Nodes & 740,000 & 740,000 \\
\hline Total Weight (Empty) & $183.500 \mathrm{lb}$ & $183,500 \mathrm{lb}$ \\
\hline ULD/Cargo Weight & $12.420 \mathrm{lb}$ & $21,660 \mathrm{lb}$ \\
\hline Cabin Contents Weight & $21.580 \mathrm{lb}$ & $10,420 \mathrm{lb}$ \\
\hline Fuel Weight & $66,100 \mathrm{lb}$ & $62,000 \mathrm{lb}$ \\
\hline Total Weight (Loaded) & $283.600 \mathrm{lb}$ & $277,580 \mathrm{lb}$ \\
\hline
\end{tabular}

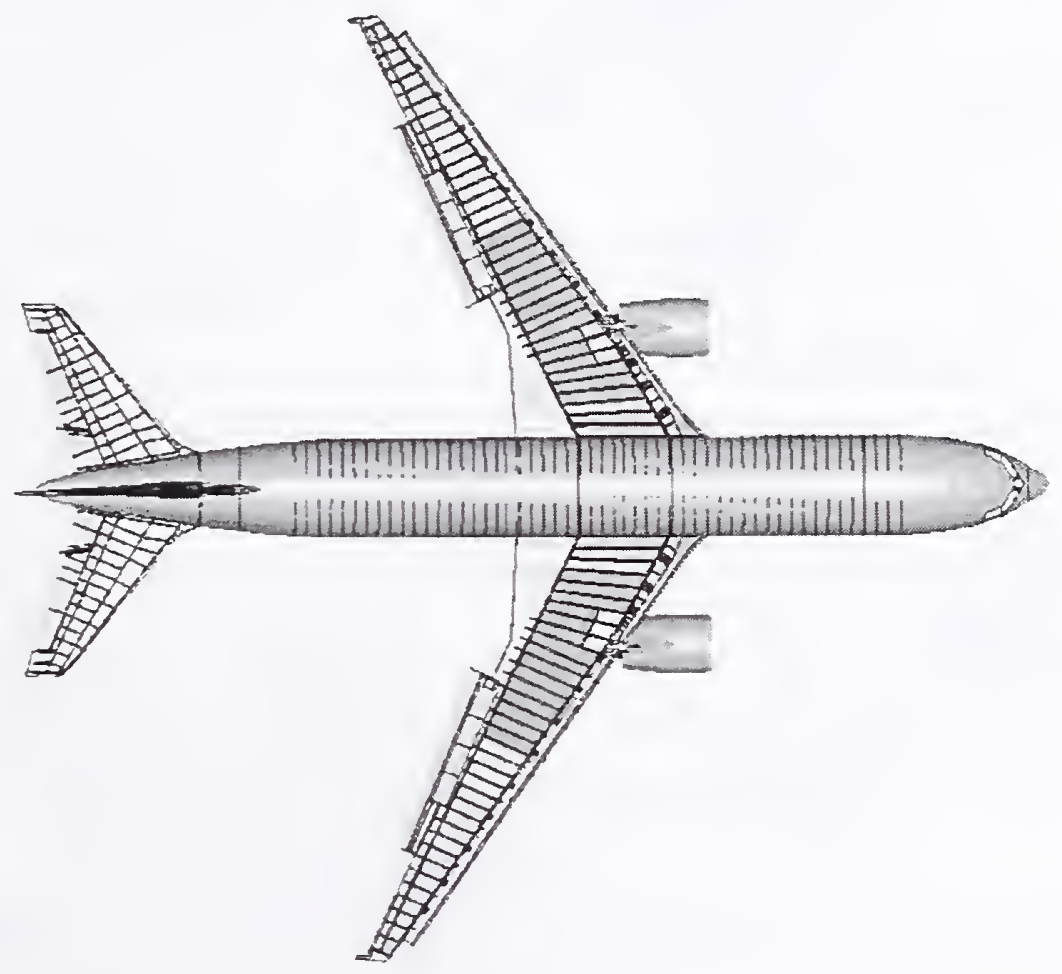

Figure 4-10. Boeing 767-200ER with fuel load at time of impact. 


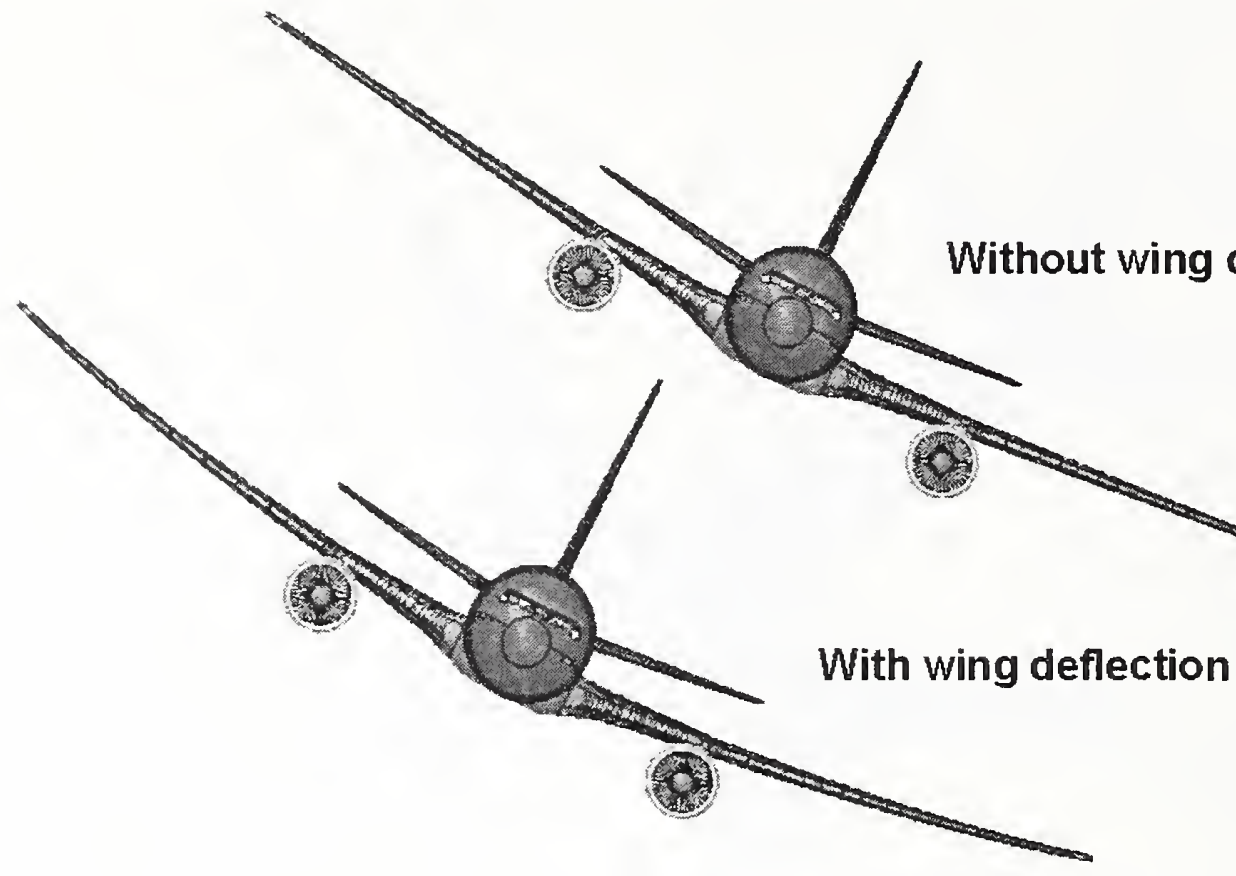

Figure 4-11. Boeing 767-200ER model wing deflections.

\subsubsection{Airframe Model Development}

The airframe model developed for the Boeing 767-200ER contained most of the significant structural components in the aircraft. The models of the fuselage, empennage, and wing structures were developed completely using Belytschko-Tsay shell elements. Models for the landing gear and engines were primarily developed using shell elements, but contained some brick elements as well. The model was developed in a parameterized form where the mesh resolution was determined by a single element characteristic size parameter. This approach was selected early in the development to allow flexibility in the model size and resolution as the model development and impact analyses progressed. The objective was to develop a mesh with typical element dimensions between 1 in. and 2 in. for small components, such as spar or rib flanges, and element dimensions of 3 in. to 4 in. for large parts such as the wing or fuselage skin.

Detailed models of the empennage and landing gear are shown in Figure 4-12 and Figure 4-13, respectively. Ribs, spars, rudder, and elevator were all modeled in detail in the empennage. Tires and hubs, the main strut and truck, and support bracing were all included in the landing gear model. The underside of the airframe in the model is shown in Figure 4-14, illustrating the position of the retracted main landing gear in the wheel well. Also shown in the figure are the Unit Load Devices (ULDs shown in red with blue edges). The density of these containers was scaled to include the weight of the cargo. 


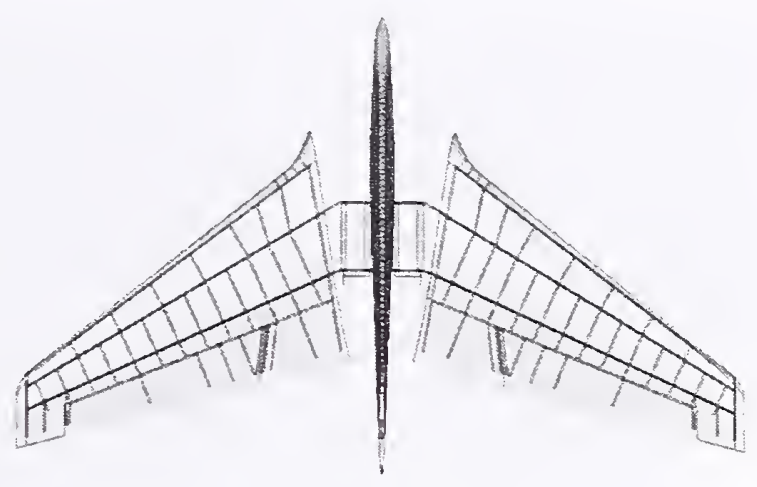

(a) Top view

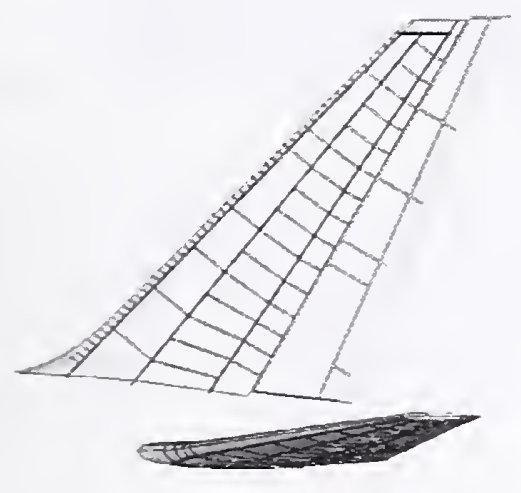

(b) Side view

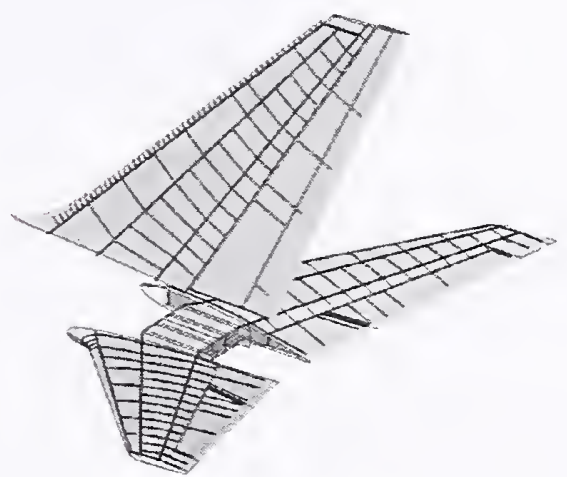

(c) Oblique view

Figure 4-12. Empennage model for the 767-200ER aircraft model.

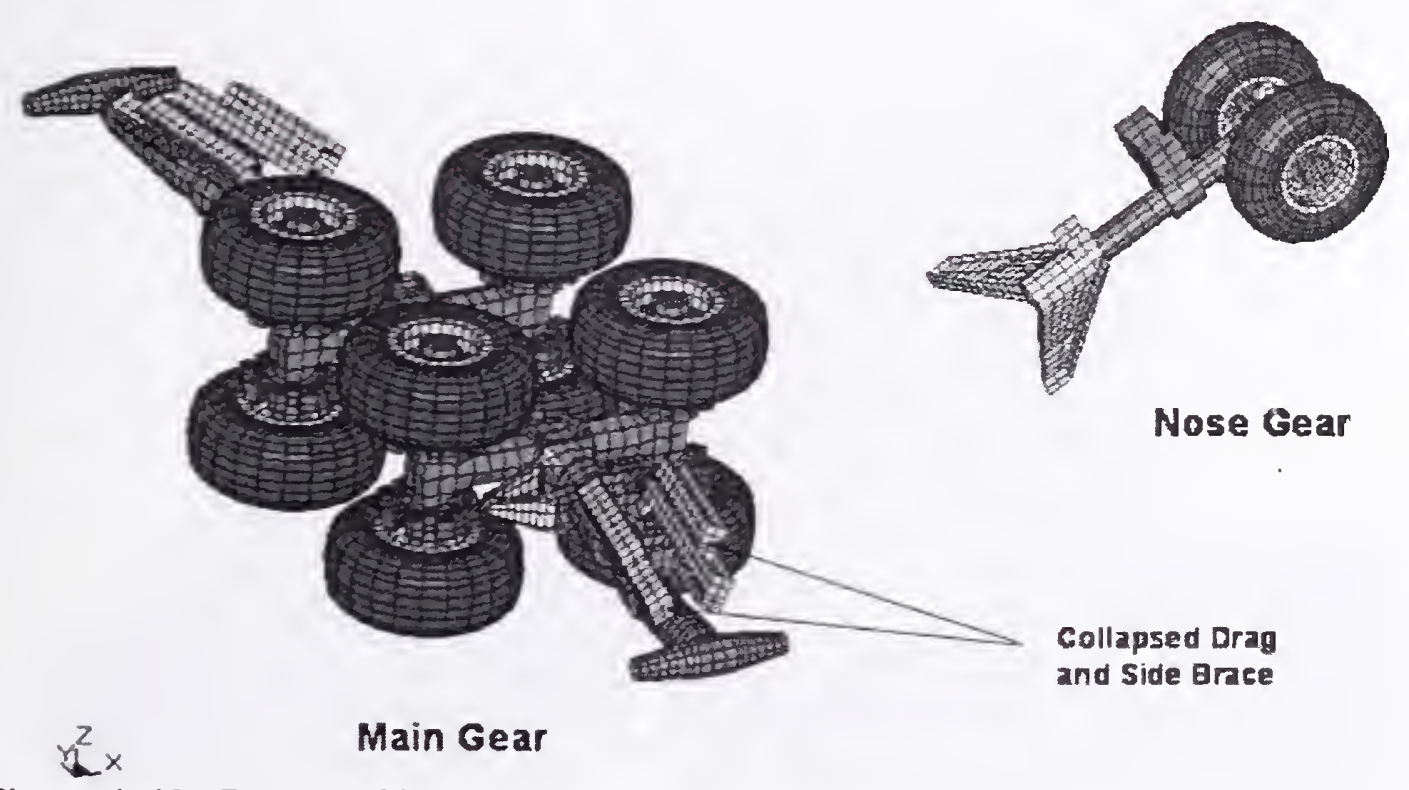

Figure 4-13. Retracted landing gear components for the 767-200ER aircraft model. 


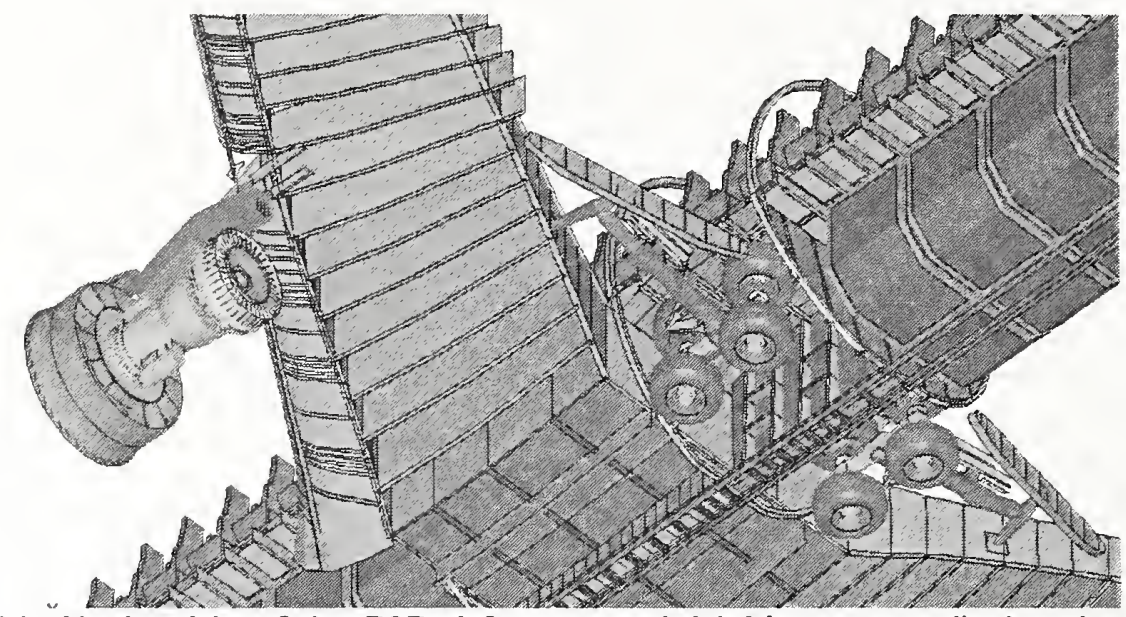

Figure 4-14. Underside of the 767 airframe model (skin removed) showing retracted landing gear.

Figure 4-15 shows the model of the wing structure, including the center wing, which attaches the port and starboard outboard wings. The wing stringers were not explicitly modeled to help reduce the size of the model. The stringers have a z-section geometry with typical dimensions of approximately $1 \mathrm{in}$. flanges and a two in. web with a thickness of approximately $1 / 8$ in. These stringers run along the wing span over the top and bottom of the wing ribs as shown by part number 178 in Figure 4-16. To account for the weight and strength of the riveted skin/stringer construction, an 'effective' wing skin was used, as discussed in Section 4.3.2.

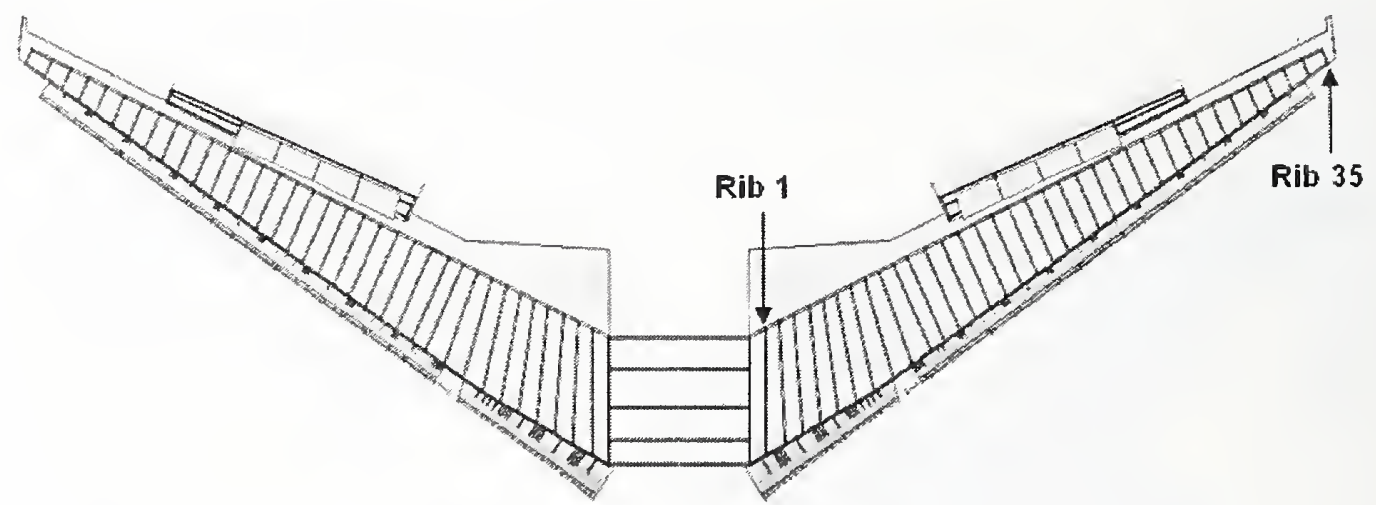

(a) Complete wing model
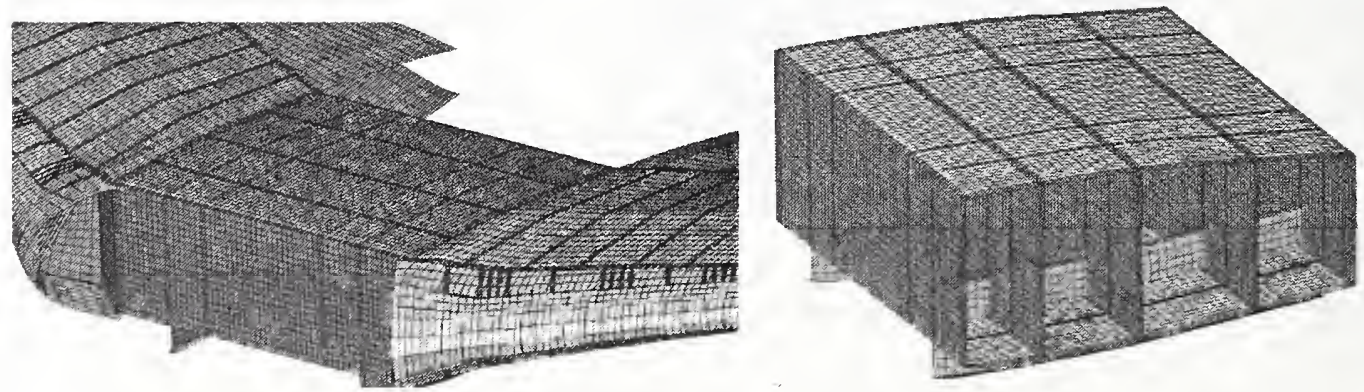

(b) Center wing structures

Figure 4-15. Complete wing structures for the Boeing 767 aircraft model. 


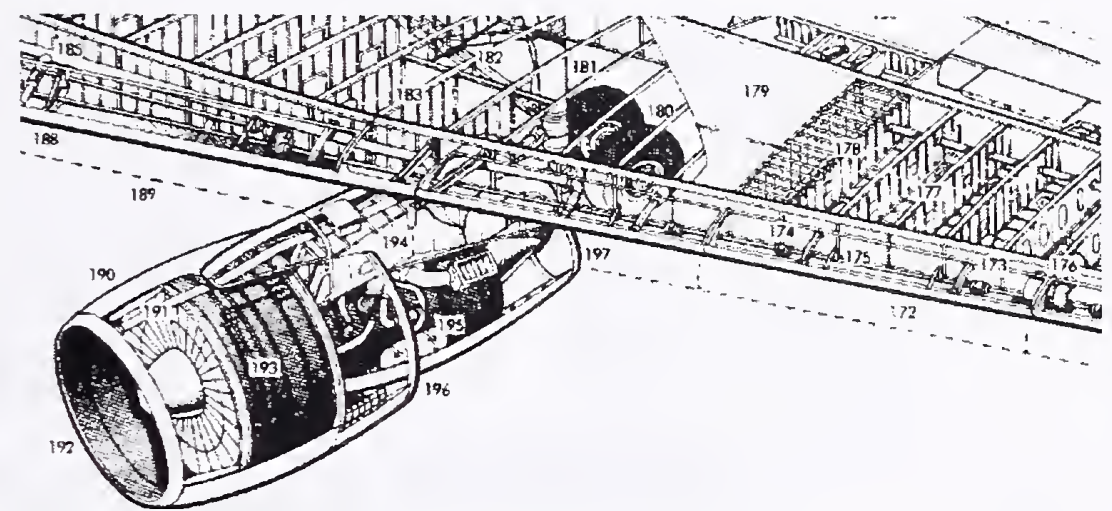

Source: Taken from Boeing Aircraft Cutaways. Cutaway $@$ Mike Badrocke.

Reproduced with permission of Osprey Publishing Ltd., www.ospreypublishing.com

Figure 4-16. Wing structural diagram of a Boeing 767-200.

A model of the fuselage was assembled with a stringer and frame construction supporting the external skin, as shown in Figure 4-17. A tied interface was used to connect the stringers to the frames and skin using the tied surface to surface contact algorithm in LS-DYNA. In this algorithm, nodes on a slave surface are constrained to nodes on a master surface provided they are within a certain distance of the master surface node. This distance is a function of the element thickness or diagonal length. The wing was integrated into the fuselage structure through attachment of the center wing to the keel and front and rear spar bulkheads, as shown in Figure 4-18. These components were also attached using a tied interface. Due to model size constraints, the forward and aft portions of the fusclage were modelcd without the detailed stringer/frame construction. Instead, the weight of thesc components was smcared into the skin by increasing the skin thickness and scaling down the strength by a factor of 40 pcrcent, as described in Section 4.3.2.

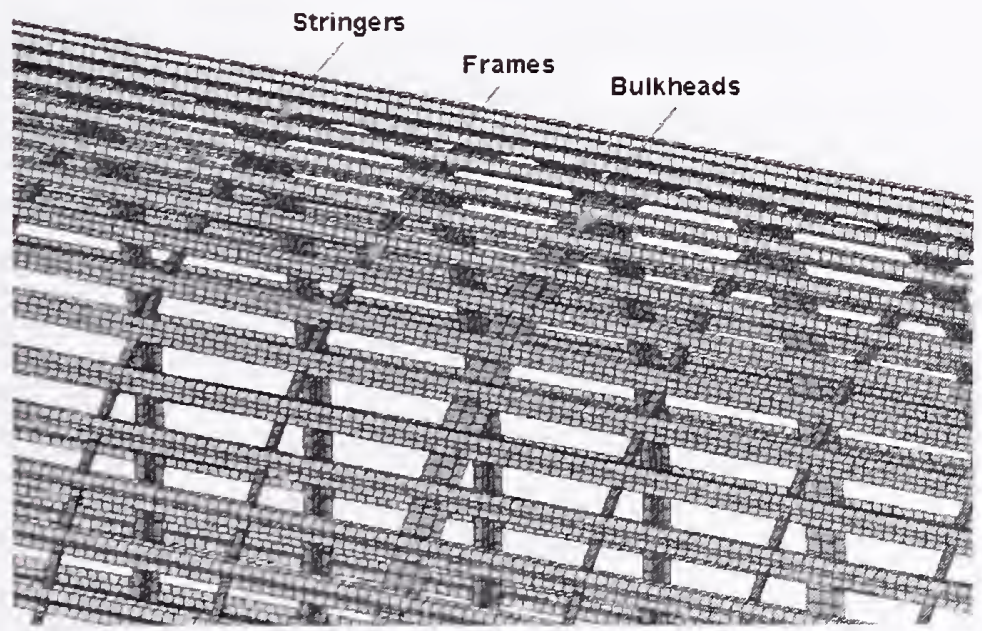

Figure 4-17. Model of fuselage interior frame and stringer construction. 


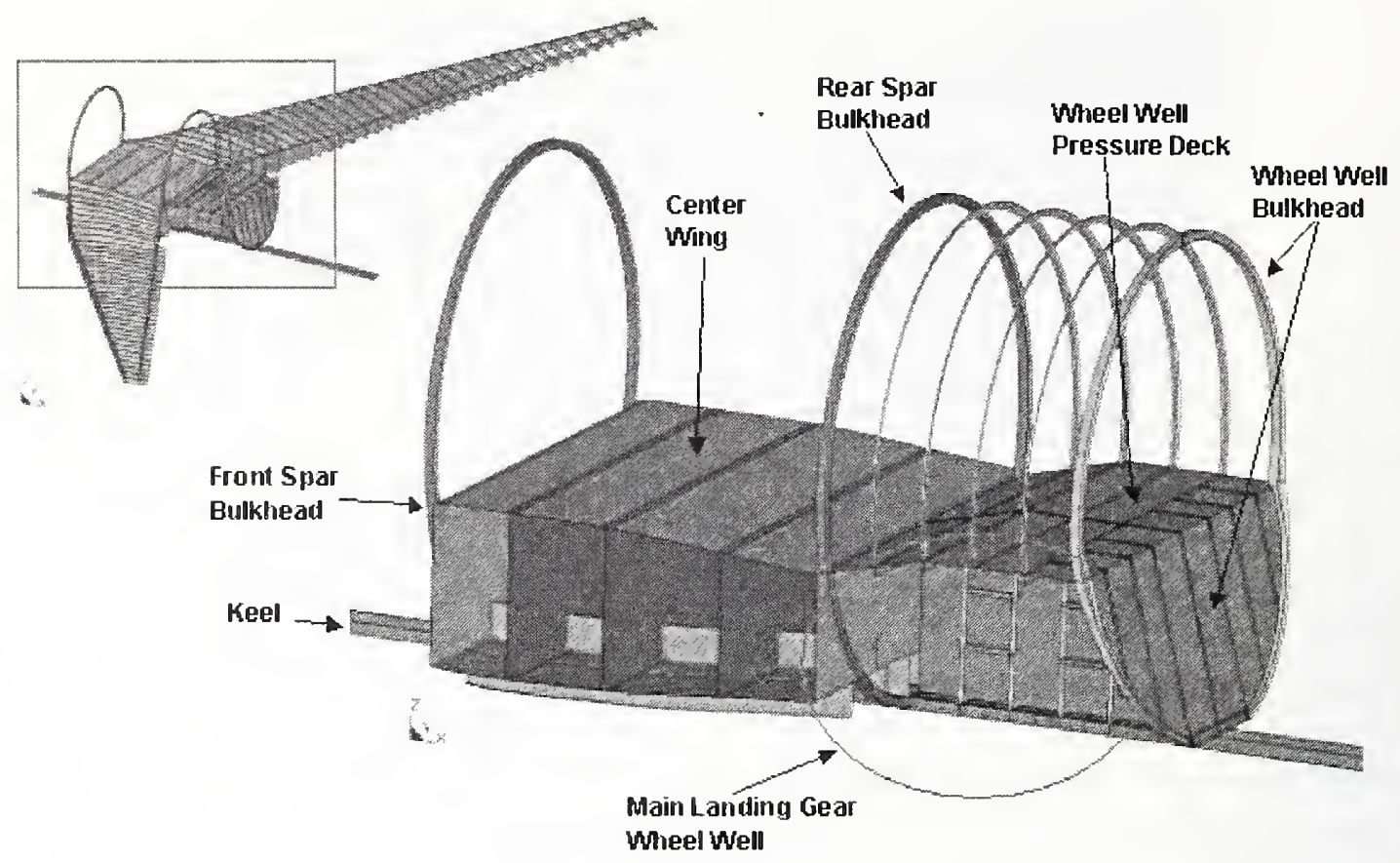

Figure 4-18. Integration of the fuselage and wing structures.

The density of various parts of the aircraft was increased to include the mass of parts of the structure not specifically modeled, as well as other non-structural components. Density scale factors and total weights for each major component are shown in Table 4-4. The difference in scale factors for flights AA 11 and UAL 175 were due to differences in passenger and cargo weight. In both cases the weight of the cargo, passengers, and crew were incorporated in the ULD (cargo weight) and the seats (passenger, crew, and carry on luggage weight). The weight of the modeled wings and empennage were doubled to account for the weight of small structural details, such as stiffeners, not specifically modeled, as well as hydraulic lines and fluid pumps, actuators, inboard flaps and outboard ailerons, flap and rudder connections, and other non-structural components. The weight of the landing gear was increased by a smaller amount (1.5) to account for hydraulic fluid and smaller structural components not included in the model. The weight of the fuselage was adjusted to match the published empty weight for the aircraft. That the scale factor for the fuselage was larger than for other components is reasonable as many heavy items in the fuselage were not specifically modeled (e.g., electronics, air conditioning, power units, ductwork, electronic wiring, cargo floor, actuator motors, insulation, hydraulics, galley, and lavatories). These structural and nonstructural components could not be modeled in detail due to the constraints on model size.

\subsubsection{Wing Section Component Model Development}

A wing section model was developed to perform the component level and subassembly level analyses (Chapters 5 and 6, respectively). The full wing contains 35 ribs, with rib 1 closest to the fuselage and rib 35 near the wing tip, as seen in Figure 4-15(a). The wing section model developed in this section included the section of the wing from rib 14 to rib 18 as shown in Figure 4-19. 
Table 4-4. Density scale factors and weights for aircraft components.

\begin{tabular}{|l|c|c|c|c|}
\hline $\begin{array}{c}\text { Major Aircraft } \\
\text { Component }\end{array}$ & $\begin{array}{c}\text { Density Scale } \\
\text { Factor (AA11) }\end{array}$ & $\begin{array}{c}\text { Total Weight } \\
\text { (AA11) }\end{array}$ & $\begin{array}{c}\text { Density Scale } \\
\text { Factor (UAL175) }\end{array}$ & $\begin{array}{c}\text { Total Weight } \\
\text { (UAL175) }\end{array}$ \\
\hline Wings & 2.0 & $37,000 \mathrm{lb}$ & 2.0 & $37,000 \mathrm{lb}$ \\
\hline Enmennage & 2.0 & $8,350 \mathrm{lb}$ & 2.0 & $8,350 \mathrm{lb}$ \\
\hline Fuselage & 6.68 & $103,050 \mathrm{lb}$ & 6.68 & $103,050 \mathrm{lb}$ \\
\hline Landing Gear & 1.5 & $8,400 \mathrm{lb}$ & 1.5 & $8,400 \mathrm{lb}$ \\
\hline Engines (with cowlings) & 1.2 & $20,100 \mathrm{lb}$ & 1.2 & $20,100 \mathrm{lb}$ \\
\hline ULD & 1.43 & $12,400 \mathrm{lb}$ & 2.50 & $21,650 \mathrm{lb}$ \\
\hline Seats & 1.29 & $28,200 \mathrm{lb}$ & 0.78 & $17,050 \mathrm{lb}$ \\
\hline Fuel & 1.0 & $66,100 \mathrm{lb}$ & 1.0 & $62,000 \mathrm{lb}$ \\
\hline Total Weight & & $283,600 \mathrm{lb}$ & & $277,600 \mathrm{lb}$ \\
\hline
\end{tabular}

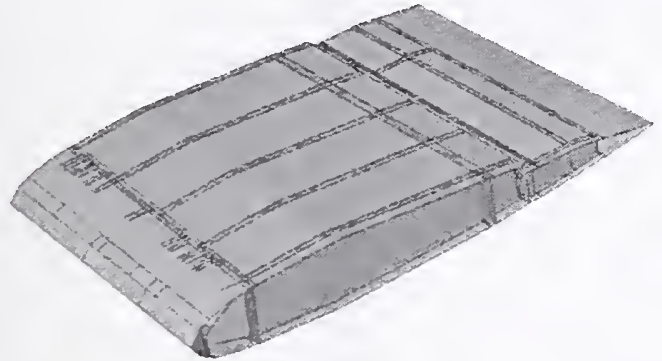

(a) Small wing section model

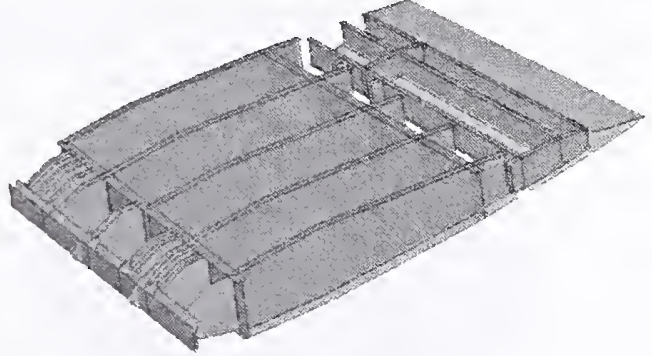

(b) Internal structure (skin removed)

Figure 4-19. Wing section model for component level and subassembly analyses.

The main spars, wing ribs, leading edge ribs, nose beams, leading edge slats, and outboard flaps were all included in the wing section model. The internal structure of the wing (i.e., ribs, spars, nose beams, etc.), as shown in Figure 4-19(b), were attached to one another by merging nodes. To simulate the riveted connection between the external skin and the internal structure, the skin was attached to the leading edge ribs, the spars, and the ribs and spars of the trailing edge flap with a surface-to-surface tiebreak contact algorithm. This algorithm is discussed in more detail shortly. Nonstructural components, such as hydraulic lines, and mechanical components, such as slat actuators, were not included in the model geometry. The density of the spars, ribs, and other structural components were increased by a factor of two to account for this nonstructural mass.

The wing structure of the Boeing 767 contains a riveted stringer-skin construction between the front and rear spars as shown by part numbers 178 and 179 in Figure 4-16. The large number of relatively small stringers would require a large number of shell elements if modeled explicitly. The individual stringers were not expected to have a large effect on the impact response due to their relatively small cross section compared to tower structures. As a result, the stringers were not explicitly included in the wing model as they add significant complexity and size to the model. Instead, the stringers were included in an 'effective' wing skin in the model used for the component and subassembly analyses (Figure 4-19).

The effective wing skin was developed to account for the weight and strength of the riveted skin/stringer construction with a reduced overall model size. For this purpose, a simplified wing section model, 
containing a uniform stringer-skin construction and a simple rectangular cross-section, was also developed (Figure 4-20) to evaluate different modeling options for the effective skin and determine the corresponding skin strength and weight. The wing section component models utilized Belytschko-Tsay shell elements.
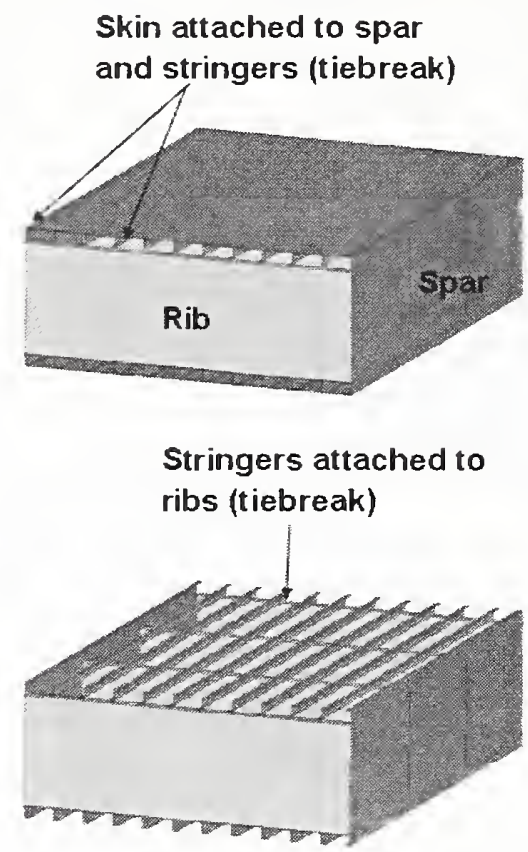

(a) Simplified wing construction

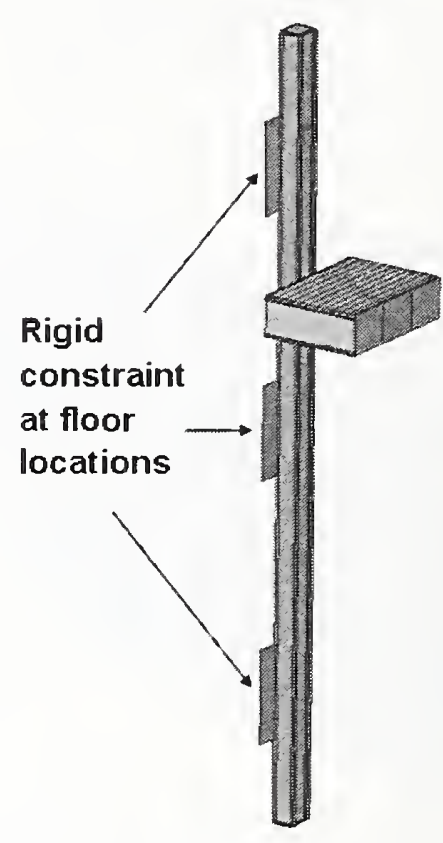

(b) Impact configuration

\section{Figure 4-20. Simplified wing section model and impact analysis used for the effective skin model development.}

A suitable effective skin was developed by first modeling a wing segment containing the stringer and skin construction, as shown in Figure 4-20(a). The model consisted of four ribs of uniform height, a front and rear spar, ten z-stringers, and a top and bottom skin. In this model, both top and bottom skins and stringers were of the same materials as the top wing construction in the Boeing 767. The skin was attached to the stringers using the surface-to-surface tiebreak contact algorithm in LS-DYNA. A single rivet attachment was assumed for the skin-stringer and stringer-rib attachments in the simplified wing section model. The skin was also attached to the spars using a double-rivet tiebreak criterion. This model was impacted into an exterior column of the WTC tower, as shown in Figure 4-20(b). Ribs, stringers, spars, and skin were all meshed with 0.5 in. shell elements.

The surface-to-surface tiebreak contact algorithm uses a biaxial failure criterion governed by the equation:

$$
\left(\frac{\sigma_{n}}{\sigma_{n}^{f}}\right)^{2}+\left(\frac{\sigma_{s}}{\sigma_{s}^{f}}\right)^{2} \geq 1
$$

where $\sigma_{\mathrm{n}}$ and $\sigma_{\mathrm{s}}$ are the normal and shear stresses on an element, respectively. The $\sigma^{\mathrm{f}}$ are the corresponding magnitudes of the uniaxial normal and shear failure stresses. When this failure criterion is met, nodal displacements between tied nodes are no longer constrained, except to restrict penetrations of 
one element segment through another. The reader is referred to the LS-DYNA Keyword User's Manual for a more complete discussion on this algorithm. Data from biaxial testing of riveted aluminum joints were used to estimate the values for $\sigma^{f}$, as shown in Figure 4-21. The data shown is for 5/32 in. rivets in 0.063 in. plates, where failure occurs at the intersection of the countersunk head and the rivet shank. Assuming that the failure mode remained the same in the aircraft wing, failure data were scaled to those for $1 / 4$ in. diameter rivets. Various rivet diameters were used, depending on plate thickness $(5 / 32$ in., $3 / 16$ in.. and $1 / 4$ in.). The largest was used for this study. The aircraft skin thickness in the simplified wing construction was assumed to be $0.1 \mathrm{in}$. The rivet spacing was four times the rivet diameter. Rivet spacing was needed to determine $\sigma^{\mathrm{f}}$.

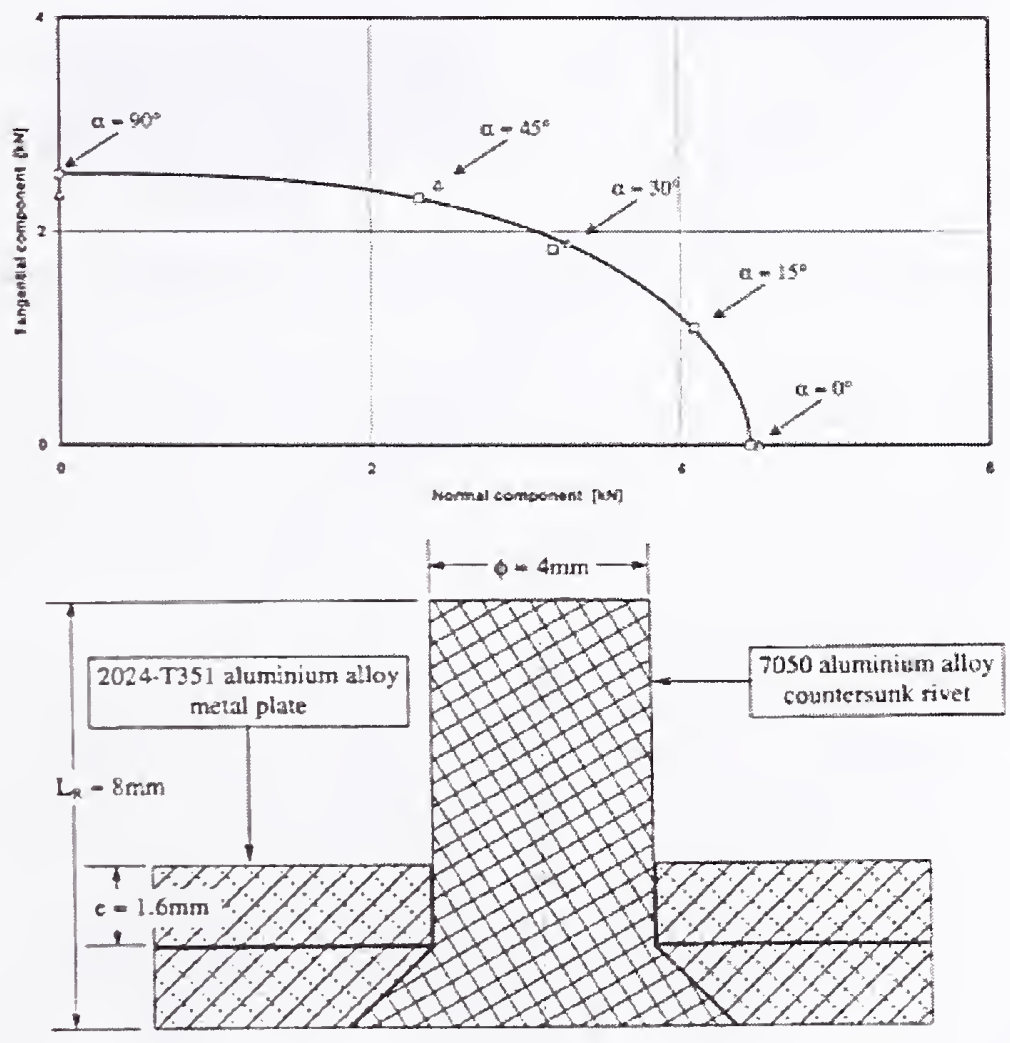

Source: Reprinted from Finite Elements in Analysis and Design, Vol. 30, Langrand, B., E. Deletombe, E. Markiewicz, and P. Drazetic, "Riveted join modeling for numerical analysis of airframe crashworthiness," Figure 1 on page 23 and Figure 12 on page 36, Copyright (2001), with permission from Elsevier.

\section{Figure 4-21. Riveted joint configuration and failure data under mixed-mode loading.}

Two alternatives were considered for an effective skin of the riveted stringer/skin construction. The first alternative was to increase the thickness of the skin to include the mass of the stringers. The second option was to increase the density of the skin to include the mass of the stringers. In both cases the skin yield strength was reduced by 40 percent to match the impact behavior of the effective skin wing segment with that of the riveted stringer/skin construction. In both options, the effective skin was only riveted to the front and rear spars and not the ribs. This behavior most closely resembled the skin behavior seen for the model with stringers and skin. Damage to each model immediately after impact with an exterior column is shown in Figure 4-22. 


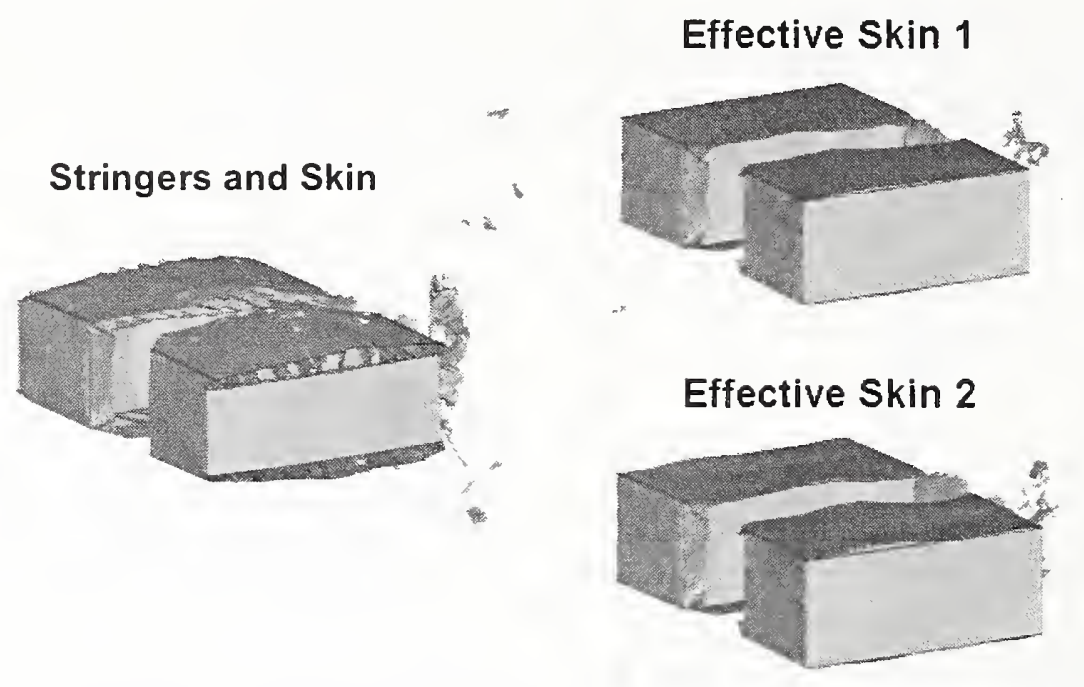

Figure 4-22. Comparison of wing section damage with the different modeling options.

The kinetic energy of the wing segment and the internal energy of the exterior column were used to evaluate the effective skin performance. Yield strengths for each of the effective skins were modified until the residual kinetic energy of the wing segment debris most closely matched that of the model with the stringer/skin construction, as shown in Figure 4-23. Both effective skin options could be made to closely match the kinetic energy of the riveted stringer/skin construction. Also shown in the figure are the results for a tied and unbonded (not tied) stringer/skin construction.

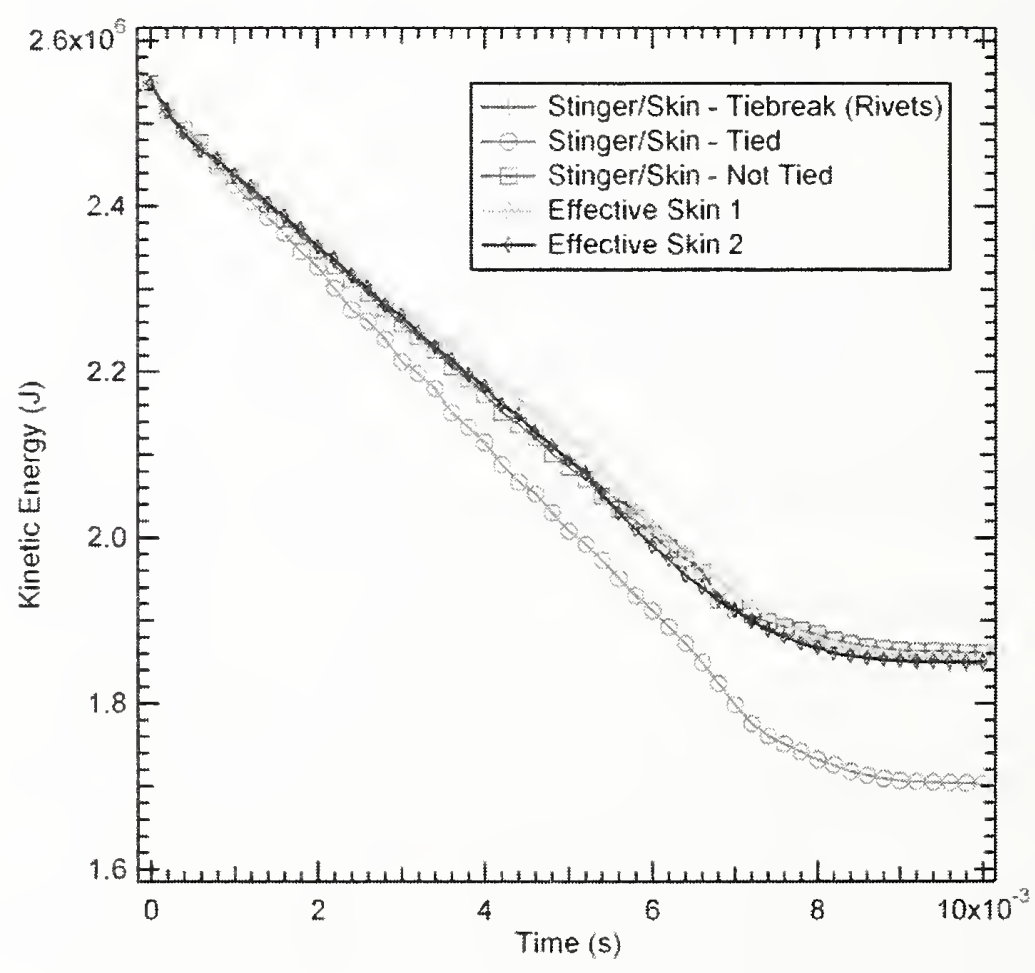

Figure 4-23. Kinetic energy of the wing model. 
Internal energy of the exterior columns during impact by the various wing segment models is shown in Figure 4-24. Both effective skin options simulate reasonably well the damage to the exterior columns. This is also shown physically in Figure 4-25. However, the effective skin with increased density (i.e., 'Effective Skin 2') imparted less damage to the exterior column than did the stringer/skin construction or the first effective skin option. Therefore the first option with increased skin thickness was used in the subsequent wing and aircraft models.

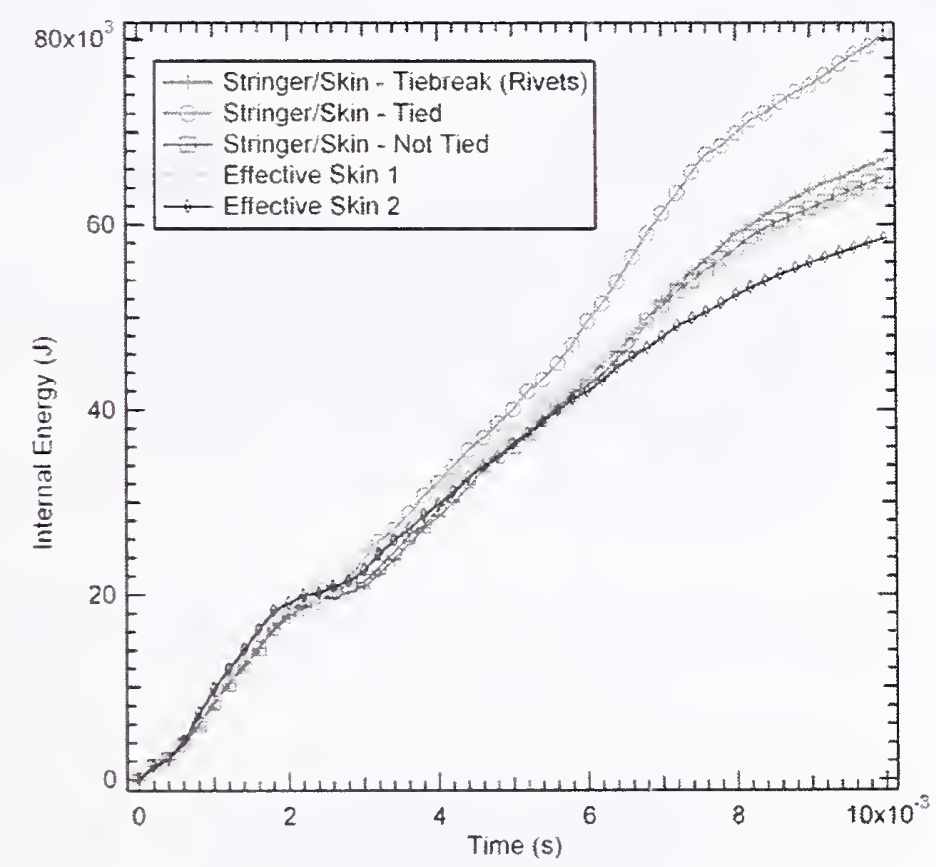

Figure 4-24. Internal energy of the exterior column.

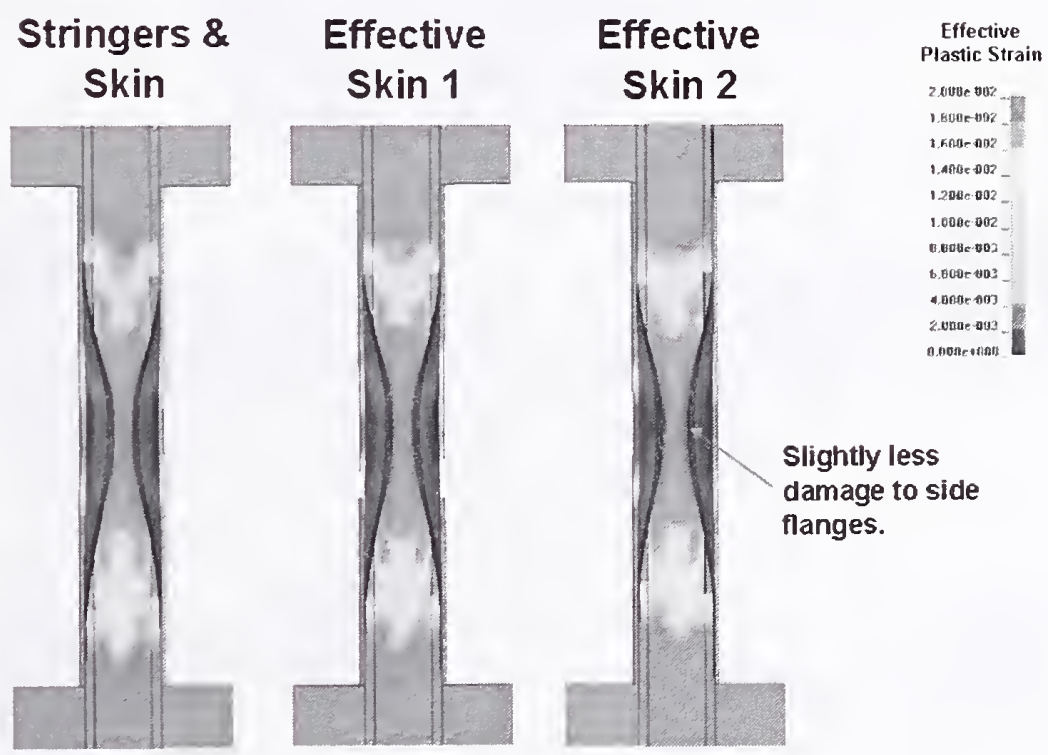

Figure 4-25. Damage to an exterior column from a wing section with each skin type. 


\subsubsection{Engine Model Development}

The Pratt \& Whitney PW4000 turbofan engine has a very complex structure as shown in Figure 4-26. The engine is an important component of the aircraft with the potential to produce significant impact damage to the WTC tower structures (e.g., fail core columns). As a result, special care was given to the development of the engine model to include all the details of the engine construction.

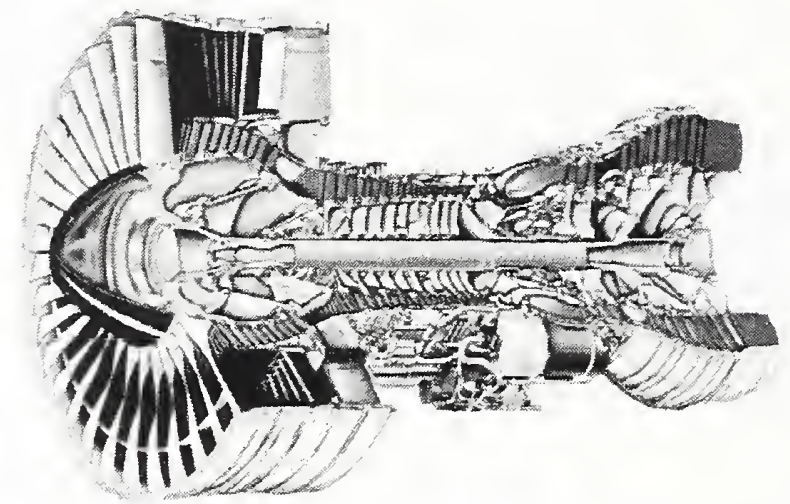

Used with permission.

Figure 4-26. Pratt \& Whitney PW4000 turbofan engine.

The approach used to capture the geometry of the engine was to start with a cross-sectional drawing provided by Pratt \& Whitney that clearly indicated many of the engine geometric details. In addition, the drawing had sufficient detail that the component thicknesses could be estimated. The primary structural components were identified and approximated with simplified geometry as illustrated in Figure 4-27. Known engine dimensions were used to determine the scale factor for the drawing. The simplified geometry of the engine structures could then be captured using a common digitization procedure. An example drawing with digitized coordinate locations included is shown in Figure 4-28.

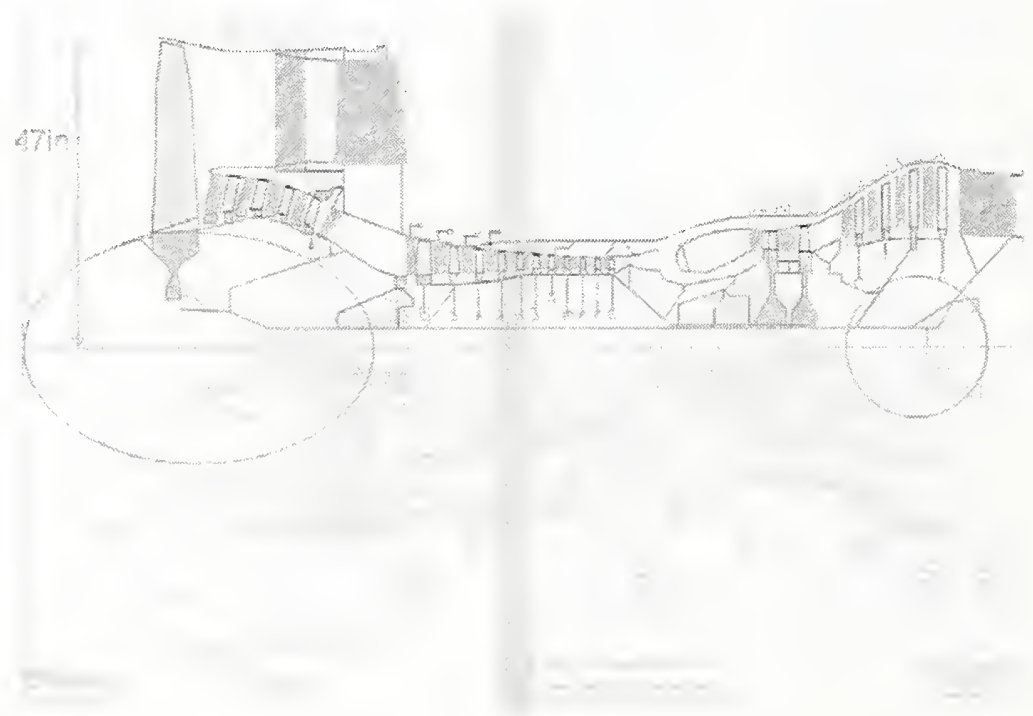




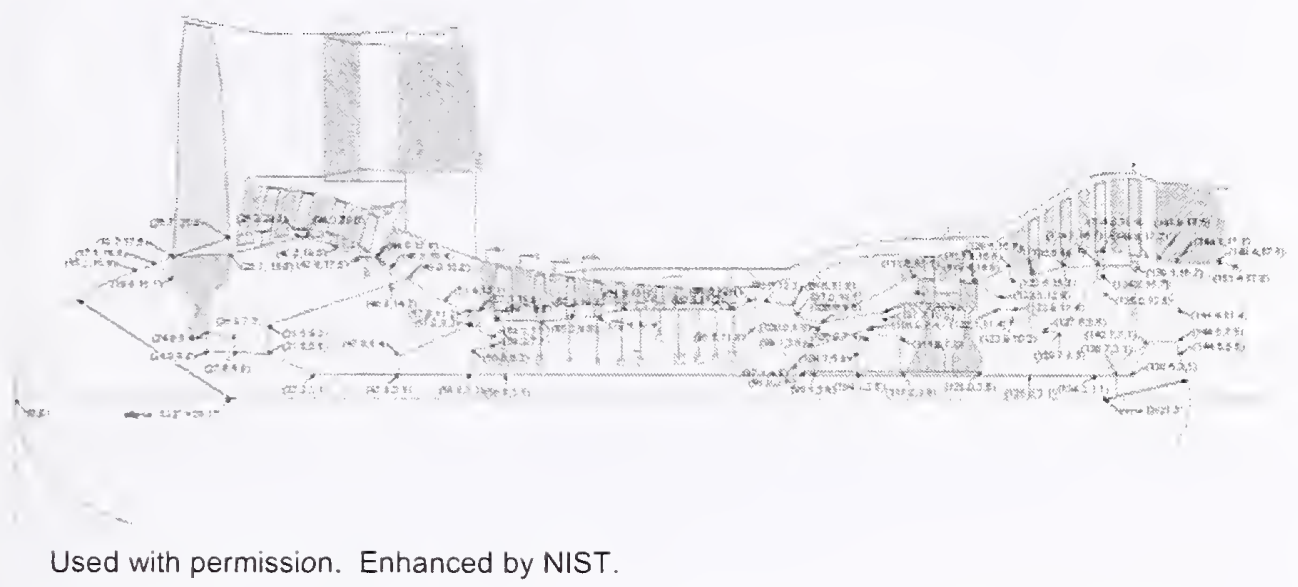

Figure 4-28. PW4000 engine cross-sectional geometry digitization.

Once the engine internal geometry was captured, the digitized geometry was imported into TrueGrid and used to generate surface definitions and part geometries for the engine model. The engine model was developed with primarily shell elements. The objective was to develop a mesh with typical element dimensions between 1 in. and 2 in. However, smaller element dimensions were required at many locations to capture details of the engine geometry. Brick elements were used for some of the thicker hubs and the roots of the compressor blades. The various components of the resulting engine model are shown in Figure 4-29. A summary of the elements used in the engine model is given in Table 4-5.
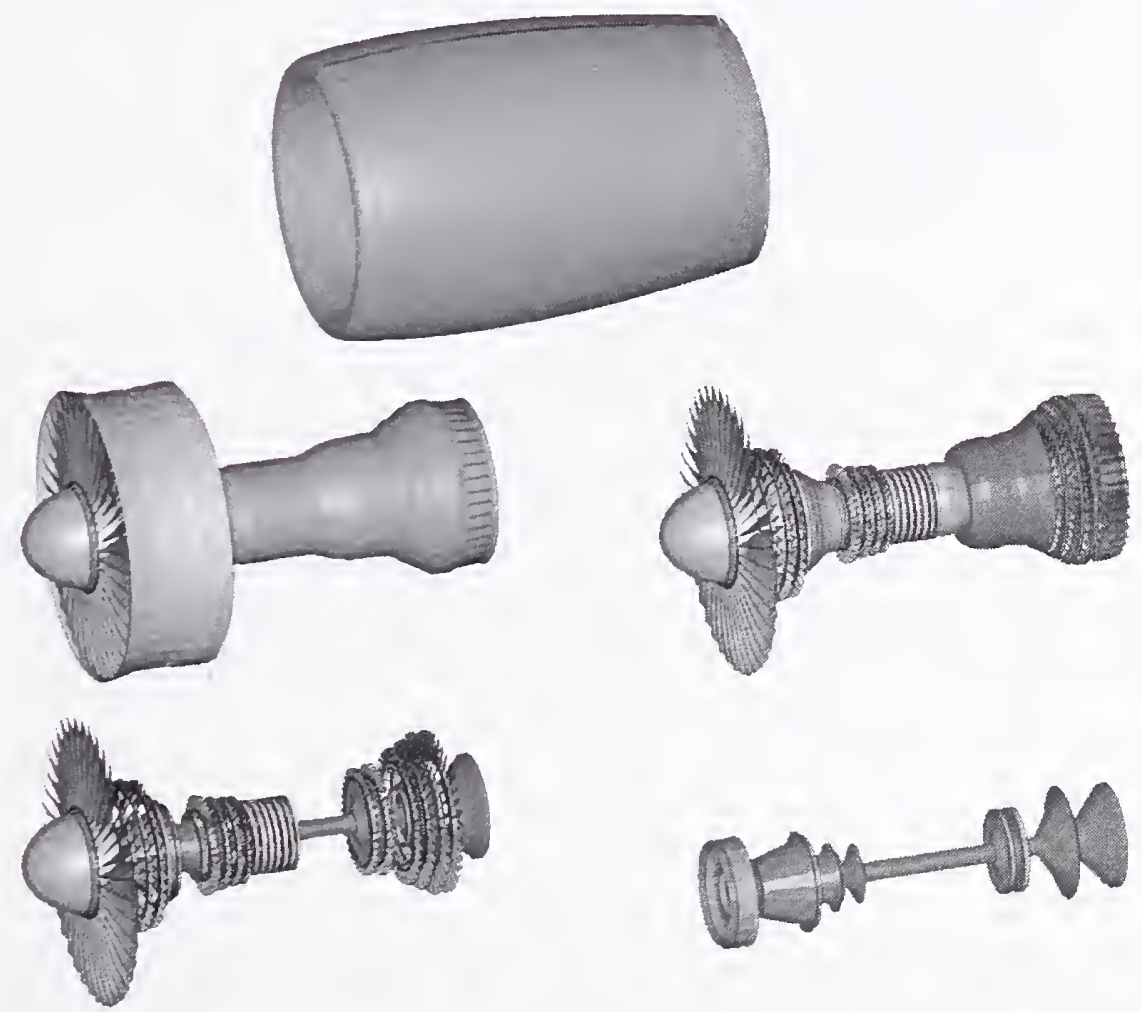

Figure 4-29. Pratt \& Whitney PW4000 turbofan engine model. 
Table 4-5. Engine model parameters.

\begin{tabular}{|l|c|}
\hline & PW4000 Engine Model \\
\hline No. Brick Elements & 9,560 \\
\hline No. Shell Elements & 54,788 \\
\hline Total Nodes & 101,822 \\
\hline Preliminary Engine Model Mass & $7,873 \mathrm{lb}$ \\
\hline Adjusted Engine Model Mass & $9,447 \mathrm{lb}$ \\
\hline
\end{tabular}

After the known primary structural components of the engine were included in the engine model, the mass of the model was calculated at $7,873 \mathrm{lb}$. The dry weight of the PW4000 engine was listed at 9,400 lb, and the JT9D-7R4 and CF6-80C2 engines weighed between 8,885 lb and 9,860 lb. These engine weights were approximately 20 percent larger than the initial model weight. The difference in weight potentially resulted from the nonstructural components (tubing, pumps, seals, bearings, etc.) that were not included in the model. To account for the difference, the density of all of the material models used for engine components was increased by 20 percent. This effectively smeared the missing mass in proportion to the original mass distribution in the model. The resulting adjusted engine model mass was $9,447 \mathrm{lb}$.

\subsection{ANALYSIS OF FUEL DISTRIBUTION AT IMPACT}

An important factor for determining impact damage and subsequent fire initiation was the distribution of the fuel in the aircraft. Both United Airlines and American Airlines provided estimates for the quantity and distribution of fuel for UAL flight 175 and AA flight 11 at the time of impact. ${ }^{1.2}$ United Airlines estimated that flight 175 contained approximately $62,000 \mathrm{lb}$ or 9,118 gal of fuel at impact with the "fuel evenly distributed between both main tanks." American Airlines estimated that flight 11 contained $66,081 \mathrm{lb}$ or $9,717 \mathrm{gal}$ of fuel at impact and "the fuel was evenly distributed between left and right wing tanks of the aircraft."

Fuel tank locations and capacities for the Boeing 767 are shown in Figure 4-30. The Boeing 767 uses an integral fuel tank where the wing skin, ribs, and spars serve as the fuel tank. There are three classes of fuel tanks onboard the 767-200ER, a main tank, a surge tank, and auxiliary tanks. The auxiliary tanks consist of port, starboard, and center fuel tanks. All tanks are shown for the port wing in Figure 4-31 along with the associated internal structures. The main tank is from rib 3 to rib 31, the port and starboard auxiliary tanks are from the inboard closure rib to rib 3. The center auxiliary tank is between the port and starboard closure ribs, and the surge tank is from rib 31 to rib 34. A dry bay is located above the engine at the forward part of the main tank between ribs 6 and 9. Baffle ribs are located at rib 5 and rib 18 .

1 Communication between United Airlines and NIST, September 5, 2003, "NIST WTC Flammable Contents Request."

2 Communication between American Airlines and NIST, August 12, 2003, "In re September 11 Litigation C\&F Ref.: DTB/MH28079." 


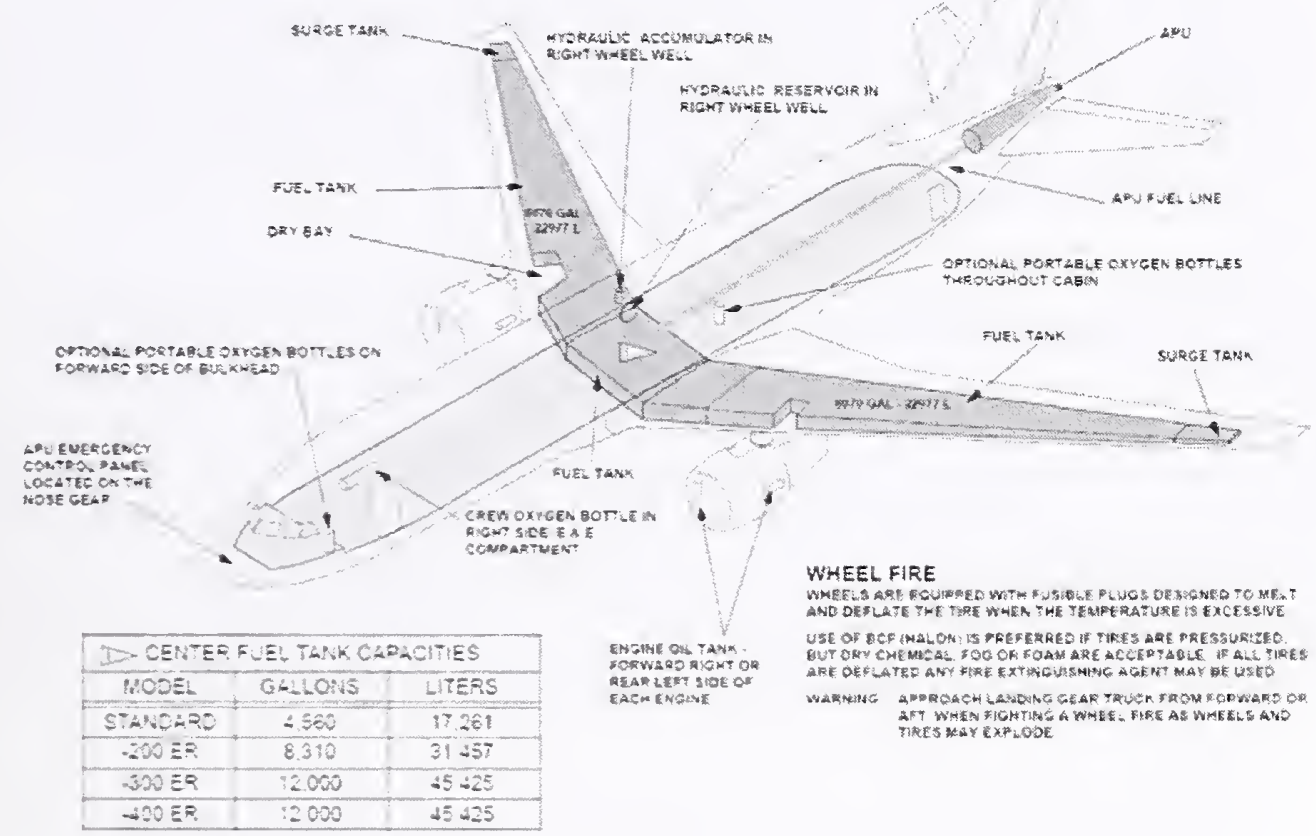

Used with permission.

Figure 4-30. Flammable material locations in a Boeing 767 (www.boeing.com).

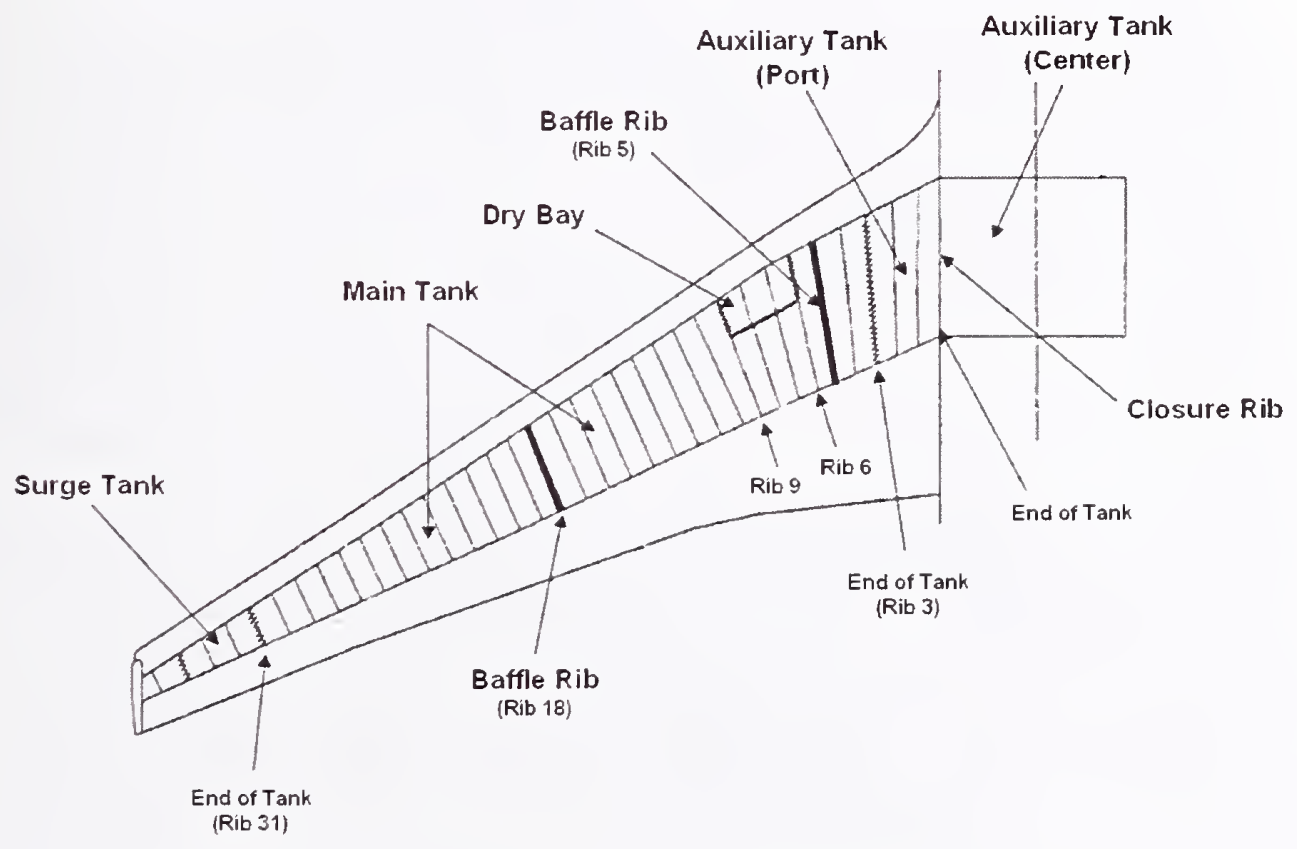

Figure 4-31. Layout of fuel tanks in the Boeing 767 wing. 
Functionality of the wing fuel tanks is such that a typical wing rib allows some fuel to flow along the wing but acts as a two-way fuel baffle to minimize fuel slosh. However, there are special rib designs that alter the position and flow of fuel within the tank. The ribs in the dry bay region, between ribs 6 and 9 , include a fuel barrier running parallel to the rear wing spar. In addition, baffle ribs (ribs 5 and 18) include a series of fuel dams that act as a one-way valve, allowing fuel flow inboard toward the sump areas (low point of tank). According to the statements from both airlines regarding fuel distribution, it is most likely that the surge tanks and all auxiliary tanks were dry at the time of impact.

Overall tank dimensions and geometry were estimated from aircraft structural references, the surface model from Digimation, and CAD drawings from Boeing. The dimensions and the approximated geometry used to calculate fuel tank capacity is shown in Figure 4-32. As shown in Figure 4-33, the front spar height is a good approximation for fuel depth in a full wing section. Using these approximate dimensions, the fuel tank capacity as a function of the distance along the wing buttock line (Figure 4-34) was calculated. The maximum capacity of each main tank was calculated to be approximately 6,500 gal. The actual main tank capacity is 6,070 gal (Figure 4-34), so the calculated fucl capacity distribution was modified to match this maximum value, as shown in Figure 4-34. Notice that the main tank capacity inboard of baffle rib 18 is approximately the same volume as the fuel onboard each aircraft at the time of impact.

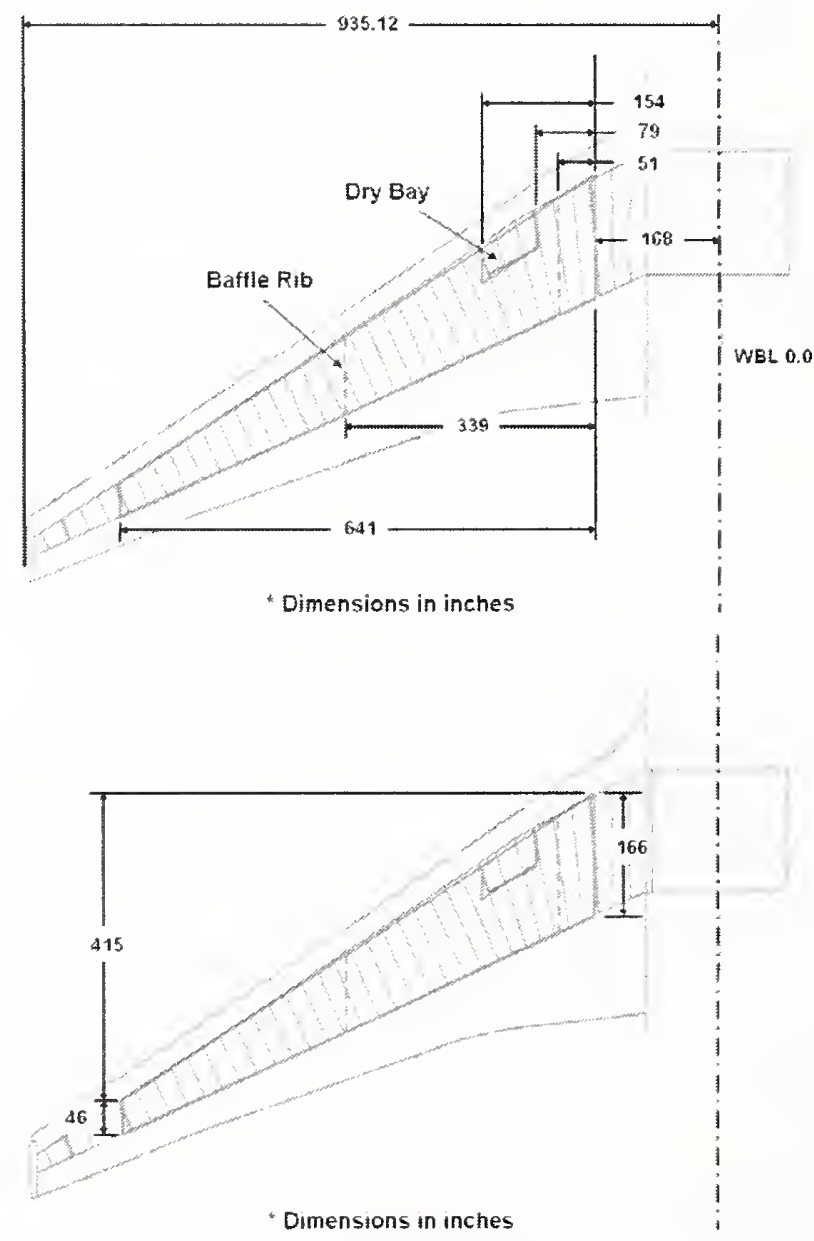

Figure 4-32. Approximate fuel tank dimensions (inches). 
Cross-section

Plane

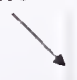

Rib 6

Dry Bay Rib

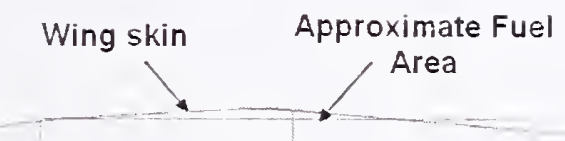

Rib 3

Inboard Tank Wall

Figure 4-33. Wing cross-sections at various rib locations.

Wing Buttock

Line

(WBL)

Rib 18

Outboard Baffle Rib

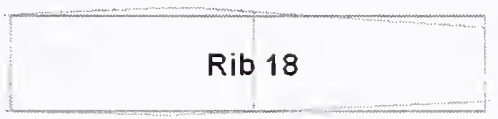


The exact location and distribution of fuel at the time of impact was complicated by the flight conditions prior to and at the time of impact. The terrorist pilots likely performed extreme flight maneuvers prior to impact, causing most of the fuel to flow inboard. Extreme banking maneuvers with inappropriate trim could cause the fuel to flow inboard quickly. High loads on the wings due to the extreme flight regime at the time of impact would also cause fuel to flow inboard by increasing the dihedral angle of the wing. Since the baffle ribs restrict fuel from flowing outboard, it is reasonable that all fuel that could flow inboard was actually inboard at the time of impact.

For simplicity, it was assumed that all fuel had moved inboard at the time of impact. Since the fuel tank capacity at the outboard baffle rib and the fuel onboard are approximately the same, a good first estimate was that the main tanks were full inboard of baffle rib 18 at the time of impact. A small amount of fuel was outboard of this rib for AA flight 11. This is shown graphically in Figure 4-35 for smooth and level flight with an undeformed wing shape. A full wing out to baffle rib 18 and dry outboard of this rib was taken as the nominal case in subsequent analyses.

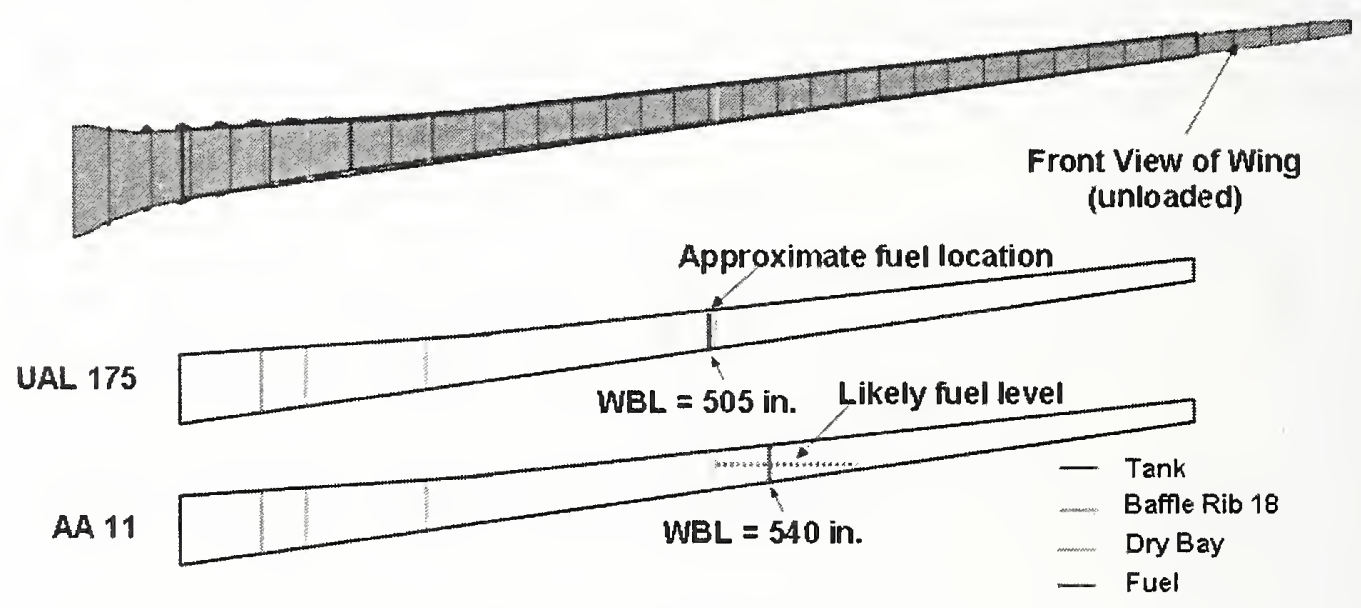

Figure 4-35. Approximate fuel locations for smooth and level flight.

\subsection{REFERENCES}

Badrocke, M. \& Gunston, B. 1998. "Boeing Aircraft Cutaways - The History of the Boeing Aircraft Company." Osprey Publishing.

Boeing Company. 1989. Aircraft Description of Boeing 767, Section 2, Document number D6-58328, www.boeing.com.

Condon \& Forsyth LLP. 2003. " In re September $11^{\text {th }}$ Litigation C\& F Ref: DTB/MH/28079," Correspondence between Condon \& Forsyth LLP and NIST, NIST document number WTC1-155-1.

"Jane's All the Worlds Aircraft," McGraw-Hill, NY, 2001.

Langrand, B., E. Deletombe, E. Markiewicz, and P. Drazetic. 2001. "Riveted joint modeling for numerical analysis of airframe crashworthiness," Finite Elements in Analysis and Design, 38. 
“LS-DYNA Keyword User`s Manual," Livermore Software Technology Corporation, Version 970, April 2003.

Midgett, J. T. 2003. "NIST WTC Flammable Contents Request," Correspondence between United Airlines and NIST, NIST document number WTC1-156-1.

“TrueGrid Manual, Version 2.1.0,” XYZ Scientific Applications, Inc., September 2001.

"World Trade Center Building Performance Study: Data Collection, Preliminary Observations, and Recommendations," Federal Emergency Management Agency, FEMA 403, May, 2002. 
This page intentionally left blank. 


\section{Chapter 5 \\ COMPONENT LEVEL ANALYSES}

\section{$5.1 \quad$ INTRODUCTION}

The primary objectives of the component modeling were to (1) develop understanding of the interactive failure phenomenon of the aircraft and tower components, and (2) develop the simulation techniques required for the global analysis of the aircraft impacts into the World Trade Center (WTC) towers. The approach taken for component modeling was to start with finely meshed, brick and shell element models of key components of the tower structure and progress to relatively coarsely meshed beam and shell element representations to be used for the subassembly and global models. This was done to develop reduced finite element models appropriate for high fidelity global impact analyses, as modeling each component with fine details would be too demanding from a computational standpoint.

In addition to determining the optimal element size and type for global modeling, other key technical areas were addressed in the component modeling phase. These issues included material constitutive modeling, treatment of connections, and modeling of aircraft fuel. The following component modeling scenarios were outlined at the start of the project:

- An exterior column impacted by an aircraft engine

- An interior column impacted by an aircraft engine

- An exterior column impacted by an aircraft wing segment with and without fuel

In addition to the above component impact analysis scenarios, a range of additional component analyses were identified that were considered important and helpful in developing the global impact models and analysis methods. These additional component analysis scenarios included:

- Bolted column end-plate connections with approximated dynamic loading

- Bolted spandrel connections with approximated dynamic loading

- Floor system with concrete slab under impact loading

The approach used deviated somewhat from the tasks above to maximize efficiency and to produce the most meaningful structural loading scenarios. Once preliminary calculations were performed it was found, for example, that the load generated by an impacting engine would totally overwhelm an interior or exterior column. Reduced shell element models based on this severe loading would match the detailed brick model, but the subtle response from lesser loading might not be as accurate. To capture the more subtle response in the column components, wing section impactors were used as an alternate to the engine for the majority of component analyses. It was found that impact of an empty wing section produced damage to the exterior columns that was near the failure threshold. Similarly, a fuel-filled wing section impacting a core column produced damage near the failure threshold. As a result, the empty wing section 
impacting an exterior column and a fuel-filled wing section impacting a core column were the primary component impact scenarios analyzed.

Development of the component models for the tower and aircraft structures were not completed at the same time. The component models for the aircraft wing were delayed by the data collection process for the aircraft structures. As a result, the wing section impact analyses on the exterior and interior core columns (Sections 5.2.1 and 5.2.2) used a preliminary wing section model that is of a lesser fidelity than the final wing model. However, the objective of these analyses was to develop the modeling methodologies for the tower components. The preliminary wing model was sufficient for obtaining a representative impact load.

\subsubsection{Analysis Methodology}

The impact analyses were performed using the LS-DYNA finite element code (LS-DYNA Version 971). LS-DYNA is a commercially available nonlinear explicit finite element code for the dynamic analysis of structures (LSTC 2003). The initial foundation of LS-DYNA was the public domain DYNA3D finite element code developed at the Lawrence Livermore National Laboratory (1986). Since 1987, the code has been extensively developed and supported by the Livermore Software Technology Corporation (LSTC) and is used for a wide variety of crash, blast, and impact applications.

LS-DYNA has several unique capabilities such as Arbitrary-Lagrangian-Eulerian (ALE) and Smooth Particle Hydrodynamics (SPH) algorithms that can be applied to the analyses of fluid-structure interaction and large-scale fracture and fragmentation of structures. These capabilities are critical for the analyses of the fuel tank break up and dispersion of fuel inside the towers upon impact. The fuel and debris dispersion is crucial for assessing the impact loads inside the tower structures and the corresponding damage to the mechanical systems.

The impact analyses described in this report used a variety of capabilities and algorithms in LS-DYNA. A brief description of these capabilities is described in this section. A significantly detailed description of the analysis methods is provided in the LS-DYNA Theoretical Manual (1998).

The fine mesh detailed component analyses typically used 8-node solid hexahedron (brick) elements with single point integration. This is the most commonly used solid element type in LS-DYNA due to its computational efficiency. The biggest disadvantage of the single point integration is the potential for hourglassing or zero energy modes. There are several methodologies for controlling hourglass modes in LS-DYNA. The typical approach used in these impact analyses was to apply a viscous hourglass control where a viscous damping was introduced that suppressed the formation of hourglass modes, but did not significantly influence the global modes.

The component impact analyses using solid elements typically had a fine mesh. As a result, damage and failure were included strictly through the constitutive algorithms. Damage criteria (such as maximum plastic strain) were tracked for each element within the constitutive model evaluation, and elements were eroded when the failure criteria were exceeded. This allowed for a direct evaluation of damage and failure within the impact simulations.

The eroded elements allowed for the initiation and extension of fracture in the model. Eroded elements no longer support any stress, and the strains in the eroded elements are no longer calculated. The 
associated mass of the elements remains with the nodes in the calculation. If adjacent elements have not reached the failure surface, the nodes remain attached to the structure. If all of the elements connected to a specific node have failed, the node becomes a free particle. Free nodes can either be eliminated from the calculation or remain in the calculation with associated inertial properties and potential for impacts against other structural components (free nodes remain in contact algorithms).

As the mesh refinement and model size were reduced, the components were typically modeled using Belytschko-Lin-Tsay shell elements. These are four node shell elements with single point integration. The Belytschko-Lin-Tsay element is a computationally efficient alternative to the Hughes-Liu element in LS-DYNA and is a widely used shell element formulation within LS-DYNA for crash, impact, and metal forming applications. Results generated with the Belytschko-Lin-Tsay element typically agree with those generated using the Hughes-Liu element. As used in the solid elements, the most common approach to introducing damage and failure for the shell elements was through the constitutive models and element erosion.

In specific applications, unique algorithms were required to introduce failure modes in the analysis. An example is the interface between the skin and internal frame structures of the aircraft. Rivets were used for the primary connection between the airframe and skin (see Section 4.3.2). The approach used to model this connection and failure during the impact event was the tied interface with failure. In this approach, interface segments (shell elements) were constrained to move together until a failure criterion was exceeded. The failure criterion was a quadratic combination of the normal and shear failure stresses at the interface. After failure, the segments were allowed to move independently but not allowed to penetrate each other (typical contact algorithm behavior).

Overall contact in the impact analyses was modeled using the automatic single surface contact algorithms in LS-DYNA. Interacting components were defined by a material list, and contact segments were automatically generated by LS-DYNA. This greatly simplified the specification of contact between various components in the aircraft and tower structures. The type 1 soft constraint option was used in the contact algorithm that determined the contact stiffness based on stability considerations, time step size, and nodal mass. This soft constraint option was found to be more robust than the default penalty formulation for modeling the complex contact behaviors in large impact and crash simulations.

\subsection{TOWER COMPONENT DEVELOPMENT AND ANALYSES}

As described above, the development and analyses of the tower and aircraft components did not all proceed in parallel. Detailed models of the aircraft components, and in particular the wing components, were not initially available due to the time required to gather information about the details of the aircraft structures. Therefore, the initial component analyses focused on the behavior of the tower structures. In many of these analyses, preliminary models were used for the aircraft component impactors. The following sections describe the development and analysis of the tower components.

\subsubsection{Exterior Column Impact Analyses}

Various exterior column component impact analyses were performed with different objectives. The preliminary impact analyses were performed on a single column using a highly refined mesh of brick elements. These analyses were used to investigate details of the column response and to develop analysis 
techniques that could be applied to the subassembly and global impact analyses. For these analyses, a simplified wing-section impactor was used since detailed structural information of the Boeing 767 wing design was not yet available. Subsequent extcrior column impact analyses were performed using less refined models of the exterior columns in full panel configurations. More detailed wing section models were developed and used in these analyses with the primary objective of studying the impact response of the aircraft wing structures and investigating various modeling techniques for including aircraft fuel in the analyses. These analyses are discussed further in Section 5.5.

An example of a preliminary analysis was a fuel-laden wing section impacting an exterior column at $470 \mathrm{mph}$, as shown in Figure 5-1. The model of the exterior column consisted of three floors of a single exterior column with a relatively fine mesh of brick elements. The plates that make up the exterior column were modeled with four elements through the thickness resulting in a total of 467,232 brick elements for the exterior column model. Adjacent nodes in the web, flange, and spandrel plates were merged together (i.e., perfectly bonded), with no special treatment of the weld geometry or materials. The specific column modeled had a $60 \mathrm{ksi}$ yield strength, while the spandrcl plates had a yield strength of $42 \mathrm{ksi}$. A preliminary bilinear clastic-plastic constitutive model was used with a 30 percent plastic strain failure criterion. The fuel was added inside the wing, completely filling the wing section volume between the forward and rear spar. The fuel was modeled using brick elements and a simple constitutive model for the fluid that had a negligible strength and linear pressure-volume behavior. A large distortion of the fluid elements was allowed ( 250 percent strain) prior to removal from the calculation. This allowed the fuel to transfer its momentum to the impacted column without the subsequent distortion of the fluid elements terminating the calculation.

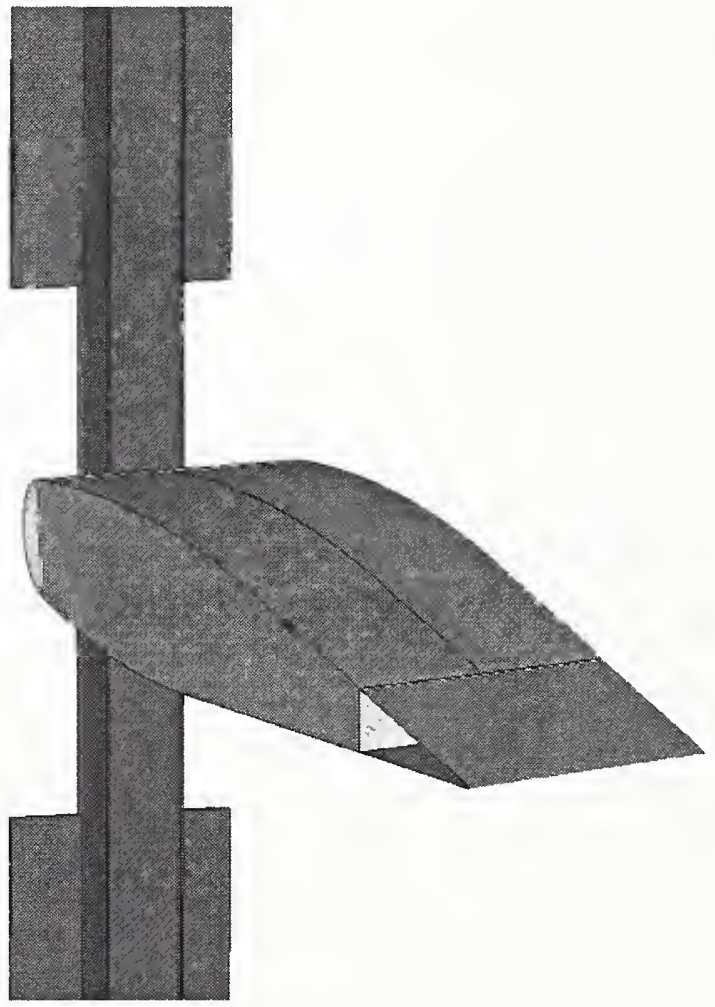

Figure 5-1. Preliminary model of a wing section with fuel impacting an exterior column. 
The impact response of the wing section and column at $5 \mathrm{~ms}$ is shown in Figure 5-2(a), with the corresponding column damage shown in Figure 5-2(b). The subsequent impact loading of the wing section with fuel completely failed the exterior column. The early time impact response, shown in Figure 5-2, initiated various failure modes in the column. Connections at the front and back web plates were sheared away from the side flange plates, and the failure of the side plates had initiated. The momentum transfer and deformations of the front web were sufficient to result in a shear out failure at the position of the internal gusset plate at the location of the lower edge of the spandrel above the impact point. Although this analysis included preliminary models for the materials and structural details, many of these damage mechanisms were observed in the recovered exterior panels from the impact zone as shown in Figure 5-3. The photograph shows an exterior column with impact damage that sheared the front web free from the side flanges. The fracture progressed along the weld until it reached the internal stiffener plate at the location of the spandrel edge. The impact of the column front web with the internal stiffener sheared the forward web across the column width similar to the calculated response shown in Figure 5-2. Although the exact loading history that created the observed damage is not known, the qualitative agreement of the calculated and observed damage modes provided a level of confidence in the modeling methodologies used.

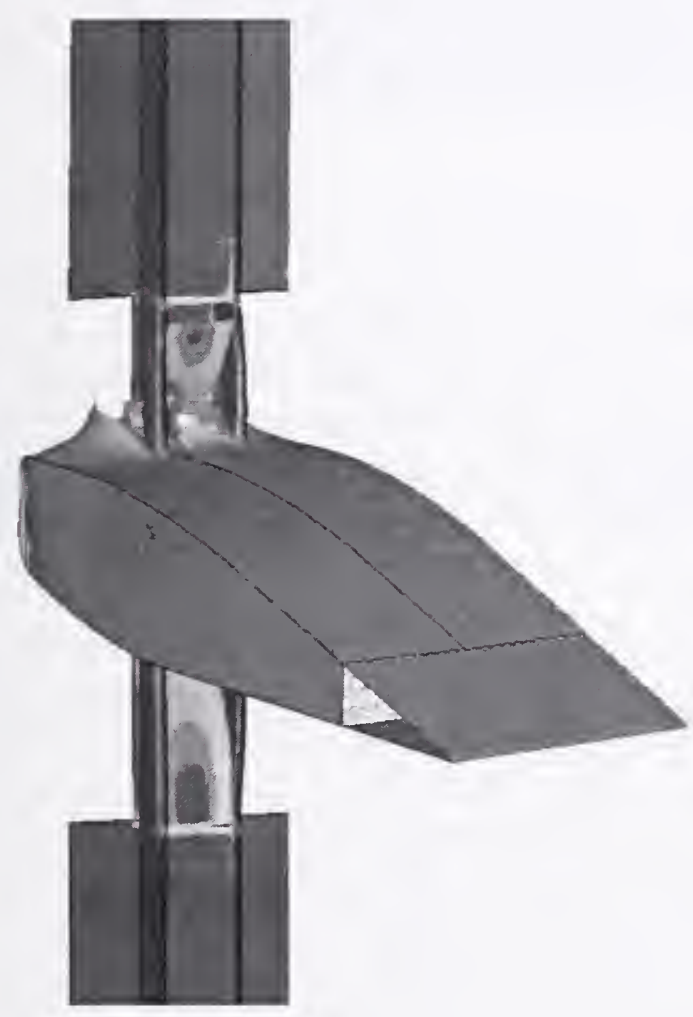

(a) Wing and column behavior

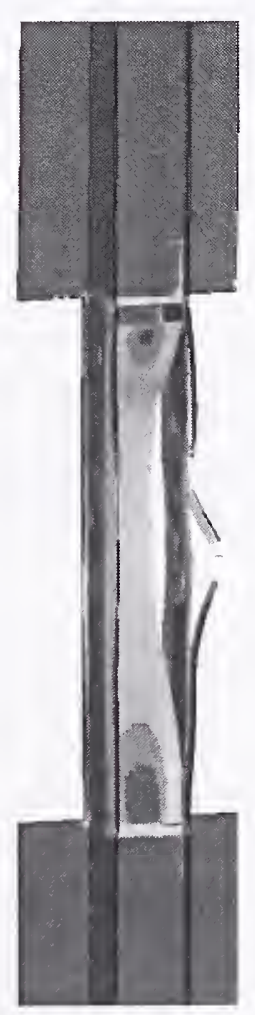

(b) Column damage

Figure 5-2. Calculated wing with fuel impact response on the exterior column. 


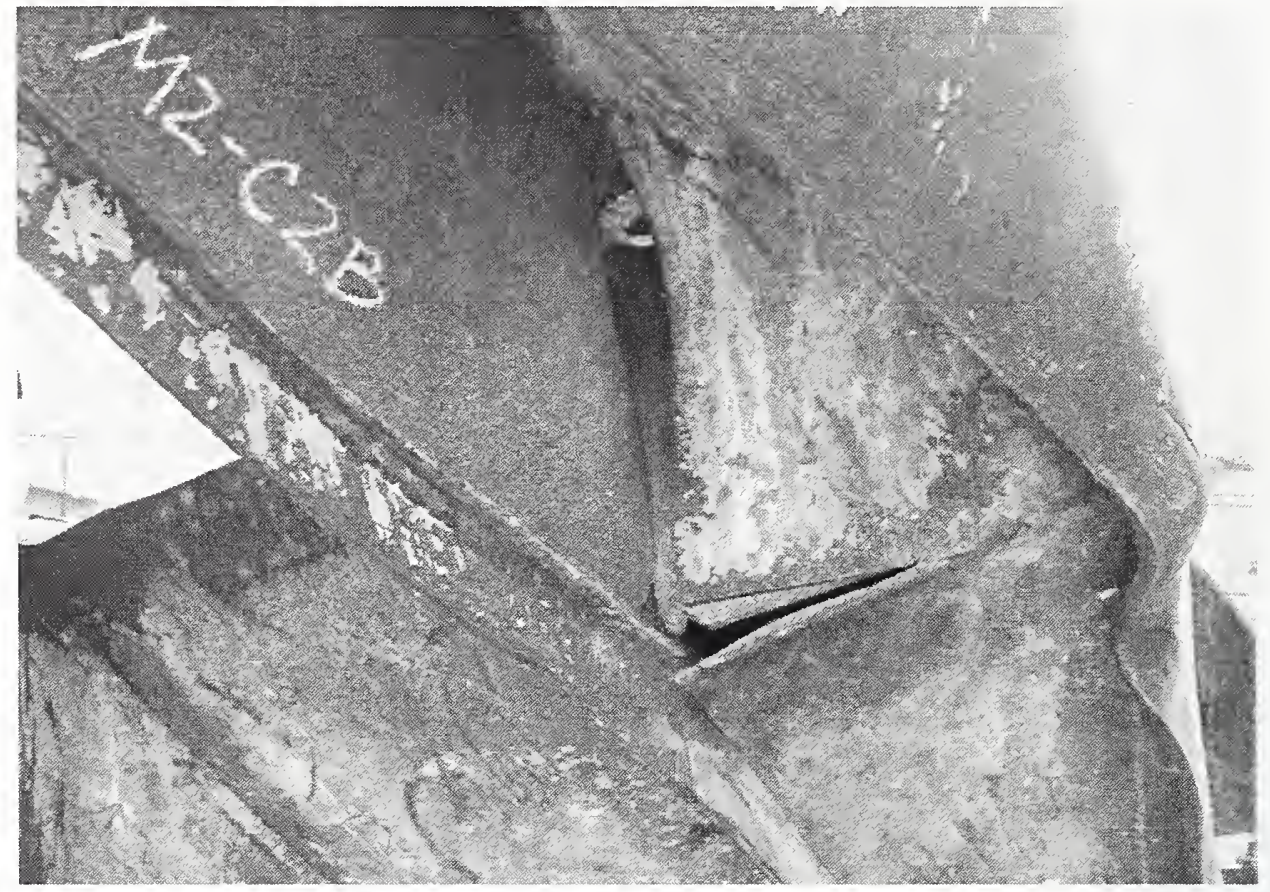

Source: NIST

Figure 5-3. Observed impact damage in the recovered WTC exterior columns.

The objective of subsequent exterior column impact analyses was to develop a model with a coarser mesh that could be applied to the global impact analyses and still capture the impact damage properly. The analyses used the preliminary wing section impactor, shown in Figure 5-1, but with the fuel removed. This empty wing section model was selected to produce significant column damage at an impact speed of $470 \mathrm{mph}$ without complete failure. This damage level was expected to be more sensitive to changes in the modeling methodologies than the complete failure produced by the impact of the wing section with fuel.

A series of these second generation exterior column impact analyses were performed to further refine modeling methods. These calculations used the updated constitutive models, described in Chapter 2, but with preliminary failure criteria. The exterior column modeled was constructed entirely with $55 \mathrm{ksi}$ steel and the spandrel plates with $42 \mathrm{ksi}$ steel. Both a model with a fine mesh of brick elements and a model with a coarser mesh of shell elements were developed. These models included a specific description of the weld geometry, with different properties. In the fine brick element model, the failure strain for the base metal, weld metal, and Heat Affected Zone (HAZ) were all set at a uniform plastic strain magnitude of 64 percent corresponding to the base metal ductility. Failure strains in the coarse shell element models were then modified until they showed a similar magnitude of impact damage and similar failure mechanisms. A comparison of parameters for the two models is given in the second and third column of Table 5-1.

The calculated impact response of the second generation component models is shown in Figure 5-4. The column model on the left has the fine mesh of brick elements, and the column model on the right has the coarse mesh of shell elements. Failure strains in the coarser model were adjusted to obtain a match of the calculated deformation and failure modes for the column. The resulting values, that closely matched the 
response. were failure strains of 12 percent and 2 percent for the base metal plates and weld zone, respectively. Contours of resultant displacements are shown on the column components. The overall response was similar in both magnitude and damage mode. The reduction in model refinement resulted in a significant reduction in run time from over $600 \mathrm{~min}$ to $9 \mathrm{~min}$. This comparison demonstrated the significance of the mesh refinement on capturing local stress and strain concentrations and the resulting effect on the failure behavior.

Table 5-1. Exterior column component analyses comparison.

\begin{tabular}{|c|c|c|c|}
\hline Column Model Type & Fine Brick Model & $\begin{array}{c}\text { Coarse Shell } \\
\text { Model } 1\end{array}$ & $\begin{array}{c}\text { Coarse Shell } \\
\text { Model } 2\end{array}$ \\
\hline Number of Brick Elements & 473,208 & 352 & 352 \\
\hline Number of Shell Elements & 0 & 9,192 & 9,192 \\
\hline Number of Beam Elements & 0 & 8 & 8 \\
\hline Minimum Element Dimension & $0.0625 \mathrm{in}$. & $1.0 \mathrm{in.}$ & $1.0 \mathrm{in.}$ \\
\hline Bulk Material Failure Strain & $64 \%$ & $12 \%$ & $34 \%$ \\
\hline Weld Zone Failure Strain & $64 \%$ & $2 \%$ & $8 \%$ \\
\hline Calculation Time $(\mathrm{CPU})^{\mathrm{a}}$ & $444 \mathrm{~min}$ & $3 \min$ & $3 \min$ \\
\hline Elapsed Time & $624 \mathrm{~min}$ & $9 \min$ & $9 \min$ \\
\hline
\end{tabular}

a. Simulation of $0.035 \mathrm{~s}$ duration impact response performed on $11 \mathrm{CPUs}$.

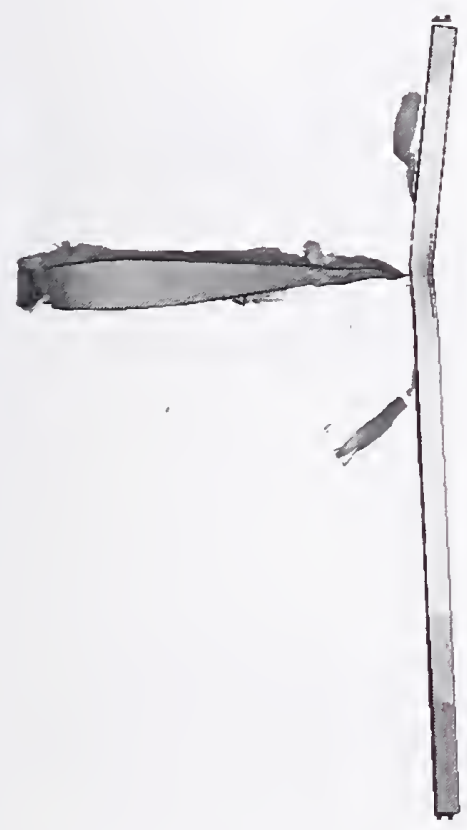

(a) Fine brick element column

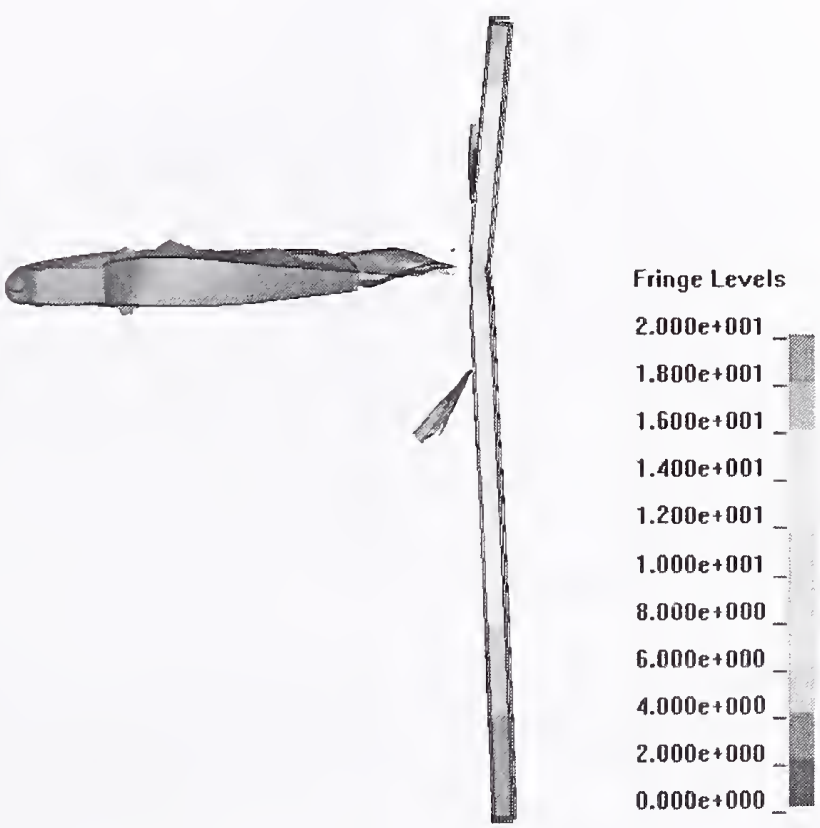

(b) Coarse shell element column

Figure 5-4. Exterior column response comparison, showing contours of the displacement magnitude (inches).

An additional exterior column impact analysis was performed using the coarse shell element model. This analysis was identical to the coarse shell element model shown above in Figure 5-4, but the failure 
criteria were obtaincd from the mesh refinement study and weld zone failure analyses described in Section 2.3.1 and Section 2.3.3. These were the failure parameters used subsequently in the global impact analyses described in Chapter 9. The updated failure strains for the base metal plates and weld zone were set at 34 percent and 8 percent, respectively. A comparison of the impact response for the two different coarse shell element models is given in Figure 5-5. Although there were differences in the calculated column displacements and failure modes, many of the features, such as extent of weld failure and wing section damage, were similar. This comparison provided some guidance as to the bounds on uncertainties in failure criteria and range of expected damage in these analyses.

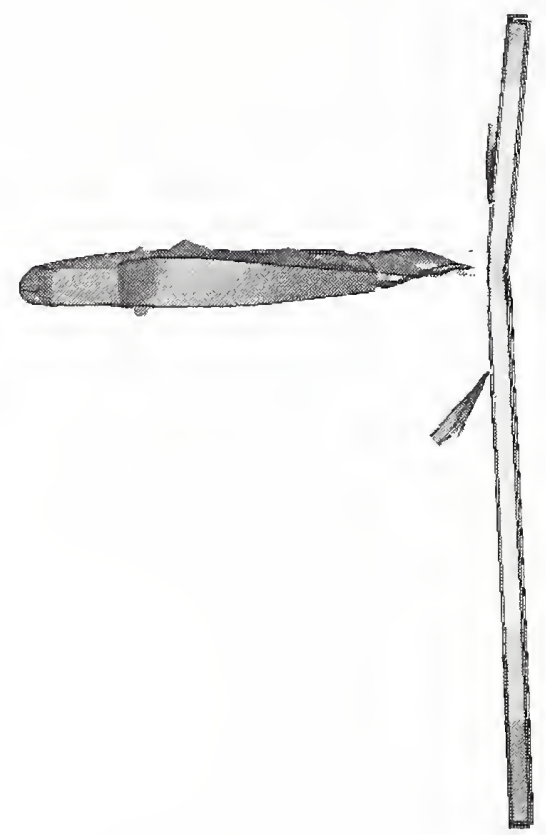

(a) Coarse shell element model 1

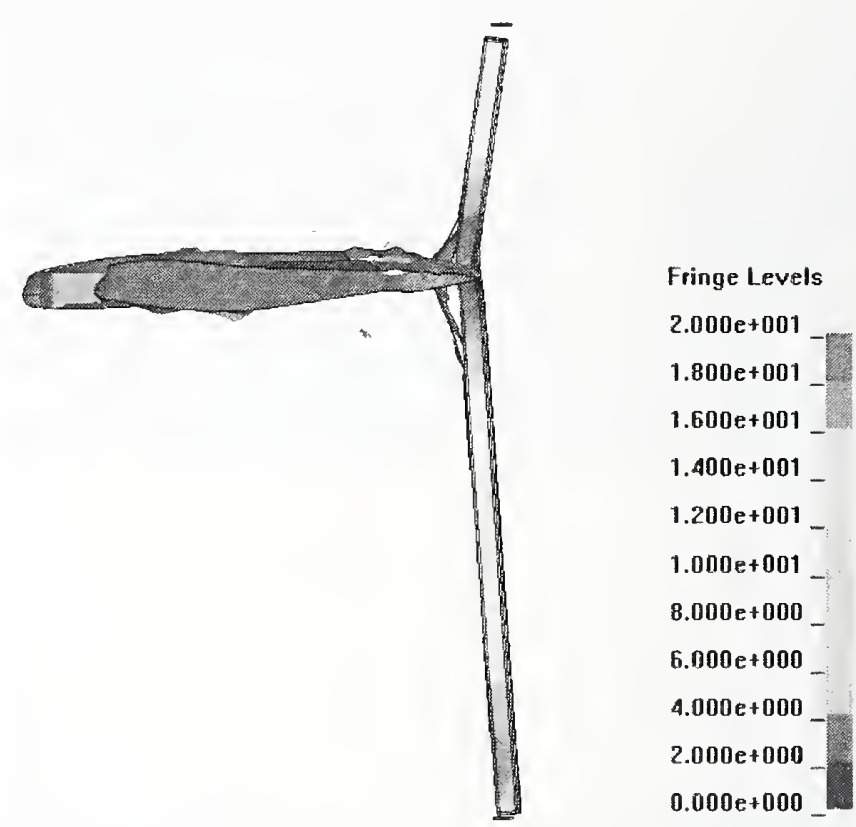

Figure 5-5. Exterior column response comparison, showing contours of the displacement magnitude (inches).

\subsubsection{Core Column Impact Analyses}

\section{Engine Impact Analysis}

Preliminary analyses of an engine impacting a single core column indicated that the impact load was sufficient to penetrate and overwhelm the column. To capture the more subtle response in the core column components, wing sections with and without fuel were studied as impactors. These studies are described in this section. Subsequent analyses of engine impacts focused on exterior panels and the combined impacts with exterior panels and core columns as described in Sections 5.2.4 and 5.3. Most useful were the engine-impact subassembly analyses described in Chapter 6, where there were sufficient tower structures to resist and potentially stop the engine. 


\section{Wing Section with Fuel Impact Analysis}

Component analyses for core columns impacted by fuel-filled wing sections were conducted for both wide flange and box type columns. Similar to the exterior column analyses, the primary purpose was to progress from the initial finely meshed, brick element models to coarser shell element models.

Figure 5-6 (wide flange core column) and Figure 5-8 (box section core column) compare the fine brick model and coarser shell model response under the same loading conditions. Figure 5-7 and Figure 5-9 show corresponding displacement and kinetic energy comparisons for, respectively, the wide flange and box section core column models. In these simulations, the constitutive and failure parameters used were identical between the fine brick model and coarser shell models. Material failure was not a significant factor for the impact behavior in this example, and the primary objective was to validate that the coarser shell element model could accurately reproduce the impact deformations. The figures indicate that the response of the coarser shell models was very similar to that of the fine brick models. Therefore, the shell element formulation and mesh refinement of the coarse model were sufficient to capture the impact damage mechanisms in this component impact scenario.

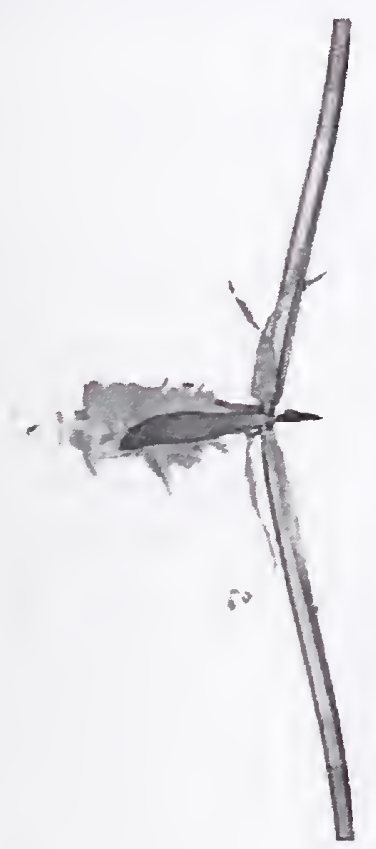

(a) Fine brick element column

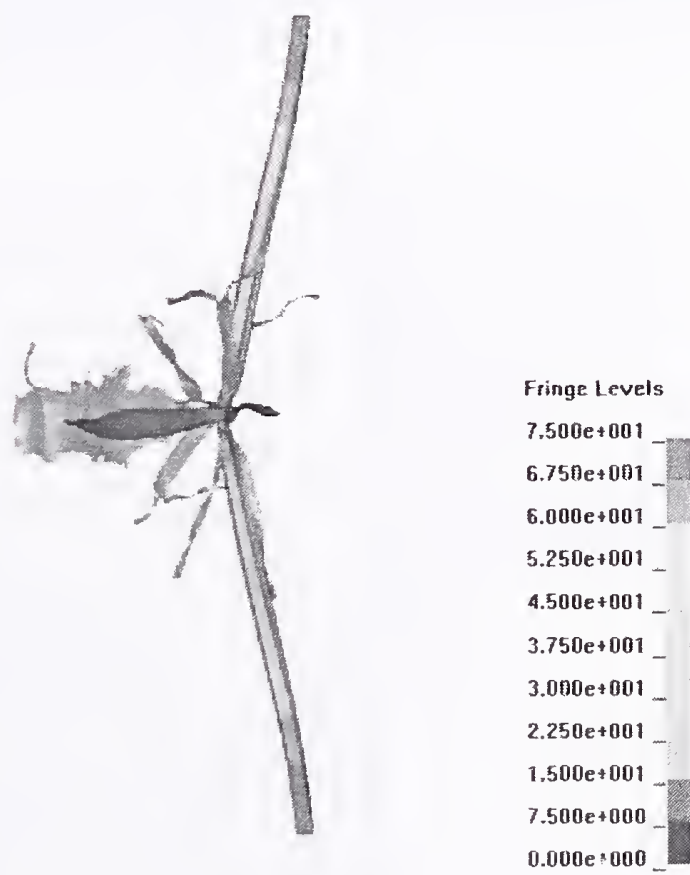

(b) Coarse shell element column

Figure 5-6. Wide flange core column response comparison, showing contours of the displacement magnitude (inches). 

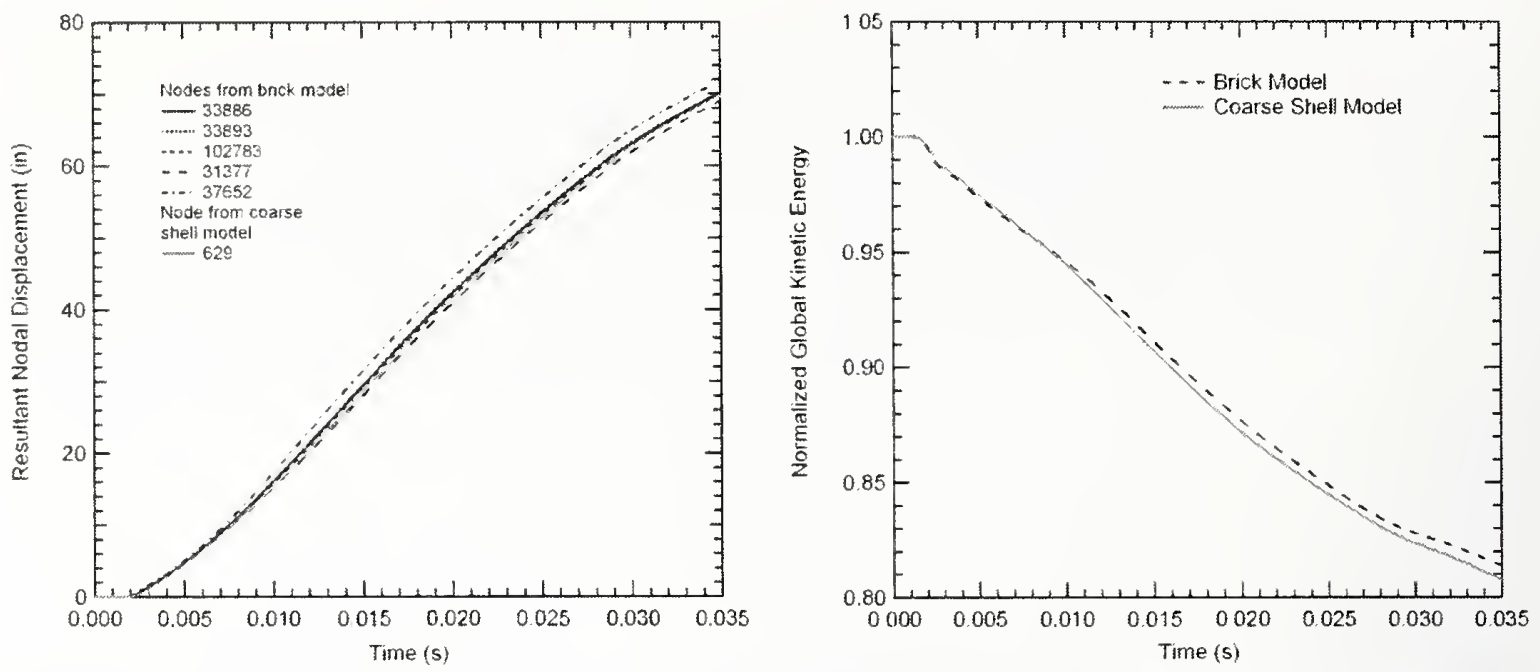

Figure 5-7. Displacement and kinetic energy comparison for wide flange core column wing impact analysis.

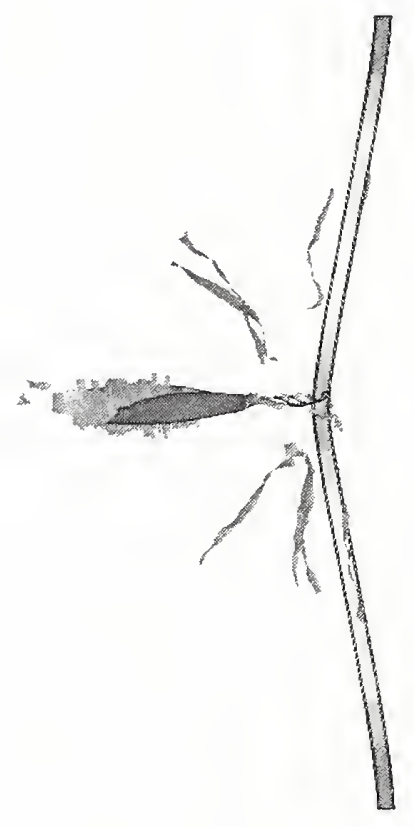

(a) Fine Brick element column

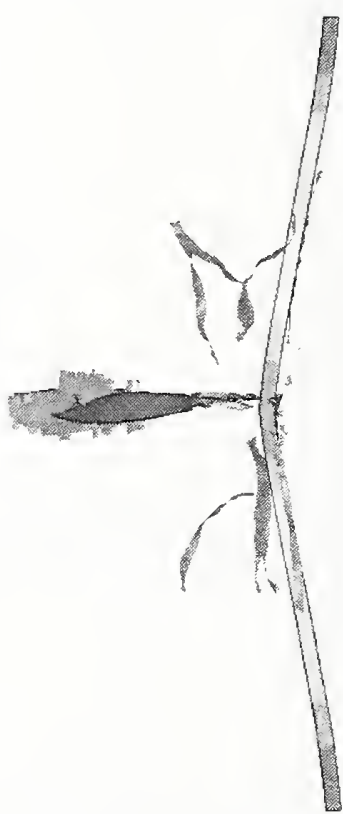

(b) Coarse shell element column

Figure 5-8. Box core column response comparison, showing contours of the displacement magnitude (inches). 

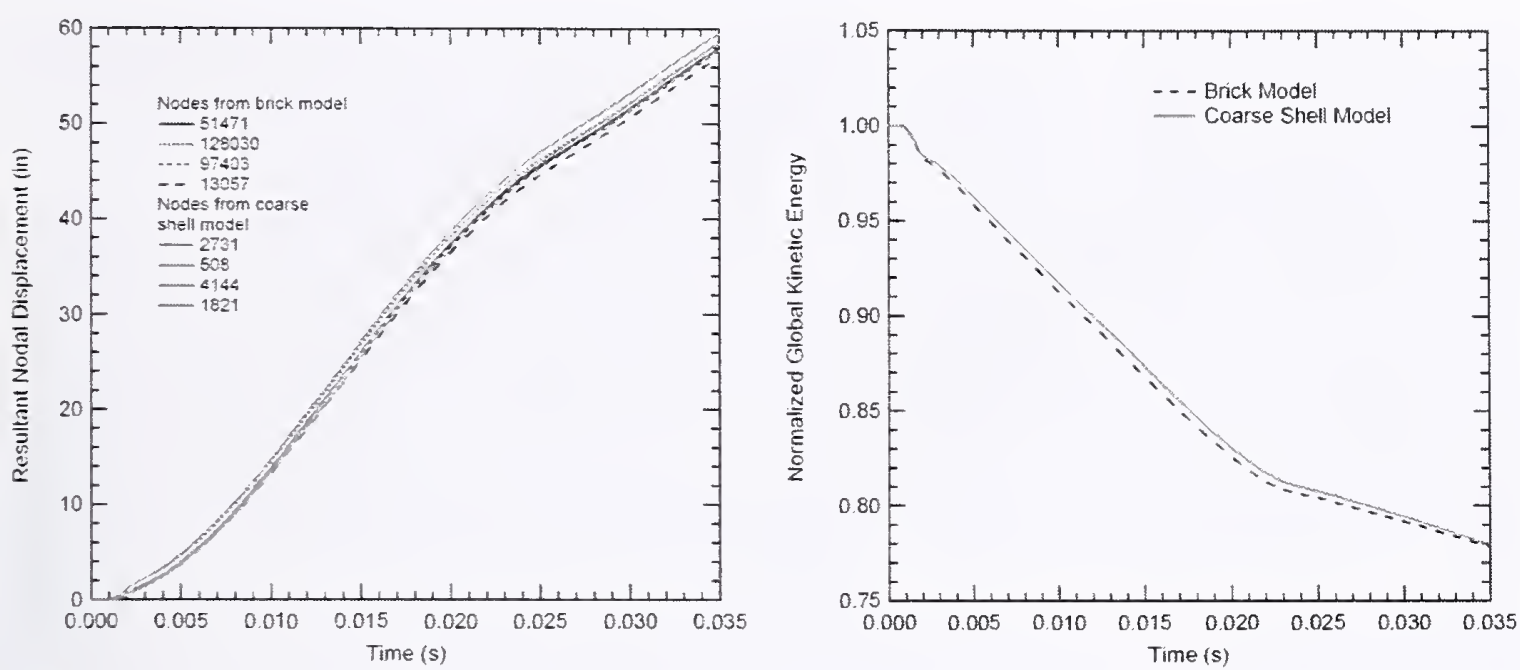

Figure 5-9. Displacement and kinetic energy comparison for box core column wing impact analysis.

\subsubsection{Bolted Connection Modeling}

There was a wide variety of different connections required for the assembly of the tower models.

Wherever possible, evidence gathered from the WTC steel and photographs was applied to determine the importance of including connection details in the model and failure modes of those connections.

Photographic and structural debris evidence clearly demonstrated that the external column connections played a significant role in the mode of column failure and extent of the external damage (FEMA 2002). For example. the bolted connections at exterior column butt plates, shown in Figure 5-10, failed primarily in the bolts. The bolted spandrel connections failed in several modes, including bearing strength failure where bolts pulled through the spandrel material, as shown in Figure 5-11.

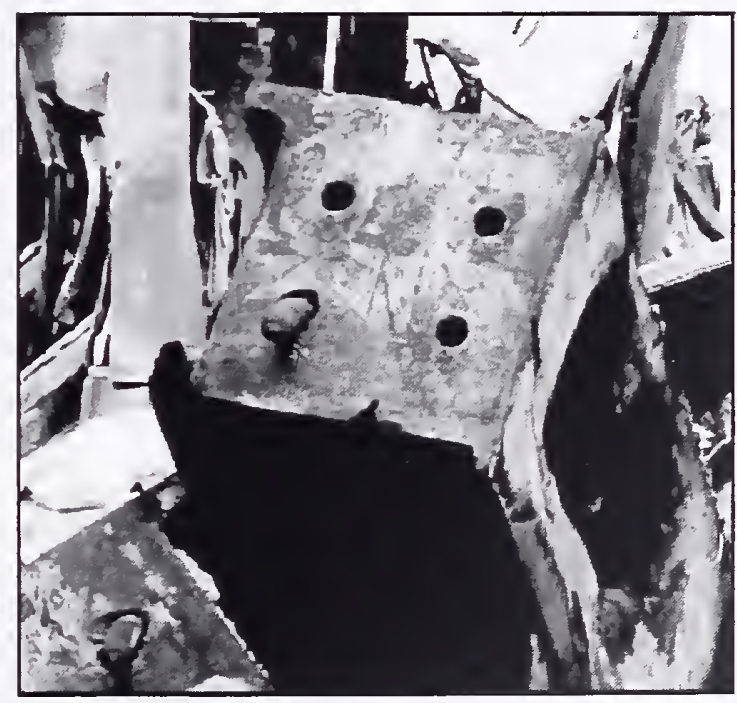

Source: FEMA 2002.

Figure 5-10. Failure behavior observed in the external column bolted joints. 

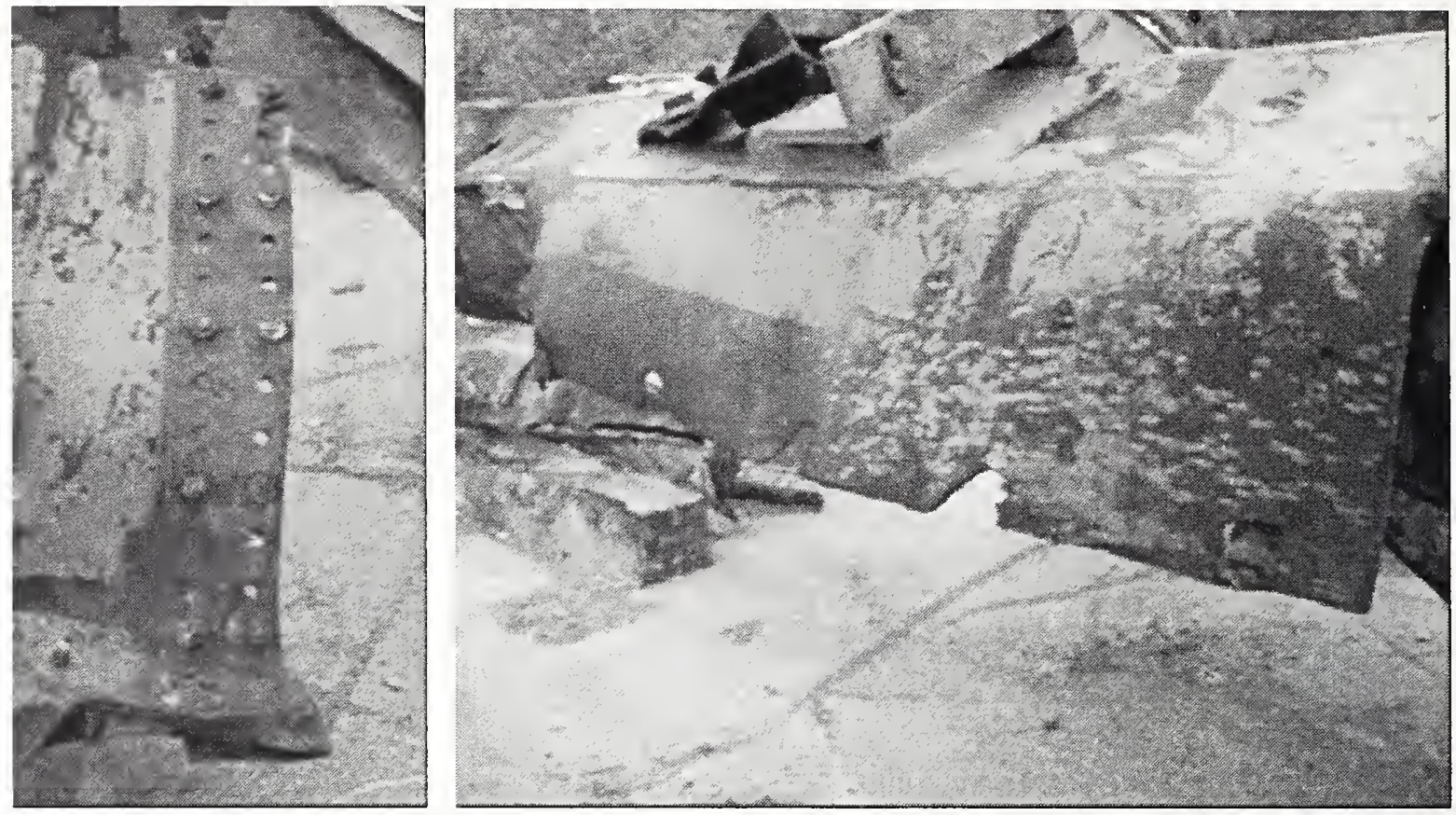

Source: NIST.

Figure 5-11. Typical bolt bearing shear failures of spandrel connections.

The objective of the connection component analyses was to develop connection models for the global impact analyses that accurately captured the capacity and failure modes of the connection. Various connection component models developed included both fine models of these complex connection components (e.g., 3-D brick element models of bolts), and simple models such as simple beam element bolt models and tied constraints with failure. A tied constraint with failure requires that two nodes or a node and a surface segment (shell element or solid element face) have tied degrees of freedom until a failure criterion is exceeded.

The coarse component models utilized many of the simplified connection and element types available in LS-DYNA to approximate the behavior observed in the fine models. For example, in the exterior column bolted connections, the bolts were modeled with elastic-plastic beam elements calibrated to match the fine model. The constitutive behavior of the beam element bolt was described previously in Section 2.3.4. Bolted joints, such as in the spandrel connections, were approximated with a tied node algorithm that constrained degrees of freedom of adjacent nodes and element faces. Various options were investigated in these component analyses, and final selections of the modeling methodology were based on both the fidelity and efficiency of the modeling approaches.

Component models of the exterior column butt plate connections are shown in Figure 5-12. The detailed model included individual bolts modeled with solid brick elements. The simplified model used coarse brick butt plates joined by beam elements representing the bolts. A dynamic analysis was carried out to calibrate the beam element bolt model. The loading condition was a dynamic separation of the two butt plates. The velocity profile used to separate the butt plates was obtained from a preliminary engine impact analysis against the exterior wall, similar to those described in Section 5.2.4. The profile was a 
linearly increasing separation velocity between the butt plates with an initial velocity of zero and a velocity of $43 \mathrm{fps}$ at a time of $5.0 \mathrm{~ms}$.

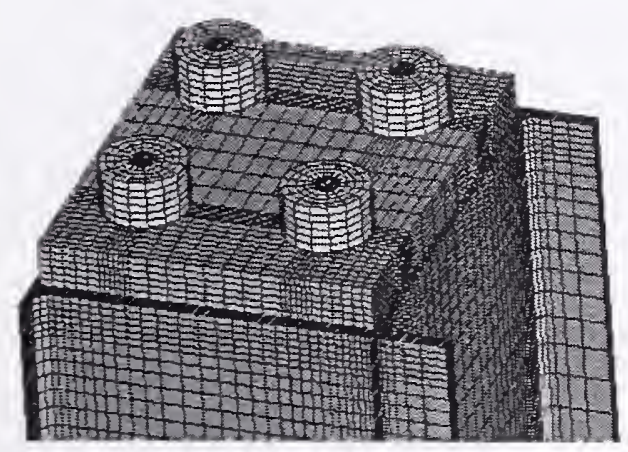

(a) Brick element bolts

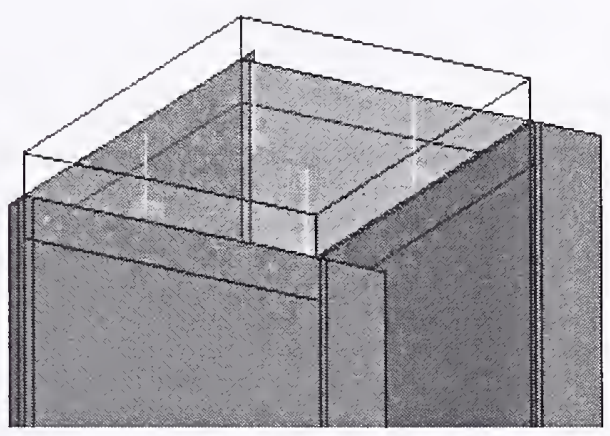

(b) Beam element bolts (butt plates shown as transparent)

Figure 5-12. Exterior column end connection treatments.

Failure strain in the beam models was calibrated such that the beam bolts failed at the same time as the brick element bolts. Failure of the bolts occurred at a time of approximately $3.0 \mathrm{~ms}$. These connection models were used in the corresponding brick and shell models of the exterior column component impact analyses shown previously in Figure 5-4. Connection failure at the column ends was quite similar in both cases, as shown in Figure 5-13. Failure of the connection is illustrated for both connection models at the same time, $35 \mathrm{~ms}$, after impact with the empty wing seginent. The primary failure mode for both models was a tensile failure of the bolts and subsequent separation of the column end butt plates.

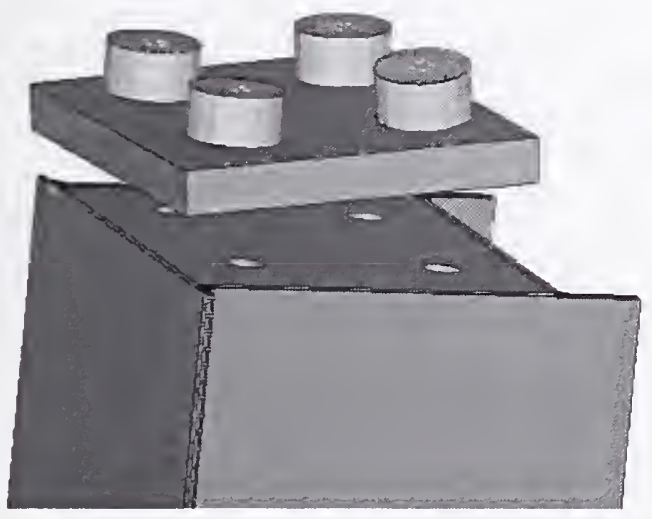

(a) Brick element bolts

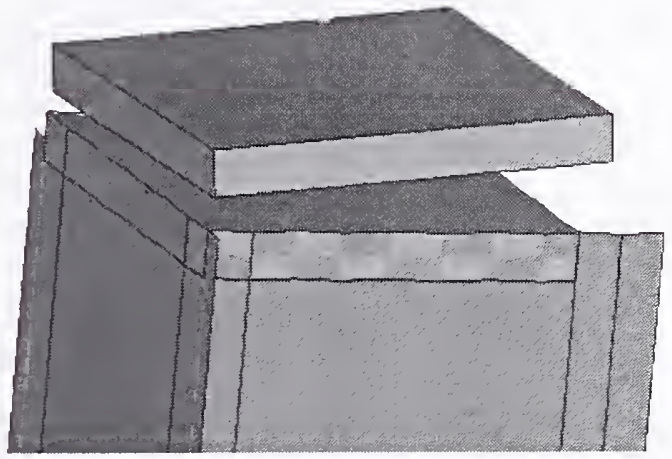

(b) Beam element bolts

Figure 5-13. Failure comparison of exterior column end connection treatments.

The spandrel connections consisted of an overlapping splice plate across a spandrel joint with rows of bolts on both sides of the joint. Typical failure of these spandrel joints in the impact zone resulted from bolt bearing shear failures, typically in the spandrel plate, as shown in the photographs in Figure 5-11. A common configuration in the impact zone would be six bolts on either side of the joint. Modeling the spandrel connection bolts using beam elements was not appropriate at this location, where the dominant response mechanism was a bolt bearing shear failure. In the exterior columns, the bolts failed primarily 
in tension, and details of the contact between bolts and butt plates were not as important for capturing the failure behavior. As a result, an alternate modeling approach was required for the spandrel splice failures.

Spandrel connections were modeled using a splice plate made up of shell elements, as shown in Figure 5-14. Connections corresponding to individual bolts were treated by tying single nodes on the splice plates (center of green squares in Figure 5-14) to the spandrels. Two material definitions were used to make up the splice plate to allow for contact between the splice plates and the spandrels, as well as having tied contact. Use of a single material definition can sometimes result in numerical instability due to conflicting constraint and interface algorithms on those segments.

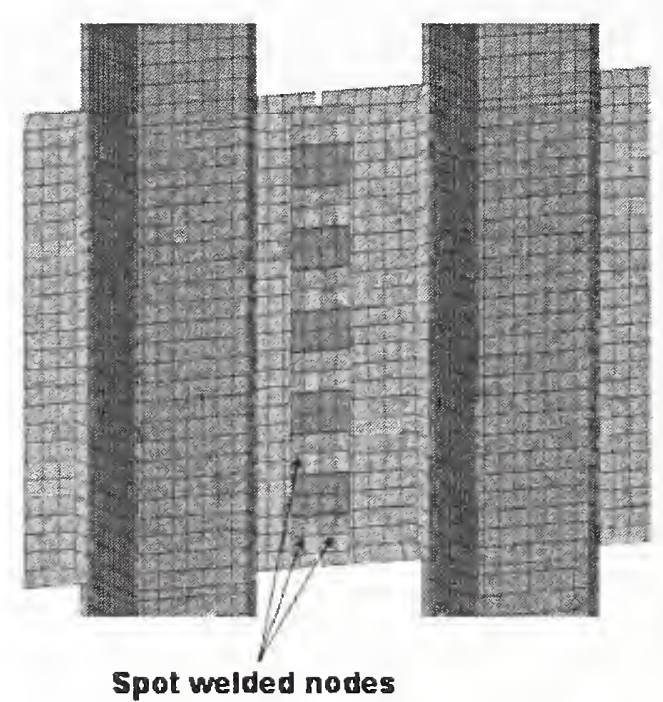

(a) Detail of connection

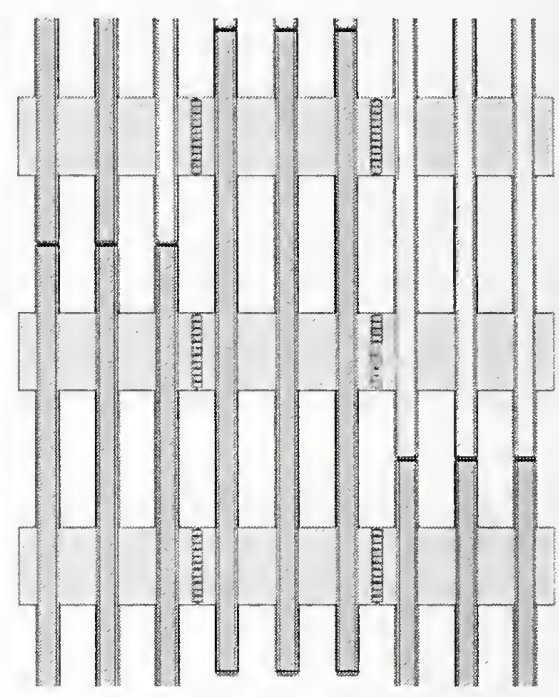

(b) Multiple panel connections

Figure 5-14. Bolted spandrel connection treatments.

The first splice plated material definition (shown in green in Figure 5-14) was used to allow the center node tied constraint (representing the bolt connection) to be aligned with the center of the spandrel plate. Since this material included the tied constraint, it was not included in the automatic contact definition. The second material definition in the splice plate (shown in red in Figure 5-14) had a standoff distance equal to one half of the combined thickness of the spandrel and splice plate and was included in the automatic contact definition. Both material definitions had the same constitutive properties. The application of the spandrel splice plate connection model was demonstrated in the following engine impact component analyses (see Figure 5-17).

\subsubsection{Engine Impact Analysis}

An example of an engine impacting an assembly of exterior panels is shown in Figure 5-15. The analysis included an engine impacting an exterior panel of WTC 1 and was centered on panel 124 at floor 96 (the impact was centered on the middle spandrel). The initial engine impact speed was $500 \mathrm{mph}$. In this example, a shell element panel with medium mesh density was used (typical exterior panel element size on the order of 2 in.). Columns were connected with beam element representations of individual bolts. Spandrels were merged together in this model (i.e., splice plates were not used). Fixed butt plates were bolted at the free column end, and no boundary conditions were applied to represent the floors. Velocity 
time-histories for representative engine core materials are shown in Figure 5-16. The plot shows an overall reduction in speed of about $67 \mathrm{mph}$ after impact with the exterior wall.

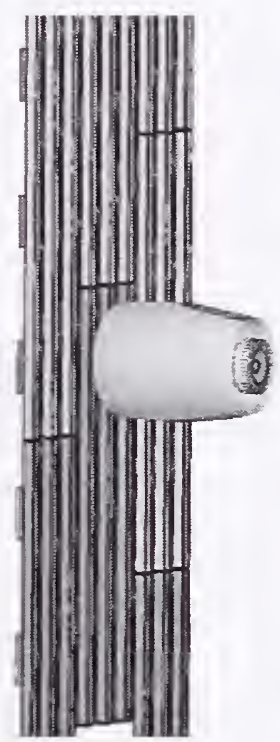

(a) Initial configuration

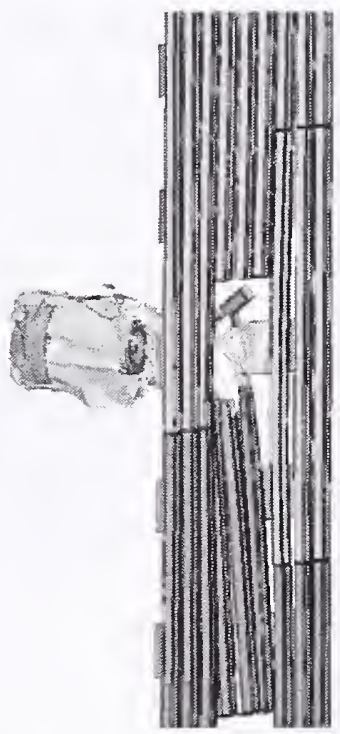

(b) Impact response at $\mathbf{4 0} \mathrm{ms}$

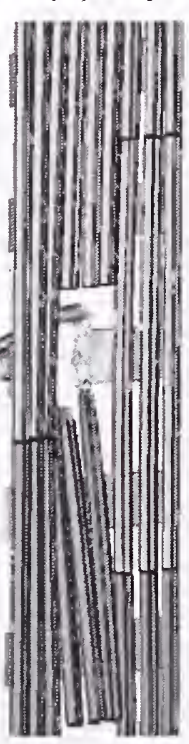

(b) Impact response at $80 \mathrm{~ms}$

Figure 5-15. Example engine impact analysis with exterior columns. 


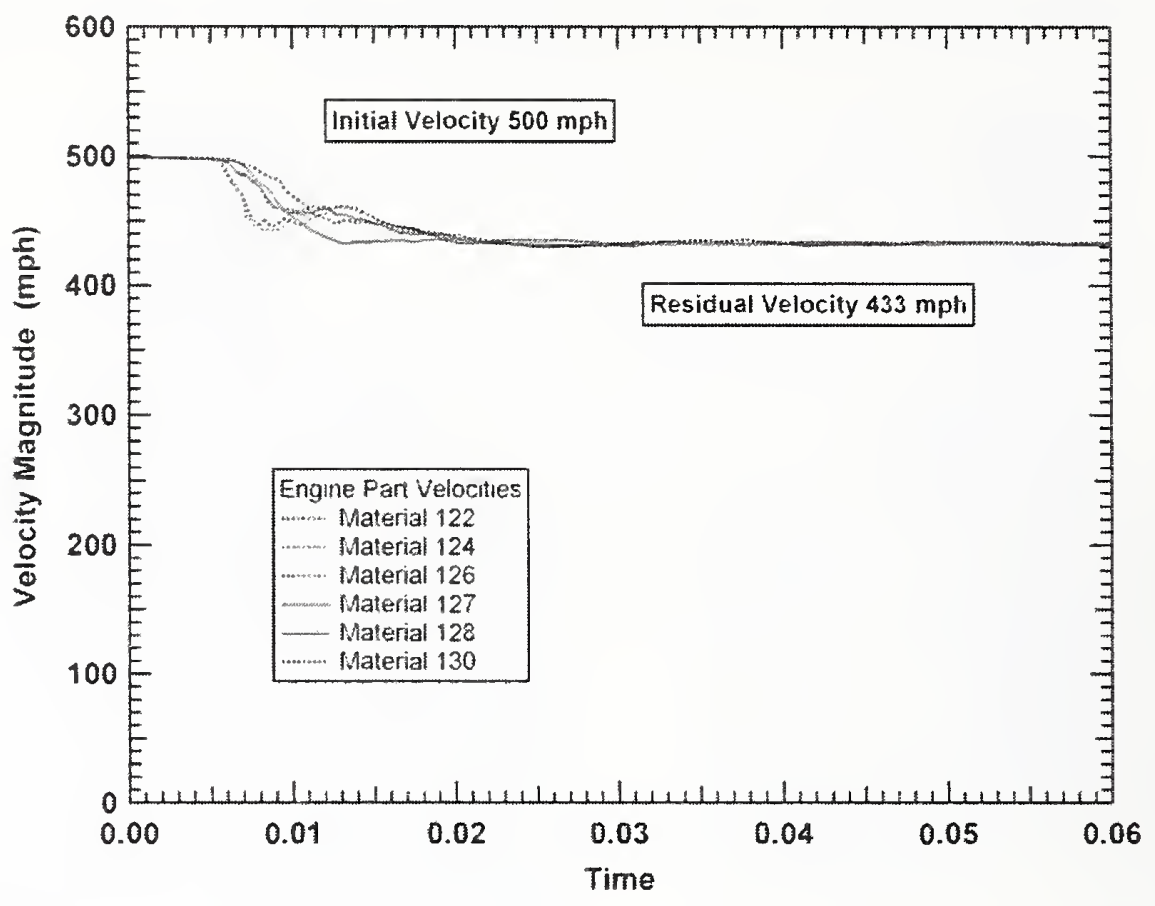

Figure 5-16. Engine velocity history for the exterior wall impact.

A second engine impact analysis was performed with similar conditions except that the impact location was moved downward by one half of a floor height to create an impact centered between spandrels. A comparison of the two calculated impact behaviors is shown in Figure 5-17. In both analyses the engine broke through the exterior wall with relatively little break up of the engine core. The impact centered between spandrels resulted in a reduction of the engine core speed by about $56 \mathrm{mph}$.

A final revision of the analysis described above included adding splice plates at the spandrel connections as explained in Section 5.2.3. Figure 5-18 shows a comparison of both models. The figure shows exterior wall damage as seen from the outside without engine components. Contours of plastic strain are shown in the plot with blue being zero strain and red being at the failure strain threshold ( 20 percent in this case). Material exceeding the maximum failure strain was eroded and no longer shown in Figure 517. The analyses differed most in spandrel failure modes. Spandrels failed at the column connection in the merged spandrel case, while the splice plate connection failed when the splice plate was included in the model. In the latter case, a realistic bearing stress type tear-out mode was observed in the splice plate. Engine core velocities for the three engine impact analyses are compared in Figure 5-19 for a single representative engine component. The splice plate model resulted in a $74 \mathrm{mph}$ speed reduction of the engine core. The splice model resulted in the largest reduction in the speed of the engine. In this case, the entire spandrel was carried away by the engine, resulting in a larger transfer of momentum.

The comparison described above suggests that the splice plate had a relatively small influence on the exterior wall strength. The addition of the splice plate had approximately a 10 percent effect on the change in engine velocity during impact and penetration of the exterior wall. However, the spandrel connection model did not introduce a large computational cost and resulted in a more appropriate failure 
mode for the spandrels in the impact zone. Therefore, the spandrel splice connections were maintained in subsequent impact analyses.

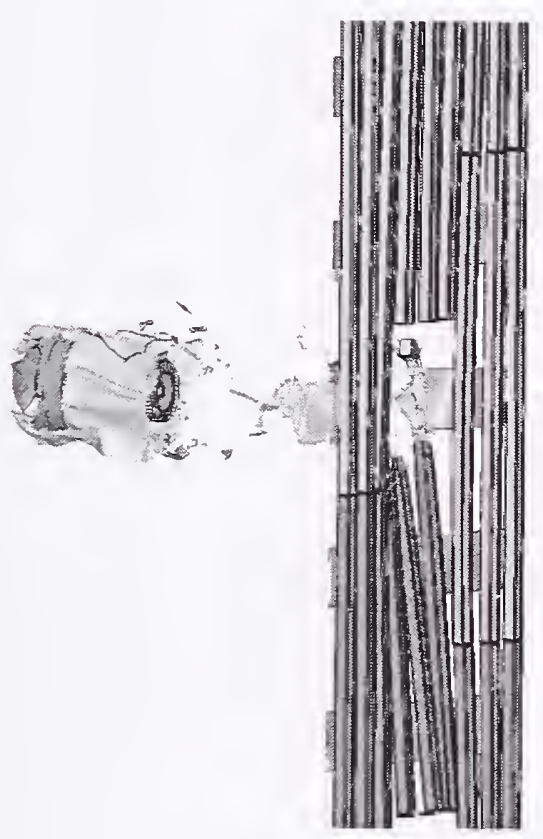

(a) Spandrel centered impact
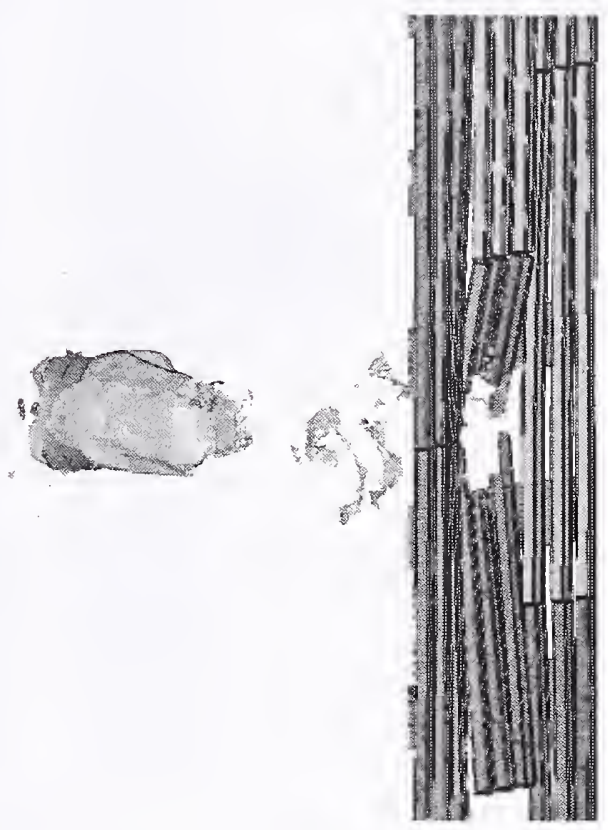

(b) Between spandrel impact

Figure 5-17. Example engine impact analysis with different impact locations.

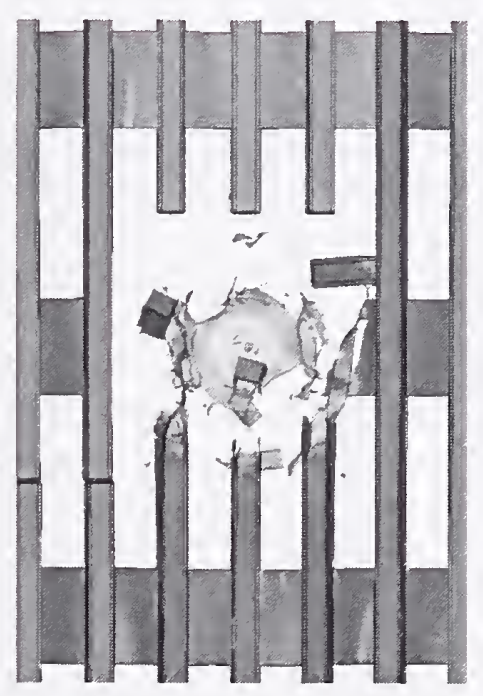

(a) Merged spandrel analysis

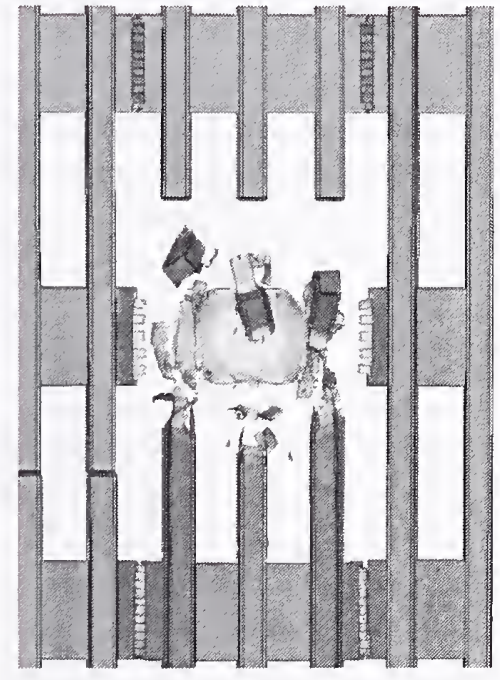

(b) Spliced spandrel analysis

Figure 5-18. Example engine impact analysis with different spandrel connection treatments. 


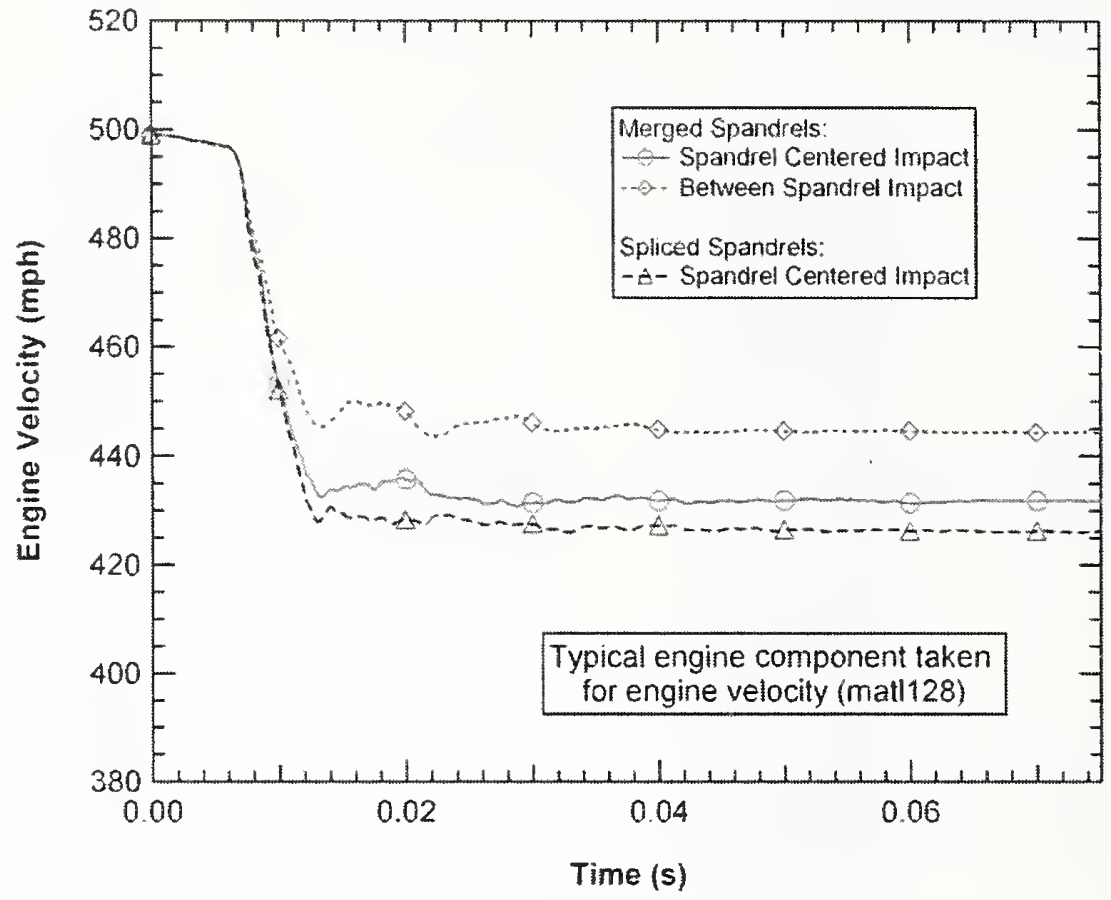

Figure 5-19. Engine velocity history for the exterior wall impact.

\subsection{COMBINED ENGINE IMPACT ANALYSES}

A combined engine impact analysis was performed to demonstrate the damage response to both exterior and interior columns. The impact configuration was an engine impacting at $560 \mathrm{mph}$ against a set of exterior columns in a single exterior panel, an interior box column, and an interior wide flange column. The columns were modeled using shell elements. The spacing between exterior and core columns was reduced to shorten the run time necessary for the complete impact scenario. The simulation included three external panels stacked vertically such that the impacted column was bolted to additional panels both above and below. The core column models were several floors tall to reduce the influence of the clamped boundary conditions at the ends.

The impact scenario is illustrated in Figure 5-20(a). The calculated impact damage is shown at a time of $90 \mathrm{~ms}$ in Figure 5-20(b). The calculated engine impact response completely failed all of the columns with a residual velocity of the engine of approximately $224 \mathrm{mph}$. The deformations of the column included large lateral displacements, which would be significantly reduced if the constraint effects of the concrete floor slab were included in the model. The deceleration profile of the major engine debris fragment is shown in Figure 5-21. The majority of the engine structure had been broken into fragments by the combination of the three impacts. The resulting size, strength, and velocity of the engine debris were not likely to produce severe impact damage or failure to a subsequent core column.

This example illustrates the large level of damage produced by a massive aircraft component, such as an engine, at high impact velocity. The impact energy was sufficient to overwhelm a single core column and, therefore, made it difficult to determine the effects of column component modeling parameters on the impact response. 


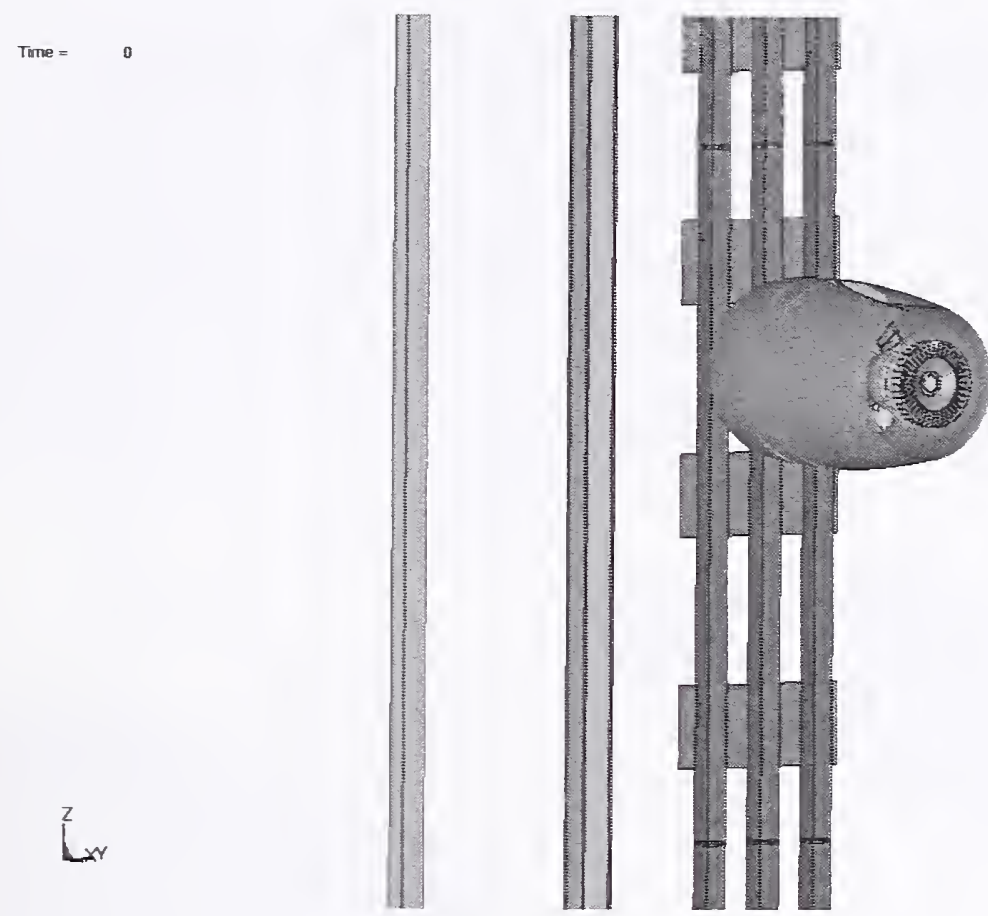

(a) Initial configuration

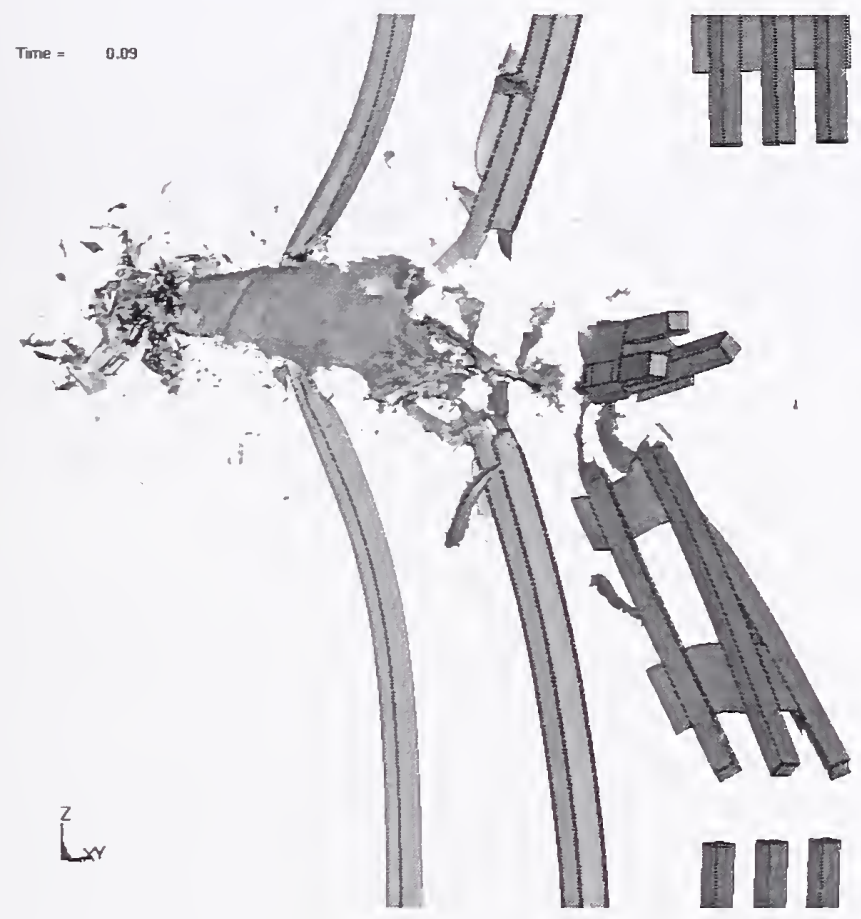

(b) Impact response at $90 \mathrm{~ms}$

Figure 5-20. Example engine impact analysis with interior and exterior columns. 


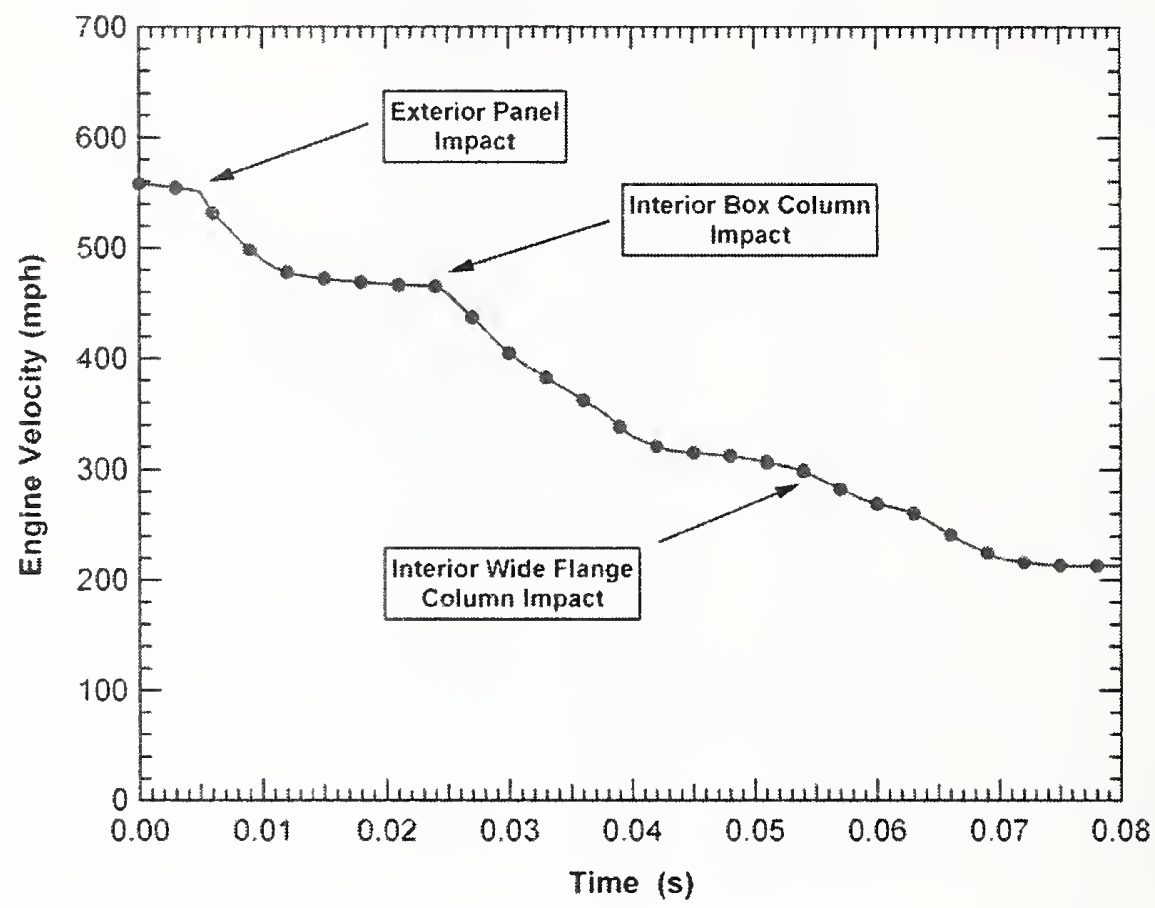

Figure 5-21. Example engine impact analysis with exterior and interior columns.

\subsection{FLOOR ASSEMBLY COMPONENT ANALYSES}

The truss floor structures outside the core played a significant role in the aircraft impact and penetration resistance of the towers. The failure and penetration of the floor structures were important for assessing the extent of damage and the spread of fuel and debris through the structure. The integrity of the floor structures could also be significant in the analysis of the subsequent fire behavior in the towers. As a result, floor truss component impact analyses were performed to ensure that the impact and penetration resistance of the simplified truss floor models used in the global impact analyses were properly modeled. Dynamic loading of the truss floor structure was achieved by direct impact by a simplified impactor.

Component models of a section of the composite floor assembly outside the core were generated and used in the impact analyses. The models included the concrete slab, the metal decking, and the primary and bridging trusses. The dampers were not included in the models for the reasons explained in Section 3.2.3. Detailed floor component models used a combination of brick elements for the concrete slab, beam elements for the truss round bar diagonals, and shell elements for the remainder of the structures, including the truss upper and lower chords and metal decking. This model is shown in Figure 5-22. A simplified model was then developed with coarser shell and beam elements as shown in Figure 5-23. The less-refined floor assembly models reduced the size of the model by an order of magnitude and the run times by more than 80 percent as can be seen from Table 5-2. 
Table 5-2. Truss floor assembly component analyses comparison.

\begin{tabular}{|l|c|c|}
\hline \multicolumn{1}{|c|}{ Model Type } & Fine Brick Model & Coarse Shell Model \\
\hline No. Beam Elements & 6,928 & 3,440 \\
\hline No. Brick Elements & 230,778 & 0 \\
\hline No. Shell Elements & 148,256 & 39,000 \\
\hline Total Nodes & 372,084 & 48,971 \\
\hline CPU Time & $16,796 \mathrm{~s}(4.7 \mathrm{~h})$ & $2,482 \mathrm{~s}(0.7 \mathrm{~h})$ \\
\hline Elapsed Time & $26,553 \mathrm{~s}(7.3 \mathrm{~h})$ & $4,454 \mathrm{~s}(1.2 \mathrm{~h})$ \\
\hline
\end{tabular}

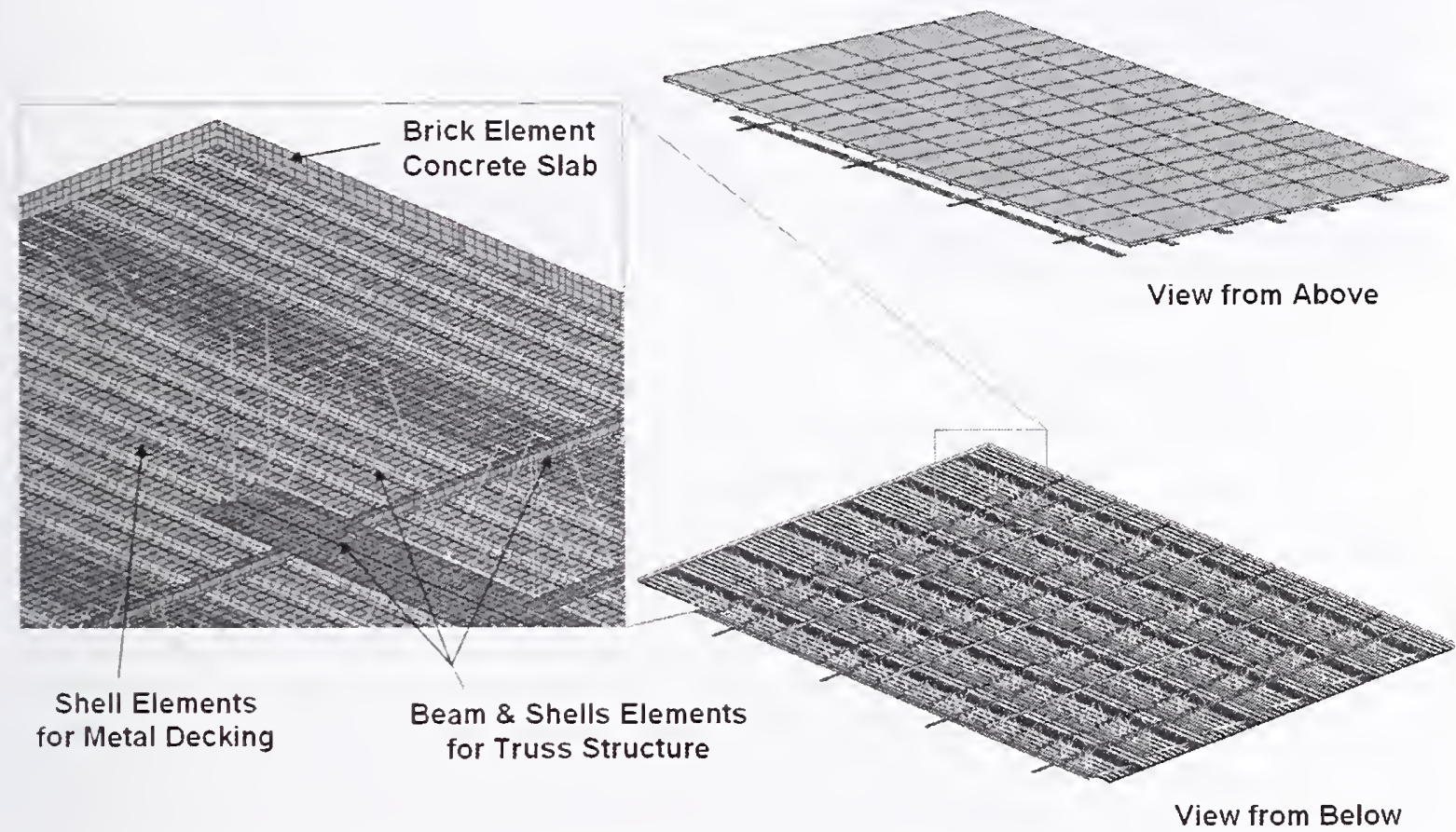

Figure 5-22. Detailed model of the truss floor. 

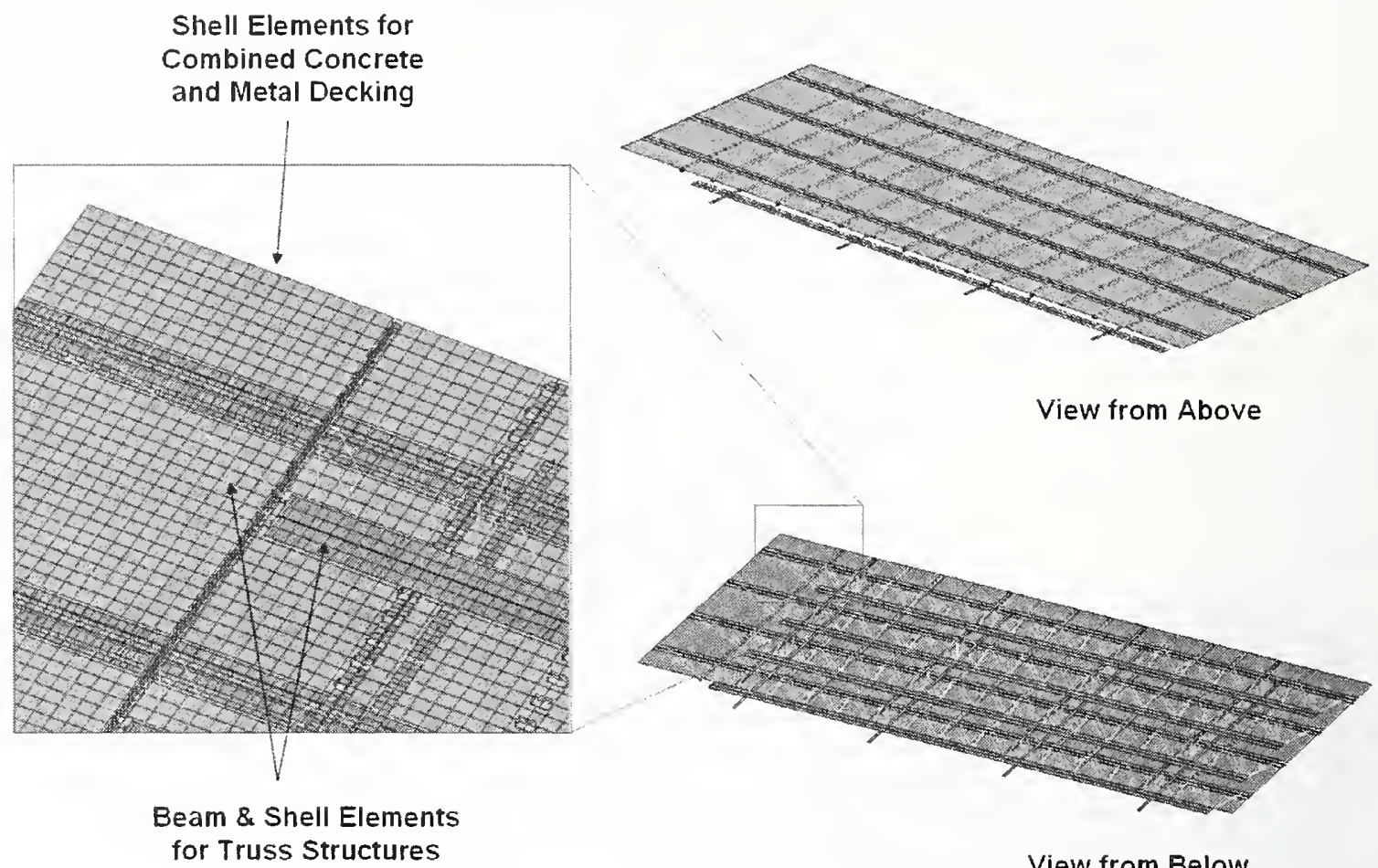

View from Above

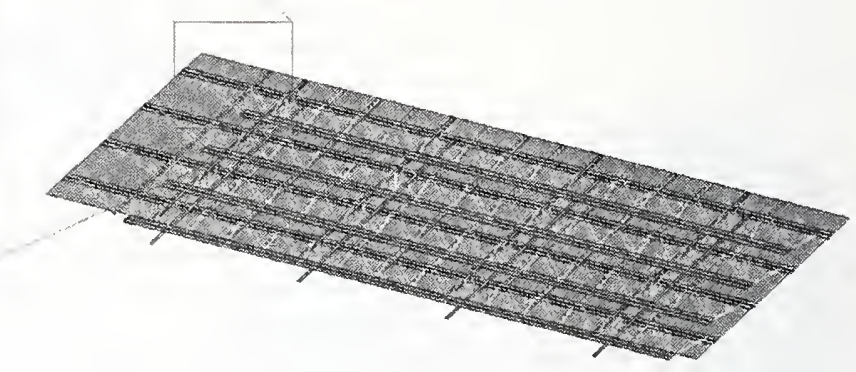

View from Below

Figure 5-23. Simplified model of the truss floor.

The concrete constitutive model used in the brick elements of the detailed floor model was described previously in Section 2.4. The design for the floor truss structures specified that material yield strength was to be taken equal to $50 \mathrm{ksi}$ for all steel members unless otherwise specified. Therefore, the constitutive model developed for the $50 \mathrm{ksi}$ tower steel, described in Section 2.2, was used for all of the truss structure components and metal decking. The exact strength of the metal decking could not be confirmed; however, the relative contribution of the metal deck was small compared to the much thicker concrete slab (see Figure 5-24). Therefore, the uncertainty on metal deck strength was not expected to have a significant effect on the truss floor strength.

The coarse floor model used an effective material model for the combined concrete slab and metal decking so that these parts would not need to be meshed separately. As the concrete constitutive model described in Section 2.4 (pseudo-tensor model) was developed for brick elements, and does not work for shell elements, a piecewise plasticity model was used for the effective slab-decking behavior. A tabular yield strength was developed based on the rule of mixtures of the elastic-plastic metal decking with the unconfined compressive behavior for the concrete. The combined slab and decking stress-strain curve was compared to the concrete unconfined compressive behavior in Figure 5-24. The strength of the combined floor slab was dominated by the concrete strength at low strain levels (below 1 percent strain). However, as the concrete was fragmented and removed as debris, the residual strength was equivalent to that of the metal deck alone and remained ductile until a strain of 30 percent was reached, corresponding to the failure strain of the $50 \mathrm{ksi}$ material. This combined slab material model had the same rate effect multiplier as the concrete constitutive model described previously in Section 2.4 and shown in Figure 2-32. 


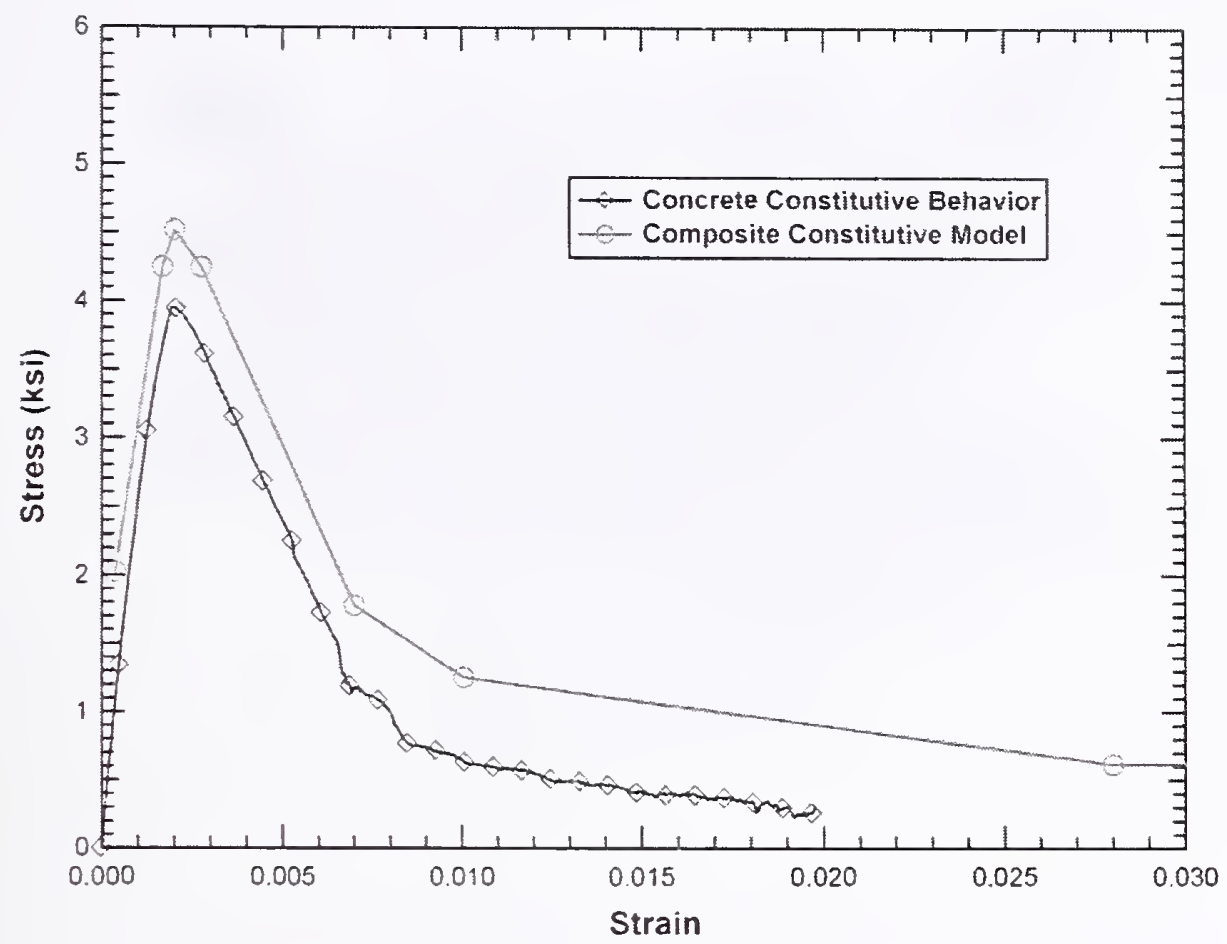

Figure 5-24. Constitutive behavior for the combined concrete and metal decking.

The impactor used in the component modeling was a simplified plow type impactor which promoted repeatable damage, not complicated by all the debris and randomness associated with an engine-floor impact. The weight of the plow impactor was comparable to an engine, and the impact velocity was $500 \mathrm{mph}$, applied horizontally. The response of the floor to the plow type impactor was similar to the response to an aircraft engine, but without the complications of the detailed engine impact bchavior, based on preliminary engine-floor impact simulations. An example analysis with a plow impactor and the fine mesh floor model is shown in Figure 5-25. The calculated impact damage with the coarser shell element floor system model is shown in Figure 5-26. This component impact configuration was useful for comparing the differences in response with changes in the modeling methods or refinement. The calculated plow impactor deceleration profile for the brick and shell element models are compared in Figure 5-27. The comparison shows that the simplifications did not significantly change the impact loads in the floor assembly. 


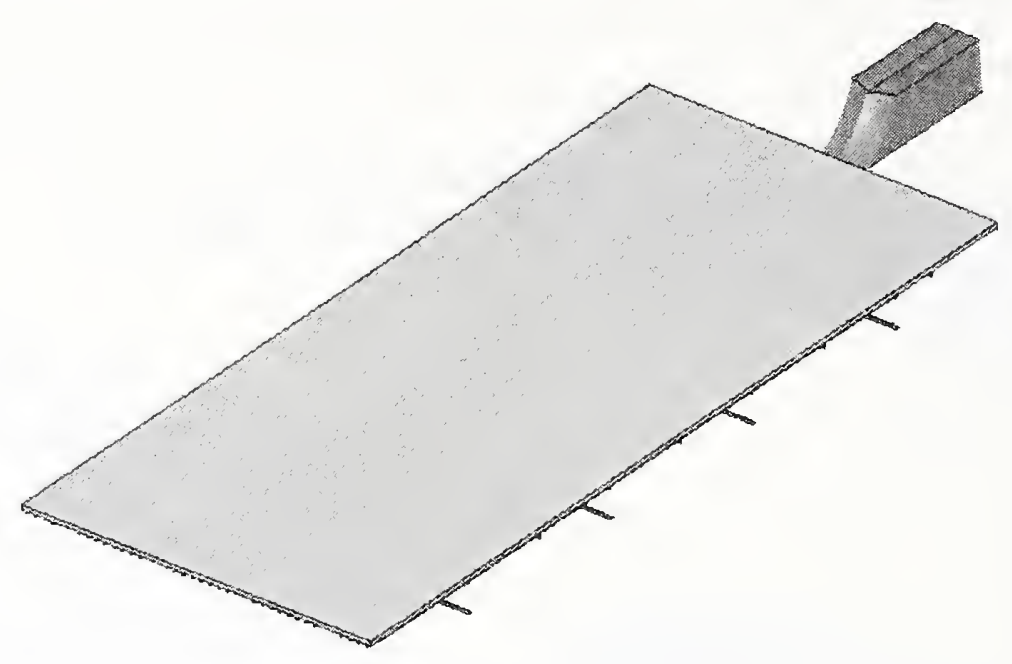

(a) Initial configuration

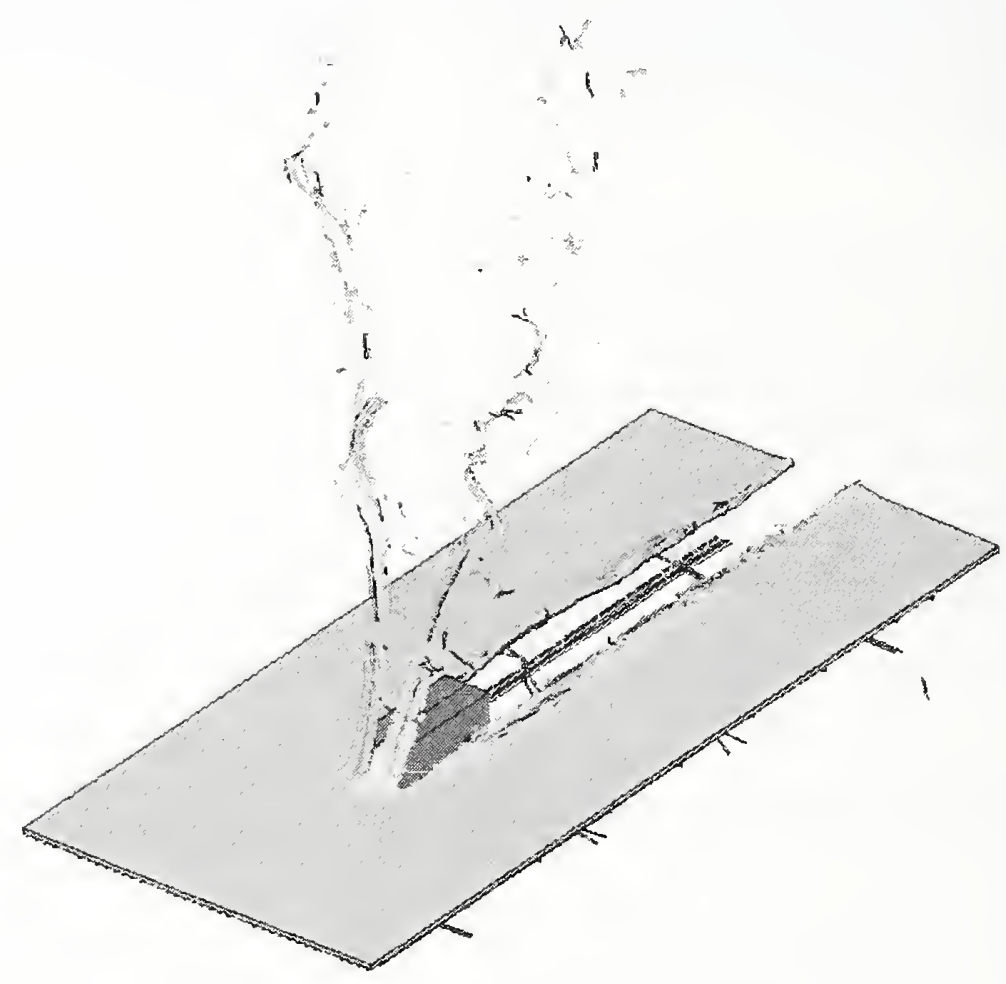

(b) Impact response at $0.10 \mathrm{~s}$

Figure 5-25. Floor assembly impact analysis with brick element concrete slab. 


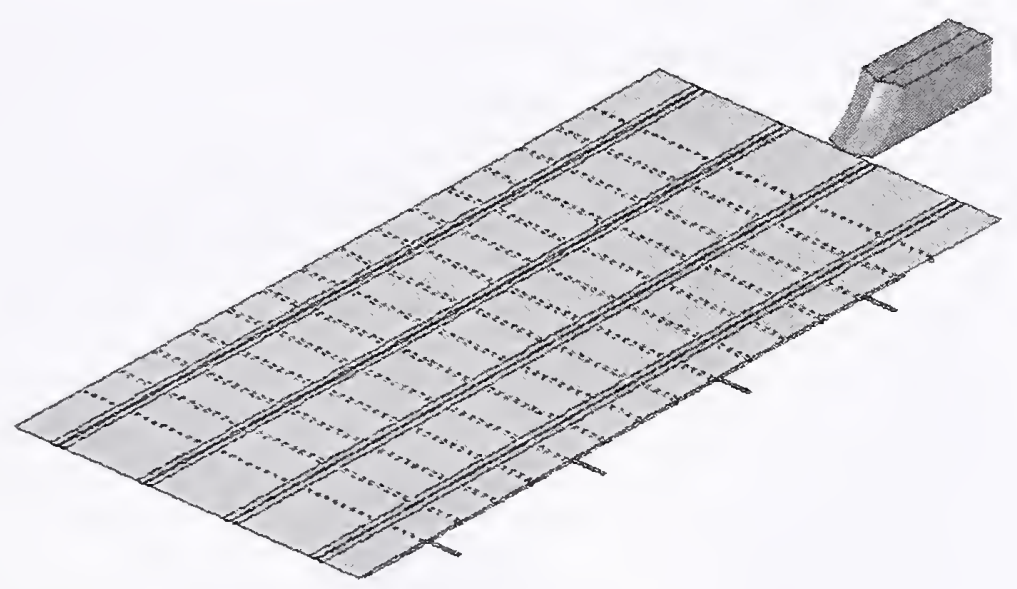

(a) Initial configuration

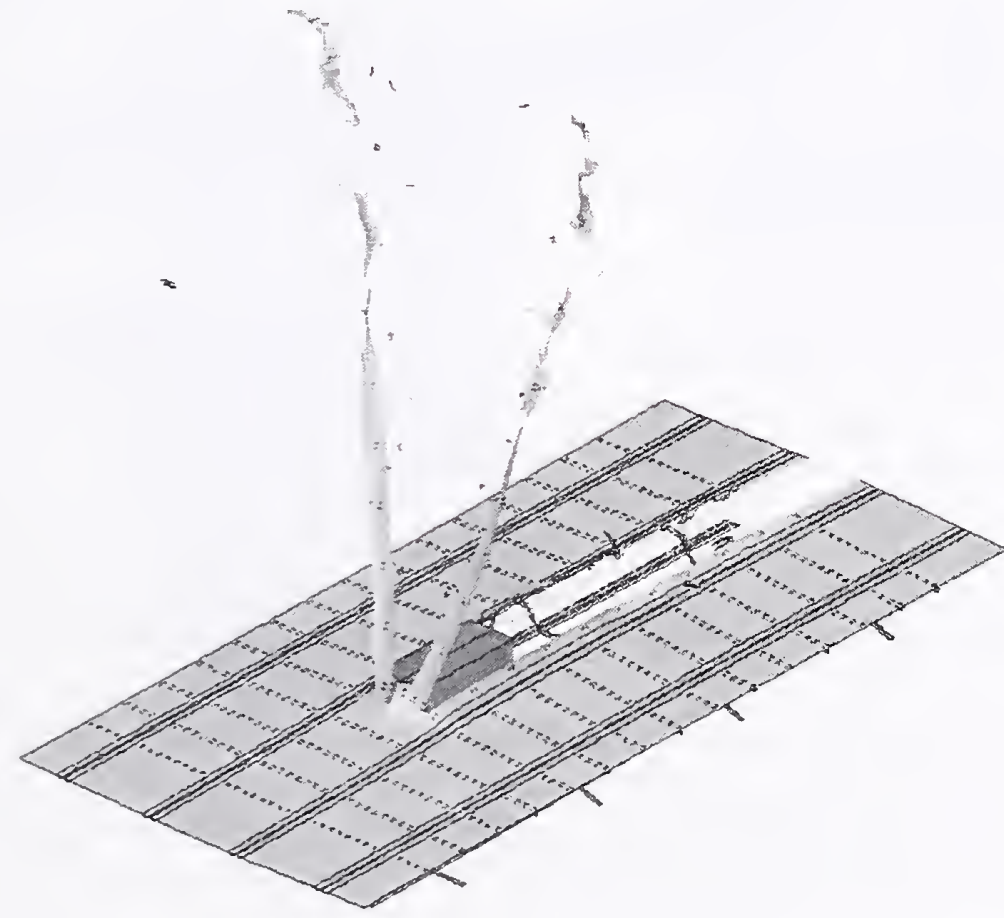

(b) Impact response at $0.10 \mathrm{~s}$

Figure 5-26. Floor assembly impact analysis with shell element concrete slab. 


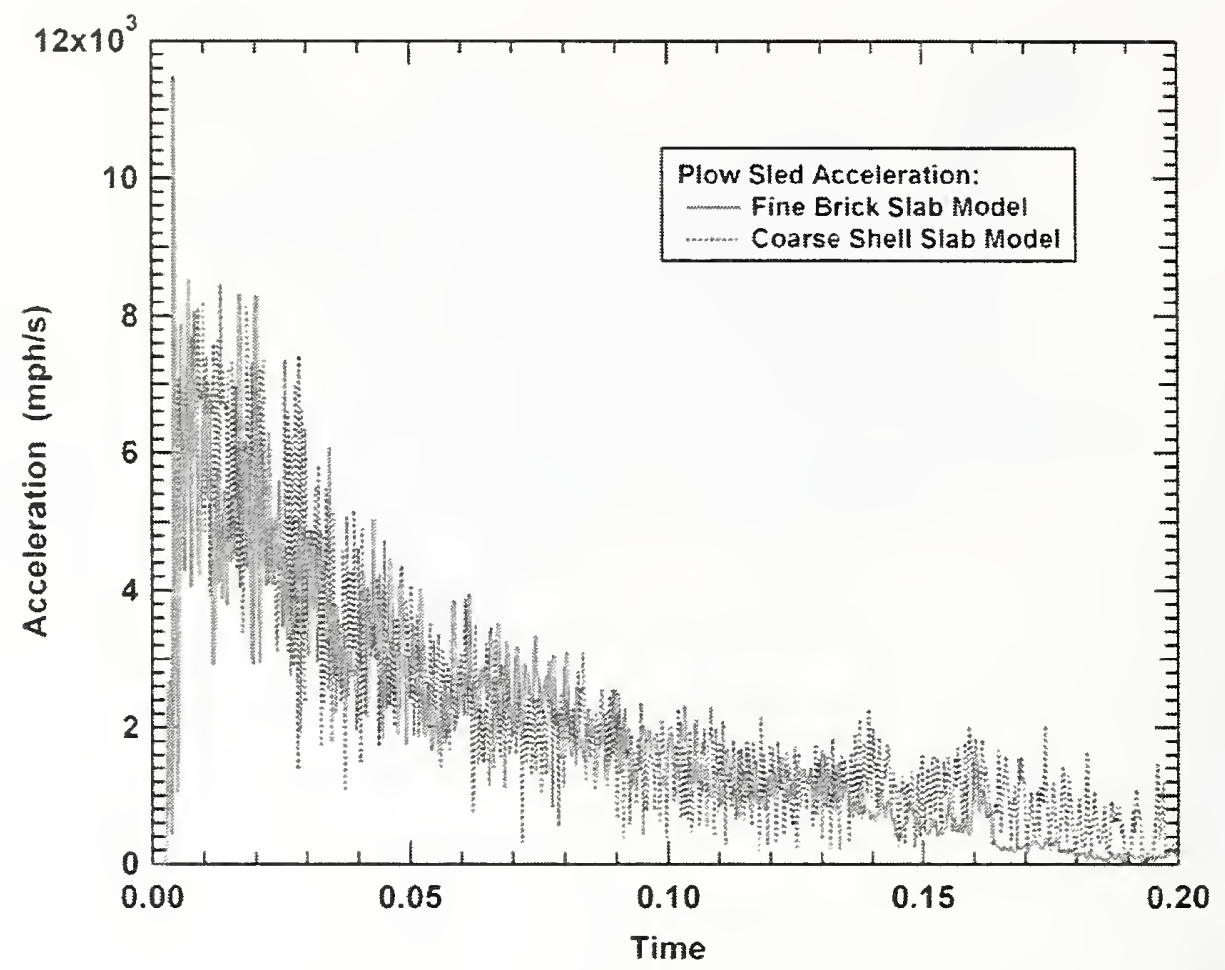

Figure 5-27. Comparison of brick and shell element floor assembly impact analyses.

\subsection{AIRCRAFT WING SECTION COMPONENT ANALYSES}

The aircraft wing section component models were the last of the component models to be developed. Having established acceptable tower component models, the cxterior panel model typc 300 was then used to evaluate an aircraft wing section component model. Construction of the wing section model was previously discussed in Section 4.3.2. The focus in this section is on developing a coarse wing model for the global impact analysis and evaluating methods for modeling fuel in the wing. This coarse model of the aircraft wing and associated failure modeling criteria are important not only for modeling the wing accurately, but also to establish the modeling methodology for the entire airframe. Element size, tied interfaces, and failure criteria developed in this section were implemented in the model for the entire airframe.

\subsubsection{Empty Wing Section Component Model Development and Analysis}

A significant challenge in developing an aircraft model suitable for performing the global analyses was to reduce the number of nodes and elements in the model to a manageable size. This was a challenging task because the detailed geometry of the fracture and tearing of aluminum that occurred during impact could not be modeled well with the coarse mesh needed in the global model. Instead, elements were given a reduced failure strain in the coarse mesh model so that the energy absorbed approximated that of the tearing aluminum structure. An appropriate reduction in failure strain was found by conducting component analyses of coarse and fine mesh wing section models. In both cases, the wing section was impacted into a pair of cxterior panels of a WTC tower. 
Development of the wing section component model was previously described in Section 4.3.2. The finely meshed wing component model had a mesh fine enough to capture the tearing of the wing. In this analysis, the fine and coarse wing models impacted the same target panel in order to maintain accurate failure modeling of the panels and a reasonable runtime appropriate for the uncertainty analyses. The resulting model for the exterior panel had 10,400 shell elements (columns and spandrels), 264 solid brick elements for the butt plates, and 48 beam elements for the bolts. This model is shown with the wing in its initial position in Figure 5-28.

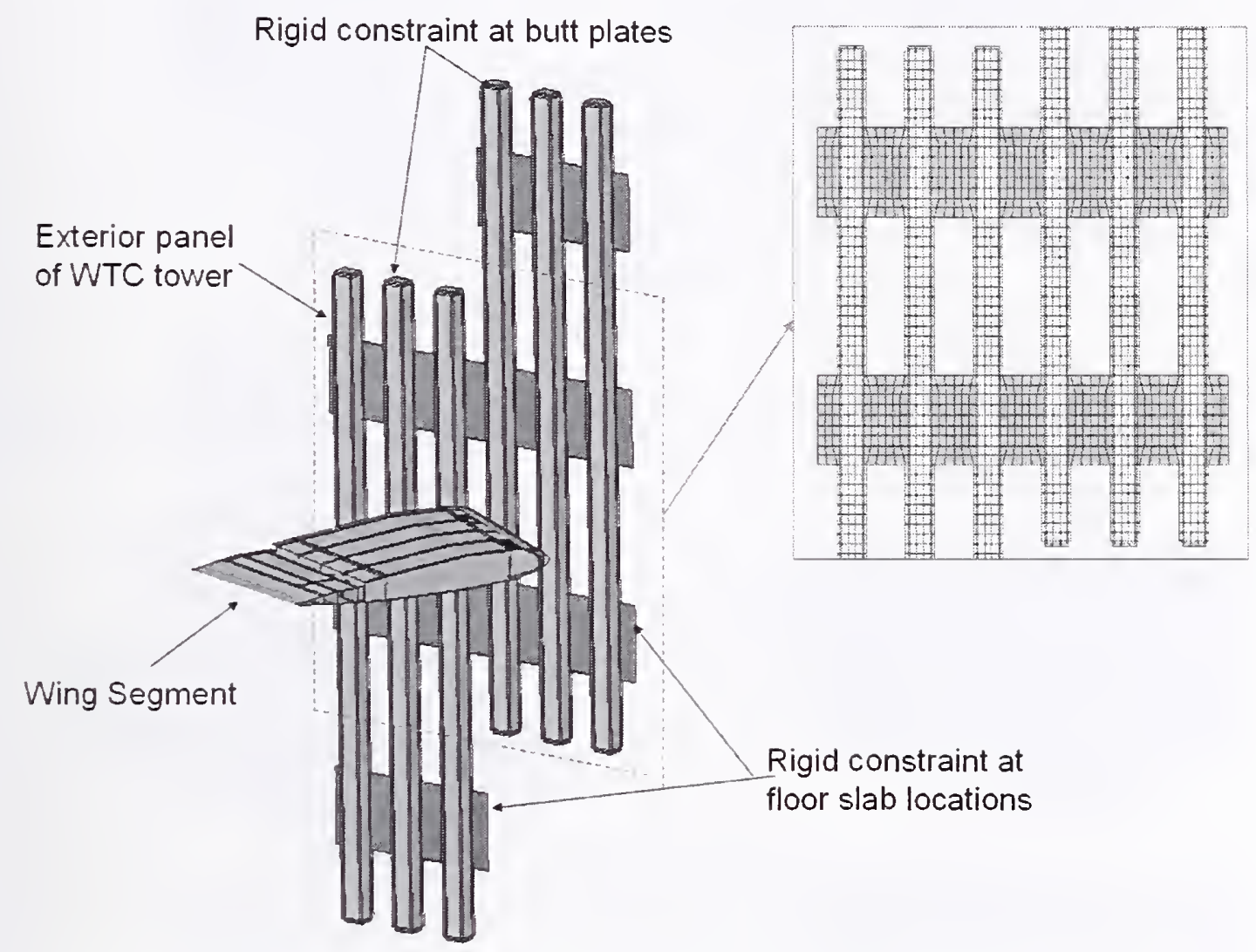

Figure 5-28. Empty wing section impact model with two exterior panels.

The wing section impacted the panels half way between spandrels at $442 \mathrm{mph}$. The wing section impacted with a lateral trajectory offset 3 degrees relative to the panel normal, as shown in Figure 5-29. This was done to impart a less symmetric loading on the exterior columns, which was more realistic for the global impact. The wing was oriented with no pitch or roll, so the angle of the leading edge was that of the sweep angle of the wing relative to the fuselage.

The fine component model of the aircraft wing, as shown in Figure 5-30, was modeled with a typical element size of approximately $0.5 \mathrm{in}$. for a total model size of approximately 245,000 shell elements. Material properties and constitutive models discussed in Section 2.5 were used in the component model. Data from the Military Handbook (MIL-HDBK-5F 1987) for elongation at failure were used as the failure criteria of the $0.5 \mathrm{in}$. elements. Elements were eroded when the effective plastic strain in the element met 
this failure criterion. Total run time for this fine component model was approximately 7 hours on 12 processors.

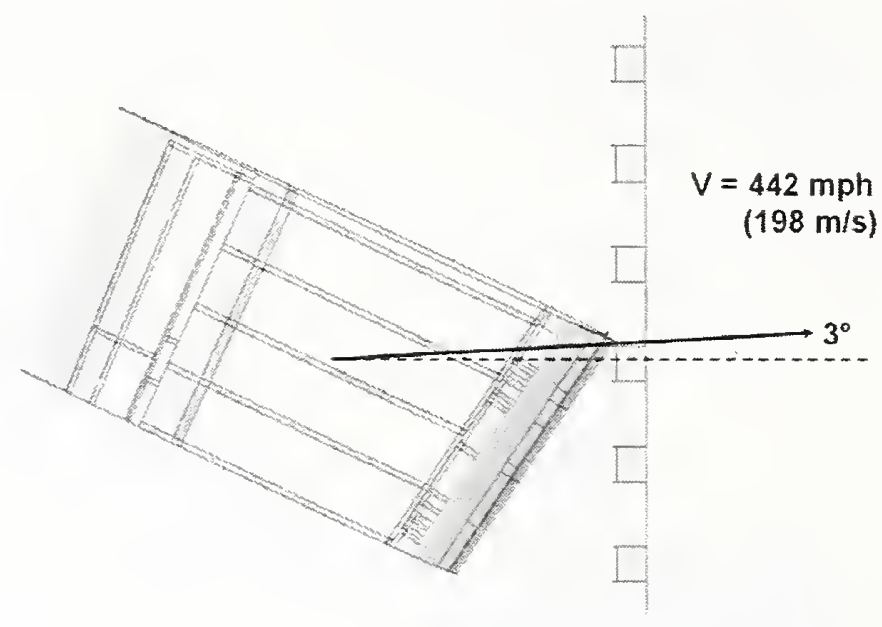

Figure 5-29. Wing segment showing the initial impact conditions on the exterior panels.
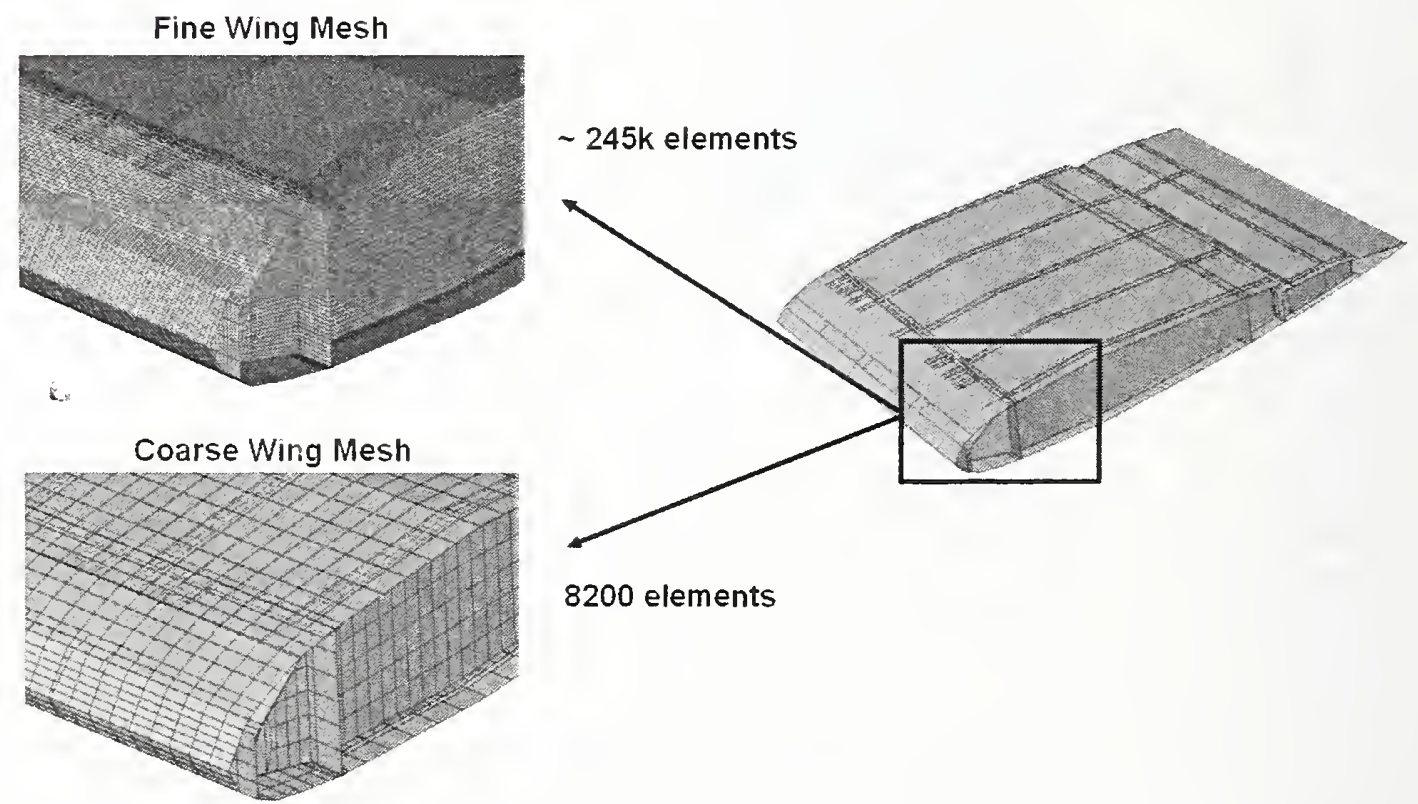

8200 elements

Figure 5-30. Coarse and fine mesh used in the small wing component model.

The fine-mesh empty wing section impacting two exterior panels of the WTC tower is shown in Figure 5-31. The spars, ribs, and skin were torn by the impact against each column. As a result, significant material was free to pass between the columns. The residual kinetic energy of the aircraft debris was 43 percent of the initial kinetic energy. Damage to the exterior panel is shown in Figure 5-32. 

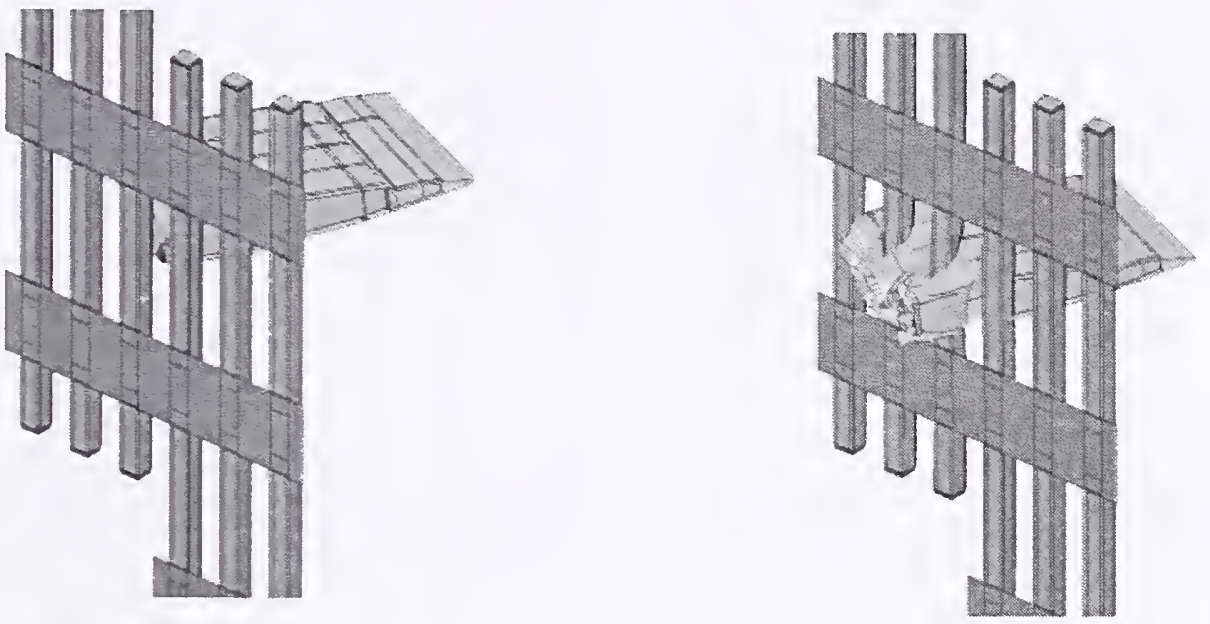

$\mathrm{t}=0.0 \mathrm{~s}$

$\mathrm{t}=0.01 \mathrm{~s}$
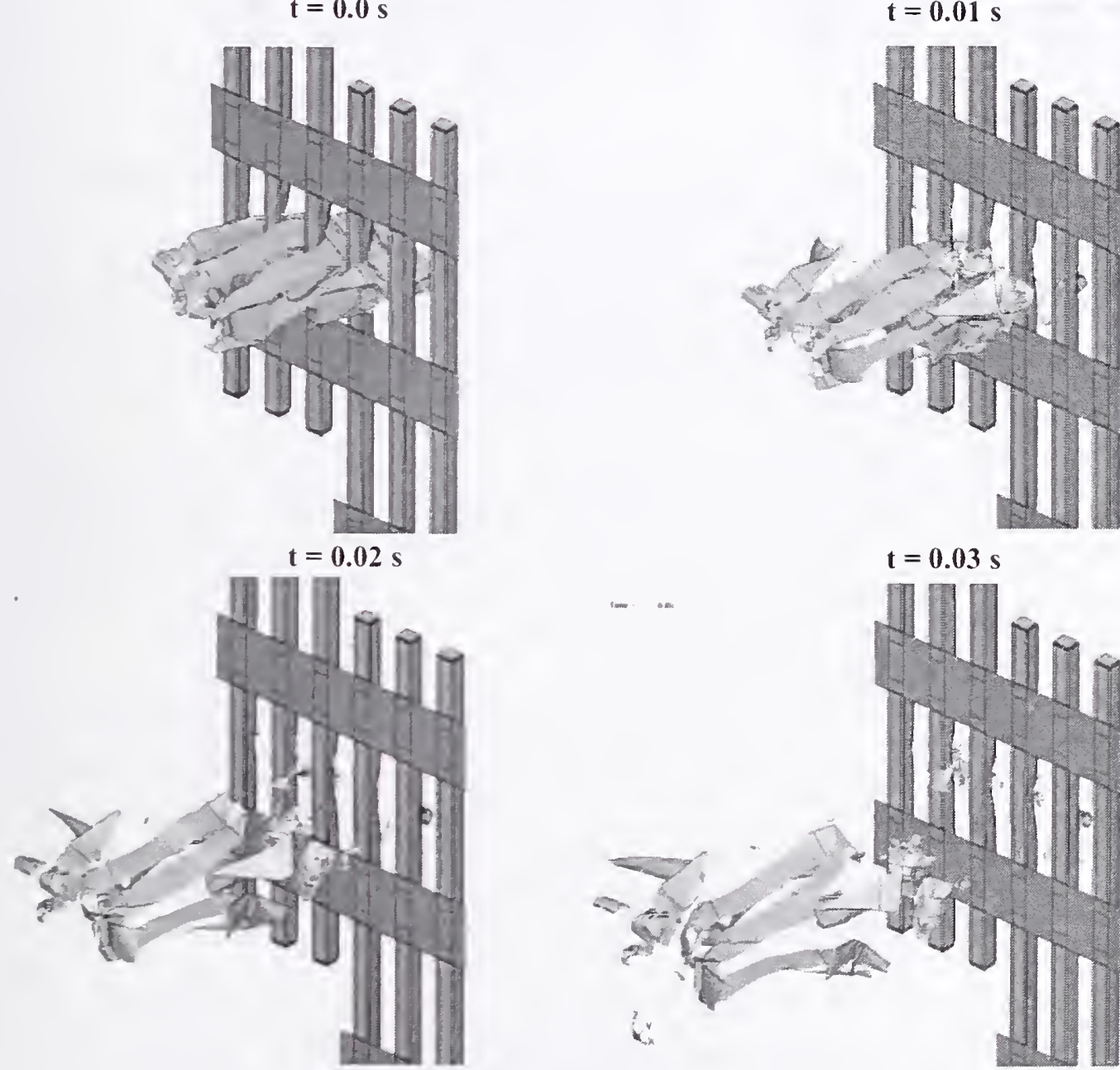

$\mathrm{t}=0.04 \mathrm{~s}$

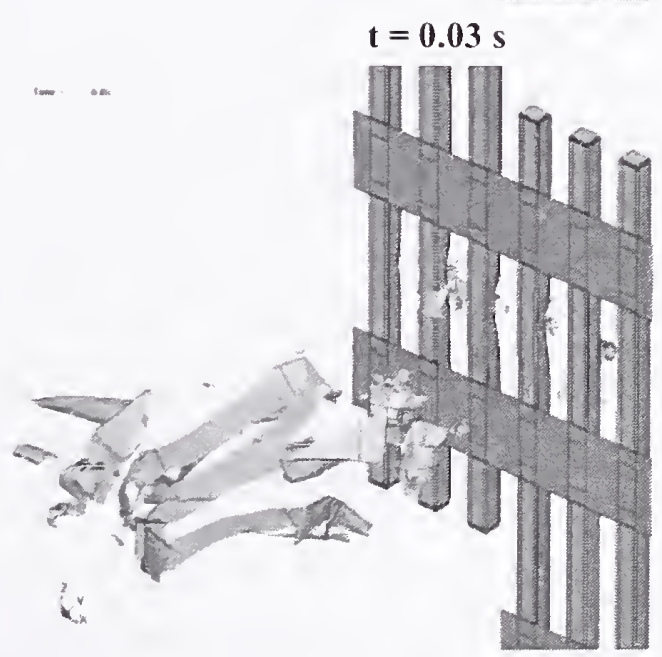

$t=0.05 s$

Figure 5-31. Calculated impact of a fine-mesh empty wing section with two exterior panels at $442 \mathrm{mph}$. 


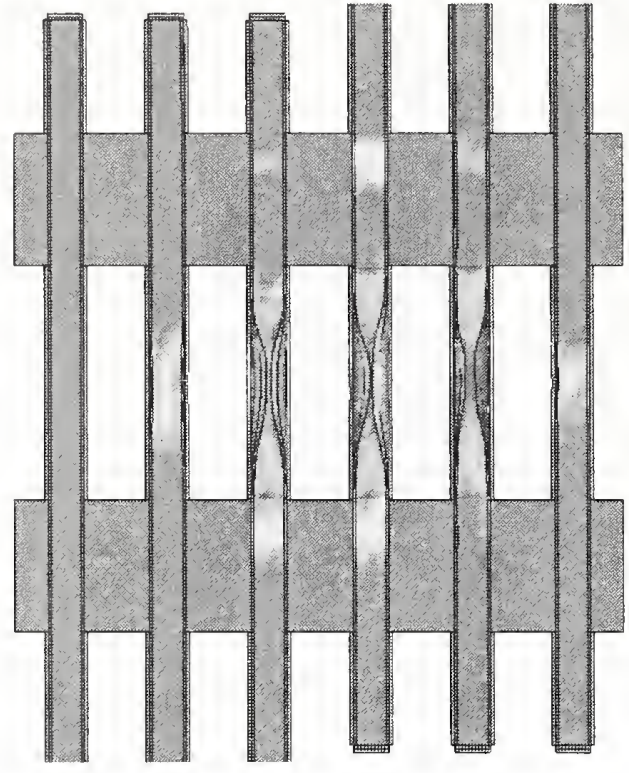

(a) Front (building exterior)

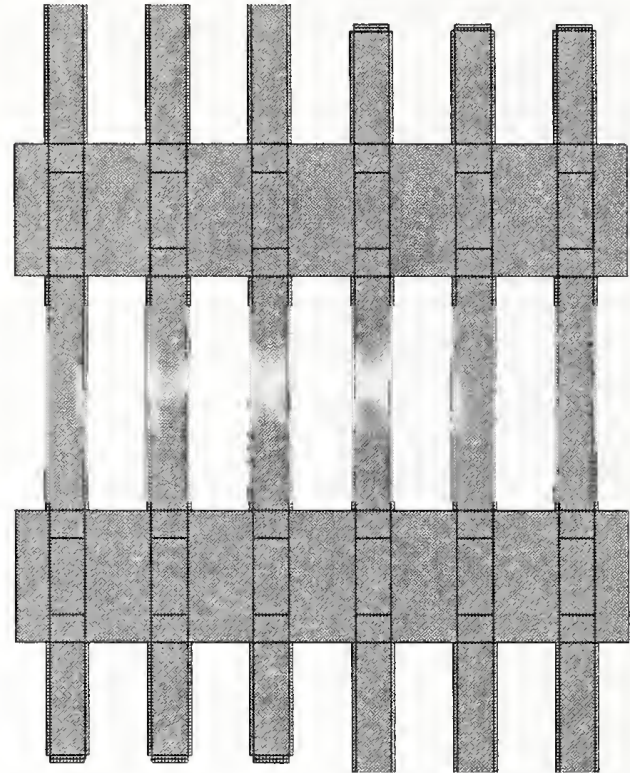

Fringe Levels

$5.000 \mathrm{e}-02$

$4.500 \mathrm{e}-02$

4.000e-02

$3.500 \mathrm{e}-02$

$3.000 \mathrm{e}-02$

$2.500 \mathrm{e}-02$

2.000e-02

$1.500 \mathrm{e}-02$

$1.000 \mathrm{e}-02$

5.000e-03

$0.000 e+00$

Figure 5-32. Fine-mesh empty wing section impact damage to the exterior panel.

The calculated impact response produccd large-scale damage and fragmentation of the empty wing section and moderate damage to the exterior columns. The internal energy absorbed by the panels was 4 percent of the initial kinetic energy. The damage included distortion of the columns, plastic strains, and fracture of the welded front web connections within the columns. However, the columns were not completely severed and still maintained some load carrying capacity.

In order to mect the size constraints imposed by the global analyses, the coarse mcsh size required for the wing structure needed to be an order of magnitude larger than that for the finely-meshed wing section. The coarse-mesh wing component is shown in Figure 5-30. This model had a typical element size of approximately $4 \mathrm{in}$. to $5 \mathrm{in}$. for the primary components. The total model size of the coarse wing section component model was approximately 8,200 elements.

When the coarse wing section model was used in the impact analysis without any adjustment in the failure strain, the impact response was significantly different. More of the wing material was eroded, and the wing structures had a much tougher behavior resulting in lower residual velocities of the wing debris. The residual kinetic energy of the wing section debris was reduced from 43 percent to 18 percent of the initial kinetic energy. Much of the additional kinetic energy loss for the coarse wing section model was absorbed in the panels. The damage to the columns was significantly larger with the internal energy increasing from 4 percent to 18 percent of the initial kinetic energy.

Additional wing section-panel impact analyses were used to determine failure models for the coarse mesh model in order to most closely match the impact response of the fine mesh model. Obtaining an exact match was not possible due to competing mechanisms in the calculation. Reducing the failure strains for the wing materials would reduce the damage to the exterior panel (improved agreement with the fine mesh analysis). However, the greater amount of erosion in the wing section structures resulted in reduced residual kinetic energy for the wing debris (poorer agreement with the fine mesh analysis). The final 
model parameters were determined by balancing the observed impact response, the damage to the panels, and the residual kinetic energy of the wing debris. The difficulty in developing the coarse wing model was that the plastic strain at failure needed to be reduced significantly for the large elements used. It was found that reductions in the plastic failure strain of over 70 percent were necessary. The initial approach, shown in Figure 5-33(a), was to simply reduce the element erosion strain to the appropriate value depending on the element size (see Section 2.3.1).

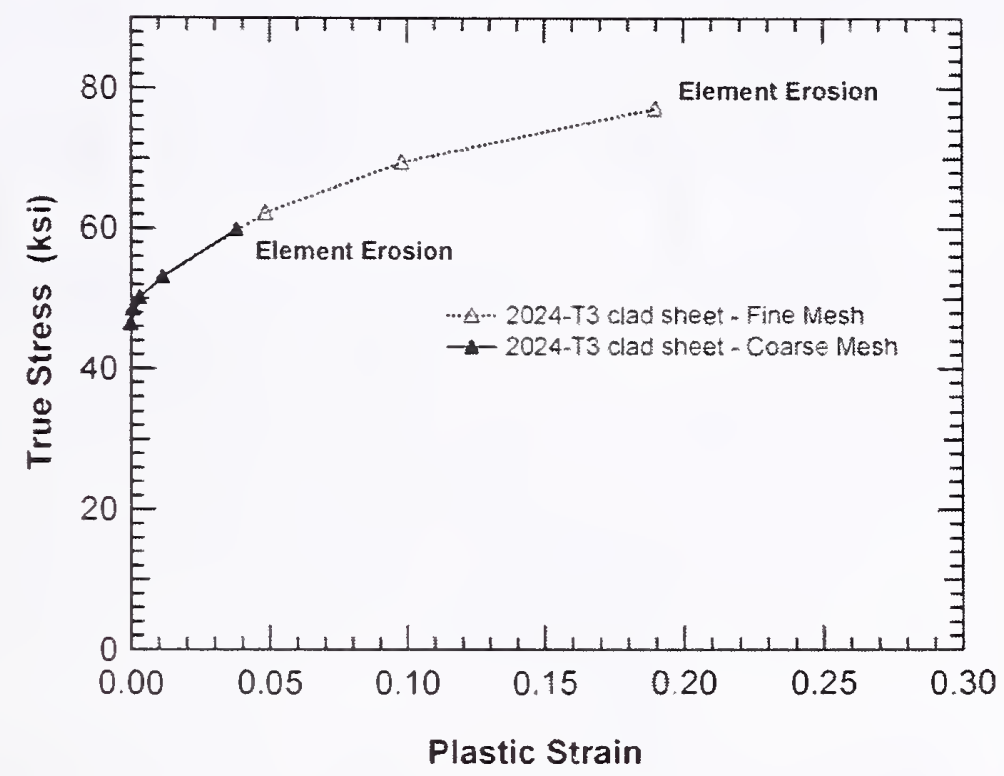

(a) Initial failure model.

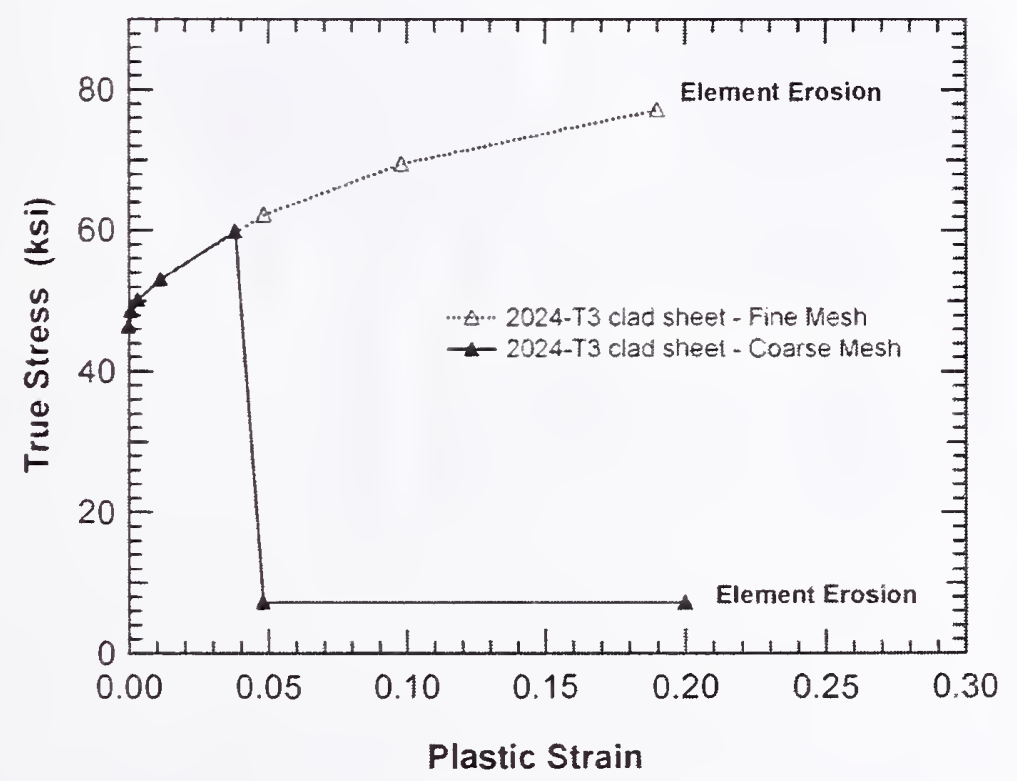

(b) Modified failure model.

Figure 5-33. Failure modeling approaches for the coarse wing section model. 
The problem with using very low erosion strains to represent material failure was that elements eroded quickly, and their inertia was not completely transferred to the columns prior to being eroded. An alternative approach was applied that avoided the potential shortcomings of the first method for treating material failure. The modified approach was to reduce the load carrying capacity of an element at a given value of plastic strain, representing 'failure', but to only erode the elcment at larger strains. An example of this treatment of material failure is shown in Figure 5-33(b). In this example, the true stress in an element was decreased at 20 percent of the original fine mesh failure strain. Beyond this strain, a degraded true stress of $7 \mathrm{ksi}$ was used. This level was selected to balance the need for a reduced strength in the material with stability of the degraded element behavior. Note that the strain energy of the modified failure model, Figure 5-33(b), was very similar to that of the initial failure model, Figure 5-33(a).

Wing sections modeled with both the initial and modified failure modeling methodologies are shown in Figure 5-34 for a time when the wing section partially penetrated the exterior columns. For the initial failure approach, shown in Figure 5-34(a), the elements in the path of the column showed little strains as they impacted and eroded against the column. There may not have been sufficient time to transfer the momentum of these elements to the columns prior to element erosion. Element strains near the impact zone for the modified failure approach, shown in Figure 5-34(b), were much larger. This indicates that elements stayed in the calculation longer, allowing more time for load to be transferred between the wing structures and exterior columns. Therefore, this modified modeling approach was adopted for subsequent wing impact analyses.

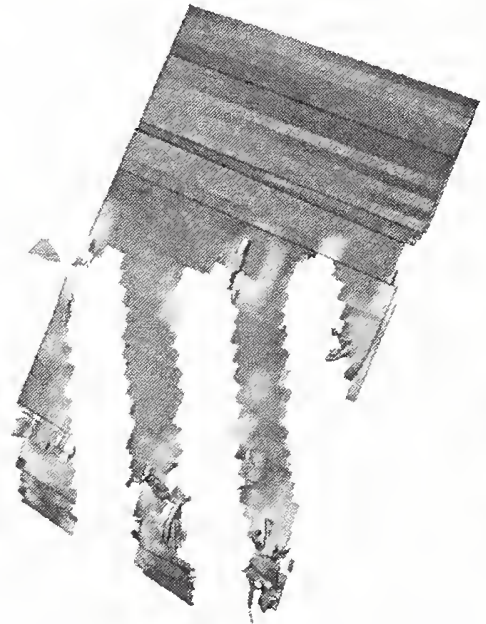

(a) Baseline failure model
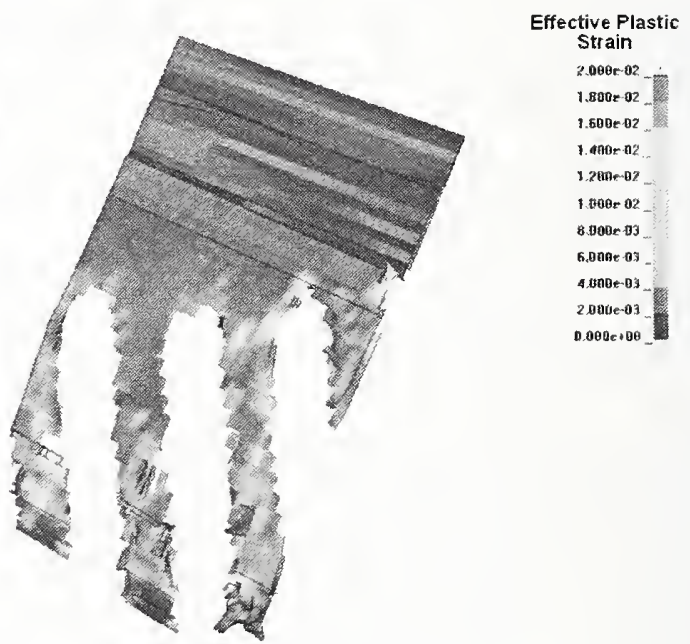

(b) Modified failure model

\section{Figure 5-34. Wing section response for two material failure criteria.}

A final parameter investigated in the coarse wing section component analyses was the modeling of wing structure connectivity on impact response. Analyses were performed with both a tied interface (i.e., without failure, between the internal structure and skin) and with a tiebreak interface. The surfaceto-surface tiebreak and surface-to-surface tied contact algorithms were discussed in Section 3.3.2. It was found that the connection between the internal structure and the skin did influence the failure of wing elements. When a tied contact was used, the model response improved. The fragmented debris of the 
fine and coarse mesh models with tied and tiebreak contact are shown in Figure 5-35. Note that debris with the tied coarse mesh most closely resembles that of the finely meshed wing..

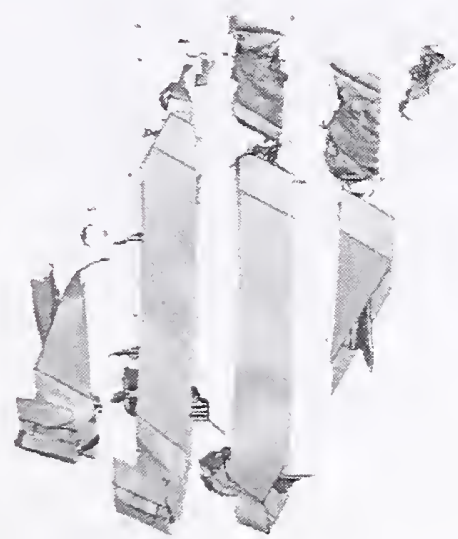

(a) Fine mesh

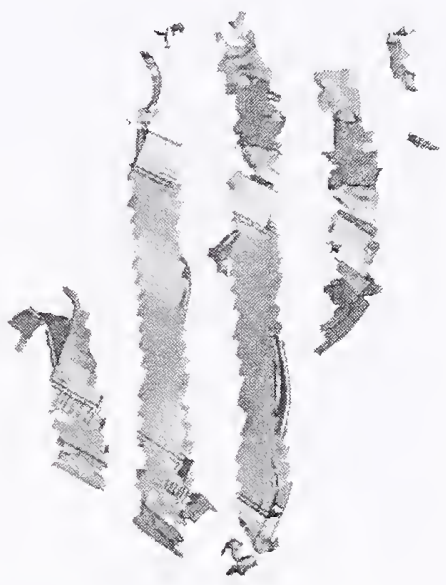

(b) Coarse mesh-tied

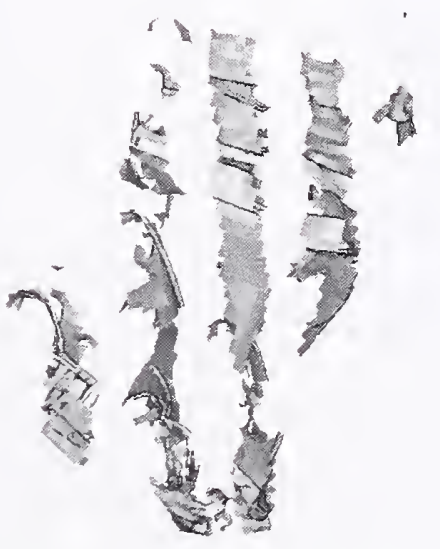

(b) Coarse mesh- tiebreak

Figure 5-35. Fine and coarse mesh fragmentation.

The calculated impact response for the final coarse wing section model is shown in Figure 5-37. The corresponding damage to the exterior panels is shown in Figure 5-38. The calculated impact behavior was reasonably close to that of the detailed wing section response shown previously in Figure 5-31 and Figure 5-32. The tabulated true stress-plastic strain data used in the final model for the various aircraft aluminum alloys are shown in Figure 5-36.

Overall, the coarse-mesh model did a reasonable job of approximating the fine-mesh behavior despite the challenge of simulating the tearing and fragmentation of aluminum with such large elements. In both cases the damage extended over approximately one floor, and the columns were still intact. The front plate was pushed inward, but did not fail. The side flanges were also bent inward, but did not fail. The back plate sustained minor damage. Most of the difference in damage appeared to be in the side flanges, resulting in larger internal energy absorption in the panel. The larger elements of the wing section and their limited ability to conform well with the column geometry resulted in more damage to these flanges. Despite the coarse wing section having a lower residual kinetic energy, the wing broke up in a similar 
fashion to the finely meshed model, as shown by the debris in Figure 5-35(a) and (b). This debris had more eroded material and, therefore, less mass and kinetic energy, because of the inability of large elements to smoothly conform to the line of material tearing.

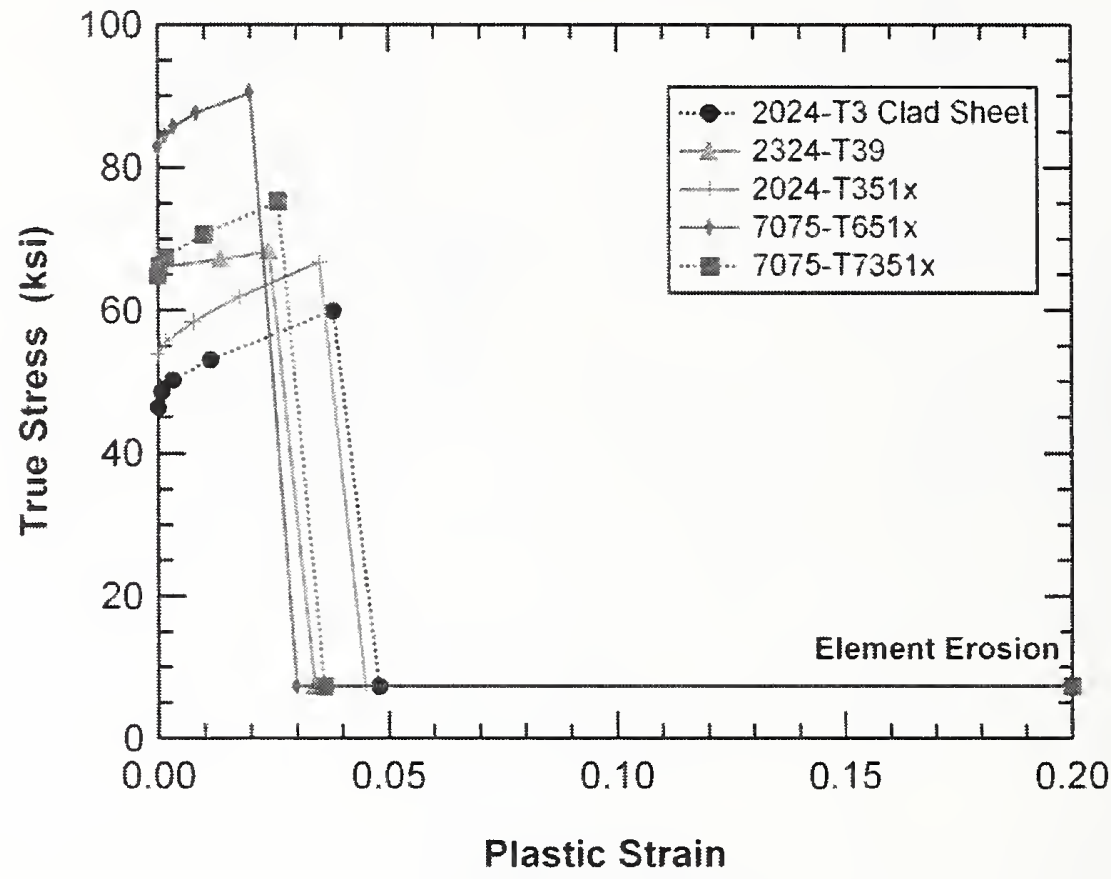

Figure 5-36. Aluminum model for coarse-mesh aircraft components.

A final check of the methodology developed here for failure of the coarsely meshed aircraft components is the visible impact results from the global analysis. As will be further discussed in Chapter 9, the damage pattern predicted in the global analyses agreed reasonably well with that observed in photographs. This is even true in the outboard parts of the wings where there was no fuel and the exterior columns did not completely fail.

\subsubsection{Modeling of Aircraft Wing Section Impact with Fuel}

A significant portion of the weight of a Boeing 767 wing is from the fuel in its integral fuel tanks. At the time of impact, it is estimated that each aircraft had approximately $10,000 \mathrm{gal}$ of fuel onboard. Upon impact, this fuel was responsible for large distributed loads on the exterior columns of the WTC towers and subsequently on interior structures, as it flowed into the building. Therefore, it could have a significant effect on the damage inflicted on the building structure. Modeling of the fluid-structure interaction is necessary to predict the extent of this damage and the fuel dispersion within the building to help establish the initial conditions for the fire dynamics modeling. 

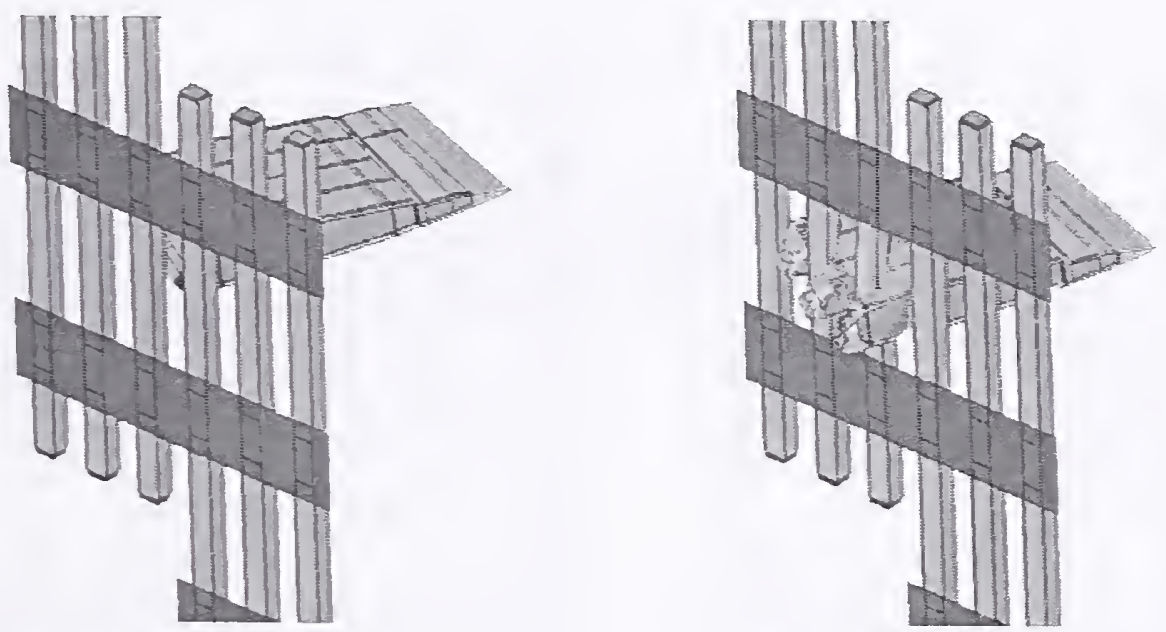

$t=0.0 s$

$t=0.01 s$
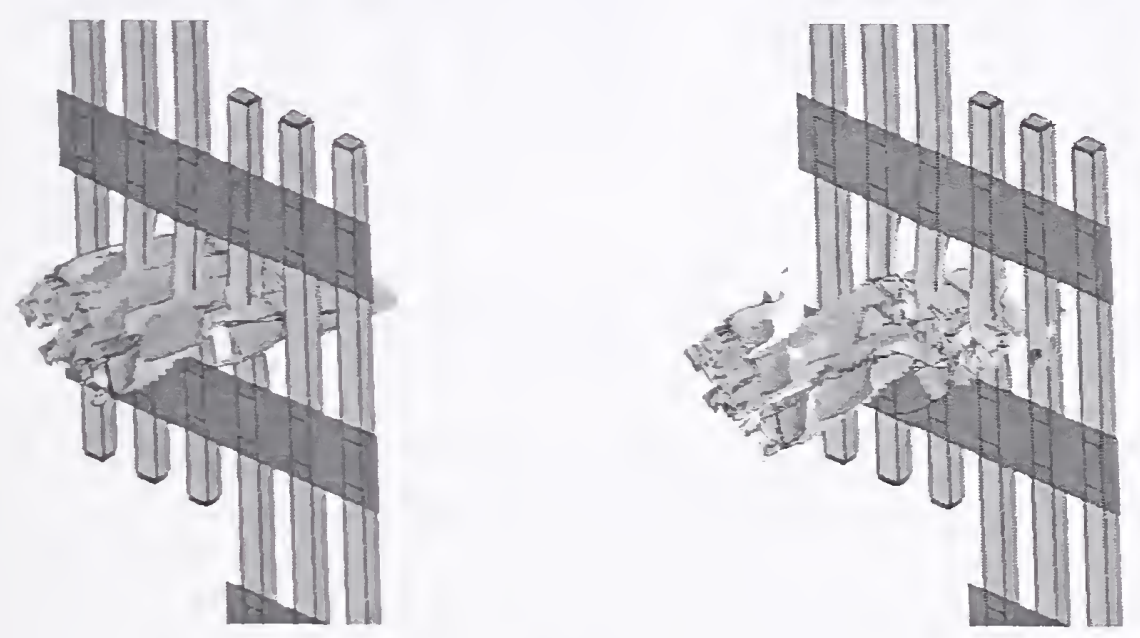

$\mathrm{t}=0.02 \mathrm{~s}$

$t=0.03 \mathrm{~s}$

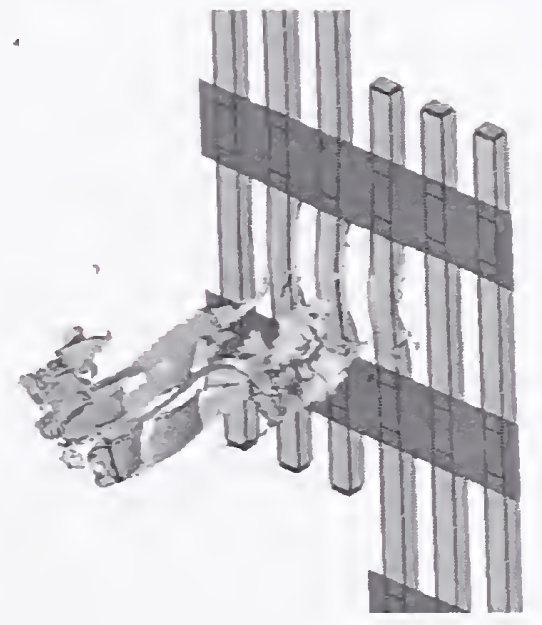

$t=0.04 \mathrm{~s}$

Figure 5-37. Calculated impact of a coarse-mesh empty wing section with two exterior panels at $442 \mathrm{mph}$. 


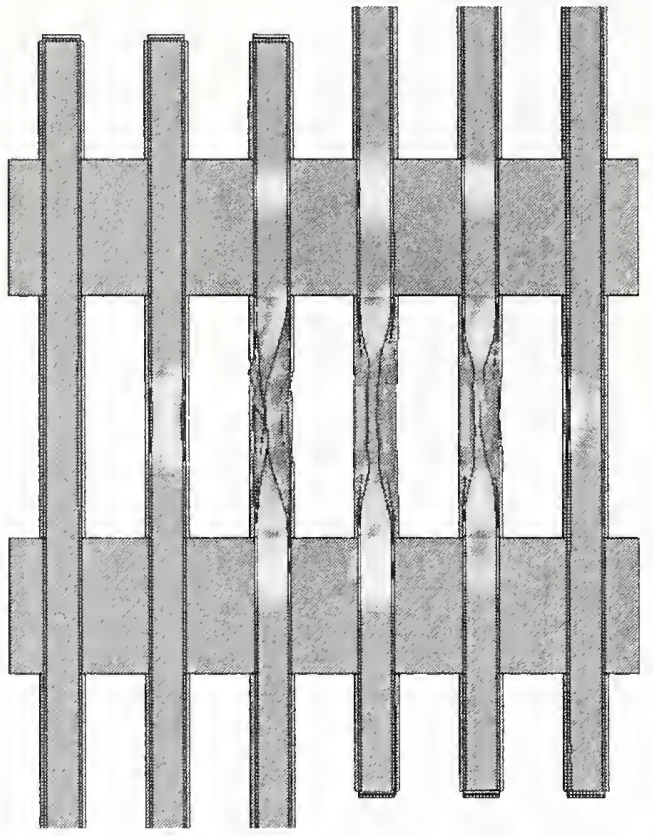

(a) Front (building exterior)

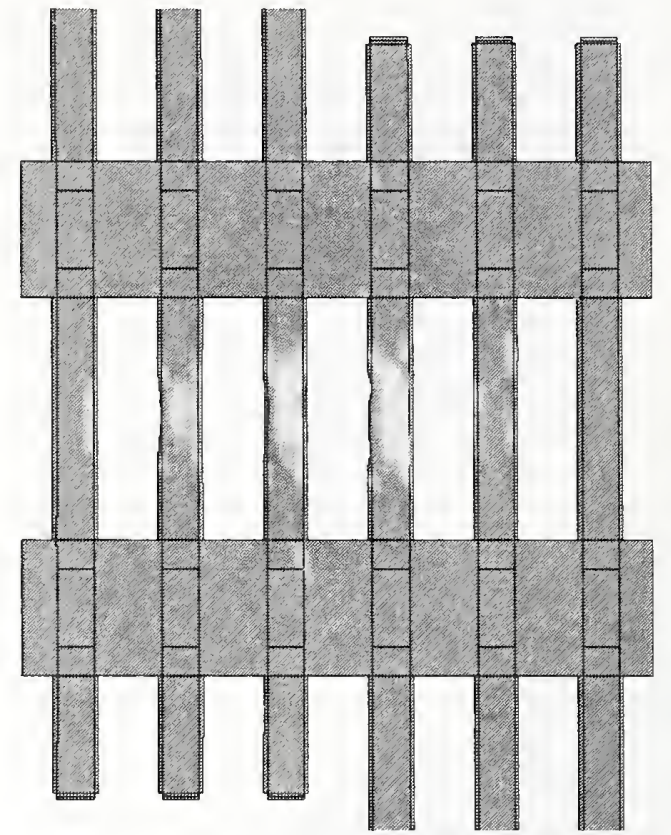

(b) Back (building interior)

Figure 5-38. Impact damage to the exterior panel from a coarse-mesh empty wing section at $442 \mathrm{mph}$ contours of effective plastic strain are shown.

A number of approaches to solving Fluid-Structure Interaction (FSI) problems are available in LSDYNA. One approach is the standard Lagrangian finite element analysis with erosion, where the fuel is modeled using a deformable mesh. This approach accounts for the inertial effects of the fuel, but does not simulate the fuel flow during impact well due to limitations on mesh distortion. The Arbitrary-

Lagrangian-Eulerian (ALE) method has been developed as one good approach to solve fluid and solid material interaction. With this methodology, fluids are modeled with an Eulerian mesh, which allows for materials to flow between mesh elements. Solid materials are modeled with a moving Lagrangian mesh. With ALE, both mesh types can interact.

An alternative approach is to use mesh-free methods such as Smoothed Particle Hydrodynamics (SPH). SPH modeling for fuel effects has the advantage of a smaller mesh size and, potentially, much faster run times than ALE analyses. Both ALE and SPH methods were applied to the analysis of fuel impact and dispersion and are compared here.

\subsubsection{Impact Analysis of a Wing Section with Fuel}

The small wing segment was used for performing component level analyses of the wing with fuel. The small wing segment was from rib 14 to rib 18 , the outboard baffle rib. For this location, the segment was considered to be completely filled with fuel (approximately 850 gal). Figure 5-39 shows the fuel-filled wing section model with an SPH and ALE mesh for the fuel, shown in blue. The fuel was modeled with $6,720 \mathrm{SPH}$ fuel particles and 110,825 ALE elements for the fuel and surrounding air region, shown in Figure 5-40. The wing section model was finer than that for the empty wing component analysis $(24,000$ shell elements for this model versus 8,200 in the previous analysis). 


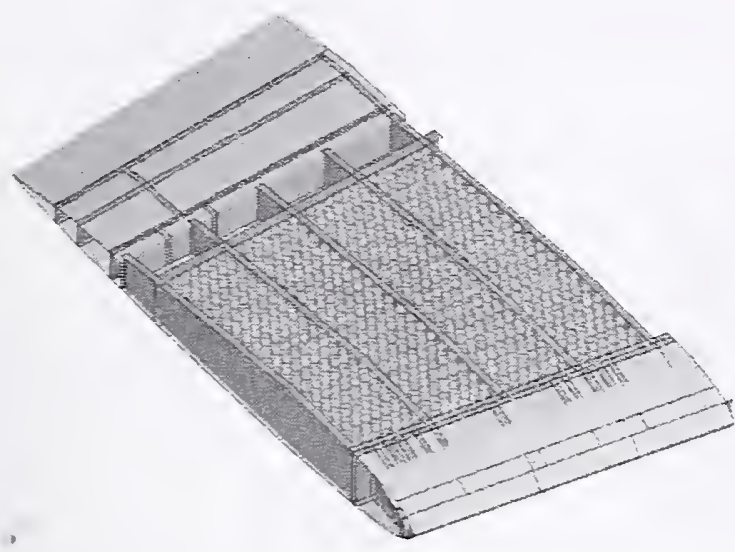

(a) SPH mesh

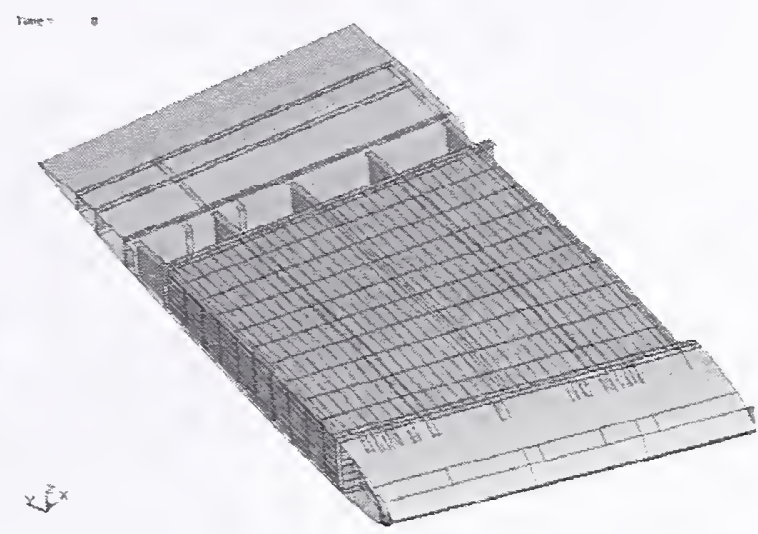

(b) ALE mesh

Figure 5-39. SPH and ALE fuel in the small wing segment.

For these component analyses, the impacted structures were the same two exterior panels used in the empty wing section analysis described in Section 5.5.1. Model size and parameters are shown in Table 5-3. The exterior panel also contained 48 beam elements for the bolts connecting the butt plates. In these initial wing section impact analyses, water was used to model the fuel, although it was later changed to JP-4 jet fuel for the global analyses. The only significance of using water in the analyses here was that the density of water is $62.3 \mathrm{lb} / \mathrm{ft}^{3}$ where that for JP-4 is approximately $48.3 \mathrm{lb} / \mathrm{ft}^{3}$.

Table 5-3. Wing with fuel component modeling parameters.

\begin{tabular}{|l|c|c|}
\hline & Exterior Panel & Wing Component \\
\hline Shell Elements & 54.096 & 23.733 \\
\hline Solid/ALE Elements & 2,112 & 110.825 \\
\hline Mass & $16,854 \mathrm{lb}$ & $1,014 \mathrm{lb}$ \\
\hline
\end{tabular}

The model configuration for the component analysis with an ALE treatment of the fuel is shown in Figure 5-40. An ALE mesh surrounding the wing segment and the panels was needed for the fuel to flow into. In ALE analyses, material is advected from one element to the next so that a mesh is needed for initially "empty" regions. In this case, this mesh was filled with stationary air to interact with the fuel. The wing segment trajectory was that of a normal impact at $500 \mathrm{mph}$ at mid-height between spandrels. The wing was oriented with no pitch, yaw, or roll. Therefore, the leading edge impacted the panels with the sweep angle of the wing relative to the fuselage, as shown in Figure 5-41. The two exterior panels were constrained rigidly at the butt plates and at the floor slab locations. For comparison, it is important to note that subsequent runs of the empty wing section at a speed of $500 \mathrm{mph}$, not specifically discussed in the previous section, resulted in more damage than shown in Figure 5-38, but still did not completely fail the columns. 


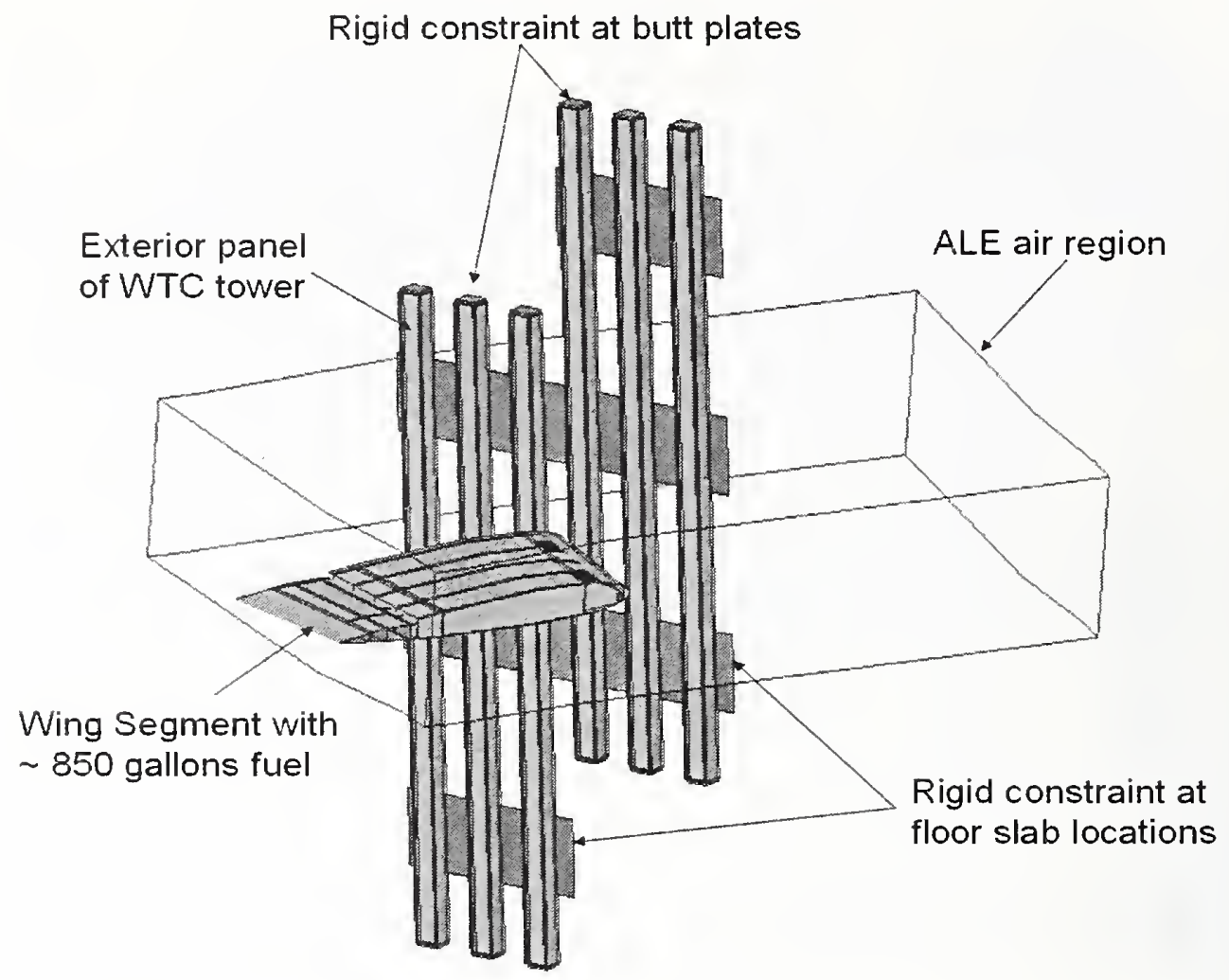

Figure 5-40. Wing segment, fuel, and exterior panel configuration.

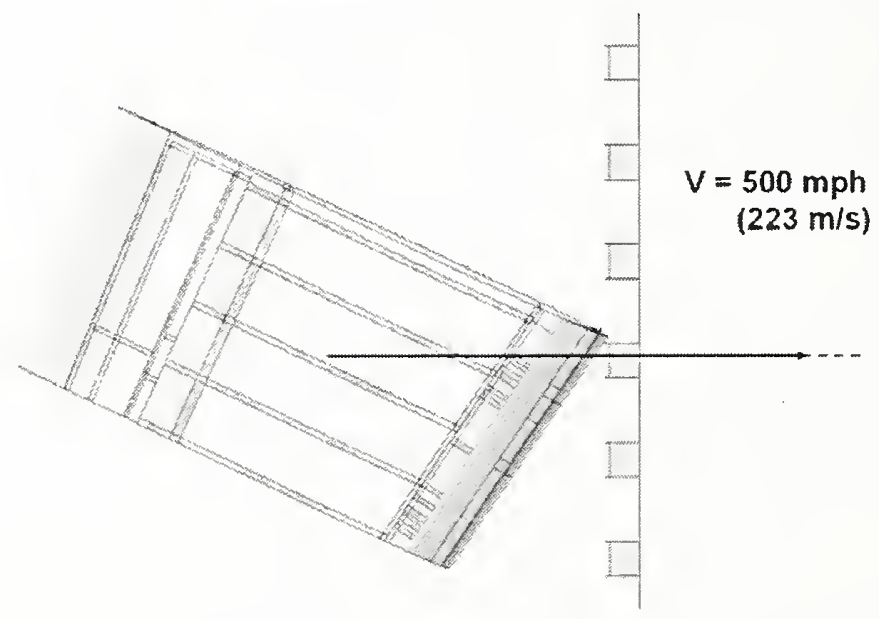

Figure 5-41. Wing segment orientation prior to impact. 
Fuel was modeled with both the ALE and SPH models using the MAT_NULL material model and Gruneisen equation of state model. The pressure in the Gruneisen equation of state is estimated as

$$
p=\frac{\rho_{o} C^{2} \mu\left[1+\left(1-\frac{\gamma_{0}}{2}\right) \mu-\frac{a}{2} \mu^{2}\right]}{\left[1-\left(S_{1}-1\right) \mu-\frac{\mu^{2}}{\mu+1} S_{2}-\frac{\mu^{3}}{(\mu+1)^{2}} S_{3}\right]^{2}}+\left(\gamma_{o}+a \mu\right) E
$$

for compressed materials and

$$
p=\rho_{o} C^{2} \mu+\left(\gamma_{o}+a \mu\right) E
$$

for expanded materials. The $\mathrm{E}$ is the internal energy, $\mu=\rho / \rho_{o}-1$, and $\rho$ is density. Air in the ALE mesh was modeled as an ideal gas using the Ideal Gas equation of state model. Parameters for these models are shown in Table 5-4. The reader is referred to the LS-DYNA user's manual (2003) for a more complete description of these models. These material models were used in order to appropriately treat the constitutive behavior of the fuel, which had no deviatoric strength, only a viscosity. However, the constitutive behavior is of secondary importance as the predominant effect of the fuel is an exchange of momentum with the impacted structure.

Table 5-4. Fuel and air model parameters.

\begin{tabular}{|l|c|c|}
\hline & Fuel (Water) & Air \\
\hline MAT_NULL & & \\
\hline Density - $\rho_{0}\left(\mathrm{lb} / \mathrm{ft}^{3}\right)$ & 62.3 & 0.0737 \\
\hline $\begin{array}{l}\text { Dynamic Viscosity Coefficient } \\
\left(\mathrm{lb} \cdot \mathrm{s}^{2}{ }^{2}\right)\end{array}$ & $1.82 \mathrm{E}-05$ & $3.66 \mathrm{E}-07$ \\
\hline EOS_GRUNEISEN & & \\
\hline $\mathrm{C}(\mathrm{in} / \mathrm{s})$ & $6.48 \mathrm{E}+04$ & - \\
\hline $\mathrm{S}_{1}$ & 1.921 & - \\
\hline $\mathrm{S}_{2}$ & -0.096 & - \\
\hline$S_{3}$ & 0.0 & - \\
\hline$\gamma_{0}$ & 0.35 & - \\
\hline$E_{0}(\mathrm{ft}-\mathrm{lb})$ & $2.14 \mathrm{e}+05$ & - \\
\hline EOS_IDEAL_GAS & & \\
\hline $\mathrm{C}_{\mathrm{p}}(\mathrm{Btu} / \mathrm{lb} \cdot \mathrm{F})$ & - & 0.172 \\
\hline $\mathrm{C}_{\mathrm{v}}(\mathrm{Btu} / \mathrm{lb} \cdot \mathrm{F})$ & - & 0.240 \\
\hline $\mathrm{T}_{\mathrm{o}}(\mathrm{R})$ & - & 1,028 \\
\hline $\mathrm{V}_{\mathrm{o}}$ & - & 1.0 \\
\hline
\end{tabular}

Fluid-structure interaction was modeled using two separate algorithms, one for ALE and the other for SPH. The first, when using an ALE mesh for fuel, is the CONSTRAINED_LAGRANGE_IN_SOLID algorithm. The second, for an SPH fuel mesh, is the automatic nodes to surface contact algorithm. The 
reader is referred to the LS-DYNA user's manual for a more complete description of both the ALE and SPH approaches for solving fuel-structure interaction problems.

Impact of the wing section using the ALE and SPH methods are shown in Figure 5-42 and Figure 5-43, respectively. In both cases the columns of the exterior panels were completely destroyed due to impact. Recall that this was not the case for the empty wing section with an equivalent initial impact speed. Close-ups of the damage to the exterior panels are shown in Figure 5-44. Figure 5-45 through Figure 5-48 show close-up plan and side view comparisons of the fuel dispersion and wing break up predicted by the two fuel modeling methods. While both modeling approaches gave comparable results for the damage to the exterior wall panels, the SPH modeling method predicted greater fuel dispersion and wing break up than when using ALE, as can be shown clearly in the side view. Without experimental data, it is difficult to evaluate which method provides a more accurate solution.

Run-times from these component analyses clearly indicate that the SPH method is more practical for the global impact analyses. The current SPH model runs significantly faster than the ALE method as it requires a smaller mesh and does not need to rezone after each time step, as is done in the ALE method. In addition, the ALE method requires a mesh for both the fuel region and the air zone into which the fuel can flow. In the example shown, this required the addition of approximately 100,000 solid elements for the ALE analysis. These calculations indicate that the ALE analysis run-times are as much as 10 times longer than those for the SPH analyses. Therefore, the SPH method was selected as the modeling technique for the global analyses.

\subsection{SUMMARY}

The set of engine impact analyses described in this chapter demonstrates how an engine traveling at speeds of approximatcly $500 \mathrm{mph}$ completely overwhelms a single column. Therefore, such component analyses are not as useful as desired in determining the sensitivity of modeling parameters in the impact response. A final configuration consisting of twenty interior core columns was developed for performing the uncertainty analyses during engine impact. This analysis is described further in Chapter 8 .

The WTC towers and Boeing 767 aircraft are extremely complex structural systems, and including all of the structural details of both the aircraft and towers in the global impact analyscs would result in very large models. The component analyses were used to determine model simplifications that could reduce the overall model size while maintaining fidelity in determination of the impact damage. 

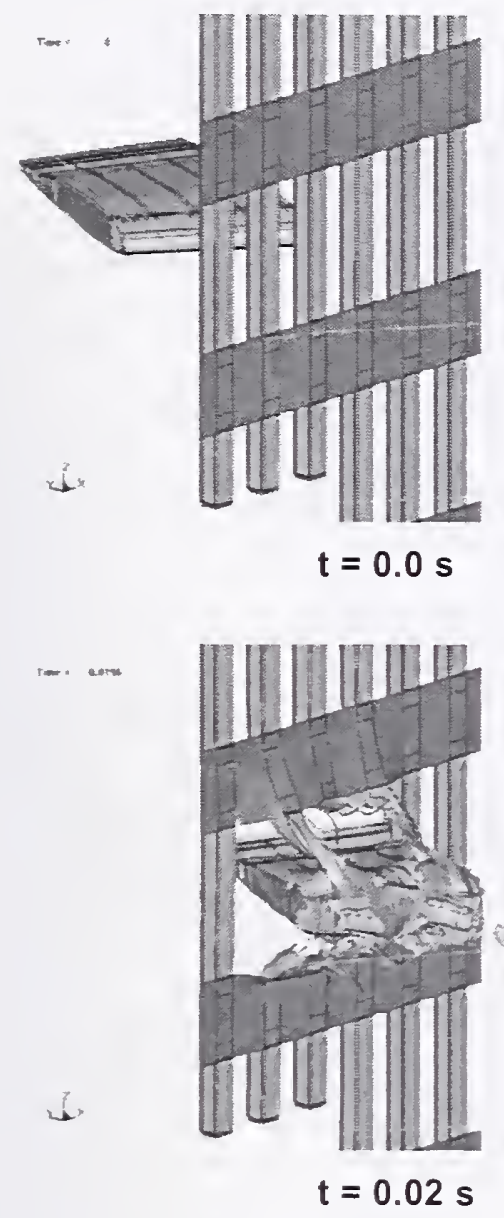

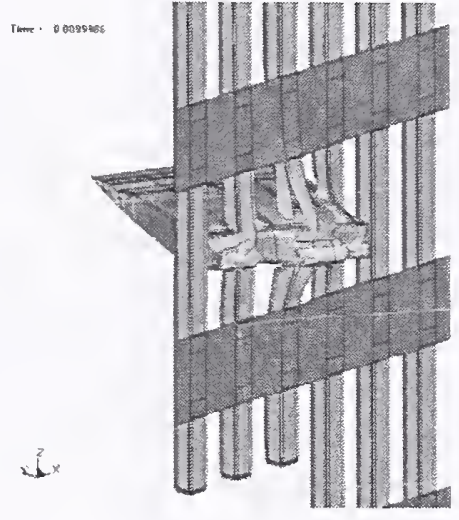

$\mathrm{t}=0.01 \mathrm{~s}$
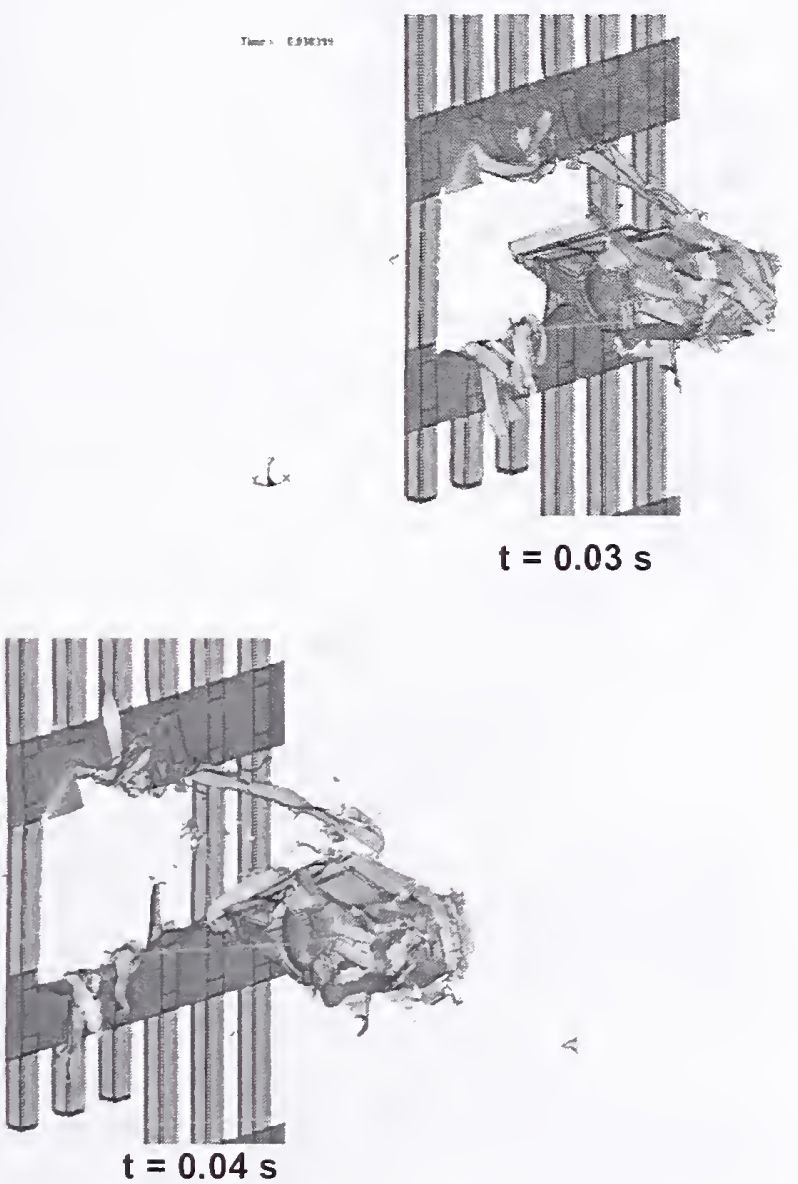

Figure 5-42. Calculated impact of a coarse mesh wing section laden with fuel modeled using ALE elements. 


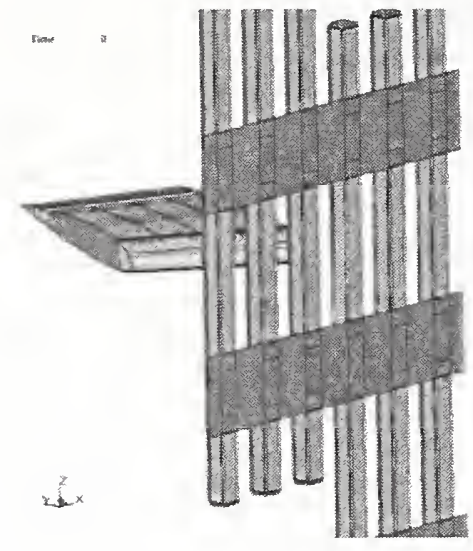

$$
\mathrm{t}=0.0 \mathrm{~s}
$$
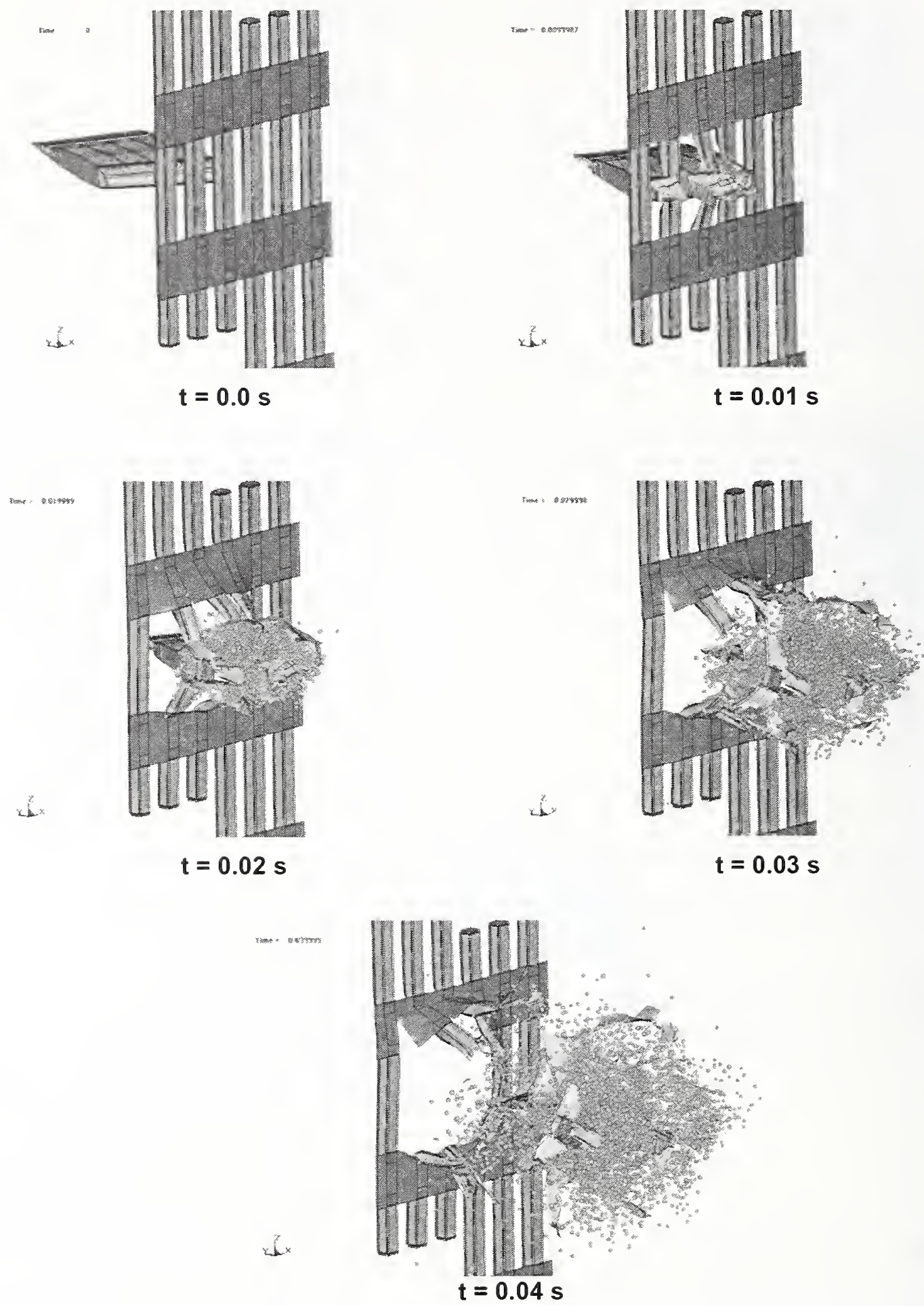

Figure 5-43. Calculated impact of a coarse mesh wing section laden with fuel modeled using SPH particles. 


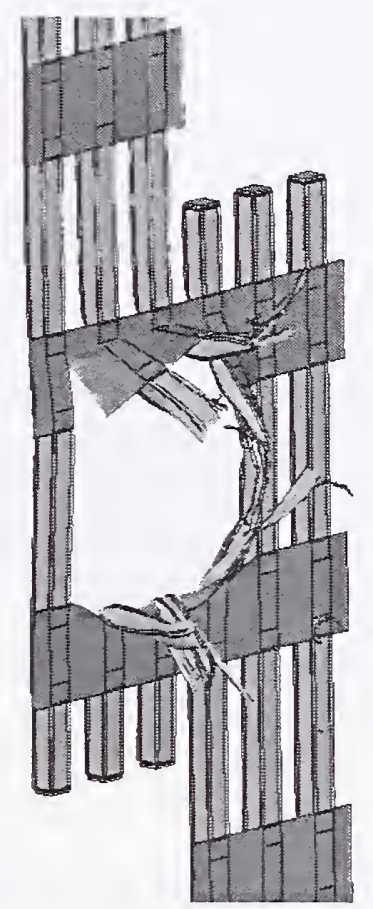

(a) With SPH fuel

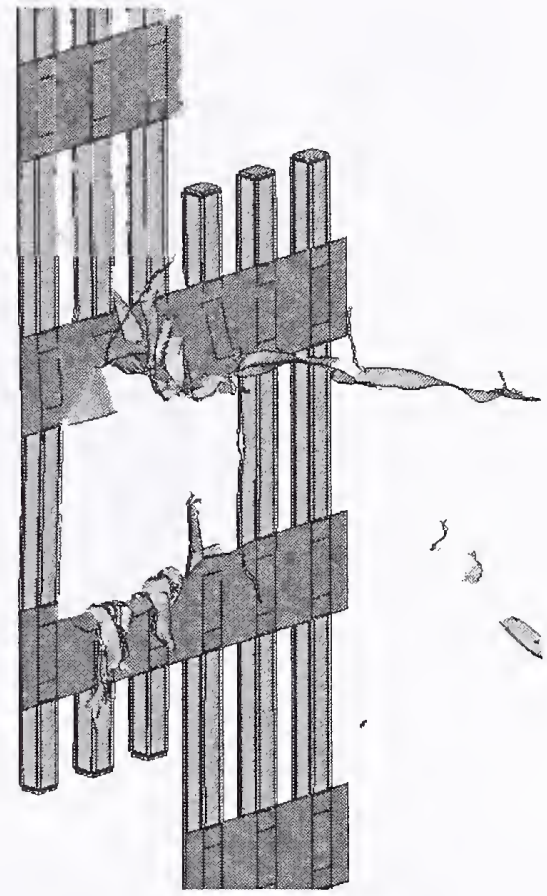

(b) With ALE fuel

Figure 5-44. Exterior panels after impact with a wing segment with fuel.

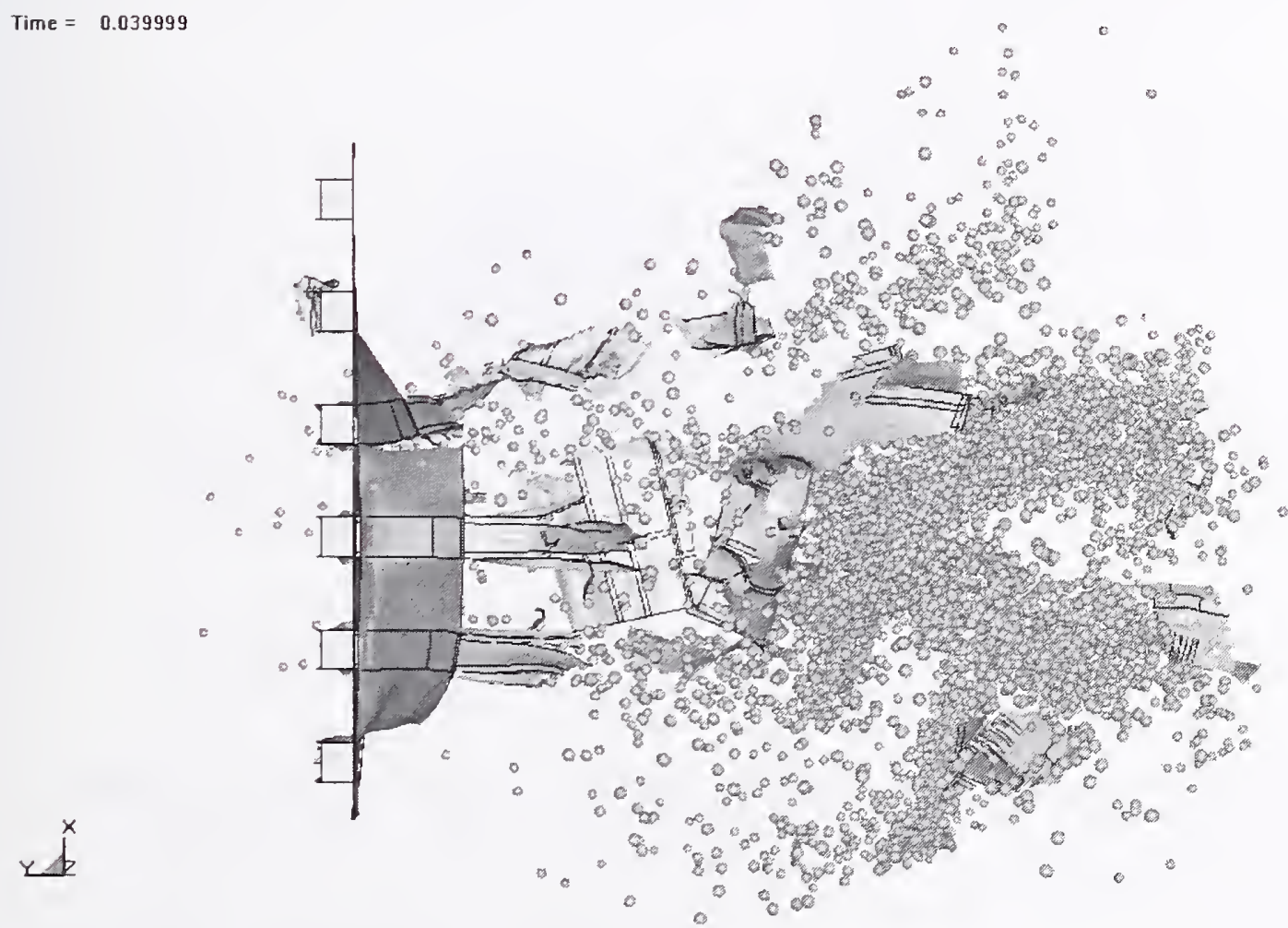

Figure 5-45. SPH analysis of structural damage and fuel dispersion at 0.04 s (top view). 


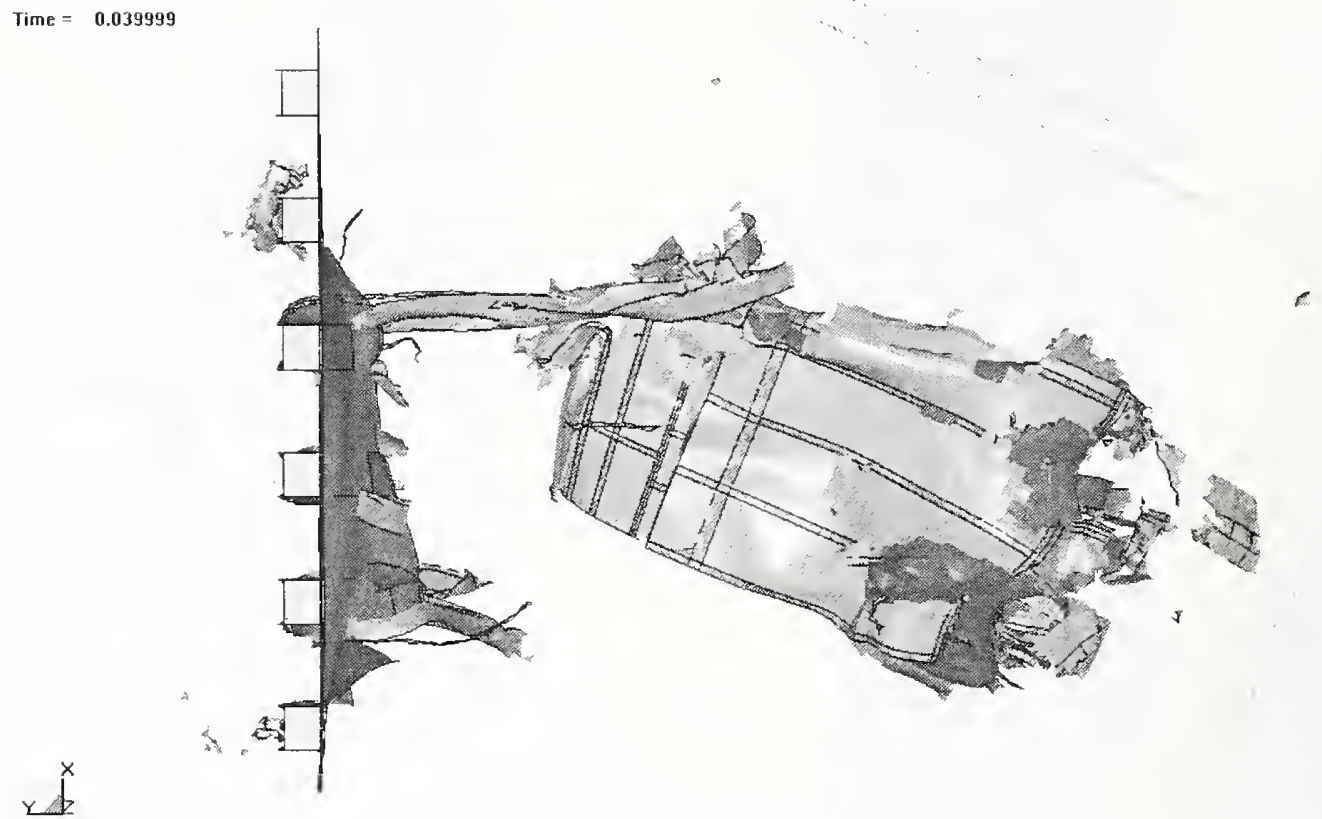

Figure 5-46. ALE analysis of structural damage and fuel dispersion at $0.04 \mathrm{~s}$ (top view).

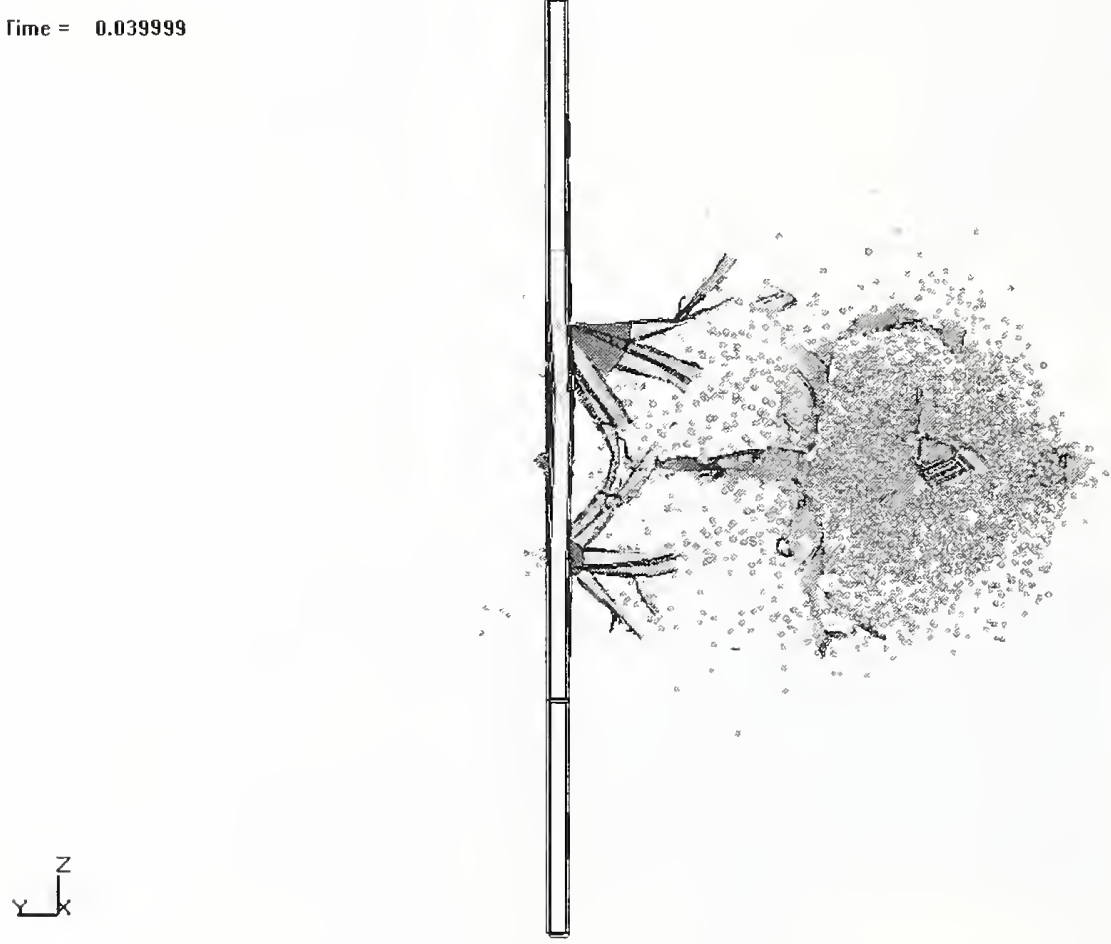

Figure 5-47. SPH analysis of structural damage and fuel dispersion (side view). 


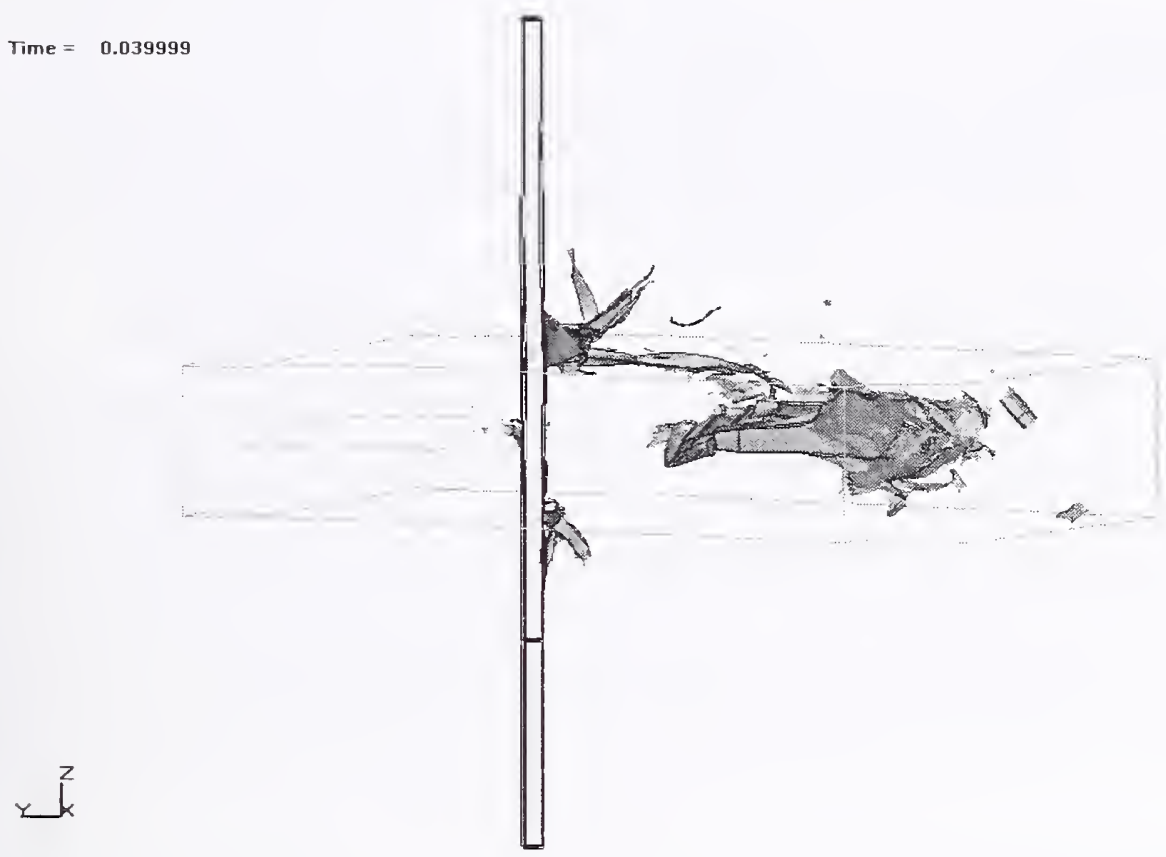

Figure 5-48. ALE analysis of structural damage and fuel dispersion (side view).

A series of component impact analyses were performed using models of tower exterior columns, core columns, and floor assemblies with wing section and engine models as impactors. These models were used to develop the simulation techniques required for the global analysis of the aircraft impacts into the WTC towers. The following results were obtained from the component impact analyses:

- A $500 \mathrm{mph}$ engine impact against an exterior wall panel resulted in a penetration of the exterior wall and failure of impacted exterior columns. If the engine did not impact a floor slab, the majority of the engine core remained intact through the exterior wall penetration with a reduction in velocity between 10 percent and 20 percent. The residual velocity and mass of the engine after penetration of the exterior wall was sufficient to fail a core column in a direct impact condition.

- A normal impact of the exterior wall by an empty wing segment outboard of rib 14 of the Boeing 767 wing produced significant damage to the exterior columns, but not necessarily complete failure. This is consistent with photographs showing the exterior damage to the towers due to impact.

- A fuel-filled wing section impact resulted in complete failure of the exterior columns. This is also consistent with photographs of the exterior damage. The resulting debris propagating into the building maintained the majority of the initial momentum prior to impact.

- Three different numerical techniques were investigated for modeling impact effects and dispersion of fuel: (1) standard Lagrangian finite element analysis with erosion, (2) Smoothed Particle Hydrodynamics (SPH) analysis, and (3) Arbitrary-Lagrangian-Eulerian (ALE) analysis. Of these approaches, SPH analyses were adopted for modeling fuel in the global impact analysis due to computational efficiency. 


\subsection{REFERENCES}

FEMA 304, May 2002, World Trade Center Building Performance Study: Data Collection, Preliminary Observations, and Recommendations, Federal Emergency Management Agency.

Hallquist, J.O., "DYNA3D User's Manual (Nonlinear, Dynamic Analysis of Solids in Three Dimensions)," University of California, Lawrence Livermore National Laboratory, Report UCID-19156, Revision 2, 1986.

"LS-DYNA Keyword User's Manual," Livermore Software Technology Corporation, Version 970, April 2003.

“LS-DYNA Theoretical Manual,” Livermore Software Technology Corporation, May 1998.

“TrueGrid Manual, Version 2.1.0," XYZ Scientific Applications, Inc., September 2001. 


\section{Chapter 6 \\ SUBASSEMBLY IMPACT ANALYSES}

\section{$6.1 \quad$ INTRODUCTION}

The subassembly analyses are a transition between the component analyses described in Chapter 5 and the global impact analyses described in Chapter 9. The analyses were separated into two primary sets: preliminary and final subassembly analyses. The preliminary subassembly analyses were used mainly to investigate different modeling techniques and associated model size, run times, numerical stability, and impact response. These preliminary subassembly analyses were performed concurrently with the component analyses described in Chapter 5. Therefore, many components in the preliminary subassembly model were not those ultimately used in the global impact models. As a result, some of the constitutive properties, failure criteria, and mesh resolutions were modified later. An example of these preliminary subassembly analyses is presented in this Chapter.

The final subassembly analyses were performed using the same modeling methodologies as the global impact analyses, described in Chapter 9. The constitutive models and mesh refinement were identical to those used subsequently in the impact zone of the global impact analyses. The final subassembly model was used to investigate the sensitivity of the impact response to modeling parameters, as well as for the uncertainty analyses described in Chapter 8.

\subsection{PRELIMINARY SUBASSEMBLY ANALYSES}

A preliminary analysis of the tower subassembly impacted by an aircraft engine was performed using the tower structures in the impact area of World Trade Center (WTC) 1. The subassembly model for this analysis consisted of a single width exterior panel (panel number 121 A), three floor assemblies (floor 95 to floor 97) of the same width extending from the exterior panel to the core, and two core columns, as shown in Figure 6-1. The core framing and slab were not included in the model with the exception of the core perimeter beams. The core columns used in the model were numbers 503 and 603 between floor 94 and floor 98. A detailed model of the truss floor structure was used. The floor model contained many more elements than the subsequent truss floor model used in the global impact analyses. The concrete slab was modeled with brick elements. and the diagonal round bar members in the floor trusses were modeled with beam elements. The remainder of the structures, including the columns, metal decking, and truss upper and lower chord components, were modeled with shell elements. The final model contained approximately 793,000 nodes, 404,000 brick elements, 385,000 shell elements, and 11,000 beam elements. 


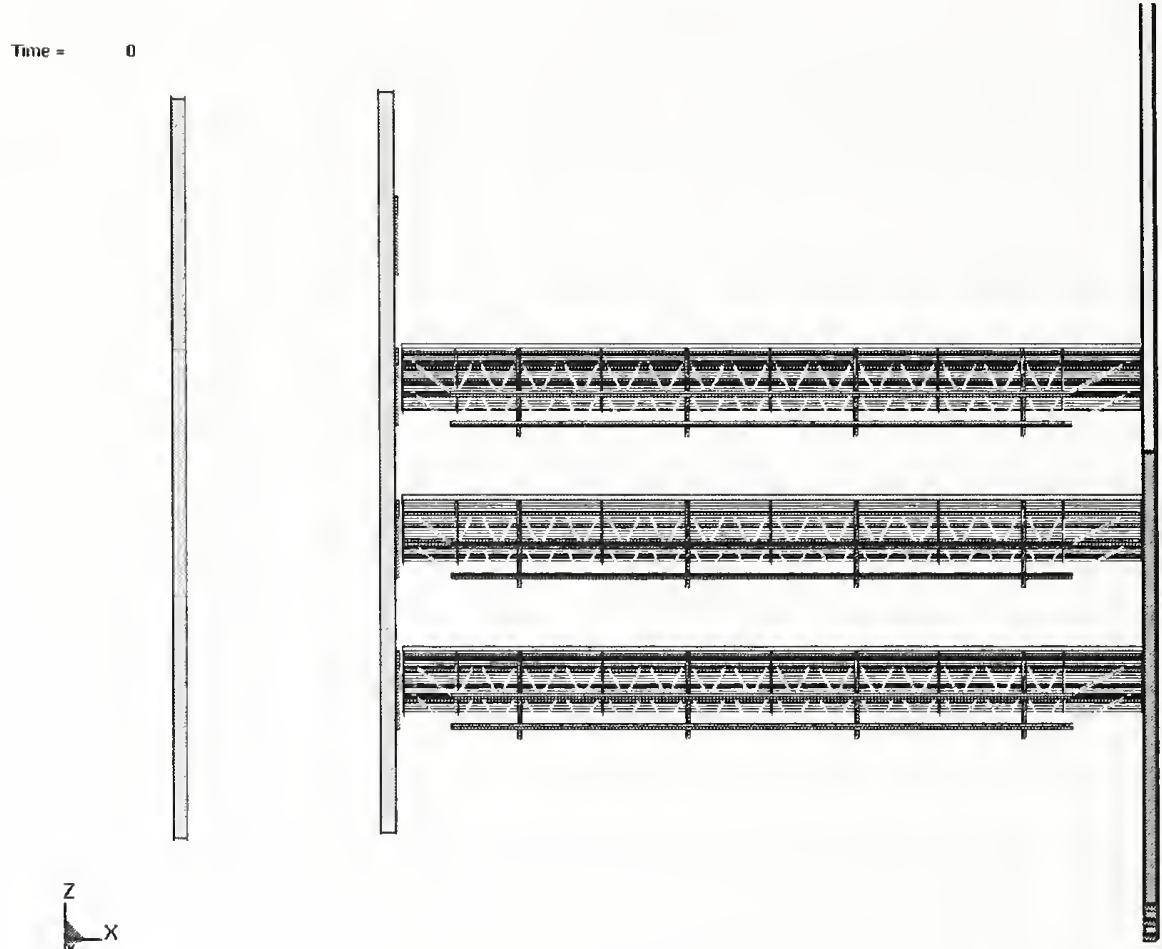

(a) Initial configuration

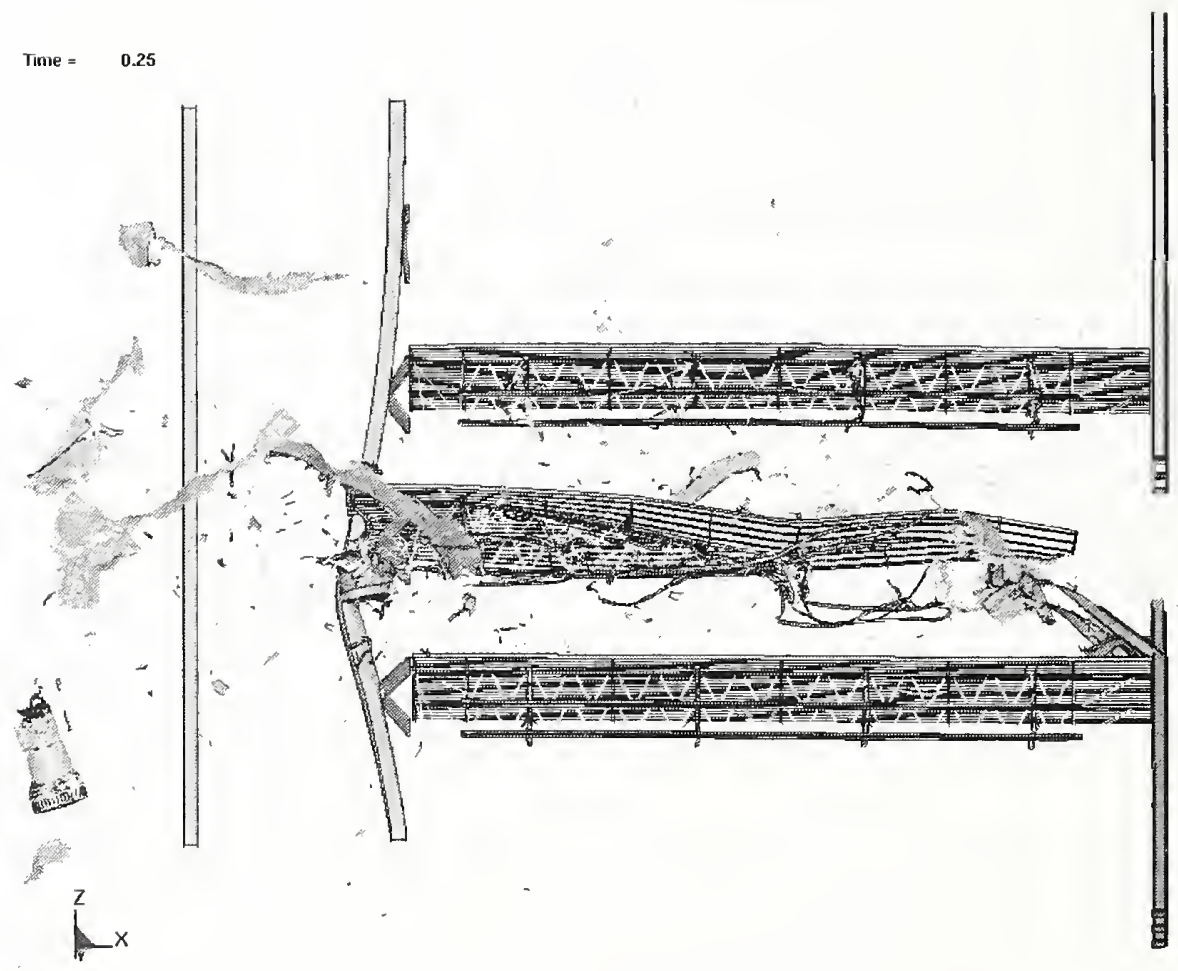

(b) Impact response at $0.25 \mathrm{~s}$

Figure 6-1. Example engine impact subassembly analysis. 
The impact response of the tower subassembly when impacted by an engine at $500 \mathrm{mph}$ is shown in Figure 6-1(b) and Figure 6-2. Engine impact was centered on the spandrel at floor 96. The trajectory of the engine was normal to the exterior panel. The engine significantly penetrated the floor structure and caused significant damage to the core column (503) upon impact.

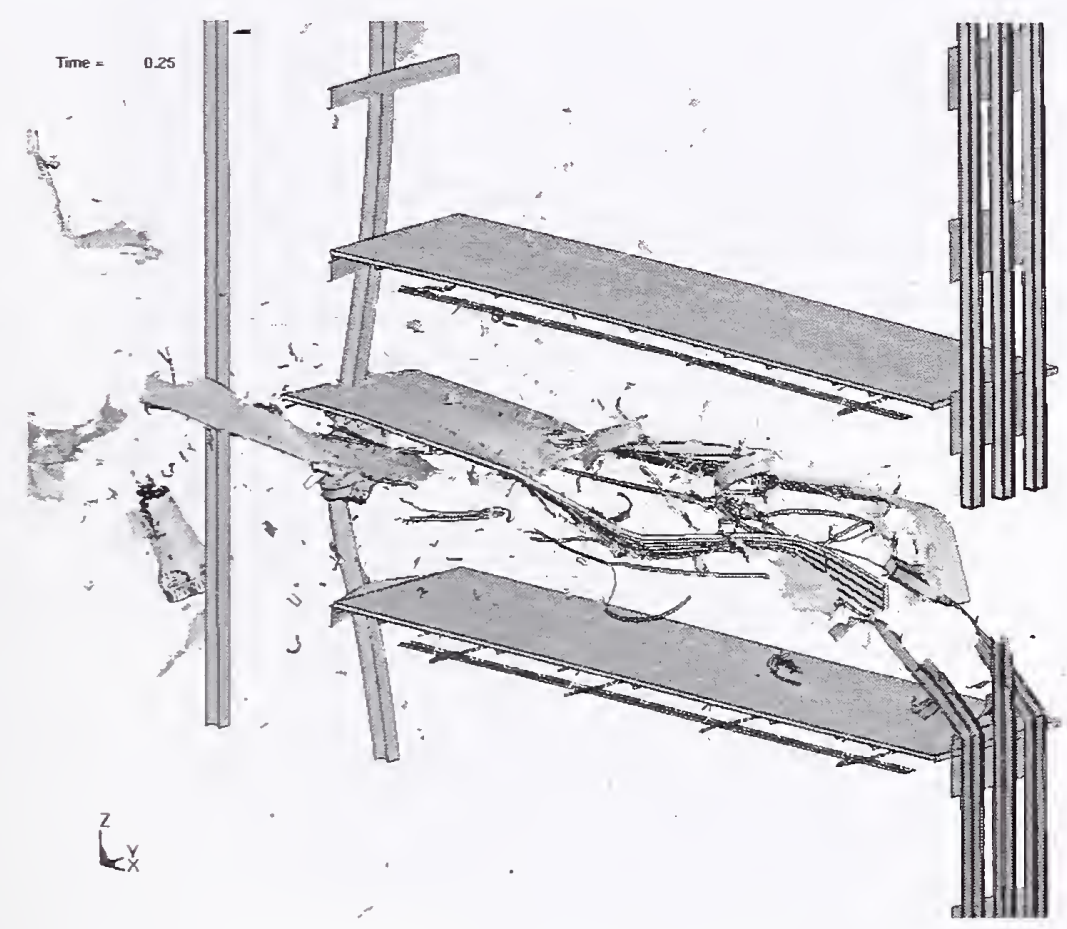

Figure 6-2. Oblique view of the subassembly engine impact damage.

The impact response of this preliminary subassembly model was influenced by many of the preliminary modeling assumptions applied. Unconstrained boundary conditions on the side of the floor slab influenced the deformation of the truss floor structures. In addition, the concrete in this analysis was assumed to have an unconfined compressive strength of $3 \mathrm{ksi}$ and strain rate hardening was not yet included in the concrete constitutive model. The result was an over estimation of the impact damage to the floor structures in the model. However, the preliminary subassembly analyses still were useful in developing simplified models for the bolted column connections, as described in Section 5.2.3, and to refine the modeling approach for various impact conditions. Additional applications of the final subassembly models are described in the following sections.

\subsection{FINAL SUBASSEMBLY ANALYSES}

The final subassembly model was developed using structural components from the impact zone on the north face of WTC 1 (Side 100). The model, shown in Figure 6-3, was used to further evaluate the response of structural connections, material and failure models, and other issues affecting global impact analyses. The model was three floors tall, spanning floors 95-97, three exterior panels wide, and extended from the exterior wall through to the first two rows of core columns. The core columns included in the subassembly model were column numbers 502-504 and 602-604. The exterior wall in the subassembly model included the exterior panels that extended into floors 95-97, as well as two panels above and below the panel spanning all three floors. Exterior column numbers in the model ranged from 
column 117 through 125. The structural components in the final subassembly model included the exterior panels, core framing, truss floor structures, and interior contents (workstations). These structural components arc shown separately in Figure 6-4. The concrete slab in the core was not included in this model.

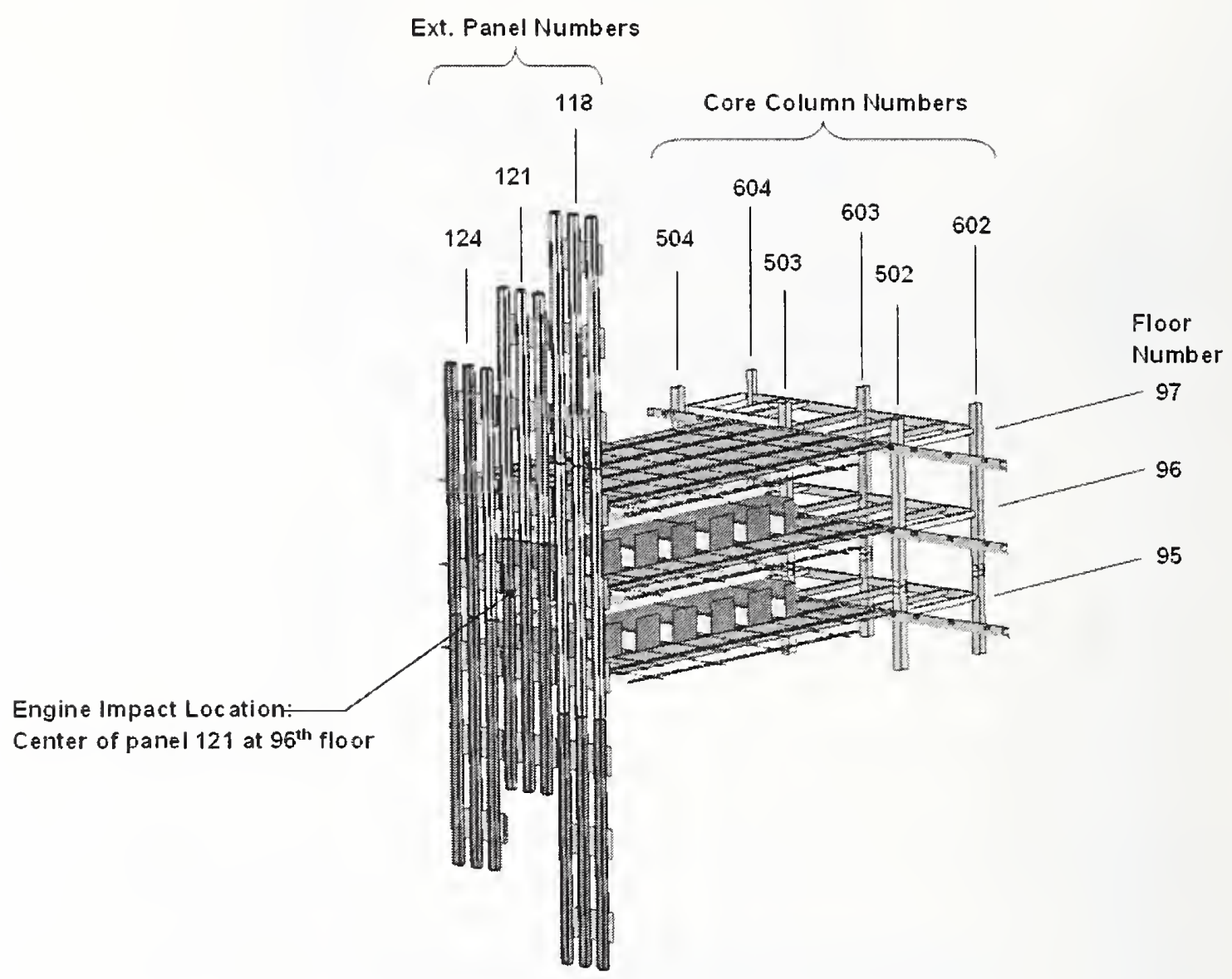

Figure 6-3. Final WTC tower subassembly model. 


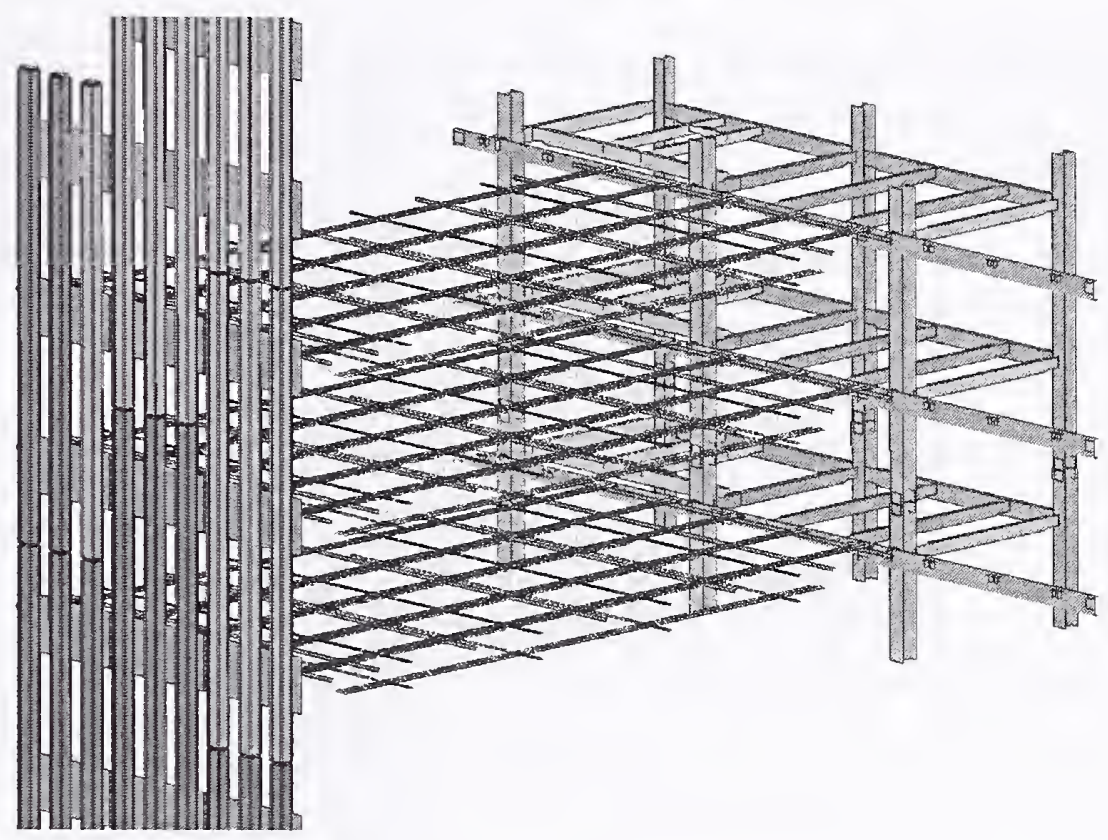

(a) Framing for the subassembly model

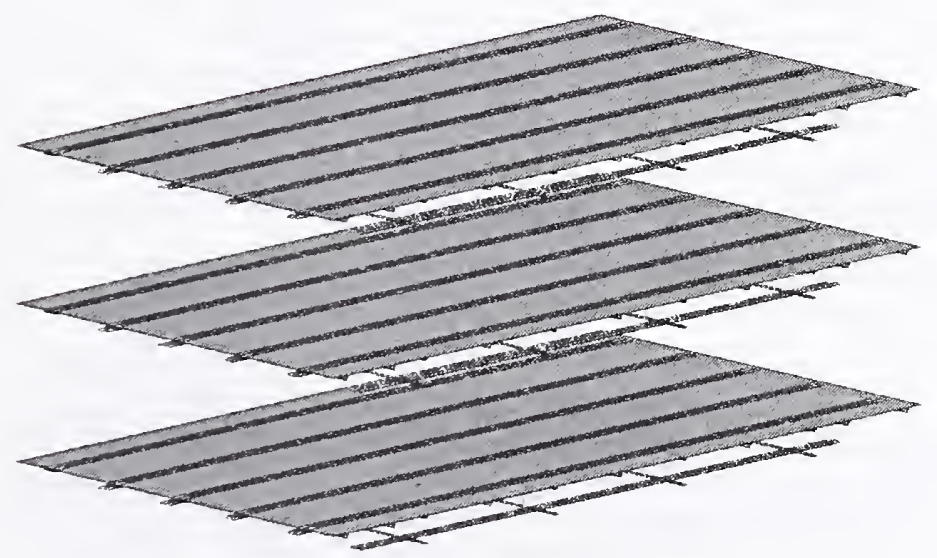

(b) Truss floor components in the subassembly model

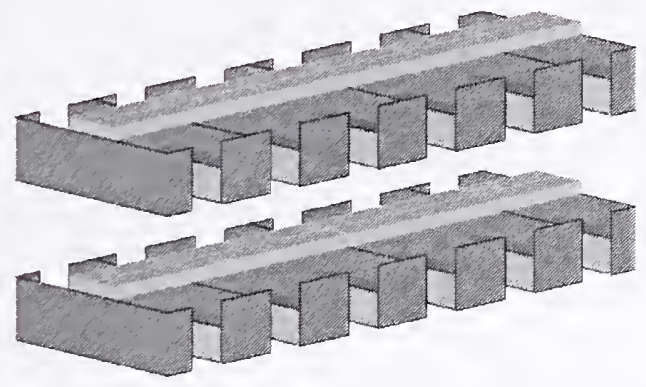

(c) Workstations in the subassembly model

Figure 6-4. Details of the final WTC tower subassembly model. 
The vertical displacements were constrained at the top and bottom of the free ends of the core columns. For the exterior columns, a bolted connection was added to an adjacent butt plate for which the vertical motions were constrained. The lateral displacements were constrained at the free spandrel edges and at the sides of the truss floor structures. This model offered much more realistic boundary conditions on the impacted portion of the structure than the preliminary model discussed in Section 6.2. In addition, the greater width of the exterior wall and truss floor structures in this model reduced the influence of the boundary conditions on the impact response.

\subsubsection{Engine Impact Subassembly Analyses}

The engine model used in the subassembly analyses was based on the structural design information from the Pratt \& Whitney PW4000 turbofan engine. The development of the engine model was described previously in Section 4.3.3. The objective of these analyses was to investigate the impact response to a variety of impact conditions while using different modeling methodologies. Most of these engine impact analyses are describcd in Chapter 8 as part of the uncertainty analyses. A few specific engine impact analyses are described here to illustrate the characteristic engine impact behavior and the effects of specific model parameters on the impact response.

The initial position and orientation of the aircraft engine in one sample calculation is shown in Figure 6-5. The engine had an initial velocity of $413 \mathrm{mph}$ and a trajectory with a lateral approach angle of 4 degrees from the exterior panel normal and a vertical approach angle of 7.6 degrees below the horizontal. The impact point was centered approximately $6 \mathrm{ft}$ below the $97 \mathrm{th}$ floor so that the initial impact did not engage a significant portion of the truss floor structures. The calculated impact response of the subassembly is shown in Figure 6-6. The engine penetrated the exterior wall and continued into the interior of the building along the initial downward trajectory. As the engine continued into the subassembly model, it plowed through the interior building contents (workstations) and eventually skipped off of the truss floor slab at the 96th floor.

A side vicw of the impact behavior at different times is shown in Figure 6-7. The engine penetrated the exterior wall following the initial downward trajectory. As the engine continued downward it impacted the workstations and the truss floor structures of floor 96 . The engine motion was redirected by the impact with the truss floor and continued its motion toward the core, penetrating additional workstations. At a time of $0.25 \mathrm{~s}$ the engine entered the core as shown in Figure 6-7(c). The impact conditions of this analysis resulted in a collision of the engine with core column 503. The speed-time history of the engine core in this impact analysis is shown in Figure 6-8. The deceleration that occurred in the first 5 ms was primarily from the penetration of the exterior wall and the floor slab and truss of floor 97 . This deceleration was larger than that observed in Section 5.2 .4 by approximately 25 percent. The analysis in Section 5.2.4 was that of only exterior panels without any floors attached or boundary conditions to approximate their effect. This difference in deceleration was due to the reinforcing effect of the floor structure on the exterior panel, as well as impact with the floor structure. 


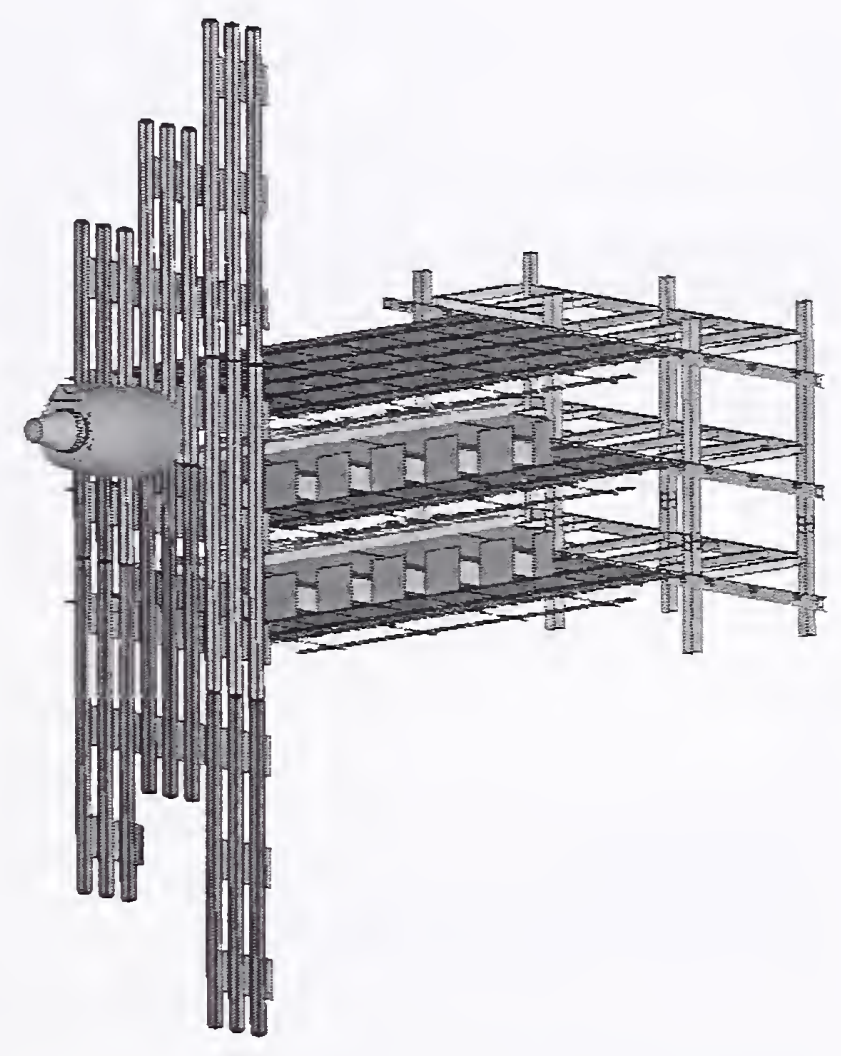

Figure 6-5. Final subassembly model for engine impact analysis.

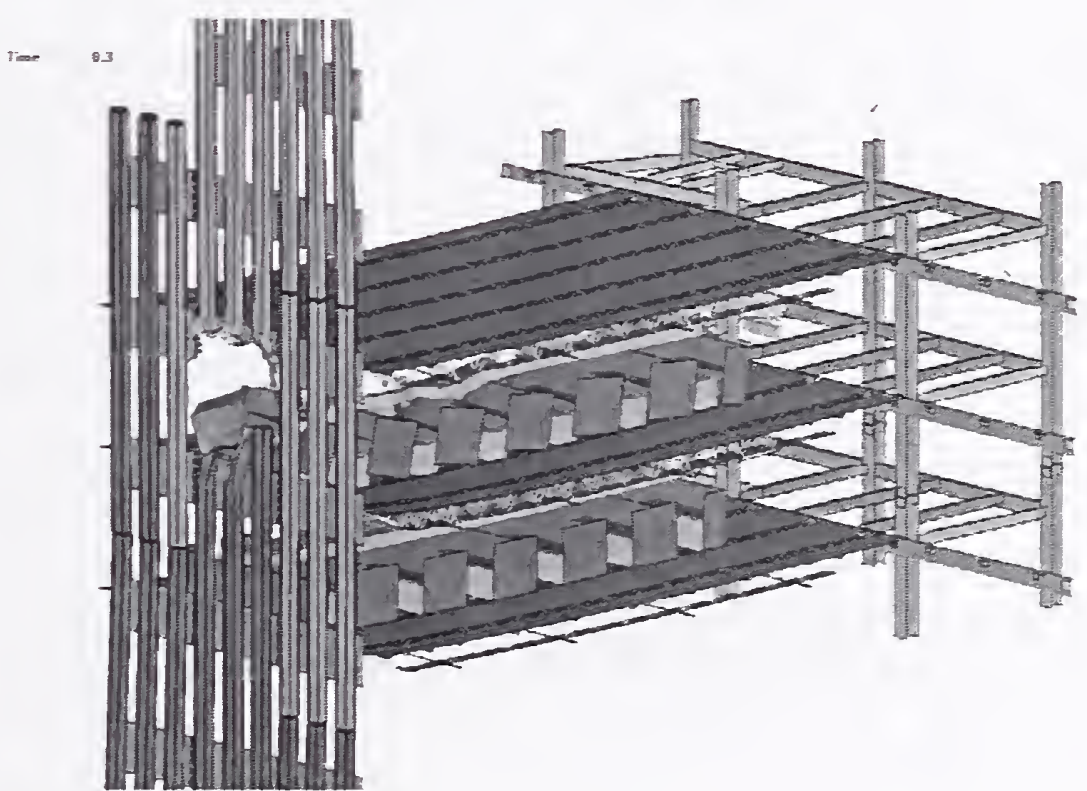

Figure 6-6. Calculated response for the baseline engine impact analysis. 


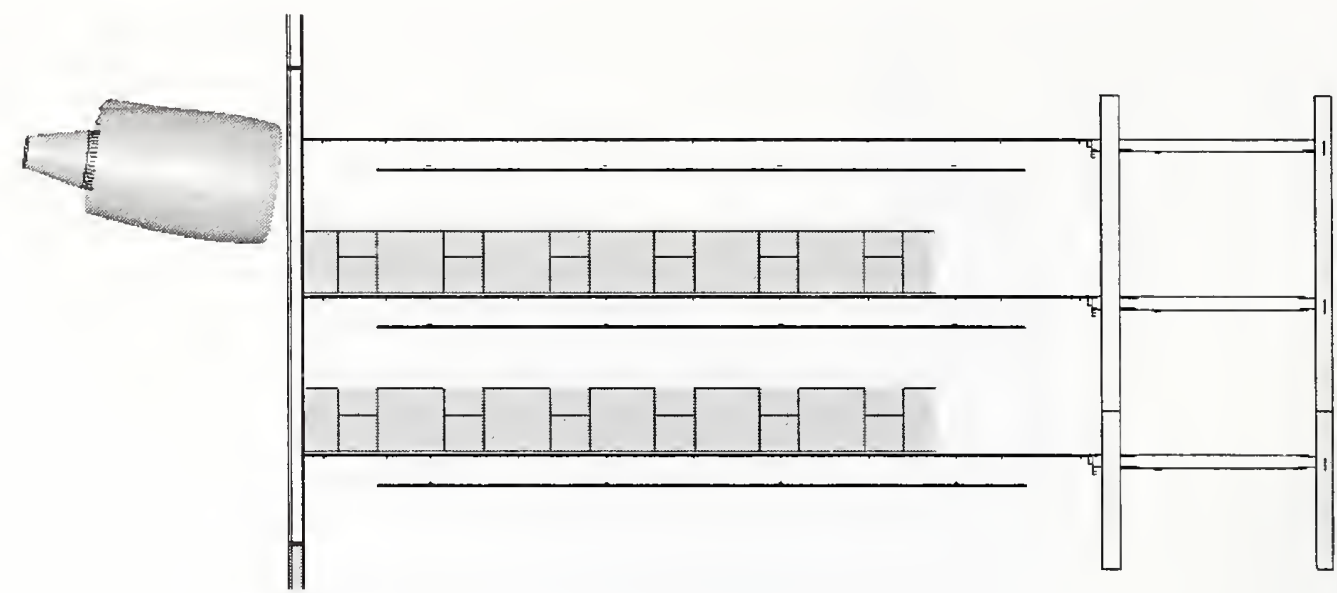

(a) Time $=0.00 \mathrm{~s}$

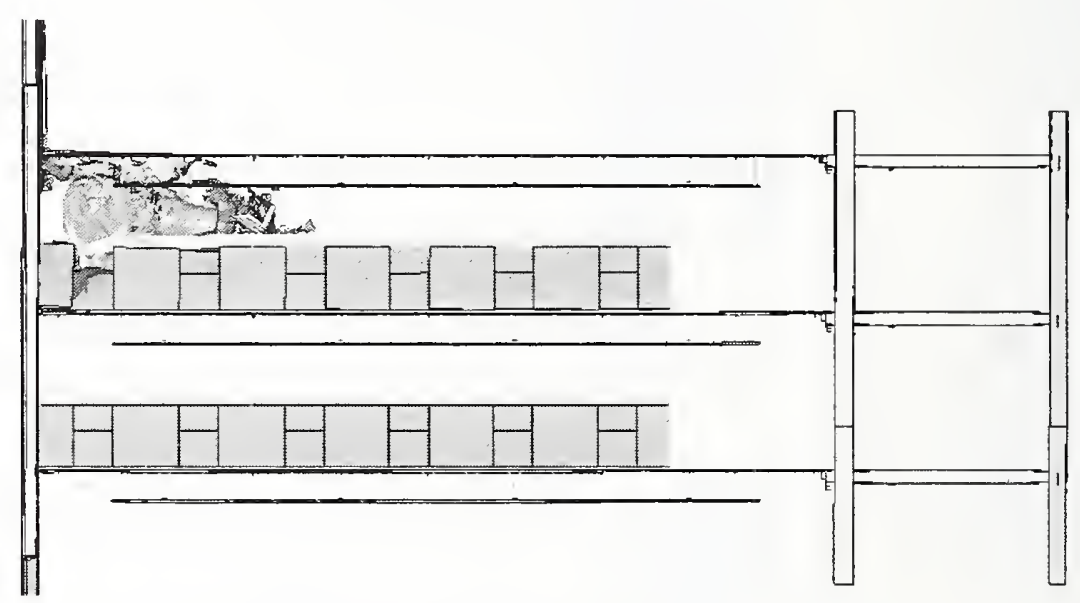

(b) Time $=0.05 \mathrm{~s}$

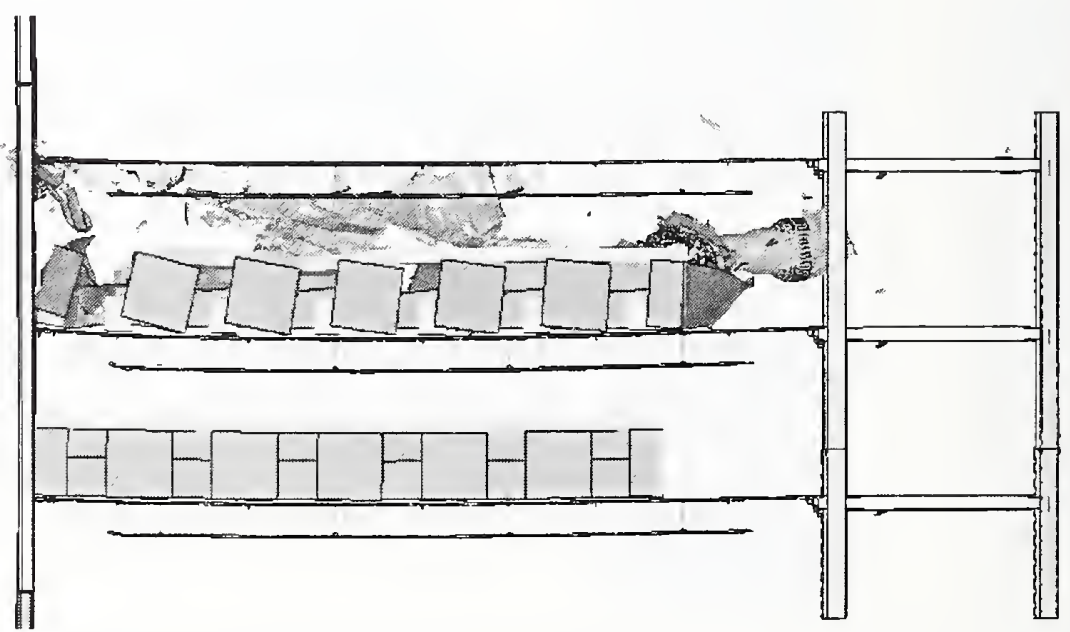

(c) Time $=0.25 \mathrm{~s}$

Figure 6-7. Baseline engine impact and break up behavior (side view). 


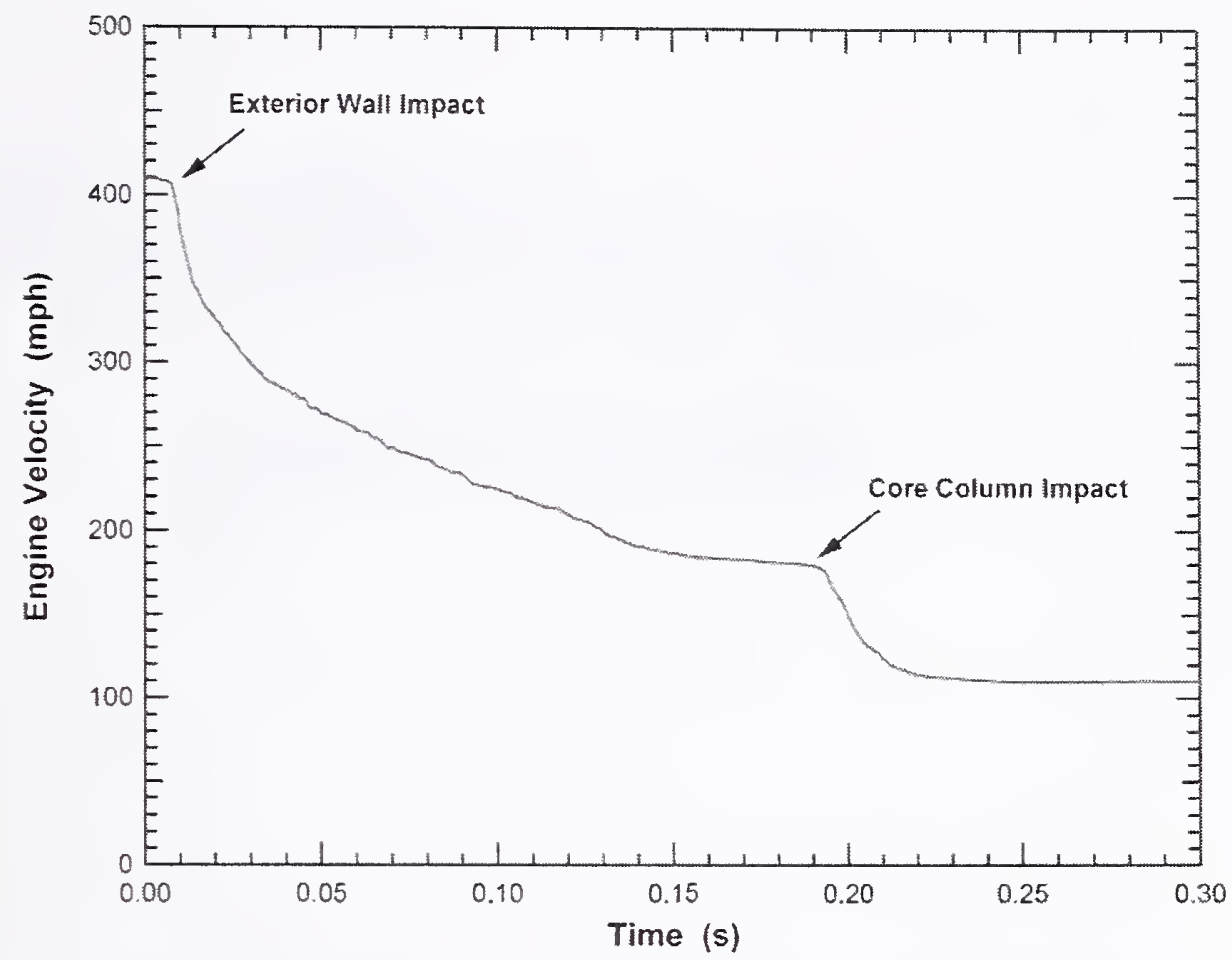

Figure 6-8. Speed history for the baseline engine subassembly impact analysis.

\section{Building Contents Strength Effects}

Two subassembly engine impact analyses were performed to investigate the influence of the strength of the building contents (in this case, workstations) on the impact response. The baseline strength of the building contents (partitions and workstations) was estimated to be 500 psi. As a comparison, the second calculation used identical impact conditions, but the building contents had virtually no strength ( $0.5 \mathrm{psi})$.

The deceleration histories for the engine core in the two subassembly analyses are compared in Figure 6-9. The deceleration that occurred in the first 3 to $5 \mathrm{~ms}$ was primarily from the penetration of the exterior wall. In this phase of the impact response, the engine spced was reduced from the impact specd of $413 \mathrm{mph}$ to approximately $375 \mathrm{mph}$. The majority of the subsequent deceleration to a time of $0.25 \mathrm{~s}$ was the result of the engine impacting the workstations. For the 500 psi workstations, the engine was decelerated to a speed of $100 \mathrm{mph}$ as the engine entered the core. The engine impacting the low strength workstations had a residual speed of $130 \mathrm{mph}$ entering the core. Although there was a $30 \mathrm{mph}$ difference in the impact response as a result of the workstation strength, the total loss of speed produced by the impact with the building contents was about $150 \mathrm{mph}$. Therefore, the deceleration was dominated by the mass of the workstations. 


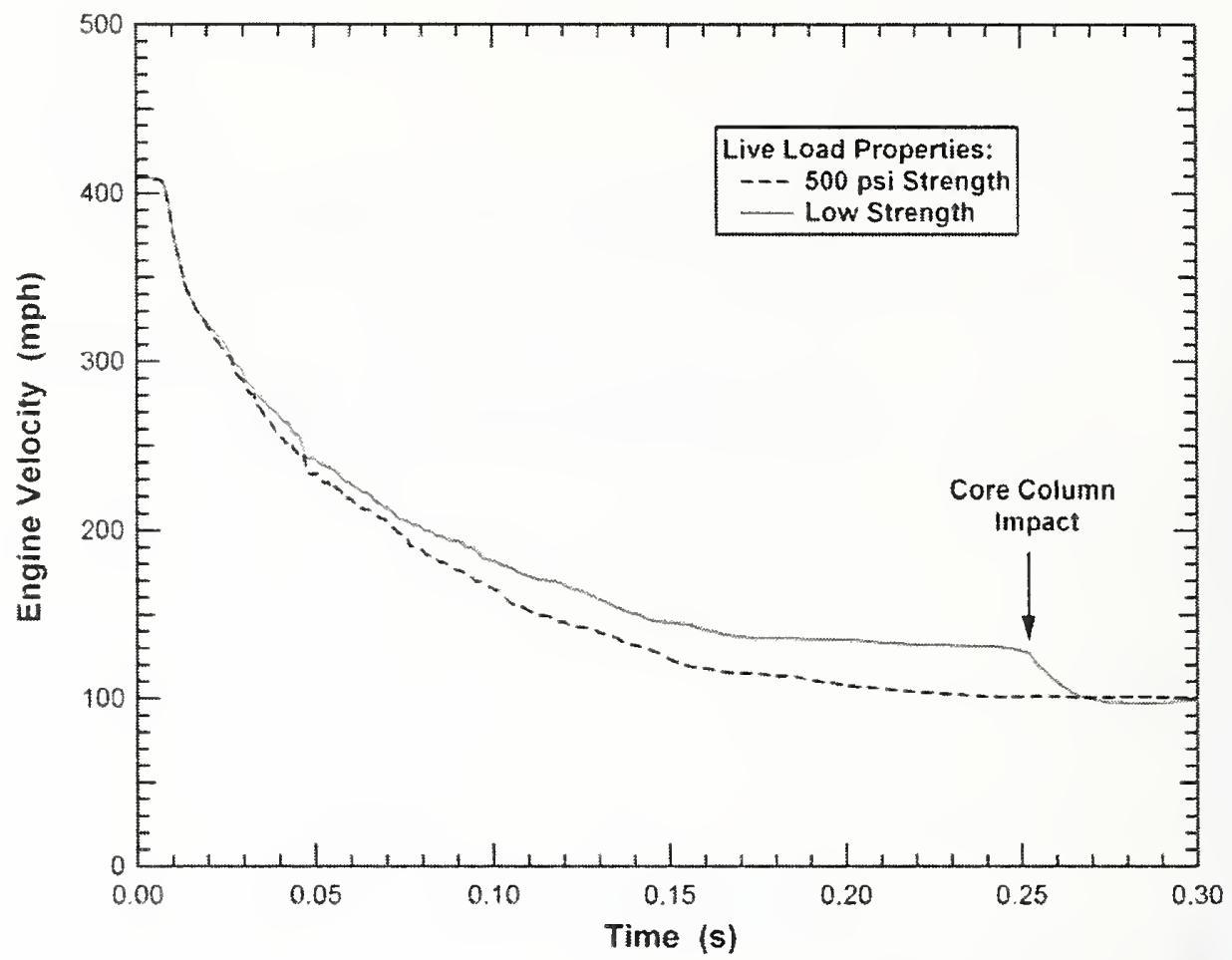

Figure 6-9. Effect of the building content strength on engine impact behavior.

\section{Truss Floor Concrete Strength Effects}

A pair of subassembly engine impact analyses was performed to investigate the influence of the floor concrete strength on the impact response. For this evaluation, initial conditions of the engine were selected so that there was significant interaction of the impacting engine with the truss floor structures, as shown in Figure 6-10. The building contents (workstations) are not visualized in Figure 6-10(b) and (c) so the engine impact response can be more clearly seen. The engine impact was close to being centered on the truss floor slab with a downward trajectory of 13.6 degrees and an impact speed of $473 \mathrm{mph}$. The impact response resulted in a significant penetration of the truss floor slab. As a result of the downward trajectory, the engine ended up on the lower of the two floors and at a time of $0.25 \mathrm{~s}$ was approaching the core structures.

The concrete used in the truss floor section was a lightweight concrete with a design compressive strength of $3 \mathrm{ksi}$. However, due to aging and material variation above the specified minimum strength, the expected strength of the truss floor concrete at the time of the impact was above the $3 \mathrm{ksi}$ specification. The engineering estimate of the actual strength was approximately $4 \mathrm{ksi}$ (NIST NCSTAR 1-6). This strength was used in the majority of the analyses in this study. To demonstrate the effect of the concrete strength on the impact behavior, an additional engine subassembly impact analysis was performed with the specified $3 \mathrm{ksi}$ strength to demonstrate the influence of the concrete strength on the impact behavior. 


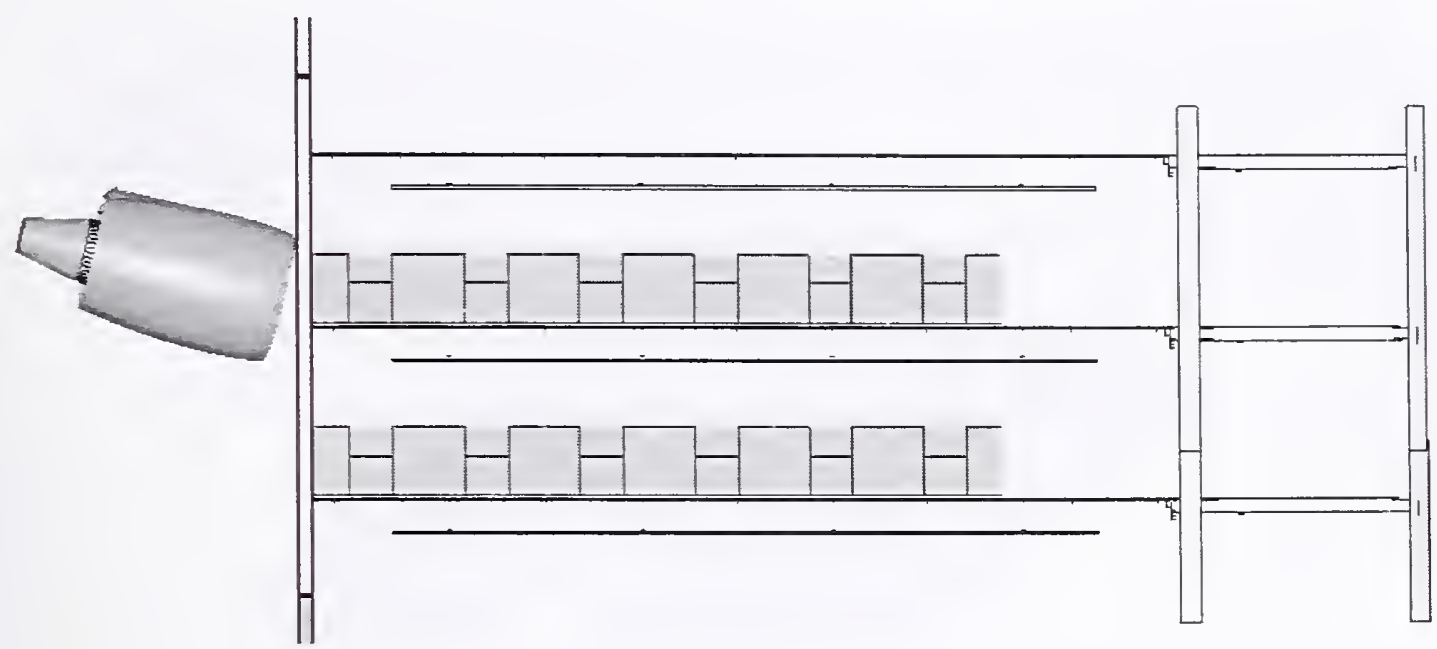

(a) Time $=0.00 \mathrm{~s}$

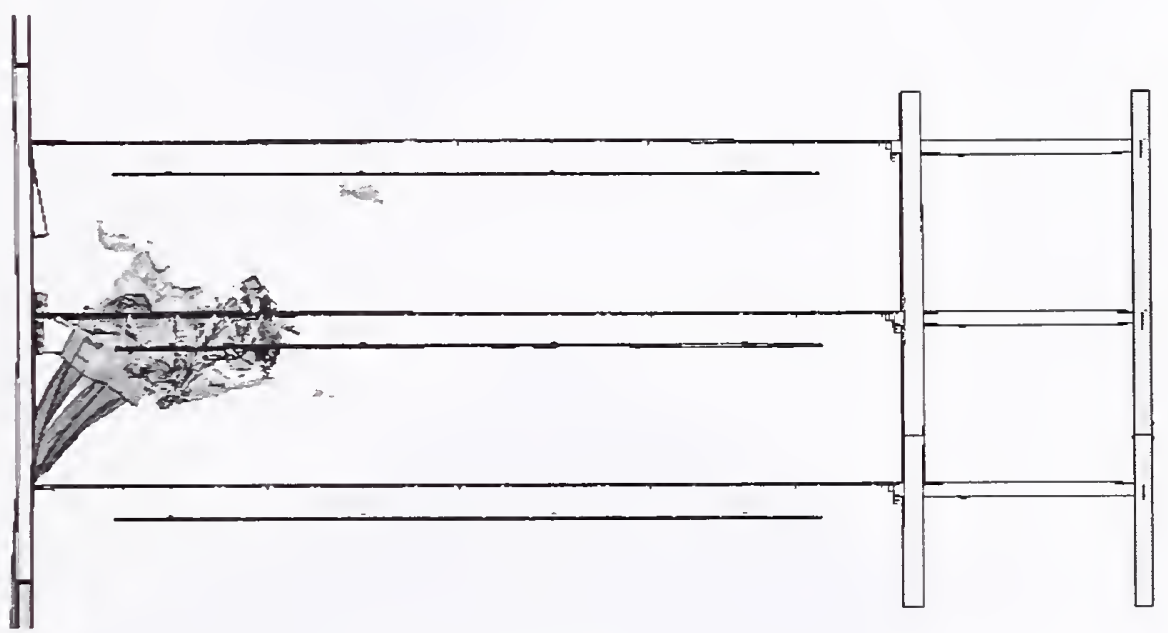

(b) Time $=0.05 \mathrm{~s}$

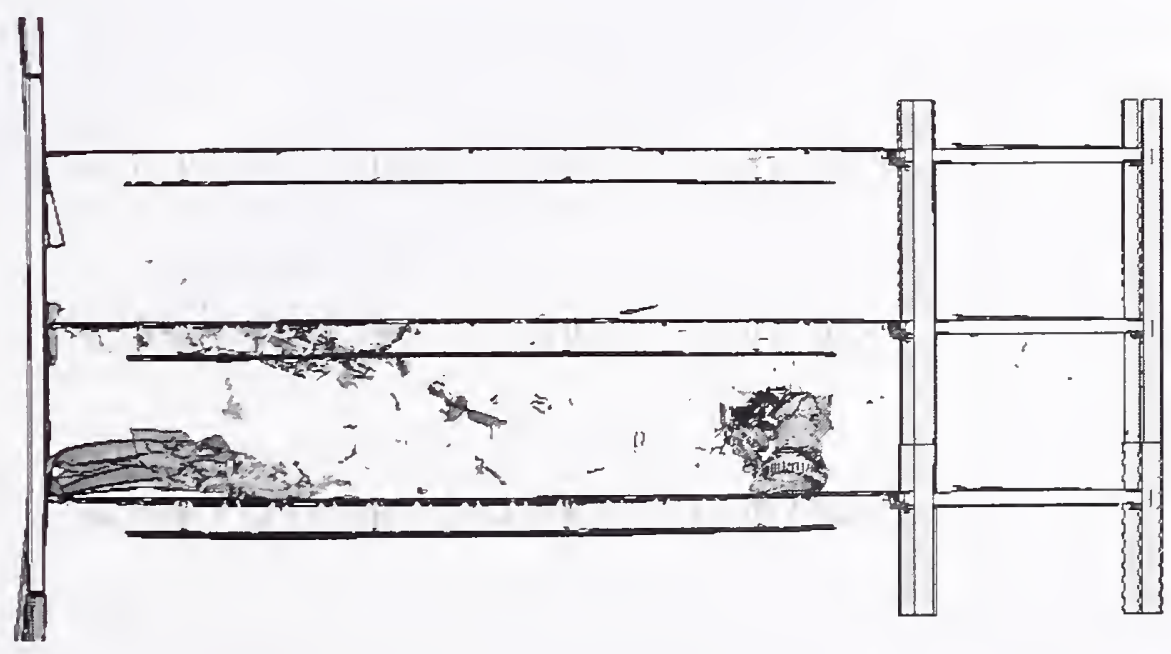

(c) Time $=0.25 \mathrm{~s}$

Figure 6-10. Engine impact for concrete strength evaluation (side view). 
The engine speed-time histories for the analyses with $3 \mathrm{ksi}$ and $4 \mathrm{ksi}$ concrete are compared in Figure 6-11. The engines had nearly identical speeds at $50 \mathrm{~ms}$ when the interaction with the truss floor was complete and approximately a $5 \mathrm{mph}$ difference in speed at the end of the simulation. The speed difference was introduced by a slightly different tumbling behavior of the two engines as they moved through the building contents. When the rotational axis of the engine was not coincident with the engine trajectory, a larger amount of mass was engaged and the engine was decelerated more rapidly.

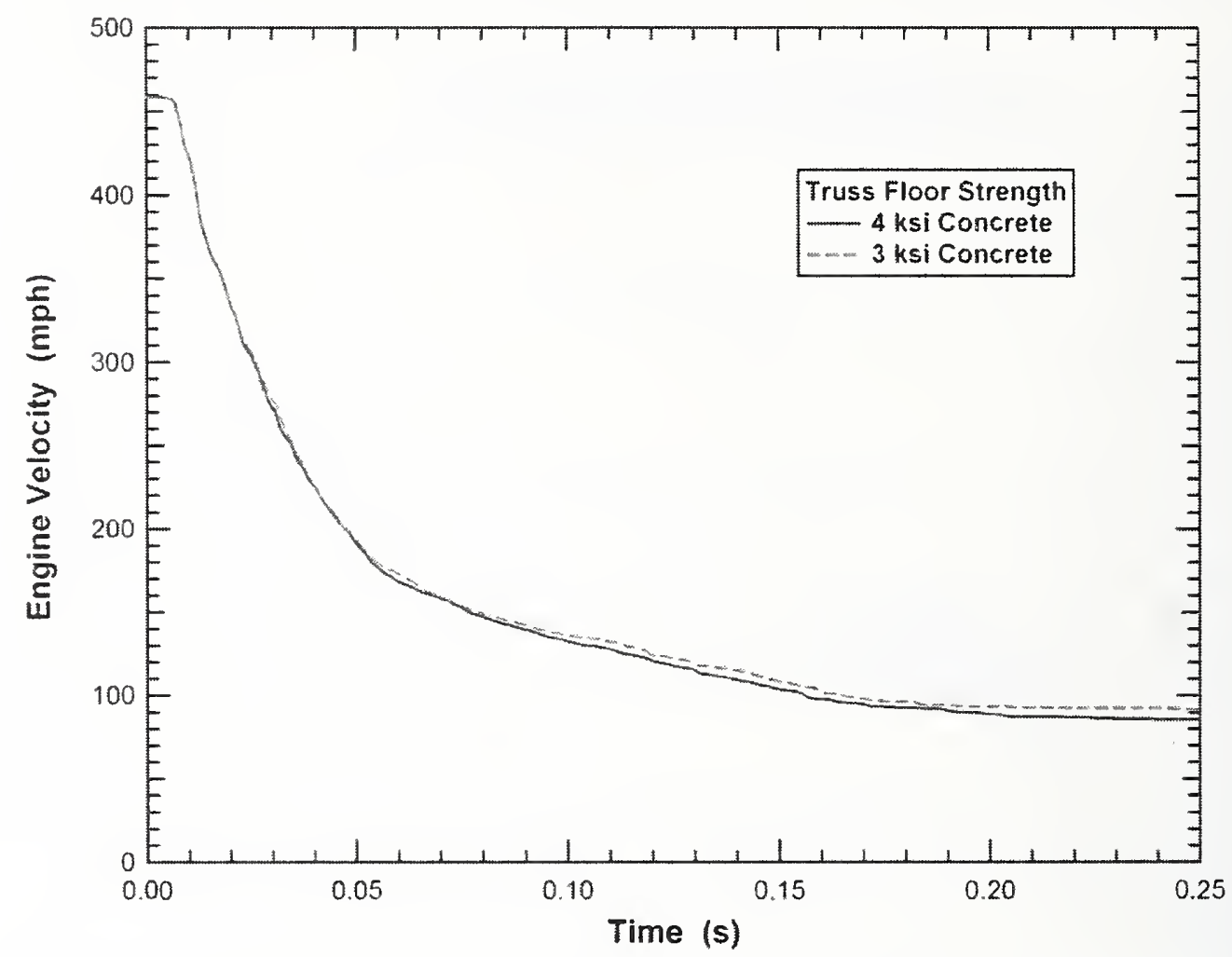

Figure 6-11. Effect of the concrete strength on engine impact behavior.

A comparison of the engine impact damage to the truss floor structures with the $3 \mathrm{ksi}$ and $4 \mathrm{ksi}$ strength concrete is shown in Figure 6-12. The comparison shows that the two truss floors had very similar impact damage. A hole was created in both truss floors that extended from the outer wall back to approximately the second bridging truss. The mass of the concrete slab appears to have a greater effect on the engine deceleration and damage to the floor than does the concrete strength. 
Time $=0.2$

Contours of Effective Plastic Strain

max ipt. value

$\min =0$, at elem 39445

$\max =0.150001$, at elem 49843

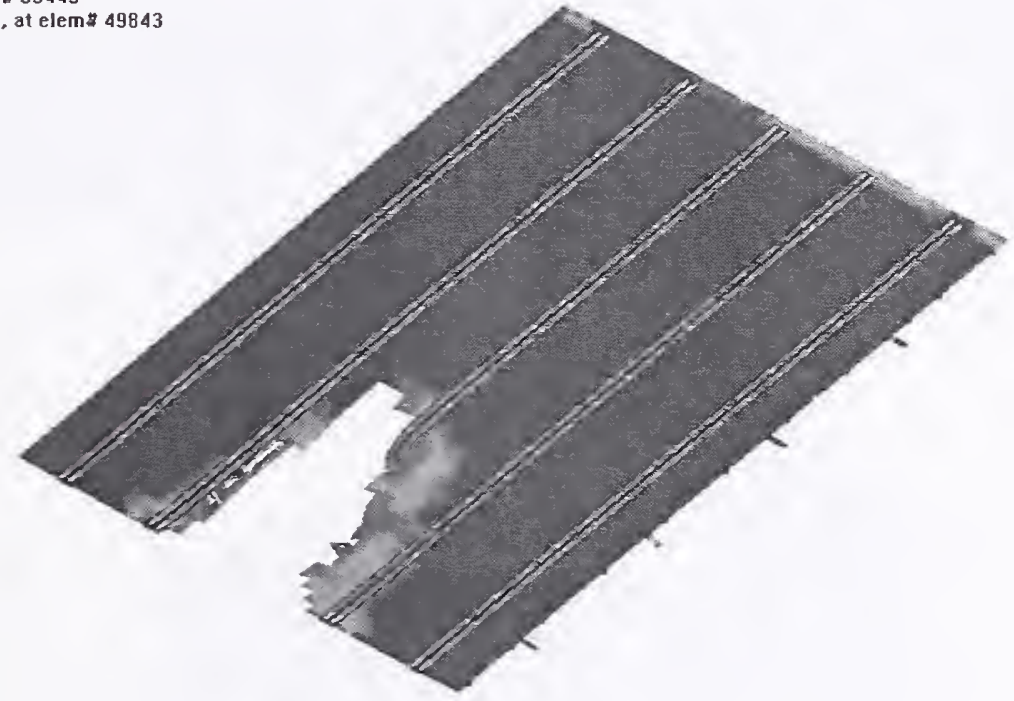

Fringe Levels

$2.000 \mathrm{e}-02$

$1.800 \mathrm{e}-02$

$1.600 \mathrm{e}-02$

$1.400 \mathrm{e}-02$

$1.200 \mathrm{e}-02$

$1.000 \mathrm{e}-02$

B.000e-03

$6.000 \mathrm{e}-03$

$4.000 \mathrm{e}-03$

$2.000 \mathrm{e}-03$

$0.000 e+00$

(a) 4 ksi concrete truss floor damage

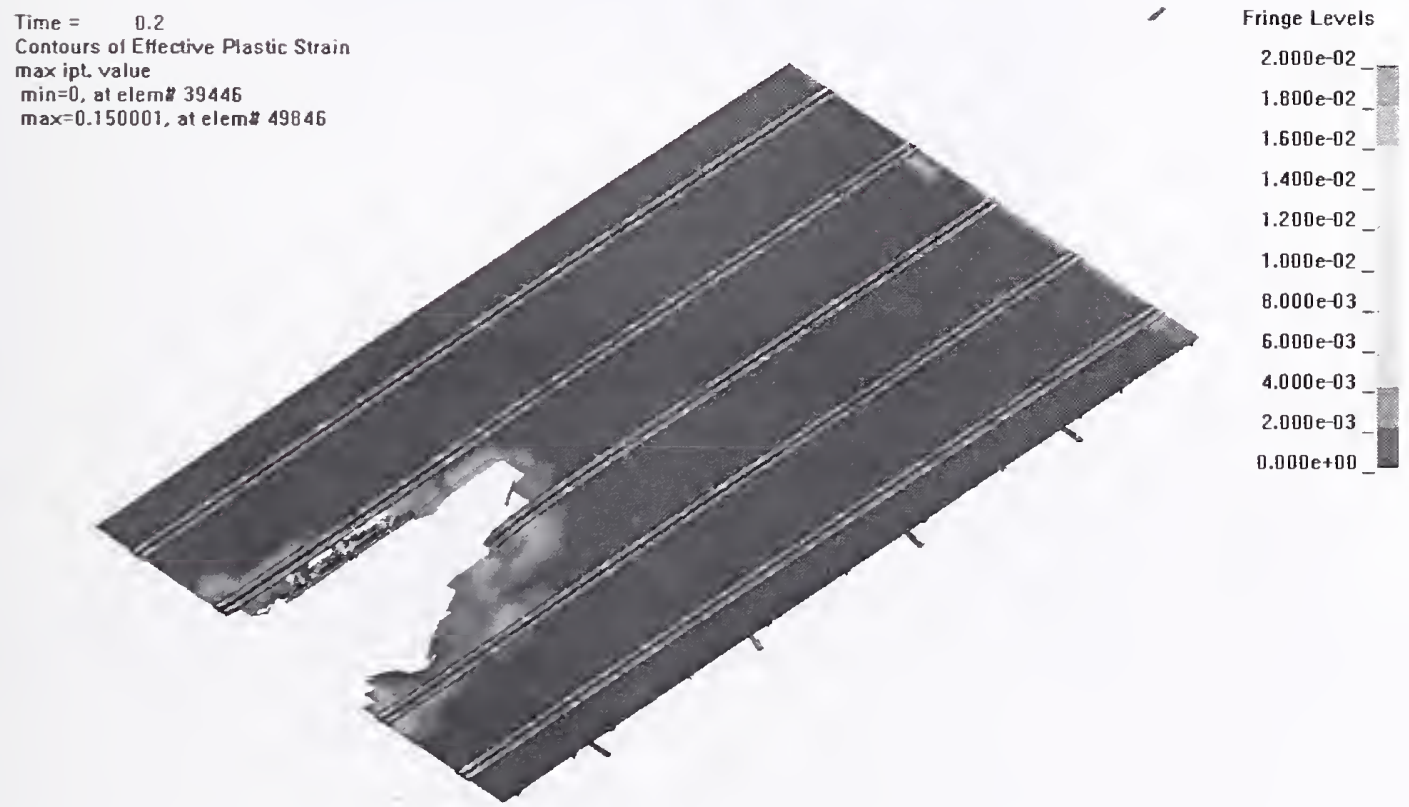

(b) $3 \mathrm{ksi}$ concrete truss floor damage

Figure 6-12. Truss floor damage from the engine impact.

The above comparison of the subassembly engine impact analyses with the truss floor illustrates that the assumptions on the compressive strength of the concrete is not expected to have a significant influence on the predicted impact damage. The baseline strength of the concrete was assumed to be $4 \mathrm{ksi}$ for subsequent impact analyses in this study. 


\subsubsection{Wing Section Impact Subassembly Analyses}

Fuel-filled wing section impact subassembly analyses were performed using the final subassembly model discussed in Section 6.3.1. The development of the wing section impactor was described previously in Chapter 4 . The combined wing section and tower subassembly model for the baseline impact conditions is shown in Figure 6-13. The fuel-structure interaction in this analysis was modeled using SPH particles, as discussed in Section 5.5.3.

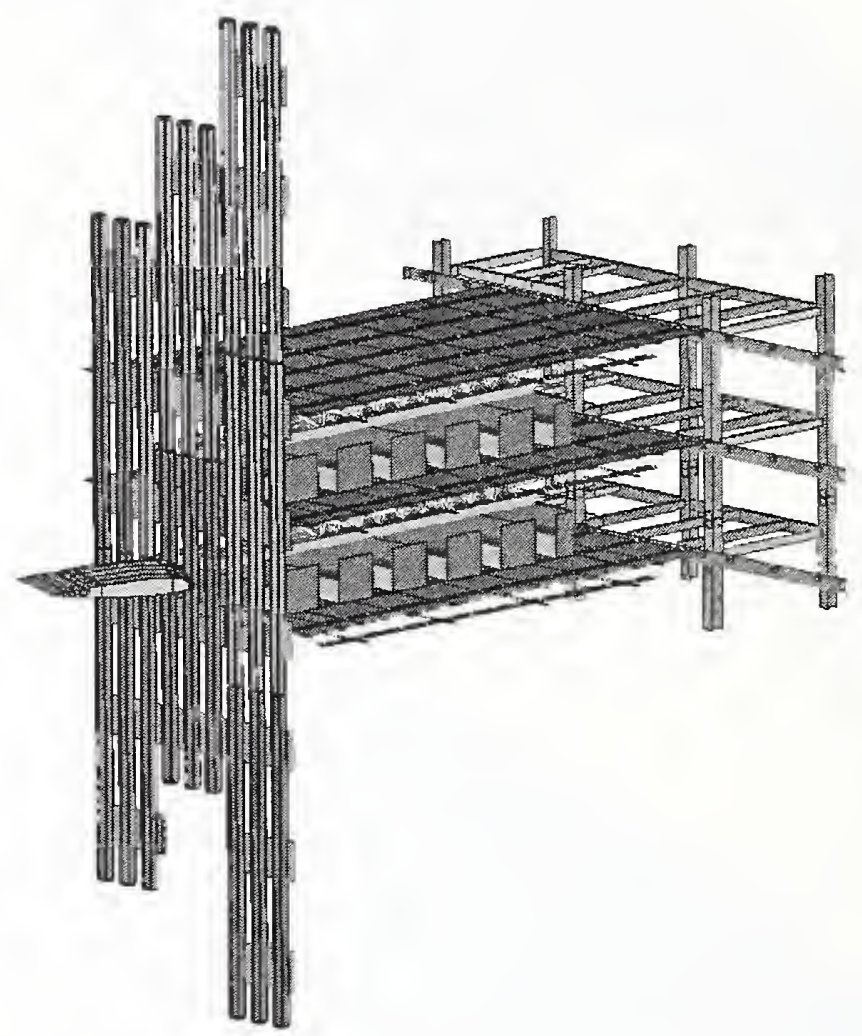

Figure 6-13. Final subassembly model for wing section impact analysis.

The impact response for the baseline subassembly wing section impact analysis is shown in Figure 6-14. In the first $50 \mathrm{~ms}$, the wing section penetrated the exterior wall and was torn apart by the interaction with the exterior columns. The aircraft fuel formed a relatively dense cloud that covered the full height of the floor and extended $20 \mathrm{ft}$ to $30 \mathrm{ft}$ into the building. At a time of $0.25 \mathrm{~s}$, as shown in Figure 6-14(c), the wing section impact caused significant damage to the workstations on the impact floor, and the fuel cloud expanded through to the core of the subassembly. 


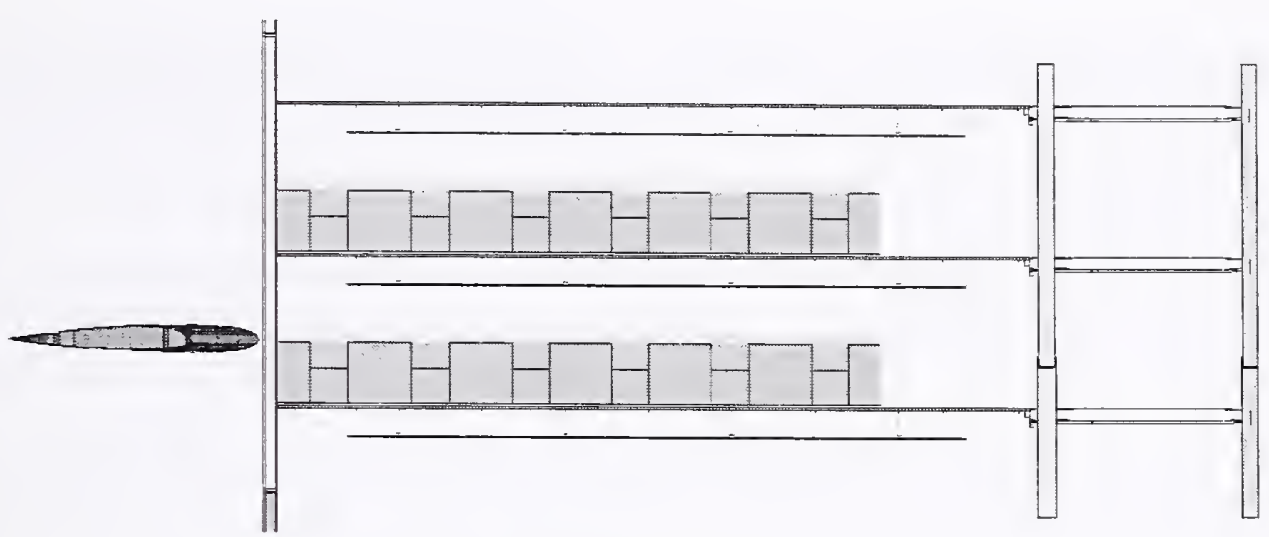

(a) Time $=0.00 \mathrm{~s}$

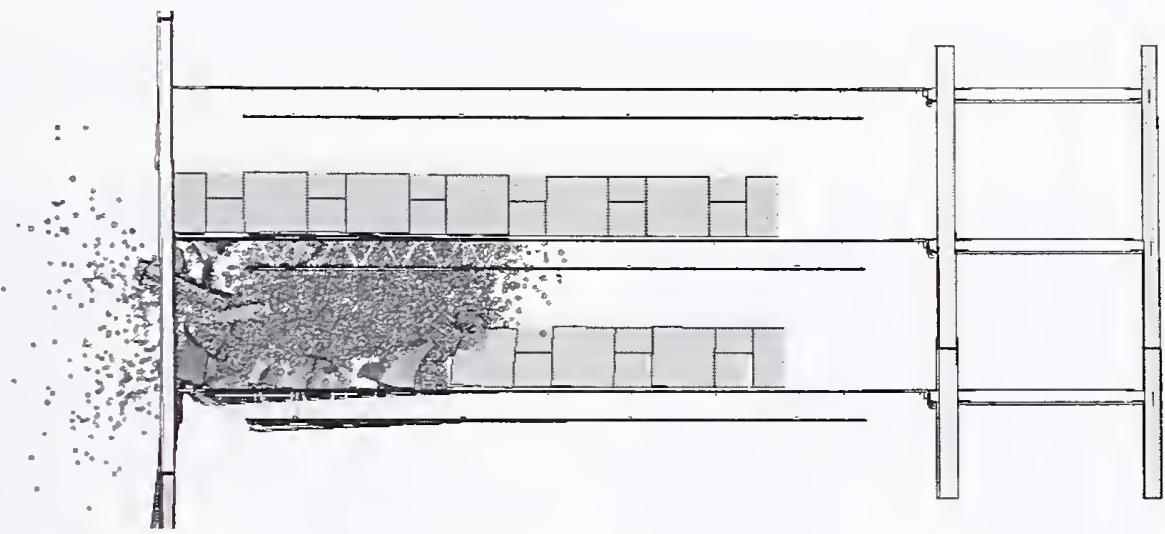

(b) Time $=0.05 \mathrm{~s}$

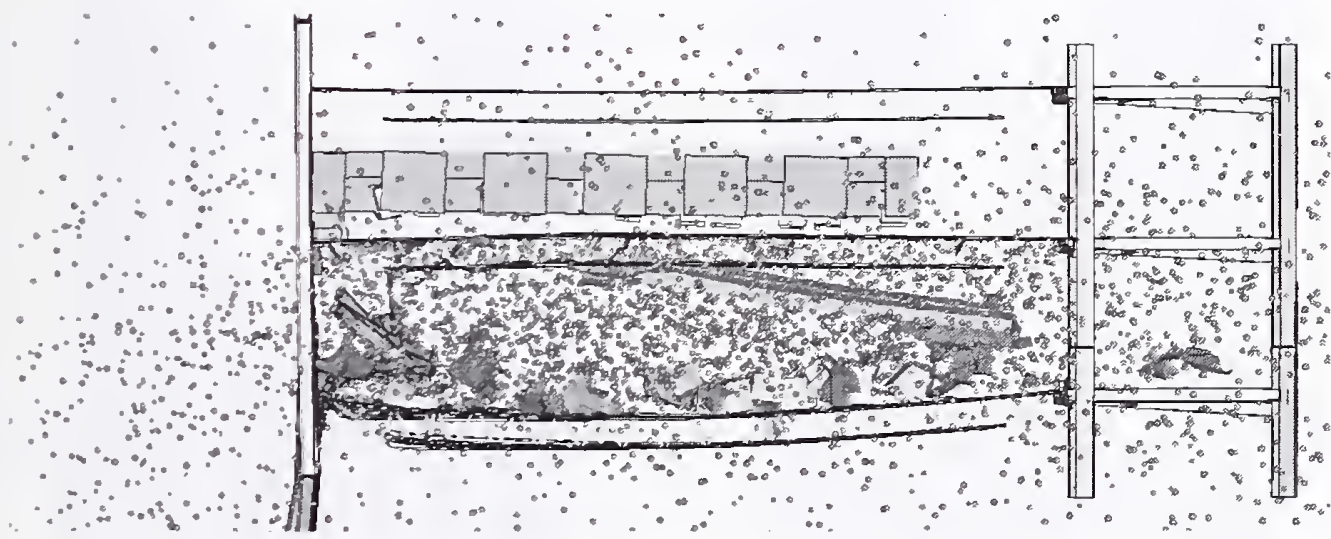

(c) Time $=0.25 \mathrm{~s}$

Figure 6-14. Baseline wing section impact and break up behavior (side view).

The damage produced by the wing section impact, shown in Figure 6-14, is different in many ways from the engine impact analyses shown in Figure 6-7. Both impactors started with similar kinetic energies; the wing-section impactor had an initial kinetic energy of $5.0 \times 10^{7} \mathrm{lb} \cdot \mathrm{ft}$ and the engine impactor had $5.8 \times 10^{7} \mathrm{lb} \cdot \mathrm{ft}$. The wing impactor completely destroyed the workstations, where the engine only cut a path through the center of the subassembly. The wing caused extensive floor buckling despite having no initial vertical component to its velocity, unlike the engine. With the wing section, damage 
predominantly occurred from the exterior panel to the core with little to no damage to the core. The difference in response is due to the brcak up and expansion of the wing components and fuel cloud. This debris and fuel expands more than the damaged engine components and can, therefore, engage more tower materials before reaching the core.

The difference in the impact behavior for the engine and wing section can be shown by the comparison of the impactor resultant momentum histories, shown in Figure 6-15. Although the wing section initially had approximately 20 percent lower momentum than the engine, the wing section impact transferred a larger percentage of the momentum to the tower in a much shorter duration. Therefore, the wing section resulted in greater damage near the impact point at the tower exterior. However, for comparable impact mass, the engine had a significantly larger energy entering the core and corresponding potential for damaging the core columns.

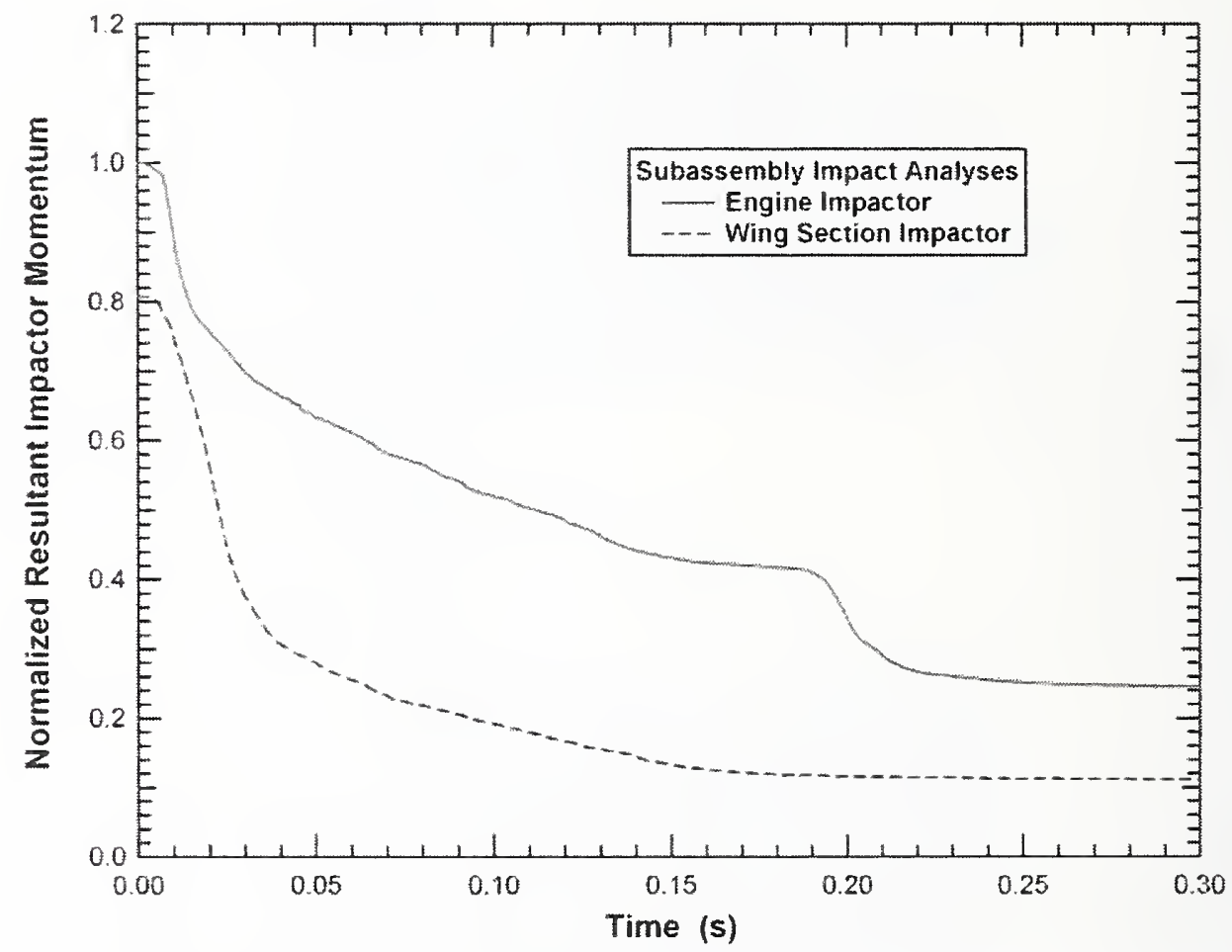

Figure 6-15. Impactor momentum histories for the engine and wing section analyses.

\section{Weld Zone Ductility Effects}

The wing section impact analyses were used to investigate the effect of the exterior column weld toughness on the impact response. This weld existed between the four plates comprising the column cross sections. As described in Chapter 2, the ductility of the weld zones was developed based on experimental characterization of the steel behavior, as well as simulation of the weld fractures in column segments subjected to impact loads. In the analyses, the maximum average weld zone ductility for the various grades of steel in the exterior columns was set at 8 percent. The extension of the weld fractures at elevated strain rates and under the very high stress concentrations at the crack tip can result in a 
significantly reduced ductility from that required for crack initiation. Thcrefore, it was of interest to investigate the influence of a significantly reduced ductility of the weld zone on the impact response.

Two wing section impact analyses were performed to investigate the influence of the weld ductility on the impact response. In the first analysis, the baseline value of 8 percent for the weld ductility was used for the $55 \mathrm{ksi}$ steel columns. In the second analysis, a failure strain of 1 percent was used to investigate the effects of a more brittle crack extension. This low ductility would more accurately simulate the conditions of a brittle crack extension along the exterior column welds.

Damage to the exterior panels due to both the baseline and brittle weld behavior is shown in Figure 6-16. The damage was very similar with only subtle differences in the fragmentation of the failed columns. The calculated global energy balance and the absorption of energy by the exterior panels are shown in Figure 6-17. Of the approximately $8.9 \times 10^{6} \mathrm{lb} \cdot \mathrm{ft}$ of energy absorbed by the exterior wall, approximately 1 percent to 2 percent of that energy was absorbed in the weld zone. The impact response in the two analyses was nearly identical, indicating that weld ductility had a negligible effect on the impact behavior and damage to the tower.

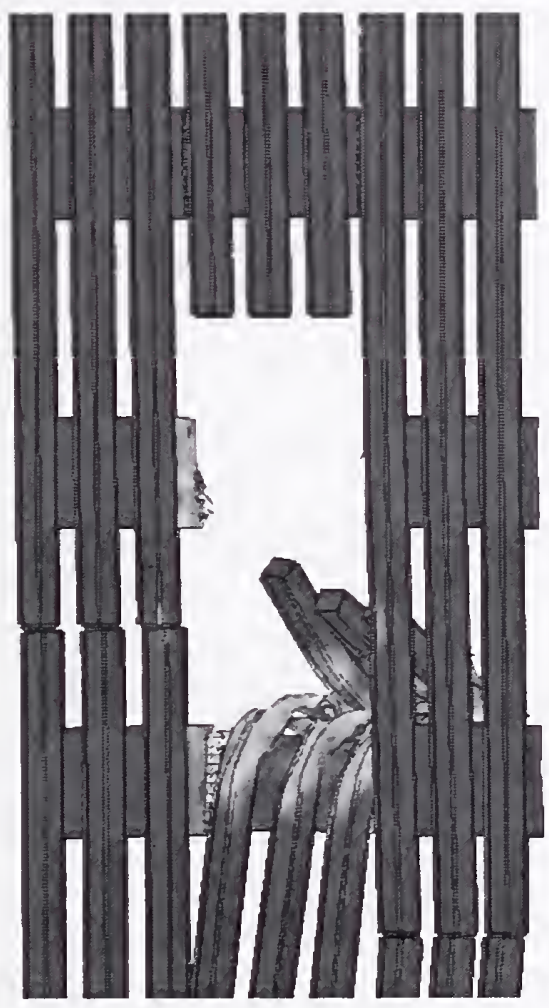

(a) Baseline response

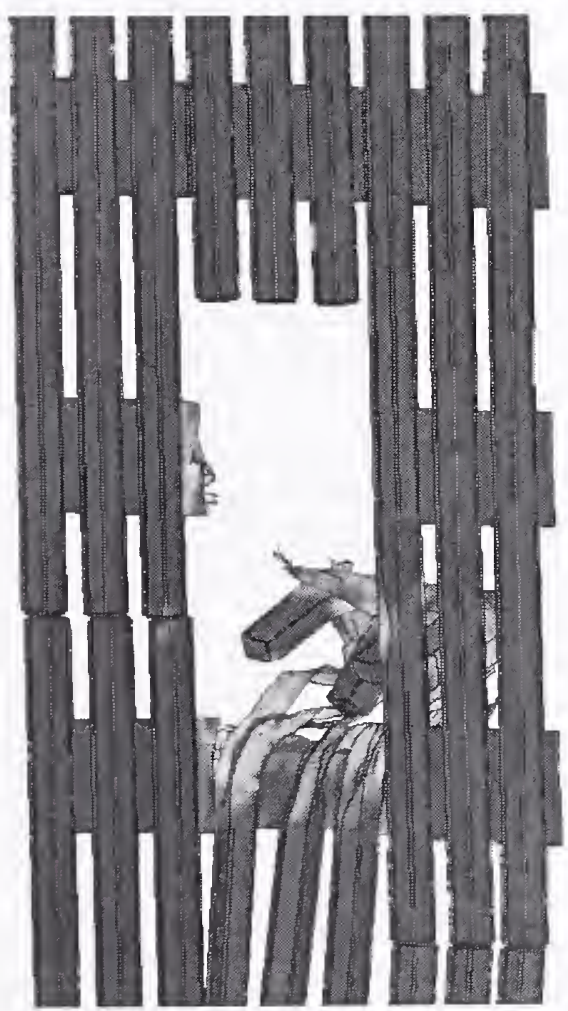

(b) Brittle weld response

Figure 6-16. Exterior wall damage for the wing section impact analyses. 


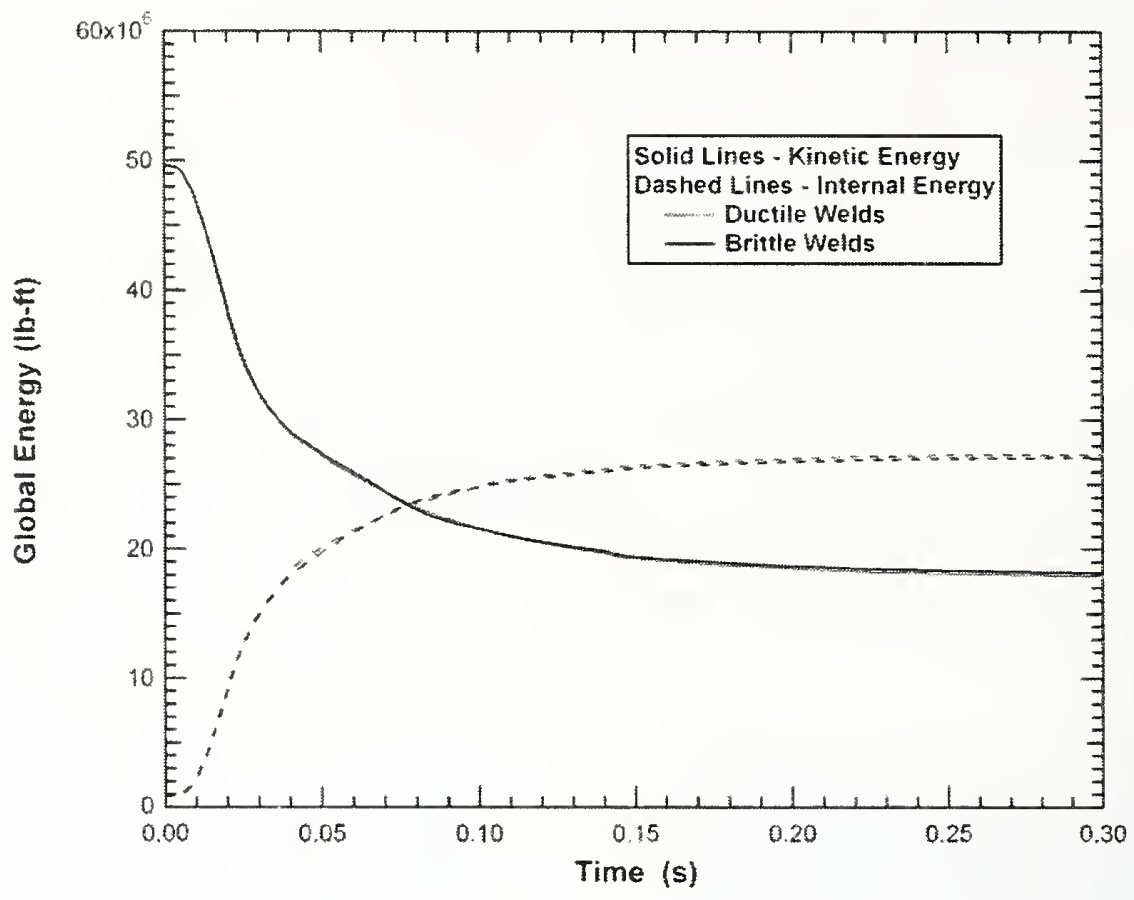

(a) Global energy balance

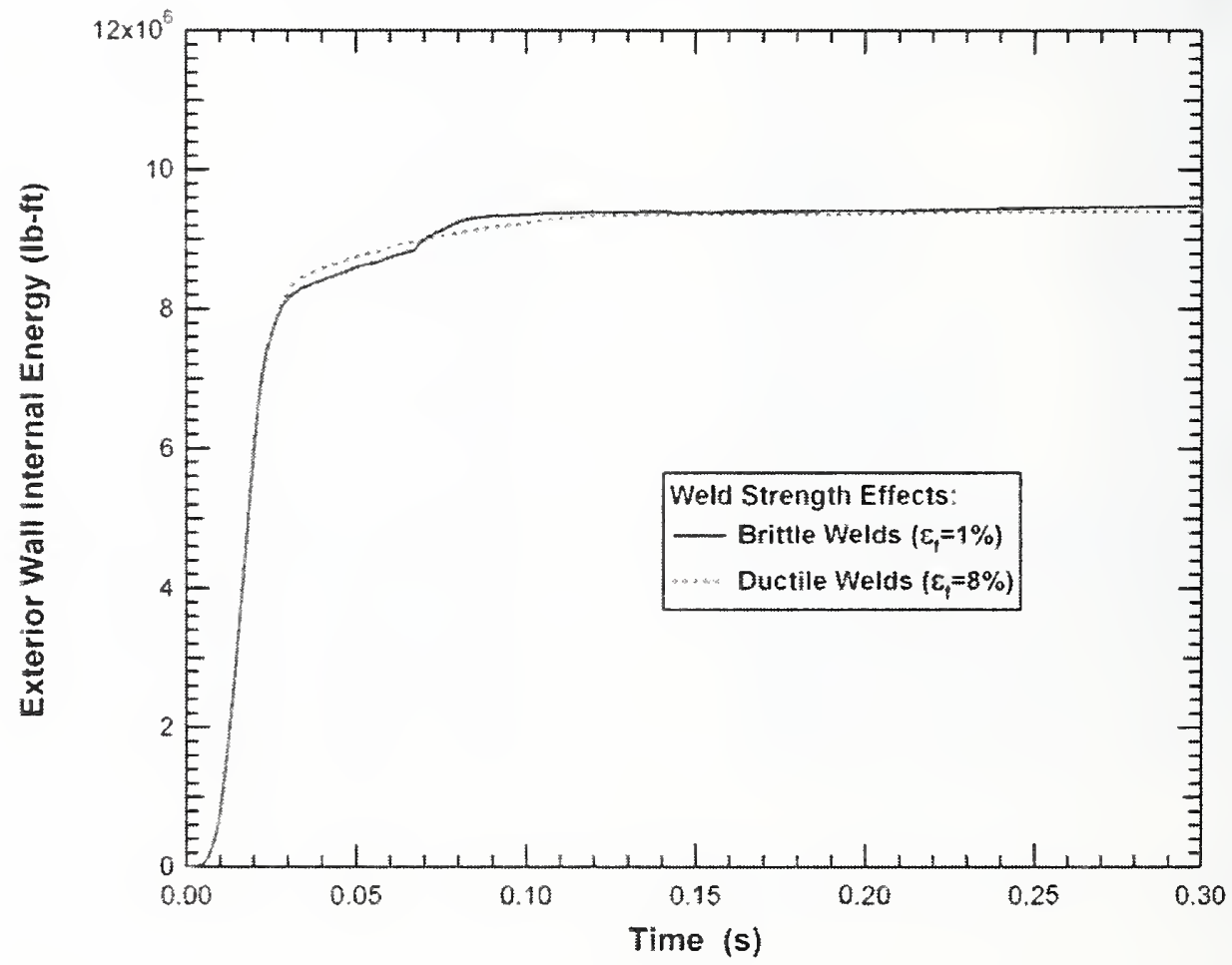

(b) External wall energy absorption

Figure 6-17. Effect of the weld strength on wing section impact response. 


\subsection{SUMMARY}

The subassembly analyses were used as a transition between the component levcl analyses and the global impact analyses. With the subassembly analyses, more complex structural behavior not captured in the component analyses could be investigated with significantly shorter run times than required for the global analyses. The subassembly analyses were primarily used to investigate different modeling techniques and associated model size, run times, numerical stability, and impact rcsponse. The final subassembly model used structural components from the impact zone on the north face of WTC 1. The structural components in the final subassembly model included the exterior panels, core framing, truss floor structures, and interior contents (workstations).

The subassembly model was impacted by an aircraft engine and by a segment of a fuel-filled wing. The subassembly model was used to investigate the effect of a number of modeling parameters on the response and damage estimates. For the engine impact simulations, these parameters included the strength of both the building nonstructural contents and the concrete slab. For the wing impact simulations, the effect of the ductility of the exterior column weldment on the impact response was investigated. The results of these parametric studies indicated the following:

- The deceleration profile of the impacting engine indicatcd that the response of the nonstructural building contents was dominated by the mass of the workstations, rather than by their strength.

- Varying the strength of the floor concrete slab from $4 \mathrm{ksi}$ to $3 \mathrm{ksi}$ did not result in significant change in the impact response. It appears that the mass of the concrete slab had a greater effect on the engine deceleration and damage to the floor than did the concrete strength.

- Varying the ductility of the weld zone in the exterior columns from 8 percent to 1 pcrcent did not result in any noticeable difference in the damage pattern or the encrgy absorbed by the exterior panels, indicating that the wcld ductility had a negligible effect on the impact response.

\subsection{REFERENCES}

"LS-DYNA User's Manual: Nonlinear Dynamic Analysis of Structures in Three Dimensions," Livermore Software Technology Corporation, Version 940, June 1, 1997. 
This page intentionally left blank. 


\section{Chapter 7 \\ ANALYSES OF AIRCRAFT IMPACT CONDITIONS}

\section{$7.1 \quad$ INTRODUCTION}

This chapter describes the estimation of the initial impact conditions of the aircraft which hit the World Trade Center (WTC) towers from available evidence. Important initial conditions for the impact analysis included impact speed. aircraft orientation and trajectory, and location of aircraft nose at impact. Two videos captured the approach and impact of the American Airlines flight 11 (AA 11) aircraft that impacted the WTC 1 tower, and several videos captured the United Airlines flight 175 (UAL 175) aircraft that impacted the WTC 2 tower. In addition, there is a large body of photographic evidence that was used to determine the impact location and orientation relative to the towers. These videos and photographs were analyzed to estimate, with the best accuracy possible, the velocity magnitude (speed), horizontal and vertical angles of incidence, and roll angle of each aircraft during impact with each tower.

The analysis of the initial aircraft impact conditions was performed in two steps. The first step was to perform an analysis of the video footage of the two impact events. This analysis compared the various videos and used visual references and known dimensions and positions of towers to determine the flight conditions prior to impact (Section 7.2). The second step was to use the photographic evidence of the impact damage to refine the details of the impact position, orientation, and trajectory (Section 7.3). The impact orientation and trajectory parameters are defined in Figure 7-1.

Two vectors are defined in Figure 7-1, one for the velocity vector of the aircraft (the trajectory) and one for the orientation of the aircraft. There is no reason to assume that these two vectors were coincident, although they could have been at the time of impact. Both vectors are described in terms of a vcrtical angle around structure east as shown in the figure, and a lateral angle, which is measurcd clockwise around the tower axis from structure north. The orientation is also described in terms of a wing-tip roll angle, as shown in the figure.

The resolution of the video footage was not sufficient to measure wing deflections or impact points more accurately than within $\pm 6 \mathrm{ft}$. In the two videos that captured the WTC 1 impact, there also was not enough resolution to obtain an accurate orientation of the aircraft. Consequently, the impact point and roll angle of AA 11 were determined using only the still frame photographs of the impact damage to the north side of WTC 1. Since UAL 175 impact was capturcd by several videos, the trajectory and orientation measurements could be made from the available vidco footage. The still frame photography of the damaged WTC 2 structure again was used as the primary source to determine the impact location. The following sections describe the analysis methodologics used to determine the motion parameters and impact conditions. 


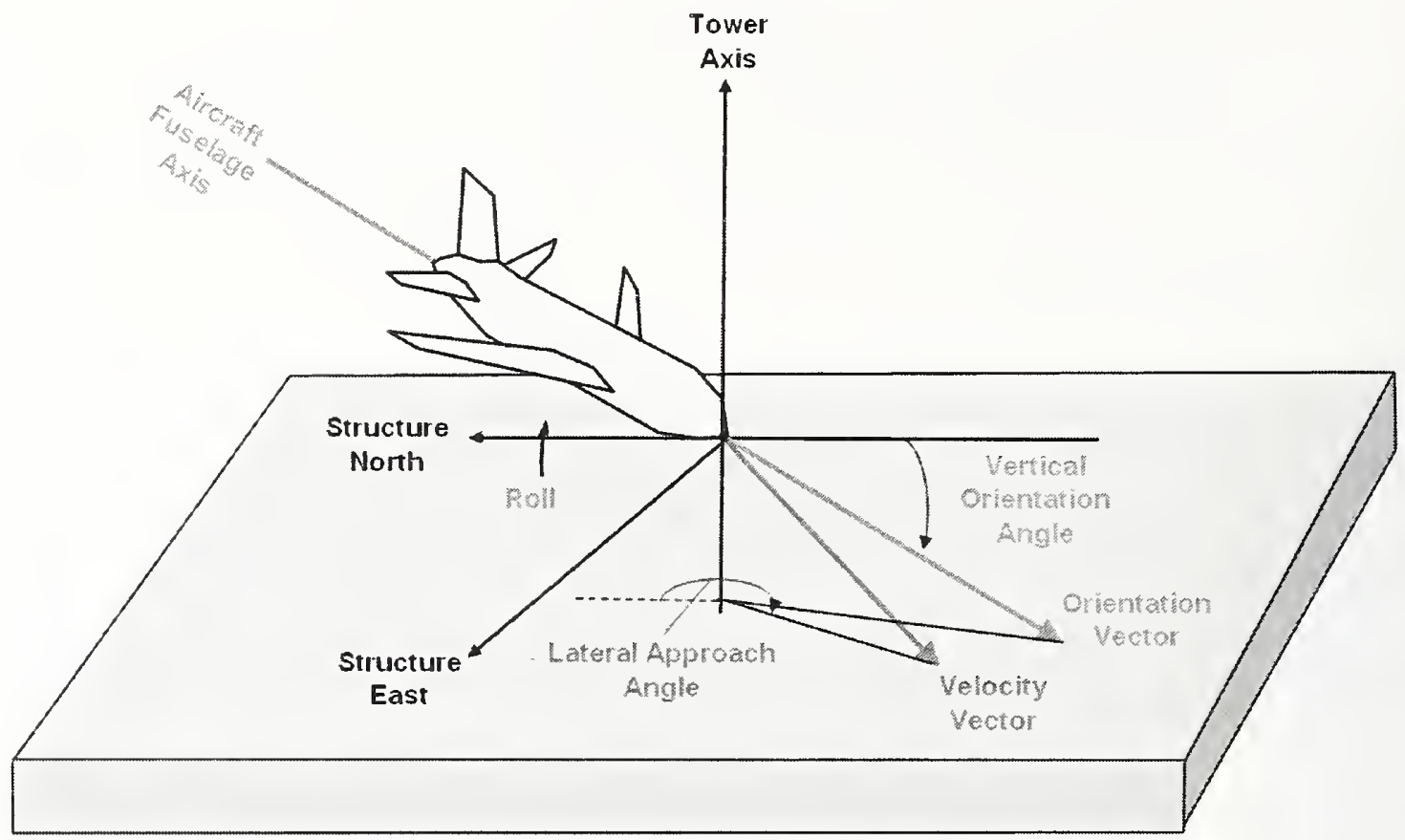

Figure 7-1. Definitions of the aircraft impact parameters.

\subsection{MOTION ANALYSIS METHODOLOGY}

\subsubsection{Videos Used in the Analysis}

The first task in the analysis of the aircraft impact conditions was the review and selection of appropriate video and photographic data. An extensive library of video and photographic evidence of the WTC tower impacts has been collected by the National Institute of Standards and Technology (NIST). The available videos in the NIST WTC collection were reviewed to select the best video footage of the aircraft's approach and impact with each tower. NIST had already digitized the footage, which was stored in files with AVI formats. The WTC 1 aircraft impact was captured in two videos, and both were used in the analysis. Several videos captured the aircraft impact into WTC 2 tower, and seven of them were used in the analysis. The image coordinates of the aircraft nose, tail, wing tips, aileron, and several locations on the towers were measured in each frame of the videos. Adobe Photoshop was used to determine the $\mathrm{X}$ and $\mathrm{Y}$ image coordinates. Table $7-1$ provides a summary of the videos used to analyze impact conditions. Still images from each of these video records are provided in Appendix A. 
Table 7-1. Videos used for the analysis of aircraft impact conditions.

\begin{tabular}{|c|c|c|l|}
\hline Digitized Video & $\begin{array}{c}\text { Original } \\
\text { Video Format }\end{array}$ & $\begin{array}{c}\text { Tower } \\
\text { Impact }\end{array}$ & \multicolumn{1}{|c|}{ Description } \\
\hline V1 & NTSC & WTC 1 & $\begin{array}{l}\text { Footage taken at ground level at the corner of Church and } \\
\text { Lispenard streets. Taken north and east of the towers. }\end{array}$ \\
\hline V2 & PAL & WTC 1 & $\begin{array}{l}\text { Footage taken from the entrance of the Brooklyn Battery } \\
\text { Tunnel, heading west. Taken south and east of the towers. }\end{array}$ \\
\hline V3 & NTSC & WTC 2 & Footage taken from a helicopter north and west of the towers. \\
\hline V4 & NTSC & WTC 2 & $\begin{array}{l}\text { Footage taken at ground level near the Castle Clinton National } \\
\text { Monument. Footage taken south and east of the towers. }\end{array}$ \\
\hline V5 & NTSC & WTC 2 & Footage taken from Brooklyn, south and east of the towers. \\
\hline V6 & NTSC & WTC 2 & $\begin{array}{l}\text { Footage taken from the 13th floor of John Street, east of the } \\
\text { towers. }\end{array}$ \\
\hline V7 & NTSC & WTC 2 & $\begin{array}{l}\text { Footage taken at ground level fron the corner of Church and } \\
\text { Liberty. Taken south and east of the towers. }\end{array}$ \\
\hline V8 & NTSC & WTC 2 & Footage taken from a helicopter north of the towers. \\
\hline V9 & NTSC & WTC 2 & $\begin{array}{l}\text { Footage taken from a moving vehicle on FDR drive, heading } \\
\text { west just before the Brooklyn Bridge. Footage taken north and } \\
\text { east of the towers. }\end{array}$ \\
\hline
\end{tabular}

The second column in Table 7-1 lists the original format of the various videos that were analyzcd. The National Television System Committee (NTSC) video format is the standard television format in the United States. The Phase Alternating Line (PAL) video format is common in Europe and parts of Asia. Any image data from the interlaced field of the videos were neglected. It was also assumed that the digitized NTSC videos had a rate of 29.97 images per second, while the PAL videos had a rate of 25 images per second. The digitized images had sizes of $720 \times 480$ pixels (NTSC) and $720 \times 576$ pixels (PAL). The original video footage was assumed to have an aspect ratio of $1.33 / 1$, so the $\mathrm{X}$-values of the measured image coordinates were adjusted to account for the actual aspect ratio. The image coordinates were also shifted relative to the locations of fixed points in the field of view (corners of a tower) to eliminate the effects of movement and shaking of the camera.

\subsubsection{Complex Motion Analysis Procedures}

A complex motion analysis was the method originally used in this study to calculate the spced, orientation, and trajectory vectors of the aircraft. However, subsequent analysis mcthodologies, as discussed in the following sections, provided more accurate estimates of speed and orientation. The quality and limited video footage available produced greater uncertainty using the complex motion analysis methodology. Therefore, this analysis was only used to definc the aircraft trajectory. The following is a discussion of the complex motion analysis and an assessment of its accuracy.

The methodology used in this analysis to determine the aircraft impact conditions was previously developed for other applications (Cilke 1995). Figure 7-2 depicts the analysis procedure. The image coordinates of the moving object (the aircraft) and two stationary positions on the structures within the field of view were triangulated with the known real-world positions of the structures and camera. The camera was assumed to be a pin hole type camera, i.e., all the light rays pass through a single focal point and project onto a flat surface that records the image. The result was the definition of the vector 
extending from the camera to the measured object. Note that the position of the object along the vector was unknown. The vector was then intersected with a surface defined by a set of vectors extending from a second camera to the measured object in multiple frames. The result was the real world position of the object at one instant in time. The global positions of other points on the object and positions of the object in multiple frames were then used to define the orientation and trajectory of the object. Note that in ideal test conditions, where the video cameras and reference positions are precisely surveyed and the camera field of view is designed, the uncertainties in the measured object velocities range from 1 percent to 1.5 percent.

\section{Step 1:}

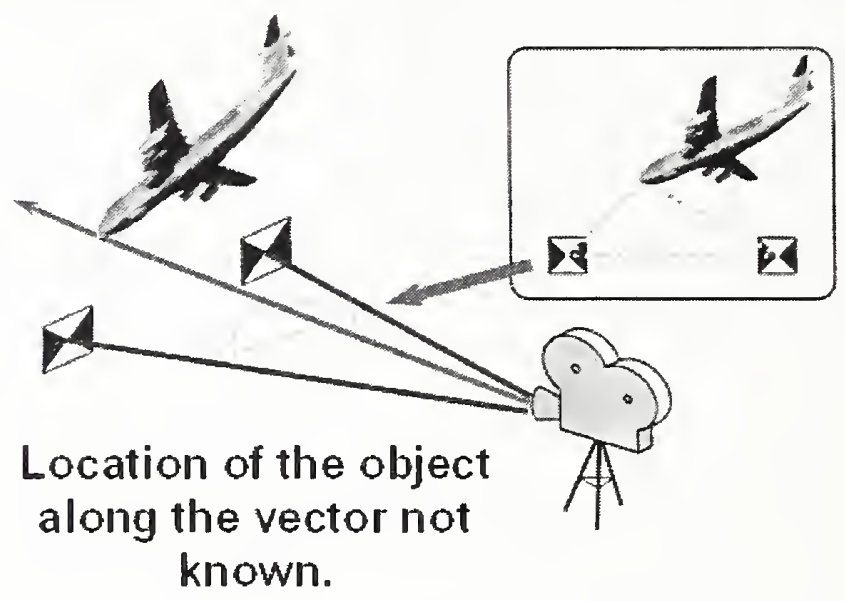

\section{Step 2:}

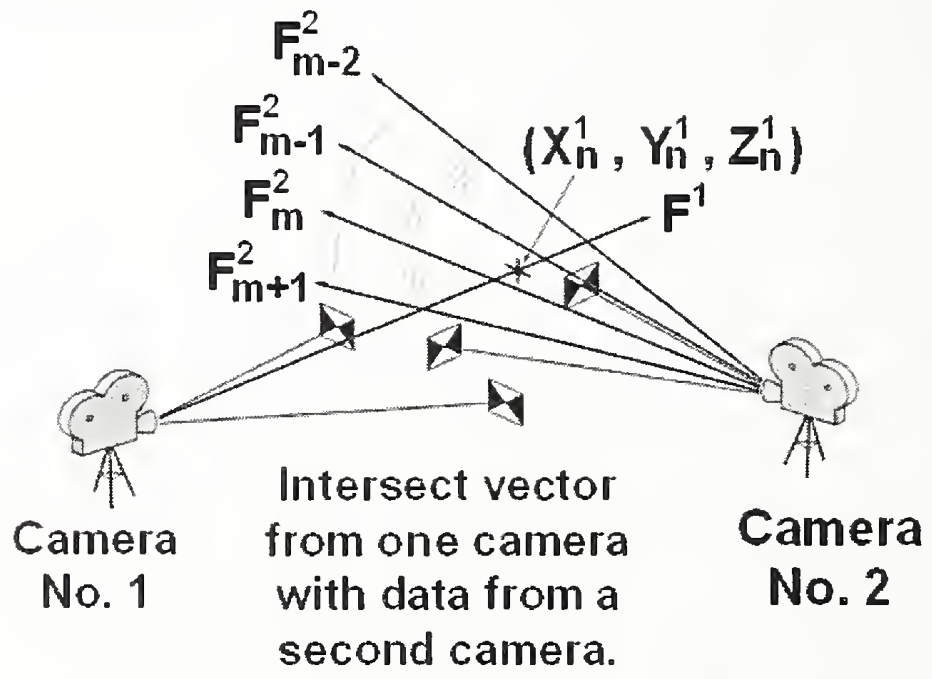

Figure 7-2. Procedures to measure object motions using multiple cameras. 
For the WTC aircraft motion analysis, various locations on the two towers were used as fixed reference locations. The four corners of the towers at three floor levels were used, as they could be easily identified in the video footage. Additional points on the WTC 1 antenna were also used as reference locations. Figure 7-3 shows the reference locations used on the towers. The tower reference positions were at the center of each beveled corner. Similarly, Figure 7-4 shows a plan view of the reference locations of the corners. Note that a local coordinate system is defined in the figure that is orthogonal to the sides of the structures. Structure north is approximately $29^{\circ}$ clockwise from True North. The coordinates of the reference locations were determined by using the original construction drawings of the towers. While the locations on the structure could be determined with high fidelity, the coordinates (X. Y, and $\mathrm{Z}$ ) of the cameras had to be estimated through an iterative process.

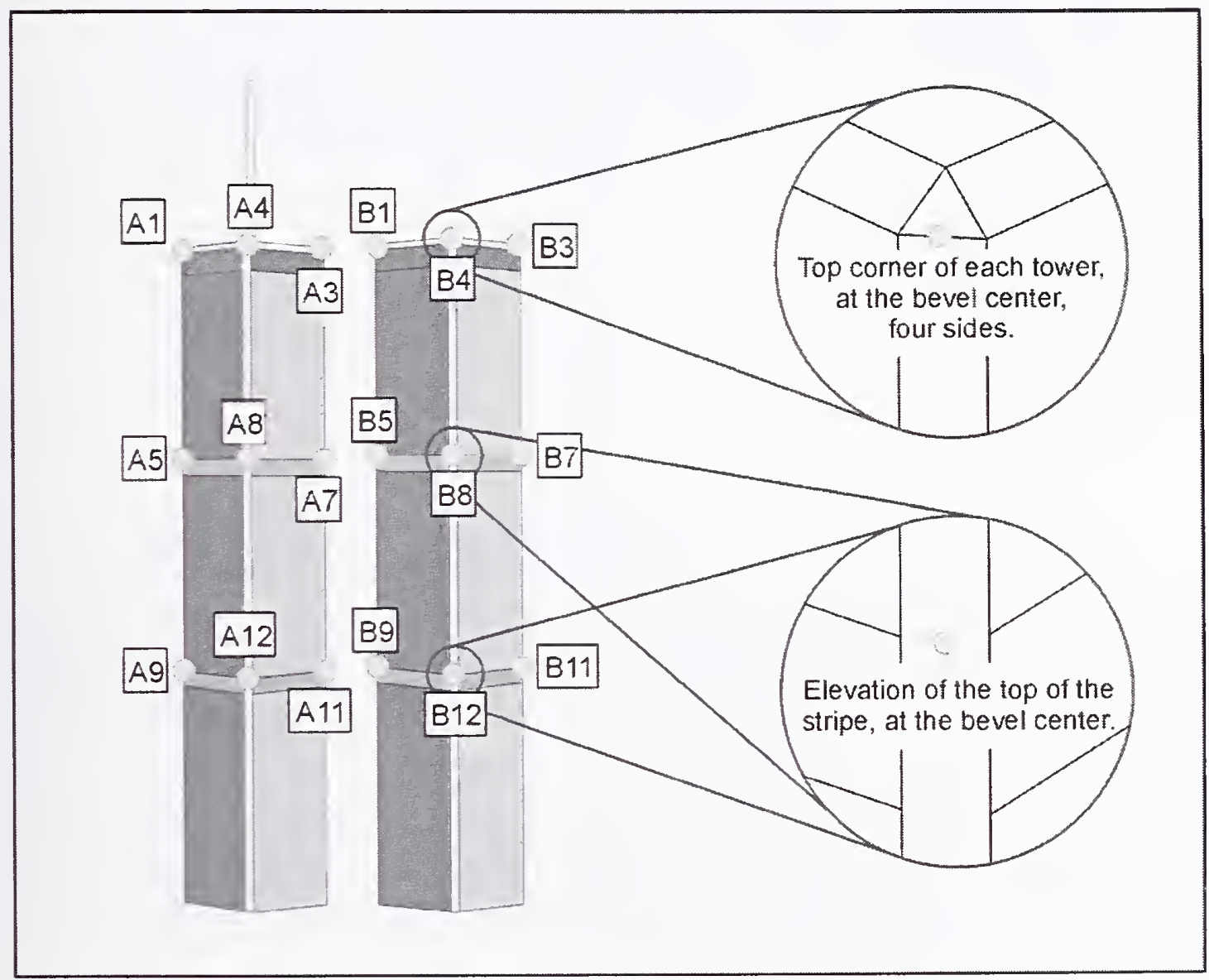

Figure 7-3. Reference locations on the WTC towers for video footage motion analysis. 


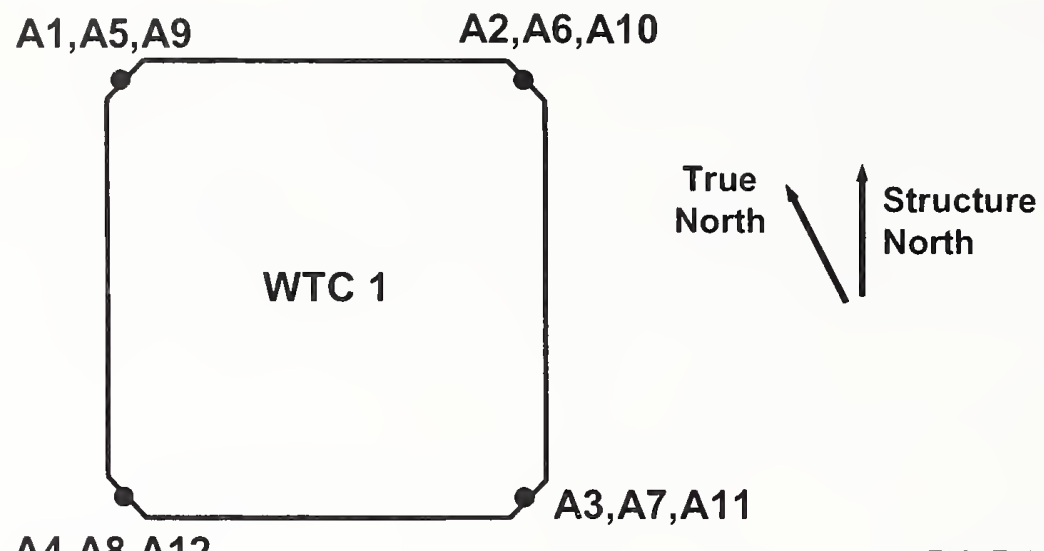

$\mathrm{A} 4, \mathrm{~A} 8, \mathrm{~A} 12$

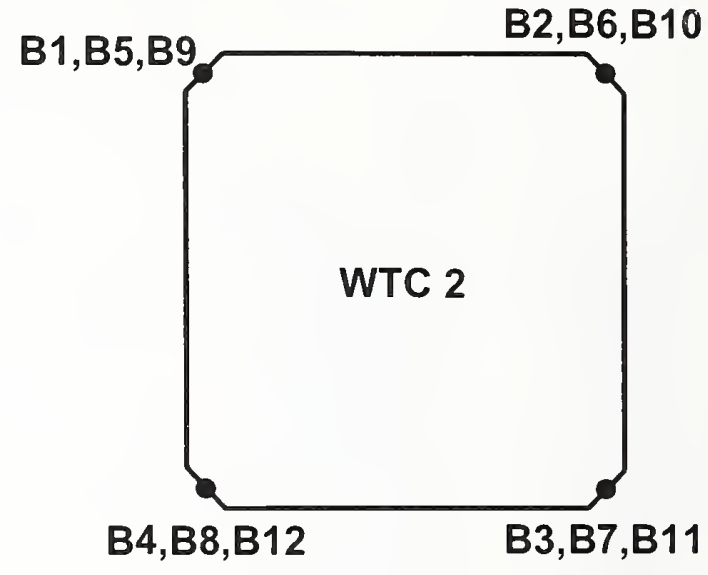

Figure 7-4. Plan view of the reference locations on the WTC towers.

With the camera locations estimated, motion analyses were performed using the complex motion analysis technique. For the WTC 1 aircraft impact, image data from the V1 video were correlated with the data from the V2 video. The analysis produccd a speed of $435 \pm 30 \mathrm{mph}$ for the WTC 1 aircraft at time of impact.

For the WTC 2 aircraft impact, data from each of the V1, V5, and V9 videos were correlated with the other two cameras to determine the motion of the aircraft prior to impact. The other cameras were less effective with this analysis technique. Videos V6 and V7 viewed the aircraft for only a few frames, which could not be intersected with many frames from the other cameras. Videos V3 and V8 were both taken from the north. The last second before the aircraft struck the WTC 2 tower was obscured by the towers. As a result, the cameras' data did not intersect with the other cameras' fields of view. Data from the two helicopters, V3 and V8, could not be effectively correlated with each other, as their viewpoints were too similar.

Image data from videos V4, V5, and V9 converged to a tight set of trajectory angles and aircraft orientations. These angles are provided later in Table 7-3. The uncertainties in the measured angles were derived from three components. First, there was a significant amount of scatter in the measured image coordinates. The perceived motion and orientation of the aircraft varied between frames, due to the relatively low resolution of the images and the motion of the camera fields of view. The scatter in the image data contributed to approximately $\pm 2^{\circ}$ to $\pm 4^{\circ}$ of the image uncertainty. The tips of the aircraft 
wings were more difficult to define accurately; the scatter in the wing measurements led to an estimated uncertainty of $\pm 4^{\circ}$ in the roll angle. Second, the uncertainties in the camera locations contributed to the uncertainties in measured angles. Since there was more uncertainty in the cameras' horizontal positions than the vertical positions, the measured horizontal azimuths had larger uncertainties $\left( \pm 2^{\circ}\right)$. Third, the potential distortion in the field of view distorted the measured angles. The uncertainty of the measured angles due to image distortion was estimated to be $\pm 1^{\circ}$.

The initial analyses using the complex motion methodology indicated the UAL 175 aircraft impact speed to be about $497 \mathrm{mph}$, which was heavily based on the V4 footage. However, subsequent analyses showed that the cameras did not provide an accurate aircraft impact speed. The cause of this inaccuracy was traced to three possible causes. First, the range of the camera could only be estimated. If the camera was close to the object motion, the range of the camera would have a significant effect on the perceived scale of the object in motion. Second, the scale of the image was determined from the dimensions of the towers in the field of view, which took up a relatively small portion of the field of view. As a result, the uncertainties in the measured image distances increased. Third, and most important, there were measurable distortions in the camera fields of view. For example, in the V5 footage, the camera pans from left to right. tracking UAL 175 as it approaches the south tower. The tower initially appears from the right edge of the image and moves to the center. The length of the aircraft (which remained in the center of the field-of view) appeared to decrease by 1.5 percent. However, the width of the south tower's east edge appeared to decrease by 7 percent, indicating a significant distortion in the field of view. As a result, a simplified motion analysis procedure was used to determine the speed of the WTC 2 aircraft (Section 7.2.3). The complex motion analysis was used only to define the aircraft orientation and trajectory vectors.

\subsubsection{Simplified Motion Analysis Procedures}

The simplified motion analysis procedure determined the impact speed by scaling the displacement of the aircraft within the field of view with the aircraft's apparent fuselage length. Figure 7-5 depicts the simplified procedure to determine the aircraft speed. For several videos of the WTC towcr impacts, linear regressions were performed for the image $\mathrm{X}$ and $\mathrm{Y}$ coordinates as functions of time. The displacements of the nose, tail, and wing tips were measured. The apparent length of the fuselage within each image was determined from the nose and tail regression lines, and the apparent displacement of the aircraft between images was normalized to the apparent length of the fuselage. Multiplying the result by the length of the aircraft determined the aircraft speed (there are constant time steps between frames). Finally, a geometric correction was made if the fuselage orientation and trajectory were not aligned.

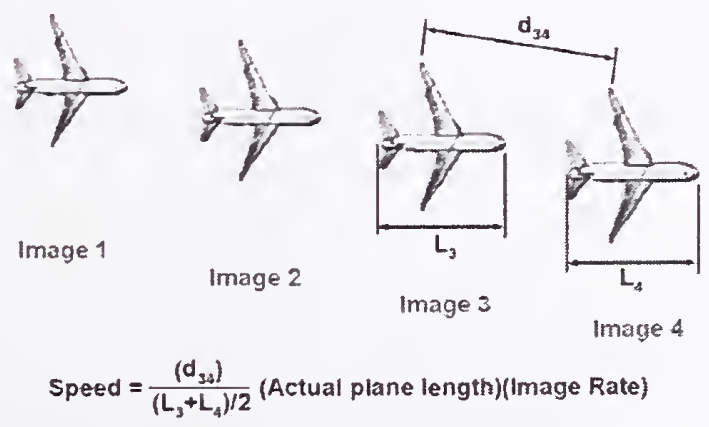

Figure 7-5. Simplified motion analysis procedure to determine aircraft speed. 
The fuselage length of the Boeing 767-200ER aircraft is $155 \mathrm{ft}$ as shown in Figure 7-6. However, for the simplified motion analysis the fuselage was assumed to have an apparent length of $153 \pm 2 \mathrm{ft}$. The adjustment in apparent fuselage length was a result of the relatively low resolution of the video footage. As a sharp object enters a region captured by a single pixel, the background dominates the pixel color value until the object has entered by a significant fraction. The low resolution could not accurately capture the shape of the aircraft nose and tail, and the aircraft nose in the videos appeared to be blunter than the actual Boeing 767-200ER nose. The average length of the fuselage in the videos analyzed was approximately 75 pixels (but varied depending on the footage). It was assumed that the resolution effect resulted in an apparent loss of approximately a half pixel at each end of the fuselage ( $1 \mathrm{ft}$ at each end of the fuselage). As a result, the apparent length of the fuselage in the video footage was approximately $2 \mathrm{ft}$ less than the specified length.
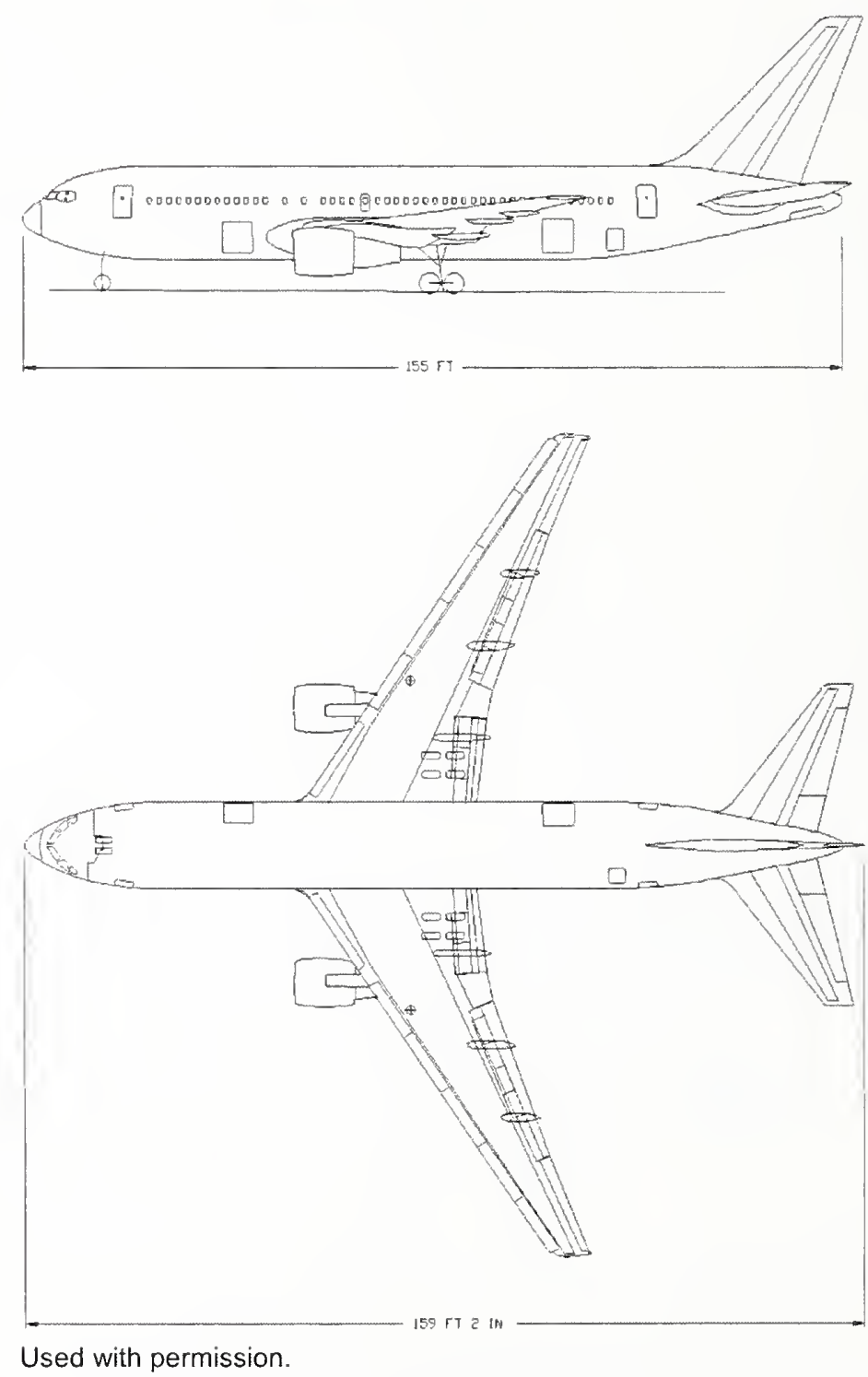

Figure 7-6. Dimensions of the Boeing 767-200 aircraft and fuselage. 
The simplified motion analysis technique was used for the analysis of aircraft speed for both tower impacts. For the WTC 1 impact, only the V1 video could be used to determine the aircraft speed with this technique. The second video, V2, could not be used to obtain an accurate measure of speed as the aircraft was traveling away from the camera. The simplified analysis produced a speed of $451 \mathrm{mph} \pm 30 \mathrm{mph}$, which is $16 \mathrm{mph}$ higher than the value obtained from the complex motion analysis technique. Both of these values for the WTC 1 impact speed fall within the uncertainties in the corresponding analyses. As a result, the WTC 1 aircraft impact speed provided in Table 7-3 is the average of the two speeds obtained using the complex and simplified motion analysis techniques.

The videos with a viewing angle approximately perpendicular to the UAL 175 flight direction were used to estimate impact speed. The results of the simplified motion analyses from each camera for UAL 175 are provided in Table 7-2. The uncertainties in Table 7-2 were based on the scatter in the measured displacements. the aircraft length within the image, and uncertainty in the actual aircraft length as seen in the images due to unknown orientation. A systematic error in calculating the aircraft speed was introduced due to the lateral fuselage orientation relative to trajectory. The uncertainty in this value was due to the aircraft maneuvers during approach. In calculating the uncertainty in speed, an uncertainty of \pm 3 degrees in orientation was assumed.

Table 7-2. Measured UAL 175 impact speed using the simplified analysis technique.

\begin{tabular}{|c|c|}
\hline Video Reference & Calculated Aircraft Speed \\
\hline V4 & $573 \mathrm{mph} \pm 55 \mathrm{mph}$ \\
\hline V5 & $556 \mathrm{mph} \pm 27 \mathrm{mph}$ \\
\hline V6 & $535 \mathrm{mph} \pm 23 \mathrm{mph}$ \\
\hline V7 & $523 \mathrm{mph} \pm 31 \mathrm{mph}$ \\
\hline V9 & $557 \mathrm{mph} \pm 53 \mathrm{mph}$ \\
\hline Best Estimate Speed & $542 \mathrm{mph} \pm 24 \mathrm{mph}$ \\
\hline
\end{tabular}

A speed estimate was then calculated from the individual videos. A mean value was calculated using the weighted average of the mean values. The measurement precision (the reciprocal of the variance) was used as a weight factor on the mean values. If measurements were independent, the uncertainty in the mean could be calculated by summing the individual measurement precisions. giving $443 \mathrm{mph} \pm 21 \mathrm{mph}$ for AAl 1 and $542 \mathrm{mph} \pm 14 \mathrm{mph}$ for UAL 175. However, some uncertainties were systematic, and the actual bound on the uncertainty was larger as a result. Therefore, this uncertainty range was increased to $\pm 30 \mathrm{mph}$ and $\pm 24 \mathrm{mph}$ for AA 11 and UAL 175, respectively. A summary of the impact conditions derived from video analysis is shown in Table 7-3.

The simplified motion analysis technique was used for the analysis of aircraft speed for both tower impacts. For the WTC 1 impact, only the V1 video could be used to determine the aircraft speed with this technique. The second video, V2, could not be used to obtain an accurate measure of speed as the aircraft was traveling away from the camera. The simplified analysis produced a speed of $451 \mathrm{mph} \pm 30 \mathrm{mph}$, which is $16 \mathrm{mph}$ higher than the value obtained from the complex motion analysis technique. Both of these values for the WTC 1 impact speed fall within the uncertainties in the corresponding analyses. As a result, the WTC 1 aircraft impact speed provided in Table 7-3 is the average of the two speeds obtained using the complex and simplified motion analysis techniques. 
Table 7-3. Summary of measured aircraft impact conditions from video analysis.

\begin{tabular}{|c|c|c|}
\hline & AA 11 (WTC 1) & UAL 175 (WTC 2) \\
\hline Impact Speed (mph) & $443 \pm 30$ & $542 \pm 24$ \\
\hline $\begin{array}{l}\text { Vertical Approach Angle } \\
\text { (Velocity vector) }\end{array}$ & $\begin{array}{c}10.6^{\circ} \pm 3^{\circ} \text { below horizontal } \\
\text { (heading downward) }\end{array}$ & $\begin{array}{c}8^{\circ} \pm 4^{\circ} \text { below horizontal } \\
\text { (heading downward) }\end{array}$ \\
\hline $\begin{array}{l}\text { Lateral Approach Angle } \\
\text { (Velocity vector) }\end{array}$ & $\begin{array}{c}180.3^{\circ} \pm 4^{\circ} \text { clockwise from } \\
\text { Structure North }\end{array}$ & $\begin{array}{c}19^{\circ} \pm 6^{\circ} \text { clockwise from } \\
\text { Structure North }\end{array}$ \\
\hline $\begin{array}{l}\text { Vertical Fuselage Orientation } \\
\text { from horizontal }\end{array}$ & - & $\begin{array}{c}3^{\circ} \pm 4^{\circ} \text { below horizontal } \\
\text { (heading downward) }\end{array}$ \\
\hline $\begin{array}{l}\text { Lateral Fuselage Orientation } \\
\text { from Structure North }\end{array}$ & - & $\begin{array}{c}8^{\circ} \pm 6^{\circ} \text { clockwise from } \\
\text { Structure North }\end{array}$ \\
\hline Roll Angle (left wing downward) & $25^{\circ} \pm 4^{\circ}$ & $38^{\circ} \pm 4^{\circ}$ \\
\hline
\end{tabular}

a. Structure North is approximately 29 degrees clockwise from True North.

The videos with a viewing angle approximatcly perpendicular to the UAL 175 flight direction were used to estimate impact speed. The results of the simplified motion analyses from each camera for UAL 175 are provided in Table 7-2. The uncertainties in Table 7-2 were based on the scatter in the measured displacements, the aircraft length within the image, and uncertainty in the actual aircraft length as seen in the images due to unknown orientation. A systematic error in calculating the aircraft speed was introduced due to the lateral fuselage orientation relative to trajectory. The uncertainty in this value was due to the aircraft maneuvers during approach. In calculating the uncertainty in speed, an uncertainty of \pm 3 degrees in orientation was assumed.

A speed estimate was then calculated from the individual videos. A mean value was calculated using the weighted average of the mean values. The measurement precision (the reciprocal of the variance) was used as a weight factor on the mean values. If measurements were independent, the uncertainty in the mean could be calculated by summing the individual measurement precisions, giving $443 \mathrm{mph} \pm 21 \mathrm{mph}$ for AA1 1 and $542 \mathrm{mph} \pm 14 \mathrm{mph}$ for UAL 175. However, some uncertainties were systematic, and the actual bound on the uncertainty was larger as a result. Therefore, this uncertainty range was increased to $\pm 30 \mathrm{mph}$ and $\pm 24 \mathrm{mph}$ for AA 11 and UAL 175, respectively. A summary of the impact conditions derived from video analysis is shown in Table 7-3.

Original results from the simplified motion analysis produced a mean speed for UAL 175 of $546 \mathrm{mph}$. Therefore, this speed was used in running the global impact analysis, discussed in Chapter 9. Subsequent refinement of the analysis and associated uncertainties produced the slightly lower mean value of $542 \mathrm{mph}$ as discussed above. Because this difference in speed is less than 1 percent and well within the uncertainty range, the speed used for the baseline impact analysis was not modified.

\subsection{REFINEMENT OF AIRCRAFT IMPACT CONDITIONS}

Estimates for the aircraft impact locations, orientations, and trajectories were further refined based on the damage patterns documented on the exterior of the WTC towers. The general approach was to visualize the aircraft within the range of flight conditions estimated from the video analysis (Section 7.2) and project the impact points of the wings, fuselage, engines, and vertical stabilizer onto the exterior wall of 
each tower. A damage pattern was then estimated and compared to that obtained previously from analysis of the video and photographic evidence.

The estimated damage to the north face of WTC 1 is shown in Figure 7-7 along with approximate impact locations for various aircraft components of AA 11. Estimated impact locations for various aircraft components (wind tips, vertical stabilizer tip, and engines) were added to the figure to fit the damage profile. For AA 11, it was found that the fuselage orientation needed to be 2 degrees above the vertical approach angle ( 2 degrees nose-up). The difference in the lateral approach angle and the fuselage orientation from structure north is 0 degrees.

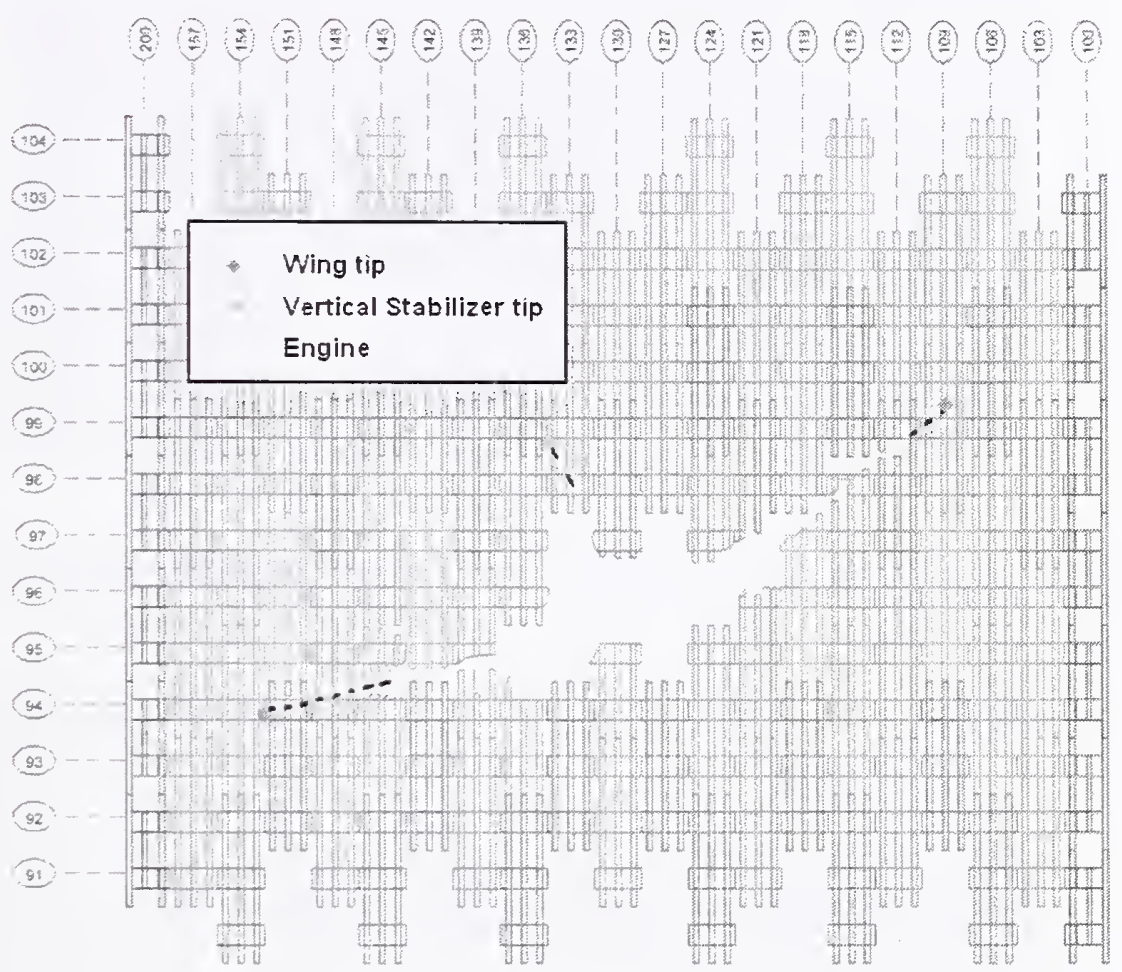

Figure 7-7. Estimated impact locations of aircraft components superimposed on the damaged face of WTC 1.

An example impact condition is shown in Figure 7-8 where the vertical approach angle was 10.6 degrees (fuselage orientation from horizontal $=8.6$ degrees) and the lateral approach angle was 180 degrees (fuselage orientation from structure north $=180$ degrees). The position of the vertical stabilizer tip was the most critical factor in determining this relationship. The impact points of the wing tips were known to within approximately $\pm 2 \mathrm{ft}$. This corresponded to an uncertainty in the roll angle of approximately \pm 2 degrees. Since no accurate orientation information could be derived from the video analysis, analysis of the damage pattern was critical in determining the aircraft orientation at the time of impact. 


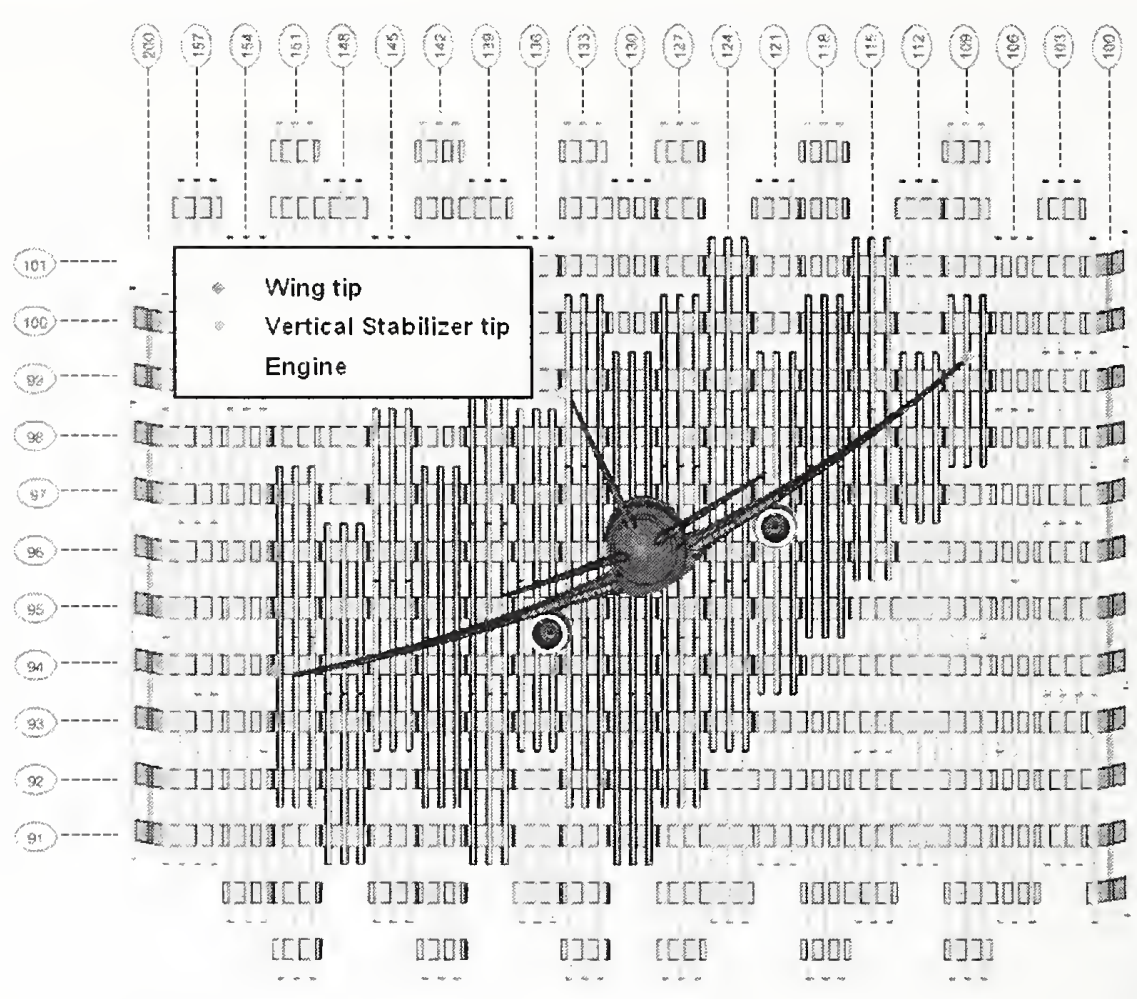

Figure 7-8. An orientation and trajectory of AA 11 that matches the impact pattern (vertical approach angle $=10.6^{\circ}$, lateral approach angle $=0^{\circ}$ ).

The estimated damage to the face of WTC 2 is shown in Figure 7-9, along with approximate impact locations for various aircraft components of UAL 175. From these impact locations, the combinations of flight conditions that were consistent with the observed impact damage could be determined.

Figure 7-10 shows the south face of WTC 2 with the aircraft model positioned in the impact orientation and location estimated from the video analysis, as summarized in Table 7-3. The viewpoint of the figure is along the trajectory axis so that the projection of each aircraft component onto the tower face represents its approximate impact location, assuming no significant structural deformation prior to impact of an aircraft component with the building exterior. During the impact simulation, little structural deformation was observed in parts of the aircraft that had not yet impacted the towers. The vertical stabilizer, the last part of the aircraft to enter the building and which has the longest time to experience structural deformation, impacted close to this projected impact location.

The impact conditions shown in Figure 7-10, which were based on video analysis alone, would cause the starboard wing tip to miss the building and are, therefore, not physically reasonable. Also shown in the figure are the estimated impact locations for the wing tips, vertical stabilizer, and engines. These also did not align well with the observed impact damage. Translation of the aircraft alone does not account for the discrepancy in the impact point shown in the figure. Both a translation of $3.3 \mathrm{ft}$ higher and $9.8 \mathrm{ft}$ further west was needed, along with a specific relationship between the trajectory and orientation, in order for the impact pattern to match. The final impact points, defined as the location where the nose of each aircraft initially contacted the towers, are provided in Table 7-5. 


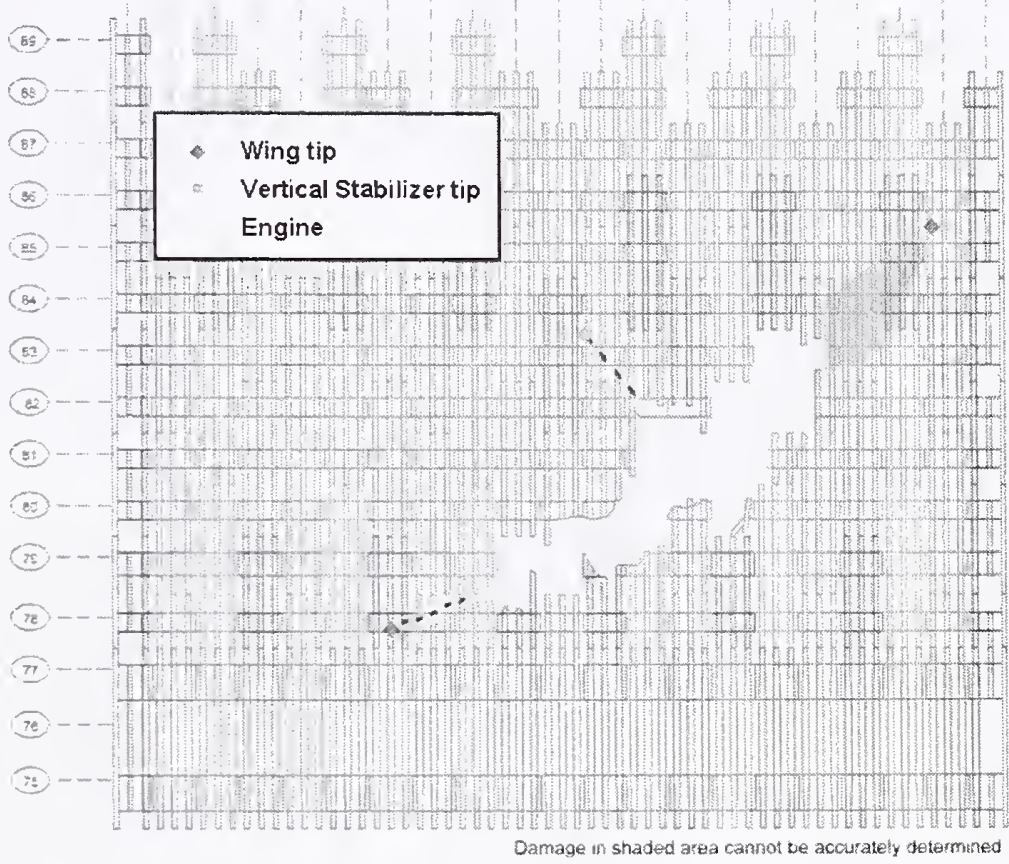

Figure 7-9. Estimated impact locations of aircraft components superimposed on the damaged face of WTC 2.

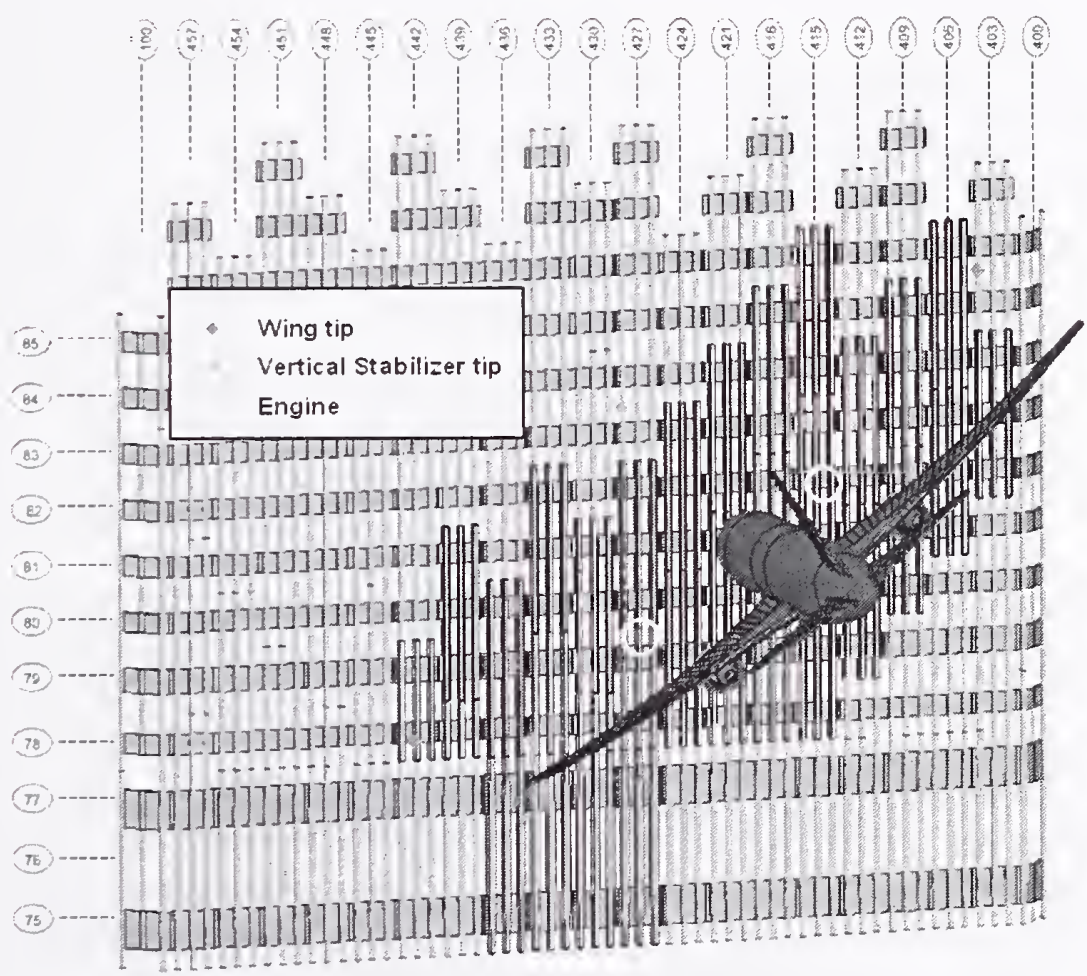

Figure 7-10. Baseline orientation and trajectory of UAL 175 from video analysis. 
It was found that a strict relationship between the aircraft trajectory and orientation nceded to be maintained in order to achieve an impact pattern consistent with the damage observed on the south wall of WTC 2. The fuselage orientation needed to be $1^{\circ}$ above the vertical approach angle (i.e., 1 degrec noseup). The differcnce in the lateral approach angle and the fuselage orientation from structure north was 3 degrees as listed in Table 7-4. An example impact condition for UAL 175 is shown in Figure 7-11, where the vertical approach angle was 6 degrees (fuselage orientation from horizontal $=5$ degrees) and the lateral approach angle was 13 degrees (fusclage orientation from structure north $=10$ degrees). Larger or smaller angles resulted in projected impact points with the engines spaced too far horizontally or vertically or with the tip of the vertical stabilizer in the wrong location. Also, note that the impact point of the nosc had becn moved from original estimates, as previously discussed, and that the roll angle was maintained. A second example of an acceptable impact condition, this time with a lateral approach angle of 17 degrees, is shown in Figure 7-12.

Table 7-4. Summary of refined aircraft impact conditions.

\begin{tabular}{|c|c|c|}
\hline & AA $11(W T C 1)$ & UAL 175 (WTC 2) \\
\hline lmpact Speed (mph) & $443 \pm 30$ & $542 \pm 24$ \\
\hline $\begin{array}{l}\text { Vertical Approach Angle } \\
\text { (Velocity vector) }\end{array}$ & $\begin{array}{c}10.6^{\circ} \pm 3^{\circ} \text { below horizontal } \\
\text { (heading downward) }\end{array}$ & $\begin{array}{c}6^{\circ} \pm 2^{\circ} \text { below horizontal } \\
\text { (heading downward) }\end{array}$ \\
\hline $\begin{array}{l}\text { Lateral Approach Angle } \\
\text { (Velocity vector) }\end{array}$ & $\begin{array}{c}180.3^{\circ} \pm 4^{\circ} \text { clockwise from } \\
\text { Structure North }\end{array}$ & $\begin{array}{l}15^{\circ} \pm 2^{\circ} \text { clockwise from } \\
\text { Structure North }^{\mathrm{a}}\end{array}$ \\
\hline $\begin{array}{l}\text { Vertical Fuselage Orientation } \\
\text { Relative to Trajectory }\end{array}$ & $\begin{array}{c}2^{\circ} \text { nose-up from the vertical } \\
\text { approach angle }\end{array}$ & $\begin{array}{l}1^{\circ} \text { nose-up from the vertical } \\
\text { approach angle }\end{array}$ \\
\hline $\begin{array}{l}\text { Lateral Fuselage Orientation } \\
\text { Relative to Trajectory }\end{array}$ & $\begin{array}{c}0^{\circ} \text { clockwise from lateral } \\
\text { approach angle }\end{array}$ & $\begin{array}{c}-3^{\circ} \text { clockwise from lateral } \\
\text { approach angle }\end{array}$ \\
\hline Roll Angle (left wing downward) & $25^{\circ} \pm 2^{\circ}$ & $38^{\circ} \pm 2^{\circ}$ \\
\hline
\end{tabular}

a. Structure North is approximately 29 degrees clockwise from True North.

Table 7-5. Aircraft impact locations on the WTC towers.

\begin{tabular}{|l|c|c|}
\hline & $\begin{array}{c}\text { Horizontal } \\
\text { Location }\end{array}$ & $\begin{array}{c}\text { Vertical } \\
\text { Location }\end{array}$ \\
\hline AA 11 (WTC 1) & $\begin{array}{c}2.0 \pm 3 \mathrm{ft} \text { west of } \\
\text { centerline }\end{array}$ & $\begin{array}{c}1.6 . \pm 4 \mathrm{ft} \text { above } \\
96^{\text {th }} \mathrm{floor}\end{array}$ \\
\hline UAL 175(WTC 2) & $\begin{array}{c}23.1 \pm 3 \mathrm{ft} \text { east of } \\
\text { centerline }\end{array}$ & $\begin{array}{c}0.6 . \pm 4 \mathrm{ft} \text { above } \\
81 \mathrm{st} f l o o r\end{array}$ \\
\hline
\end{tabular}

The relationship between aircraft trajectory and orientation was then used to reduce the uncertainty of these parameters. The uncertainty in the vertical approach angle from the video analysis varied from 4 degrees to 12 degrees, as shown in Table 7-3, and the fuselage orientation from horizontal from 1 degree to 7 degrees. As a 1 degree difference needed to bc maintained in order for the impact pattern to match the observed damage, uncertainty in the vertical approach angle was reduced to 6 degrees \pm 2 degrees and the fuselage oricntation from horizontal to 4 degrees \pm 1 degree. Uncertainty in the lateral approach angle and the fuselage orientation from structure north was similarly reduced, as shown in Table 7-4. The impact points of the wing tips were known to within approximately $\pm 2 \mathrm{ft}$. This corresponded to an uncertainty in the roll angle of approximately \pm 2 degrees. 


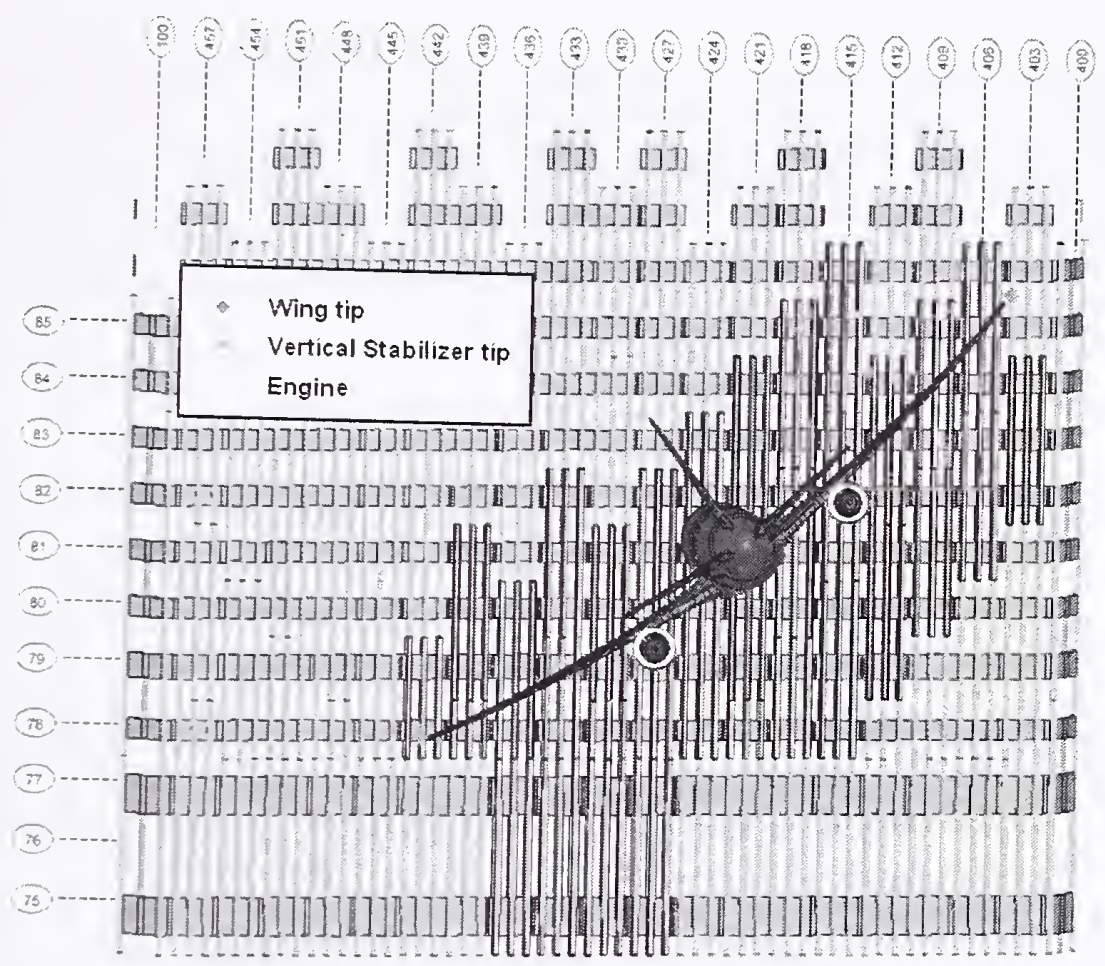

Figure 7-11. An orientation and trajectory of UAL 175 that matches the impact pattern (vertical approach angle $=6^{\circ}$, lateral approach angle $=13^{\circ}$ ).

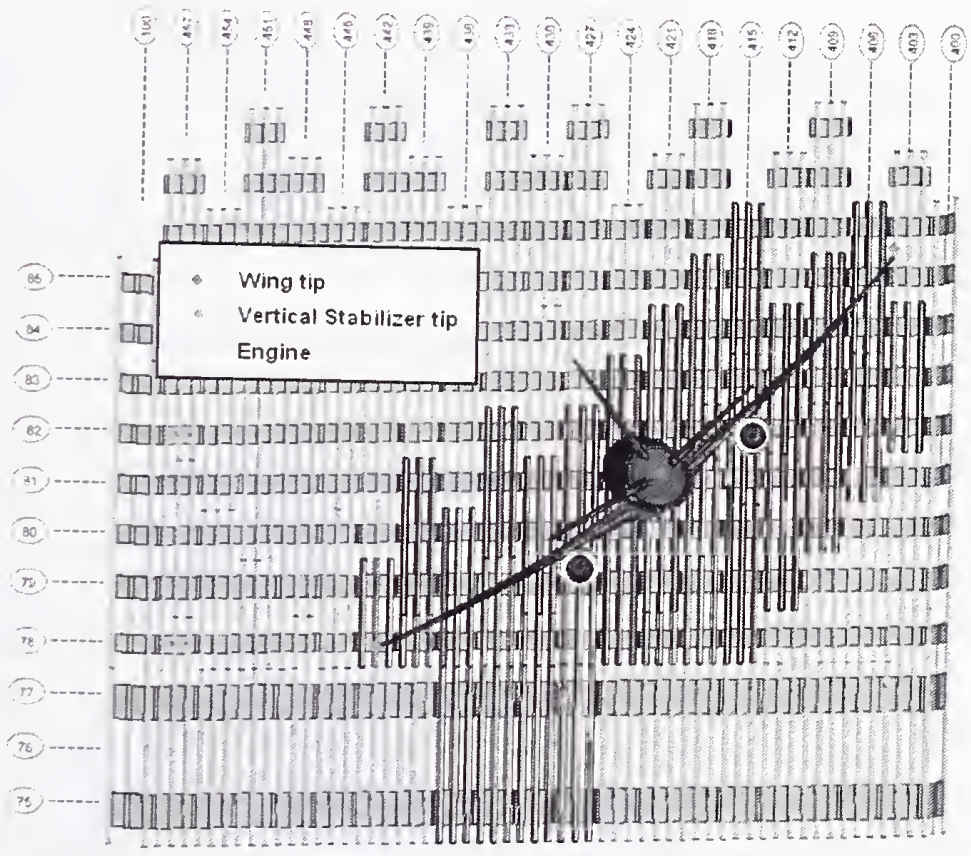

Figure 7-12. An orientation and trajectory of UAL 175 that matches the impact pattern (vertical approach angle $=6^{\circ}$, lateral approach angle $=17^{\circ}$ ). 
Although the lateral approach angle of UAL 175 had a nominal value of 15 degrees, additional observable information was used to define a most probable flight condition. Figure 7-13 shows the top view of WTC 2 with the engines and landing gear in their pre-impact location. Also shown is the projected trajectory of the starboard engine of UAL 175 with an initial lateral approach trajectory of $13^{\circ}$ instead of $15^{\circ}$, assuming the engine was not significantly deflected as it passed through the building. With this lateral trajectory, the starboard engine would exit the tower at the northeast corner, consistent with the observables from video and photographic evidence

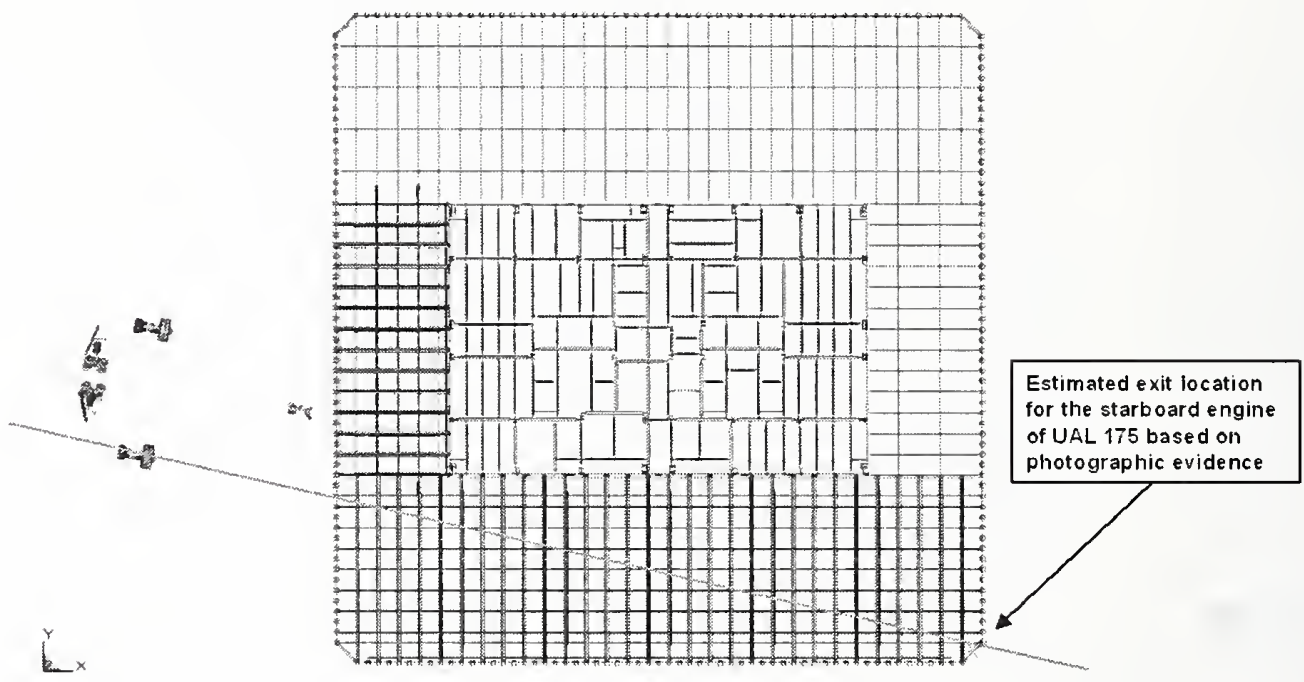

Figure 7-13. Projected trajectory of the starboard engine of UAL 175 with an initial lateral approach angle of $13^{\circ}$.

It is possible that the tower structure and/or contents deflected the engine from its initial lateral trajectory. The global simulations described in Chapter 9 used a standard configuration for building contents similar to WTC 1. This configuration did not cause substantial deviation in the trajectory of the starboard engine. This lateral trajectory was, therefore, the most likely and was adopted for the global analyses.

\subsection{COMPARISON WITH ALTERNATE AIRCRAFT IMPACT CONDITIONS}

Alternate analyses and values of the aircraft impact initial conditions have been performed and reported by other studies. The objective of this analysis was to provide an independent assessment using the full database of video and photographic evidence collected and maintained by NIST. Many of these data sources may not have been available in the previous analyses. In this section, a comparison is presented between the aircraft impact conditions estimated in this study and those reported earlier. This comparison provides an opportunity to review the methodologies applied, as well as assists in the determination of the uncertainties in the impact conditions. The comparison includes estimates or analyses performed by the Federal Emergency management Agency (FEMA), Hart-Weidlinger, and Massachusetts Institute of Technology (MIT) and the analyses presented in this chapter (NIST). The analysis methodologies or data sources used for the FEMA estimate of the impact conditions were not available. As a result, an evaluation of those estimates of impact conditions and determination of their uncertainties could not be made.

Table 7-6 compares the results of the motion analyses for the AA 11 impact. Both the Hart-Weidlinger and MIT analyses utilized the Doppler shift of the engine noise to determine the aircraft speed. The Hart- 
Weidlinger velocity analysis was based on AA 11 approaching the north tower at an angle $4^{\circ}$ shallower than the analyses presented here (NIST analysis in Table 7-6). If the Hart-Weidlinger analysis had the aircraft approaching at a steeper angle, it would have reported a speed much closer to the MIT and NIST analyses. One significant difference in the analyses of the AA 11 impact conditions was that none of the previous analyses had the opportunity to utilize the V2 video. This second video from a different location was very helpful in determining the motion parameters of the AA 11.

Table 7-6. AA 11 (WTC 1) aircraft impact analysis comparison.

\begin{tabular}{|l|c|c|c|c|}
\hline & FEMA $^{\mathbf{a}}$ & $\begin{array}{c}\text { Hart- } \\
\text { Weidlinger }^{\mathbf{b}}\end{array}$ & MIT $^{\mathbf{c}}$ & NIST \\
\hline Best Estimate Speed (mph) & 470 & 500 & 429 & 443 \\
\hline Speed Error Estimate (mph) & & $+30 /-50$ & \pm 51 & \pm 30 \\
\hline Lateral Approach Angle (clockwise) & & $4.3^{\circ}$ & & $0.3^{\circ} \pm 4^{\circ}$ \\
\hline Vertical Approach Angle (downward) & & $6.2^{\circ}$ & & $10.6^{\circ} \pm 3^{\circ}$ \\
\hline Aircraft Roll (left wing down) & & $20.7^{\circ}$ & & $25^{\circ} \pm 2^{\circ}$ \\
\hline
\end{tabular}

a. FEMA World Trade Center Building Performance Study, May 2002. Analysis methodology or data source not availabłe.

b. Levy, M., and Abboud, N.. 2002, "World Trade Center - Structural Engineering Investigation," Hart-Weidlinger.

c. The Towers Lost and Beyond, Massachusetts Institute of Technology, Eduardo Kausel.

Table 7-7 compares the results of the various motion analyses for the UAL 175 impact. The HartWeidlinger and the analyses presented here were consistent with the exception of the lateral approach angle. The MIT estimates of impact speed are low compared to the other analyses. However, assuming a lateral approach angle of $20^{\circ}$ would have increased the MIT estimate of the UAL 175 impact speed to $524 \mathrm{mph}$.

Table 7-7. UAL 175 (WTC 2) aircraft impact analysis comparison.

\begin{tabular}{|l|c|c|c|c|}
\hline & FEMA $^{\mathbf{a}}$ & $\begin{array}{c}\text { Hart- } \\
\text { Weidlinger }^{\mathbf{b}}\end{array}$ & MIT $^{\mathbf{e}}$ & NIST \\
\hline Best Estimate Speed (mph) & 590 & 550 & 503 & 542 \\
\hline Speed Error Estimate (mph) & & & \pm 38 & \pm 24 \\
\hline Lateral Approach Angle (clockwise) & & $11.7^{\circ}$ & $15^{\circ}$ & $15^{\circ} \pm 2^{\circ}$ \\
\hline Vertical Approach Angle (downward) & & $2.7^{\circ}$ & $0^{\circ}$ & $6^{\circ} \pm 2^{\circ}$ \\
\hline Aircraft Roll (left wing down) & & $30.1^{\circ}$ & & $38^{\circ} \pm 2^{\circ}$ \\
\hline
\end{tabular}

a. FEMA World Trade Center Building Performance Study, May 2002. Analysis methodology or data source not available.

b. Levy, M.. and Abboud, N.. 2002, "World Trade Center - Structurał Engineering lnvestigation," Hart-Weidlinger.

c. The Towers Lost and Beyond. Massachusetts Institute of Technology, Eduardo Kausel.

\subsection{SUMMARY}

Three different methods were used to determine the impact conditions for the two aircraft that impacted the WTC towers. The initial impact conditions included aircraft speed, horizontal and vertical angles of incidence, roll angle of each aircraft, and the location of nose impact with each tower. The first method used a comparison of videos from different positions to calculate the three-dimensional trajectory of the aircraft. The second method used the relative frame-by-frame motion in a single video, scaled to the length of the aircraft in the video to calculate the impact speed. Finally, analysis of the impact damage on the face of each tower was used to refine the relative impact orientation and trajectory. This was done by 
matching the projected impact points of the wings, fuselage, engines, and vertical stabilizer onto the exterior wall of each tower to the observed damage pattern.

\subsection{REFERENCES}

Cilke, R.W., 1995, "Motion Picture Analysis Procedures for Impact Parameters of Air-Delivered Weapons," FCT-LR-95-6, prepared by Applied Research Associates, Inc., Letter Report to the Defense Nuclear Agency, June.

FEMA, 2002, "World Trade Center Building Performance Study: Data Collection, Preliminary Observations and Recommendations," FEMA 403, May.

Foecke, T., and Pitts, W., NIST Predecisional Documents, Presentations, and Personal Communications.

Kausel, E., "The Towers Lost and Beyond," Massachusctts Institute of Technology, May 2002, http://web.mit.edu/civenv/wtc/index.html.

Levy, M., and Abboud N., 2002, "World Trade Center - Structural Engineering Investigation," HartWeidlinger Technical Report, Prepared for Wachtel, Lipton, Rosen, and Katz, August 1.

Lipton, E., and J. Glanz, 2002, "First Tower to Fall Was Hit at Higher Speed, Study Finds," The New York Times, February 23.

The Boeing Company Website, www.boeing.com. 


\section{Chapter 8 \\ UNCERTAINTY ANALYSES}

\section{$8.1 \quad$ INTRODUCTION}

The objectives of the uncertainty analyses were to assess the effect of uncertainties associated with the aircraft and World Trade Center (WTC) towers on the level of impact-induced damage to the towers and to determine the most influential modeling parameters that affect the damage estimates. Uncertainty arises in these analyses from the following key parameters:

1. Aircraft impact parameters: aircraft speed, horizontal and vertical angles of incidence, orientation, and location of impact.

2. Material properties: high strain rate material constitutive behavior and failure criteria for the towers and the aircraft.

3. Aircraft mass and stiffness properties and the jet fuel distribution in the aircraft.

4. Tower parameters: Structural strength and mass distribution, connection and joint positions relative to impact and joint failure behavior.

5. Nonstructural building contents that may absorb energy imparted by the aircraft impact.

An important class of uncertainty that is not listed in these key parameters is the inaccuracy associated with mathematical or numerical models. These uncertainties, also known as modeling errors, are deterministic in nature, but are often treated as random variables to characterize the effects of the analysis methodologies on the calculated response. All of these variables do not necessarily have a significant effect on the estimated impact damage to the WTC towcrs. An example of such modeling parameters is the resolution of the finite element model and the associated element sizes. Other examples include modeling of erosion and contact in the finite element calculations (see Section 8.2.1 for description of some of these parameters).

Because of the complexity of the problem, down-selection of all possible uncertainty parameters to a refined list applicable to a limited number of global impact analyses needs to be justified. Engineering experience and intuition alone are not sufficient. Therefore, parameter screening was conducted using design of experiments methodology. Screening was first conducted at the component and subassembly levels using orthogonal factorial design techniques in order to identify the most influential parameters and reduce the number of parameters to a more manageable number for the global impact analyses. These component and subassembly uncertainty analyses are the subject of this chapter.

A Plackett-Burman experimental design (Plackett, R.L., and Burman, J.P. 1947) was used for the screening of parameters in the analyses discussed in this chapter. Plackett-Burman (P-B) designs are twolevel designs, run at high and low values for each parameter. For k parameters, Plackett-Burman designs require $4 \times[\operatorname{int}(\mathrm{k} / 4)+1]$ runs, i.e., the least multiple of 4 , greater than $\mathrm{k}$. One additional run, with all parameters held at their nominal or central values, is also performed. There are several advantages to using a Plackett-Burman design for the screening of parameters. First, P-B designs require fewer runs 
than the usual $\mathrm{k}+1$ runs needed for a "one at a time plus center point" design. Parameters are also allowed to vary throughout the entire set of runs, each parameter simultaneously in the presence of each other's variation.

\subsection{COMPONENT AND SUBASSEMBLY LEVEL UNCERTAINTY ANALYSES}

Two sets of component-level uncertainty analyses were performed. The first set of uncertainty analyses was that of an aircraft engine impacting a collection of core columns. As discussed in Chapter 5, a single core column impacted solidly by an engine was completely overwhelmed and destroyed. This response made it difficult to determine differences in impact behavior caused by uncertainties in the impact parameters. A collection of columns was, therefore, selected to obtain a more sensitive measure of column damage to engine impact. The second set of component level uncertainty analyses was for an empty aircraft wing scction impacting two exterior panels, the same configuration discussed in Section 5.5.1. Finally, the subassembly uncertainty analysis was that of the configuration discussed in Chapter 6 impacted by an aircraft engine.

\subsubsection{Engine - Core Column Component Uncertainty Analyses}

The impact configuration for the enginc and core column impact uncertainty analysis is shown in Figure 8-1. The assembly of core columns was selected from the core column arrangement on floor 96 of WTC 1. The first column impacted by the engine was column 503 in the assembly (Figure 8-1). The other columns in the assembly had the same positions relative to each other as existed in the core structure, but were moved closer together. The reduced column spacing was used so that the subsequent motion of the engine and debris following the initial impact would interact with additional columns. This is shown for a sample configuration in Figure 8-1(b). In this arrangcment, a range of impact orientations and severity were obtained in each simulation as appropriate for the engine interacting with the tower core structures.

The core columns' top and bottom were attached to a steel plate of the same material as the column. These plates were rigidly constrained around their edges. These boundary conditions were selected to approximate the compliance of the continuous columns in the tower core frame structure. A more rigid constraint at the column ends was found to initiate failures at column ends with small column impact deformations and energy absorption. Columns were one story in height.

Thirteen uncertainty parameters were used in the engine-core column impact analyses, as shown in Table 8-1. The flight parameters, including speed and vertical and horizontal impact locations, were varied in this analysis. Impact spced in this analysis was based on previous estimates for the impact speed of flight UAL 175 that impacted the WTC 2 tower. A wide range of uncertainty in impact speed was used in these analyses for two reasons. First, these uncertainty analyses were performed before the analysis of the impact conditions was performed and the impact speed was more accurately determined. The second reason was that the aircraft engine lost an unknown amount of speed when penetrating the exterior of the building. Therefore, the velocity at which the engine reached the core was not accurately known. The variations in the horizontal and vertical impact locations were selected to be appropriate for the problem geometry used, and thus, the impact point was moved from being centered on the first column to half the width between columns horizontally and to the top of the engine at the ceiling height 
vertically. The minimum values for horizontal and vertical impact locations were the same as the baseline values for symmetry considerations.

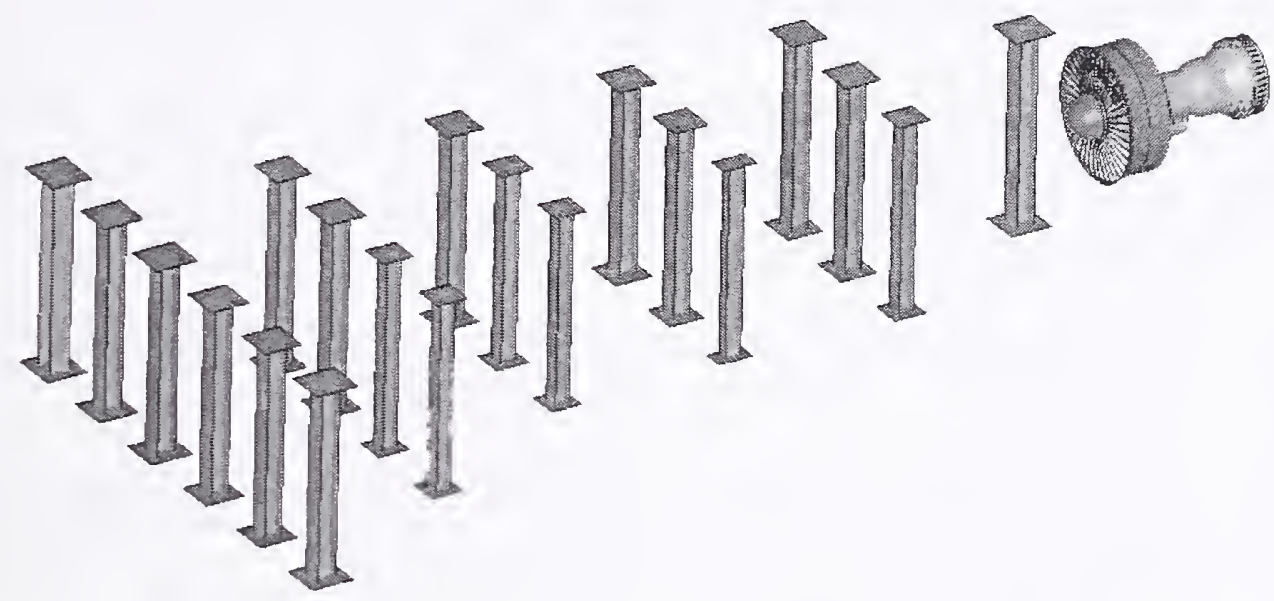

(a) Initial configuration

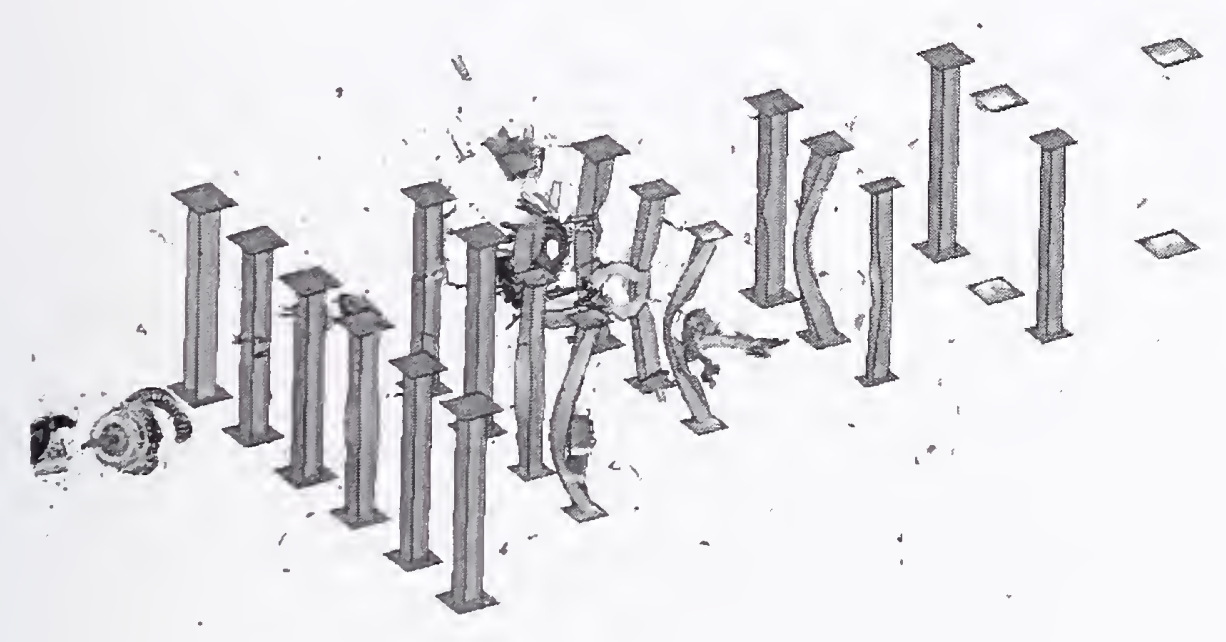

(b) Impact response at $0.20 \mathrm{~s}$

Figure 8-1. Example engine impact into an assembly of core columns.

Strength and failure strain were varied in both the engine and tower columns. The tower material strengths were varied by 15 percent, and the engine material strengths were varied by 35 percent. For the tower steels, the baseline strength values were those obtained from the test data. A large variation in failure strain was considered for both structures. Strain rate effects on both the column and engine materials strength were also considered. A magnitude of 1 in the table was the baseline strain rate enhancement of strength discussed in Chapter 2 (obtained by modification of the parameter $\mathrm{C}$ in the Cowper and Symonds model). A magnitude of 10 was ten times this enhancement. At the time of this study, final data were not yet available for strain rate effects in the tower materials, so this large variation was selected. Subsequent data, as discussed in Chapter 2, was used to reduce this uncertainty to a scale factor of 0.1 to 2.0 in the rest of the uncertainty analyses. In addition to these material parameter 
uncertainties, different data sources cited different materials for many of the engine components, so the two different material sets were considered here.

Table 8-1. Engine-core column impact uncertainty parameters.

\begin{tabular}{|c|c|c|c|c|c|}
\hline \multicolumn{2}{|c|}{ Uncertainty Parameters } & $\begin{array}{c}\text { Parameter } \\
\text { ID }\end{array}$ & $\begin{array}{c}\text { Minimum } \\
\text { Value }\end{array}$ & $\begin{array}{c}\text { Baseline } \\
\text { Value }\end{array}$ & $\begin{array}{c}\text { Maximum } \\
\text { Value }\end{array}$ \\
\hline \multirow{3}{*}{$\begin{array}{c}\text { Flight } \\
\text { Parameters }\end{array}$} & Speed & 1 & $392 \mathrm{mph}$ & $485 \mathrm{mph}$ & $579 \mathrm{mph}$ \\
\hline & Vertical Impact Location & 2 & $0.00 \mathrm{ft}$ & $0.00 \mathrm{ft}$ & $2.03 \mathrm{ft}$ \\
\hline & Horizontal Impact Location & 3 & $0.00 \mathrm{ft}$ & $0.00 \mathrm{ft}$ & $3.00 \mathrm{ft}$ \\
\hline \multirow{4}{*}{$\begin{array}{c}\text { Engine } \\
\text { Parameters }\end{array}$} & Material Assignment Set ${ }^{a}$ & 4 & 1 & 1 & 2 \\
\hline & Material Strength & 5 & $65 \%$ & $100 \%$ & $135 \%$ \\
\hline & Failure Strain & 6 & $50 \%$ & $100 \%$ & $150 \%$ \\
\hline & Strain Rate Effects & 7 & $10 \%$ & $100 \%$ & $1000 \%$ \\
\hline \multirow{3}{*}{$\begin{array}{c}\text { Tower } \\
\text { Parameters }\end{array}$} & Material Strength & 8 & $85 \%$ & $100 \%$ & $115 \%$ \\
\hline & Failure Strain & 9 & $50 \%$ & $100 \%$ & $150 \%$ \\
\hline & Strain Rate Effects & 10 & $10 \%$ & $100 \%$ & $1000 \%$ \\
\hline \multirow{3}{*}{$\begin{array}{c}\text { Model } \\
\text { Parameters }\end{array}$} & Erosion Parameter $^{\mathrm{a}}$ & 11 & 1 & 1 & 2 \\
\hline & Contact Parameter $^{3}$ & 12 & 1 & 1 & 2 \\
\hline & Friction Coefficient & 13 & 0.0 & 0.3 & 0.6 \\
\hline
\end{tabular}

a. Discrete parameter.

Several deterministic parameters, or modeling parameters, were also considered. The first was the erosion parameter in the contact algorithm of LS-DYNA. When an element exceeds the failure criterion, the element is eroded or removed from the calculation. When all of the elements attached to a specific node have eroded, that node becomes free or unattached from any of the other structures in the calculation. However, the free nodes still have mass and momentum. Depending on the selection of the erosion parameter, the free nodes can be maintained or eliminated in the contact algorithms. Deleting nodes may reduce the impact loads on the structure by eliminating their momentum from subsequent impacts. However, maintaining the deleted nodes in the contact algorithms can sometimes lead to computational instability. Provided the failed part of the structure had lost the majority of its initial momentum, the removal of free nodes from contact calculations should have had little effect on the results. Varying the erosion parameter in the uncertainty analyses helped to evaluate the significance of this effect.

Finally, two additional contact parameters were considered. These are the contact type and the friction coefficient between contacting parts. The contact parameter alternates the numerical algorithm used to model contact. A parameter set to 0 uses a penalty treatment and 1 uses the soft constraint algorithm. The penalty formulation is the default option in LS-DYNA and is the most efficient contact algorithm. The soft constraint option uses the nodal mass and global time step to calculate the local interface stiffness. This algorithm typically is more robust and often necessary for calculations with large variations in material elastic bulk moduli (e.g., steel and tower internal contents). A more complete explanation of the differences in these contact types can be found in the LS-DYNA user's manual. For the coefficient of friction between contacting parts, a large variation was considered. This large uncertainty stems from various sources. Reference values for the coefficient of friction for aluminum on stcel is approximately 0.45 (Oberg et. al. 1990). However, in this impact situation there were many 
possible complexities that served to modify the effective friction coefficient. These factors included, among others, painted and unpainted surfaces, erosion of metal and painted surfaces, and changcs in properties of paint and metal from heating. In addition, the ability of the contact algorithms to smoothly calculate the interface normal and frictional forces is reduced with a coarser mesh resolution. The friction coefficient was therefore varied from 0.0 to 0.6 .

A fractional factorial $2^{13-9}$ experimental design was selected for this study, as shown in Table 8-2, with the intent of identifying the significant parameters affecting the impact responsc. The uncertainty factor IDs are listed across the top of the table, with the run number on the left hand side. Minimum and maximum cases from Table $8-1$ are shown by -1 and +1 , respectively. Baseline cases are shown by 0 .

Table 8-2. Fractional factorial $2^{13-9}$ experimental design (with centerpoint) for the enginecore column impact analyses.

\begin{tabular}{|c|c|c|c|c|c|c|c|c|c|c|c|c|c|}
\hline $\begin{array}{l}\text { Runs } \\
\mathrm{ID} \rightarrow\end{array}$ & 1 & 2 & 3 & 4 & 5 & 6 & 7 & 8 & 9 & 10 & 11 & 12 & 13 \\
\hline 1 & 1 & 1 & -1 & 1 & 1 & -1 & -1 & 1 & 1 & -1 & -1 & -1 & 1 \\
\hline 2 & 1 & 1 & -1 & -1 & -1 & 1 & 1 & -1 & -1 & 1 & 1 & -1 & 1 \\
\hline 3 & 1 & -1 & -1 & 1 & -1 & 1 & -1 & 1 & -1 & 1 & -1 & 1 & -1 \\
\hline 4 & 1 & -1 & -1 & -1 & 1 & -1 & 1 & -1 & 1 & -1 & 1 & 1 & -1 \\
\hline 5 & -1 & 1 & 1 & 1 & 1 & 1 & -1 & -1 & -1 & -1 & 1 & -1 & -1 \\
\hline 6 & -1 & 1 & 1 & -1 & -1 & -1 & 1 & 1 & 1 & 1 & -1 & -1 & -1 \\
\hline 7 & -1 & -1 & 1 & 1 & -1 & -1 & -1 & -1 & 1 & 1 & 1 & 1 & 1 \\
\hline 8 & -1 & -1 & 1 & -1 & 1 & 1 & 1 & 1 & -1 & -1 & -1 & 1 & 1 \\
\hline 9 & 0 & 0 & 0 & 0 & 0 & 0 & 0 & 0 & 0 & 0 & 0 & 0 & 0 \\
\hline 10 & 1 & 1 & 1 & 1 & -1 & 1 & 1 & -1 & 1 & -1 & -1 & 1 & -1 \\
\hline 11 & 1 & 1 & 1 & -1 & 1 & -1 & -1 & 1 & -1 & 1 & 1 & 1 & -1 \\
\hline 12 & 1 & .1 & 1 & 1 & 1 & -1 & 1 & -1 & -1 & 1 & -1 & -1 & 1 \\
\hline 13 & 1 & -1 & 1 & -1 & -1 & 1 & -1 & 1 & 1 & -1 & 1 & -1 & 1 \\
\hline 14 & -1 & 1 & -1 & 1 & -1 & -1 & 1 & 1 & -1 & -1 & 1 & 1 & 1 \\
\hline 15 & -1 & 1 & -1 & -1 & 1 & 1 & -1 & -1 & 1 & 1 & -1 & 1 & 1 \\
\hline 16 & -1 & -1 & -1 & 1 & 1 & 1 & 1 & 1 & 1 & 1 & 1 & -1 & -1 \\
\hline 17 & -1 & -1 & -1 & -1 & -1 & -1 & -1 & -1 & -1 & -1 & -1 & -1 & -1 \\
\hline
\end{tabular}

The reduction in load carrying capacity of the damaged assembly of columns as a fraction of the original capacity was selected as the response parameter for this study. The complex variation in the damage modes and nonlinear damage behavior made it difficult to estimate the reduction in load carrying capacity. Therefore a set of simplified engineering analyses were used to calculate the change in load carrying capacity for each column. The baseline strength was assumed to be the full plastic load level or yield strength multiplied by the cross sectional area. The main factors that were considered for the reduction in load carrying capacity were the reduction in cross scctional arca from failed material, deflections of the column centerline that influence the global collapse behavior, and cross-section damage or distortions that modify the local stress distribution.

The first factor that reduced the load carrying capacity was the fraction of the cross-section that had failed under the impact load. The load carrying capacity was reduced by the ratio of the remaining to initial cross-sectional areas. The second factor used to calculate the residual column strength was the maximum centerline displacement of the column produced by the impact damage. The effect of the centerline displacement was determined using classical solid mechanics analysis of an axial compressive load, centered on the column ends and aligned with the original longitudinal axis of the column. At the point of maximum centerline displacement, the axial compressive load resulted in both a uniform compressive force and a moment equal to the force multiplied by the centerline displacement. The column was assumed to fail when the maximum compressive stress in the column reached the yield stress. For simplicity, the bending was assumed to be aligned with the direction of the maximum principal moment of inertia for the column. 
The last factor that reduced the load carrying capacity of a column was the local distortion in the crosssectional shape. The magnitude and type of distortion of the cross-section was difficult to quantify due to the large variation in impact conditions and damage. To simplify this characterization, a cross-section damage scale was developed, where the damage was classified in integer magnitudes varying from 0 to 5 , where 0 indicates no damage to the cross-section and 5 represents the greatest damage (large distortions and close to failure). The cross-section distortion of each column was evaluated in the final state of the simulation, and engineering judgment was used to categorize the damage magnitude for each column. Example cross-section damage levels for various core columns are shown in Figure 8-2. For each level of increasing damage, the load carrying capacity was reduced by 10 percent.

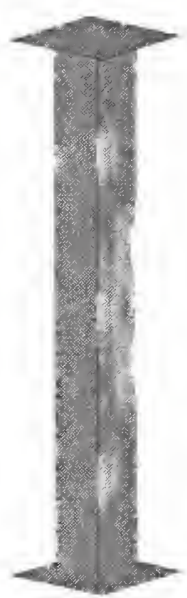

1

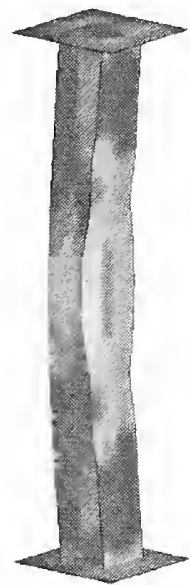

2

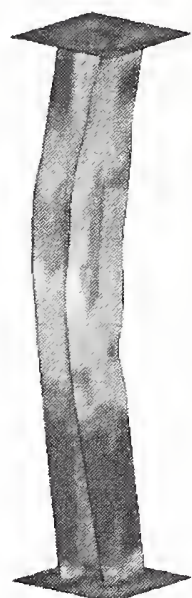

3

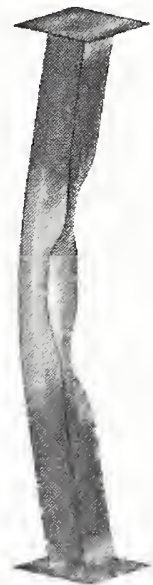

4

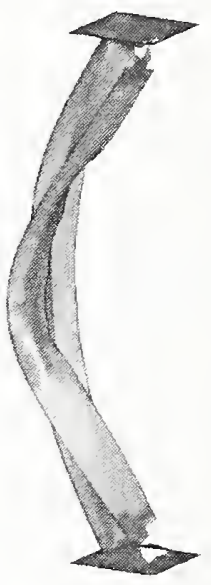

5

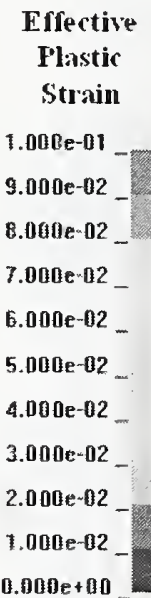

0.

Figure 8-2. Measures of cross-section damage to a core column.

The total reduction in load carrying capacity of a single column was calculated by multiplying the reductions from each factor: the global centerline displacement, cross-section area reductions, and crosssection distortion. The total reduction in capacity of the collection of columns was calculated by summing over all the columns in the model.

A main effects plot for the engine-core column impact analyses is shown in Figure 8-3. The strain rate effect (parameter 10) on column steel strength, horizontal impact location (parameter 3), column materials failure strain (parameter 9), and engine materials strength (parameter 5) had the largest impact on the residual load carrying capacity of the assembly of core columns. The uncertainty in the strain rate effects had the largest effect on the response for these analyses. However, the effect of strain rate was exaggerated by the large variation considered in these analyses. Data made available after the conclusion of this set of engine impact calculations reduced the uncertainty in this parameter to a factor of 2 , not 10 , for the maximum variation. If the magnitude of uncertainty in the strain rate parameter was reduced by a factor of 5, it is expected that the importance of this uncertainty parameter would be significantly less.

Horizontal impact location (parameter 3 ) was the second most significant parameter affecting the residual load capacity of the columns. The importance of the horizontal impact position was probably magnified by the problem geometry used. For the baseline and minimum value analyses, the impact was aligned horizontally with a row of columns, and the impact would typically result in complete failure of several columns aligned with the engine trajectory. For the maximum value analyses, the horizontal impact 
location was centered between rows of columns, and the impact typically had several glancing impacts as the engine passed between columns. For this impact scenario, significantly fewer columns were completely failed by a solid engine impact.

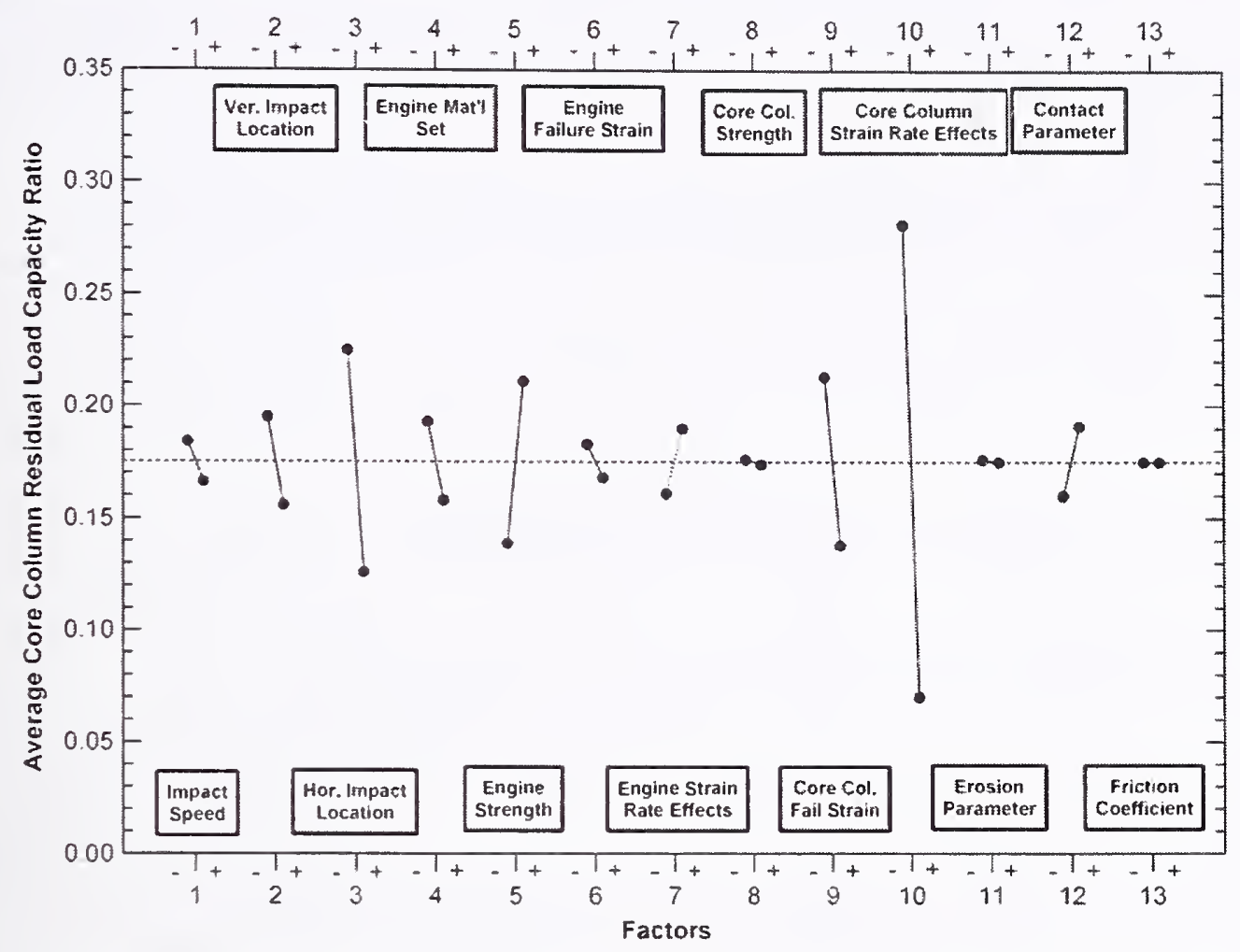

Figure 8-3. Main effects plot for the engine - core column impact analyses.

Interpretation of this strong significance of the horizontal impact location for the subassembly or global impact analyses was difficult since variations in the flight conditions and initial impact location on the tower exterior were not easily related to the resulting trajectory of the engine through the core. This argument also applies to the vertical impact location.

Although the variation in engine speed resulted in nearly a 50 percent increase in the engine impact momentum, the engine speed did not have a dominant effect on the residual load capacity of the core columns. The relative importance of some parameters can be easily seen. The impact location was more dominant than impact speed since a solid impact at lower speed caused more damage than a glancing impact at higher speed. The impact response mechanisms controlling the relative importance of other parameters were less clear. A contributing mechanism seen was the introduction of tumbling motions of the engine. A side-on impact by the engine produced significantly less damage than a head-on impact (impact trajectory and orientation both aligned with the engine axis of rotation). Similarly, the impact of engine debris caused significantly less damage than a relatively intact engine. As a result, the changes in material ductility and strength could introduce engine impact responses that resulted in significant changes in the cumulative column damage.

The uncertainty parameters with the smallest effect on the load carrying capacity were the core column strength, erosion parameter, and friction coefficient (parameters 8,11 , and 13, respectively). Note that 
the friction and erosion parameters were found to have an insignificant effect in this problem geometry compared to a more observable effect in the wing section impact (Section 8.2.2). This is potentially a result of the much larger surface area of failed material and element erosion in the relatively low strength empty wing section as it was torn apart in passing through the exterior columns. Remaining portions of the light empty wing sections were not likely to have sufficient momentum to impart significant structural damage to the core columns.

Based on these results, the following parameters were considered to be potentially significant in the subassembly and global impact analyses:

- Aircraft materials strength.

- Tower materials failure strain.

- Tower material strain rate dependence.

- Engine materials set (possibly secondary significance).

\subsubsection{Empty Wing Segment - Exterior Panel Uncertainty Analysis}

The empty wing segment and exterior panel models discussed in Section 5.5.1 were selected as an impact configuration to perform the second component-level uncertainty analysis in this study. The wing segment and panel model are shown in Figure 8-4. The impact of a fuel-laden wing segment was found to overwhelm the exterior panel and was, therefore, not used here. The impact of an empty wing section was expected to produce significant damage to the exterior columns, but not catastrophic failure. This level of damage was observed in the photographs of the damage to the exterior columns of the WTC towers where the wing was not laden with fuel.

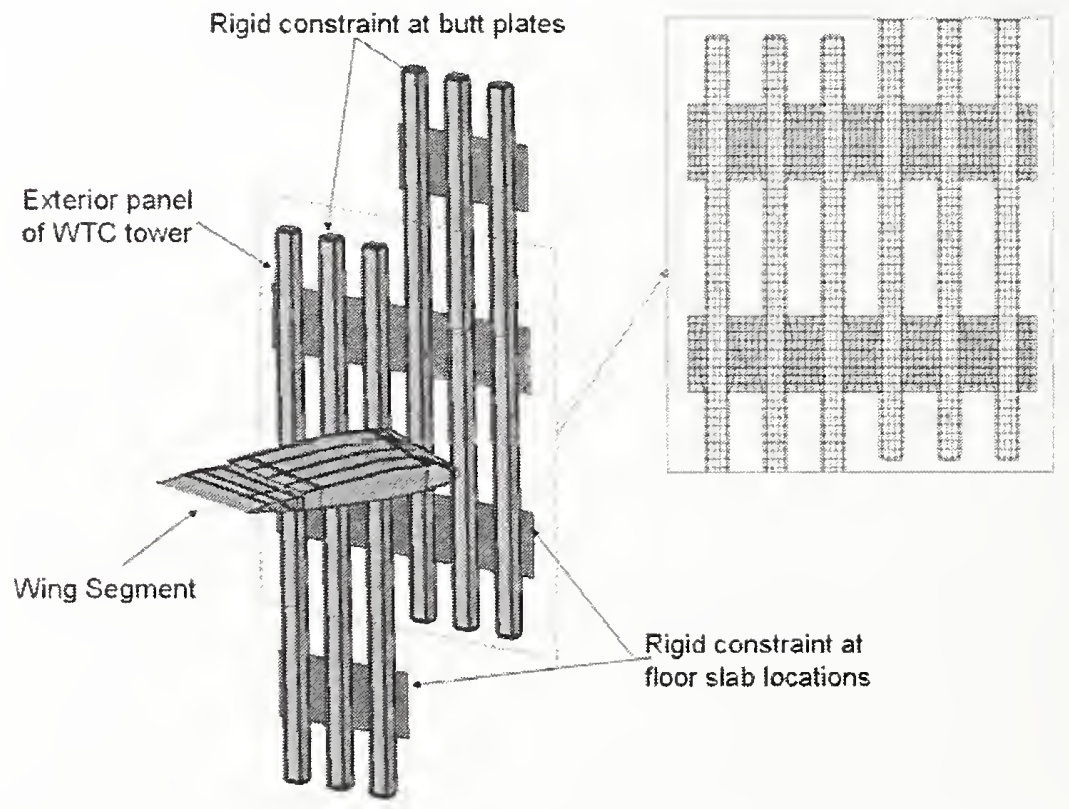

Figure 8-4. Impact configuration for the wing-panel analyses. 
Thirteen uncertainty parameters were selected for the wing-panel impact analyses, as listed in Table 8-3. The flight or trajectory parameter uncertainties were obtained from the video and photographic analysis of impact conditions of the impact of AA 11 into the WTC 1 tower, as discussed in Chapter 7. The trajectory angle of the wing segment was varied between $-4^{\circ}$ and $+4^{\circ}$, as shown in Figurc $8-5$. Strength and failure strain were varied in both the wing and tower structures. Strength of the towcr matcrials were probably known with greater certainty than the aircraft materials due to the detailed testing performcd by National Institute of Standards and Technology (NIST). The tower material strengths were, therefore, varied by 15 percent, while the wing material strengths were varied by 35 percent. The element erosion strain, at which elements of the wing structure were deleted from the calculation, was also varied. This parameter was not a reflection of material failure, as discussed in Section 5.5.1, but rather a reflection of how long the nodes and mass of an element remained in the calculation after material failure. Therefore, the erosion strain was included in this example as a modeling parameter. The reader is referred to Chapter 5 for more discussion on this parameter. In addition to these material uncertainties, strain rate effects on the tower materials strength were also considered.

Table 8-3. Wing-panel impact uncertainty parameters.

\begin{tabular}{|c|c|c|c|c|c|}
\hline \multicolumn{2}{|c|}{ Uncertainty Parameters } & $\begin{array}{c}\text { Parameter } \\
\text { ID }\end{array}$ & $\begin{array}{c}\text { Minimum } \\
\text { Value }\end{array}$ & $\begin{array}{c}\text { Baseline } \\
\text { Value }\end{array}$ & $\begin{array}{c}\text { Maximum } \\
\text { Value }\end{array}$ \\
\hline \multirow{2}{*}{$\begin{array}{c}\text { Flight } \\
\text { Parameters }\end{array}$} & Speed & 1 & $413 \mathrm{mph}$ & $443 \mathrm{mph}$ & $521 \mathrm{mph}$ \\
\hline & Lateral Approach Angle & 2 & $-4.0^{\circ}$ & $0.0^{\circ}$ & $4.0^{\circ}$ \\
\hline \multirow{4}{*}{$\begin{array}{l}\text { Wing } \\
\text { Parameters }\end{array}$} & Material Strength & 3 & $65 \%$ & $100 \%$ & $135 \%$ \\
\hline & Failure Strain & 4 & $50 \%$ & $100 \%$ & $150 \%$ \\
\hline & Rivet Strength & 5 & $50 \%$ & $100 \%$ & $150 \%$ \\
\hline & Weight Factor & 6 & 1.5 & 2.0 & 3.0 \\
\hline \multirow{3}{*}{$\begin{array}{c}\text { Tower } \\
\text { Parameters }\end{array}$} & Material Strength & 7 & $85 \%$ & $100 \%$ & $115 \%$ \\
\hline & Failure Strain & 8 & $50 \%$ & $100 \%$ & $150 \%$ \\
\hline & Strain Rate Effects & 9 & $10 \%$ & $100 \%$ & $200 \%$ \\
\hline \multirow{4}{*}{$\begin{array}{c}\text { Model } \\
\text { Parameters }\end{array}$} & Erosion Parameter ${ }^{a}$ & 10 & 1 & 1 & 2 \\
\hline & Erosion Strain & 11 & 0.2 & 0.3 & 0.4 \\
\hline & Contact Parameter $^{\mathrm{a}}$ & 12 & 1 & 1 & 0 \\
\hline & Friction Coefficient & 13 & 0.0 & 0.3 & 0.6 \\
\hline
\end{tabular}

a. Discrete parameter.

The weight of the tower exterior panels is known from the detailed structural design information. However, there is significant uncertainty in the weight of the wing, since not all of the minor structural details and non-structural masses were modeled explicitly in the wing. The weight scalc factor of the wing was, therefore, varied. This scale factor was based on engineering estimatcs, as described in Chapter 4. Therefore, a significant variation in the wing section weight scale factor was considered here. The rivet conncction strength between the interior structure and skin was also varied. Rivet sizes uscd between each component in the wing were not known. A large variation in strength was, therefore, considered. 


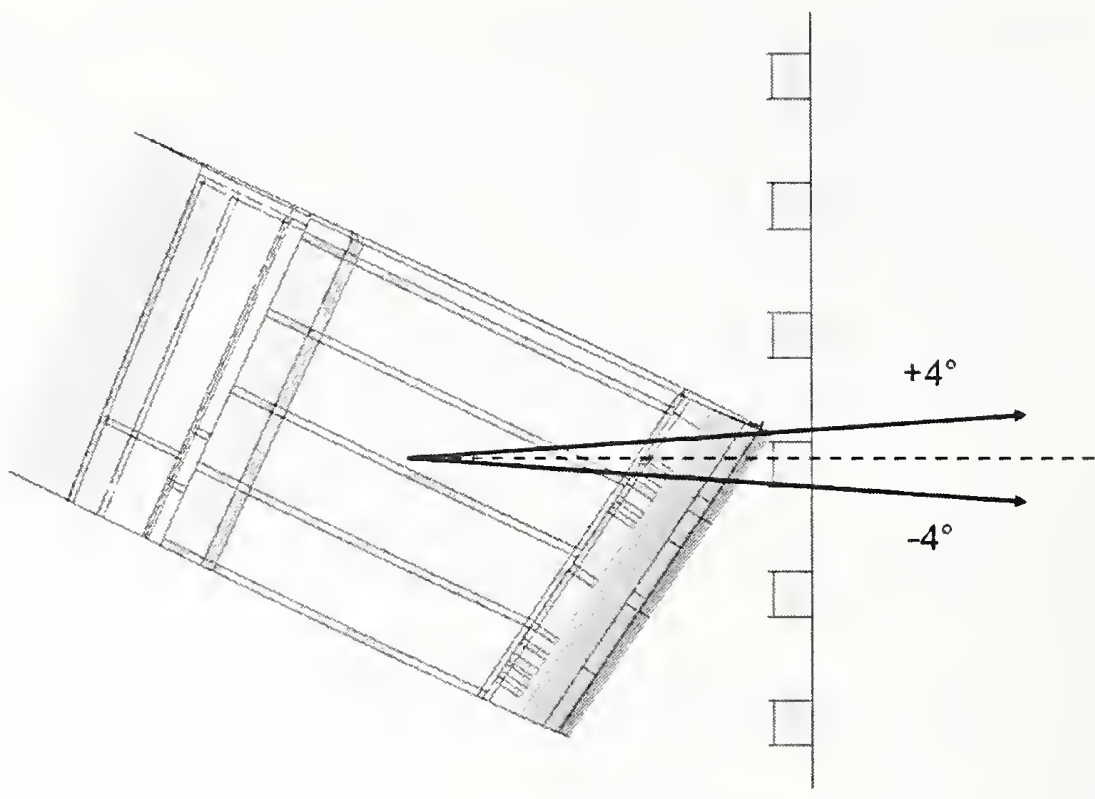

Figure 8-5. Wing segment showing the variation in impact conditions on the exterior panels.

Three deterministic parameters, or modeling parameters, were considered. These parameters were the erosion parameter and two contact parameters, contact type and friction coefficient. These parameters were the same as those used in the wing section exterior panel uncertainty analysis and were discussed in Section 8.2.1.

The matrix of uncertainty parameters used for the engine-core column and the wing-panel impact uncertainty analyses were very similar, as listed in Table 8-1 and Table 8-3, respectively. The primary differences were the uncertainty parameters used for the impact conditions. The uncertainty range used for the engine-core column impact speed was much larger to allow for variations in the impact speed at the core. The engine-core column impact parameters included variations in the horizontal and lateral impact location, while the wing impact analyses varied the lateral approach angle as an impact parameter. The uncertainties in the material properties for the aircraft and tower components were quite similar, with the exception of the uncertainty bounds on the strain rate effects for the tower materials that were reduced significantly for the wing section impact as a result of additional data obtained on the tower steels.

A $2^{13-9}$ fractional factorial experimental design was used for the wing-panel impact analyses as shown in Table 8-4. The uncertainty factor IDs are listed across the top of the table, with the run number on the left hand side. Minimum and maximum cases from Table $8-3$ are shown by -1 and +1 , respectively. Baseline cases are shown by 0 . The residual linear momentum of the wing and panel debris was used as the response parameter for this analysis. It represents a measure of the potential of the debris to inflict damage to interior structures and to move non-structural masses. This residual momentum was measured by placing a rigid wall in the path of the debris field and recording the change in momentum of the wall. The wall was placed at a sufficient distance from the panel such that contact with the wall had no influence on components impacting the panel. 
Table 8-4. Fractional factorial $2^{13-9}$ experimental design (with centerpoint) for the wingpanel impact analyses.

\begin{tabular}{|c|c|c|c|c|c|c|c|c|c|c|c|c|c|}
\hline $\begin{array}{l}\text { Putus } \\
\text { ID } \rightarrow\end{array}$ & 1 & 2 & 3 & 4 & 5 & 6 & 7 & 8 & 9 & 10 & 11 & 12 & 13 \\
\hline 1 & 1 & 1 & -1 & 1 & 1 & -1 & -1 & 1 & 1 & -1 & .1 & -1 & 1 \\
\hline 2 & 1 & 1 & -1 & -1 & -1 & 1 & 1 & -1 & -1 & 1 & 1 & -1 & 1 \\
\hline 3 & 1 & -1 & -1 & 1 & -1 & 1 & -1 & 1 & -1 & 1 & -1 & 1 & .1 \\
\hline 4 & 1 & -1 & -1 & -1 & 1 & -1 & 1 & -1 & 1 & -1 & 1 & 1 & 1 \\
\hline 5 & -1 & 1 & 1 & 1 & 1 & 1 & -1 & -1 & -1 & -1 & 1 & -1 & -1 \\
\hline 6 & -1 & 1 & 1 & -1 & -1 & -1 & 1 & 1 & 1 & 1 & -1 & -1 & -1 \\
\hline 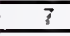 & -1 & -1 & 1 & 1 & -1 & -1 & -1 & -1 & 1 & 1 & 1 & 1 & 1 \\
\hline 8 & -1 & -1 & 1 & -1 & 1 & 1 & 1 & 1 & -1 & -1 & -1 & 1 & 1 \\
\hline 9 & 0 & 0 & 0 & 0 & 0 & 0 & 0 & 0 & 0 & 0 & 0 & 0 & 0 \\
\hline 10 & 1 & 1 & 1 & 1 & -1 & 1 & 1 & -1 & 1 & -1 & -1 & 1 & -1 \\
\hline 11 & 1 & 1 & 1 & -1 & 1 & -1 & -1 & 1 & -1 & 1 & 1 & 1 & -1 \\
\hline 12 & 1 & -1 & 1 & 1 & 1 & -1 & 1 & -1 & -1 & 1 & -1 & -1 & 1 \\
\hline 13 & 1 & -1 & 1 & -1 & -1 & 1 & -1 & 1 & 1 & $\begin{array}{l}-1 \\
\end{array}$ & 1 & -1 & 1 \\
\hline 14 & -1 & 1 & -1 & 1 & -1 & -1 & 1 & 1 & -1 & -1 & 1 & 1 & 1 \\
\hline 15 & -1 & 1 & -1 & -1 & 1 & 1 & -1 & -1 & 1 & 1 & -1 & 1 & 1 \\
\hline 16 & -1 & -1 & -1 & 1 & 1 & 1 & 1 & 1 & 1 & 1 & 1 & -1 & -1 \\
\hline 17 & -1 & -1 & -1 & -1 & -1 & -1 & -1 & -1 & -1 & -1 & -1 & -1 & -1 \\
\hline
\end{tabular}

A main effects plot for the wing-panel impact analyses is shown in Figure 8-6. To generate a main effects plot, all responses at the minimum and maximum cases for a parameter were averaged and denoted as the '-' and '+' values for a parameter, as shown in the figure. The figure indicates that uncertainty in the wing weight had the largest effect on the response of the wing-panel study. However, the relative uncertainty in the total aircraft mass was much smaller than that of the wing itself. The aircraft mass was known to within 5 percent, as discussed in Chapter 4 . Redistributing the wing mass with the baseline scale factor of 2 to 3 (a 50 percent change in wing mass), for example, resulted in only an 18 percent change in fuselage weight. The wing weight was also dominated by the mass of the fuel, which weighs approximately twice as much as the empty wing itself. Therefore, in the context of the global analyses, this result was interpreted as the variation in the total aircraft weight was more important than any uncertainty in the wing weight distribution.

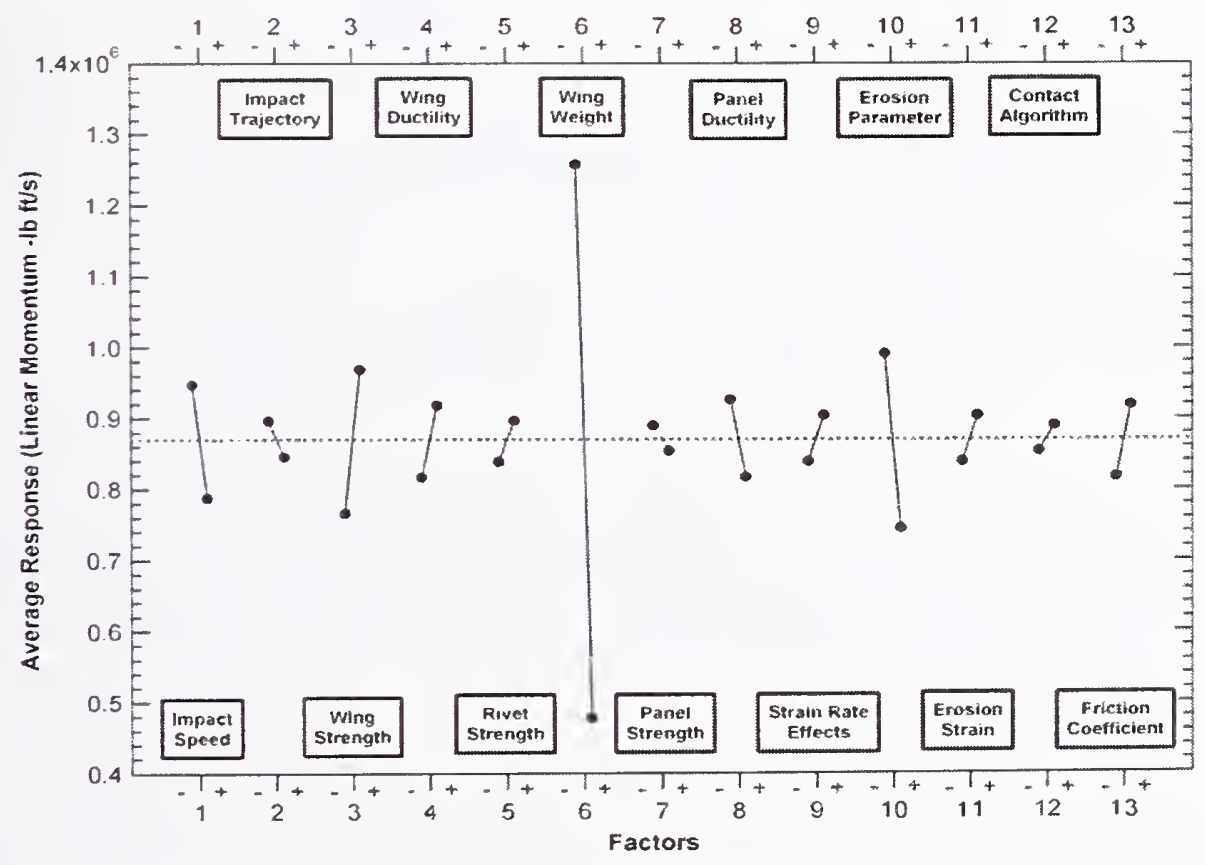

Figure 8-6. Main effects plot for the wing-panel impact analyses. 
Sccondary unccrtainty factors included the erosion parameter, impact speed, wing material yield strength and ductility, tower materials ductility, and the friction coefficient. The erosion parameter had a larger effect than the other factors. Although the erosion parameter was significant in these analyses, it caused computational stability problems in some analyses. The negative effect of maintaining the free nodes in contact outweighed the benefit of keeping this momentum in the global impact calculation.

Based on these results and the above discussion, variation in the following parameters were considered to be potentially significant in the subassembly and global impact analyses (not listed in order of importance):

- Impact speed.

- Aircraft materials strength.

- Aircraft materials ductility.

- Total aircraft weight.

- Tower materials ductility.

- Friction coefficient.

- Erosion parameter

\subsubsection{Engine-Subassembly Uncertainty Analysis}

Figure 8-7 shows the configuration selected to perform the engine-subassembly uncertainty analysis. The subassembly model is the same as that described in Chapter 6 . The analysis included an engine impacting a strip of the tower with a width of three exterior wall panels and extending through the truss floor system to the core for a height of three floors. Eleven parameters were selected as the critical uncertainty factors in this analysis, as shown in Table 8-5. Four flight parameters, including speed, vertical impact location, horizontal approach angle, and lateral approach angle were varied in this analysis. Uncertainties from the video and photographic analysis of impact conditions of flight AA 11 impacting the WTC 1 tower were used. Analyses of these impact conditions and associated uncertainties were described in Chapter 7. The baseline vertical impact location was approximately centered between spandrels on the 96th floor.

Variation in the vertical impact locations moved the impact point by $3.28 \mathrm{ft}$ as shown in Figure 8-8. The initial vertical approach angle was considered important because this parameter contributed significantly to the vertical load magnitude on the truss floor structures. The lateral approach angle in this analysis determined the path of the engine through the building contents and influenced the potential for an impact on a core column. Horizontal impact location was not varied because variations in the lateral approach angle yielded a similar result on the impact behavior. 


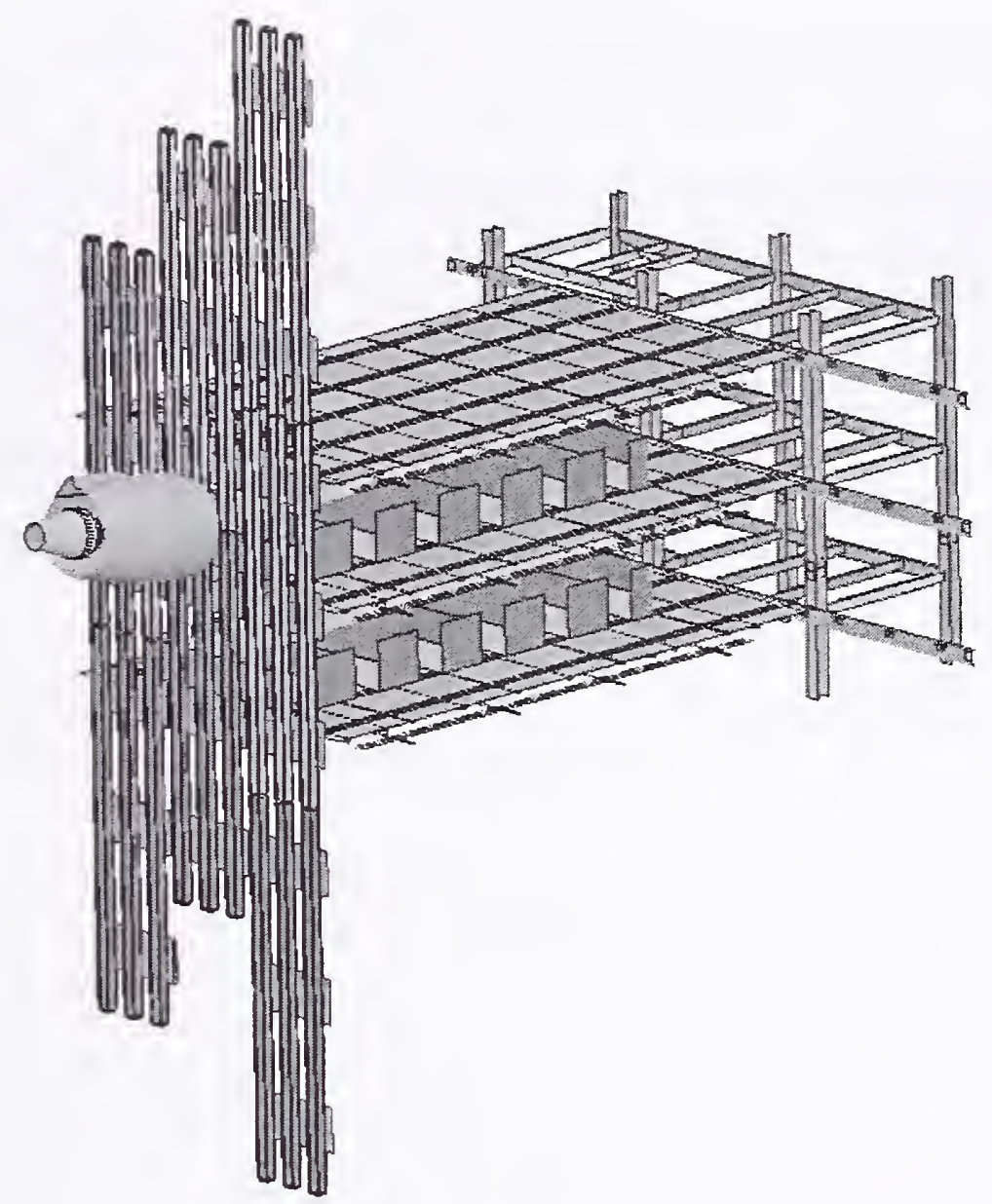

Figure 8-7. Impact configuration for the engine-subassembly impact analyses.

Table 8-5. Engine-subassembly impact uncertainty parameters.

\begin{tabular}{|c|c|c|c|c|c|}
\hline \multicolumn{2}{|c|}{ Uncertainty Parameters } & $\begin{array}{l}\text { Parameter } \\
\text { ID }\end{array}$ & $\begin{array}{c}\text { Minimum } \\
\text { Value }\end{array}$ & $\begin{array}{c}\text { Baseline } \\
\text { Value }\end{array}$ & $\begin{array}{c}\text { Maximum } \\
\text { Value }\end{array}$ \\
\hline \multirow{4}{*}{$\begin{array}{c}\text { Flight } \\
\text { Parameters }\end{array}$} & Speed & 1 & $414 \mathrm{mph}$ & $443 \mathrm{mph}$ & $472 \mathrm{mph}$ \\
\hline & Vertical Impact Location & 2 & $-3.28 \mathrm{ft}$ & $0.00 \mathrm{ft}$ & $3.28 \mathrm{ft}$ \\
\hline & Vertical Approach Angle & 3 & $7.6^{\circ}$ & $10.6^{\circ}$ & $13.6^{\circ}$ \\
\hline & Lateral Approach Angle & 4 & $0.0^{\circ}$ & $2.0^{\circ}$ & $4.0^{\circ}$ \\
\hline \multirow{2}{*}{$\begin{array}{c}\text { Engine } \\
\text { Parameters }\end{array}$} & Material Assignment Set ${ }^{a}$ & 5 & 1 & 1 & 2 \\
\hline & Material Strength & 6 & $65 \%$ & $100 \%$ & $135 \%$ \\
\hline \multirow{4}{*}{$\begin{array}{c}\text { Tower } \\
\text { Parameters }\end{array}$} & Material Strength & 7 & $85 \%$ & $100 \%$ & $115 \%$ \\
\hline & Failure Strain & 8 & $50 \%$ & $100 \%$ & $150 \%$ \\
\hline & Strain Rate Effects & 9 & $10 \%$ & $100 \%$ & $200 \%$ \\
\hline & Tower Contents Weight & 10 & $60 \%$ & $100 \%$ & $160 \%$ \\
\hline $\begin{array}{c}\text { Model } \\
\text { Parameters }\end{array}$ & Erosion Parameter ${ }^{a}$ & 11 & 1 & 1 & 2 \\
\hline
\end{tabular}

a. Discrete parameter. 


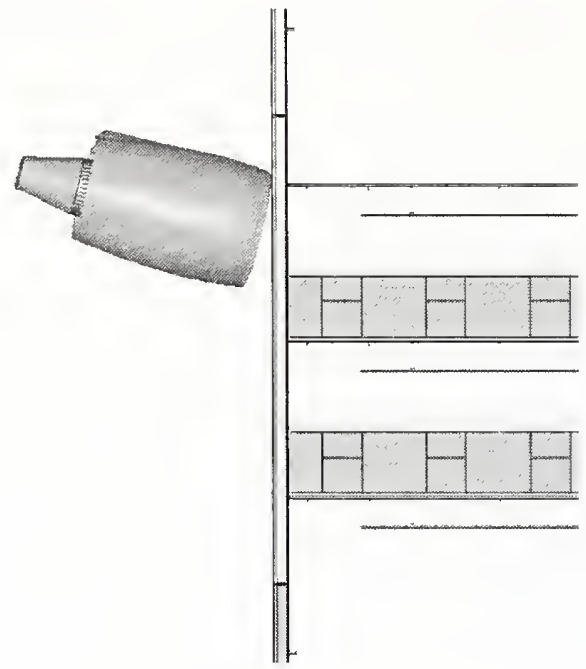

(a) Maximum

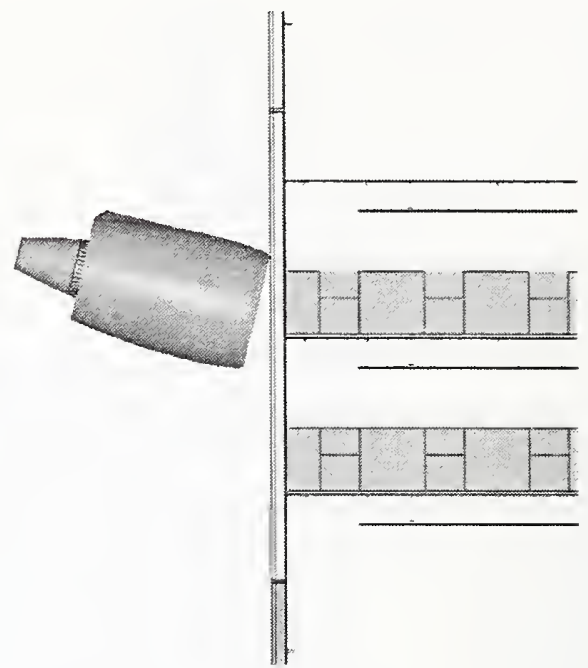

(b) Mininimum

Figure 8-8. Variation in vertical impact location for the engine-subassembly impact analyses.

Tower materials failure strain and strain rate effects were considered in this analysis because of their importance as indicated in the engine-core column component analysis. However, the magnitude of the uncertainty in the strain rate effects was reduced to a more appropriate level as high rate material test data were obtained and evaluated. Engine material strength and the engine material set were included in this study for the same reason. Strength uncertainties were varied in the same way as in the component-level uncertainty analyses. Tower material strength was also considered, as the strength of the exterior columns, floor trusses, and concrete slab had not been investigated in the previous uncertainty analyses.

An additional source of uncertainty that is appropriate for the subassembly analysis was the weight of the interior building contents (modeled here with partitions and workstations) of the towers. A description of the building contents and assumed weight distribution in the global tower models were described in Chapter 3. The variations used for the weight (densities) of the building contents were 60 percent and 160 percent of the baseline weight. Finally, the only modeling uncertainty parameter included was the erosion parameter. Neither variation in the contact parameter or the coefficient of friction parameter had a significant effect in the component-level uncertainty analyses, and thus, their variations were not considered in the global analyses.

A Placket-Burman experimental design of 11 factors was selected for this study, as shown in Table 8-6. The residual kinetic energy of the engine materials as it entered the core of the building was selected as the response parameter for this study. This energy reflected the potential of the engine to inflict damage to the core columns after penetrating through the tower exterior and truss floor region of the building. 
Table 8-6. Placket-Burman experimental design of 11 factors for the enginesubassembly impact analyses.

\begin{tabular}{|c|c|c|c|c|c|c|c|c|c|c|c|}
\hline $\begin{array}{l}\text { Puns } \\
\text { ID } \rightarrow\end{array}$ & $\times 1$ & $\times 2$ & $\times 3$ & $\times 4$ & $\times 5$ & $\times 6$ & $\times 7$ & $\times 8$ & $\times 9$ & $\times 10$ & $\times 11$ \\
\hline 1 & 1 & 1 & 1 & 1 & 1 & 1 & 1 & 1 & 1 & 1 & 1 \\
\hline 2 & -1 & 1 & -1 & 1 & 1 & 1 & -1 & -1 & -1 & 1 & -1 \\
\hline 3 & -1 & -1 & 1 & -1 & 1 & 1 & 1 & -1 & -1 & -1 & 1 \\
\hline 4 & 1 & -1 & -1 & 1 & -1 & 1 & 1 & 1 & -1 & -1 & -1 \\
\hline 5 & -1 & 1 & -1 & -1 & 1 & -1 & 1 & 1 & 1 & -1 & -1 \\
\hline 6 & -1 & -1 & 1 & -1 & -1 & 1 & -1 & 1 & 1 & 1 & -1 \\
\hline 7 & -1 & -1 & -1 & 1 & -1 & -1 & 1 & -1 & 1 & 1 & 1 \\
\hline 8 & 1 & -1 & -1 & -1 & 1 & -1 & -1 & 1 & -1 & 1 & 1 \\
\hline 9 & 1 & 1 & -1 & -1 & -1 & 1 & -1 & -1 & 1 & -1 & 1 \\
\hline 10 & 1 & 1 & 1 & 1 & -1 & 1 & 1 & -1 & 1 & -1 & -1 \\
\hline 11 & -1 & 1 & 1 & 1 & -1 & -1 & -1 & 1 & -1 & -1 & 1 \\
\hline 12 & 1 & -1 & 1 & 1 & 1 & -1 & -1 & -1 & 1 & -1 & -1 \\
\hline 13 & 0 & 0 & 0 & 0 & 0 & 0 & 0 & 0 & 0 & 0 & 0 \\
\hline
\end{tabular}

A main effects plot for the engine-subassembly impact analyses is shown in Figure 8-9. Vcrtical impact location, tower materials strength, and the engine vertical approach angle had the largest effect on the residual kinetic energy of the engine materials. Parameters with the smallest effect on the residual kinetic energy of the engine were the engine materials' set and strength.

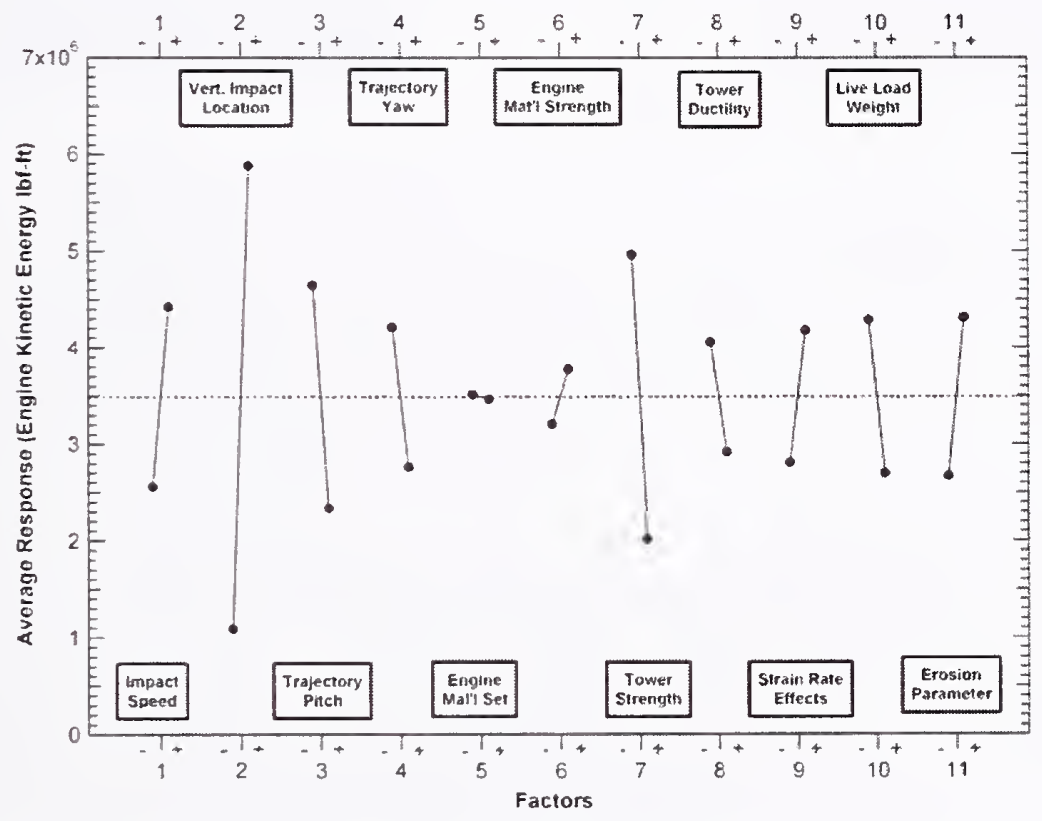

Figure 8-9. Main effects plot for the engine subassembly impact analyses.

The vertical impact location had the largest effect on the impact response. For the uppermost engine impact location, the engine tended to glance off the floor slab and continued into the core on the same floor, as shown in Figure 8-10. In four of the six runs where the impact point was in the lower position (runs $3,4,6$, and 7) the engine was stopped before reaching the core. In these runs, there was significant penetration and interaction with the floor slab, which resulted in a large deceleration and deflection of the engine trajectory. 

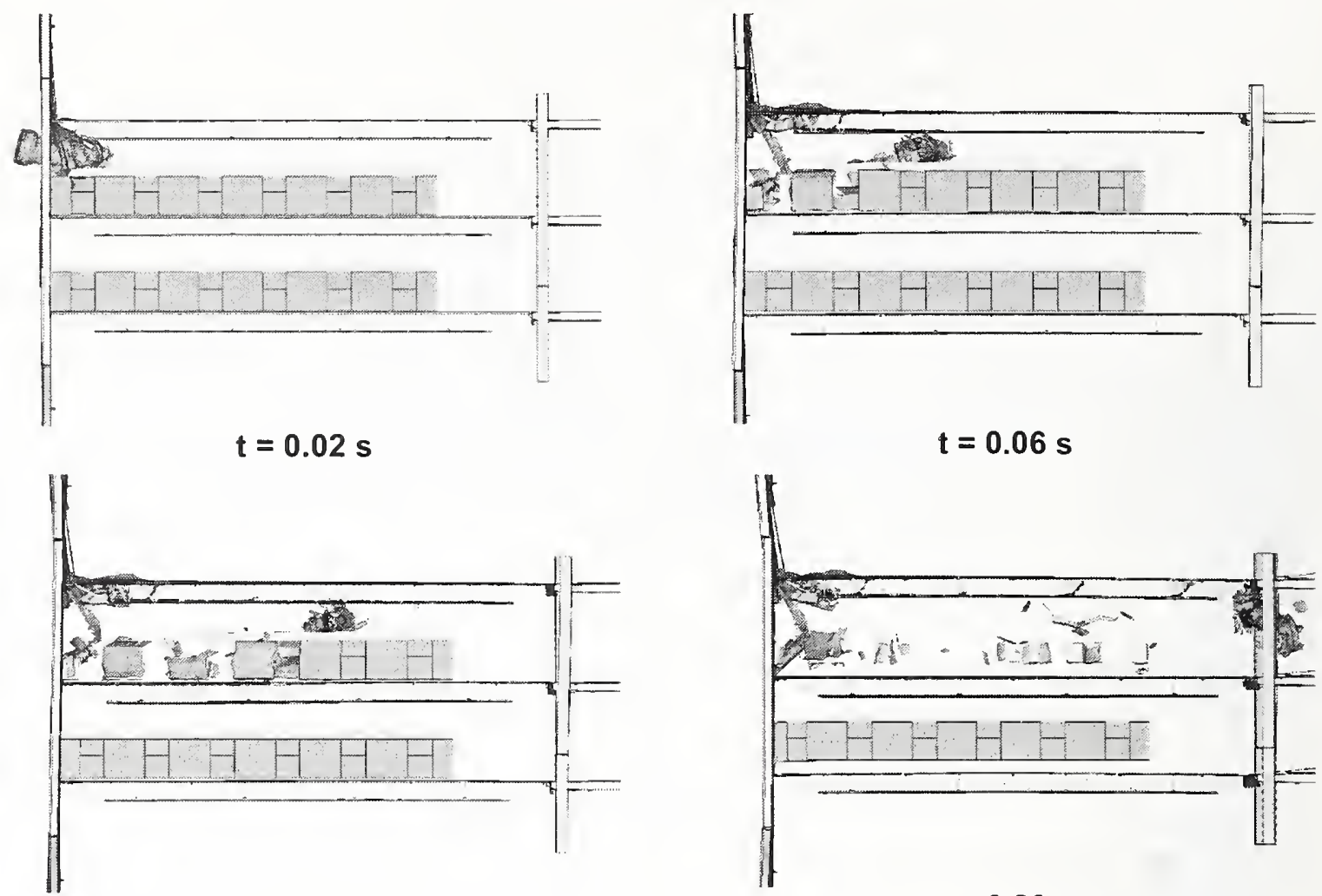

$\mathrm{t}=0.10 \mathrm{~s}$

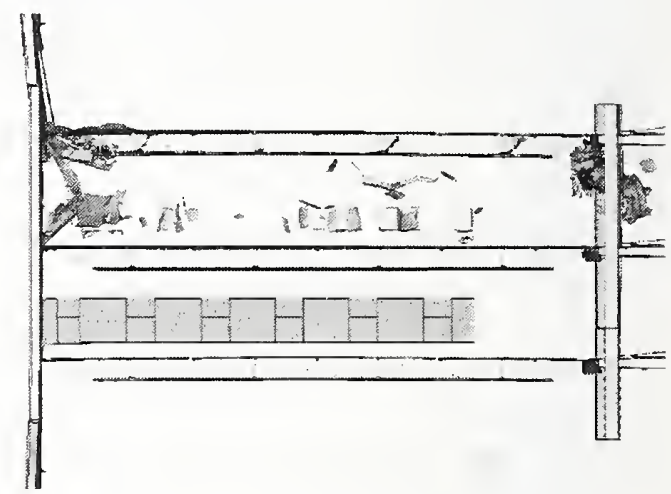

$\mathrm{t}=0.30 \mathrm{~s}$

Figure 8-10. Engine impact response and trajectory for run 1.

Based on these results, the following parameters were of primary importance in the subassembly uncertainty analyses:

- Vertical impact location.

- Tower materials strength.

- Engine vcrtical approach angle.

Of secondary importance, but still yielding appreciable change in the impact response were

- Impact speed.

- Engine latcral approach angle.

- Building contents weight.

- Strain rate effccts.

- Tower materials ductility.

Of the primary factors, the vertical impact location uncertainty was difficult to interpret for the global impact analyses. The vertical impact location of an engine rclative to the floor slab was obviously 
important for the subsequent response of that engine. However, the global impact analyses included the impact response of the entire aircraft. This spanned several floors and included two engines, landing gear, the fuselage, luggage and cargo, and many other components. Altering the vertical impact point for the aircraft, as well as the trajectory (roll, vertical approach, and lateral approach angles), and the aircraft orientation influences where various aircraft components impact the tower relative to floor levels.

Therefore, modification of the vertical impact location for a specific engine in these subassembly analyses has a much different effect (and stronger influence on impact damage) than changing the vertical impact location of the entire aircraft. In addition, changing impact parameters, such as the aircraft pitch, changcs the vertical impact point of the engines.

\subsection{GLOBAL IMPACT ANALYSES PARAMETER SELECTION}

Based on the three uncertainty analyses described above, the modeling parameters found to be significant in each analysis are summarized in Table 8-7. Secondary parameters are identified with a ' - . Based on these results and on engineering judgment as explained below, the following parameters were selected for variation in the global impact analyses:

- Impact velocity.

- Vertical approach angle.

- Lateral approach angle.

- Total aircraft weight.

- Aircraft materials failure strain.

- Tower materials failure strain.

- Building contents weight.

The impact speed and vertical approach angle were selected as significant parameters in the global analysis due to their importance in the component and subassembly impact response. The vcrtical approach angle played a primary role in the magnitude of the vertical impact loads on the truss floor structures. Lateral approach angle was also selected, despite its secondary importance in the component and subassembly analyses, as this parameter dictated to a large extent where aircraft debris traveled and what part of the core was affected by this debris, an effect not captured in the component or subassembly analyses. The vertical impact location was not considered in the global impact analysis, despite being significant in the subassembly analysis. However, the aircraft contained a large collcction of components. A change in the vertical location may increase the damage imparted from a particular componcnt, but will simultaneously decrease the damage due to another component, resulting in less pronounced overall effect. 
Table 8-7. Summary of significant modeling parameters.

\begin{tabular}{|c|c|c|c|c|}
\hline & & $\begin{array}{c}\text { Engine-Core } \\
\text { Column } \\
\text { Component }\end{array}$ & $\begin{array}{c}\text { Wing Section - } \\
\text { Exterior Panel } \\
\text { Component }\end{array}$ & $\begin{array}{c}\text { Engine - } \\
\text { Subassembly } \\
\text { Impact }\end{array}$ \\
\hline \multirow{4}{*}{$\begin{array}{l}\text { Flight } \\
\text { Parameters }\end{array}$} & Impact velocity & & $\checkmark$ & $\checkmark-$ \\
\hline & Vertical impact location & & & $\checkmark$ \\
\hline & Vertical Approach Angle & & & $\checkmark$ \\
\hline & Lateral Approach Angle & & & $\sqrt{-}$ \\
\hline \multirow{4}{*}{$\begin{array}{l}\text { Aircraft } \\
\text { Parameters }\end{array}$} & Aircraft materials strength & $\checkmark$ & $\checkmark$ & \\
\hline & Aircraft materials failure strain & & $\checkmark-$ & \\
\hline & Wing section weight & & $\checkmark$ & \\
\hline & Engine materials set & $\sqrt{-}$ & & \\
\hline \multirow{4}{*}{$\begin{array}{l}\text { Tower } \\
\text { Parameters }\end{array}$} & Tower materials strength & & & $\checkmark$ \\
\hline & Tower materials failure strain & $\checkmark$ & $\sqrt{-}$ & $\sqrt{-}$ \\
\hline & $\begin{array}{l}\text { Tower materials strain rate } \\
\text { effects }\end{array}$ & $\checkmark$ & & $\sqrt{-}$ \\
\hline & Live load weight & & & $\sqrt{-}$ \\
\hline \multirow{2}{*}{ Model } & Friction coefficient & & $\sqrt{-}$ & \\
\hline & Erosion Parameter & & $\checkmark$ & \\
\hline
\end{tabular}

Variations in the strength and ductility (failure strain) of materials had a similar effect on the amount of energy absorbed. An increase in yield strength or an increase in failure strain resulted in an increase in the energy absorbing capacity of the structure. The yield strength of materials was typically known more accurately than the failure strains. This is particularly true within the finite element analyses, where the value of the failure strain needed to be assigned based on the model resolution and failure criteria used. This effect was described in detail in Section 2.3.1. As a result, only the uncertainties in the material failure strain were used as a material uncertainty parameter for both the aircraft and tower in the subsequent global impact analyses.

The uncertainty in the weights associated with building contents (corresponding to service live loads) was found to be of secondary importance in the engine-subassembly impact analysis. In the global impact analyses, the live load contents were expected to play a more significant role in confining the fuel and debris dispersion. In addition, the partition walls were significant for controlling the subsequent spread of fire through the towers. As a result, the uncertainty in building contents weight was included as an uncertainty parameter in the global analysis.

The wing section weight was found to be an important parameter for the wing section - exterior panel impact analyses. For the global analyses, the total aircraft weight was carried forward as an uncertainty parameter. The uncertainty in the total aircraft weight was, however, significantly smaller than the uncertainty in the weight of the empty wing section impactor. An uncertainty of \pm 5 percent was used for total aircraft weight.

The engine materials set and the friction coefficient were not found to be sufficiently significant in any of the uncertainty analyses and were, therefore, not included in the global analysis. Similarly, the erosion parameter was found to be significant only for the wing-section impact analyses. The importance of this 
parameter was amplified in this example as a rcsult of the relatively low weight and strength of the empty wing-section impactor and the large amount of material failure and erosion as the wing was segmented by the exterior columns. The fact that the erosion parameter uncertainty had a negligible effect on the other analyses and potentially had negative consequences for the stability of the global impact analyses led to the elimination of this parameter from the global impact analyses.

\subsection{REFERENCES}

“LS-DYNA Keyword User’s Manual," 2003. Livermore Software Technology Corporation, Version 970, April.

Oberg, E., F. D. Jones, and H. L. Horton. 1990. Machinery's Handbook, $23^{\text {rd }}$ Edition, Industrial Press Inc., NY, p. 2202-2203.

Plackett, R. L., and Burman, J. P.. 1947. "The Design of Optimum Multifactorial Experiments," Biometrika, 33. 
This page intentionally left blank. 

